Darstellung und Geheimnis in Mittelalter und Früher Neuzeit 


\section{Episteme in Bewegung}

Beiträge zu einer transdisziplinären Wissensgeschichte

Herausgegeben von Gyburg Uhlmann im Auftrag des Sonderforschungsbereichs 980

„Episteme in Bewegung.

Wissenstransfer von der Alten Welt

bis in die Frühe Neuzeit"

\section{Band 21}

2021

Harrassowitz Verlag · Wiesbaden 


\title{
Darstellung und Geheimnis in Mittelalter und Früher Neuzeit
}

\author{
Herausgegeben von \\ Jutta Eming und Volkhard Wels
}

2021

Harrassowitz Verlag · Wiesbaden 
Die Reihe „Episteme in Bewegung“ umfasst wissensgeschichtliche Forschungen mit einem systematischen oder historischen Schwerpunkt in der europäischen und nicht-europäischen Vormoderne. Sie fördert transdisziplinäre Beiträge, die sich mit Fragen der Genese und Dynamik von Wissensbeständen befassen, und trägt dadurch zur Etablierung vormoderner Wissensforschung als einer eigenständigen Forschungsperspektive bei.

Publiziert werden Beiträge, die im Umkreis des an der Freien Universität Berlin angesiedelten Sonderforschungsbereichs 980 „Episteme in Bewegung. Wissenstransfer von der Alten Welt bis in die Frühe Neuzeit" entstanden sind.

Herausgeberbeirat:

Anne Eusterschulte (FU Berlin)

Kristiane Hasselmann (FU Berlin)

Andrew James Johnston (FU Berlin)

Jochem Kahl (FU Berlin)

Klaus Krüger (FU Berlin)

Beate La Sala (FU Berlin)

Christoph Markschies (HU Berlin)

Tilo Renz (FU Berlin)

Anita Traninger (FU Berlin)

Gefördert durch die Deutsche Forschungsgemeinschaft (DFG) -

Projektnummer 191249397 - SFB 980.

Abbildung auf dem Umschlag:

Titelkupfer von Athanasius Kircher: Oedipus Aegyptiacus. Rom 1652

(Rijksmuseum, Amsterdam)

\section{(c) $(1) \Theta \Theta$}

Dies ist ein Open-Access-Titel, der unter den Bedingungen der CC BY-NC-ND 4.0-Lizenz veröffentlicht wird. Diese erlaubt die nicht-kommerzielle Nutzung, Verbreitung und Vervielfältigung in allen Medien, sofern keine Veränderungen vorgenommen werden und der/die ursprüngliche(n) Autor(en) und die Originalpublikation angegeben werden. Weitere Informationen: https://creativecommons.org/licenses/by-nc-nd/4.0/

Die Bedingungen der CC-Lizenz gelten nur für das Originalmaterial. Die Verwendung von Material aus anderen Quellen (gekennzeichnet durch eine Quellenangabe) wie Schaubilder, Abbildungen, Fotos und Textauszüge erfordert ggf. weitere Nutzungsgenehmigungen durch den jeweiligen Rechteinhaber.

Der Harrassowitz Verlag behält sich das Recht vor, die Veröffentlichung vor unbefugter Nutzung zu schützen. Anträge auf kommerzielle Verwertung, Verwendung von Teilen der Veröffentlichung und/oder Übersetzungen sind an den Harrassowitz Verlag zu richten.

Bibliografische Information der Deutschen Nationalbibliothek

Die Deutsche Nationalbibliothek verzeichnet diese Publikation in der Deutschen

Nationalbibliografie; detaillierte bibliografische Daten sind im Internet

über https://www.dnb.de abrufbar.

Informationen zum Verlagsprogramm finden Sie unter

https://www.harrassowitz-verlag.de

(c) bei den Autoren

Verlegt durch Otto Harrassowitz GmbH \& Co. KG, Wiesbaden 2021

Gedruckt auf alterungsbeständigem Papier.

Druck und Verarbeitung: Memminger MedienCentrum AG

Printed in Germany

ISSN 2365-5666

eISSN 2701-2522

DOI: $10.13173 / 2365-5666$
ISBN 978-3-447-11548-3

eISBN 978-3-447-39050-7

DOI: $10.13173 / 9783447115483$

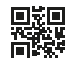




\title{
Zum Geleit
}

\author{
Andrew James Johnston und Gyburg Uhlmann
}

Der an der Freien Universität Berlin angesiedelte Sonderforschungsbereich 980 „Episteme in Bewegung. Wissenstransfer von der Alten Welt bis in die Frühe Neuzeit", der im Juli 2012 seine Arbeit aufgenommen hat, untersucht anhand exemplarischer Problemkomplexe aus europäischen und nicht-europäischen Kulturen Prozesse des Wissenswandels vor der Moderne. Dieses Programm zielt auf eine grundsätzliche Neuorientierung wissensgeschichtlicher Forschung im Bereich der Vormoderne ab. Sowohl in der modernen Forschung als auch in den historischen Selbstbeschreibungen der jeweiligen Kulturen wurde das Wissen der Vormoderne häufig als statisch und stabil, traditionsgebunden und autoritätsabhängig beschrieben. Dabei waren die Stabilitätspostulate moderner Forscherinnen und Forscher nicht selten von der Dominanz wissensgeschichtlicher Szenarien wie dem Bruch oder der Revolution geprägt sowie von Periodisierungskonzepten, die explizit oder implizit einem Narrativ des Fortschritts verpflichtet waren. Vormodernen Kulturen wurde daher oft nur eine eingeschränkte Fähigkeit zum Wissenswandel und vor allem zur - nicht zuletzt historischen Reflexion dieses Wandels zugeschrieben. Demgegenüber will dieser SFB zeigen, dass vormoderne Prozesse der Wissensbildung und -entwicklung von ständiger Bewegung und auch ständiger Reflexion geprägt sind, dass diese Bewegungen und Reflexionen aber eigenen Dynamiken unterworfen sind und in komplexeren Mustern verlaufen, als es eine traditionelle Wissensgeschichtsschreibung wahrhaben will.

Um diese Prozesse des Wissenswandels fassen zu können, entwickelte der SFB 980 einen Begriff von ,Episteme', der sich sowohl auf ,Wissen' als auch ,Wissenschaft' bezieht und das Wissen als ,Wissen von etwas' bestimmt, d. h. als mit einem Geltungsanspruch versehenes Wissen. Diese Geltungsansprüche werden allerdings nicht notwendigerweise auf dem Wege einer expliziten Reflexion erhoben, sondern sie konstituieren sich und werden auch reflektiert in Formen der Darstellung, durch bestimmte Institutionen, in besonderen Praktiken oder durch spezifische ästhetische oder performative Strategien.

Zudem bedient sich der SFB 980 eines speziell konturierten Transfer-Begriffs, der im Kern eine Neukontextualisierung von Wissen meint. Transfer wird hier nicht als Transport-Kategorie verstanden, sondern vielmehr im Sinne komplex verflochtener Austauschprozesse, die selbst bei scheinbarem Stillstand iterativ in Bewegung bleiben. Gerade Handlungen, die darauf abzielen, einen erreichten 
Wissensstand zu tradieren, zu kanonisieren, zu kodifizieren oder zu fixieren, tragen zum ständigen Wissenswandel bei.

Gemeinsam mit dem Harrassowitz Verlag hat der SFB die Reihe „Episteme in Bewegung. Beiträge zu einer transdisziplinären Wissensgeschichte“ ins Leben gerufen, um die Ergebnisse der Zusammenarbeit zu präsentieren und zugänglich zu machen. Die Bände, die hier erscheinen, werden das breite Spektrum der Disziplinen repräsentieren, die im SFB vertreten sind, von der Altorientalistik bis zur Mediävistik, von der Koreanistik bis zur Arabistik. Publiziert werden sowohl aus der interdisziplinären Zusammenarbeit hervorgegangene Bände als auch Monographien und fachspezifische Sammelbände, die die Ergebnisse einzelner Teilprojekte dokumentieren.

Allen ist gemeinsam, dass sie die Wissensgeschichte der Vormoderne als ein Forschungsgebiet betrachten, dessen Erkenntnisgewinne von grundsätzlichem systematischen Interesse auch für die wissensgeschichtliche Erforschung der Moderne sind. 


\section{Inhalt}

Jutta Eming, Volkhard Wels

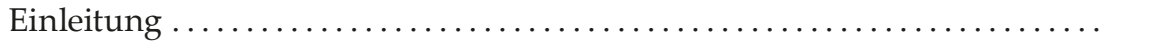

\section{Ästhetisierungen}

Friedrich Wolfzettel

Der gefangene Mythos befreit sich durch seine Rätsel

Überlegungen zum altfranzösischen Lai de l'Oiselet ................. 17

Jutta Eming

Evokation und Episteme. Zu Wissensmodi des Wunderbaren

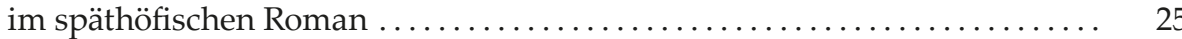

Falk Quenstedt

,Paradisieren'. Rätselspannung, Lehre und religiöse Erfahrung

im Jüngeren Titurel

Volkhard Wels

Alphidius und Lamspring um 1600. Verrätselungen in der

frühneuzeitlichen $(\mathrm{Al})$ Chemie in religionshistorischem Kontext

67

Susanne Reichlin

Wer weckt mich? Die Geheimnishaftigkeit der Wächterstimme

im geistlichen Wecklied Jch wachter (RSM PeterA/3/1h) ..

\section{Inszenierungen von Geheimnis und Rätsel}

Maximilian Benz

Verrätseltes Erzählen vom Mysterium

Wer nimmt was auf Munsalvæsche wahr?

Beate Kellner

Rätsel und Geheimnis im Wartburgkrieg. Epistemologische und

ästhetische Dimensionen des Rätselwettstreits

Glenn Ehrstine

Gattung \& Geheimnis. Zum Begriff des Mysterienspiels

Stephan Müller

Der Buchstabe ist die Botschaft. Praktiken des Verbergens und Offenbarens in mittelalterlichen ,Geheimschriften' - und wie sie im Kontext

von Herrschaft und Mystik benutzt werden 
Johannes Traulsen

Geheime Allianzen und soziale Mobilität im Iwein Hartmanns von Aue ...

201

\section{Geheimnis und Offenbarung}

Beatrice Trînca

Geheimnisse in Übersetzung

$\mathrm{Zu}$ den Stigmata in deutschen Franziskus-Viten

Yoshiki Koda

Rhetorik und Parrhesia. Zum Offenbarungsmodus von Geheimlehren

in Antike und Mittelalter

Simon Brandl

Das Mysterium der incarnatio verbi in Alexander von Suchtens

frühparacelsistischem Traktat De tribus facultatibus (um 1565) ..

Ute Frietsch

Solve Coagulata! Verflüssige die Schöpfung! Die pseudo-paracelsische

Schrift Philosophia ad Athenienses als Rätsel und Offenbarung ............

Kristiane Hasselmann

Spielräume des Selbst. Zum Verhältnis von Darstellung und Geheimnis in der Bruderschaft der Freimaurer

Autor*innenverzeichnis 


\title{
Einleitung
}

\author{
Jutta Eming, Volkhard Wels
}

\begin{abstract}
Als Hans, einer der wichtigsten Protagonisten aus Ernst Lothars Roman Der Engel mit der Posaune, sich in den dreißiger Jahren in Wien kurz vor dem erzwungenen ,Anschluss' Österreichs an Nazi-Deutschland aus Anlass seiner Lehrlingsrede in die Freimaurerloge begibt, der er vor kurzem beigetreten ist, befindet er sich in einem Zustand gespannter Erwartung. Er konnte

sich einer ihn unerwartet umfangenden Geheimnisatmosphäre nicht erwehren [...]. Die Geheimnislosigkeit der Epoche, eine Konsequenz des Städtegeistes, dessen steriler Intellekt das Geheimnis der Schöpfung vor aller Augen entgeheimniste und damit um die Aura brachte! Dann wandten seine Gedanken sich der geheimnisvollen Macht zu, der er seit kurzem angehörte. Wie wurde diese Macht geübt, die seit Jahrhunderten den Laien zu fabeln gab? ${ }^{1}$
\end{abstract}

\section{Geheimnis als Epochensignatur?}

Die Begriffe von Geheimnis, die im Zitat aus Lothars Roman begegnen, scheinen sehr hoch gegriffen. Denn hier wird dem Geheimnis das Gewicht einer Epochensignatur zugeschrieben, einer nostalgischen Lebensform (gegen den „Städtegeist“), einer atmosphärischen, ja sakralen Qualität („Aura“), welche die Dauer „,von Jahrhunderten" heraufbeschwört und ihr damit Geltung verleiht. Der Protagonist in Lothars Roman findet sich kurz danach in dieser Erwartung auch enttäuscht. Die Freimaurer hatten in der ersten Hälfte des 20. Jahrhunderts eine ursprüngliche Funktion, Kernzellen und Motor bürgerlicher Öffentlichkeit zu werden, längst eingebüßt, ${ }^{2}$ und Hans fällt es angesichts der in puppenhafter Kostümierung, leeren Ritualen ${ }^{3}$ und banalen Gesprächsgegenständen erstarrten Freimaurer-Versammlung schwer, „ernst zu bleiben“. ${ }^{4}$

1 Ernst Lothar: Der Engel mit der Posaune. Roman eines Hauses. Mit einem Nachwort von Eva Menasse. Wien 2016 (engl. 1944), S. 470.

2 Vgl. Jürgen Habermas: Strukturwandel der Öffentlichkeit. Untersuchungen zu einer Kategorie der bürgerlichen Gesellschaft. Frankfurt a. M. 1962/1990, S. 95-96. Dass ,Geheimgesellschaften' als solche in einer viel längeren vormodernen Tradition stehen, hat etwa Georg Schuster: Die geheimen Gesellschaften, Verbindungen und Orden. 2 Bde. Wiesbaden 1991 (Nachdruck einer Ausgabe von 1905), herausgearbeitet.

3 Zu performanztheoretischen Aspekten der Freimaurer vgl. Kristiane Hasselmann: Die Rituale der Freimaurer. Zur Konstitution eines bürgerlichen Habitus im England des 18. Jahrhunderts. Bielefeld 2009, zur Geheimhaltung ebd., S. 36-52 et passim.

4 Lothar: Der Engel mit der Posaune (Anm. 1), S. 470. 
Die Sehnsucht des Helden nach einer längst vergangenen Epoche verweist auf eine kultur- und wissenschaftsgeschichtliche ,große Erzählung' (Lyotard), welche die Moderne mit dem Gestus nüchterner ,Entzauberung der Welt ${ }^{\prime 5}$ in Verbindung bringt. Solche ,Entzauberung' gründet nicht zuletzt in einem aufklärerischen Fortschrittsparadigma, das gesellschaftliche Ungleichheit und menschliche Unmündigkeit beenden will - so bei Karl Marx, der im wirkmächtigen ersten Kapitel seines Kapitals das ökonomische Kern-Verhältnis der bürgerlichen Gesellschaft analysiert. Dafür bedient er sich einer Rhetorik, welche die Verschleierungen des (Tausch-)Werts der Ware, also eben dieses Kern-Verhältnisses, zugleich abbilden und dechiffrieren soll. Der vierte Unterabschnitt dieses Kapitels trägt

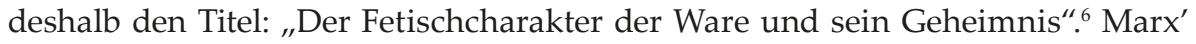
Kernargumentation in diesem Abschnitt betrifft eine Subjekt-Objekt-Verkehrung, die sich im Wert der Ware manifestiert: Dieser Wert scheint aus ihr selbst abgeleitet zu werden, während er tatsächlich das Resultat des ökonomischen Prozesses ist, aus dem sie hervorgeht und in dem der Wert der Ware Arbeitskraft eine Schlüsselrolle spielt. Marx spricht in diesem Zusammenhang davon, dass gesellschaftliche Verhältnisse die "phantasmagorische Form" von Dingen annähmen, was sich begrifflich nur mittels einer Anleihe aus der "Nebelregion der religiösen Welt" fassen ließe, eben durch den Fetischismus. ${ }^{7}$

Die Abgrenzung vom Geheimnisvollen, die (Auf-)Lösung des Geheimnisses, steht demgemäß in einer aufklärerischen, progressiven Tradition. ${ }^{8}$ Das Geheimnis muss gelüftet, die Täuschung aufgedeckt, der Schleier gehoben werden; alles muss ans Tageslicht und an die Öffentlichkeit kommen. ${ }^{9}$ Dem entgegen stünde ein vormodernes, verschattetes, aber gerade dadurch auch ästhetisch faszinierendes ,Zeitalter des Geheimnisses‘. ${ }^{10}$ Bis in die jüngste Gegenwart hinein wird dieses wesentlich gerade auf die christliche Religion zurückgeführt. ${ }^{11}$ Der Theologe Jörg Lauster vertritt in seiner Kulturgeschichte des Christentums unter dem Titel „Die Ver-

5 Die Formel von der ,Entzauberung der Welt' wird in erster Linie mit Max Weber in Verbindung gebracht, wurde von diesem aber weder geprägt noch in seinen Schriften klar konturiert. Vgl. zur Kritik etwa Hans Joas: Die Macht des Heiligen. Eine Alternative zur Geschichte von der Entzauberung. Berlin 2017.

6 Karl Marx: Das Kapital. Kritik der politischen Ökonomie. Erster Band. Buch I: Der Produktionsprozeß des Kapitals. Berlin 1962 (zuerst Hamburg 1890) (Karl Marx und Friedrich Engels: Werke. Bd. 23), S. 85-98.

7 Marx: Das Kapital (Anm. 6), S. 86.

8 Vgl. dazu - mit revisionistischem Akzent - Manfred Voigts: Thesen zum Verhältnis von Aufklärung und Geheimnis. In: Schleier und Schwelle. Bd. 2: Geheimnis und Offenbarung. Hg. von Aleida und Jan Assmann in Verbindung mit Theo Sundermeier. München 1998, S. 65-80.

9 Zur - scheinbaren - Paradoxie, dass sich dabei gerade die Epoche der Aufklärung geheimer Gesellschaften wie der Freimaurer oder der Illuminaten bedienen zu müssen glaubte, vgl. Manfred Agethen: Geheimbund und Utopie. Illuminaten, Freimaurer und deutsche Spätaufklärung. München 1987.

10 Dies wiederum nicht nach Marx, der im Gegenteil die ökonomischen Verhältnisse des Mittelalters als „nicht verkleidet“ bezeichnet. Vgl. Marx: Das Kapital (Anm. 6), S. 92.

11 Vgl. dazu auch die prominent gewordene Publikation des muslimischen Autors Navid Kermani: Ungläubiges Staunen. Über das Christentum. 5. Aufl. München 2015. 
zauberung der Welt" die Auffassung, dass die christliche Lehre die europäische Welt seit ihren Anfängen mit einer transzendenten Dimension des Geheimnisvollen überzogen habe, um dann nach den Säkularisierungsschüben der anbrechenden Moderne in Kunst und Literatur Residuen zu finden. ${ }^{12}$ Eine Variante der ,großen Erzählung' von der ,Moderne' als einer Säkularisierungsbewegung liegt damit darin, dass Ästhetisierung an die Stelle der Religion und letztere vom Zentrum zugleich an die Peripherie der Gesellschaft tritt. Die Beiträge des vorliegenden Bandes, welche auf eine im September 2018 an der Freien Universität Berlin im Sonderforschungsbereich Episteme in Bewegung gehaltene internationale und interdisziplinäre Tagung zurückgehen, können nicht zum Wenigsten als Versuche gelesen werden, solchen übergreifenden Erzählungen die komplexe Fülle des historischen Materials entgegenzuhalten.

\section{Die Fülle des Materials und ihre Kontexte}

Der Stellenwert des Geheimnisses als eines verborgenen Wissens lässt sich für die mittelalterliche Kultur tatsächlich kaum bestreiten, und nirgends wird dies sichtbarer als im Bereich der Religion und in den verschiedenen Formen, in denen sie Spuren Gottes in der menschlichen Welt konzeptualisiert. Das Christentum ist - wie das Judentum und der Islam - eine Religion, die sich offenbart, und dies in erster Linie in der Schrift, sodann auch in der Fleischwerdung Gottes durch Jesus Christus. Bevor Luther dem biblischen Wort die Kraft zutraute, Gläubige unmittelbar zu erreichen, bedurfte es allerdings anspruchsvoller exegetischer Operationen durch Spezialisten, um dessen Sinn zu enthüllen. Eine ähnliche Hermeneutik erforderte die Natur als Schöpfungs- und Offenbarungswerk Gottes. Im religiösen Kontext erscheint das Geheimnis als mysterium, als Gotteserfahrung und als geheimes Wissen Gottes (oder Geheimnis Gottes, das der Offenbarung des Johannes gemäß noch in der Apokalypse als aufgeschlagenes Buch präsentiert wird, welches nicht gelesen werden darf). Die Eucharistie - als wohl prominentestes Beispiel eines christlichen Rituals - bildet insofern möglicherweise einen Modellfall für mittelalterliche Auffassungen des Geheimnisses, als es Teilhabe an einem Vorgang bietet, der sich dem Verstehen entzieht. ${ }^{13}$

Das Mittelalter hätte somit in einer letztlich nicht historisch einsinnig progressiven Entwicklung die Tendenz zum Geheimnis gegenüber älteren Epochen nicht vermindert, sondern noch verstärkt. Um Formen der Übertragung geheimnisvollen Wissens im sprachlichen Gestus adäquat abzubilden, wurden zugleich viele verschiedene Formen und Figuren uneigentlichen Sagens noch aus der antiken

12 Jörg Lauster: Die Verzauberung der Welt. Eine Kulturgeschichte des Christentums. 4. Aufl. München 2016. Bezeichnenderweise erfährt dagegen Kermani (Anm. 11) sein ,Staunen' über die christliche Religion und ihre Glaubenssätze gerade aus der Anschauung ihrer Kunst.

13 Vgl. Wilhelm Schmidt-Biggemann: Sakrament. Geheimnis, Magie, Kult und Recht. In: Der Begriff der Magie in Mittelalter und Früher Neuzeit. Hg. von Jutta Eming und Volkhard Wels. Wiesbaden 2020, S. 35-46. 
Tradition adaptiert. ${ }^{14}$ In der weltlichen Literatur erscheinen sie gattungsübergreifend wieder, daneben haben die säkularen Bereiche weitere Modi der Offenbarung und des Verborgenen oder des Offensichtlichen und Versteckten hervorgebracht. Dazu gehört der viel untersuchte Bereich der heimlichkeit in der mittelalterlichen Kultur und Literatur, der in seinem Verhältnis zur (höfischen) Öffentlichkeit nicht das vormoderne Korrelat bürgerlicher Privatheit bildet, sondern das meint, was am Hof nicht sichtbar wird und entzogen bleibt, sein Funktionieren aber mit bedingt. Er hat in der Mediävistik eine Vielzahl interdisziplinärer Studien inspiriert, die zumeist soziologisch und historisch orientiert waren. ${ }^{15} \mathrm{Zu}$ erinnern ist in diesem Zusammenhang auch an die Institutionalisierung der Beichte als einer ,Technologie des Selbst' (Foucault) und an paradoxe Konstellationen aus Verbergen und Enthüllen wie im Falle der ,stummen Sünde', der Homosexualität. ${ }^{16}$ An vielen literarischen Texten des Mittelalters - am prominentesten vielleicht in den Tristan-Romanen - lassen sich Reflexe dieser Relationierung eines Bereichs höfischer Öffentlichkeit und heimlichkeit als der zwei Ebenen zeigen, auf denen Figuren agieren und die sie austarieren müssen. ${ }^{17}$ Für die höfische Literatur des Mittelalters gilt eine Ästhetik der heimlichkeit in Bezug auf den Liebesdiskurs quer durch die verschiedenen Gattungen als kennzeichnend. ${ }^{18}$

Wesentlichen Anteil daran hat die religiöse, insbesondere die mystische Literatur, welche die außerordentliche Liebeserfahrung einer stufenweisen Annäherung an Gott und Vereinigung mit ihm an der Grenze des Sagbaren vergegenwärtigt. ${ }^{19}$ Auf diese Tradition bezieht sich im vorliegenden Band Beatrice Trîncas komparatistischer Beitrag zum Geheimnis des Heiligen Franziskus: seinen sich

14 Vgl. zu diesem Zusammenhang einführend Arnold Angenendt: Geschichte der Religiosität im Mittelalter. Darmstadt 1997, S. 167-173.

15 Dies gilt insbesondere für die Forschungen von Gerd Althoff, vgl. ders.: Spielregeln der Politik im Mittelalter. Kommunikation in Frieden und Fehde. Darmstadt 1997. Althoff machte dabei unter anderem auf ,ungeschriebene Gesetze' aufmerksam, welche mittelalterliche Politik und Gesellschaft erfolgreich organisierten (vgl. ders.: Ungeschriebene Gesetze. Wie funktioniert Herrschaft ohne schriftlich fixierte Normen, ebd., S. 282-304). Zu solchen Regeln kann gehören, dass sie erst im Moment eines Verstoßes überhaupt als solche sichtbar werden, vgl. zu letzterem insbesondere: Der Fehltritt. Vergehen und Versehen in der Vormoderne. Hg. von Peter von Moos. Köln, Weimar, Wien 2001.

16 Vgl. Brigitte Spreitzer: Die stumme Sünde. Homosexualität im Mittelalter. Göppingen 1988; dies.: Verquere Körper. Zur Diskursivierung der ,stummen Sünde’ im Mittelalter. In: Genderdiskurse und Körperbilder im Mittelalter. Eine Bilanzierung nach Butler und Laqueur. Hg. von Ingrid Bennewitz und Ingrid Kasten. Münster, Hamburg, London 2002, S. 11-28.

17 Vgl. Rüdiger Brandt: Enklaven, Exklaven. Zur literarischen Darstellung von Öffentlichkeit und Nichtöffentlichkeit im Mittelalter. Interpretationen, Motiv- und Terminologiestudien. München 1993; Jutta Eming: Emotion und Expression. Untersuchungen zu deutschen und französischen Liebes- und Abenteuerromanen des 12.-16. Jahrhunderts. Berlin, New York 2006; Werner Röcke: Im Schatten höfischen Lichts. Zur Trennung von Öffentlichkeit und Privatheit im mittelalterlichen Tristan-Roman. In: Licht. Religiöse und literarische Gebrauchsformen. Hg. von Walter Gebhard. Frankfurt a. M. u. a. 1990, S. 37-76.

18 Vgl. Beatrice Trînca: Amor conspirator. Zur Ästhetik des Verborgenen in der höfischen Literatur. Mit 5 Abbildungen. Göttingen 2019.

19 Niklaus Largier: Die Kunst des Begehrens. Dekadenz, Sinnlichkeit und Askese. München 
als stigmata in seinen Körper einprägenden Visionen. Diese werden in lateinischen und deutschsprachigen Texten auf unterschiedliche Weise diskursiviert: Während in den lateinischen Franziskus-Viten das Geheimnis der Gnadenerfahrung in Unsagbarkeitsformeln gekleidet wird, zeichnen sich die deutschsprachigen Fassungen dieser Viten durch plastische Veranschaulichung aus. Auch Yoshiki Koda arbeitet in seinem Beitrag gerade das Gelingen einer Offenbarung göttlicher Geheimnisse im Kommunikationsraum mystischen Sprechens heraus, und er zeigt, dass der mittelalterliche Mystiker-Poet damit in der Tradition des griechischen Parrhesiasten steht, des - nach Michel Foucault - vierten Typos des antiken Wahrheitssprechers neben Prophet, Weisem und Fachmann. Stephan Müller hingegen geht davon aus, dass die Offenbarung durch Schrift immer in einen Prozess der Transformation überführt wird, der in der Mystik durch die Entwicklung eines eigenen Alphabets, wie sie von Hildegard von Bingen überliefert ist, eine adäquate Darstellung findet. Diese Art der ,Geheimschrift' ist, wie Müllers Beitrag zeigt, zwischen 800 und 1500 zugleich auch aus anderen Kontexten als exklusive kommunikative Praxis überliefert, was nicht zuletzt darauf verweist, dass (die Beherrschung von) Schrift im Mittelalter selbst ein arcanum darstellte. Wie Susanne Reichlin in ihrem Beitrag zu einem in mehreren Handschriften überlieferten geistlichen Tagelied des 15. Jahrhunderts zeigt, kann noch eine konventionelle lyrische Form, hier eine Sündenschlaf-Allegorie, geheimnisvolle Züge erlangen. Dies vollzieht sich hier - in Plusstrophen einer Handschrift - im Wechsel von einer, weckenden' zur, geweckten' Sprechinstanz, welcher auch die Modi von rätselhaftem und geheimnisvollem Sprechen miteinander konfrontiert und nach der Fremd- eine Selbstbeobachtung etabliert. Diese Transformation ist, wie die Kotexte der Handschrift nahelegen, vermutlich vom mystischen Diskurs beeinflusst.

Die mittelalterliche Kultur kennt ferner die Tradition der sogenannten secretaSchriften, einerseits in der Nachfolge einer seit dem 12. Jahrhundert in Europa bekannten arabisch-pseudoaristotelischen ,Weisheitslehre' für Alexander den Großen (10. Jahrhundert), welche das Genre der sogenannten ,Fürstenspiegel’ einleitet (Secretum Secretorum), ${ }^{20}$ andererseits in der Überlieferung von Pseudo-Alberts De secretis mulierum (Ende 13. / Anfang 14. Jahrhundert), einer frauenheilkundlichen Schrift. Beide richten sich an ein ausschließlich männliches Publikum. ${ }^{21}$

2007; Hildegard Elisabeth Keller: My Secret is mine. Studies on Religion and Eros in the German Middle Ages. Leuven 2000.

20 Vgl. die neueren Auseinandersetzungen mit der Tradition von Michele Campopiano: Secret Knowledge for Political and Social Harmony. The Secretum Secretorum between the Middle East and Europe, sowie von Helen Fulton: A ,Mirror of the Gentry'. Vernacular Versions of the Secretum Secretorum in Medieval Wales and England, beide in: Prodesse et delectare. Case Studies on Didactic Literature in the European Middle Ages / Fallstudien zur didaktischen Literatur des europäischen Mittelalters. Hg. von Norbert Kössinger und Claudia Wittig. Berlin, Boston 2019, S. 39-56 und S. 57-82. Vgl. außerdem grundlegend die komparatistische Untersuchung von Regula Forster: Das Geheimnis der Geheimnisse. Die arabischen und deutschen Fassungen des pseudo-aristotelischen Sirr al-asrar / Secretum secretorum. Wiesbaden 2006.

21 Vgl. die Analyse von Karma Lochrie: Covert Operations. The Medieval Uses of Secrecy. 
Insbesondere die Frühe Neuzeit gilt geradezu als Hoch-Zeit des Geheimnisses. Das 15. und 16. Jahrhundert ist zudem eine Hoch-Zeit der europäischen Verbreitung religiöser Spiele, die zum Beispiel in Frankreich und England - nicht jedoch im deutschsprachigen Raum - als Mysterien bezeichnet werden. Dem geht Glenn Ehrstine in seinem Beitrag nach. Er zeigt, dass die im Deutschen verbreitete Bezeichnung figura gerade auf Mysterien christlichen Glaubens zielt, welche die Spiele erfahrbar machen, indem etwa in einem Fronleichnamsspiel den Zuschauern die gnadenspendenden Mysterien des Sakraments offenbart werden oder in einem Osterspiel der Erlösungstod Christi vermittelt wird. Auch hier hat im Übrigen - wie Ehrstine zeigt - die Offenbarung des Geheimnisses eine ökonomische Dimension.

Auf der Ebene der Ökonomie, aber auch der politischen Theorie oder der entstehenden ,Naturwissenschaften' spielt das Geheimnis in der Frühen Neuzeit ebenfalls eine bedeutende Rolle. In der politischen Theorie eines Macchiavelli und mehr noch eines Justus Lipsius wird die Lehre von den arcana imperii - den Staatsgeheimnissen, die im öffentlichen Interesse geheim sind, weil sie den Fortbestand des Staates selbst sichern - zu einem der Kernelemente der politischen Theorie des Absolutismus ausgebaut. ${ }^{22}$ In der ökonomischen Praxis entwickelt sich eine regelrechte "Ökonomie des Geheimen“, die Kapital aus Praktiken der Geheimhaltung schlägt, indem sie das Geheimnis verkauft. ${ }^{23}$ Francis Bacon konzipiert die entstehenden ,Naturwissenschaften' als Praktiken der ,Enträtselung.. ${ }^{24}$ Das ,Experiment' ist dabei die Frage, die - wenn sie richtig gestellt ist - eine Antwort der Natur hervorruft, in der sich dann ein Gesetz oder eine Regel zu erkennen gibt, so dass sich die Entdeckung der ,Naturgesetze‘ als Enträtselung vollzieht.

Im Gegensatz zu dieser Enträtselung der Natur durch die ,Naturwissenschaften' scheint die Alchemie zu stehen, die sich gerade nicht - wie die spätere Chemie - einer Entschlüsselung der Phänomene verschrieben hat, sondern die Natur in einer geheimnisvollen Bildersprache zu deuten versucht. Die Alchemie des Mittelalters und der Frühen Neuzeit lebt geradezu von der Rätselhaftigkeit und dem

Philadelphia 1999, S.93-134. Dass die frauenmedizinischen Quellen selbst vielfach noch aufzudecken sind, erläutert Britta-Juliane Kruse: Verborgene Heilkünste. Geschichte der Frauenmedizin im Spätmittelalter. Berlin, New York 1996. Sie rechnet außerdem zumindest für die volkssprachigen Traktate auch mit einem weiblichen Adressatenpublikum aus medizinischen Praktikerinnen. Vgl. ebd., S. 100-112. Vgl. zum Kompex Gender und Geheimnis außerdem Ann Marie Rasmussen: Introduction [to Special Issue „Gender and Secrecy“]. In: Journal of Medieval and Early Modern Studies 30 (2000), H. 1, S. 1-4.

22 Vgl. neben dem Standardwerk von Michael Stolleis: Arcana imperii und Ratio status. Bemerkungen zur politischen Theorie des frühen 17. Jahrhunderts. Göttingen 1980 zuletzt etwa Norbert Campagna: Legitimität der ,arcana imperii' und des Diskurses über die ,arcana imperii' bei Gabriel Naudé. In: Staatsgeheimnisse. Arkanpolitik im Wandel der Zeiten. Hg. von Rüdiger Voigt. Wiesbaden 2017, S. 53-90.

23 Vgl. Daniel Jütte: Das Zeitalter des Geheimnisses. Juden, Christen und die Ökonomie des Geheimen (1400-1800). Göttingen 2012.

24 Hole Rößler: Rätselhafte Offenheit. Verfahren der Verrätselung und ihre soziale Produktivität in der frühneuzeitlichen Wissenschaft. In: Verrätselung und Sinnzeugung in Spätmittelalter und Früher Neuzeit. Hg. von Beatrice Trînca. Würzburg 2016, S. 181-215. 
Geheimnisvollen ihrer Darstellungsformen, von der Aurora consurgens und dem Buch von der heiligen Dreifaltigkeit bis hin zum Lamspring, dem Splendor Solis, zu Michael Maiers Atalanta fugiens und Johann Valentin Andreaes Chymischer Hochzeit Christiani Rosenkreutz. Wer diese Texte jedoch als Darstellungen von Wissen ernst nimmt, muss erkennen, dass in diesem Fall die Rätselhaftigkeit auf den Formen der Darstellung beruht - und nicht Geheimnisse zur Darstellung gebracht werden. ${ }^{25}$ Der Beitrag von Volkhard Wels zeigt am Beispiel des Alphidius und des Lamspring, wie ein scheinbar geheimnisvoller Text auch sehr gut aus der literarischen Tradition einer spielerischen Rätselhaftigkeit heraus verstanden werden kann. ${ }^{26}$ Nicht Geheimhaltung ist die Funktion der alchemischen Bildlichkeit, sondern auf Enträtselung zielende Verrätselung natürlicher, nämlich in der Natur zu beobachtender Prozesse. Damit aber wäre die frühneuzeitliche Alchemie gar nicht so weit weg von der Enträtselung der Natur, wie sie Francis Bacon von den ,Naturwissenschaften' (darunter die Chemie an einer der ersten Stellen) fordert.

Allerdings kann die Alchemie in der Frühen Neuzeit zweifellos auch mit Heilserwartungen theologischer Art verknüpft sein und dann tatsächlich Geheimnisse zur Darstellung bringen. Gerade der frühe Paracelsismus lebt von dieser Verbindung, wie Ute Frietsch in ihrem Beitrag an der pseudo-paracelsischen Philosophia ad Athenienses (1564) erörtert. Diese entwickelt (vielleicht vor dem Hintergrund des platonischen Timaios) eine alchemische Schöpfungslehre, die zumindest so gelesen werden konnte, dass sie die biblisch bezeugte creatio ex nihilo in Frage stellte.

Die paracelsischen und - fast mehr noch - die pseudo-paracelsischen Texte zeichnen sich in jedem Fall durch ein hohes Maß an gewollter Unverständlichkeit aus. In vielen Fällen ist diese Unverständlichkeit der Tatsache geschuldet, dass diese Texte beanspruchen, Ausdruck einer höheren Wahrheit zu sein, einer göttlichen Offenbarung. Sie sind - wie in mittelalterlich-theologischer Tradition mithin geheimnisvoll, weil sie eine Wahrheit zur Darstellung bringen, die sich in unverhüllter Form gar nicht darstellen lässt. Wie Simon Brandl an Alexander von Suchtens paracelsistischem Traktat De tribus facultatibus (um 1565) nachweist, deutet dieser das Geheimnis der incarnatio verbi, der Fleischwerdung des Wortes, als Präfiguration mystischer und alchemischer Denkfiguren. Wie in der mystischen Literatur des Mittelalters ist die poetische Darstellung Ausdruck der Notwendigkeit, das Unsagbare - die Vereinigung mit Gott - in immer neuen Bildern

25 Stellvertretend zur Alchemie vgl. Lawrence M. Principe: The Secrets of Alchemy. Chicago, London 2013.

26 Zur Abgründigkeit von Rätselspielen im Rahmen höfischer Geselligkeit in der Frühen Neuzeit vgl. Katja Gvozdeva: Spielprozess und Prozess der Zivilisation. Emotionales Rätsel in Italien und Frankreich zwischen 1479 und 1638. In: Scham und Schamlosigkeit. Grenzverletzungen in Literatur und Kultur der Vormoderne. Hg. von Katja Gvozdeva und Hans Rudolf Velten. Berlin, Boston 2011, S. 363-395. Zur Rätselkultur der Frühen Neuzeit vgl. ferner Heike Bismark: Rätselbücher. Entstehung und Entwicklung eines frühneuzeitlichen Buchtyps im deutschsprachigen Raum. Mit einer Bibliographie der Rätselbücher bis 1800. Tübingen 2012. Zur mittelalterlichen Tradition vgl. Tomas Tomasek: Das deutsche Rätsel im Mittelalter. Tübingen 1994. 
und Metaphern darzustellen. Dichterische Verrätselung erscheint als simulacrum von Offenbarungswissen.

\section{3 Ästhetisierung des Geheimnisses}

1935, also fast gleichzeitig mit dem eingangs zitierten Roman von Ernst Lothar, hat Walter Benjamin in seinem Aufsatz Das Kunstwerk im Zeitalter seiner technischen Reproduzierbarkeit den Begriff der "Aura“ entfaltet. Wie der Protagonist von Lothars Roman, der an der Geheimnislosigkeit der Moderne leidet, thematisiert Benjamin die Erfahrung des Verlusts der „Aura“ des Kunstwerkes in einer Moderne, die durch ihre technischen Möglichkeiten alles überall und jederzeit verfügbar macht. „Indem das Zeitalter ihrer technischen Reproduzierbarkeit die Kunst von ihrem kultischen Fundament löste“, so Benjamin, „erlosch auf immer der Schein ihrer Autonomie.“27 Was Benjamin dabei als „Aura“ bestimmt, ist der religiös fundierte Schleier des Geheimnisses, den das Kunstwerk in der Moderne verliert. Die Trauer über diesen Verlust, die Kritik der geheimnislosen Moderne, die mit ihren technischen Möglichkeiten die "Aura“ zerstört und das Geheimnis entschleiert, ist als romantische Reminiszenz Benjamins Aufsatz genauso eingeschrieben wie das Pathos des Fortschritts gegenüber neuen Formen kollektiver Kunstrezeption in Fotographie und Kino.

Nostalgie, wenn nicht Larmoyanz hinsichtlich der Sehnsucht nach einer Wiederkehr des Geheimnisses prägt einen wesentlichen Teil der Moderne. Am Anfang dieser Nostalgie stehen dabei romantische Dichtungen, allen voran die Erzählungen Ludwig Tiecks oder E.T.A. Hoffmanns. Das schönste Beispiel ist aber vielleicht der „Taugenichts“ Eichendorffs. Er zieht in die Welt hinaus, weil ihm das bürgerliche Erwerbsstreben seines Vaters, eines Müllers, unbefriedigt lässt, denn:

Wem Gott will rechte Gunst erweisen,

Den schickt er in die weite Welt,

Dem will er seine Wunder weisen

In Berg und Wald und Strom und Feld. ${ }^{28}$

Das eigentliche Wunder, das dem Taugenichts gewiesen wird, ist natürlich ein Geheimnis, nämlich die geheime Fügung seines Schicksals, das ihn durch eine Welt führt, die er nicht versteht, ja deren geheimnisvolle Dimension er nicht einmal wahrnimmt, so sehr gerade diese sein Schicksal bestimmt. Aber sein Gottvertrauen und seine Naivität - mithin eben nicht das bürgerliche Erwerbsstreben - führen ihn bis nach Rom, in den Mittelpunkt des katholischen Glaubens, und dann wieder zurück nach Wien, zurück zur Geliebten und in die Ehe. Hinter dem Alltag der Welt liegt das Geheimnis des Glaubens. Der Taugenichts bleibt ein ,tumber Tor', der keine Fragen stellt, gerade dadurch aber - im Unterschied zu

27 Walter Benjamin: Das Kunstwerk im Zeitalter seiner technischen Reproduzierbarkeit. Frankfurt a. M. 1963, S. 22.

28 Joseph von Eichendorff: Aus dem Leben eines Taugenichts. Berlin 1925, S. $6 f$. 
Parzival - sein Glück findet. Selten wird die Kontinuität in der Verbindung von Religion und Ästhetik, die gleichermaßen ästhetische und religiöse Aufladung des Geheimnisses vom Mittelalter bis in die Moderne besser greifbar als in dieser Linie, die von Parzival zum Taugenichts führt. Sie könnte allerdings zugleich übersehen lassen, dass bereits die Vormoderne den Verlust des Geheimnisses als einer ästhetischen Qualität des Lebens reflektiert und literarisch zur Darstellung bringt. Friedrich Wolfzettel zeigt dies im vorliegenden Band eindringlich in einer Studie zum altfranzösischen Lai de l'Oiselet vom Anfang des 13. Jahrhunderts. In diesem Exempel erscheint das Geheimnis in einer epochenspezifischen Form als Mythos, welcher programmatisch ,gebändigt' werden muss.

Die Geheimnislosigkeit des bürgerlichen Alltags ist es, an welcher der Protagonist des eingangs zitierten Romans von Ernst Lothar leidet. Und das Leiden an dieser Geheimnislosigkeit prägt auch noch markante Stimmen der Gegenwart wie die von Karl Heinz Bohrer. Bohrer hat in seinem vor einiger Zeit publizierten Lebensrückblick Jetzt. Geschichte meines Abenteuers mit der Phantasie seine Autobiographie in ihrer Verschränkung mit literarischen Vorlieben und der daraus entwickelten Theoriebildung dargelegt und sich im Zuge dessen vehement für eine Ästhetisierung im Sinne einer, Vergeheimnissung' des Lebens ausgesprochen. Was er beschreibt, könnte man in gewisser Weise als Versuch einer Re-Etablierung der Erfahrung des Wunders oder des Wunderbaren beschreiben:

Die Priorität von Alltäglichkeit war unerträglich geworden. Die Wochenenden, an denen man draußen auf der Straße umherging, waren so deprimierend. Warum? Ich hatte die Vorstellung, dass der nicht arbeitende, feiertägliche, eintagsferiengelaunte Mensch dann die ganze Unerheblichkeit des sogenannten Lebens offenbarte. Denn eigentlich ereignete sich nichts. Langsam wurde an dem scheinbar analytischen Phantasie-Interesse das Obsessive einer ganz anderen Begierde deutlich: nämlich nach dem, was man das ,höhere Leben' nennt. Die Surrealisten hätten das nicht so genannt. Aber das war es doch, was sie gewollt hatten! Es lag sogar ein verkappter religiöser Affekt darin. ${ }^{29}$

Der unbedingten Sehnsucht nach dem ,höheren Leben', die Bohrer hier als eine seiner Grunderfahrungen beschreibt, begegnet er mit einer Ästhetisierung des Erlebens, genauer, einer Suche nach dem einzigartigen Moment. Er findet ihn in der Literatur ebenso wie im eigenen Alltag, den er bewusst so weit wie möglich verfremdet, weshalb er auch nicht in Deutschland lebt, sondern in London und Paris. Es geht um ein ,höheres Leben', ausdrücklich keine ,höhere Wahrheit', auch kein Phantasma, ${ }^{30}$ keine Sinnstiftung. ${ }^{31}$ Aber es ist kein Zufall, dass Bohrer es mit einem religiösen Erlebnis in Verbindung bringt. Worte wie Wunder, Wunderbares, Zauber, Fantasie, Geheimnis fallen in seinem Buch sehr oft. Und die Grundlinie

29 Karl Heinz Bohrer: Jetzt. Geschichte meines Abenteuers mit der Phantasie. Berlin 2017, S. 47.

30 Vgl. Bohrer: Jetzt (Anm. 29), S. 102.

31 Vgl. Bohrer: Jetzt (Anm. 29), S. 103. 
der Verbindung zum Geheimnis, die er selbst andeutet, könnte die problematische These sein, dass in der Moderne die Ästhetik die Religion abgelöst habe. Aber Bohrer geht es um etwas noch Spezifischeres: Um eine ästhetische Erfahrung, die - wie beim Wunder - ursprünglich oder traditionell an das Religiöse geknüpft ist, als Erlebnismoment jedoch so genussvoll wird, dass sie die religiösen Sinngehalte, die sie transportiert, tendenziell in Vergessenheit geraten lässt. Das Ästhetische hätte dann also Priorität vor dem Religiösen, das Geheimnis wird inszeniert und soll nicht gelüftet werden, oder nicht unmittelbar, weil es die Inszenierung womöglich zerstören würde.

Doch solche Inszenierungsformen hat es schon in der mittelalterlichen Literatur gegeben, ein Beispiel wäre - auch hier wieder - der Parzival in seiner vielleicht bekanntesten Passage, der Begegnung des Helden mit dem Gral. Im vorliegenden Band untersucht Maximilian Benz die Strategien ,verrätselnden' Erzählens in Wolframs von Eschenbach Roman, mit denen der Gral als zentrales Mysterium ästhetisch entfaltet wird. Der Gral erscheint dabei als Geheimnis, das auf paradoxe Weise zugleich enthüllt werde wie verborgen bleibe. Anders als Bohrer es behauptet, sind eine Ästhetik des Geheimnisses und Formen der Ästhetisierung des NichtWissens oder Noch-nicht-Wissens demnach nicht der Moderne zuzuschlagen. In der mittelalterlichen Literatur ist die Epiphanie oder das Erscheinen des Heiligen in der Welt gerade ästhetisch vermittelt und plausibilisiert. Es gilt, dass Gott in den Wundern zu erkennen ist, die er wirkt, ${ }^{32}$ und dass deshalb über das Wunder auch Wissen erworben wird. Spätestens seit dem Parzival - bzw. seinem altfranzösischen Prätext - wird in der mittelhochdeutschen Literatur außerdem eine Tendenz manifest, die höfische Welt des Artusromans um eine Dimension des hypertrophen Wunderbaren zu ergänzen, deren Funktionen nicht einsichtig werden. Anstatt eine Verständnishilfe zu bieten, scheinen religiöse Anklänge in Darstellungsmustern höfischer Romane dann das Geschehen eher weiter zu verdunkeln.

Zwischen Phänomenen des Wunderbaren und dem Geheimnis bestehen dabei viele Affinitäten. Prima vista ließe sich sagen, dass das Wunderbare eher auf eine Offenbarung von Wissen zielt, das Geheimnis auf sein Verbergen. Manchmal kann Wissen allerdings auch gerade daraus bestehen, ein Geheimnis nicht zu lüften. Den hypertrophen Darstellungsformen des Wunderbaren in den späthöfischen Romanen Diu Crône Heinrichs von dem Türlin und Apollonius von Tyrland von Heinrich von Neustadt als Formen der Ver- und Enthüllung von Wissen geht Jutta Emings Beitrag nach. Sie untersucht dabei zugleich, wie sich Ansätze zur Unterscheidung zwischen Geheimnis und Rätsel oder von Rätselhaftem und Ge-

32 Vgl. hierzu grundlegend Umberto Eco: Kunst und Schönheit im Mittelalter. München, Wien 1991 (it. 1987). Dass dies nicht heißt, dass mittelalterliche Kunst grundsätzlich religiös zu interpretieren ist, elaboriert - mit Verweis auf die antiken, insbesondere rhetorischen Wurzeln der mittelalterlichen Begriffe des Ästhetischen - Mary J. Carruthers: The Experience of Beauty in den Middle Ages. Oxford 2013, vgl. ebd. auch zu ludischen Qualitäten des Geheimnisvollen S. 61-70. 
heimnisvollem als atmosphärischen Qualitäten und Inszenierungsstrategien für ihr Verständnis produktiv machen lassen.

\section{Geheimnis und Rätsel}

Trotz der unbestrittenen Evidenz der hier nur knapp skizzierten Phänomene, die sich bis in die Semantik hinein verfolgen lassen, ${ }^{33}$ will der vorliegende Band gerade die großen Dichotomien von Wunder und Wissen, Religion und Ästhetik, Geheimnis und Rätsel, sofern sie entlang von Epochengrenzen formuliert werden, nicht übernehmen. Es ging den Herausgeber*innen darum, die genannten Dimensionen zwar historisch, aber auch auf synchroner und systematischer Ebene zu verstehen und auf den Feinebenen der Analysen Charakteristika von Geheimnis und Rätsel zu erarbeiten, die sowohl als Wissensformen als auch als ästhetische Strategien funktionieren. Rätsel und Geheimnis sind dafür auf unterschiedliche Formen der Darstellung zu beziehen. Eine zentrale Rolle in den meisten Beiträgen dieses Bandes spielt dabei die Frage, welches Wissen aus welchen Gründen als Rätsel oder Geheimnis dargestellt wird.

Das Geheimnis - und auch in diesem Sinne ist das Zitat aus Lothars Roman paradigmatisch - übernimmt zentrale kulturstiftende Funktionen. Das Geheimnis lässt sich verstehen als eine Form, Wissen zu schützen oder nur exklusiv zugänglich zu machen, und dies in letzter Instanz ganz unabhängig von der Epoche. Wie Aleida und Jan Assmann im Rahmen ihrer vielbändigen Reihe zum Geheimnis (in Anlehnung an Georg Simmel) feststellen, ist das Geheimnis als Wissensform sogar der „,kulturstiftende und Gesellschaft ermöglichende Akt schlechthin“, eine Wissensform, die „im Hinausdenken über ihre Grenzen zugleich Formen einer Respektierung des Unwißbaren oder Vorenthaltenen ausbildet und auf diese Weise in der Dimension des Wissens einen gemeinschaftlich bewohnbaren sozialen Raum konstituiert. "34 Das Geheimnis setzt Handlungen in Gang - zum Beispiel solche der Geheimhaltung oder der Offenbarung - und schafft auf diese Weise soziale Netzwerke. ${ }^{35}$ Kristiane Hasselmann zeichnet in ihrem Beitrag solche Dynamiken am Beispiel der komplexen Geschichte frühmoderner Freimaurer-Bruderschaften nach, deren Geltung sich in einer ausgefeilten Relationierung von Darstellung und Geheimnis und daran geknüpfter Rituale zum Ausdruck bringt. Sie beglaubigen - wie Hasselmann im Anschluss an Jan Assmann zeigen kann ostentativ die Teilhabe an einem letztlich religiös fundierten Offenbarungswissen. Auch weitere Beiträge des vorliegenden Bandes versuchen, soziale Funktionen des

33 Vgl. auch den Band: wildekeit. Spielräume literarischer obscuritas im Mittelalter. Zürcher Kolloquium 2016. In Verbindung mit Ricarda Bauschke-Hartung und Franz-Josef Holznagel hg. von Susanne Köbele und Julia Frick. Berlin 2018.

34 Aleida und Jan Assmann: Das Geheimnis und die Archäologie der literarischen Kommunikation. Einführende Bemerkungen. In: Schleier und Schwelle. Bd. 1: Geheimnis und Öffentlichkeit. Hg. von dens. in Verbindung mit Alois Hahn und Hans-Jürgen Lüsebrink. München 1997, S. 7-16, hier S. 7.

35 Vgl. Lochrie: Covert Operations (Anm. 21), passim. 
Geheimnisses vornehmlich für die Literatur und Kultur des Mittelalters und der Frühen Neuzeit in Mikroanalysen auszuloten, ohne zugleich die große Erzählung des Geheimnisses als einer Epochensignatur fortzuschreiben. Dazu gehört eine Untersuchung von Johannes Traulsen zu Funktionen von Geheimhaltung im höfischen Roman. Bei dieser geht es darum, den Figuren Handlungsspielräume zu erschließen und eine Bewegung zwischen unterschiedlichen sozialen Gruppen, ja soziale Mobilität selbst zu ermöglichen.

Die Relationierung von Verbergen und Enthüllen, wie sie für das Geheimnis geltend gemacht wird, liegt allerdings ebenso dem Rätsel zugrunde, was die Frage nach einer internen Differenzierung zwischen beiden aufwirft. Für beide gilt, dass sie etwas in dem Maße der Wahrnehmung entziehen, wie sie es zugleich zu erkennen geben - und umgekehrt. Geheimnis und Rätsel sind beide prozessual und performativ als Darstellungsformen aufzufassen, die auf Auflösung oder Enträtselung angelegt sind. Dies impliziert die Aktivierung unterschiedlicher Wissensbestände, auch solcher, die nicht im engeren Sinne literarischer oder künstlerischer Natur sind. Es ist also zu fragen, was für ein Wissen es jeweils ist, das geheim gehalten oder verrätselt wird, welche ästhetischen Verfahren bei seiner Enthüllung/Verdeckung eingesetzt werden und wie sich die Funktionen geheimnisvoller oder rätselhafter Darstellung erklären lassen, insbesondere mit Blick auf die damit verknüpften Formen der Aneignung von Wissen. Weiter wäre zu untersuchen, wie Geheimnis und Rätsel innerliterarisch und performativ zwischen denen differenzieren, die das Geheimnis aufdecken und das Rätsel lösen, und denen, die das nicht können. In dem einen Fall könnte es eher um Initiation, Offenbarung und Glauben gehen, in dem anderen Fall eher um Kompetenz. Ferner dienen Rätsel und Geheimnis immer auch dem Aufbau erzählerischer Spannung: Sie binden die Rezipienten so in die Dialektik von Darstellen und Vorenthalten ein, dass diese das Interesse an der Erzählung nicht verlieren.

Während das Rätsel die Möglichkeit seiner Enträtselung zu implizieren scheint, kann das Geheimnis auch allen Versuchen seiner Enthüllung widerstehen. Als Adjektive und Adverbien werden Geheimnis und Rätsel oft als Substitute füreinander verwandt (rätselhaft/geheimnisvoll), aber als Substantive zeigen sie eine größere Entfernung zueinander. Das Rätsel hat etwas mit willentlichem Verbergen zu tun, es schützt - wie z. B. in den in der Vormoderne weit verbreiteten Apollonius-Romanen das Tabu eines Inzests - und gibt es in seiner speziellen, nach Auflösung heischenden Form zugleich etwas preis. Dieser Mechanismus ist bereits aus dem Rätsel der Sphinx im Ödipus-Stoff bekannt. Um Rätsel zu lösen, braucht es Kompetenz oder Intelligenz. Dem Geheimnis nähert man sich in vielen Fällen dagegen eher emotional, teilweise über das Wunder. Das Geheimnis wird eher der visuellen Sphäre zugeschlagen, das Rätsel der sprachlichen. Das Geheimnis gilt eher als sakral, das Rätsel kann auch ganz profan der Unterhaltung dienen. ${ }^{36}$ Das

36 Jochen Hörisch: Vom Geheimnis zum Rätsel. Die offenbar geheimen und profan erleuchteten Namen Walter Benjamins. In: Schleier und Schwelle (Anm. 8), Bd. 2, S. 161-178, hier S. 162. 
Geheimnis gehört, so Jochen Hörisch, der ,verzauberten Welt‘ an, das Rätsel der säkularen: „Rätsel lösen statt den Schleier des Geheimnisses zu durchschauen: das ist die neue intellektuelle, ästhetische und philosophische Grundgeste, die sich im neunzehnten Jahrhundert durchsetzt." ${ }^{\prime 37}$ Während der Diskussionen der Tagung zeigte sich allerdings, dass Geheimnis und Rätsel schwer zu differenzieren sein können - und zwar ebenso im historisch konkreten Fall wie systematisch.

\section{Geheimnis und Darstellung als Problem der Wissensgeschichte}

Damit ist grob umrissen, welche Problematik mit den titelgebenden Begriffen dieses Bandes angesprochen ist. Geheimnis und Darstellung sind als komplementäre Begriffe zu denken, denn es gibt kein Geheimnis, das nicht in irgendeiner Form zur Darstellung gelangen muss, um überhaupt Geheimnis sein zu können. Das Geheime ist, so paradox das anmuten mag, nur dann geheim, wenn seine Heimlichkeit dargestellt wird. Das Rätsel ist nur dann ein Rätsel, wenn es als solches erkannt wird. Die Darstellung des Geheimnisses ist seine literarische - oder allgemeiner: seine ästhetische - Form. Was dagegen im Geheimnis verheimlicht und im Rätsel verborgen wird, ist immer und überall ein Wissen.

Es geht dabei nicht um ein schlichtes Abbildungsverhältnis, denn die Pointe an Geheimnis und Rätsel ist eben gerade, dass das Wissen als solches nicht dargestellt wird. Man mag das als einen - zumindest partiell - negativen Transfer begreifen. ${ }^{38}$

Geheimnis und Rätsel sind Formen der Wissensübertragung - und zwar nicht nebenbei oder zufällig, sondern im Kern. Es handelt sich um Formen eines Wissenstransfers, dessen Spezifik eben darin besteht, dieses Wissen so zu vermitteln, dass es nicht unmittelbar zugänglich ist. Die Fragen, die sich aus der Perspektive einer Wissensgeschichte aufdrängen, lauten: Was ist das für ein Wissen, das solcherart vermittelt wird? Welche Funktion haben Geheimnis und Rätsel in dieser Form des Transfers? Viele Beiträge des Bandes adressieren diese Aspekte explizit; doch selbst eine auf den ersten Blick eher poetologische Frage wie die nach Bedingungen der Konstruktion von literarischer Spannung hat epistemische Dimensionen. Dies zeigt Falk Quenstedt in seinem Beitrag zum Jüngeren Titurel (um 1260/70), der sich auf den Parzival Wolframs von Eschenbach als Prätext bezieht und dabei mit ,Rätselspannung,' also einem Aufschub von Wissenswertem arbeitet, das sich wiederum in Darstellungsformen des Wunderbaren manifestiert. Abgründige Varianten des Wissenserwerbs durch Rätsellösung, die in hohem Maße an die ästhetische Form gebunden sind, analysiert Beate Kellner in ihrer Untersuchung zum Rätselwettstreit in verschiedenen Überlieferungsträgern der Wartburgkrieg-Tradition. Was sich auf den ersten Blick als Rätsellösung ausnimmt, kann zum Beispiel eine neue Verrätselung darstellen. Der über verschiedene Bild-

37 Hörisch: Vom Geheimnis zum Rätsel (Anm. 36), S. 164f.

38 Vgl. zum Thema den Band zur 7. Jahrestagung des SFB 980 „Episteme in Bewegung“: Dynamiken der Negation. (Nicht)Wissen und negativer Transfer in vormodernen Kulturen. Hg. von Şirin Dadaş und Christian Vogel. Wiesbaden 2021. 
felder, poetische Redeweisen und alludierte Prätexte ausgetragene Wettstreit bezieht sich sowohl auf den Vorrang des Dichtens als auch auf Grenzen des Wissens.

Einige Tagungsteilnehmer*innen haben anregende und für das Thema fruchtbare Vorträge gehalten, die leider im Band nicht mehr vertreten sind. Zu ihnen gehört der im Jahr 2020 verstorbene Thomas Lentes, an dessen Beitrag und an dessen Person wir hiermit abschließend noch einmal eigens erinnern möchten. Thomas Lentes hielt den Eröffnungsvortrag und erörterte in ihm, vor dem Hintergrund eines neuen Forschungsprojekts, die christliche Sakralisierung der Beschneidung Jesu. Im Mittelpunkt seines Vortrags stand die Paradoxie, in der die kirchlich institutionalisierte Feier der Erinnerung an die circumcessio Christi durch den jüdischen Ursprung dieses Rituals steht. Sie ließ sich, wie Lentes zeigt, durch dessen Neuinterpretation als Mysterium auflösen, indem sich hinter dem Akt der Beschneidung Christi die rituelle forma einer Beschneidung der ,Vorhaut des Herzens' verbirgt: Der alte, sündhafte Mensch, in Adam präfiguriert, wird gleichsam ,freigeschnitten' und in Christus neugeboren. Wir bedauern es sehr, diesen Beitrag hier nicht mehr veröffentlichen zu können. 
Ästhetisierungen 



\title{
Der gefangene Mythos befreit sich durch seine Rätsel
}

\author{
Überlegungen zum altfranzösischen Lai de l'Oiselet
}

Friedrich Wolfzettel

Der von dem berühmten Romanisten Erhard Lommatzsch übersetzte und in den Geschichten aus dem alten Frankreich 1947 veröffentlichte Lai de l'Oiselet ${ }^{1}$ vom Anfang des 13. Jahrhunderts scheint die Erleichterung über das Ende nationalsozialistischer Gleichschaltung von Kunst und Wissenschaft zu spiegeln. Erzählt wird die folgende exemplarische Geschichte:

Ein begüterter Bauer hat den einst von einem Magier geschaffenen Zaubergarten aus dem Nachlass eines Ritters erworben. Der Garten, der keine Jahreszeiten kennt, ähnelt einem Paradies, in dessen Mitte sich neben einer Quelle ein herrlicher Baum erhebt. Von diesem lässt ein Vöglein, kaum größer als ein Zaunkönig, zweimal am Tag, morgens und abends, seinen Gesang erschallen, durch den der ewig blühende Garten erhalten wird. Auch der als habgierig und neidisch charakterisierte Bauer hört den wundersamen Gesang und will das Tier fangen, um es zu verkaufen oder in einen Käfig zu sperren. Noch am selbigen Abend bemächtigt er sich des Vögleins, das ihm eine Lehre in höfischer Sittsamkeit erteilt und ihn mit dem Hinweis, dass es in Gefangenschaft niemals singen werde, um die Freilassung bittet. Dafür wolle es dem Bauer drei für ihn nützliche Lehren erteilen. Neugierig lässt sich der Bauer darauf ein, fühlt sich aber alsbald durch die scheinbare Banalität der beiden ersten Weisheiten zum Narren gehalten. Sie lauten: ,Glaube nicht alles, was man dir sagt!' und: ,Beweine nicht, was du niemals besaßest!' Dann erzählt das Vöglein von einem Edelstein in seinem Leib, der dem Bauer durch die Freilassung entgangen sei, und fügt die dritte Weisheit an: ,Wirf nicht fort, was du in Händen hast!' Erst jetzt wird dem Bauer der Sinn auch der beiden ersten Lehren klar. Das Vöglein aber spottet über die Leichtgläubigkeit des Bauern und verlässt für immer den Garten, dessen Zauber für alle Zeiten gebrochen ist.

Das von Gaston Paris 1884 kritisch edierte und kommentierte Exempel ${ }^{2}$ von nur 410 Achtsilberversen war im Mittelalter weit verbreitet und blieb bis in die

1 Geschichten aus dem alten Frankreich. Übertr. von Erhard Lommatzsch. Frankfurt a. M. 1947, S. 27-38.

2 Le Lai de l'Oiselet. Poème français du XIIIe siècle. Hg. von Gaston Paris. Paris 1884, wiederabgedruckt in: Légendes du Moyen Âge. Par Gaston Paris. Paris 1903, S. 274-291. Die Edition bildet die Grundlage der hier benützten Nouvelles courtoises. Occitanes et françaises. Éditées, traduites et présentées par Suzanne Méjean-Thiolier et Marie-Françoise Notz-Grob. Paris 1996, S. 426-449. 
Spätaufklärung lebendig. Von Christoph Wieland stammt die im Teutschen Merkur 1778 publizierte Erzählung Der Vogelsang oder die drei Lehren, die der Vorliebe der Aufklärung für den Aphorismus wohl entgegenkam. Der französische Lai basiert auf dem 22. Exempel der Disciplina clericalis des Petrus Alfonsi, ${ }^{3}$ dem Exemplum de Rustico et Avicula, von dem auch die 167. Geschichte der Gesta Romanorum, eine Fassung im Libro del Caballero Zifar und die romanhaft erweiterte Fassung von John Lydgate, The Churl and the Bird, im 14. Jahrhundert, beeinflusst wurden. Varianten finden sich in der Legenda aurea, in den Exempla von Jacques de Vitry und im Dialogus creaturarum des Nicolas de Bergame. Das zum folkloristischen Typus AarneThompson 150 (Motif K 604), The Three Teachings of the Bird, gehörende Exemplum geht letztlich auf indisch-buddhistische, arabische und auch jüdische Quellen zurück. Von letzteren stammt wahrscheinlich das Motiv des Paradiesgartens. Die höfische Überformung des altfranzösischen Lai, in Übereinstimmung mit einer breiten Tradition der Gattung seit Marie de France, zeigt den Einfluss des tristanischen Donnei des Amanz. ${ }^{4}$ Das lange vorherrschende stoffgeschichtliche Interesse ${ }^{5}$ ist erst in neuerer Zeit durch das gattungsgeschichtliche Interesse für die Formen des récit bref und den üblich gewordenen Begriff der höfischen Novelle in der französischen Forschung ergänzt worden. Ich will in der Folge auf die spezifische Rolle des Wunderbaren als einer besonderen Form des Mythischen eingehen, das gerade in der Gattung des Lai auffällig oft im Mittelpunkt steht.

Abgesehen von der Dialektik der nicht verstandenen Rätsellehren und der damit verbundenen topischen Polemik gegen die Beschränktheit des vilain erscheint der Lai zunächst als eine Apotheose höfischer Lebensart und Freude, die im Gesang des Vögleins zum Ausdruck kommt und in dem Wunder einer immerblühenden Natur gleichsam symbolisch verkörpert wird. Der Garten ist so in der Tat das durch Höfischkeit wiedergewonnene Paradies. Von einem Nigromanten entworfen - das Motiv finden wir in Chrétiens Cligès, in Floire et Blancheflor oder im Filocolo des Boccaccio ${ }^{6}$-, wird der Garten eben durch den Vogelgesang zum Inbegriff höfischer Freiheit im Zeichen der Freude. Wer immer diesen Gesang vernimmt, ob Alt oder Jung, ob Hochgestellt oder Arm, heißt es da in den zusätzlichen Ausführungen des lehrreichen Vögleins, vergisst die Beschwerlichkeiten des Lebens und partizipiert an der wunderbaren Kraft des Gesanges:

3 Siehe Haim Schwarzbaum: International Folklore Motifs in Petrus Alphonsi's Disciplina clericalis. In: Sefarad 21, 22 und 23 (1961, 1962 und 1963), hier Bd. 22, S. 50-52.

4 Vgl. Michel Potelle: Le Conte de l'oiselet dans le Donnei des Amanz. In: Mélanges offerts à Rita Lejeune. 2 Bde. Hg. von Fred Dethier. Gembloux 1969, Bd. 2, S. 1299-1307.

5 Franz Tyroller: Die Fabel von dem Mann und dem Vogel in ihrer Verbreitung in der Weltliteratur. Berlin 1912.

6 Vgl. Friedrich Wolfzettel: Wassersymbolik und Zeitenwende bei Boccaccio. In: Wasser in der mittelalterlichen Kultur. Gebrauch - Wahrnehmung - Symbolik. Hg. von Gerlinde HuberRebenich, Christian Rohr und Michael Stolz. Berlin, Boston 2017, S. 465-471. 


$\begin{array}{ll}\text { Car dou chant issent les amors } & \begin{array}{l}\text { Denn die Liebe geht aus dem Gesang } \\ \text { hervor, } \\ \text { der die Blumen, die Bäume und alles, } \\ \text { was wächst, } \\ \text { Qui en vertu tienent les flors }\end{array} \\ \text { Et les arbres et tot le més; } & \begin{array}{l}\text { sprießn lässt. }\end{array}\end{array}$

(V.119ff.)

Dem Vöglein fällt somit die Rolle eines höfischen Sängers zu, der über die engeren Standesgrenzen hinaus zum Träger eines neuen Lebensgefühls wird und eine neue, die Natur bezwingende Kraft von Musik und Sprache repräsentiert:

Li oiseaus fu si afaitiés

A dire lais et noveaus sons

Et rotruenges et chançons

Gigue ne harpe ne viele

$\mathrm{N}^{\prime} \mathrm{i}$ vausist pas une cenele.
Der Vogel war so dazu berufen, Lais und neue Melodien, Rotrouengen und Lieder von sich zu geben; Gigue, Harfe oder Viele wären keinen Deut besser gewesen.

(V.90ff.)

Dabei liegt der Akzent eben weniger auf dem Motiv des ewigen Frühlings und seiner immerwährenden Fruchtbarkeit als auf der verwandelnden Kraft des - höfischen - Gesangs, der dem verständnislosen vilain als mythische Kraft entgegentritt. Mit Blick auf die fast 600 Jahre jüngere Ballade Goethes, Der Sänger, möchte man von einer vorweggenommenen Autonomieerklärung der Kunst sprechen; denn auch das oiselet singt, wie "der Vogel singt, der in den Zweigen wohnet", und wird nur durch den Zauber des eigenen Gesangs belohnt. Der unverstandene Mythos aber wird zum Geheimnis, das in den Rätseln des Vogels zurückschlagen wird. Die der Gattung inhärente Spannung zwischen dem Wunderbaren und der Wirklichkeit - „el chant avoit une merveille“ (V. 95; „dem Gesang wohnte eine wunderbare Kraft inne") - wird so zwar sozialgeschichtlich konkretisiert, indem der reich gewordene vilain den Wundergarten eines "chevaliers gentis" (V. 23; ,eines edlen Ritters“) erwirbt, zugleich aber über die sozialen Gegebenheiten hinausgehoben. Die Erinnerung an die höfischen Werte, an die "clerc et dames et chevalier“ (V. 181; „die Kleriker, Damen und Ritter“), die einst an diesen Ort kamen, um dem Gesang des Vögleins zu lauschen und die höfischen Werte, Großzügigkeit, Tapferkeit und „cortoisies" (V. 185f.) zu lernen, schließt nicht aus, dass ein vilain oder Bürger sich bei diesem Gesang wie ein Kaiser oder König fühlt (V. 104ff.) und der Jüngling sich wie für die Liebe gemacht vorkommt (V.110ff.). Die ständeübergreifende Macht dieses höfischen Gesangs wird dadurch unterstrichen, dass nicht die klassischhöfische Nachtigall der mittelalterlichen Tradition aufgerufen wird, sondern eine unbestimmbare Mischung aus Sperling, Zaunkönig, Nachtigall, Amsel, Drossel und Star, wunderbar edel, „merveilles gens“ (V.79), aber eben außerhalb der höfischen Topik und außerhalb einer bestimmbaren Wirklichkeit, dazu auserlesen, 
in einem topischen, gerade für die Gattung Lai typischen Ambiente von Baum und Quelle ${ }^{7}$ die reale Zeit und den Wechsel der Jahreszeiten zu überwinden. Das Vöglein verkörpert so eine höhere Wirklichkeit, die in ritueller Weise des Morgens und des Abends zu Besuch kommt, sich aber nicht vereinnahmen lässt und daher auch für eine Gefangenschaft - wie etwa die chinesische Nachtigall - nicht verfügbar ist. $\mathrm{Zu}$ den Leitmotiven der Freude und Lieblichkeit gesellt sich so das Motiv der Freiheit, die - wie schon gesagt - als Vorwegnahme des neuzeitlichen Autonomiegedankens erscheint, die aber vor allem der sich anbahnenden Verbürgerlichung des adligen Lebens die Gültigkeit höfischer Werte in einem neuen, mythisch zu nennenden Rahmen entgegenhält - so wie der adlige Paradiesgarten zum mythischen Aufenthaltsort des vilain geworden ist.

Das Geheimnisvolle ist allgemein geworden, wie auch die vom Vogel verkündeten Rätsellehren allgemeingültiges Erfahrungswissen repräsentieren. Doch ist eben diese Allgemeingültigkeit des mythischen Entwurfs gleichsam eine List der Geschichte: „Li oiseaus fu plains de voisdie“ (V. 270; „der Vogel war voller List“), wie es nach der Freilassung durch den Bauern heißt. Der Bauer wartet auf eine gewinnbringende Offenbarung, aber die Lehren des Vogels verweisen auf die Alltäglichkeit der im Garten und im Vogel selbst anschaulich gewordenen mythischen Dimension. Die der Zeit enthobene Fülle des Seins und das frische Wasser des Lebens in der sprudelnden Quelle ermöglichen auch einem vilain, sich zu erfrischen. Es bedarf keines höfischen Quellabenteuers. Freilich ist jeder Bemächtigungsversuch zum Scheitern verurteilt, denn die oben genannte Freiheit ist die Bedingung des alltäglich gewordenen Mythos. Und ein gefangener Vogel ähnelt einem gerupften Vogel, wie es nach der Freilassung heißt: „Mas estoit et tos hericiés, / Car laidement fu manoiés“ (V. 263f.; "schlimm sah er aus und arg zerzaust, denn er war schlecht behandelt worden"). Quelle, Baum und Vogel bilden so den Dreiklang der mythischen Grundierung des Lebens, die eben in den drei Weisheiten des Vogels zum Ausdruck kommen soll.

Die drei selbstverständlichen Weisheiten haben hier die Funktion von Rätseln, die der Bauer nicht begreift und durch die sich der im Vogel verkörperte Mythos selbst aus der Gefangenschaft befreit. Rätsel und Geheimnis haben in der mittelalterlichen Literatur eine lange Tradition. Frédérique Le Nan hat in seiner großen Monographie Le Secret dans la littérature narrative arthurienne (1150-1250) von $2002^{8}$ die breite lexikalische und motivgeschichtliche Bedeutung des Motivs - von der göttlichen Offenbarung und der arthurischen Feenwelt bis zur höfischen Psychologie des Verbergens und Verschweigens - für das Selbstverständnis der Gattung Roman an sich geltend gemacht. Und mit Sylviane Messerli ${ }^{9}$ oder Daniel Poirion ${ }^{10}$ könnte man ergänzend auf die Rolle des ödipalen imaginaire gerade für den mit-

7 Hierzu Pierre Gallais: La Fée à la Fontaine et à l'Arbre. Un archétype du conte merveilleux et du récit courtois. Amsterdam, Atlanta 1992.

8 Frédérique Le Nan: Le Secret dans la littérature narrative arthurienne (1150-1250). Paris 2002.

9 Sylviane Messerli: Edipe enténébré. Légendes d'CEdipe au XIIe siècle. Paris 2002.

10 Daniel Poirion: Edyppus et l'énigme du roman médiéval. In: Senefiance 9 (1980), S. 287-298. 
telalterlichen Roman verweisen. Ein ganzer Begriffsbereich mit seinen onomastischen Varianten spiegelt die zentrale Funktion, eine verborgene oder geheime Wahrheit zum Sprechen zu bringen und dem Roman in der Gestalt seines Helden einen gnoseologischen Stempel aufzudrücken. Verglichen mit solchen Vorgaben hat das secret in unserem Lai eine deutlich andere Dimension. Es geht nicht um eine verborgene Gegebenheit, sondern um ein offenes Geheimnis, an dem der unbedarfte Held aufgrund seiner Habgier scheitert. Mit den letzten Sätzen des Lai:

Or sachent bien totes et tuit;

Li proverbes dit en apert:

,Cil qui tot convoite tot pert.'
So sollen alle, Mann und Frau, wissen wie es das Sprichwort offen sagt: ,Wer alles haben will, wird alles verlieren.

(V.408ff.)

Diese proverbiale Weisheit hätte der mythischen Einkleidung nicht bedurft. Aber erst letztere schafft den Rahmen der Verblendung für die in den höfischen Motiven zum Ausdruck gebrachte Ganzheitlichkeit des Seins, die dem vilain nicht zugänglich ist. Die moralistische Literatur übernimmt so die Aufgabe, eine Dimension in den Blick zu rücken, ohne die der Zauber des Lebens verdorren würde. Das Exempel um den gierigen vilain wird zum Exempel über den nicht begriffenen Mythos, der für den Bauer zum Rätsel wird, weil er das Leben nicht verstanden hat. Unter dem Deckmantel moralistischer Didaxe - mit J. Donovan kann man den Lai ja auch als klassisches Beispiel eines „lai didactique“ verstehen ${ }^{11}$ - bringt der Lai de l'Oiselet eine tiefere, hinter der Didaxe liegende Dimension mythischer Ganzheit zur Sprache, die an kein besonderes Geheimnis geknüpft ist, weil sie offen zutage liegt, und lediglich auf ein Problem des Verstehens verweist. Die letzten Worte des Vögleins sind nicht zufällig eine Lektion des Verstehens:

,On dit que tés n'entent qui ot Et tés parole par grant sens

Qui en soi a pou de porpens;

Tés parole de cortoisie

Qui ne la savroit faire mie, Et tés cuide estre bien senés Qui a folie est assenés.'
,Man sagt, dass manche hören, ohne zu verstehen; manch einer mag die klugen Reden, ohne selbst denken zu können; mancher spricht von Höfischkeit, ohne selbst imstande zu sein, sie zu üben; und mancher hält sich für weise, der sich wie ein Narr benimmt.'

(V.394ff.)

11 Mortimer John Donovan: The Breton Lay. A Guide to Varieties. Notre Dame, IN 1969, S. 189. 
Der vertrocknete Garten ${ }^{12}$ ist offensichtlich auch das Symbol für ein vertrocknetes Sein. Der moralisierende Autor nützt den alten Stoff nicht nur, um den Verlust der höfischen Tugenden zu beklagen, sondern um den Verlust der ganzheitlich mythischen Dimension des Lebens anzudeuten und deren Schönheit in Bildern höfischer Tradition anschaulich zu machen. Der offene, ungewöhnliche Schluss - ist das überhaupt ein Schluss, fragen sich die Herausgeber der Ausgabe in den Lettres gothiques $^{13}$ - scheint auch die Frage nach dem Ziel über das orientalische Weisheitsmotiv hinaus nahelegen zu wollen. Der Vogel flog weg, heißt es lakonisch, „et de tel eür s'en ala / qu'ainc puis el vergier ne revint“ (V. 402f.; "Und das Schicksal wollte es, dass er nie mehr in den Garten zurückkehrte."). Der Wegflug des Vogels, der Inkarnation mythischer Kraft, impliziert den Triumph und zugleich den Verlust des Mythischen, der sich der höfischen Einkleidung bedient hat. Der Lai verweist so auf eine wesentliche Qualität des sog. Mittelalters, die ich auch in mei-

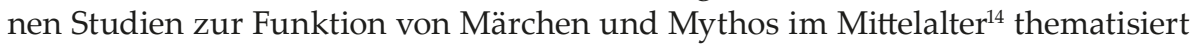
habe und die für die Bestimmung von Epochengrenzen von ausschlaggebender Bedeutung ist: die Dialektik von höfisch-klerikaler Kultur und mythisch-folkloristischem Substrat. Sie ist das eigentliche Geheimnis des Mittelalters und bildet den entscheidenden Unterschied zu der dann über Jahrhunderte verbindlichen kulturellen Norm der klassischen Mythologie zwischen Renaissance und Aufklärung. Alle Versuche, das sog. ,Mittelalter' abzuschaffen, scheitern an dieser Epochenschwelle. Das Mittelalter ist die letzte Epoche, in der Hochkultur und Folklore bzw. Mythos zusammenkommen und welche eben diese - nicht konfliktfreie - Begegnung in der Literatur selbst thematisiert. Im Lai de l'Oiselet ist der höfisch verkleidete und idealisierte Mythos durch die schnöde Gier des vilain bedroht. Aber als Träger der mythischen, mit dem Garten verbundenen Botschaft verkörpert er am Ende auch den Rückzug und endgültigen Verlust des mythischen Ideals, das sich für immer entzieht und an eine Reihe anderer Beispiele für einen Verlust des Mythos erinnert, die die Epoche des Mittelalters charakterisieren. Ich denke an den Abschied der Drachenfee Melusine von ihrer Familie - auch sie fliegt davon, ohne je zurückzukommen, wenn auch die familiären Verhältnisse eine andere Konstellation erfordern -; ich denke an den von der geliebten Fee Niniane verratenen und eingemauerten Magier Merlin, dessen Beseitigung übrigens ebenfalls moralistisch gerechtfertigt wird; ich denke, unabhängig von der eucharistischchristologischen Überfrachtung des Motivs, an den Gral, dessen Fülle sich der Gesellschaft entzieht, oder auch an die mythische Tristanliebe, die unvereinbar mit der Realität bleibt; oder ich denke an die Gattung der Traumvision, in der das Mythische zur Vision wird, aus der der Träumer am Ende erwacht, und nicht zuletzt an das Mythische, das wie etwa bei Marie de France nur mehr störend in die

12 Hierzu Charmaine Lee: Il Giardino rinsecchito. Per una rilettura del Lai de l'Oiselet. In: Medioevo Romanzo 5 (1978), S. 66-84.

13 Paris: Lettres gothiques (Anm. 2), S. 398.

14 Friedrich Wolfzettel: Le Conte en palimpseste. Studien zur Funktion von Märchen und Mythos im französischen Mittelalter. Stuttgart 2005. 
Gegenwart hineinragt und zum nicht mehr auflösbaren Rätsel geworden ist. In jedem Fall wird die ,Stimme des Mythos' damit programmatisch zum Schweigen gebracht oder rätselhaft verfremdet. Die Bändigung, Moralisierung oder Ignorierung des Mythischen wird so zu einem Leitmotiv der mittelalterlichen Literatur. Kaum je aber ist diese Tendenz so offen programmatisch thematisiert wie im Lai de l'Oiselet, der das Mythische als Bedingung von Kreativität ausweist und so als Exempel für die kulturelle Verlusterfahrung im Mittelalter gelten könnte. Er ist ja schon recht klein und unscheinbar geworden, der Vogel, der den lebendigen Mythos verkörpert. 



\title{
Evokation und Episteme
}

\section{Zu Wissensmodi des Wunderbaren im späthöfischen Roman}

\author{
Jutta Eming
}

Die Emotion der Verwunderung ${ }^{1}$ wird seit der Antike in der einen oder anderen Weise als Einfallstor für Wissen erachtet. Am bekanntesten wurde Aristoteles' Formulierung aus der Metaphysik, dass Verwunderung (thaumazein) den Anfang der Philosophie bildet. ${ }^{2}$ In der Vormoderne vertritt, wie Lorraine Daston und Katharine Park zeigten, Verwunderung die konventionelle Haltung gegenüber Objekten der Erkenntnis: Wundern oder Elementen des Wunderbaren. Gerade im Mittelalter bilden Wunder und naturgeschichtliches Wissen dabei keine Gegensätze. ${ }^{3}$ Dies ändert sich erst im Verlaufe des 17. und 18. Jahrhunderts durch heterochrone Entwicklungen, ${ }^{4}$ in deren Folge sich wissenschaftliche Neugier als Leithaltung der Forschung etabliert und sich von Verwunderung und Wunderbarem löst, welche im gleichen Zuge in den Bereich des kulturell Trivialen abgedrängt werden. ${ }^{5}$ Die Einsicht, dass Emotionen - darunter Verwunderung, Staunen, Bewunderung - immer auch rationale Elemente enthalten und dass Verwunderung eine „,vom Verstand kultivierte Disposition sein [kann] ", fällt vorerst dem kulturellen Vergessen anheim. ${ }^{7}$

$1 \mathrm{Zu}$ Verwunderung als Emotion vgl. etwa Lorraine Daston: Die kognitiven Leidenschaften. Staunen und Neugier im Europa der frühen Neuzeit. In: Wunder, Beweise und Tatsachen. Zur Geschichte der Rationalität. Hg. von ders. Aus dem Englischen von Gerhard Herrgott, Christa Krüger und Susanne Scharnowski. Frankfurt a. M. 2001, S. 77-97.

2 Vgl. Aristoteles: Metaphysik. Schriften zur Ersten Philosophie. Übersetzt und hg. von Franz F. Schwarz. Stuttgart 1970, 982b, S. 21: „Weil sie sich nämlich wunderten, haben die Menschen zuerst wie jetzt noch zu philosophieren begonnen [...]".

3 Vgl. Benedicta Ward: Miracles in the Middle Ages. In: The Cambridge Companion to Miracles. Hg. von Graham H. Twelftree. Cambridge u. a. 2011, S. 149-164, hier S. 149.

4 Lorraine Daston und Katharine Park heben diese Ungleichzeitigkeit im letzten Kapitel ihrer Untersuchung: Wonders and the Order of Nature. 1150-1750. New York 1998, mit dem Titel "The Enlightenment and the Anti-Marvelous“, S. 329-363, ausdrücklich hervor.

5 Vgl. das achte Kapitel „The Passions of Inquiry“ bei Daston und Park: Wonders (Anm.4), S. 303-328.

6 Baldine Saint Girons: Schrecken, Staunen, Wundern. In: Poetiken des Staunens. Narratologische und dichtungstheoretische Perspektiven. Hg. von Nicola Gess u. a. Paderborn 2019, S. 13-31, hier S. 14.

7 Die Emotionalitätsforschung hatte es deshalb als dringliche Aufgabe betrachtet, den Konnex von Emotionalität und Rationalität nachzuweisen. Vgl. Agnes Heller: Theorie der Gefühle. Hamburg 1981; Ronald de Sousa: The Rationality of Emotion. 5. Aufl. Cambridge, MA; London 1997; Carola Meier-Seethaler: Gefühl und Urteilskraft. Ein Plädoyer für die emotionale 
Das Verhältnis von Verwunderung oder Staunen ${ }^{8}$ und Erkenntnis oder Wissen wird in der philosophischen, wissens- und wissenschaftsgeschichtlichen sowie der literaturwissenschaftlichen Forschung dabei ganz überwiegend als eines der Ersetzung, wenn nicht Ausschließung, behandelt. Die Substitution kann sich graduell und zeitlich weit oder weniger weit gedehnt oder instantan vollziehen," im Allgemeinen aber gilt: Wissen tritt an die Stelle von Staunen; Wissen ist dort, wo Staunen nicht (mehr) ist. Genau dies ist bei Aristoteles vorgezeichnet: Die Begierde, sich von Nicht-Wissen zu befreien, wird durch das thaumazein angestoßen, „denn in dem Bewundern steckt die Begierde zum Lernen, so daß das Bewundernswerte etwas Begehrenswertes darstellt. ${ }^{\prime 10}$ Angelegt ist das bereits bei Platon, insbesondere im Theaitet (155D). ${ }^{11}$ Wenn dem thaumazein jedoch ein Erkenntnis-

Vernunft. 3., durchgesehene Aufl. München 2001. Vgl. außerdem Wunder, Beweise und Tatsachen (Anm. 1).

8 Die grundsätzlich nicht triviale Frage, wie sich Staunen und Verwunderung zueinander verhalten, muss für die Zwecke dieses Beitrags dabei nicht eigens verfolgt werden. Vgl. zum Thema etwa den Aufsatz von Saint Girons: Schrecken, Staunen, Wundern (Anm. 6); sowie Stefan Matuschek: Über das Staunen. Eine ideengeschichtliche Analyse. Tübingen 1991, S. 8-23.

9 Solche allmählichen Substitutionsverhältnisse sind komplex und vielfältig zu denken. Thomas Leinkauf: Zur Funktion des ,Wunderbaren' (mirabile) in Philosophie und Poetologie des 16. Jahrhunderts. In: Mirabiliratio. Das Wunderbare im Zugriff der Frühneuzeitlichen Vernunft. Hg. von Christoph Strosetzki. Heidelberg 2015, S. 45-67, hat hinsichtlich der Ersetzung von Verwunderung durch Rationalität in der Frühen Neuzeit systematisch zwischen einem philosophischen und einem poetologischen Typ des Wunderbaren unterschieden. In Bezug auf ersteren bespricht er zunächst ein mirabile, das einen epistemischen Prozess einleitet und dessen Funktion darin besteht, überwunden zu werden. Das Wunderbare hat in diesem Fall einen provisorischen Charakter, und es ist grundsätzlich intelligibel. Davon unterscheidet Leinkauf dann ein mirabile, das am Ende eines epistemischen Prozesses steht und eine Erkenntnisstufe markiert, auf der ein absoluter Gegenstand sich nur noch bestaunen lässt (ebd., S. 47). Dieser ist an sich wunderbar, lässt sich nicht begrifflich fassen und ist kein Resultat eines urteilenden Aktes. Im christlichen Denken ist die Schöpfung ein Beispiel für ein solches ,finales' mirabile. Schließlich konzeptualisiert Leinkauf (I, iii) ein mirabile, das einen ganzen Erkenntnisprozess begleitet (ebd., S. 47) (= komitatives mirabile). Ein Beispiel dafür wäre ein Phänomen wie der Magnetismus, der historisch unterschiedliche Erklärungsansätze evoziert hat. Wissen wird dieser Variante gemäß auf der begleitenden Basis von Nicht-Wissen gewonnen. Der (II) poetologische Grundtyp des Wunderbaren meint dagegen eine seitens eines Dichters intentional erzeugte Wirklichkeit (ebd., S. 49), die wissenschaftliche Analyse richtet sich hier auf die Frage, wie genau eine ,überraschende' Wirkung erzeugt wird. Leinkaufs Ausführungen sind auch aus dem Grunde wichtig, weil sie nicht nur für das 16. Jahrhundert, sondern bereits für das Mittelalter zutreffen.

10 Aristoteles: Rhetorik. Übersetzt, mit einer Bibliographie, Erläuterungen und einem Nachwort von Franz G. Sieveke. München 1980, rhet. 1.11.21 / 1371a, S. 63. Ich danke Christian Vogel für seine Bereitschaft, diese Stellen mit mir zu diskutieren.

11 Vgl. Leinkauf: Zur Funktion des ,Wunderbaren' (Anm. 9), S. 51. Die Aussage ergeht im Text durch die Sprecherfigur Sokrates, die gegenüber Theaitetos erklärt: „Denn dies ist eben, was einem Philosophen widerfährt: die Verwunderung; ja, es gibt keinen anderen Anfang der Philosophie als diesen [...].“ Platon: Theaitet. In der Übersetzung und mit den Erläuterungen Friedrich Schleiermachers. Revision und Nachwort von Reinhard Thurow. Frankfurt a. M. 1979, S. 36. 
mangel mit Blick auf einen Erkenntnisgegenstand zugrunde liegt, hört hinsichtlich dieses Gegenstandes das thaumazein auf, sobald dieser Mangel behoben ist.

Wie das englische Wort wonder sowohl das Verb der Verwunderung bezeichnen kann als auch den Gegenstand, an dem es sich entzündet, scheint sich an dieser grundlegenden Relation nichts zu ändern, wenn sie vom Vorgang (sich wundern) hin zum Gesamtszenario (dem Wunderbaren, s. u.) erweitert wird. Staunen oder Verwunderung und das Wunderbare ermöglichen dieser Auffassung gemäß zwar Wissen, aber transportieren es nicht selbst. Im Gegenteil, das Genre der frühneuzeitlichen Reisebeschreibungen etwa, das wesentliche Bestände des Wunderbaren als Wissen vermittelt, ist dem Verdikt anheimgefallen, in den Bereich der „Erfindung " ${ }^{\prime 12}$ zu gehören. Stephen Greenblatts These, die Reisenden in die ,Neue Welt' seien "samt und sonders Lügner" gewesen, die sich in ihren schriftlichen „Repräsentationstechniken“ der etablierten Rhetoriken des Wunderbaren bedient hätten, um ihre machtpolitischen und ökonomischen Interessen zu verschleiern, ${ }^{13}$ kann für die Einschätzung von Staunen und Verwunderung in diesem Genre immer noch schwerlich überschätzt werden. ${ }^{14}$

Insgesamt findet sich zwar keine regelrechte Zurückweisung, aber doch eine auffällige Vernachlässigung der Möglichkeit, ${ }^{15}$ dass dem Wunderbaren eine Form von Rationalität eignet und dass es folglich nicht nur durch Wissen abgelöst wird, sondern selbst eine Form des Wissens repräsentiert. ${ }^{16}$ Die weit verbreitete und entsprechend selbstverständlich reproduzierte Ausschließungsrelation wird al-

12 Stephen Greenblatt: Wunderbare Besitztümer. Die Erfindung des Fremden: Reisende und Entdecker. Berlin 1994.

13 Greenblatt: Wunderbare Besitztümer (Anm. 12), S. 17.

14 Dies zeigt noch Udo Friedrich: Kaufmann - Abenteurer - Pilger. Figuren und Diskurse des Staunens in Reisebeschreibungen der Frühen Neuzeit. In: Staunen als Grenzphänomen. Hg. von Nicola Gess u. a. Paderborn 2017, S. 177-204, indem er einerseits Beispiele dafür anführt, dass Staunen sich mit Techniken zur Erschließung der Fremde verflicht (ebd., S. 192) und andererseits die Überwindung des Staunens als ultima ratio von Erkenntnisprozessen erachtet (ebd., S. 203f.).

15 Eine wichtige Ausnahme bilden Arbeiten von Martin Baisch, vgl. etwa den Beitrag: Neugier - Faszination - Ambiguität. Inszenierungsformen und -funktionen im höfischen Roman. In: Staunen als Grenzphänomen (Anm. 14), S. 231-246; ferner Susanne Friede: ,Ci rappresenta una sconvenevolissima inventione.' Überlegungen zum Status der Grottesche um die Mitte des Cinquecento. In: Mirabiliratio (Anm. 9), S. 297-313.

16 Dabei hat die Frage, welche Form von Wissen und Wahrheit (literarische) Texte vermitteln, wiederum eine sehr lange Tradition. Vgl. dazu: Literatur und Wissen. Ein interdisziplinäres Handbuch. Hg. von Roland Borgards u. a. Stuttgart 2013. Selbstverständlich gilt je zu bestimmen, welche Form von Wissen gemeint ist. Dies ist nicht zuletzt disziplinenabhängig. Wenn der Historiker Stephen Greenblatt erklärt, er habe sich angesichts der konventionalisierten Ausdrucksmuster des Wunderbaren „davor gehütet, die geschriebenen oder gezeichneten Repräsentationen der Europäer als genaue und verläßliche Dokumente über Land und Leute der Neuen Welt anzusehen" (Ders.: Wunderbare Besitztümer [Anm. 12], S. 17), dann ist dies gerade aus literaturwissenschaftlicher Sicht eine nachvollziehbare Entscheidung. Die Frage wäre dennoch, welche anderen Möglichkeiten es gibt, die Hermeneutik der Fremde als Wissen zu beschreiben. 
lerdings gerade dann brüchig, wenn nicht mehr nur von der Haltung der Verwunderung, sondern vom Wunderbaren als einem Erzählkomplex ausgegangen wird.

Das Anliegen des vorliegenden Beitrags ist es, hinsichtlich einer Auswertung des literarischen Wunderbaren als Form(en) des Wissens, exemplarische Lektüren vorzustellen. Im Mittelpunkt stehen Texte, die von Begegnungen mit dem Wunderbaren nicht im Stile der zuletzt genannten frühneuhochdeutschen Reisebeschreibungen erzählen - oder nur insofern, wie erstere für die Erzählweisen der letzteren immer noch modellbildend waren. Es geht um Romane, denen eine hoch entwickelte Selbstbezüglichkeit, Literarizität und Neigung zum ästhetischen Spiel zugeschrieben werden. Dabei greifen sie auf Erzählmuster zurück, die sich als das Wunderbare bezeichnen lassen und die, wie zunächst eingehender argumentiert werden soll, auf spezifisch literarische Weise Wissen vermitteln.

Zur Besonderheit entsprechender Darstellungsmodi gehört, dass sie Erkenntnis medial und material binden und zum Beispiel an spezielle Objekte, Räume und mit diesen verbundene Interaktionslogiken knüpfen. Dies kann Tendenzen annehmen, Möglichkeiten des Verständnisses auch zu problematisieren, Wissen zu entziehen und Ästhetiken der Verschlüsselung zu entwickeln. Auf ihnen liegt im folgenden Beitrag der Akzent. Er untersucht solche Tendenzen unter den Leitkategorien des Rätsels und des Geheimnisses, in zweiter Linie auch des Rätselhaften und des Geheimnisvollen, und fragt danach, was sie für das Verständnis des Wunderbaren je implizieren.

\section{Zur Unterscheidung von Rätsel und Geheimnis}

Gemeinsam ist Rätsel und Geheimnis, dass sie vielfältige Formen uneigentlichen Sprechens und figurativer Darstellung nutzen und schon darin Poetiken des Wunderbaren affin sind. In einem mittelhochdeutschen Text hat die Kennzeichnung eines Phänomens als wunder deshalb eine schier unerschöpfliche Bandbreite an Referenzen. ${ }^{17}$ In vielen mittelalterlichen Romanen, insbesondere der späthöfischen Zeit, können Inszenierungsmodi des Wunderbaren sich ferner zu einer atmosphärischen Qualität verdichten, die vielfach als rätselhaft oder geheimnisvoll bezeichnet worden ist, weil sie beim literarischen Protagonisten oder beim Helden Fragen evoziert. ${ }^{18}$ Mitunter erscheint eine solche Atmosphäre selbst dadurch nicht wirklich aufgelöst, dass die literarischen Helden sich dezidiert Fragen stellen. Die Atmosphäre, so hat man das auch gesehen, tritt auf solche Weise in den Vorder-

17 Vgl. auch Michelle Karnes: Marvels in the Medieval Imagination. In: Speculum 90 (2015), S. 327-365, hier S. 365, die von der "fundamental mysteriousness of the marvel“ spricht.

18 Nach Auffassung des französischen Romanisten Francis Dubost ist eine solche Evokation von Fragen der Moment, in dem das Erzählen vom Wunderbaren im mittelalterlichen Roman in das Erzählen vom Fantastischen kippt. Vgl. ders.: Aspects fantastiques de la littérature narrative médiévale (XIIème-XIIIème siècles). L'Autre, l'Ailleurs, l'Autrefois. 2 Bde. Genf 1991; ders.: La Merveille médiévale. Paris 2016. Diese Auffassung ist allerdings aus verschiedenen Gründen umstritten (s. u.). 
grund, der ästhetische Impetus scheint den epistemischen zu überformen. ${ }^{19}$ Für das Rätselhafte und Geheimnisvolle gilt ferner, dass beide etwas in dem Maße der Wahrnehmung entziehen, wie sie es zugleich zu erkennen geben - und umgekehrt. Während das Rätselhafte allerdings die Möglichkeit seiner Enträtselung zu implizieren scheint, kann das Geheimnisvolle auch allen Versuchen seiner Enthüllung widerstehen.

Werden Geheimnis und Rätsel als Adjektive und Adverbien also oft als Substitute füreinander verwandt (rätselhaft/geheimnisvoll), zeigen sie als Substantive eine größere Entfernung zueinander. Das Rätsel hat etwas mit willentlichem Verbergen zu tun, es schützt, z. B. ein Tabu, und gibt es, wie im Ödipus-Mythos am Beispiel der Sphinx, zugleich preis. André Jolles zufolge birgt ein Rätsel in diesem Sinne „nicht nur die Möglichkeit der Lösung in sich, sondern auch die Lösung selbst. [...] Der Aufgebende, der verrätselt, verrät andererseits in seinem Rätsel. “20 Eine solche zwingende Dialektik von Verschlüsseln und Verraten gilt für das Geheimnis grundsätzlich nicht. Um Rätsel zu lösen, braucht es Kompetenz oder Intelligenz. Dem Geheimnis nähert man sich tendenziell emotional, teilweise über Verwunderung. Das Geheimnis wird eher der visuellen Sphäre zugeschlagen, das Rätsel der sprachlichen; das Geheimnis gilt eher als sakral, das Rätsel eher als profan, ja als witzig. ${ }^{21}$ Das Geheimnis gehört, so Jochen Hörisch, der ,verzauberten Welt' an, das Rätsel der säkularen: „Rätsel lösen statt den Schleier des Geheimnisses zu durchschauen: das ist die neue intellektuelle, ästhetische und philosophische Grundgeste, die sich im neunzehnten Jahrhundert durchsetzt. “ ${ }^{\prime 22}$

Grundsätzlich gibt es in der mittelalterlichen Literatur viele Möglichkeiten, vom Geheimnis oder geheimnisvoll zu erzählen. Typisch für die Konstitution einer geheimnisvollen Atmosphäre ist eine retardierende Erzähltechnik, die das Wunderbare entfaltet und dabei kontinuierlich Fragen evoziert, deren Auflösung aufgeschoben wird oder gar nicht erfolgt. Im Geheimnis und Geheimnisvollen spitzt sich damit zu, was in Darstellungsformen des Wunderbaren immer schon angelegt ist: Als Präsentationsform von Wissen, das in hohem Maße medial und materiell vermittelt ist, kann das Wunderbare Kipp-Momente generieren, in de-

19 Vgl. Walter Haug: Literaturtheorie im deutschen Mittelalter. Von den Anfängen bis zum Ende des 13. Jahrhunderts. Darmstadt 1985, S. 250-278; Max Wehrli: Wigalois. In: Der Deutschunterricht 17 (1965), S. 18-35.

20 André Jolles: Einfache Formen. Legende, Sage, Mythe, Rätsel, Spruch, Kasus, Memorabile, Märchen, Witz. 5. Aufl. Tübingen 1974, S. 146.

$21 \mathrm{Vgl}$. zu dieser Gegenüberstellung auch die Einleitung des vorliegenden Bandes; sowie Jochen Hörisch: Vom Geheimnis zum Rätsel. Die offenbar geheimen und profan erleuchteten Namen Walter Benjamins. In: Schleier und Schwelle. Bd. 2: Geheimnis und Offenbarung. Hg. von Aleida und Jan Assmann in Verbindung mit Theo Sundermeier. München 1998, S.161-178, hier S. 162. Es ist zu betonen, dass solch eine Gegenüberstellung nur Tendenzen markieren kann, keine festen Merkmale. Vgl. dazu Tomas Tomasek: Das deutsche Rätsel im Mittelalter. Tübingen 1994, S.24ff. und S. 154f., der für ein dynamisches Verständnis von Rätsel votiert, welches sich auch in den verschiedenen Traditionssträngen der mittelalterlichen Rätselliteratur manifestiere.

22 Hörisch: Vom Geheimnis zum Rätsel (Anm. 21), S. 164f. 
nen Nicht-Verstehen akzentuiert wird. Gerade das Rätselhafte und Geheimnisvolle betreffen den Bereich der Evokationen, also der Anmutungen, Insinuationen, Atmosphären und Stimmungen, es sind nicht nur epistemische, sondern auch ästhetische Kategorien. ${ }^{23}$ Mit diesen Möglichkeiten: Wissen zu vermitteln oder womöglich nur zu evozieren, spielt der späthöfische Roman des Mittelalters.

\section{Das Wunderbare im mittelalterlichen Roman als Konfiguration des Wissens}

In der Literatur des Mittelalters ist das Wunderbare schon aus dem Grund epistemisch konfiguriert, als es sich über heterogene Wissenstraditionen konstituiert: aus Theologie, Historiographie, Naturgeschichte und Enzyklopädik, Medizin, Architektur und Ingenieurskunst u. v. m. Diese Traditionen werden im literarischen Text jedoch medien- und gattungsspezifisch neu kontextualisiert. Spezifisch literarische Formen, die dabei entstehen, konstituieren das Wunderbare als eigene Kategorie des Wissens, das durch literarische Inszenierungs- und Darbietungsweisen generiert wird. ${ }^{24}$

Dieser Begriff des Wunderbaren umfasst die historischen Kategorien der miracula und mirabilia, aber er ist nicht mit ihnen identisch. ${ }^{25}$ Als miracula lassen sich Vorgänge in literarischen Texten bezeichnen, die auf das Wirken und Eingreifen des christlichen Gottes zurückgeführt und entsprechend, ob vom Erzähler oder von Protagonisten, benannt werden. Mirabilia treten dagegen in Beschreibungen einer exotischen Fremde auf, etwa in Reisen in den ,Orient' auf der Ebene von monstra wie Pygmäen, Zyklopen, Kopffüßler oder Hundsköpfe. Gerade dadurch, dass sie in immer neue Kontexte transferiert werden, stellen sie bis weit in die Frühe Neuzeit hinein Verbindlichkeit und Geltung von Wissen her. In den deutschsprachigen Texten des Mittelalters wird im Übrigen für beide Bereiche die Bezeichnung wunder verwendet oder das Derivativ wunderlîche. ${ }^{26}$

23 Vgl. dazu auch Klaus Ridder: Wunder-Staunen und Melancholie-Trauer. Stimmungen am Gral im Parzivalroman Wolframs von Eschenbach. In: Staunen als Grenzphänomen (Anm. 14), S. 157-173; sowie ders.: Les ambiances dans l'espace du Graal dans le Parzival de Wolfram von Eschenbach. In: Das Geheimnisvolle im Mittelalter und anderswo. Le Mystérieux au Moyen Age et ailleurs. Colloque international en l'honneur d'Alexander Schwarz à l'occasion de son 65ème anniversaire. Hg. von Danielle Buschinger und Mathieu Olivier. Amiens 2015, S. 71-81.

24 Diese Konzeptualisierung des über das Wunderbare vermittelten Wissens berührt sich in vielerlei Hinsicht mit Joseph Vogls Ansatz zu „Poetologien des Wissens“, vgl. dazu Armin Schäfer: [Art.] Poetologie des Wissens. In: Literatur und Wissen (Anm. 16), S.36-41; vgl. zur Beschreibung des Wunderbaren in seinen epistemischen Dimensionen Jutta Eming, Falk Quenstedt und Tilo Renz: Das Wunderbare als Konfiguration des Wissens. Grundlegungen zu seiner Epistemologie. Working Paper des SFB 980 „Episteme in Bewegung“ 12/2018. Freie Universität Berlin, URL: https://refubium.fu-berlin.de/handle/fub188/26668 (12.12.2018).

$25 \mathrm{Vgl}$. auch die Ausführungen zum synkretistischen Konzept des mittelalterlichen merveilleux von Daniel Poirion: Le merveilleux dans la littérature française du Moyen Age. Paris 1982; ferner den Überblick bei Jutta Eming: Funktionswandel des Wunderbaren. Studien zum Bel Inconnu, zum Wigalois und zum Wigoleis vom Rade. Trier 1999, S. 5-37.

26 Einen analogen Geltungsbereich für das frz. Lexem merveille beschreibt Dubost: La Merveille médiévale (Anm. 18), S. 9-17. 
Weder enzyklopädische oder naturgeschichtliche noch literarische Texte sind ,fest' im Sinne einer Tradierung identischen Wissens, ${ }^{27}$ sondern kontinuierlich an der Aktualisierung und weiteren Ausarbeitung der Topik von den Wundern des Orients beteiligt. ${ }^{28}$ Literarische Texte folgen gemäß ihrer unterschiedlichen Darstellungsinteressen eigenen Auswahlkriterien. Das Wunderbare ist in der Literatur des Mittelalters und der Frühen Neuzeit deshalb kein feststehendes Ensemble aus bestimmten Räumen, Figuren, Orten, Monstren und exotischen Objekten, sondern Teil einer je neu konfigurierten Semantik von Anderswelten, ${ }^{29}$ die sich nicht nur in Erzählungen von Reisen in den Orient findet, sondern, entlang gattungsspezifischer Schwerpunktsetzungen, auch im nordischen Sagenraum ${ }^{30}$ oder im inselkeltisch geprägten höfischen Roman, im hellenistischen Liebes- und Abenteuerroman oder im antikisierenden Roman.

Ein charakteristisches Merkmal des Wunderbaren als Konfiguration des Wissens liegt im mittelalterlichen Roman darin, dass es implizite Fragen nach Möglichkeiten des Verstehens und Erkennens aufwirft. Gerade Staunen manifestiert sich im Innehalten, ${ }^{31}$ es gilt als Grenze, ${ }^{32}$ an der die Potentialität des Moments in seiner Fülle eröffnet und als solche ausgekostet wird, bevor sie sich in weitere Emotionen entfaltet. Das Wunderbare kann zur Darstellung bringen, was ansonsten verborgen bliebe. ${ }^{33}$ Darin hat das Wunderbare eine konstitutive Affinität zum Geheimnis. Als charakteristisch für die Darstellung zum Beispiel von Anderswelten gelten poetische Strategien, die eine „Dialektik von Verborgenheit und Enthüllung“ und „Vieldeutigkeit und Verrätselung“ konstituieren. ${ }^{34}$ Judith Klinger stellt in diesem Sinne zum kymrischen Preiddeu Annwn (um 900) fest, dieser inszeniere

27 Dies vermittelt für das Mittelalter eindrucksvoll die Überlieferung des Physiologus, vgl. dazu Christian Schröder: [Art.] Physiologus. In: Deutschsprachige Literatur des Mittelalters. Studienauswahl aus dem ,Verfasserlexikon' (Band 1-10). 2., völlig neu bearbeitete Aufl. Besorgt von Burghart Wachinger. Berlin, New York 2001, Sp. 708-722.

28 Eben dies zeichnet, folgt man Wilhelm Schmidt-Biggemann, Topik und Wissensordnungen grundsätzlich aus: „Topoi, die sich im Ganzen zeigen, können je im Ganzen zwar identifiziert werden, aber sie haben unter dieser Intention nicht den Charakter von ontologisch unabhängigen Elementen. Die gemeinschafts- und damit sinnbildende Struktur des Ganzen zeigt sich erst im Arrangement der Teile und in der Ordnung, in der sich das Ganze entfaltet." Wilhelm Schmidt-Biggemann: Was macht Wissen verlässlich? Überlegungen zum Verhältnis von Wissenschafts- und Wissensgeschichte. In: Muster im Wandel. Zur Dynamik topischer Wissensordnungen in Spätmittelalter und Früher Neuzeit. Hg. von Wolfgang Dickhut, Stefan Manns und Norbert Winkler. Göttingen 2008, S. 13-29, hier S. 22f.

29 Einen fundierten Überblick vermittelt Judith Klinger: [Art.] Anderswelten. In: Literarische Orte in deutschsprachigen Erzählungen des Mittelalters. Ein Handbuch. Hg. von Tilo Renz, Monika Hanauska und Mathias Herweg. Berlin, Boston 2018, S. 13-39.

30 Vgl. Howard Rollin Patch: The Other World. According to Descriptions in Medieval Literature. Cambridge, MA 1950.

31 Vgl. den emotionstheoretischen Beitrag von Johannes Windrich: Ergriffenheit. Staunen als Zäsur. In: Staunen als Grenzphänomen (Anm. 14), S. 125-140.

32 Vgl. dazu Staunen als Grenzphänomen (Anm. 14).

33 Vgl. das Kapitel „La pensée de l'impensable dans la fiction médiévale“ in Dubost: La Merveille médiévale (Anm. 18), S. 21-48.

34 Klinger: Anderswelten (Anm. 29), S. 17 und 16. 
mit einer „gezielten Verrätselung“35 die "Anderswelt als Geheimnis, das sich nur unter spezifisch poetischen Bedingungen aufschließen lässt. “"

Vermittelt über Reaktionen von Neugier und Staunen, Angst oder Befremdung wird der Wissensdrang literarischer Protagonisten auf solche Weise je anders geweckt und - z. B. als ,Forscherdrang', als ,Schaulust' oder ,Abenteuersuche' - weiter entwickelt, ${ }^{37}$ dabei werden diesem Wissensdrang, je nach narratio, einerseits Lizenzen erteilt und andererseits Grenzen bereitet. Einzelne Räume wie Städte und Paläste, luxuriöse Objekte, Figuren oder soziale Gemeinschaften werden mit Begehrensstrukturen oder mit Ästhetiken der Überwältigung korreliert, die sich zum Beispiel zur Kunstbetrachtung erweitern, Diskurse über Macht und Herrschaft anschließen, Identitätsentwürfe verhandeln oder Narrationen anstoßen, welche die Möglichkeit von Wissen und Erkenntnis selbst problematisieren. Dabei lassen sich eigene, gattungsspezifische Darstellungsstrategien beobachten: Objekte erfahren im höfischen Roman, anders als in antikisierenden Narrativen oder in Romanen mit einer sogenannten Orientreise, selten ausführliche Ekphrasen. Umso wichtiger werden für das Erzählen die Umstände, unter denen die Objekte, oft magische Dinge, gehandhabt werden, welche Kompetenzen sie evozieren und welche Affordanzen sie implizieren. ${ }^{38}$ Das Wunderbare zeigt eine genderspezifische Signatur, da sich sein Kontrast zu vertrauten Horizonten nicht zuletzt in stark positionierten weiblichen Figuren manifestiert - als Herrscherinnen (Dido, Candacis), Geliebte und Gattinnen (Melusine) oder in Lebensgemeinschaften (Occidraten, Amazonen, verschiedene Wundervölker in Indien, welche noch Jean de Mandeville ${ }^{39}$ beschreibt).

Erst im Gesamtzusammenhang der Narration oder der Erzählsequenz, in der zum Beispiel ein Objekt mittels einer descriptio und mit bewährten Verfahren von evidentia vergegenwärtigt wird, beim Protagonisten Staunen oder Furcht hervor-

35 Klinger: Anderswelten (Anm. 29), S. 17.

36 Klinger: Anderswelten (Anm. 29), S. 18.

37 Es gehört zur Poetizität von Literatur, dass diese Möglichkeiten sich weniger systematisch entwickeln, als die Übersichtstabelle von Saint Girons: Schrecken, Staunen, Wundern (Anm. 6), S. 29, dies darstellt. Vgl. zum Thema auch den Beitrag von Fritz Breithaupt: Staunen als Belohnung der Neugier. Wunder, Überraschung und Frage in narrativer Hinsicht. In: Poetiken des Staunens (Anm. 6), S. 37-49.

38 Barbara Johnson: Persons and Things. Cambridge, MA; London 2008, gehörte zu den ersten, die diese Beziehungen für literarische Texte analysiert haben. Vgl. für die mittelalterliche Literatur, mit besonderem Akzent auf einer Tendenz, der zufolge Subjekt-Objekt-Relationen nicht immer klar kenntlich werden, jetzt Bettina Bildhauer: Medieval Things. Agency, Materiality, and Narratives of Objects in Medieval German Literature and Beyond. Columbus, OH 2020.

39 Vgl. Sir John Mandevilles Reisebeschreibung. In deutscher Übersetzung von Michael Velser. Nach der Stuttgarter Papierhandschrift Cod. HB V 86. Hg. von Eric John Morrall. Berlin 1974, S. 107,24-108,10; dazu Marina Münkler: Erfahrung des Fremden. Die Beschreibung Ostasiens in den Augenzeugenberichten des 13. und 14. Jahrhunderts. Berlin 2000, S. 147-221, Kap. II „Paradigmen der Fremdbeschreibung“. Zu Mandevilles Beschreibung fernöstlicher Gemeinschaften, die - auch hinsichtlich der Verhältnisse der Geschlechter - utopische Züge tragen, vgl. die Habilitationsschrift von Tilo Renz: Utopische Entwürfe des späten Mittelalters. Freie Universität Berlin 2020 (unveröff. Manuskript). 
ruft und in Interaktion mit ihm tritt, entsteht die Konfiguration, welche Wissen hervorbringt. Für ein altes Wissensmotiv wie das der Begegnung mit einer Sirene ist deshalb nicht die Schönheit der Dämonin oder die Verführungskraft ihres Gesangs allein konstitutiv, sondern auch die Form der List, mit der sie überwunden wird. ${ }^{40}$ In diesem Sinne lässt sich das Wunderbare als Episteme verstehen, das dialogisch und dynamisch verfasst, ebenso kognitiv und emotional wie stofflich-figural determiniert ist und in literarisch inszenierten Handlungen durchgespielt wird.

Das bekannteste Beispiel aus einem mittelalterlichen Roman, in dem Fragen der Möglichkeit des Erkennens thematisiert und problematisiert werden, bildet die Begegnung des Titelhelden aus Wolframs von Eschenbach Parzival mit dem kranken Gralkönig Anfortas und die dabei inszenierte Gralprozession, die zentralen Erzählmustern der Begegnung mit einem Objekt des Wunderbaren im mittelalterlichen Roman folgt und zugleich über sie hinausgeht. ${ }^{41}$ Parzivals fehlendes Vermögen, angesichts dieser Inszenierung adäquat zu reagieren, konstituiert ein epistemisches Problem, dessen Lösung den verbleibenden langen Roman strukturiert. Aufschlussreich für den Zusammenhang des Geheimnisvollen ist dabei, dass der Text eine Erläuterung des zentralen Objekts gerade verweigert. Der Gral ist ein dinc, ${ }^{42}$ über dessen genauere Beschaffenheit sich die Forschung bis heute nicht einig ist. ${ }^{43}$ Alle Betonung liegt auf seiner Inszenierung, die einer merklichen Verrätselung folgt. ${ }^{44}$ Verschiedene Merkmale der Szenographie des Parzival haben

40 Vgl. zu den Transformationen des Motivs in der Literatur- und Wissensgeschichte Andreas Kraß: Meerjungfrauen. Geschichten einer unmöglichen Liebe. Frankfurt a. M. 2010; Bernd Roling: Drachen und Sirenen. Die Rationalisierung und Abwicklung der Mythologie an den europäischen Universitäten. Leiden, Boston 2010.

41 Vgl. dazu Jutta Eming: Aus den swarzen buochen. Zur Ästhetik der Verrätselung von Erkenntnis und Wissenstransfer im Parzival. In: Magia daemoniaca, magia naturalis, zouber. Schreibweisen von Magie und Alchemie in Mittelalter und Früher Neuzeit. Hg. von Peter-André Alt, ders., Tilo Renz und Volkhard Wels. Wiesbaden 2015, S.75-99. Zum Wissen im Parzival und in der Szene generell auch Martin Baisch: Ästhetisierung und Unverfügbarkeit. Strategien der Inszenierung von Wissen bei Wolfram und Chrétien. In: Wolframs Parzival-Roman im europäischen Kontext. Tübinger Kolloquium 2012. In Verbindung mit Susanne Köbele und Eckart Conrad Lutz hg. von Klaus Ridder. Berlin 2014, S. 207-250. Vgl. auch Ridder: WunderStaunen und Melancholie-Trauer (Anm. 23), der das epistemische Problem aus dem Problem der Wahrnehmung einer Stimmung herleitet, was hinsichtlich der emotional-rationalen Doppelstruktur des Wunderbaren ganz konsequent ist. Ähnlich ders.: Les ambiances dans l'espace du Graal (Anm. 23).

42 Wolfram von Eschenbach: Parzival. Studienausgabe. 2. Auflage. Mittelhochdeutscher Text nach der sechsten Ausgabe von Karl Lachmann. Übersetzung von Peter Knecht. Mit Einführungen zum Text der Lachmannschen Ausgabe und in Probleme der Parzival-Interpretation von Bernd Schirok. Berlin, New York 2003, V. 235,23.

43 Vgl. mit Betonung auf der Dynamik, die gerade diese Uneindeutigkeit für den Roman bedeutet, jetzt auch Bettina Bildhauer: Gral. In: Abecedarium. Erzählte Dinge im Mittelalter. Hg. von Peter Glasner, Sebastian Winkelsträter und Birgit Zacke. Berlin 2019, S. 91-97.

44 Vgl. dazu Eming: Aus den swarzen buochen (Anm. 41), außerdem Dubost: La Merveille médiévale (Anm. 18), S. 16, zur analogen Szene in Chrétiens de Troyes Perceval ou Le conte du Graal: "C'est une énigme que le Graal apporte à Perceval, et non une révélation." Vgl. auch den Beitrag von Maximilian Benz im vorliegenden Band. 
in späteren literarischen Texten Schule gemacht und wurden weiter entwickelt. Gerade im späthöfischen Roman des 13. und des 14. Jahrhunderts werden Anderswelten noch luxuriöser, die in ihnen zu vollziehenden Aventiuren noch komplexer, die Monstren dämonischer. Die Kompetenzen der literarischen Helden müssen sich in der Konfrontation mit diesen Phänomenen anpassen und über den relativ einfachen Nexus aus Kampf und Eroberung hinausgehen.

In der Germanistik hatte insbesondere Walter Haug auf die Tendenz einer zunehmenden und nicht mehr aufzulösenden Verrätselung hingewiesen, sie dabei jedoch nicht auf den Parzival zurückgeführt, sondern - am Beispiel von Wirnts von Grafenberg Wigalois und Heinrichs von dem Türlin Diu Crône - auf die Auseinandersetzung ,nachklassischen' Erzählens mit dem arturischen Roman in der Nachfolge von Chrétien de Troyes und Hartmann von Aue. ${ }^{45}$ In diesen Texten wird das Wunderbare ambivalent, uneindeutig und, so ließe sich sagen, geheimnisvoll. Gerade wenn atmosphärische Qualitäten einbezogen werden, verschwimmen die Konturen zwischen den epistemischen Haltungen zum verborgenen Wissen. ${ }^{46}$ In dieser ,zunehmend phantastischer werdenden Szenerie ${ }^{\prime 47}$ changieren die Reaktionen der literarischen Protagonisten zwischen einer mitunter bemerkenswerten Versatilität, Verunsicherung und Überwältigung. Ein bekanntes Beispiel ist der Held des Wigalois, der nicht nur mit Pferd und Waffe, sondern auch mit verschiedenen magischen Hilfsmitteln umgehen muss, die er in Gefahrensituationen in einem verzauberten Reich einzusetzen hat, der sich in solchen aber auch schon einmal hilfesuchend an Gott wendet - oder einschläft. ${ }^{48}$

An zwei verschiedenen Beispielen, der Crône Heinrichs von dem Türlin (um 1230) und am Apollonius von Tyrland von Heinrich von Neustadt (um 1300) werde ich im Folgenden Inszenierungsstrategien des Wunderbaren untersuchen. Dabei greife ich Probleme auf, die leitend für die Ausrichtung unserer Tagung und dieses Bandes gewesen sind: Lassen sich Ansätze zur Unterscheidung zwischen Geheimnis und Rätsel oder von Rätselhaftem und Geheimnisvollem als atmosphärischen Qualitäten und Inszenierungsstrategien für ihr Verständnis produktiv machen? Was tragen sie für die Konzeptualisierung vom Wunderbaren als Wissen aus? Sollen die evozierten Geheimnisse und Rätsel überhaupt in Wissen überführt werden? Oder ist es paradoxerweise gerade Bestandteil von Wissen, ein Geheimnis zu bewahren? Mein Fokus liegt dabei zum einen auf der Bindung von

45 Vgl. Haug: Literaturtheorie (Anm. 19), S. 250-278.

46 Bereits Max Wehrli hatte in einer bekannt gewordenen Formulierung das Atmosphärische des Wigalois beschrieben und als ,beinahe romantisch' bezeichnet, vgl. Wehrli: Wigalois (Anm. 19), S. 22.

47 Haug: Literaturtheorie (Anm. 19), S. 255. Die Implikationen des Begriffs des Fantastischen thematisiere ich hier nicht weiter, obwohl dieser nach Auffassung des Romanisten Francis Dubost gerade das Geheimnisvolle der mittelalterlichen Literatur erfasst. Die vieldiskutierte Theorie von Dubost ist jedoch zu voraussetzungs- und für das Wunderbare in meiner Sicht nicht hinreichend ertragreich, um hier eingehender diskutiert zu werden, vgl. dazu Eming: Aus den swarzen buochen (Anm. 41).

48 Vgl. Eming: Funktionswandel des Wunderbaren (Anm. 25), S. 184-215. 
Erkenntnis oder Wissen an Objekte, zum anderen auf der Konstruktion des jeweiligen Protagonisten und der ihm zugeschriebenen Handlungsmacht, affektiven Verfassung und intellektuellen Statur. Ich frage also auch danach, ob das Geheimnis einen anderen Heldentypus erfordert oder generiert als das Rätsel.

\section{Die Wahrung höfischer Geheimnisse in der Crône}

Diu Crône Heinrichs von dem Türlin, so genannt nach einer Stelle im Epilog, wird um 1230 datiert. Die Dichtung kann, abhängig von der Perspektive, sowohl den deutschen Artus- als auch den deutschen Gralromanen des 13. Jahrhunderts zugeordnet werden. ${ }^{49}$ Als kennzeichnend gilt gleichermaßen eine Ent-Funktionalisierung des Aventiure-(Abenteuer-)Prinzips als Form ritterlicher Bewährung und seine Übersteigerung in neuen Bildwelten. In der Crône ist nicht durchgängig deutlich, wer eigentlich gegen und für wen kämpft, und worum.

Aus der Crône ließen sich sehr viele Beispiele für die Hypertrophie des Wunderbaren und die Tendenz zum Geheimnis anführen; ich beschränke mich auf einen Auszug aus den sogenannten Wunderketten. Sie sind für meinen Zusammenhang von Interesse, weil sie dezidiert über die Konfrontation mit einem literarischen Protagonisten erzählt werden, der auf sie reagiert - oder eher nicht reagiert, das gilt als eine ihrer Besonderheiten. Gawein, in einer großen Zahl von Artusromanen Exponent des Artusrittertums, wird hier in einer Verfassung präsentiert, die an den vom Anblick des Gral gebannten Parzival erinnert, nämlich passiv, regungslos, unfähig, in eine vor ihm filmgleich ablaufende Szenenfolge einzugreifen.

Bis zu der Stelle, an der es zur im Folgenden diskutierten Szene kommt, hat sich im Roman schon sehr viel ereignet und der Protagonist hat mehrere der kurz skizzierten bildstarken Aventiuren erlebt. Alle Szenen bilden wiederum Teile der genannten Wunderketten und weisen untereinander Binnenbezüge auf, ein Zusammenhang, der hier nicht weiter verfolgt werden muss..$^{50}$

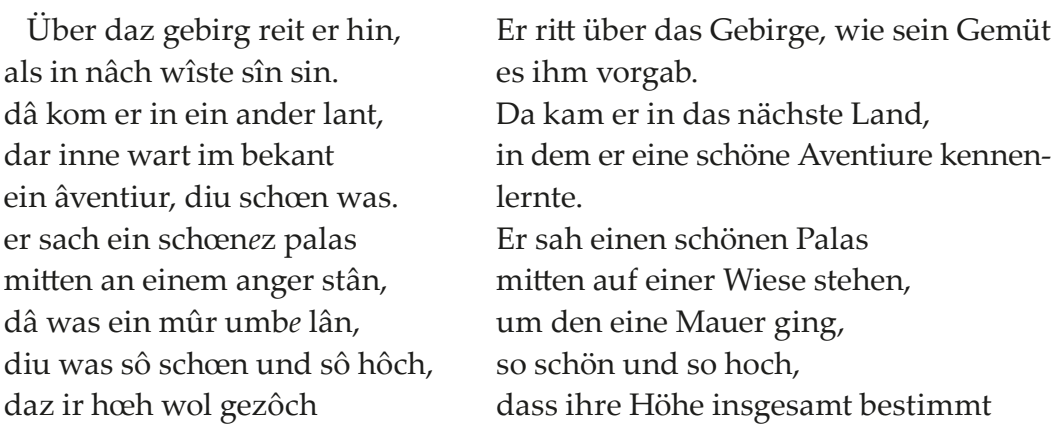

49 Vgl. Volker Mertens: Der deutsche Artusroman. Stuttgart 1998, wo der Text unter dem Titel „Abenteuer ohne Grenzen“ verzeichnet ist (ebd., S. 185-204), und vom selben Autor: Der Gral. Mythos und Literatur. Stuttgart 2003, wo er in einem Kapitel mit dem Titel „Der Gral als höchstes Abenteuer" (ebd., S. 125-133) besprochen wird.

50 Einen Überblick vermittelt Gudrun Felder: Kommentar zur Crône Heinrichs von dem Türlin. Berlin, New York 2006, S. 358-403. 
zwelf klâftern mit alle:

ez was ein cristalle

durchsihtic und dünne.

dar inne hôrt er wünne,

diu was sô süez und sô grôz,

daz in ir klein verdrôz,

von vrœlîchem gesange..$^{51}$ zwölf Klafter erreichte:

Alles war aus Kristall,

durchsichtig und dünn.

Aus dem Inneren hörte er am fröhlichen

Gesang eine Vielfalt an Vergnügungen

die so süß und überwältigend war,

dass er daran Gefallen fand.

Die Szene nimmt ein klassisches Syntagma des Erzählens vom Wunderbaren auf: den Anblick einer schönen fremden Stadt, gebaut aus kostbaren Steinen, auf die der Held scheinbar mehr oder weniger zufällig trifft. Sie ist in unzähligen Romanen Auftakt eines außergewöhnlichen Abenteuers, das Züge des Übergangs in eine Anderswelt trägt. ${ }^{52}$ Häufig ist der Anblick ambivalent, auf Grund von Schönheit und Luxus glücksverheißend, auf Grund von Fremdheit bedrohlich. In der vorliegenden Szene scheint zunächst alles auf eine angenehme Begegnung hinzudeuten, sogar auf Liebe, durch die süßen Töne, die aus dem Inneren des Palastes dringen. So könnte eine Beziehung zu einer Fee in einer Anderswelt beginnen. Aber dann kommt es zu einem plötzlichen Umschlag der Stimmung und der Zeichen.

dar nâch vil unlange
sach er vom walde schrîten
über velt her wol wîten
ein gebûrn, der was vreissam,
gar swarz sam ein râm,
und was wol sehs klâfter lanc.
ein slegel er vor im swanc
von einem gar rôten stâl,
den swanc er vür sich alle mâl
über velt wol drîzec schrit,
und sag iu zwâr, man het dâ mit
geladen ein starken wagen,
daz er in kûm het getragen,
der vier rosz bedorft wol,

Bald danach sah er einen schrecklichen Bauern, der schwarz wie Ruß war, weither aus dem Wald über das Feld schreiten.

Er war etwa sechs Klafter groß und schwang vor sich eine Keule aus ganz rohem Stahl; die schwang er ständig etwa 30 Schritt weit vor sich her über das Feld, und ich schwöre, man hätte damit einen starken Wagen beladen können, der bestimmt vier Pferde gebraucht hätte, und selbst der hätte die Keule kaum zu tra-

51 Heinrich von dem Türlin: Diu Crône. Kritische mittelhochdeutsche Leseausgabe mit Erläuterungen. Hg. von Gudrun Felder. Berlin, Boston 2012, V. 14267-14283. Die weiteren Versangaben erscheinen direkt im laufenden Text. Die Übersetzung folgt hier und im Folgenden weitgehend Heinrich von dem Türlin: Die Krone. Unter Mitarbeit von Alfred Ebenbauer † ins Neuhochdeutsche übersetzt von Florian Kragl. Berlin, Boston 2012.

52 Vgl. Nikolaus Ruge: [Art.] Stadt, Markt, Platz. In: Literarische Orte (Anm. 29), S. 502-518. Zu Beziehungen des für mittelalterliche literarische Stadtbeschreibungen maßgeblichen Modells von Karthago in Heinrichs von Veldeke Eneasroman vgl. Hartmut Kugler: Die Vorstellung der Stadt in der Literatur des deutschen Mittelalters. München, Zürich 1986, Kap. II, S. 38-78. Zur Verschränkung von Stadtbeschreibungen mit der Topik des Himmlischen Jerusalems, auch für Jenseitswelten, vgl. ebd., Kap. III, S. 79-141. 
ob ich dem mær gelouben sol.

er lief nackent unde bar über daz velt mit wille dar gên dirre vrœlîchen schar.

Alsô zuo dirre mûr kam geloufen dirre gebûr, den slegel er über ahsel reit und sluoc mit solher girscheit an die mûr ein sô vesten slac, daz sie mit alle belac ûf der erd dâ von unde bran. dar inne die meid wolgetân, die ê der vröude phlâgen, vil swigend lâgen, und begunden alle brinnen. dô sich ûzen und innen daz palas ensamt enphienc, der gebûr in daz viur gienc und schurt mit sînes slegels stil der meid über einander vil ze houfen in dem viure. nu besûfte vil tiure, Gâwein dirre meide tôt daz er in ûz solher nôt mit niht gehelfen kunde. dar under ez begunde nahten an der stunde. gen vermocht, wenn ich der Geschichte glauben soll.

Der Bauer lief splitternackt zielstrebig über das Feld in Richtung dieser fröhlichen Schar. Als er die Mauer erreicht hatte,

schwang er die Keule über die Schulter und schlug einen so gewaltigen Schlag gegen die Mauer, derart grauenerregend, dass sie davon ganz und gar einstürzte und zu brennen begann.

Die schönen Mädchen drinnen, die sich zuvor dem Vergnügen hingegeben hatten, schwiegen und lagen ganz still;

alle fingen sie Feuer.

Als nun das Haus außen und innen in Brand geriet, ging der Bauer in das Feuer und fegte mit seinem Keulenstiel viele der Mädchen übereinander und haufenweise ins Feuer. Nun bekümmerte Gawein der Tod dieser Mädchen sehr und auch, dass er ihnen unmöglich aus dieser Not helfen konnte.

Unterdessen brach die Nacht herein.

(V. 14284-14322)

Ein gebûr, also ein Bauer oder wilder Waldmensch, läuft auf den Palast zu, tatsächlich eine hybride Figur, die verschiedene Exponenten des Gegenhöfischen in sich vereint, nämlich Riese, Bauer und Monstrum. Er übt mit dem überdimensionierten schweren Schlegel, den er bei sich trägt, eine offenbar nicht zu kontrollierende Gewalt aus. Auf diese Weise kommt es zu einem merkwürdigen, über bekannte natürliche Kausalitäten nicht zu erklärenden Vorgang, dem gemäß die Gewalt des Schlags den Palast entzündet, und schließlich zu dem grausamen Vorgang, dass die Mädchen in das Feuer getrieben werden - obwohl sie möglicherweise zu diesem Zeitpunkt bereits verbrannt sind, wodurch das Geschehen eine ,bizarr-sinnlose ${ }^{53}$ Note erhält. Dem gegenüber steht Gawein, der keine Gelegenheit zu haben scheint, sich dem Monstrum in den Weg zu stellen, und das Feuer nicht stoppen

53 Vgl. Haug: Literaturtheorie (Anm. 19), S. 257 (allgemein zur Ästhetik der Crône). 
kann, aber über den Tod der Mädchen starkes Bedauern, vielleicht Mitleid empfindet - dies wäre dann eine Reminiszenz an den Parzival.

Anders als im Parzival aber werden die Bilder hinsichtlich der Gründe für das Geschehen im verbleibenden Roman nicht mehr aufgelöst. Wer sind die Mädchen, woher kommt der wilde Mann, warum greift er sie an? Das bleibt rätselhaft - oder bleibt es geheimnisvoll? Wenn ,rätselhaft' eine Situation bezeichnet, die intellektuell unverständlich bleibt, dann ersteres. Uta Störmer-Caysa spricht mit Blick auf die Crône davon, dass eine „intellektuelle Aufgabe, die prinzipielle Art des Gegenübers zu durchschauen“ gestellt werde, sowie von „Rätselspiele[n] zwischen Figur und Hörer über die Einschätzung einer Situation “. ${ }^{54}$ Geheimnisvoll im Sinne einer atmosphärischen Qualität würde man diese Szene nicht nennen, dafür fehlen auch charakteristische Signalwörter wie ungehiure und wunder. ${ }^{55}$ Allerdings stellen das Adjektiv vreissam sowie der Hinweis darauf, dass Gawein affiziert ist, wichtige Rezeptionssignale dar. Denn das Rätsel, da es eine intellektuelle Anforderung darstellt, affiziert nicht. So lässt sich festhalten: Der Vorgang zeigt ebenso Elemente des Rätselhaften wie des Geheimnisvollen, und er steckt außerdem insofern voller Geheimnisse, als die Gründe für das, was sich vollzieht, im Verborgenen liegen. Und dies gilt nicht nur auf der innerdiegetischen Ebene für den Protagonisten, sondern auch für die Rezipienten.

In der Forschung wurde lange versucht, die Bilder mit Blick auf religiöse Konnotationen zu deuten, hinsichtlich ihrer Verbindung zur Todesthematik der Crône oder auch der Komplementarität von Tod und Gral. ${ }^{56}$ Bezüge zu mittelalterlichen Jenseitsdarstellungen liegen auf der Hand, ${ }^{57}$ sie sind ebenso gegeben wie Bezüge zu vielen verschiedenen Prätexten, die mit Elementen des Wunderbaren arbeiten, aber sie reichen nicht aus, das Geschehen zu erklären. So geht man mittlerweile eher davon aus, dass bewusst verrätselt oder zumindest offengelassen werden soll, welcher internen Logik die sich abrollenden Vorgänge folgen. Johannes Keller hat in den Wunderketten der Crône eine Ästhetik des Fantastischen im Sinne von Francis Dubost identifiziert, einer Kehrseite des Wunderbaren, die Angst erweckt

54 Uta Störmer-Caysa: Grundstrukturen mittelalterlicher Erzählungen. Raum und Zeit im höfischen Roman. Berlin, New York 2007, S. 211.

55 Franz Simmler: Lexik und Wortbildung zur Bezeichnung des Geheimnisvollen in ausgewählten literarischen, religiösen und fachsprachlichen Texten. In: Das Geheimnisvolle im Mittelalter (Anm. 23), S. 105-153, vertritt am Beispiel der aus dem 15. Jahrhundert überlieferten Melusine die These, dass entsprechende Wörter das Geheimnisvolle konstituieren, wenn sie es auch nicht direkt benennen.

56 Wegweisend war hier ein Beitrag von Ulrich Wyss: Die Wunderketten in der Crône. In: Die mittelalterliche Literatur in Kärnten. Vorträge des Symposions in St. Georgen, Längsee vom 8. bis 13.9.1980. Hg. von Peter Krämer. Wien 1981, S. 269-291.

57 Sie wurden besonders herausgearbeitet von Johannes Keller: Diu Crône Heinrichs von dem Türlin. Wunderketten, Gral und Tod. Bern u. a. 1997; ders.: Jenseitsstrukturen in den Wunderketten der Crône Heinrichs von dem Türlin. In: Homo Medietas. Aufsätze zu Religiosität, Literatur und Denkformen des Menschen vom Mittelalter bis in die Neuzeit. Festschrift für Alois Maria Haas zum 65. Geburtstag. Hg. von Claudia Brinker-von der Heyde und Niklaus Largier. Bern u. a. 1999, S. 437-453. 
und nichts erklären, sondern die Unverständlichkeit ausstellen will. ${ }^{58}$ Gerade die Haltung Gaweins würde dem entsprechen.

Aber geht es nicht trotzdem auch um Wissen? Wie Ulrich Wyss bereits vor längerem feststellte, „scheint es, als würden sie [scil.: die Bilder] zu uns reden - nur eben in einer Sprache, die wir nicht ohne weiteres verstehen." ${ }^{59}$ In der Szenenfolge wird eine Menge an Informationen präsentiert, allerdings nicht in explizit gemachten Lehren oder Reflexionen, Dialogen oder Soliloquien, sondern in der Form von Handlungsfolgen, Interaktionen, Objekten, Medien und Materialien. Die Nennung des Materials ,Kristall', in Verbindung mit einem Gebäude, ruft ein Wissen um Anderswelten auf. Ferner wird vermittelt, dass Schönheit - hier vertreten durch den Palast, seine exquisiten Baustoffe und die Mädchen - gemäß dem mittelalterlichen Äquivalenz-Prinzip zwar das Gute bedeuten kann - hier vertreten durch die außerordentlich schöne Musik -, aber nicht davor bewahrt ist, zerstörerische Gegenkräfte anzuziehen. Die Szene zeigt die Unvorhersehbarkeit und Unbegründbarkeit antihöfischer Gewalt, die Unmöglichkeit, junge Mädchen zu schützen - die vielleicht schutzlosesten Mitglieder der höfischen Gesellschaft überhaupt. Der überdimensionierte Schlegel, der die exquisitesten Kulturleistungen zum Verschwinden bringt, setzt dies ins Bild, ebenso wie der Akt des Verbrennens als der einer kompletten Auslöschung. Ja, die Strategien der Verrätselung selbst vermitteln Wissen: dass es nämlich Ereignisse gibt, die zur kompletten Machtlosigkeit verurteilen, in der die üblichen Handlungskompetenzen nicht mehr greifen, in der nichts bleibt als Bedauern. Aber es handelt sich nicht um ein Bedauern über Versäumnisse - wie im Parzival -, sondern um Einsicht in die eigene Machtlosigkeit. ${ }^{60}$

Im Parzival hatte die gegenhöfische Welt - insbesondere die Einsamkeit des Waldes - entgegen aller dort gestalteter Ambivalenzen auch das Versprechen vermittelt, Zumutungen der höfischen Welt kompensieren zu können: Herzeloyde will ihren kleinen Sohn Parzival in der Einöde von Soltane vor der destruktiven Anforderung permanenter ritterlicher Gewaltbereitschaft schützen; Sigune findet einen Raum für ihre Trauer um den toten Geliebten Schionatulander; Parzival trifft auf den Einsiedler Trevrizent, der ihn über seine Zugehörigkeit zur Grals-

58 Vgl. Johannes Keller: Fantastische Wunderketten. In: Das Wunderbare in der arthurischen Literatur. Probleme und Perspektiven. Hg. von Friedrich Wolfzettel. Tübingen 2003, S. 225-248. Auch Keller problematisiert in diesem Zusammenhang, dass die Dichotomie eines ,schönen' Wunderbaren und eines, angsterregenden' Fantastischen, auf denen alle Theorien des Fantastischen beruhen, ersteren Begriff zu stark einengt. Auch in Bezug auf die antike poetologische Tradition (Aristoteles) ist dies fraglich; vgl. dazu Störmer-Caysa: Grundstrukturen (Anm. 54), S. 209f.; sowie Saint Girons: Schrecken, Staunen, Wundern (Anm. 6).

59 Wyss: Wunderketten (Anm. 56), S. 272.

60 Vgl. Wyss: Wunderketten (Anm.56), S. 281: „Natur ist dazu da, tapfer ertragen zu werden, nicht Objekt technischer Manipulation und der Ausbeutung kraft menschlicher Arbeit. Dazu paßt, daß das Feuer ohne jedes prometheische Pathos ins Spiel kommt: Es entzündet sich in der ,Crône' meistens von selbst und wird ausschließlich als zerstörerische Macht gesehen, als Gefahr; im besten Fall dient es dazu, Leichen verschwinden zu lassen." 
welt aufklärt. Darauf verweist die Crône zurück. Auch in ihr ist die Welt des Abenteuers insofern nicht autonom oder selbstgenügsam, als sie sich immer reflektierend auf den Hof bezieht. Zugleich jedoch kann sie, wie mir scheint, dabei seine Geheimnisse enthüllen. Die Auseinandersetzung mit Wolframs Parzival, welche die Crône führt, liegt in der diskutierten Szene - der noch viele, weitaus opulentere zur Seite zu stellen wären - in der Erkenntnis, dass keine Rückzugs- oder Ausweichmöglichkeit in eine gegenhöfische Welt besteht, die irgendwie heilsam wäre, Orientierung bieten würde, die Grundlage für eine zukünftige glückliche Existenz legen könnte oder Erklärungen über frühere Versäumnisse bereit hielte. Die höfische Kultur funktioniert auch über eine Kehrseite zerstörerischer Kräfte, welche sich gegen den Willen ihrer Agenten und entgegen ihrer besten Absichten durchsetzen. Warum greift Gawein nicht ein? Diese Frage ist oft handlungstheoretisch gemeint und wird entsprechend beantwortet: Warum tut er nichts, warum hilft er niemandem? Dabei ist mit dem Ansichtigwerden einer den Bildfolgen immanenten Fatalität, Vergeblichkeit und Todesverfallenheit die zentrale Erkenntnis schon benannt. Gawein hat Einsicht in das Geheimnis der höfischen Gesellschaft bekommen und wird es für sich behalten; es ist ",seinem Rittertum die kommunikative Dimension abgeschnitten." ${ }^{\text {161 }}$

Geheimnisse und ihre Wahrung sind zugleich aber Bedingung des Gelingens von Kultur:

Der kulturstiftende und Gesellschaft ermöglichende Akt schlechthin ist die Ausbildung einer Wissensform, die im Hinausdenken über ihre Grenzen zugleich Formen einer Respektierung des Unwißbaren oder Vorenthaltenen ausbildet und auf diese Weise in der Dimension des Wissens einen gemeinschaftlich bewohnbaren sozialen Raum konstituiert. ${ }^{62}$

Dass die höfische Gesellschaft auf einem Bereich des heimlichen beruht, der in ihrer Literatur poetisch verarbeitet wird, ist lange erkannt und viel untersucht. ${ }^{63}$ Die Crône gestaltet einen Helden, dem ein geheimes Wissen in unablässigen Bildfolgen präsentiert wird, ein Wissen, das unbegrifflich bleibt ${ }^{64}$ und dessen Erkenntnisgehalt nicht zur Gänze eingeholt, aber aus den schockartig miteinander konfrontierten Bildern dennoch herausgeschält werden kann und im Übrigen auch in der Forschung immer wieder in diesem Sinne benannt worden ist: dass die höfische Gesellschaft eine perennierende Kette von Gewalt, Verlust, Dest-

61 Wyss: Wunderketten (Anm. 56), S. 281.

62 Aleida und Jan Assmann: Das Geheimnis und die Archäologie der literarischen Kommunikation. Einführende Bemerkungen. In: Schleier und Schwelle. Bd.1: Geheimnis und Öffentlichkeit. Hg. von dens. in Verbindung mit Alois Hahn und Hans-Jürgen Lüsebrink. München 1997, S. 7-16, hier S. 7.

63 Vgl. zuletzt, in Auseinandersetzung mit vorangegangener Forschung, Beatrice Trînca: Amor conspirator. Zur Ästhetik des Verborgenen in der höfischen Literatur. Göttingen 2019.

64 Damit lässt es sich, zumindest in einigen Aspekten, als figuratives Wissen begreifen, vgl. dazu Ralf Konersmann: Vorwort. Figuratives Wissen. In: Wörterbuch der philosophischen Metaphern. Hg. von dems. Darmstadt 2007, S. 7-21. 
ruktivität erzeugt und sich gerade deshalb reproduzieren kann. Deshalb kann Gawein am Ende des Romans in eine intakte, auf Dauer gestellte Artuswelt, in welcher die Abenteuer immer wieder von neuem beginnen könnten, zurückkehren. Trotz aller Evokation einer rätselhaften Atmosphäre in der Crône - zentrales Erzählmovens im Roman ist nicht das Geheimnisvolle oder Rätselhafte als Stimmung, sondern die Geheimnisse um die Gründe, welche die Prolongierung des höfischen Abenteuers ermöglichen.

\section{Rätsel und Sprachmacht im Apollonius}

Der Apollonius-Roman und die Crône werden in poetologischer Hinsicht vielfach zusammen genannt. Dabei gehört der Apollonius einer anderen Gattung an: dem hellenistischen Roman bzw. Liebes- und Abenteuerroman; sein Abenteuerteil ist folglich nicht in der höfischen Welt der inselkeltischen Romantradition angesiedelt, sondern im Mittelmeerraum, und der Text ist bereits in der Antike bezeugt. Einer erhaltenen lateinischen Version, entstanden um 215 n. Chr., ging vermutlich eine griechische voraus, darauf deuten zwei kurze Papyrusfragmente hin. Diese sog. Historia ist in vielen verschiedenen Textzeugen und in unterschiedlichen Redaktionen überliefert und in Mittelalter und Früher Neuzeit in beinahe ganz Europa verbreitet; deutsche Übertragungen entstehen 1419 und 1461.

Die frühneuzeitlichen Autoren scheinen Heinrichs von Neustadt Version, die ich jetzt zugrunde lege, aber nicht gekannt zu haben. Sie stellt eine große Besonderheit dar. Denn der antike Handlungskern, der von einer Inzesthandlung ausgeht und diese sowie die Trennung des Titelhelden Apollonius von seiner Tochter zum Anlass für Fragen nach dem Zusammenhang von Familienführung und rechter Herrschaft nimmt, ist bei Heinrich von Neustadt um einen riesigen Binnenteil erweitert, der den Umfang der eigentlichen Handlung um ein Vielfaches übersteigt. Für eine Episode hat erneut der Parzival ziemlich eindeutig als Prätext gedient. Wie die Crône arbeitet der Roman mit einem Reservoir an hypertrophen Elementen des Wunderbaren und einem aus ihnen zu beziehenden Wissen. ${ }^{65}$ Auffällig ist ferner das in beiden Romanen prominent vertretene Thema der Tugendproben, der Apollonius-Roman scheint sich dabei direkt auf den früheren Text zu beziehen. Allerdings präsentieren die Texte zwei sehr unterschiedliche Helden. Und dies führt, wie ich weiterhin jetzt zeigen möchte, auch zu je unterschiedlichen Formen des vorenthaltenen Wissens und der modi operandi, welche diese bei den Protagonisten erzeugen: Während Gawein die Geheimnisse der höfischen Welt erfährt, löst Apollonius Rätsel. ${ }^{66}$

Apollonius ist nur auf den ersten Blick ein herkömmlicher mittelalterlicher Protagonist, der sich kämpfend, erobernd, befreiend und richtend ein beträcht-

65 Vgl. zur Nähe (unter Aspekten von Temporalität) Störmer-Caysa: Grundstrukturen (Anm. 54), S. 116.

66 Die zentrale lateinische Rätselüberlieferung des Symphosius ist vermutlich wesentlich durch den Apollonius-Roman im europäischen Mittelalter verbreitet worden, vgl. Mathilde Hain: Rätsel. Stuttgart 1966, S.2. 
liches Herrschaftsgebiet im Mittelmeerraum aufbaut. Apollonius' Erfolg gründet nämlich auch auf seiner Fähigkeit, Rätsel zu lösen. Sprechen in Rätseln ist metaphorisch und geschlechtsspezifisch vieldeutig. ${ }^{67}$ Ein Rätsel kann eine immanente hierarchische Struktur aufweisen, wie Jolles am Gegensatz zur Mythe expliziert:

Im Gegensatz zur Mythe enthält das Rätsel eine Frage, die gestellt wird, um zu untersuchen, ob der Befragte eine gewisse $W$ ü r de besitzt, und wenn diese Frage beantwortet wird, liefert sie den Beweis, daß der Befragte w ü r d i g ist. [...] Der Ratende dagegen ist nicht Einer, der die Frage eines anderen beantwortet, sondern Einer, der zu jenem Wissen zugelassen, in jene Gruppe aufgenommen sein will und der durch seine Antwort beweist, daß er dazu reif ist. ${ }^{68}$

Es ist deshalb folgerichtig, dass Apollonius im Rahmen einer Brautwerbung Rätsel aufgegeben werden: Er wirbt um die Tochter des Königs von Antiochus, wie viele Fürsten erfolglos vor ihm, indem er sich der Bedingung unterwirft, ein von diesem gestelltes Rätsel zu lösen. ${ }^{69}$ Die Formulierungen des Rätsels geben verschlüsselt $\mathrm{zu}$ verstehen, dass Antiochus mit seiner Tochter in einem Inzest-Verhältnis lebt. Dies erfasst Apollonius sofort und konfrontiert den König, dem er sich damit als ebenbürtig erweist, mit der Lösung. Rätsel sind zudem das zentrale Mittel, um an einem sehr viel späteren Punkt der Handlung, gegen Ende seiner großen Abenteuerreise, zu seiner eigenen Tochter zurückzufinden: Da er Tarsia als Kind zurückgelassen hatte, erkennt er sie nicht in der jungen Frau, die geschickt wird, um den in seiner Klage um die scheinbar verlorene Familie in Trauer Versunkenen abzulenken und aufzuheitern. Nachdem er sich zunächst unwillig gezeigt hat, ihr überhaupt zuzuhören, weckt eine Reihe anspruchsvoller Rätsel, die Tarsia ihm zu stellen weiß, sein Interesse. Die entsprechenden Textstellen sind hier nicht im Einzelnen zu betrachten. Von Interesse ist vielmehr die Funktion des Rätsellösens für den Roman und seinen Protagonisten. Wie es scheint, codieren Rätsel das zentrale Geheimnis des Textes, einen Vater-Tochter-Inzest, aktualisieren in dieser Konstellation intertextuelles Wissen über die Ödipus-Tradition und formieren Apollonius als exemplarischen Protagonisten, der sich bei seiner Abenteuerfahrt auch auf seine Intelligenz und seine Sprachmacht berufen kann.

Dies zeigen Passagen, in denen die Abenteuerwelt ausschweifend gestaltet wird. Apollonius erobert oder befreit gleich mehrere Reiche, die luxuriös ausgestattet sind, aber vielfach von Monstren beherrscht werden, die äußerst detailreich beschrieben sind. Wie in der Crône ist es dabei mitunter zwar schwer, eine Hand-

67 Vgl. Jolles: Einfache Formen (Anm. 20), S. 146.

68 Jolles: Einfache Formen (Anm. 20), S. 135.

69 Brautwerbung als traditionelles Rätselmotiv nennt Hain: Rätsel (Anm. 66), S. 41; Tomasek: Das deutsche Rätsel im Mittelalter (Anm.21), geht davon aus, dass das Inzesträtsel bereits in der griechischen Romanfassung enthalten war, während die Tarsia-Rätsel (s. u.) aus der Sammlung des Symphosius interpoliert worden sind, vgl. ebd., S. 176. Vgl. ausführlich zu den Tarsia-Rätseln bei Heinrich von Neustadt ebd., S. 184-199. 
lungslogik zu erkennen. Immer werden jedoch vorgängige Muster des Erzählens vom Wunderbaren aufgenommen und potenziert.

Im Roman Heinrichs von Neustadt werden dabei auch Wissensbereiche aufgerufen, die nicht in erster Linie als literarische zu bezeichnen wären. Große Teile gehen auf die Weltchronik von Rudolf von Ems zurück, die erste Weltchronik in der deutschen Volkssprache. Einige Passagen repräsentieren außerdem naturgeschichtliches Wissen aus sehr viel älteren Überlieferungsschichten, etwa über den Kampf der Pygmäen mit Vögeln, der zu ihren Lebensbedingungen zählt. Generell ist die Verbindung von geographischen Beschreibungen mit denen der dort lebenden Völker und ihrer Lebensbedingungen für naturkundliche Texte typisch, so für die Historia naturalis von Plinius d. Ä.; die Erwähnung von Menschenfressern ist geradezu ein Topos. Im Apollonius-Roman wird die Darstellung der Stadt Chrysa, um die es jetzt geht, mit Darstellungsmodi aus dem Bereich des (irdischen) Paradieses verknüpft. Sie ist ein ander paradey $\beta^{70}{ }^{70}$ das man betreten, und in dem man leben und sogar lieben kann. ${ }^{71}$ Apollonius hat mit Ydrogant und Serpanta zwei fürchterliche Monstren erlegt, die das Land in ihrer Gewalt hatten, und die ausführlich in ihrer Monstrosität beschrieben werden, bevor er vom Fürsten des Landes empfangen und durch einen Palast geführt wird, dessen kostbare Ausstattung ebenfalls detailliert beschrieben ist. Wieder gibt es einen Blick auf die Stadt von Ferne, aber sie stellt sich anders dar als in der früheren Szene der Crône:

Di edel statt Crisande

Hett ain mawr, di was hoch.

Ain schoner grabe dar umb zoch

Gar schone geformierett.

Dy stat was geczieret
Die edle Stadt Chrysanda

war mit einer hohen Mauer versehen,

um welche sich ein schön angelegter

Stadtgraben zog.

Die Stadt war so trefflich mit Türmen

verziert,

Mit tueren, das mich sein wundert: dass es mich Wunder nimmt:

Der waren da drew hundert,

Dreihundert an der Zahl,

Mit mermelstain gemaurett, achteckig und mit

Acht egk gefigurett.

70 Heinrichs von Neustadt Apollonius von Tyrland nach der Gothaer Handschrift, Gottes Zukunft und Visio Philiberti nach der Heidelberger Handschrift. Hg. von Samuel Singer. Berlin 1906, S.3-328, hier V. 8848. Die Übersetzung folgt bis auf kleinere Abweichungen Helmut Birkhan in: Leben und Abenteuer des großen Königs Apollonius von Tyrus zu Land und zur See. Ein Abenteuerroman von Heinrich von Neustadt verfaßt zu Wien um 1300 nach Gottes Geburt. Übertragen mit allen Miniaturen der Wiener Handschrift C, mit Anmerkungen und einem Nachwort von Helmut Birkhan. 2. Aufl. Hg. von dems. Bern 2005. Im Folgenden werden die Versangaben direkt in den laufenden Text gesetzt.

71 Tilo Renz hat herausgearbeitet, wie die unterschiedlichen Wissensmodi der Erzählsequenz das Land Chrysa als utopischen Ort hervorbringen; vgl. Tilo Renz: Die Gemeinschaft der Crisaner. Wissensformen des Utopischen. In: Erzählte Ordnungen - Ordnungen des Erzählens. Studien zu Texten vom Mittelalter bis zur Frühen Neuzeit. Hg. von Daniela Fuhrmann und Pia Selmayr. Berlin, Boston (vorauss. 2021). 
Da was schon gesetzett auff Auff yeden turne ain gulden knauff. Reich ercker stunden da enpor. Vier und zwaintzig purgtor Gingen in di schonen statt. Payde steig und pfatt Sind mit mermel uberlaitt. Di strassen sind langk und prait. Mitten in der statt was Ain herliches palaß. Welt irs geren hören,

Mit vier und zwaintzig roren̄ Was ain prunne dar gelait Mit so grosser reichait Als es der furste wolte. Wol tausent march von golde An den prunneñ sind gewant:
Auf jeden der Türme war ein goldener Knauf gesetzt und herrliche Erker ragten hervor. Nicht weniger als vierundzwanzig Tore führten in die prächtige Stadt.

Alle Stege und Wege waren mit Marmor gepflastert, die Straßen lang und breit. Im Herzen der Stadt erhob sich ein herrlicher Palas, vor dem der Fürst einen wunderbaren Brunnen mit - wenn ihr es genau wissen wollt vierundzwanzig Rohren hatte errichten lassen.

Für diesen von Meisterhand gebauten Brunnen waren wohl tausend Mark

Geworcht hett in ains maister hant. in Gold hingegeben worden.

(V. 11075-11101)

Wie im früher besprochenen Text nähert sich der Blick von Ferne der schönen Stadt, deren Tore und hohe Mauern erneut wichtige Elemente der Beschreibung darstellen, aber diesmal ausführlicher geschildert sind. Hier ist das Gebäude in höherem Maße Bedeutungsträger als in der Crône, wo das Gebäude in eine dynamische Handlungssequenz eingebunden worden war. Gold als edelstes Metall stellt für sich schon eine Art von Klimax des an Reichtum Vorstellbaren dar, das deshalb in der nun weiter entfalteten Rhetorik der Verwunderung auch immer wieder genannt ist. Zudem setzt die Narration auf numerische Potenzierungsformeln: Die Stadt hat mehr von allem, was man bislang gesehen hat, und immer in besonders raffinierter Ausfertigung, und doch alles, wessen es in der Tradition von Stadtdarstellungen für ein funktionierendes Gemeinwesen bedarf, insbesondere einen Brunnen, über dessen Beschaffenheit später noch mehr erzählt wird. Es ist kaum möglich, resümierend einen Eindruck davon zu geben, in welchem Umfang in der Beschreibung Chrysas auch in der weiteren erzählerischen Gestaltung eine Opulenz des Wunderbaren entfaltet wird, die auch frühere Episoden des Romans in den Schatten stellt - zum Beispiel erstrahlen alle Wände und Böden des Palastes in Gold, Edelsteinen und anderen kostbaren Materialien; es gibt glücksbringende Gärten mit künstlichen Vögelbäumen, die berückende Töne erzeugen, es leben dort goldfarbene Tiere, alle Personen sind in kostbarsten Gewändern angetan $\mathrm{u}$. v. m.

Das Reich von Chrysa weist verschiedene Objekte auf, die in der Tradition von Automaten stehen. Sie sind typisch für Romane, welche im Orient situiert sind. 
Hier handelt es sich um verschiedene Medien, welche Unverfügbares zugänglich machen, wie Wissen, aber auch die Herrschaft über Raum und Zeit. ${ }^{72}$ Eine wichtige Rolle spielt eine Spiegelsäule, welche sofort sichtbar macht, wie und wo sich die Person befindet, an die der Betrachter gerade denkt. Sie ist ein Geheimnisträger besonderer Art, denn gleich zweimal im Roman macht sie einen Ehebruch sichtbar. Es gibt einen Jungbrunnen, schließlich die achteckige, aus einem spiegelnden Diamant geschliffene Säule, auf der Stufen angebracht sind. Diese funktionieren nach dem Muster der Tugendprobe: Die Stufen setzen einen Schleudermechanismus in Gang und werfen alle Personen mit Schwung hinunter, die sich in ihrem Leben einmal der Feigheit schuldig gemacht haben. Damit verbunden ist eine Statue der Göttin Venus, von der man sich über die eigenen Verfehlungen noch einmal belehren lassen muss.

Wichtig gerade an den zuletzt genannten Elementen ist für die Handlung, dass der Held Apollonius es nur bis zur vierten Stufe der Säule schafft und dann unfreiwillig auf seinem Rücken landet. Er lässt sich daraufhin auf ein ,Gebet’ mit Venus ein, in deren Verlauf er die Göttin davon überzeugen will, dass er zu Unrecht von der diamantenen Säule heruntergeworfen worden sei. Mir ist aus den Texten, die ich überblicke, keine vergleichbare Episode bekannt, in der ein Held erfolgreich versucht, eine irgendwie als transzendent zu denkende Instanz davon zu überzeugen, dass sie Unrecht hat. Zunächst bittet er um Auskunft darüber, welchen Fehlverhaltens er sich schuldig gemacht habe:

Tyrus di göttynne patt:

,Venus, frauwe! tü mir kunt

Wa und an welcher stund

Ich sey gewesen ain zage,

So will ich an disem tage

Nach deinen genaden pussen.'

Er kniete ir zu den fussen.
Der Tyrer betete zur Göttin:

,Herrin, tu mir kund, wo und wann ich eine Memme gewesen bin, so will ich dies noch heute büßen, um deine Gnade zu erlangen.' Er kniete zu Füßen des Bildes.

(V. 12119-12125)

Daraufhin ertönt eine Stimme, und Venus lässt verschiedene Vorwürfe bezüglich seiner bereits erbrachten Kämpfe verlauten, in denen er sich feige verhalten habe. So sei er vor dem kentaurenähnlichen Wesen Piramort geflohen, und die monströsen Wesen Kolkan und Ydrogant habe er falsch, nämlich feige von hinten bzw. im Schlaf erschlagen. Anstatt sich nun aber in die von ihm zunächst in Aussicht gestellte Buße zu ergeben, begegnet Apollonius diesen Vorwürfen wie folgt:

72 Vgl. zum Thema jetzt grundlegend die Studie von Britta Maria Wittchow: Erzählte mediale Prozesse. Medientheoretische Perspektiven auf den Reinfried von Braunschweig und den Apollonius von Tyrland. Berlin, Boston 2020. 
Do sprach der von Tyrlant ,Venus, grosser haylant! [Sic!], Ich will mit meynen trewen sagen Das ich pey allen meynen tagen Mit wissen nie kainen man Vor zaghait geflohen han. [...]

Kolkan und Ydrogant

Sein für zway tier erkant!

Ich mocht ir anders nicht enhan

Ich muste sy also pestan.

$\mathrm{Ob}$ mir dein gnad das gicht:

Pyramors, den floch ich nicht:

Der tracke mit dem fewre

Was so ungehewre.

Ich sage das an meynen ait,

Es ist auch di warhait:

Wer in ain fewr sprunge,

Ob im da misselunge,

Mein syn mich dar zu zeucht.

[...]

Ich wär von hundert mannen

Nie geflohen ainen dritt. [...]
Da sprach der Held von Tyrus:

,Venus, große Heilerin!

Ich will dir bei meiner Treue beschwören

dass ich all meine Tage

wissentlich niemals aus Feigheit

vor einem Menschen geflohen bin.

Kolkan und Ydrogant

muss man als zwei Tiere ansehen.

Ich hätte sie anders nicht überwältigen

können,

außer auf diese Art.

Und wenn deine Gnade mir das

zugestehen will:

Ich flüchtete nicht vor Piramort, sondern

vor dem ungeheuren Drachen mit seinem

Feuer.

Ich sage die Wahrheit und bin gerne bereit,

es zu beeiden:

Mein natürlicher Instinkt sagt mir,

dass der dem Untergang geweiht wäre,

der in ein Feuer spränge.

Vor hundert Mann wäre ich nicht

einen Schrittbreit gewichen.'

(V. 12146-12182)

Apollonius macht sich kurzerhand geschickt die naturwissenschaftliche Diskussion seit der Antike über den Status monströser Wesen hinsichtlich der Alternative Mensch oder Tier zunutze und entscheidet sie zu seinen Gunsten: Bei den betreffenden Wesen habe es sich um Tiere gehandelt, sein Verhalten sei deshalb angemessen gewesen. In Bezug auf seine Flucht argumentiert er sodann taktischinstrumentell: Flucht sei im Falle eines Feuers das einzig Sinnvolle; vor einem Menschen wäre er nicht davongelaufen. Apollonius analysiert hier gleichsam das Verhalten, das Gaweins Passivität in der früher betrachteten Episode mit ausgemacht hatte: Gegen einen starken Brand ist nichts auszurichten. Venus gefallen seine Antworten so gut, dass sie ihm jetzt Zugang zur Säule gewährt.

Nach Auffassung der Forschung erweist sich damit Tugend als verhandelbar. ${ }^{73}$ Es kommt dabei nicht darauf an, ob Apollonius etwas Richtiges oder Wahres ge-

73 Vgl. Almut Schneider: Chiffren des Selbst. Narrative Spiegelungen der Identitätsproblematik in Johanns von Würzburg Wilhelm von Österreich und in Heinrichs von Neustadt Apollonius von Tyrland. Göttingen 2004, S. 67-72. 
sagt hat; er hat - im Unterschied zu anderen Stellen des Romans - auch kein Rätsel gelöst. Signifikant sind in erster Linie Einfallskraft, eventuell List, und das rhetorische Geschick, mit dem er sich verteidigen kann. Dies ist ein Echo der RätselSituation. Es funktioniert auch, weil Venus als ,heidnische' Göttin keine so absolute Instanz darstellt wie der christliche Gott, ja als transzendente Instanz in ihrer Autorität relativiert wird. ${ }^{74}$ Aber unzweifelhaft vertritt sie im Romanhorizont eine überlegene und zudem dadurch eine Macht-Position, dass sie über Wissen verfügt, welches Handlungsspielräume eröffnet oder verwehrt.

\section{Rätsel und Geheimnis als Möglichkeiten mittelalterlichen Erzählens}

Rätsel und Geheimnis lassen sich als produktive Formen des Umgangs mit Wissen auffassen, die gleichsam aus unterschiedlichen Richtungen bestimmt sind: Während sich epistemische Produktivität beim Rätsel im Vorgang der Entschlüsselung zeigt, liegt diese beim Geheimnis im Vorgang des Verbergens. Die Geheimnisse höfischer Kultur, derer Gawein während seiner Abenteuerfahrt ansichtig wird, gibt er an niemanden weiter. Er würde sie auch kaum benennen können.

Apollonius ist dagegen einer jener mittelalterlicher Helden, die über die Umgangsweisen mit dem Wunderbaren Kompetenzen erwerben - aber ich wüsste keine vergleichbare Stelle, an der das so radikal gestaltet ist wie hier, indem Wissensvorsprung und Urteilsvermögen einer übergeordneten Instanz herausgefordert und durch eine alternative Perspektive relativiert werden. Wichtig ist, wie grundsätzlich im Rätsel, weniger, was verhandelt wird, als die Sprachmacht, mittels derer die Lösung manifest wird, schließlich das Selbstbewusstsein, mit dem Apollonius einer transzendenten Instanz entgegentritt, von der er sich die Frage von Schuld und Buße nicht autoritär verordnen lässt, sondern diese relativiert und dialogisiert. Damit befindet er sich zugleich am entgegengesetzten Pol zum Helden Gawein, der das letzte Geheimnis nicht lösen kann oder will - und vielleicht gerade dadurch Erkenntnis unter Beweis stellt. Und es zeigt sich: Rätsel und Geheimnis sind keine zwingende Konsequenz aus der Hypertrophie des Wunderbaren, sondern Strategien des Erzählens, die sich in unterschiedlicher Weise mit diesem verbinden können.

74 So pointiert Wittchow: Erzählte mediale Prozesse (Anm. 72), S. 463. Dies liegt in ihrer Sicht zentral darin begründet, dass Venus sich überhaupt auf ein Gespräch einlässt (ebd., S. 464) und sich damit mit Apollonius' Eloquenz konfrontiert sieht und ihre Urteile verhandelbar macht. 



\title{
,Paradisieren'
}

\section{Rätselspannung, Lehre und religiöse Erfahrung im Jüngeren Titurel}

\author{
Falk Quenstedt
}

Bei seinen Streifzügen durch den „Wald der Fiktionen“ stellt Umberto Eco fest: „Wenn etwas Großes und Aufregendes geschehen soll, muß die Kunst des Hinhaltens kultiviert werden. ${ }^{\prime 1}$ Dem Jüngeren Titurel geht es zweifellos um Großes. Das zeigt schon allein der Umfang dieses Textes von rund 6300 Strophen, was 45000 Reimpaarversen entspricht. ${ }^{2}$ Aber geht es ihm auch um Aufregendes? Wohl kaum, zumindest nicht in den Augen der älteren Forschung. So wurde dem Roman nicht nur seine Fülle an ausgreifenden und ständig eingestreuten gelehrten Exkursen zu Tugenden und Naturkunde zum Vorwurf gemacht, sondern auch sein Mangel an Spannung: Der Text sei einfach langweilig. ${ }^{3}$ Eine „Kunst des Hinhaltens“ im Sinne spannungsvollen, aufregenden Erzählens sei dem Jüngeren Titurel gleichgültig, der Text schildere eine Welt ohne Geheimnis ${ }^{4}$ und ersetze Erzählen durch Lehre. $^{5}$ In diesem Sinne wurde denn auch die vielzitierte Prologaussage, dass ,[d]irre aventưre kere [...] nicht wan ein lere“ (65,1f.; „,die Wendungen der Erzäh-

1 Umberto Eco: Im Wald der Fiktionen. Sechs Streifzüge durch die Literatur. Harvard-Vorlesungen. Aus dem Ital. übers. von Burkhart Kroeber. München, Wien 1994, S. 70.

2 Vgl. Volker Mertens: Der deutsche Artusroman. Stuttgart 1998, S. 263.

3 So schon Karl Lachmann, der den Jüngeren Titurel in einem Brief von 1819 an Jacob Grimm in Reaktion auf die Wertschätzung des Textes durch Karl Rosenkranz ein „langweiliges, todtes und geziertes Werk" nennt, vgl. Ulrich Wyss: Den Jüngeren Titurel lesen. In: Germanistik in Erlangen. Hundert Jahre nach der Gründung des Deutschen Seminars. Hg. von Dietmar Peschel. Erlangen 1993, S. 95-113, hier S. 96; Briefwechsel der Brüder Jacob und Wilhelm Grimm mit Karl Lachmann. Bd. 1. Hg. von Albert Leitzmann. Jena 1927, S. 16. Elisabeth Schmid führt Langeweile als Lektüreerfahrung weniger auf die gelehrten Inhalte als auf die unwandelbare Idealität der Figuren zurück, was es ihnen nicht erlaube, Erfahrungen zu machen, vgl. Elisabeth Schmid: ,Dâ stuont âventiur geschriben an der strangen'. Zum Verhältnis von Erzählung und Allegorie in der Brackenseilepisode von Wolframs und Albrechts Titurel. In: Zeitschrift für deutsches Altertum und deutsche Literatur 117 (1988), H. 2, S. 79-97, hier S. 96. Den Langeweile-Vorwurf kritisiert etwa Thomas Neukirchen: Schuldige Helden. Zum Verhältnis zwischen Secureiz von Tabrunit und Tschinotulander im Jüngeren Titurel Albrechts. In: Der Jüngere Titurel zwischen Didaxe und Verwilderung. Neue Beiträge zu einem schwierigen Werk. Hg. von Martin Baisch u. a. Göttingen 2010, S. 221-234, hier S. 225.

4 So Wyss: Den Jüngeren Titurel lesen (Anm. 3), S. 105.

5 „Während sich für Wolfram die Wahrheit im epischen Prozeß entfaltet, wird sie von Albrecht direkt sprachlich vermittelt. Wahrheit wird nicht erzählt, sie ist lehrbar geworden." Alfred Ebenbauer: Albrecht: Jüngerer Titurel. In: Interpretationen. Mittelhochdeutsche Romane und Heldenepen. Hg. von Horst Brunner. Stuttgart 1993, S. 353-372, hier S. 364. 
lung nichts als Lehre") seien, interpretiert. ${ }^{6}$ Die jüngere Forschung hat dieses Urteil in Frage gestellt, vor allem hinsichtlich der Rolle des Erzählens in seinem Verhältnis zur Lehre. Dabei wurde die in sehr besonderer Weise formulierte Kritik am ,dunklen' oder ,wilden' Erzählen Wolframs von Eschenbach und die Bestrebungen des Jüngeren Titurel, diesen zu korrigieren, klarer konturiert. ${ }^{7}$ Auch wurden Momente narrativ hergestellter Irritation ${ }^{8}$ und Komik ${ }^{9}$ ausgemacht. All das will zu dem biederen Bild eines endlos belehrenden poeta doctus, der sich eines in seiner Umständlichkeit unverständlichen Stils bedient, nicht mehr recht passen. ${ }^{10}$

Daran anknüpfend möchte ich im Folgenden zeigen, dass im Jüngeren Titurel - zumindest in einzelnen Episoden - Spannung durchaus eine wichtige Rolle spielt, wobei ganz deutlich eine „Kunst des Hinhaltens" kultiviert wird. Diese Bedeutung von Spannung zeigt sich nicht nur im Vollzug, sondern wird vom Text in poetologischen Passagen auch reflektiert. Es handelt sich allerdings um eine besondere Form von Spannung. Sie ist nicht auf den Ausgang eines Geschehens oder das ,Wie' seines Verlaufs ausgerichtet. ${ }^{11}$ Und sie zielt auch nicht auf Identifikation oder Empathie mit den Figuren. ${ }^{12}$ Vielmehr geht es um eine Form

6 Ich zitiere den Jüngeren Titurel nach der Edition: Albrechts Jüngerer Titurel. Nach den Grundsätzen von Werner Wolf. Hg. von Kurt Nyholm. 4 Bde (Bd.1-2 hg. von Werner Wolf). Berlin 1955-1995. Strophen- und Versangaben im Fließtext beziehen sich auf diese Ausgabe.

7 Vgl. Andrea Lorenz: Der Jüngere Titurel als Wolfram-Fortsetzung. Eine Reise zum Mittelpunkt des Werks. Bern u. a. 2002; Thomas Neukirchen: Die ganze aventiure und ihre lere. Der Jüngere Titurel Albrechts als Kritik und Vervollkommnung des Parzival Wolframs von Eschenbach. Heidelberg 2006.

8 Vgl. Julia Zimmermann: Irritationen. Über die Unzuverlässigkeit des Wahrnehmens im Jüngeren Titurel. In: Der Jüngere Titurel zwischen Didaxe und Verwilderung (Anm. 3), S. 273-296.

9 Vgl. Johannes Keller: Fern von Komik und Humor? Der Jüngere Titurel. In: Der Jüngere Titurel zwischen Didaxe und Verwilderung (Anm. 3), S. 103-117.

10 In diesen Zusammenhang gehört auch die These Volker Mertens', dass es sich beim Jüngeren Titurel um einen Text handelt, der „nicht verstanden werden will“. Die These bezieht sich vor allem auf die klanglich-musikalische Dimension des Textes, hinter der semantische und narrative Zusammenhänge zurückstünden. Vgl. Volker Mertens: Kontingenz und Sprache im Jüngeren Titurel. Der Text, der nicht verstanden werden will. In: Der Jüngere Titurel zwischen Didaxe und Verwilderung (Anm. 3), S. 183-199; Volker Mertens: ,Musikalischer Stil' in mittelalterlicher Literatur. In: Literarischer Stil. Mittelalterliche Dichtung zwischen Konvention und Innovation. XXII. Anglo-German Colloquium Düsseldorf. Hg. von Ricarda Bauschke-Hartung, Elizabeth Andersen und Silvia Reuvekamp. Berlin, Boston 2015, S. 287-301.

11 Dieser gängigen, auf Clemens Lugowski zurückgehenden Unterscheidung von ,Ob-überhaupt' und ,Wie'-Spannung ist ein historischer bzw. epochaler Nexus eigen. Während die Spannung auf den Ausgang unter der Voraussetzung eines gegenüber der Vormoderne gewandelten Kontingenzbewusstseins typisch für moderne Formen des Erzählens sei, wäre die ,Wie'-Spannung charakteristisch für mittelalterliches Erzählen. Vgl. Armin Schulz: Erzähltheorie in mediävistischer Perspektive. Hg. von Manuel Braun, Alexandra Dunkel und Jan-Dirk Müller. Berlin, Boston 2012, S. 297; Clemens Lugowski: Die Form der Individualität im Roman. Mit einer Einleitung von Heinz Schlaffer. 2. Aufl. Frankfurt a. M. 1994, S. 40f.

12 Konzeptualisierungen von suspense, die beim Verhältnis von Figur und Rezipierenden ihren Ausgang nehmen, sind in psychologisch orientierten Ansätzen medien- und filmwissenschaftlicher Studien dominant; einflussreich ist hier etwa Dolf Zillmann: The Psychology of Suspense in Dramatic Exposition. In: Suspense. Conceptualizations, Theoretical Analyses, 
von Spannung, die sich als ,Rätsel-', ,Neugier-' oder auch ,Warum'-Spannung bezeichnen lässt. ${ }^{13}$

Diese Rätselspannung kann einer Poetik des Wunderbaren zugerechnet werden: Im Erzählprozess kommen Phänomene zur Darstellung oder es erscheinen Figuren, die vom gewohnten Lauf der Dinge abweichen. ${ }^{14}$ Sie lösen damit bei anderen Figuren und gegebenenfalls auch bei den Rezipienten Verwunderung aus und lassen die Frage entstehen, um wen oder was es sich bei diesen Objekten des Staunens handelt, warum es sie gibt, und wie sie erklärt werden können. ${ }^{15}$

Formen von Rätselspannung bieten sich als Mittel der Wissensvermittlung an, denn sie gehen mit der Produktion von Neugier einher. Ihr ästhetisches Potential sollte dabei jedoch nicht aus dem Blick verloren werden. Eine Verbindung zwischen der Verlaufsform des Erzählens und Wissensvermittlung nimmt auch der Jüngere Titurel ausdrücklich in den poetologischen Passagen des Prologs vor: Nicht einfach

and Empirical Explorations. Hg. von Peter Vorderer. Hillsdale 1996, S. 199-231. Allgemein zur medienwissenschaftlichen Spannungsforschung vgl. Matthias R. Hastall: [Art.] Spannung. In: Handbuch Medienwirkungsforschung. Hg. von Wolfgang Schweiger und Andreas Fahr. Wiesbaden 2013, S. 263-278.

13 Der Begriff der „Geheimnis- oder Rätselspannung“ wurde von Theoretikern des Detektivund Kriminalromans benutzt, um eine Spannungsform zu beschreiben, die - im Unterschied zur prospektiven Spannung auf den Ausgang - auf die retrospektive Aufdeckung eines Ereignisses bezogen ist, vgl. Peter Nusser: Der Kriminalroman. 4. Aufl. Stuttgart, Weimar 2009, S. 32; Jochen Vogt: Der Kriminalroman. Poetik, Theorie, Geschichte. München 1998, S. 89. Vgl. dazu auch Thomas Anz: Spannung - eine exemplarische Herausforderung der Emotionsforschung. Aus Anlass einiger Neuerscheinungen zu einem wissenschaftlich lange ignorierten Phänomen. In: literaturkritik.de. URL: http://literaturkritik.de/id/14010 (07.02.2017). Eine von Neugier getragene Spannung konzipieren Matías Martínez und Michael Scheffel im Rahmen einer Trias von Spannungsformen, hier im Rekurs auf die „klassische Detektivgeschichte" Edgar Allen Poes, vgl. Matías Martínez und Michael Scheffel: Einführung in die Erzähltheorie. 10. Aufl. München 2016, S. 152f. Den Begriff der „Warum-Spannung“ verwendet Hastall (Ders.: [Art.] Spannung [Anm. 12], S. 265). Mit Blick auf die mittelalterliche Literatur unterscheidet Jauß verschiedene Typen ästhetischer Erfahrung und sieht dabei (im Rückgriff auf Robert Guiette) für den höfischen Roman eine ,Passion für das Rätsel’ als typisch an. Dynamiken der Verrätselung würden gewissermaßen zum wirkungsästhetischen Selbstzweck, um einen „Reiz des Dunklen, noch nicht Aufgelösten, der die Neugier des Lesers fasziniert und ihn die endliche Auflösung fast bedauern läßt" hervorzurufen. Hans Robert Jauß: Ästhetische Erfahrung als Zugang zu mittelalterlicher Literatur. In: Alterität und Modernität der mittelalterlichen Literatur. Hg. von dems. München 1977, S. 411-427, hier S. 420. Jauß’ Kennzeichnung ließe sich prinzipiell auch als "Geheimnis- oder Rätselspannung" beschreiben, nur dass es hier nicht darum geht, ein zurückliegendes Ereignis, wie im Detektiv- oder Kriminalroman, sukzessive aufzudecken, sondern Elemente des Wunderbaren einer Erklärung zuzuführen - oder eben auch nicht.

$14 \mathrm{Zu}$ diesem Aspekt als Grundlage einer Definition des literarischen Wunderbaren vgl. Jutta Eming: Funktionswandel des Wunderbaren. Studien zum Bel Inconnu, zum Wigalois und zum Wigoleis vom Rade. Trier 1999, S.33-37.

15 Für eine detaillierte Darstellung dieses Konzepts des Wunderbaren vgl. Jutta Eming, Falk Quenstedt und Tilo Renz: Das Wunderbare als Konfiguration des Wissens. Grundlegungen zu seiner Epistemologie. Working Paper des SFB 980 „Episteme in Bewegung“ 12/2018. Freie Universität Berlin, URL: https://refubium.fu-berlin.de/handle/fub188/26668 (12.12.2018). 
die aventure ist mit Lehre gleichzusetzen, sondern der ",aventüre kere“, also der Gang der Erzählung, welcher sowohl „krump“ als auch „slihte“ $(65,1)$ sein könne. ${ }^{16}$

Auch behandelt der Text solche poetologischen Fragen nicht allein diskursiv. Mehrfach werden Kunstwerke beschrieben und in ihrer Wirkung auf intradiegetische Rezipierende dargestellt. Dabei geht es nicht nur um die Vermittlung von Lehrinhalten, sondern auch ein beglückender Effekt auf rezipierende Figuren wird zur Darstellung gebracht und als paradiesischer Zustand charakterisiert. Aufgrund seiner läuternden und beglückenden Wirkung auf die Figuren kann das als religiöse Erfahrung beschrieben werden. Der Jüngere Titurel verwendet hierfür mehrfach den Begriff des ,Paradisierens'. Das gehäufte Auftreten dieses sonst kaum verwendeten Begriffs ist eine Besonderheit des Textes. ${ }^{17}$ Das Verb „paradîsen“ wird dabei sowohl auf die Wirkung von Lehre $(2805,4)$ als auch von Kunst $(6272,4)$ und Dichtung $(6327,4)$ bezogen. ${ }^{18}$

Um nun das Verhältnis von Rätselspannung, Wissensvermittlung und religiöser Erfahrung im Jüngeren Titurel genauer fassen zu können, werde ich im Folgenden zunächst intradiegetische Darstellungen des ,Paradisierens' beschreiben und anschließend mit autoreflexiven poetologischen Passagen des Textes zusammenführen. Danach werde ich anhand einer einzelnen Episode, die das Wunderbare besonders breit entfaltet, die These entwickeln, dass die in dieser Episode zum Tragen kommende Dynamik von Rätselspannung dem Zweck dient, eine narrativ lange hinausgezögerte Enthüllung im Sinne einer ,Befreiung' zu inszenieren. Ich möchte zeigen, dass hier ein Moment spannungslösender, lustvoller Erkenntnis evoziert wird. Im Zuge dessen werden Einsichten in ethische, naturkundlichtechnische und heilsgeschichtliche Zusammenhänge vermittelt. Das Wunderbare kommt damit im Jüngeren Titurel, gerade durch die ihm eigene Verknüpfung ästhetischer und epistemischer Elemente, als ein Mittel des ,Paradisierens' der Rezipierenden durch die Erzählung in den Blick.

16 Vgl. Thomas Neukirchen: ,Dirre aventiure kere‘. Die Erzählperspektive Wolframs im Prolog des Jüngeren Titurel und die Erzählstrategie Albrechts. In: Erzähltechnik und Erzählstrategien in der deutschen Literatur des Mittelalters. Saarbrücker Kolloquium 2002. Hg. von Wolfgang Haubrichs. Berlin 2004, S. 283-303, hier S. 289f.

17 Das Verb mhd. paradîsen (vgl. Matthias Lexer: Mittelhochdeutsches Handwörterbuch. Nachdr. der Ausg. Leipzig 1872-1878. Bd. 2. Stuttgart 1992, Sp. 205) erscheint im Jüngeren Titurel in Partizipial- und Infinitivform, vgl. 103,3; 197,2; 369,2; 546,4; 2905,4; 5855,3; 5931,2; 6273,4; 6327,4. Der Begriff findet selten Verwendung in der mittelhochdeutschen Literatur. Eine Recherche in der Mittelhochdeutschen Begriffsdatenbank (http://www.mhdbdb.sbg.ac.at) zeigt Belege in nur vier weiteren Texten, drei davon benutzen paradîsen nur an einer Stelle (Göttweiger Trojanerkrieg [entst. 1270-1300], 1915; Lohengrin [entst. zw. 1283-86 oder nach 1338], 3890; Die Minneburg [entst. um 1340], 3424), einer an zwei Stellen (Lannzilet in Ulrich Fuetrers Buch der Abenteuer [15. Jahrhundert], 58,7 und 245,7); alle vier Texte entstanden etwa zeitgleich mit oder nach dem Jüngeren Titurel.

18 Der Begriff wird auch unmittelbar auf den Prozess des Eingangs in das Himmelsreich bzw. auf die himmlische Existenz bezogen: 546,4; 5844,3. 


\section{Zum Text}

Der Jüngere Titurel ist Anfang der 1270er Jahre fertiggestellt worden. Erst kurz vor Ende nennt sich ein Albrecht als Autor (5961,1); zuvor gibt sich die Erzählinstanz als Wolfram aus und übernimmt viele Stilmerkmale der Erzählerfigur Wolframs. ${ }^{19}$ Der Text war, das zeigt die Überlieferung, sehr erfolgreich, was auch damit zusammenhängt, dass er für einen Text Wolframs von Eschenbach gehalten wurde. ${ }^{20}$ Der Text schließt an die beiden Fragmente von Wolframs Titurel an, die er inkorporiert. Im Prolog lässt die Erzählinstanz jedoch erkennen, dass es vor allem um den Anschluss an Wolframs Parzival geht, und zwar in besonderer Weise: „swaz Parzival da birget, daz wirt zu liehte braht an vakel zunden“ $(86,4)$. Auch Elemente des Willehalm Wolframs werden übernommen. Es handelt sich um eine Summe wolframschen Erzählens, die Heldenepik und Artusroman zusammenführt. ${ }^{21}$ Dabei werden häufig gerade Geschehnisse, die Wolfram nur kurz erwähnt oder die bei ihm ganz im Dunkeln bleiben, auserzählt - , ans Licht gebracht‘. ${ }^{22}$

Der Jüngere Titurel lässt sich in eine Rahmen- und eine Binnenhandlung untergliedern, die miteinander verbunden sind. Der Rahmen handelt von der Geschichte des Gralsgeschlechts, die er in den Verlauf der Welt- und Heilsgeschichte integriert, und vom Bau des Gralstempels, der analog dazu innerhalb der konkreten Geografie der Ökumene verortet wird. Der Text widmet diesem Bauwerk, seinen Außen- wie Innenräumen, eine ausführliche Ekphrasis. ${ }^{23}$ Die Binnenhandlung spielt zur Lebenszeit Artus', der ebenfalls zur historischen Figur wird. Erzählt wird von der Lebens- und Liebesgeschichte Tschinotulanders und Sigunes, von den Wirrnissen rund um ein kostbares, schrifttragendes Brackenseil sowie von den - bei Wolfram in den Gawein-Büchern des Parzival ausgespart bleibenden - Reisen Parzivals bis hin zu seiner Erwählung als Gralskönig. Der Schlussteil des Rahmens behandelt die Migration der Gralsgesellschaft mitsamt Gral und Gralstempel nach Indien, wo sie im Reich des Priesterkönigs Johannes aufgeht. ${ }^{24}$

19 Die Forschung spricht diesbezüglich von ,Wolfram-Rolle` oder auch ,Wolfram-Maske', vgl. zu diesem Zusammenhang: Volker Mertens: Wolfram als Rolle und Vorstellung. Zur Poetologie der Authentizität im Jüngeren Titurel. In: Geltung der Literatur. Formen ihrer Autorisierung und Legitimierung im Mittelalter. Hg. von Beate Kellner, Peter Strohschneider und Franziska Wenzel. Berlin 2005, S. 203-226.; Annette Volfing: Medieval Literacy and Textuality in Middle High German. Reading and Writing in Albrecht's Jüngerer Titurel. New York u. a. 2007, S. 75-96.

20 Vgl. Ebenbauer: Albrecht (Anm. 5), S. 356.

21 Vgl. Mertens: Der deutsche Artusroman (Anm. 2), S. 262-265.

22 Vgl. Neukirchen: ,Dirre aventiure kere' (Anm. 16), S. 294.

23 Vgl. dazu Elisabeth Schmid: Die Überbietung der Natur durch die Kunst. Ein Spaziergang durch den Gralstempel. In: Der Jüngere Titurel zwischen Didaxe und Verwilderung (Anm. 3), S. 257-272; Haiko Wandhoff: Ekphrasis. Kunstbeschreibungen und virtuelle Räume in der Literatur des Mittelalters. Berlin, New York 2003, S. 259ff.; Steffen Brokmann: Die Beschreibung des Graltempels in Albrechts Jüngerem Titurel. Ruhr Universität Bochum 1999.

24 Allgemein zur Vorstellung von diesem Reich vgl. Tilo Renz: Das Priesterkönigreich des Johannes. In: Erinnerungsorte - Erinnerungsbrüche. Mittelalterliche Orte, die Geschichte mach(t)en. Hg. von Frank Meier und Ralf H. Schneider. Ostfildern 2013, S. 239-256. Zum Aspekt der Darstellung von Migration im Jüngeren Titurel vgl. Thomas Poser, Dagmar Schlüter und Julia Zimmermann: Migration und literarische Inszenierung. Zwischen interkultureller Abschottung 


\section{Korrektur ,dunklen' Erzählens und Rätselspannung}

Wie schon angedeutet, belässt es der Jüngere Titurel nicht beim Auserzählen Wolframs, sondern übt auch Kritik an ihm, insbesondere an seinem Erzählverfahren: Wolframs Poetik des Dunklen und des erzählerischen Hakenschlagens würde die Lehre, die seine Erzählungen enthielten, verdecken und unverständlich machen, anstatt sie klar und deutlich zum Ausdruck zu bringen. Deshalb ist diese obscuritas schädlich: „habet iuch gein der blanken! di swerz an werdicheit ie was verswachet" (49,4; „Haltet euch an das Helle! Das Schwarze war an Ehre immer schon entkräftet."). Die Erzählinstanz spricht aus einer Wolfram-Rolle heraus bzw. ,ist' Wolfram, da das Als-ob nicht markiert wird. Mehrfach bekundet ,Wolfram' im Prolog seine Absicht, die Fehler des Parzival zu berichtigen: „ich wil die krumb an allen orten slichten“ (20,3; „Ich will das Krumme überall gerade machen.“). Im expliziten Bezug auf die Metaphorik des Parzival-Prologs wird das detailliert ausgeführt. ${ }^{25}$ Selbstkritisch sagt ,Wolfram', es wundere ihn gar nicht, wenn man ihn ob seiner dunklen Metaphorik ,bekriege' $(51,2)$. Um der Lehre willen wolle er daher nun „di wilden mær hie zam gestellen“ (59,4; „die wilde Erzählung zähmen“). Es gelte, nicht den (wilden) Hasen, sondern den (zahmen) Jagdhund zu verfolgen (50,3f.). Aus dieser Argumentation heraus resultiert dann die programmatische Aussage: „Dirre aventure kere, si si krump oder slihte, / daz ist nicht wan ein lere. darumb sol ich si wisen uf die rihte“ (65,1f.; „Die Wendungen dieser Erzählung, egal ob krumm oder gerade, sind nichts als Lehre. Deshalb will ich sie in die richtige Richtung weisen.“). Die Geschichte soll noch einmal, aber besser erzählt werden, ohne obskure Metaphorik, ohne sich ihrem Sinn entziehende Handlungsverläufe, ohne im Dunkeln bleibende Stellen. ${ }^{26}$ Heißt das aber auch ohne Spannung?

und transkultureller Verflechtung. In: Europa im Geflecht der Welt. Mittelalterliche Migration in globalen Bezügen. Hg. von Michael Borgolte u. a. Berlin 2012, S. 87-100. Zur Darstellung des Indischen Reichs und zur Rezeption der Epistola presbiteri Johannis im Jüngeren Titurel vgl. Julia Zimmermann: Im Zwielicht von Fiktion und Wirklichkeit. Zur Rezeption des Presbyterbriefs in Albrechts Jüngerem Titurel. In: Mythos - Sage - Erzählung. Gedenkschrift für Alfred Ebenbauer. Hg. von Johannes Keller. Göttingen 2009, S. 547-566; Klaus Zatloukal: India - ein idealer Staat im Jüngeren Titurel. In: Strukturen und Interpretationen. Studien zur deutschen Philologie, gewidmet Blanka Horacek zum 60. Geburtstag. Hg. von Alfred Ebenbauer. Wien, Stuttgart 1974, S. 401-445.

25 Vgl. Neukirchen: ,Dirre aventiure kere‘ (Anm. 16), S. 286-294. Der Jüngere Titurel greift auf verschiedene Metaphern zurück, die Wolfram von Eschenbach im Parzival zur Darstellung seiner Poetik entwickelt. So bezieht sich der Jüngere Titurel etwa auf das Bild des hakenschlagenden Hasen (Parzival 1,18-19), das der Charakterisierung von Wolframs Erzählen dient (dabei aber selbst in vielen Aspekten dunkel bleibt): Wie ein flüchtender Hase macht die Erzählung unberechenbare Zickzack-Bewegungen, mit denen die klugen Rezipienten rechnen müssen, um die Erzählung richtig zu verstehen (vgl. Joachim Bumke: Wolfram von Eschenbach. 8. Aufl. Stuttgar, Weimar 2004, S.42f.). Weitere Bezugspunkte stellen die Metaphern vom Spiegel und vom Traum des Blinden (Parzival 1,20-25) dar, vgl. Neukirchen: ,Dirre aventiure kere' (Anm. 16), S. 286.

26 Vgl. Neukirchen: ,Dirre aventiure kere' (Anm. 16), S. 294. 
Diese Frage lässt sich anhand einer weiteren poetologischen Textstelle diskutieren, da sie - zumindest dem Prinzip nach - Rätselspannung thematisiert. ${ }^{27}$ Die Erzählinstanz schließt hier an die Diskussion des Prologs an, allerdings erst etwa in der Mitte des Gesamttextes. Die Stelle setzt mit einem Tadel ungeduldiger Rezipienten ein: „swer der aventiure, e si daz mere bringe, vil gevraget“ (2947,4; „wer ständig den Ereignissen, bevor sie die Erzählung bringt, nachfragt" ${ }^{\prime \prime}$ ), dem fehle es an „zuht“ (2947,2; „Erziehung“). Das rekurriert auf Wolframs sogenanntes Bogengleichnis, demzufolge die ,Geschichte' bestimmt, wann eine Information gegeben werden kann. ${ }^{28}$ Das Prinzip, der Geschichte nicht vorgreifen zu dürfen, um sie in adäquater Weise erfahren zu können, gilt offenbar auch für den Jüngeren Titurel. Überhaupt, wer „gưter mer" („gute Erzählungen“) nicht leiden könne, der fände auch keinen Gefallen an "güter witze“ (2948,4; „gutem Verstand“). Das Gute könne uns überhaupt nur durch Erzählungen vermittelt werden: „Aller selden beste wirt uns kunt von mæren. / immer vremde geste wir sam ein vih der ganzen tugende wern.“ (2949,1f.; „Das Beste allen Segens / allen Glücks wird uns durch Erzählungen kund. / Ohne sie wären wir - wie die Tiere - allen Tugenden gegenüber Fremde.")

Diese Apologie des Erzählens - Neukirchen spricht von einer „narrative[n] Ethik “29 - muss auch gegen Widersacher verteidigt werden, einen „meister være“ und einen „meister wider strite“ (2951,1). Beide wenden sich gegen das Erzählen, es sei ein „lugenmære“ $(2951,2)$ und „,mache herzen irre und ouch unstæte“ $(2951,3) .{ }^{30}$

27 Auf diese poetologische Passage hat hingewiesen: Neukirchen: Die ganze aventiure und ihre lere (Anm. 7), S. 344-350.

28 Das Bogengleichnis ist nicht Teil des Parzival-Prologs, sondern erscheint im 5. Buch des Romans (Parzival 241,5-30). Der Erzähler wendet sich an das Publikum und gibt an, dass er die Identität einer Figur erst dann verraten wolle, wenn es an der Zeit dafür sei. Anschließend entwickelt er ein komplexes, schwer zu deutendes, weil in sich widersprüchliches „bîspel“ (Parzival 241,9), das den Vorgang des Erzählens mit dem Spannen eines Bogens vergleicht. Darin wurde eine Analogie zum Bild des hakenschlagenden Hasen gesehen: „Das Bogengleichnis hat [...] einen logischen Knick, gleicht darin dem springenden Erzählen." (Bumke: Wolfram von Eschenbach [Anm. 25], S. 205). Eine ähnliche Auseinandersetzung eines Erzählers mit dem aufdringlich vorgreifenden Fragen einer Rezipientenstimme begegnet auch im Rahmen der ausführlichen ,descriptio' von Enites Wunderpferd in Hartmanns Erec. Wie im Jüngeren Titurel sind hier Aspekte des Wunderbaren, Ekphrasis und eine Autoreflexivität, die auf Aspekte der Zeitlichkeit des Erzählens eingeht, eng miteinander verbunden. Für eine Lektüre der Beschreibung als Auseinandersetzung mit einer Poetik des Wunderbaren und zugleich autoreflexive Inventarisierung materieller und immaterieller Elemente, die in der Kunstform des Erzählens zusammenspielen, vgl. Falk Quenstedt: The Things Narrative is Made of: A Latourian Reading of the Description of Enite's Horse in Hartmann of Aue's Erec. In: Things and Thingness. Perspectives on Material and Immaterial Objects (ca. 700-1600). Hg. von Jutta Eming und Kathryn Starkey. Berlin u. a. (Im Erscheinen).

29 Neukirchen: Die ganze aventiure und ihre lere (Anm. 7), S. 341.

30 Diese Argumente gegen das verdunkelnde Erzählen sind mittelalterlichen Vorbehalten gegenüber der Fakultät der Imagination vergleichbar, die zwar einerseits zur Mediation göttlichen (bzw. prophetischen) Wissens notwendig sei, dieses jedoch - in ihrer produktiven Eigendynamik - zugleich auch unverständlich mache, vgl. Michelle Karnes: Marvels in the Medieval Imagination. In: Speculum 90 (2015), H. 2, S. 327-365, hier S. 339. Die Diskussion der Wirkung des Erzählens ist an dieser Stelle möglicherweise durch philosophische Imagina- 
Der Vorwurf, das Herz „irre und unstæete („schwankend und unbeständig“) zu machen, könne aber gegen eine bestimmte Form von „lesen, sagen, singen“ $(2958,3)$ nicht erhoben werden. Die Erzählinstanz bringt hierfür ein spezifisch deutschsprachiges höfisches Erzählen ins Spiel, das als Mediator von Tugenden geeignet ist (2959,4; 2961,4). Diese Form des Erzählens hat durchaus affizierende Wirkung, sei aber gerade nicht verwirrend, sondern hätte vielmehr eine leitende Funktion. Zentral ist in jedem Fall, dass transparent bleibt, wo es hingeht. ${ }^{31}$

Damit möchte ich nun zu Darstellungen der Wirkung von (Erzähl-)Kunst und dem im Text so häufig angesprochenen ,Paradisieren' kommen - sie werden die poetologischen Passagen noch einmal anders akzentuieren.

\section{3 ,Paradisierende' Wirkungen: Gralstempel und Brackenseil}

Zunächst zum Gralstempel. Die ausführliche Ekphrasis dieses Bauwerks steht wie ein „Eingangsportal“32 am Anfang des Textes (329-439) und kann neben dem Prolog als eine Einführung in den Text, als Anleitung zum Verständnis der narratio gedeutet werden. ${ }^{33}$ Das mit dem Himmlischen Jerusalem und dem Tempel Salomons verglichene Bauwerk ist nicht allein von Menschenhand errichtet, sondern „mit gotes kraft gemenget“ $(367,4)$, denn der Gral zeichnet selbst den Grundriss für den Rundbau vor. Verschiedentlich kommt in dem Gebäude illusionistische Tricktechnik zum Einsatz; durchweg zielt diese dabei auf eine erbaulich-beglückende Wirkung, die sich bei den Templeisen auch einstellt. ${ }^{34}$ Auf dem Dach sind Adler so angebracht, dass sie zu schweben scheinen (429,1-4). Im Gewölbe, das den Kosmos darstellt, figurieren leuchtende Edelsteine Sonne und Mond, die sich - angetrieben durch den Mechanismus einer Planetenuhr - bewegen, darunter schweben an unsichtbaren Goldfäden Engel durch den Raum (374-376; 410). Der Kristallboden gibt den Blick auf eine Unterwasserwelt samt der dazugehörigen Meerwunder frei $(436,3 ; 438,4)$, auch hier sorgt ein technischer Mechanismus, ein

tionstheorien, die - wie Karnes verdeutlicht - auch der Diskussion des Wunderbaren breiten Raum geben, beeinflusst.

31 Diese Charakterisierung eines nützlichen Erzählens nimmt die Erzählinstanz in Auseinandersetzung mit der Kritik der beiden Meister vor. Da Menschen wie Blinde in der Welt umherirrten, bedürften sie der Leitung durch einen Sehenden (2952f.). Impliziert wird dabei, dass die Erzählung imstande ist, diese Leitung zu übernehmen.

32 Wandhoff: Ekphrasis (Anm. 23), S. 259.

33 „Wird dem Leser dieses enzyklopädische ,Fundament', auf dem das ,Haus‘ der Erzählung zu errichten ist, vorab ausgegeben, dann scheint dies die Bedeutung des Vor-Bildes für die nachfolgende narratio besonders herauszustellen. Man bekommt nicht am Ende des Textes auch noch ein Bild angeboten, um die abgeschlossene Handlung retrospektiv vielleicht in neuem Licht zu sehen, sondern man muß durch den Bild-Eingang wie durch ein Eingangsportal hindurch, um überhaupt in den Text zu gelangen. Damit wird dem Textbenutzer - durchaus auch in einem didaktischen Sinn - schon vor Beginn seiner Reise durch den Roman ein kognitiv nützliches Schema als Navigationshilfe mitgegeben." Wandhoff: Ekphrasis (Anm. 23), S. 259.

34 "Swenn in die zierde riche so vil gap vreuden luste, / so sprachens all geliche: ,got vater, herr”, und slügen sich zer bruste, / ,sint du uns hie verlihen hast sulch ere, / waz hastu dann zu himele, da iz sich hundert tusent valtet mere!"“ $(407,1-4)$. 
Rohrsystem, das über die Verbindung mit Windmühlen und Blasebälgen einen Luftstrom erzeugt (437), für Lebendigkeit. Schließlich wird in den Chören eine rankende Pflanzenwelt dargestellt, die sich im Wind wiegt und durch welche singende Vögel hindurchfliegen (398-403).

Es handelt sich also nicht um eine statische Architektur, vielmehr herrscht im Gralstempel ein bewegtes, buntes Treiben. Besonders faszinierend ist dabei die Beschreibung davon, dass lebendige Natur ,künstlich' nachgebildet wird. Was Genuss verspricht, ist einerseits die von der Kunst geschaffene Atmosphäre, die einem paradiesischen Zustand nahekommt und - wie Elisabeth Schmid sagt - eine "fromme Sinnenlust ${ }^{\prime \prime 35}$ gestattet, andererseits aber auch die Einsicht in die technisch-künstlerische Raffinesse, die diese Illusionswelten schafft. Der Text deckt nämlich immer wieder - und zwar mit großem Interesse am technischen Detail auf, welche Mechanismen diese Wirkungen hervorbringen, ein „Faszinosum des Maschinellen ${ }^{\prime \prime 36}$ tut sich hier kund. Aber nicht nur das: Es zeigt sich auch eine Lust am Enthüllen, denn durchwegs werden verborgene Kräfte vom Text transparent gemacht. Da ist es nur folgerichtig, dass der Bau explizit auch keine Krypta aufweist: „Ob si da heten grufte? nein, herre got enwelle [...] man sol uns an dem liehte kunden kristen gelouben und Kristes ammet". (408,1 und 4). Auch werden einzelne Bestandteile der verborgenen Konstruktionen als Mittel wider den Teufel beschrieben (428) ${ }^{37}$ Der Verdacht verbotener Magie wird damit klar ausgeräumt (und muss offenbar ausgeräumt werden). Der technische Illusionismus wird auch mit der Feier der Messe zusammengeführt: Zum Gesang des Priesters schwebt unter Soundeffekten eine Taube von der Decke herab. Der Gralsgemeinde kommt es vor ",sam si furre / uz paradise gelich dem heren geiste“ (353,2f.), was große Freude auslöst. „[F]romme Erbauung" und „Freude am Spektakel [stören hier nicht nur] nicht einander ${ }^{\prime \prime}{ }^{38}$ sondern scheinen sich gegenseitig zu bedingen - so wie Lehre und Erzählen, Erzählen und Lehre. Die Enthüllung verborgener Technik macht dabei einerseits den besonderen Reiz der Beschreibung aus, ${ }^{39}$ legitimiert zugleich aber auch den Illusionismus. Nichts darf im Verborgenen bleiben.

Eine vergleichbare Wirkung entfaltet die Verlesung der Inschrift des Brackenseils am Artushof. Mit diesem Artefakt wird jedoch nicht nur eine positive, sondern auch eine negative Wirkung von Erzählen thematisiert. Das zeigt schon das erste Auftreten des Seils in der Erzählung: Als Sigune und Tschinotulander

35 Schmid: Die Überbietung der Natur durch die Kunst (Anm. 23), S. 270.

36 Ebd.

37 Vgl. Schmid: Die Überbietung der Natur durch die Kunst (Anm. 23), S. 267.

38 Schmid: Die Überbietung der Natur durch die Kunst (Anm. 23), S. 270.

39 Vgl. Schmid: Die Überbietung der Natur durch die Kunst (Anm. 23), S. 267. Ob die „naturgetreue Künstlichkeit" dabei tatsächlich auf den „Triumph der künstlerischen Leistung über die Natur abzielt" halte ich für fraglich, ebd., S. 267. Mir scheint vielmehr ein Verhältnis der Analogisierung und „wechselseitige[n] Mimesis" zwischen schöpferisch-spielerischer Natur und Kunst vorzuliegen, wie diese für Ordnungen späterer Wunderkammer-Sammlungen typisch werden sollte, vgl. Robert Felfe: Einleitung. In: Frühneuzeitliche Sammlungspraxis und Literatur. Hg. von Robert Felfe und Angelika Lozar. Berlin 2006, S. 8-28, hier S. 11. 
im Wald zelten, läuft ein Bracke, ein Jagdhund, mit einer kostbaren Hundeleine vorbei (1172-74). Tschinotulander kann ihn fangen und das Brackenseil in seinen Besitz bringen. Er übergibt es Sigune. Die Leine ist Träger einer aus Edelsteinen gesetzten Schrift und Sigune beginnt sogleich den „anevanc der mære“ $(1191,1) \mathrm{zu}$ lesen. Um weiterlesen zu können, muss sie die Leine losbinden $(1201,4)$ - und der Hund läuft davon. Sigune will die Erzählung zu Ende lesen und macht den Besitz der Leine zur Bedingung ihrer Liebe, ${ }^{40}$ Tschinotulander aber wird im Kampf um das Brackenseil den Tod finden. Dessen Lektüre hat also eine verheerende Wirkung. Das Seil kann aber auch positiv wirken. Als die Schrift nämlich am Artushof durch einen Priester verlesen ${ }^{41}$ und in der Gemeinschaft gehört wird, ${ }^{42}$ fühlen sich die Rezipienten „sams an den stunden weren geborn zu vreuden vruht in paradise“ (1928,4; , als ob sie in diesem Moment als Kind der Freuden im Paradies geboren wären“).. ${ }^{43}$ Das Beispiel zeigt, dass die Gefahr negativer Wirkung prinzipiell ambivalenter Kunst durch die Vermittlung eines Priesters nicht nur gebannt wird, sondern dass Kunst auf diese Weise eine beglückende und heilsvermittelnde Wirkung entfalten kann. ${ }^{44}$ Nun beansprucht aber auch der Jüngere Titurel selbst

40 „Solch aventiur ist wesende geschriben an der strangen. / bin ich di niht uz lesende, so ist mir gar unmære [...] / [...] swaz mir ieman richeit kund gebieten.“ (1215,1-3); „so daz din munt sprech nach miner minne, / diu müst dir immer wilden, dune brehtes mir di strang [...]" (1216,3-4).

41 Neukirchen sieht im Brackenseil und seiner Konfiguration aus Tugendlehre und kostbarmagischer Materialität eine Chiffre für ein falsches Verständnis von Erzählen; dieses versage dann, wenn es allein der Unterhaltung diene, dabei aber keine Lehre vermittle, vgl. Neukirchen: Die ganze aventiure und ihre lere (Anm. 7), S.331-333. Vielmehr seien Lehre und Erzählen immer nur miteinander und durcheinander begründet möglich, und zwar insofern, als die Lehre die Macht der narratio immer wieder durchbreche, vgl. ebd., S. 340.

42 Diesem Aspekt widmet sich besonders Katharina-Silke Philipowski: ,We, daz ie man die strangen sach geschribene!'. Gehörte und gelesene Schrift in Albrechts Jüngerem Titurel. In: Internationales Archiv für Sozialgeschichte der deutschen Literatur 34 (2009), H. 1, S. 49-74.

43 Der Text hebt an dieser Stelle auch die Wirkung der Edelsteine, aus denen die Schrift gesetzt ist, als maßgeblich für ihre Wirkung hervor. Die Forschung hat darin die Inszenierung eines Gegensatzes von Zeichenhaftigkeit und Materialität der Schrift sehen wollen, bei dem der materiale Schriftträger den Transfer des semantischen Gehalts der Schrift gewissermaßen ,blockiere', vgl. Peter Strohschneider: Sternenschrift. Textkonzepte höfischen Erzählens. In: Text und Text in lateinischer und volkssprachiger Überlieferung des Mittelalters. Freiburger Kolloquium 2004. Hg. von Eckart Conrad Lutz. Berlin 2006, S.33-58, hier S. 35. Das greift auf: Martin Baisch: „lere“ lesen. Formen von Textualität im Jüngeren Titurel. In: Der Jüngere Titurel zwischen Didaxe und Verwilderung (Anm.3), S. 13-31, hier S. 27. Vgl. zu einer Lektüre des Brackenseils, die semantische und materielle Aspekte von Schrift und Schriftträger nicht gegeneinander ausspielt, sondern als wechselseitig verbundene Elemente eines figuralen Wissens fasst, Falk Quenstedt: ,der steine krefté. Figurale Implikationen der Edelsteinschrift im Jüngeren Titurel. In: Figurales Wissen. Medialität, Ästhetik und Materialität von Wissen in der Vormoderne. Hg. von Anne Eusterschulte u. a. Wiesbaden (Im Erscheinen).

44 Der Prolog birgt eine Analogie zu dieser Stelle, auf die Ingrid Hahn hingewiesen hat. Dort wird bei der Erörterung der liturgischen Bedeutung von Wasser auf die vermittelnde Funktion des Priesters eingegangen: Während die "Heiden' das Wasser nur anbeten würden, bekomme es bei den Christen erst durch die Worte des Priesters („von worten sacramenta“, 44,4) seine heilswirksame Kraft. Da Hahn das Wasser als Analogon zur lere deutet, gelangt 
eine solche Wirkmacht. Am klarsten ausgedrückt ist dieser Anspruch im letzten Vers des Textes: „alle, di iz hơren, lesen oder schriben, der sele mü paradiset" $(6327,4)$.

In der Kombination von poetologischer Reflexion und Darstellung der Wirkung von Kunsthandwerk wird deutlich, dass Albrecht beansprucht, die Erzählwelten Wolframs so vermitteln zu können, dass sie zunächst einmal nicht negativ, und - darüber hinaus, in voller Entfaltung ihres Potentials - heilswirksam sein können. Und zwar nicht allein durch Lehre. Diese ist zwar notwendige Voraussetzung, bleibt aber gebunden an eine Lusterfahrung, die durch narrativ erzeugte Spannung hergestellt wird.

\section{Ein Wunderwerk der Technik und die Transparenz der Verrätselung}

In besonders ausgeprägter Form kommt eine solche Rätselspannung in einer Episode zum Einsatz, die am Ende der umfangreichen Tschinotulander-Handlung steht und den letzten Triumph des Helden darstellt, bevor er schließlich von Orilus getötet wird. Die Episode übernimmt somit eine wichtige Scharnierfunktion am Ende der Binnenhandlung, indem sie einerseits auf Handlungsmomente zurückblicken lässt, aber auch auf die Gralsmigration in der Rahmenhandlung am Ende des Gesamttextes vorausweist.

Ich möchte zunächst kurz darstellen, wie Rätselspannung in der Episode aufgebaut wird und wie diese zum Einsatz kommt, auch und vor allem um Wissen - ethisches, naturkundliches und heilsgeschichtliches - zu vermitteln. Die Episode bildet im Gesamttext insofern eine Besonderheit, als sie intensiv auf Materialien der Alexandertradition zurückgreift. ${ }^{45}$ Allerdings geben auch andere Episoden dem Wunderbaren breiten Raum und weisen vergleichbare Erzählverfahren spannungsgenerierender Verrätselung auf. ${ }^{46}$

Kurz zur Handlung: Tschinotulander bricht von Karidol auf, um seine von Orilus besetzten Länder wieder einzunehmen; er begreift das als Schmach und fühlt sich als möglicher Gralsritter unwürdig (4734). In einem Wald trifft er auf zwei

sie zu dem Schluss, dass „dichterische Lehre [...] eine dem priesterlichen Dienst zugewiesene Funktion [erfüllt]!" Dabei ist laut Hahn in der Liturgie auch ein Moment der Spannung und finalen Erlösung zentral, den sie auf den ,Mitvollzug von Lehre' bezieht (jedoch nicht auf narrative Spannung): „Für die Hörer bedeutet das Anhören der Lesung Verwandlung, Heil, Wiedergeburt. Von der feierlich gebotenen Stille, der Erwartung des Anfangs spannt sich ein Bogen zu diesem Höhepunkt der Freude, so daß der Mitvollzug der Lehre einen inneren Weg beschreibt." Ingrid Hahn: Kosmologie und Zahl. Zum Prolog des Jüngeren Titurel. In: Geistliche Denkformen in der Literatur. Hg. von Klaus Grubmüller, Ruth Schmidt-Wiegand und Klaus Speckenbach. München 1984, S. 226-244, hier S. 243.

45 Vgl. Florian Kragl: ,Klarifunkel’. Oder: Warum beim Jüngeren Titurel der Teufel nicht im Detail steckt. In: Der Jüngere Titurel zwischen Didaxe und Verwilderung (Anm.3), S.139-182, hier S. 171.

46 So etwa Tschinotulanders Experimente mit einem Salamander-Schild, deren Ergebnisse zunächst rätselhaft bleiben, nach dem Kampf gegen die Gayloten aber von Gelehrten am Hof von Persidine, an dem sowohl Muslime wie Christen gegenwärtig sind, aufgeklärt werden (2678-2821). Ein anderes Beispiel ist die Seereise Parzivals (5597-5762). 
Riesen, die ihn sogleich angreifen (4735f.). Das Geschehen ist auf Tschinotulander hin fokalisiert erzählt. Mit ihm registriert das Publikum, dass die beiden Angreifer reich geschmückt sind, genauso wie der edle ,Heide' Secureiz, den Tschinotulander bei einer Schlacht vor den Toren Baldacs versehentlich tötete, weil ein Erkennungszeichen verloren gegangen war (4735-37). Um Erkennen und Verkennen geht es auch hier. Anfangs glaubt Tschinotulander, die beiden Riesen kämen aus dem Paradies, um den Tod des Secureiz zu rächen (4738,2-4). Dieser Gedanke erstaunt ihn sehr: „Do kund in nie genügen zewundern der geschihte“ (4738,1; „Er konnte sich angesichts der Begebenheit nicht genug verwundern. "). Ein innerer Monolog gibt Tschinotulanders Verwunderung Ausdruck: "Jesus der wunderære" $^{\prime \prime}(4739,2)$, so denkt er, hat so viele Wunder vollbracht, nichts ist unmöglich trotzdem, aus dem Paradies stammen die Riesen wohl kaum, vielleicht sind es Secureiz' Brüder (4739,1-4)? Dass es sich um ,Heiden' handelt, legt ihr Schlachtruf "Jupiter" $(4741,2)$ nahe. ${ }^{47}$ Auch das Publikum weiß nichts über die Identität der Riesen. Der Erzähler spricht das im Verlauf der Episode wiederholt an, um diese unbeantwortete Frage präsent zu halten und zu beteuern, dass er sie gleich beantworten wird..$^{48}$ Das macht das Verfahren, Rätselspannung aufzubauen, durchgehend transparent. Auch Tschinotulander selbst fragt sich immer wieder, wer sie sind, und stellt dabei weiterhin Hypothesen auf. Dieser narrative Nachvollzug von Tschinotulanders Wahrnehmungs- und Denkprozess gleicht der Darstellung eines Bewusstseinsstroms. Als einer der beiden Riesen den Schlachtruf "Paradis" $(4749,1)$ verlauten lässt, sieht sich Tschinotulander in seiner ersten beunruhigenden Vermutung bestärkt, und glaubt nun, die von Gott ins Paradies entrückten „Enoch und Elie“ $(4750,1)$ vor sich zu haben. ${ }^{49}$ Wollen sie ihn bestrafen, weil er sich der Gralsgesellschaft unwürdig erwiesen hat (4750,2-4)? Soll er etwa gegen Gott kämpfen (4751-4753)? Tschinotulander ist in seiner Weltorientierung zutiefst verunsichert, der Erzähler spricht von seinem „wanken“ $(4754,2)$. Es handelt sich allerdings um eine Irritation, die für die Rezipienten durch die Erzählerkommentare distanziert und entschärft ist: Sie wissen schon, dass er sich irren muss und dass die Auflösung gleich folgen wird.

47 Unter ,Heiden' sind in der mittelhochdeutschen Literatur meist Muslime zu verstehen. Sie werden als Polytheisten dargestellt, in deren „,vielgestaltige[n], synkretistische[n] Götterhimmel“ genauso der Prophet Mohammad (mhd. Mahmet), wie antike Götter (Jupiter, Apoll u. a.) und andere Namensformen (Tervigant, möglicherweise jüdische Tradition) eingehen, vgl. Peter Strohschneider: Kreuzzugslegitimität - Schonungsgebot - Selbstreflexivität. Über die Begegnung mit den fremden Heiden im Willehalm Wolframs von Eschenbach. In: Die Begegnung mit dem Islamischen Kulturraum in Geschichte und Gegenwart. Hg. von Stefan Krimm und Dieter Zerlin. München 1992, S. 23-42, hier S. 29. Im Jüngeren Titurel werden Muslime etwa in der Magnetberg-Episode (6097) in dieser Weise dargestellt.

48 ,ich sag iu liht her nach wol, waz si rachen“ $(4742,4)$; „wer die zwene waren, die vrage lat, biz daz der ein gewinne" $(4747,4)$.

49 Vgl. auch den Prolog, wo auf die Entrückung von Enoch und Elia als ein Wunder Bezug genommen wird (83,3f.). Hierin scheint die Verbindung zu Jesus als „wunderære“ zu bestehen. 
Als die Riesen nun neben „Paradis" auch die Schlachtrufe „Tasme“, „Vriende“ und „Tabrunit“ $(4755,1)$ benutzen - alles Ortsnamen, die von den beiden Orientfahrten des Protagonisten her bekannt sind und auf Secureiz und seine Verwandtschaft verweisen - schließt Tschinotulander daraus, dass es sich doch um ,Heiden' handeln muss, sie also, in seiner Logik, keinesfalls von Gott gesandt sein können. Das schafft Klarheit. Er steht folglich zwangsläufig auf der richtigen Seite und das gibt ihm Kraft (4756). Der Kampf dauert lange an. Die Pferde sind schon vor Erschöpfung ohnmächtig geworden und man kämpft mit den Schwertern zu Fuß weiter (4770). Aufgrund seines Vorwissens vermutet Tschinotulander mittlerweile, dass die beiden Riesen als Minneritter für Arabadille und Secundille kämpfen (4774), was ihn wiederum dazu bringt seinerseits an seine Minnedame Sigune zu denken (4775). Diese zeigte sich dem Ritter vor seinem Abschied nackt, worin die Forschung eine eigenwillige Veränderung des „bekannte[n] Motiv[s] vom kräftesteigernden Anblick der Dame“ gesehen hat, das der Jüngere Titurel hier "stark erotisiert. ${ }^{\prime 50}$ Dieses deutlich sensuell konnotierte innere Bild - „daz vil süze erblenken“ (4775,2; „das sehr süße Entblößen“) - stärkt Tschinotulander schließlich so sehr, dass einer der beiden Gegner einen Schritt zurückweichen muss, woraufhin dieser sich - einigermaßen abrupt - ergibt (4776).

Der ,Heide' bittet nun Tschinotulander darum, ihn zu töten $(4776,4)$, was dieser als einen Angriff auf seine Ehre begreift. Die ritterliche Tugend verbiete das und außerdem: Für wen hält sich dieser Fremde, wenn er meint, er müsste sterben, nur weil Tschinotulander ihn besiegt hat (4792)? Oder ist er tatsächlich von höherem Rang? Die Diskussion um die ehrenrührige Bitte setzt sich eine Weile fort und bietet reichlich Gelegenheit, ritterliche Tugendlehre auszubreiten (4778-4799). Da dabei aber die Frage der Identität der Fremden eine so große Rolle spielt, hält das auch die Rätselspannung weiterhin aufrecht. In der Zwischenzeit kommt, vom Kampflärm angelockt, ein weiterer Artusritter namens Ekunat hinzu, dem sich ein irritierender Anblick bietet („In wundert wol der mære“; 4790,1): Die Pferde liegen herum, die Ritter stehen ohne Helm und diskutieren. Wer hat hier wen besiegt (4790,2)? Noch ein Rätsel. Die Diskussion kommt erst zu einem Ende, als der Fremde sagt: Wenn ihr wüsstest, wie es um mich steht, ihr würdet verstehen, warum ich sterben möchte (4797f.). Endlich fragt Tschinotulander nach dem Grund ihres Aufenthalts $(4799,4)$ und der Bedeutung des Schlachtrufs „Paradise“ $(4800,1)$.

Die Antwort der Riesen ist über die Maßen erstaunlich, denn sie kommen tatsächlich aus dem ,Paradies' („Paradis heizt unser lant“; 4801,3). Allerdings handelt es sich nicht um "daz rechte, daz Adam verworhte mit unprise“ (4814,4; „das echte, welches Adam mit Schande verwirkte“), sondern um ein Königreich in „India diu dritte, ein ende gar der welde“ (4818,1; „im dritten Teil Indiens, am Ende der Welt"). Die Namensgebung erklärt sich daher, dass sie ihr Reich mit „listen“ (4817,3; „Klugheit") so eingerichtet haben, "daz iz sich wol dem paradis gelichet" (4817,4; "dass es dem Paradies gleicht“). Ihre „liste“ ermöglichen den

50 Mertens: Der deutsche Artusroman (Anm. 2), S. 268. 
Fremden aber nicht nur den Aufbau eines paradiesischen Reiches, sondern auch ihre Präsenz in einem Wald in der Nähe des Artushofes. Möglich macht beides ein technisches Wunderwerk, ein Flugzeug. Dessen ,historische' und gedankliche Grundlage bildet die Episode vom Greifenflug Alexanders des Großen, die aus dem Alexanderroman stammt und aufgrund der Popularität des Textes und einer weitverbreiteten Bildtradition im 13. Jahrhundert vermutlich sehr bekannt war. ${ }^{51}$ Die beiden Paradiesbewohner stammen von den Griechen, die als besonders klug gekennzeichnet werden, ab und gehen direkt auf Alexander den Großen zurück (4805,1-2). Sie heißen entsprechend „Alexander" und - wie Alexanders Vater „Philippe“ (4836,1). Über Generationen hinweg haben sie und ihre Vorfahren die technische Pionierleistung ihres Ahnherren, die Dressur der Greifen, weiterentwickelt $(4802,2-4 ; 4815,1 \mathrm{f}$.), so dass sie nun in der Lage sind, mit zwei Greifen, zwischen welche Kästen gehängt werden, in denen vier Ritter samt Ross Platz finden, eine Woche lang in der Luft zu bleiben und so weite Distanzen zurückzulegen (4815f.). Als Kraftstoff dienen dabei 30-jährige Elefanten, die den Greifen im Flug verfüttert werden $(4817,1 \mathrm{f} .)^{52}$

Die Greifen-Apparatur half ihnen dabei, ihr paradiesisches Reich zu schaffen (4817,3f.; 4820). Binnen kürzester Zeit können sie ihre Streitkräfte überallhin schaffen und außerdem die Reichtümer aus Tasme, Vriende usw. (nun erklären sich auch die Schlachtrufe) bequem in ,Paradis' versammeln. Das ist eine interessante (Um-)Akzentuierung der Alexandertradition: Dient die Greifenflugepisode sonst meist als Exempel menschlicher Hybris, erscheint der ,weise' Alexander $(4802,4)$ hier - ohne jede Kritik! - als ein Forscher, der fernöstliche, naturkundliche mirabilia nicht nur entdeckt, ${ }^{53}$ sondern auch für Menschen nutzbar macht. Der Entwurf des Flugzeugs, wie Hartmut Kugler bemerkt, weist dabei „ein erstaunlich hohes $\mathrm{Maß}$ an Rationalisierung und Funktionalisierung "54 auf. Wie beim Gralstempel dient auch hier die „Faszination des Maschinellen“ dazu, mittels eines ästhetischen Eindrucks die unbegreifliche Größe der Schöpfung fassbar zu machen. Die innovative Konstruktion des Greifenflugzeugs zielt dabei nicht zuletzt auf ein Staunen über die Meisterschaft des Erzählens, das es versteht, die Alexandertradition - auf Basis naturkundlichen Wissens - aufzugreifen und in verblüffender

51 Vgl. Hartmut Kugler: Alexanders Greifenflug. Eine Episode des Alexanderromans im deutschen Mittelalter. In: Internationales Archiv für Sozialgeschichte der deutschen Literatur 12 (1987), S. 1-25; Richard Stoneman: Alexander the Great. A Life in Legend. New Haven, CT; London 2008, S. 114-120.

52 Dass Elefanten den Greifen als Nahrung dienen, berichtet auch Marco Polo, der zur Entstehungszeit des Textes gerade von seiner Reise zurückgekehrt war (im Jahr 1269).

53 Z. B. den ",artanticum“, den Pol der Erdachse (4805,4-4807,4), oder "fenix, bellicame und salomander in fiure" (4814,1; „Phoenix, Pelikan und Salamander im Feuer").

54 Hartmut Kugler: Zur literarischen Geographie des fernen Ostens im Parzival und Jüngerem Titurel. In: „Ja muz ich sunder riuwe sin“. Festschrift für Karl Stackmann zum 15. Februar 1990. Hg. von Wolfgang Dinkelacker. Göttingen 1990, S.107-147, hier S. 130. 
Weise zu erweitern. ${ }^{55}$ Zugleich stiftet dieser Ausgriff auf orientalische Naturwunder und Wunderwerke der Technik Kohärenz im Text: Denn die beiden Riesen berichten, dass sie die Schmach der Niederlage wohl verwinden könnten, wenn sie gegen Tschinotulander gekämpft hätten (sie wissen noch nicht, dass sie das gerade getan haben), oder gar gegen einen Ritter aus der Gralsfamilie (der Tschinotulander durch die Verbindung mit Sigune ebenfalls ist) (4832,2-4833,1). Denn ihre arabischen Sterndeuter hätten ihnen vorhergesagt, dass aus dieser Gralsfamilie einst ein "herre" $(4834,1)$ zu ihnen kommen wird, dem alle Falschheit abgeht und der "priester Johan“ $(4834,3)$ heißt. Hier gibt der Text erstmals einen Ausblick auf das utopische Ende des christlichen Idealreichs in Indien.

Darauf, dass die Ausstellung der Künstlichkeit der narrativen Konstruktion überhaupt ein Anliegen des Textes ist, scheint mir ein weiteres Irritationsmoment hinzuweisen: Ekunat nämlich, der hinzugekommene Artusritter, formuliert nach den Ausführungen von Alexander und Phillip den für das Wunderbare typischen Lügenvorwurf: eine regelmäßig im Zusammenhang mit Darstellungen des Wunderbaren von der Erzählinstanz diskutierte und zurückgewiese Bezichtigung, dass das Erzählte lügenhaft sei. ${ }^{56}$ Dieser Vorwurf ist hier von der diskursiven Ebene in die Diegese verschoben. Ekunat sagt, was die beiden da erzählten, sei alles gelogen, um ihn und Tschionatulander zu überlisten (4840). Daraufhin taucht völlig unvermittelt eine weitere Stimme auf, die sich als König von Kaukasus zu erkennen gibt und behauptet: ,Ich kann alles bezeugen!' Dieser König von Kaukasus ist aber nicht zu sehen, sondern nur zu hören („Ir höret all min stimme und sit mich doch niht sehende.", 4845,1). Er führt nämlich einen Wunderstein mit sich, der ihn unsichtbar machen kann. Er sei als blinder Passagier bei Alexander und Phillip mitgereist, damit er - als Augenzeuge! - die Taten der beiden Ritter den Minnedamen zuhause im Orient beglaubigen könne (4848). Auf diese Weise die Authentizität des Greifenflugzeugs bezeugen zu wollen, das hieße wohl, den Teufel mit dem Beelzebub austreiben. Der Jüngere Titurel stellt sich hier selbst als meisterlich gearbeitetes, schillerndes Kunstwerk aus. Der Text greift dabei auch das eigene poetologische Vokabular auf, wenn der unsichtbare Zeuge den Sieg Tschinotulanders mit den Worten beglaubigt, er habe „sunder krumb mit aller slechte“ $(4849,2)$ gewonnen. Die poetologischen Aussagen der Diskursebene be-

55 Hier zeigt sich eine Nähe zur modernen Science-Fiction-Literatur, die ihre Fiktionen durch naturwissenschaftlich-technisches Wissen fundiert, vgl. Christoph F. Lorenz: [Art.] Science Fiction. In: Reallexikon der deutschen Literaturwissenschaft. 3. Aufl. Bd.3. Hg. von Jan-Dirk Müller. Berlin, New York 2007, S. 412-414, hier S. 412f.

56 Häufig wird im scholastischen Diskurs ein solcher Lügenvorwurf der fabula - im negativen Kontrast zur wahrhaftigen historia - gemacht, meist (wenngleich nicht ausschließlich) in diffamierender Absicht, vgl. Sonja Glauch: [Art.] Fiktionalität im Mittelalter. In: Fiktionalität. Ein interdisziplinäres Handbuch. Hg. von Tilmann Köppe und Tobias Klauk. Berlin, Boston 2014, S. 385-418, hier S. 388 und 410-413. In volkssprachlichen Erzählungen sind Darstellungen des Wunderbaren regelmäßig mit Wahrheitsbeteuerungen der Erzählerinstanz durchsetzt, wobei in vielen Fällen ein von der Sprechinstanz antizipierter oder auch von anderen Figuren vorgebrachter Lügenvorwurf zurückgewiesen wird. 
gegnen hier in der Erzählwelt wieder, nicht nur lexikalisch, sondern auch inhaltlich. Denn diese Beglaubigung von Tschinotulanders Ritterlichkeit wird vor allem dadurch ermöglicht, dass etwas Verborgenes ans Licht gebracht wird. Der Text schillert hier zwar, belässt aber nichts im Dunklen!

Das verweist zurück auf die Darstellung der Wirkung der Tricktechnik im Gralstempel. Denn auch dabei wird dessen Künstlichkeit immer präsent gehalten. Die Templeisen wissen um die Künstlichkeit und können die Kunst daher doppelt genießen. Dieses Wissen entschärft den Idolatrie-Vorwurf (sie wissen, es sind nur Bilder) und macht Kunst damit für die Vermittlung von Heil disponibel. Ein Indiz dafür, dass ein spielerischer Umgang mit Kunst, hier gar mit einem kunstvoll-heiteren Erzählen, und eine Sphäre des Heiligen sich nicht gegenseitig ausschließen, könnte eine Bemerkung zur Ausbildung der Töchter der Gralsgesellschaft sein, auf die Johannes Keller hingewiesen hat; es heißt dort, dass die jungen Frauen „lernten riche wort zu sprechen wilde." $(92,2) .{ }^{57}$ Der geblümte Stil des Jüngeren Titurel wäre demnach nicht nur auf der Ebene des Diskurses, der Strophenform, der Metaphorik usw. zu suchen, sondern auch in den Ranken und Blüten des Erzählens - der ",aventiure kere".

Die Inszenierung des Wunderbaren wird im Anschluss an diese staunenswerten Enthüllungen nun noch einmal intradiegetisch aufgegriffen. Denn Artus, der zufällig mit einer Jagdgesellschaft in der Nähe ist, bestaunt die Greifen. Die Episode endet mit einer witzigen Sentenz des Truchsessen Kaye, die den Topos der verkehrten Welt aufgreift: Ausgerechnet die ,Heiden', denen Gottes Huld auf Erden abginge, benutzen den Himmel, um sich fortzubewegen. Der bittere Beigeschmack in dieser Bemerkung, die eine Überlegenheit der ,Heiden' feststellt, ${ }^{58}$ löst sich dadurch auf, dass Alexander und Phillip, die Besitzer des Greifenflugzeugs und Herren über das ,Paradies', am Ende des Romans zum Christentum übertreten und Vasallen des Priesterkönigs Johannes werden.

57 Johannes Keller: Fern von Komik und Humor? (Anm. 9), S. 110f.: „Wichtig ist, dass die beiden älteren [Mädchen] lernen, kostbare Wörter oder Erzählungen in ,wilder' Form wiederzugeben. Dies scheint an dieser Stelle positiv konnotiert zu sein. Es gehört also zur gralskonformen Erziehung der Mädchen, wertvoll und ,wild' sprechen und erzählen zu können. Damit stehen sie in der Nähe der Erzähltechnik, die im Prolog vordergründig abgelehnt, hintergründig aber durchaus propagiert wird. Dass diese ,kunst', wie es hier heißt, im Zentrum der Gralswelt anzutreffen ist, verschafft ihr eine zusätzliche Legitimation."

58 In dieser Aussage ist eine ernüchternde Selbstwahrnehmung des lateinischen Westens als peripherer und rückständiger Provinz angesichts der Größe, des Reichtums und der kulturellen Überlegenheit Asiens greifbar. Artus, der ideale Repräsentant der höfischen Kultur, wird nicht nur an dieser Stelle des Jüngeren Titurel in Ansehung der höfischen Pracht muslimischer Herrscher zum Zaungast degradiert. Verwiesen sei etwa auf eine Episode, in der plötzlich wie aus dem Nichts das Heerlager eines Clarisidun neben dem Artushof auftaucht. Jenes ist ungleich prachtvoller als dieser und beschämt die arturische Gesellschaft (2359ff.), etwa auch in Bezug auf unterschiedliche Potentiale der ,milte'; vgl. dazu Manuela Schotte: Christen, Heiden und der Gral. Die Heidendarstellung als Instrument der Rezeptionslenkung in den mittelhochdeutschen Gralromanen des 13. Jahrhunderts. Frankfurt a. M. u. a. 2009, hier S. 138f. 
Es lässt sich konstatieren: Die Episode wird von Rätselspannung zusammengehalten, wobei deren schrittweise Auflösung ethische, kosmische, heilsgeschichtliche und auch narrative Zusammenhänge deutlich macht und sie in ein Staunen angesichts technischer Wunderwerke, zugleich aber auch angesichts der Meisterschaft der Dichtung, kulminieren lässt. Am Ende löst sich die Spannung in Wohlgefallen auf, gipfelt gar in einem Lachimpuls. Zielt sie damit aber nicht auch, wie das im Text anhand des Gralstempels und des Brackenseils vorgeführt wird, auf eine glücks- und heilsförderliche Wirkung? Dynamiken der Verrätselung und ihrer verzögerten Enthüllung werden genutzt, um schließlich zu einer lustvollen Auflösung der gespannten Situation zu führen, mithin eine Stimmung gelöster Heiterkeit hervorzurufen. Dass diese (auch) spielerisch und im Zuge des Ausstellens narrativer Meisterschaft erfolgt, muss - das zeigt die Tricktechnik im Gralstempel - einer heilsförderlichen Wirkung nicht widersprechen, zumal Albrecht (bzw. ,Wolfram') wie der Priester als ein Vermittler fungiert, der nichts im Dunklen belässt. Indem verborgene Techniken ausgestellt und so transparent gemacht, zudem in den Dienst von lere gestellt werden, die ebenfalls darauf zielt, verborgene Zusammenhänge der Welt aufzudecken, stehen sie nicht mehr im Verdacht, in die Irre zu führen. Das Erzählen gelangt auf diese Weise als eine Kunst, die kosmische Zusammenhänge dekuvriert und dabei - im Sinne einer durch Spannung generierten Lusterfahrung - heilsame Wirkung entfaltet, zu Geltung; als eine Kunst des ,Paradisierens'. 



\section{Alphidius und Lamspring um 1600 \\ Verrätselungen in der frühneuzeitlichen (Al)Chemie in religionshistorischem Kontext}

Volkhard Wels

Ziel der folgenden Ausführungen ist es, die auf den ersten Blick merkwürdige Vorliebe (al)chemischer Texte für die literarische, rhetorische Form des Rätsels zu erklären oder zumindest einen Vorschlag zu machen, wie diese Vorliebe historisch zu erklären sein könnte. Alchemie gilt nach wie vor - trotz des Quantensprungs, den die großen Forschungsarbeiten der letzten zwanzig Jahre erbracht haben ${ }^{1}-$ als ,Geheimwissenschaft' und ,okkulte Kunst', als Schwesterdisziplin der Magie, als verbotenes Wissen. Sie stünde damit in scharfem Kontrast zur Chemie als ,Naturwissenschaft', wie sie dann angeblich im Laufe des 17. Jahrhunderts entsteht. Nicht unwesentlichen Anteil an diesem historischen Zerrbild hat die Tatsache, dass sich zahlreiche (al)chemische Texte einer merkwürdigen Darstellungsform bedienen - sei es in Form von rätselhaften Erzählungen, sei es in Form von bildlichen Illustrationen, sei es in Form arkansprachlicher Darstellungen. Nichts davon erwarten wir von einem Text, der ein Wissen über die Natur vermitteln will (nicht zu reden vom Begriff einer ,Naturwissenschaft', den man für die Frühe Neuzeit nicht verwenden sollte). Wir erwarten eine sachliche Darstellung: die chemische Formel, die präzise Mengenangabe, die genaue Bezeichnung eines Stoffs. Rätselhaftigkeit dagegen scheint dem Sinn und Zweck der Wissensvermittlung per se zuwiderzulaufen. Es war deshalb auch immer genau dieser rätselhafte Charakter der frühneuzeitlichen (Al)Chemie, der (auf der Ebene der Darstellung) den entscheidenden Unterschied zur Chemie als ,Naturwissenschaft' ausmachte.

Indem dieser Beitrag deshalb versucht, die Rätselhaftigkeit alchemischer Texte tatsächlich als Rätselhaftigkeit im rhetorisch-technischen Sinne zu deuten, als bewusste Verrätselung, bezieht er Position gegen die Deutung der Alchemie als einer irgendwie ,geheimnisvollen' Kunst, als Mysterium im Sinne der modernen Esoterik, $^{2}$ die genau diese Texte für ihre Vorgeschichte beansprucht. Die Alche-

1 Vgl. stellvertretend Bruce T. Moran: Distilling Knowledge. Alchemy, Chemistry and the Scientific Revolution. Cambridge, MA 2005; ders.: Andreas Libavius and the Transformation of Alchemy. Separating Chemical Cultures with Polemical Fire. Sagamore Beach, MA 2007; Lawrence M. Principe: The Secrets of Alchemy. Chicago u. a. 2013 und Didier Kahn: Le fixe et le volatile. Chimie et alchimie, de Paracelse à Lavoisier. Paris 2016.

2 Der Begriff der ,Esoterik' entstammt dem 19. Jahrhundert und sollte - genauso wie der Begriff ,Naturwissenschaft' - nicht auf die Frühe Neuzeit bezogen werden. Wenn ich den Begriff hier 
mie der Frühen Neuzeit - so lautet dagegen die These, die diesem Beitrag zugrunde liegt - ist immer auch schon Chemie, ist immer schon Naturwissen, nur eben ein Naturwissen, das sich einer (aus moderner Perspektive) merkwürdigen Form bedient: des Rätsels.

Die Frage, wie dieses Bedürfnis nach Verrätselung historisch zu erklären ist, bekommt deshalb eine besondere Dringlichkeit. Meine Antwort ist leider - das sei als Warnung vorangestellt - relativ komplex. In Betracht zu ziehen ist nämlich die Tatsache, dass diese (Al)Chemie nicht nur um 1600 schon für sich genommen ein Rezeptionsphänomen darstellt (indem Texte aus dem 14. und 15. Jahrhundert bearbeitet oder ediert werden), sondern Texte auch durch konstruierte Fundlegenden und Pseudonyme zurückdatiert werden. Ihre Rätselhaftigkeit wird also historisch begründet, schon um 1600. Indem die Rekonstruktion der Textgeschichten deshalb ein Argument für meine These ist (die Verrätselung als literarische Strategie), muss ich diese Rekonstruktion auch vorführen. Es ist deshalb nicht nur im Sinne einer positivistischen Historiographie wichtig, wer sich hinter einem bestimmten Pseudonym verbirgt.

Dasselbe gilt für die sozialhistorische Rekonstruktion der Netzwerke, in denen die Verfasser und Herausgeber dieser Texte sich bewegt haben. Es ist eben kein Zufall, wie ich zu zeigen hoffe, dass es zwischen dem Frankfurter Verlag von Lucas Jennis und dem Hof von Moritz, Landgraf von Hessen-Kassel, enge personelle Verflechtungen gibt. Und es scheint mir ebenfalls kein bedeutungsloses Faktum, dass es sich dabei um ein spezifisch calvinistisches Netzwerk handelt. Auf der anderen Seite steht ein Lebenslauf wie der von Benedikt Figulus, der gerade als Paracelsist und Spiritualist nicht in dieses Netzwerk passt. Dieselben Texte werden in ihrer Rätselhaftigkeit im Umfeld des Landgrafen ganz anders gedeutet als es die Edition derselben Texte durch Figulus impliziert. Während die Rätselhaftigkeit für den Spiritualisten Figulus Ausdruck einer zunehmenden Offenbarung göttlichen Wissens ist, ist sie für den Verleger Jennis Anlass für höchst kunstvolle und extrem teure Kupferstiche. Diese Kupferstiche muss man aufgrund ihrer Herstellungskosten möglichst oft zum Abdruck bringen - ob es nun passt oder nicht, ob man sie verstanden hat oder nicht.

Wie es diese einleitenden Bemerkungen schon andeuten, bewege ich mich methodisch damit zwischen Philologie, Sozialgeschichte und Wissenschaftsgeschichte. Ich würde diesen Ansatz als einen genuin wissensgeschichtlichen charakterisieren, indem im Mittelpunkt meines Interesses das (al)chemische Wissen

verwende, meine ich diese moderne Tradition (einschließlich der psychoanalytischen Deutung der Alchemie in der Tradition Carl Gustav Jungs), die sich ihrerseits in zahlreichen Publikationen (und noch stärker im Internet) auf Texte wie den Lamspring beruft. Meine Ausführungen richten sich gegen eine solche historische Vereinnahmung, insofern mein Argument lautet, dass die Alchemie der Frühen Neuzeit nicht in die Vorgeschichte der modernen Esoterik gehört. Vgl. in diesem Sinne Lawrence M. Principe und William R. Newman: Some Problems with the Historiography of Alchemy. In: Secretes of Nature. Astrology and Alchemy in Early Modern Europe. Hg. von Anthony Grafton und William R. Newman. Cambridge 2001, S. 385-430. 
steht, wie es um 1620 vermittelt wird. Entsprechend dem Ansatz des SFB 980 „Episteme in Bewegung", aus dem dieser Beitrag hervorgegangen ist, geht es mir um eine Geschichte des (al)chemischen Wissens als eines Wissens, an dem sich paradigmatisch zeigen lässt, dass der Transfer von Wissen niemals ein ,statisches' Unterfangen ist. Die Vermittlung von Wissen in seinen historisch konkreten Darstellungsformen gehorcht überaus komplexen Dynamiken, die auf gar keinen Fall von den vermittelten Inhalten abzutrennen sind. Die rätselhaften Formen (al)chemischen Wissens machen dieses Wissen noch lange nicht zu einem irgendwie diffus ,mystischen' oder ,okkulten' Wissen. Als eine exemplarische Studie in diesem Sinne ist dieser Aufsatz zu verstehen.

\section{Alphidius und Lamspring}

1608 erscheint in einem Sammelband mit (al)chemischen Schriften, der Thesaurinella Olympica des Benedict Figulus, auch der sogenannte Alphidius. Das kurze, parabolisch Tractätlein (wie der Titel lautet) erzählt in seinem ersten Teil eine rätselhafte Geschichte:

Alphidius der Philosophus spricht: Es war ein Vatter/ der hatte einen Sohn/ denselbigen hatte er sehr lieb. Der Sohn sprach zum Vatter/ ich habe Lust außzufahren/ vnnd zu sehen die Welt/ dann man saget mir von grosser Herrlichkeit: Darüber wardt der Vatter betrübet vnd sprach: Du mein aller liebster Sohn/ wilt du mich verlassen/ vnnd von mir außfahren/ so weist du/ wann das geschicht/ daß ich ohne dich nicht leben mag. Da nun der Vatter sahe/ daß es nicht anders seyn kondte/ gab er dem Sohn einen Führer zu/ vnd bate ihn wol zu führen/ auch also zu ziehen/ damit ihm ja nichts leyds geschehen möcht. Da nam der Führer den Sohn/ vnd führet ihn mit sich in die gantze weite Welt auff den aller höchsten Berg/ allda zeiget er der Führer dem Sohn alle Schätz vnd Reichthumb der Welt. Da nun der Sohn alles gesehen hatte/ da fieng er an/ vnd sprach zu dem Führer/ komm/ vnd laß vns widerkehren/ dann ich weiß/ daß der Vatter ohne vns nicht leben mag/ wegen grosser Betrübnuß er sterben muß/ da sie nun wider kamen/ funden sie den Vatter todt ligen/ da fielen sie als baldt mit weinenden Augen auff den Vatter/ erwecken den. Da ward er als baldt widerumb lebendig/ vnd vor grosser Frewden empfieng er sie/ vnd behielt sie bey sich/ also blieben sie bey einander vnd wurden eins.

Direkt im Anschluss wird dieses Gleichnis aufgelöst:

Dieses nun Philosophischer weiß zu vergleichen vnd zu verstehen/ kan auff Gott den Vatter in der heyligen Dreyfaltigkeit/ oder einen Menschen mit Seel/ Geist/ Fleisch vnd Blut begabet gezogen werden. Also wird auch vnsere Materi gedeutet: Dann sie in ihr hat Mercurium, Sulphur. In der Putrefaction wirdt das Corpus, das ist/ der Vatter/ mortificirt/ durch die Materi/ so scheidet sich vnd fähret auß der verborgene Sohn/ das ist/ der Sulphur, die Seel/ das Blut/ als das Philosophisch Feuer, der Führer der ist Mercurius, als der Geist/ der Athem/ 
Rauch/ vnd das Wasser. Die Welt ist das Glaß oder Instrument: Der allerhöchste Berg ist der Alembic, darein kompt aller Schatz vnnd Reichthumb. Das der Sohn sihet/ das ist der Vatter/ als die Materi/ oder der Leib/ oder das Saltz vnd die todte Erde/ so im Grund ligen bleibt: Der Führer/ als der Mercurius hat in ihme verborgen den Sohn/ das ist/ den Sulphur, vnd die Animam: Diese beyde sind kalt vnd warm/ feucht vnd trucken/ Wasser vnd Feuer, Seel vnnd Geist. So baldt sie nun auff den todten Vatter/ welches ist das dürre Erdreich/ Corpus, Sal, mit irem Regen oder Threnen niderfallen/ so wirdt der todte Vatter durch seinen eygenen Sohn vnd Führer widerumb erfrischet vnd erwecket/ ja ihm wirdt auch das Leben gegeben/ vnd mit grossen Frewden nimbt er sie wider zu sich/ vnd behält sie gern bey sich/ auch bleiben diese drey in einer Gestalt bey einander/ vnd lassen sich nimmer scheiden/ etc. ${ }^{3}$

Es handelt sich also um eine verschlüsselte Darstellung grundlegender, chemischbiologischer Lebensprozesse. Die ,Materie' besteht aus den ,Prinzipien' des Körperlichen (der Vater: das Salz, die ,todte Erde'), des Seelischen (der Führer Mercurius/Sulphur, also Schwefel als das Brennbare oder das, was sich verflüchtigen lässt) und des Geistigen (der Sohn als das Wasser). Wenn in der „Putrefaction“ die Seele und der Geist die Materie verlassen, ist damit der chemische Prozess der Fäulung oder ,Abtötung' bezeichnet, indem nämlich Flüssigkeiten, Dämpfe und Gase entweichen, nach oben entsteigen. Deswegen steigt der Sohn mit seinem Führer auf den „allerhöchsten Berg", der mit dem "Alembic“ identifiziert wird, also dem Helm des Destilliergefäßes, in dem sich das Destillat niederschlägt. Im Destillierkolben bleibt dagegen die ,mortifizierte', , abgetötete', ausgetrocknete Materie zurück, die „,todte Erde“, der Vater, das Salz. Fügt man das Destillat, die ,geistige Flüssigkeit‘, den Sohn mit seinem Führer, dem Vater wieder hinzu, als „Regen oder Threnen", so belebt sich die Materie wieder und bringt neues Leben hervor. Das chemische Experiment bildet im Kleinen den Kreislauf der Natur ab.

Über den Verfasser dieses Traktats ist nichts bekannt. „Lebenszeit, Stellung und Wirkungsbereich liegen im Dunkel“, wie Joachim Telle den Kenntnisstand zusammengefasst hat. ${ }^{4}$ Zitiert wird der Alphidius in der lateinischen Alchemieliteratur bereits im 14. Jahrhundert, darunter in so berühmten Texten wie der Margarita pretiosa des Petrus Bonus und der Aurora consurgens. Die deutschsprachige Überlieferung scheint erst im 15. Jahrhundert einzusetzen, jedenfalls findet sich die früheste bekannte Überlieferung in einer auf das 15. Jahrhundert datierten Handschrift (München, Staatsbibl., Cgm. 309). ${ }^{5}$ Diese Handschrift bietet eine etwas dramatischere Version der Parabel, indem dort der Vater den Sohn nicht nur

3 Thesaurinella Olympica aurea tripartita. Hg. von Benedict Figulus. Frankfurt a. M. 1608, S. 55f. Alchemische Zeichen für Mercurius, Wasser und Feuer innerhalb des Zitats wurden aufgelöst.

4 Joachim Telle: [Art.] Alphidius. In: Die deutsche Literatur des Mittelalters. Verfasserlexikon. Bd. 11: Nachträge und Korrekturen. Berlin, New York 2004, Sp. 72-75, hier Sp. 72.

5 Vgl. Beschreibung im Handschriftencensus unter URL: http://www.handschriftencensus. de/9564. Alle Angaben im Übrigen schon bei Herwig Buntz: Deutsche alchimistische Traktate 
in sein Haus, sondern körperlich wieder aufnimmt, nämlich verschlingt. Ich zitiere diese Variante des Alphidius in einer Edition aus dem frühen 18. Jahrhundert, dort unter der Überschrift „Folgendes Rätzel mercke du Liebhaber der Kunst“:

Es war ein gewisser Haus-Vater, der hatte einen Sohn, welchen er über die massen liebte; Solchem Sohne verschaffte er einen Magister, ihn in allem Guten zu lehren und zu unterweisen. Der Magister nun und der Sohn wollten miteinander spatzieren gehen, giengen auch zusammen fort; da sagte der Magister zu dem eintzigen Sohne des Vaters: Komm her, ich will dich zu dem höchsten Berge führen, allwo du die Höhe des Himmels sehen sollest, und dessen Höhe gleichsam abmessen; Ja, was noch mehr, ich will dich auff die Spitze, oder zur Spitze, auf die höchste Höhe des Himmels führen. Der Vater war darmit zu frieden, und mit des Magistri Worten und Anführungen vergnügt; da denn der Sohn mit seinem Magister in die Höhe stieg, und alle die Schönheiten und Vortrefflichkeit des Himmels beschauete, wie unvergleichlich solches aussehe. Nachdem nun der Sohn in solchen Betrachtungen eine Zeit zubrachte, so dachte er an seinen Vater, und sprach zu seinem Magister: Ich will wieder zu meinem lieben Vater gehen, weil er ohne mich nicht leben kann, ich weiß gewiß, daß er stets nach mir ruffen und schreyen wird. Der Magister antwortete: Ich lasse dich nicht alleine fortgehen, sondern ich gehe mit, weil ich dich mit mir geführet hate, will dich also wieder in den Schooß deines Vaters liefern, damit dein Vater leben bleibe, und nicht vor Grämniß, deinethalben, sterben möge. Also gieng der Sohn wieder ins Haus seines Vaters; Als nun der Vater seinen Sohn sahe, schrie er mit lauter Stimme: O mein eintziger lieber Sohn! Mein Leben, mein Vergnügen, der ich todt war, weil du abwesend und nicht bey mir warst, nun lebe ich wieder, weil du wieder bey mir bist. Vater und Sohn nun umbfiengen und umbfasseten sich miteinander, und zusammen; Ja, der Vater aß vor grosser Liebe den Sohn, und fraß ihn, jedoch wurde der Sohn unsterblich. Nachdem nun der Vater eine gute Zeit ohne seinen Sohn gelebet, kams ihme in seinen Sinn, daß er seinen Sohn gerne wieder gegenwärtig haben möchte, und fieng an gar zu verschmachten vor Grämen, seufftzete und klagete gar sehr hertzlich, bat Gott von Grund des Hertzens, deme alle Dinge möglich, und welcher alles aus nichts erschaffen, daß ihme doch Gott der Herr seinen einigen Sohn wieder geben und lebendig machen möchte. Gott erhörte des Vaters Gebet, und gebot jhme, daß er sich sollte schlaffen legen, so dann schickte Gott einen Regen von oben her, und dissolvirte den Vater in etliche Theile; Aus solchem Wasser schuff Gott eine Erde, das ist, einen neuen Vater, welcher auch einen neuen Sohn gebahr, welcher stets im Vater blieb, und der Vater im Sohne, und zwar inseparabiliter. Uber dieses haben diese zwey, Vater und Sohn, solche nützliche Saamen und Früchte von sich gegeben, und gezeuget, welche

des 15. und 16. Jahrhunderts. München 1969, S. 101-105, einschließlich einer Wiedergabe der verschiedenen Fassungen (ebd., S. 160-164). 
nimmer sterben, sondern immerdar leben, und zwar durch die Gnade Gottes, welcher von Ewigkeit zu Ewigkeit gepreiset seyn soll, Amen. ${ }^{6}$

In dieser dramatischeren Variante ist der Alphidius in einen relativ bekannten alchemischen Vers-Bild-Traktat übernommen worden, den sogenannten Lamspring (auch Lambspring, Lambert Spring o. ä.). „Lamspring“ ist dabei der Name des Verfassers, wie er sich mit seinem Wappen zu Beginn des Textes vorstellt. Der eigentliche Titel lautet Vom Stein der Weisen oder Vom philosophischen Stein. Auch hier ist über den Verfasser wenig bis nichts bekannt, genauso wie über die Herkunft und den Zeitraum, in dem der Text entstanden sein könnte. Telle plädiert für eine Entstehung um 1500 im niederdeutschen Raum. ${ }^{7}$

Der kurze Text besteht aus einer Vorrede und fünfzehn Text-Bild-Einheiten, wobei jedem Bild ein deutendes Verspaar als Titel zugeordnet ist, gefolgt von einer lateinischen subscriptio und einem kurzen (acht bis 25 Verse umfassenden) deutschsprachigen Gedicht, das den (al)chemischen Gehalt des Bildes erklärt oder zumindest beschreibt. Der Text verarbeitet ältere (al)chemische Quellen, darunter eben nun in den Kapiteln elf bis fünfzehn den Alphidius. „Die eilffte figur" zeigt Vater, Sohn und Führer vor einer Art Schloss, die Überschrift lautet:

Der Vater/ Sohn mit sambt dem führer haben sich bey den handen/

Corpus, Spiritus, vnd Anima dardurch werden verstanden.

Die begleitenden Verse:

Es ist ein alter Vater aus Israel kommen/

Der hat nur einen einigen Sohnen/

Welchen er liebt von gantzen seinen hertzen/

Solchem bestelte er ein führer mit schmertzen/

Als der führer den einigen Sohn führen solt/

6 Fasciculus unterschiedlicher alten raren und wahren Philosophischen Schrifften vom Stein der Weisen/ aus einem alten lateinischen Manuscripto ins Teutsche übersetzet. Hg. von Christoph von Hellwig. Leipzig, Bremen 1719, S. 140f.

7 Joachim Telle: [Art.] Lamspring. In: Die deutsche Literatur des Mittelalters. Verfasserlexikon. Bd. 11: Nachträge und Korrekturen. Berlin, New York 1985, Sp. 524-530; Buntz: Alchimistische Traktate (Anm. 5), S. 89-159 bietet eine Studie des Textes, einschließlich einer kritischen und kommentierten Transkription der Salzburger Handschrift (M I 92, dt. mit lat. Übersetzung von Nicolaus Majus), digital zugänglich unter URL: http://www.ubs.sbg.ac.at/sosa/handschriften/ MI92/mI92digi.htm. Die Züricher Handschrift ist zugänglich unter URL: https://doi.org/ 10.7891/e-manuscripta-6275. Alena Richterová: Alchemical Manuscripts in the Collections of Rudolf II. In: Alchemy and Rudolf II. Exploring the Secrets of Nature in Central Europe in the $16^{\text {th }}$ and $17^{\text {th }}$ centuries. Hg. von Ivo Purš und Vladimir Karpenko. Prag 2016, S. 249-287 bietet S. 274-277 eine Wiedergabe von Abbildungen aus der Salzburger Handschrift. Zu Übernahmen aus dem „Sol und Luna“-Bildgedicht vgl. Joachim Telle: Sol und Luna. Literaturgeschichtliche Studien zu einem altdeutschen Bildgedicht. Hürtgenwald 1980, S. 102. Vgl. auch Marielene Putscher: Pneuma, Spiritus, Geist. Vorstellungen vom Lebensantrieb in ihren geschichtlichen Wandlungen. Wiesbaden 1973. 

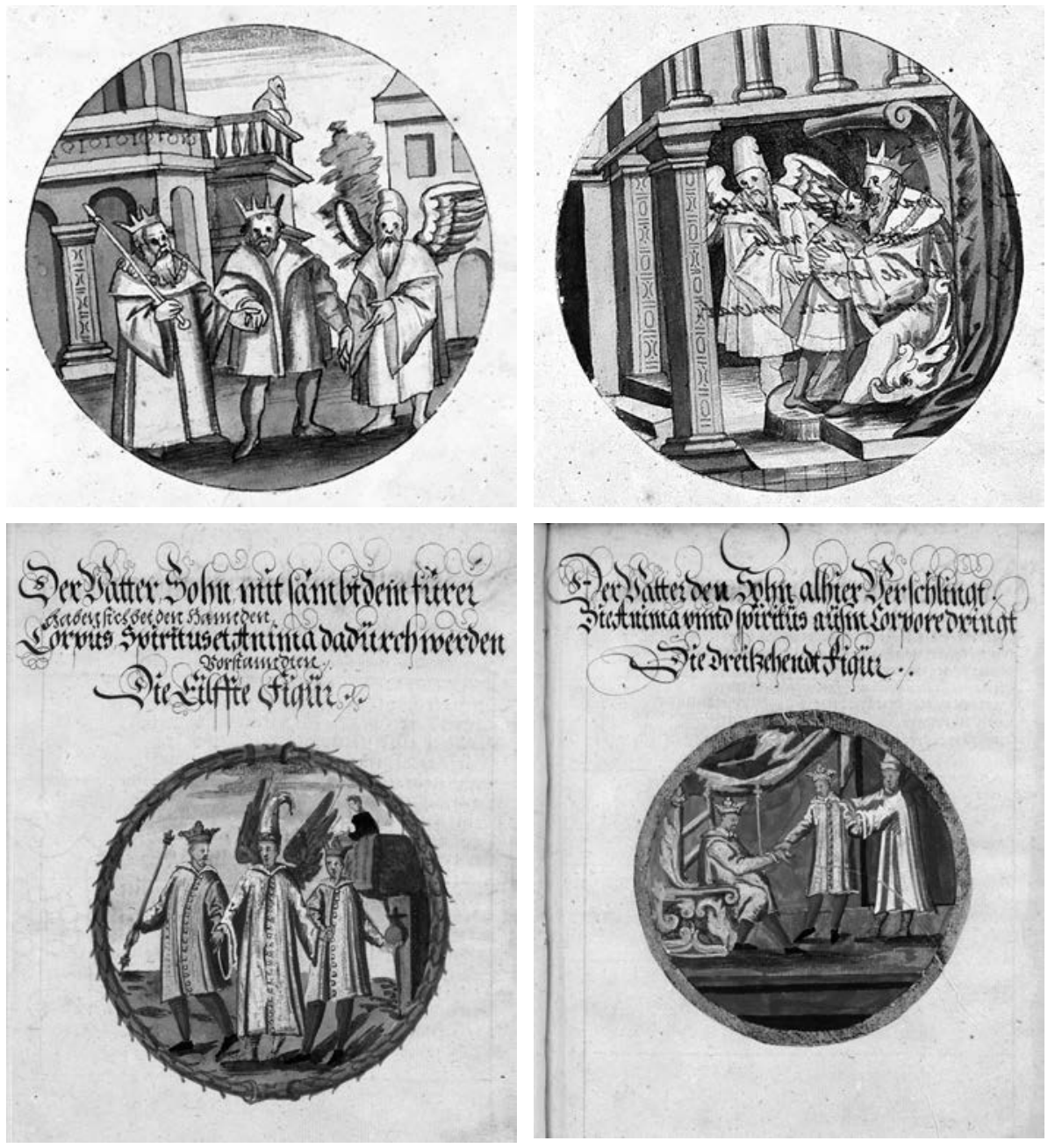

Abb. 1 und 2 (oben): Lamspring: Tractatus de lapide philosophorum. Universitätsbibliothek Salzburg, Sign. M I 92, f. 40r und f. 46r.

Abb. 3 und 4 (unten): Lamspringkh. Zentralbibliothek Zürich, Sign. MS P 2177, unpag.

$\mathrm{Zu}$ welcher statt er begert vnd auch sein wolt/

Der führer sprach zum Sohn mit diesen worten/

,Komm her ich wiel dich führen an alle orten/

Also gar auf eines hohen berges spitzen/

Auff das du erfahrest aller welt witze/

Do du die größe des Meers vnd der welt kanst schawen/

Vnd dich in großer wollust magst erfrewen/ 


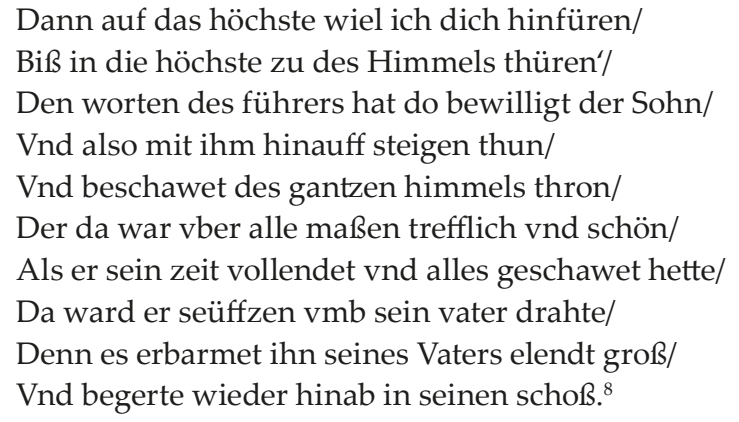

Die zwölfte Figur zeigt Sohn und Führer auf einer Bergspitze stehend (wobei der Berg jetzt in Indien verortet wird); die dreizehnte Figur, wie der zurückgekehrte Sohn von seinem Vater verschlungen wird; die vierzehnte Figur, wie der Vater, nachdem er von einem Regen „durchfeuchtet“ wurde, in einem Bett liegt und seinen Sohn wieder ausschwitzt; die fünfzehnte Figur schließlich, wie Vater, Sohn und Führer wieder vereint sind.

Was im Lamspring fehlt - und das ist ein wichtiger Unterschied -, ist die explizite chemisch-biologische Auflösung der Allegorie, wie sie der zweite Teil des $\mathrm{Al}$ phidius enthielt. Der Lamspring wird damit zu einem Rätsel im rhetorisch-technischen Sinne: Ein Rätsel, so definiert die antike Rhetorik, ist eine Allegorie, die nicht aufgelöst wird. Augustinus (Lehrer der Rhetorik, bevor er zum Kirchenvater wurde) hatte das Rätsel in dieser Tradition als "obscura allegoria“ definiert. Tatsächlich scheint es möglich, den gesamten Lamspring in diesem Sinne als eine ,dunkle, schwer verständliche Allegorie‘ zu verstehen. Auffällig ist nämlich, dass alle „Figuren" des Traktats um dasselbe Thema kreisen - oder, wie man sagen könnte, dieselbe chemisch-biologische Beobachtung verrätseln: den Zersetzungsprozess der Materie, aus dem neues Leben entsteht. So zeigt die erste Figur zwei Fische im Meer, die als spiritus und anima identifiziert werden, wobei hier das Meer das corpus darstellt. In der dritten Figur begegnen sich Einhorn und Hirsch (wiederum anima und spiritus) in einem Wald (corpus). Die sechste Figur zeigt das alchemische Sinnbild für den Kreislauf der Natur schlechthin, den Ouroboros, also einen Drachen, der sich in seinen eigenen Schwanz beißt.

Der Text spielt dabei mit (al)chemischen Fachbegriffen (etwa "mortificatio“ als ,Abtötung' der Materie) und Bildern (der auffliegende Vogel als Bild der ,Vergeis-

8 Zitiert nach der Transkription von Buntz: Alchimistische Traktate (Anm. 5), S. 134.

9 Augustinus: De trinitate XV, 9, 15: „Aenigma est [...] obscura allegoria“. Zum Rätsel als Form der gewollten Unverständlichkeit vgl. Manfred Fuhrmann: Obscuritas. Das Problem der Dunkelheit in der rhetorischen und literarästhetischen Theorie der Antike. In: Immanente Ästhetik - Ästhetische Reflexion. Lyrik als Paradigma der Moderne. Hg. von Wolfgang Iser. München 1983, S. 47-72, v. a. S. 57-59. Auch Melanchthon definiert (ausgehend von Cicero: De orat. III 167 und Quintilian: Inst. Orat. VIII 6,52) das Rätsel in seinem weit verbreiteten Lehrbuch der Rhetorik als „,species allegoriae“, vgl. Philipp Melanchthon: Elementa Rhetorices. Grundbegriffe der Rhetorik. Hg., übersetzt und kommentiert von Volkhard Wels. Berlin 2001, S. 210. 
tigung' im Sinne eines Destillationsprozesses), ohne dabei an diese Bilder irgendwelche theologischen Deutungen zu knüpfen. Natürlich liegt es nahe, das Gleichnis von König-Vater, König-Sohn und Führer auf die christliche Dreieinigkeit zu beziehen, wenn in der ,lebenden' Materie Körper, Geist und Seele so vereinigt sind wie in der Trinität Gott, Christus und der heilige Geist. Der Lamspring spielt auch zweifellos auf diese Deutung mehrfach an - genauso, wie das Figulus in seiner eingangs zitierten Fassung tut. Aber diese Art von allegorischer Deutung ist im Mittelalter und in der Frühen Neuzeit allgegenwärtig und im Lamspring nur eine weitere Dimension des Rätsels.

Mein Vorschlag lautet also, den Lamspring (und mit ihm den Alphidius) nicht im Sinne einer irgendwie diffus ,mystischen' oder ,esoterischen ${ }^{10}$ Alchemie zu verstehen, sondern als ein Rätsel im rhetorisch-technischen Sinne, als eine Verrätselung allgegenwärtiger Prozesse des Werdens und Vergehens in der organischen Welt, als eine spielerische Vergegenwärtigung biologisch-chemischer Beobachtungen. In diesem Sinne könnte man auch die „Vorrede“ des Lamspring deuten, in der es heißt, "das gantze werck der Philosophei“, also der Alchemie, „,welches alle menschen gantz vnmüglich deucht", sei im Grunde doch „eine geringe arbeit vnd gantz leicht", ja so trivial, dass der Verfasser sich lächerlich machen würde, wenn er es unverschlüsselt darstellen würde (,Do es doch ist eine geringe arbeit vnd gantz leicht/ I Wenn wirs offenbareten vnd an tag theten bringen/ I So würden wir verspott von Mann weibern vnd kinden"). ${ }^{11}$

Diese Deutung des Lamspring als eines (al)chemischen Rätsels würde sich hervorragend an eine Beobachtung anschließen, die wiederum Joachim Telle bereits gemacht hat, dass nämlich ausgerechnet die Alchemie im Mittelalter und in der Frühen Neuzeit eine große Affinität zur literarischen Form des Rätsels hat. ${ }^{12}$ Wenn diese Beobachtung in der Forschung (soweit ich sehe) ohne jede Resonanz geblieben ist, mag auch das wieder damit zusammenhängen, dass die Art von ,Spielerei` und ,Scherz', wie sie mit dem Rätsel assoziiert wird, ${ }^{13}$ überhaupt nicht zum Bild der (Al)Chemie als einer geheimnisvollen, ,mystischen' und ,esoterischen' Praxis passen will, wie es nicht nur im allgemeinen Bewusstsein, sondern genauso in der Forschung immer noch weit verbreitet ist.

Eine solche Alchemie gibt es, keine Frage, und sicherlich gibt es sie auch schon in der Frühen Neuzeit. ${ }^{14}$ Spätestens mit dem Paracelsismus wird eine solcherart

10 Zum Begriff der Esoterik vgl. Anm. 2.

11 Zitiert nach Buntz: Alchimistische Traktate (Anm. 5), S. 112.

12 Vgl. Joachim Telle: Fachschriftsteller als „Rhätersschreiber“. Rätselreime aus deutschen Alchemica der frühen Neuzeit. In: ders.: Alchemie und Poesie. Deutsche Alchemikerdichtungen des 15. bis 17. Jahrhunderts. Bd. 2. Berlin, Boston 2013, S. 989-1014.

13 Und zwar auch schon in der Frühen Neuzeit, in der sich Rätselsammlungen einer enormen Beliebtheit erfreuten, vgl. Heike Bismark: Rätselbücher. Entstehung und Entwicklung eines frühneuzeitlichen Buchtyps im deutschsprachigen Raum. Mit einer Bibliographie der Rätselbücher bis 1800. Tübingen 2012. Der spielerisch-unterhaltende Charakter kommt dabei oft schon in den Titeln dieser Rätselbücher zum Ausdruck.

$14 \mathrm{Zu}$ den unterschiedlichen Ausprägungen der frühneuzeitlichen Alchemie vgl. - stellvertre- 
spiritualistische und im Sinne des Wortes mystische Alchemie zu einer manifesten Strömung. Aber es wäre falsch, die gesamte (Al)Chemie mit dieser paracelsistischen, spiritualistischen Alchemie zu identifizieren. Der Lamspring ist dafür ein gutes Beispiel, denn er wird auch in der Frühen Neuzeit schon in diesem Sinne verstanden.

\section{Lucas Jennis und die Dyas chymica tripartita}

Bevor ich darauf zurückkomme, möchte ich auf die Rezeption des Lamspring und Alphidius um 1600 eingehen, die - so die These - gerade von deren Rätselhaftigkeit ihren Ausgang nimmt. Ohne diese Rezeption nämlich wäre der Lamspring wahrscheinlich schon völlig vergessen. Diese Rezeption ist vor allem mit dem Verlag von Lucas Jennis und dem Kupferstecher Matthäus Merian verbunden. 1625 erscheint der Lamspring bei Jennis in Frankfurt am Main mit den in der Werkstatt Merians gestochenen Kupfern. ${ }^{15}$ Es sind die Qualität dieser Kupferstiche genauso wie die beeindruckenden Bilderfindungen aus der Werkstatt Merians, die dem Lamspring bis in die Gegenwart eine Präsenz in nahezu jedem Bildband gesichert haben, der der Alchemie gewidmet ist - selbstverständlich ohne Abdruck des Textes, der dieser Art von Aufmerksamkeit nur hinderlich wäre.

Die Kupferstiche sind aber nicht das Einzige, was in der Ausgabe von Jennis neu ist. Auch die Verse wurden dem zeitgenössischen Geschmack angepasst, d. h. in (mehr oder weniger) glatte, vierhebige Verse umgedichtet. Zum Vergleich die oben zitierten Verse zur elften Figur:

Ein Alter Vater auß Jsrael schon/

Jst kommen/ hat ein eingen Son/

Welchen er liebt von gantzem Hertzen/

Bestelt jhm ein Führer mit schmertzen.

Alß der den Sohn hinführen solte/

$\mathrm{Zu}$ welcher stett er begehrt vnd wolte/

Er sprach zum Sohn mit diesen Worten/

Komm her ich will dich führen dorten/

Gar hoch auff eines Bergens spitzen/

Daß du erfahrst aller Welt witzen/

Da du des Meers größ vnd der Welt/

Kanst schawen/ Daß dirs wolgefellt/

Denn auff das Höchst will ich dich führen/

Biß wir kommen zus Himmels Thüren.

Des Führers worten glaubt der Sohn/

tend für die ältere Forschung - Moran: Distilling Knowledge (Anm. 1); ders.: Libavius and the Transformation of Alchemy (Anm. 1) und Kahn: Le fixe et le volatile (Anm. 1).

15 Die Kupferstiche sind nicht signiert. Edith Trenczak: Lucas Jennis als Verleger alchimistischer Bildertraktate. In: Gutenberg Jahrbuch (1965), S.324-337 spricht S. 334 von „Werkstattarbeiten“. Auch Jennis selbst war gelernter Kupferstecher, so dass die Kupferstiche also auch unter seiner Beteiligung entstanden sein könnten. 
Thet mit jhm hinauff steigen schon.

Beschawet da des Himmels Pracht/

Das war vber allmaß schon gemacht.

Alß er nun solches gesehen het/

Er vmb sein Vatter seuffzen thet/

Denn jhn erbarmt sein Elend groß/

Begehrt wiedr hinnab in seinen Schoß.16

Das ist sicherlich noch weit weg von den Anforderungen, die Martin Opitz 1624 - also zeitgleich mit dieser Ausgabe des Lamspring - in seinem Buch von der deutschen Poeterey formuliert hatte. Zweifellos sind diese Verse auch noch weit weg von dem verstechnischen Niveau, das im Vorfeld von Opitz bereits erreicht worden war, etwa mit den Alexandrinern nach französischem Vorbild, wie sie Dietrich von dem Werder, Tobias Hübner oder Georg Rudolf Weckherlin geschrieben hatten. Aber die Neudichtung des Lamspring zeigt ohne Zweifel eine Bemühung an, die in dieselbe Richtung geht, nämlich ein neues Bewusstsein von dem, was Verstechnik sein könnte. Das ist nicht unbedingt das, was man gerade von einem (al)chemischen Text erwarten würde.

Es ist jedoch genau dieser kulturpatriotische und sprachreformerische Impuls, der aus der Vorrede zu der Textsammlung spricht, in der der Lamspring bei Jennis erschienen ist, der Dyas chymica tripartita. Das ist: Sechs Herrliche Teutsche Philosophische Tractätlein. [...] Allen Filiis Doctrinae zu Nutz an Tag geben/ vnd mit schönen Figuren gezieret. Durch H.C.D. Die Abkürzung „H.C.D.“ wird am Ende der Widmung mit „D. Hermannus Condeesyanus“ aufgelöst. Gewidmet ist der Band Christian I. von Anhalt-Bernburg, mithin einem Fürsten, der zwar in der Geschichte der Alchemie keine Rolle spielt, dafür aber eine gewaltige Bedeutung im Vorfeld des Dreißigjährigen Krieges besitzt. Christian I. gründete nicht nur 1608 die protestantische Union, sondern war maßgeblich daran beteiligt, dass der 18-jährige Friedrich V. von der Pfalz, der spätere ,Winterkönig', die böhmische Krone annahm, was dann unmittelbar zum Dreißigjährigen Krieg führte. Wichtiger für den vorliegenden Kontext ist allerdings, dass Christian I. außerdem der Halbbruder von Fürst Ludwig I. von Anhalt-Köthen war, dem Gründer der „Fruchtbringenden Gesellschaft“, also genau der Gesellschaft, die sich einer kulturpatriotischen Sprachpflege verschrieben hatte, wie sie auch in der Vorrede zur Dyas Chymica propagiert wird. 1619 war Christian I. als 26. Mitglied in diese „Fruchtbringende Gesellschaft” aufgenommen worden.

Die Widmung der Dyas Chymica an genau diesen Fürsten ist kein Zufall. Die Widmung von „H.C.D.“ ist getragen von einem kulturpatriotischen Impuls, der gerade auf die Deutschsprachigkeit der in diesem Band versammelten (al)chemi-

16 Dyas chymica tripartita. Das ist: Sechs Herrliche Teutsche Philosophische Tractätlein. [...] Allen Filiis Doctrinae zu Nutz an Tag geben/ vnd mit schönen Figuren gezieret. Durch H.C.D. Frankfurt a. M. 1625, S. 108. 


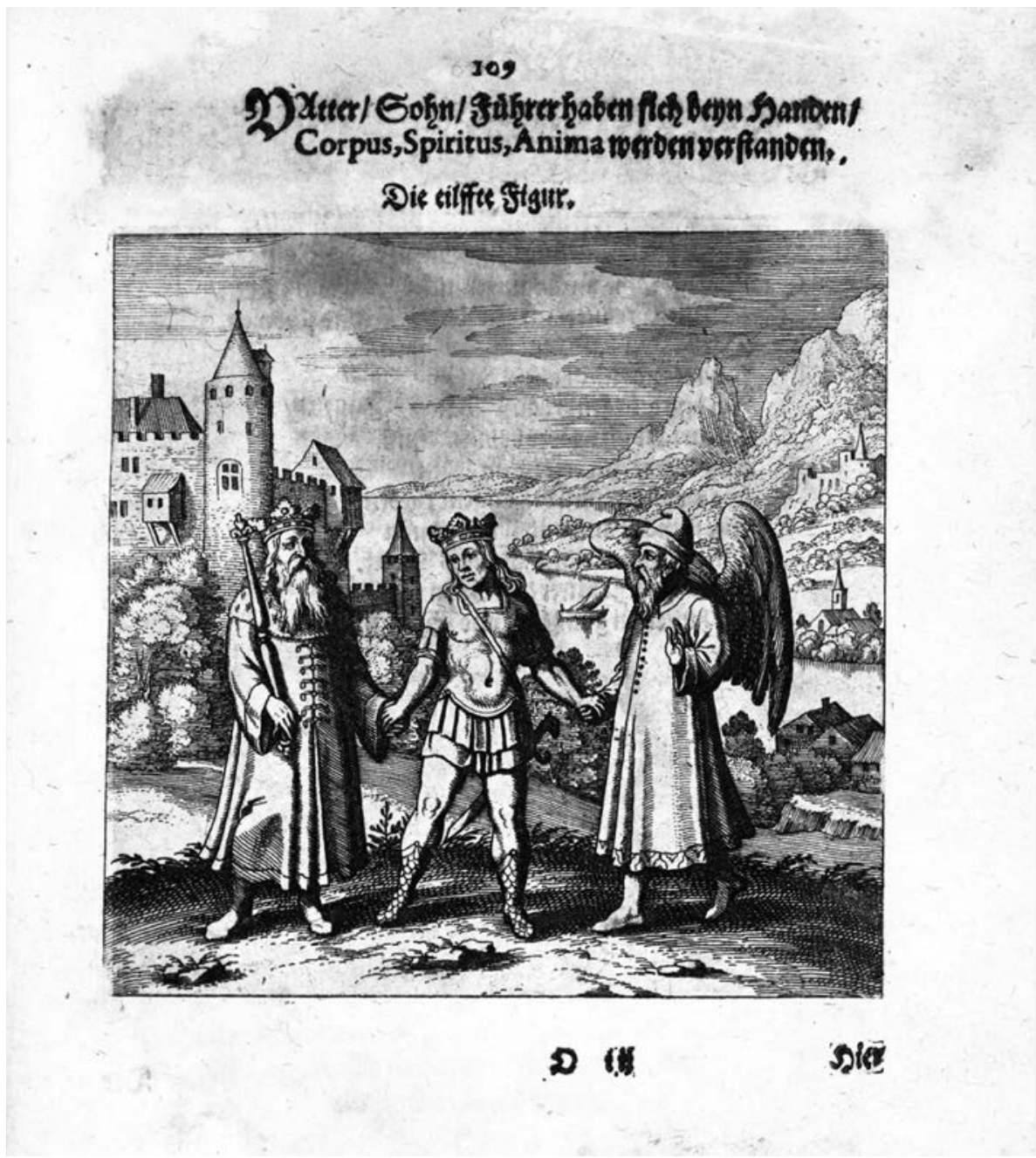

Abb. 5: Dyas chymica tripartita. Das ist: Sechs Herrliche Teutsche Philosophische Tractätlein. [...] Allen Filiis Doctrinae zu Nutz an Tag geben/ vnd mit schönen Figuren gezieret. Durch H.C.D. Frankfurt a. M. 1625, S. 109.

schen Traktate abhebt. „H.C.D.“ erklärt die Chemie geradezu zur deutschen Kunst par excellence (neben der „Buchtruckerey“), indem er in einem kurzen historischen Abriss diese Chemie von Paracelsus bis auf Albertus Magnus zurückführt. Das Mittelalter ist für „H.C.D.“ keine ,dunkle Epoche', sondern die „mittleren Zeiten", wie er sie nennt, haben gerade aufgrund ihrer Deutschsprachigkeit kulturprägende Funktion. Auch das entspricht im Übrigen dem Programm von Opitz, 


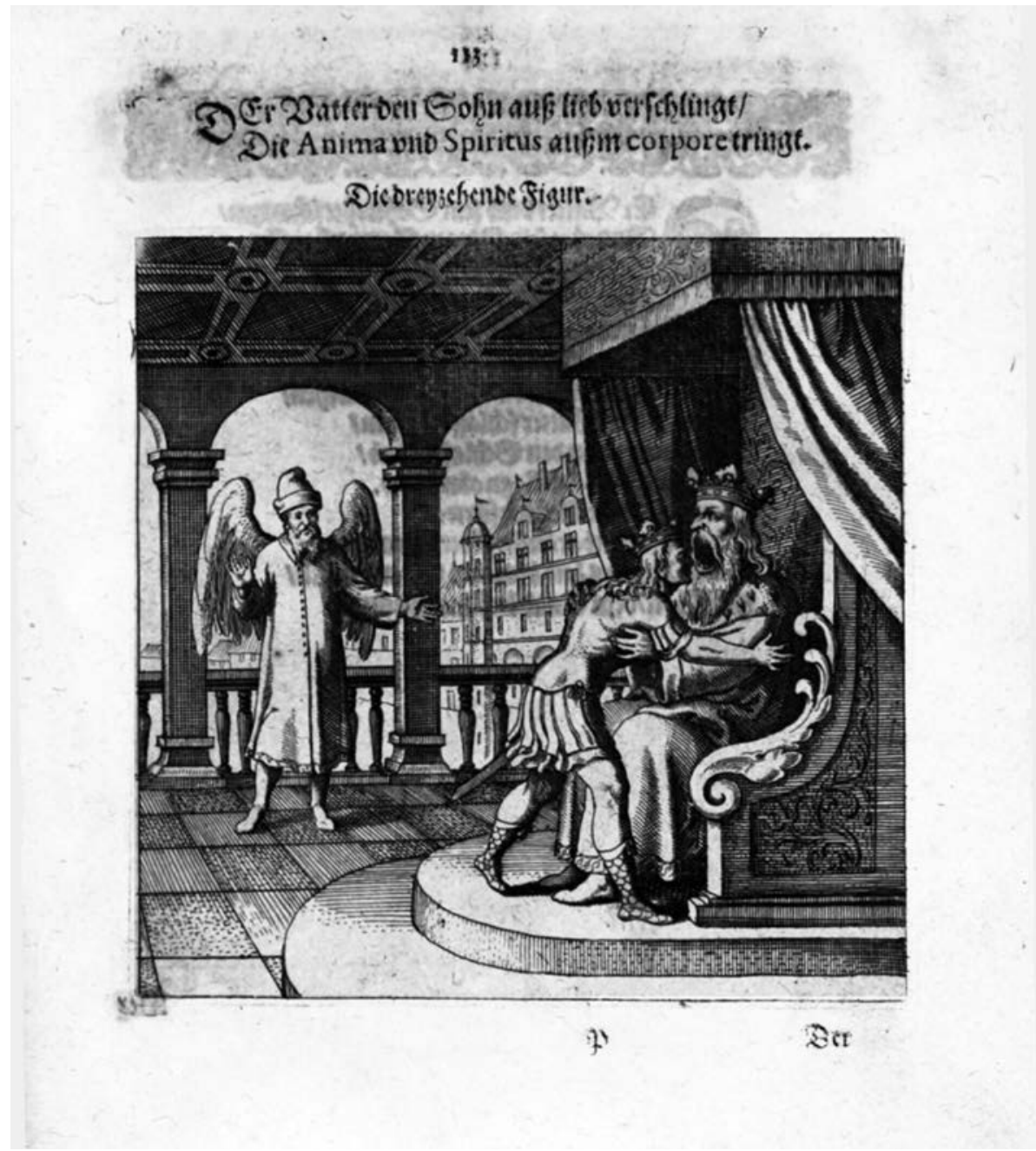

Abb. 6: Dyas chymica tripartita. Das ist: Sechs Herrliche Teutsche Philosophische Tractätlein. [...] Allen Filiis Doctrinae zu Nutz an Tag geben/ vnd mit schönen Figuren gezieret. Durch H.C.D. Frankfurt a. M. 1625, S. 113.

der sich im selben Sinne um eine Erschließung des deutschsprachigen, mittelalterlichen Schrifttums bemüht hat, etwa durch eine Edition des Annoliedes. Im Mittelpunkt der acht Traktate, die die Dyas chymica versammelt, steht deshalb auch gerade der Lamspring, zusammen mit vier Schriften von Basilius Valentinus.

Das ist insofern paradox, als nicht nur die Verse des Lamspring umgeschrieben bzw. neu gedichtet wurden - also ,gefälscht', wie man doch wohl sagen könnte -, 
sondern auch die Schriften des Basilius Valentinus eine Fälschung in dem Sinne sind, dass es sich bei diesem nicht um einen Benediktinermönch aus dem 15. Jahrhundert handelt, wie die Legende es will, sondern mit ziemlicher Sicherheit um den Berghauptmann und Salinisten Johannes Thölde (1565-1614), der um 1599 die Schriften des Basilius Valentinus angeblich nur herausgegeben hat. ${ }^{17}$ Gefunden worden seien die Manuskripte im Erfurter Peterskloster. Auch diese Fundlegende begegnet im (al)chemischen Schrifttum der Zeit öfter. ${ }^{18}$ Wer auch immer der Verfasser war - viel interessanter als seine Identität ist unter dem Gesichtspunkt der Wissensgeschichte die Tatsache, dass (al)chemisches Wissen um 1600 verrätselt und ins Mittelalter zurückdatiert wird, um ihm Autorität zu verschaffen: Nicht die Antike (wie es der Begriff der ,Renaissance' erwarten ließe), sondern das Mittelalter garantiert die Autorität (al)chemischen Wissens. Bei den Zwölf Schlüsseln des Basilius Valentinus, die „H.C.D.“ unter dem Titel Offenbarung der verborgenen Handgriffe in der Dyas chymica herausgibt, handelt es um einen weiteren Vers-BildTraktat, der seine chemischen „Handgriffe“ und Rezepte in rätselhaften Bildern vermittelt. Auch hier ist der entscheidende Unterschied zur ersten illustrierten Ausgabe von 1602 mit ihren groben Holzschnitten (Erstausgabe 1599 noch ohne Illustrationen) die buchtechnische Gestaltung und die Qualität der Kupferstiche. ${ }^{19}$

Auch die beiden einleitenden Traktate der Dyas chymica, der anonyme Güldne Traktat vom philosophischen Stein und das Aureum saeculum redivivum des „Henricus Madathanus" (Adrian von Mynsicht, Adrian Seumenicht) ${ }^{20}$ zeichnen sich durch Rätselhaftigkeit aus. Bei beiden Texten handelt es sich um narrative Texte, in denen ein Ich-Erzähler rätselhafte Dinge erlebt, die sich (al)chemisch deuten lassen.

17 Stellvertretend für die ältere Forschung vgl. den Band: Johann Thölde. Alchemist, Salinist, Schriftsteller und Bergbeamter. Hg. von Hans-Henning Walter. Freiberg 2011. Lawrence M. Principe: The Secrets of Alchemy (Anm. 1) bietet im sechsten Kapitel („Unveiling the Secrets“), S. 143-157 eine beeindruckende Entschlüsselung der Zwölf Schlüssel als Beschreibung chemischer Prozesse. Ders.: The Development of the Basil Valentine Corpus and Biography. Pseudepigraphic Corpora and Paracelsian Ideas. In: Early Science and Medicine 24 (2019), S. 549-572 rekonstruiert die Entstehungsgeschichte des Corpus, das Basilius zugesprochen wurde.

18 Figulus etwa berichtet in der Widmung der Thesaurinella, der von ihm dort herausgegebene Traktat des Vincentius Koffsky, angeblich ein Dominikaner aus Posen, gestorben 1488, sei „,im Creutzgang in einer Mawr im schwartzen Münchs Closter/ mit güldenen Buchstaben beschrieben/ vermawert" gefunden worden. (Figulus: Thesaurinella [Anm.3], S. 8) Von einem anderen, Paracelsus zugeschrieben Traktat konnte man lesen, er sei in Tirol in einer Mauer gefunden worden, in Geheimschrift verfasst und Erzherzog Maximilian für 6000 Reichstaler verkauft worden (vgl. Corpus Paracelsisticum. Bd.3. Berlin, Boston 2013, S. 1172). Zwei Karren voller theologischer Schriften des Paracelsus seien, eingemauert in einer kleinen Kammer, hinter dem Stall eines Hauses gefunden worden, in dem Paracelsus in Salzburg gelebt habe (vgl. ebd.).

19 Ein kurtz Summarischer Tractat, Fratris Basileij Valentini Benedicter Ordens/ Von dem grossen Stein der Vralten [...]. Eisleben 1599. Erste illustrierte Ausgabe Leipzig 1602. Eine lateinische Ausgabe der Zwölf Schlüssel war bei Jennis schon 1618 im Tripus Aureus Michael Maiers erschienen, mit denselben Kupferstichen. Zu Jennis' mehrfacher Verwendung von Kupferplatten vgl. unten.

20 Vgl. Rolf Gelius: [Art.] Mynsicht, Adrian von. In: Neue Deutsche Biographie. Bd. 18. Berlin 1997, S. 671. 
So verläuft sich der Erzähler des Güldnen Traktats in einem Wald und gelangt auf eine Wiese, wo alte Männer mit weißen Bärten über das große Geheimnis der Natur diskutieren usw. usw. Die beiden abschließenden Traktate des Bandes erzählen zwar keine rätselhaften Geschichten, zehren aber von der rätselhaften Symbolik der (Al)Chemie.

Rätselhaft schließlich auch die Verwendung der Pseudonyme, wie sie in der (Al) Chemie der Frühen Neuzeit allgegenwärtig sind. Nicht nur "Henricus Madathanus", "Hermann Condeesyanus" und "Basilius Valentinus" veröffentlichen ihre Schriften unter Pseudonymen, sondern auch "Salomon Trismosin" (angeblich der Lehrer des Paracelsus, in Wahrheit einer seiner Nachfolger) oder „Bernardus Trevisanus" bedienen sich dieser marktstrategisch offensichtlich erfolgreichen Methode der Rückdatierung (al)chemischen Wissens. „Christian Rosenkreuz" gehört ebenfalls in diese Reihe. Dass es sich dabei auch um eine spielerische Praxis handeln kann, illustriert „Henricus Madathanus“. Er sieht zwar die Notwendigkeit, sich hinter einem Pseudonym zu verbergen, teilt seinen wahren Namen jedoch in einem Rätsel am Ende der Vorrede mit:

Schließlichen/ damit auch der Christliche verstendige vnd würdige Leser/ eigentlich meinen Tauff: vnd Zunahmen wisse/ will ich so candidus sein/ vnd denselben folgender gestalt/ damit sich mit fug niemand vber mich zu beschweren/ geoffenbahret Haben: So wisse nun ein jeglicher/ das die zahl meines Nahmens ist M.DCXII. in welcher zahl mein gantzer Nahme durch 2. Todte vnnd 7. lebendig vollkomlich in das Buch der natur ist geschrieben worden: Vber das ist der 5. Buchstabe der fünffte theil des B. vnnd der 15. ist abermal der fünffte theil des 12. vnd laß dir hierbey genügen. ${ }^{21}$

„H.C.D.“, der Herausgeber des gesamten Bandes, löst am Ende der Widmung die Abkürzung mit dem Pseudonym „D. Hermannus Condeesyanus" auf, gibt aber ansonsten keinen Hinweis auf seine Identität. In der Vorrede begründet er das einerseits mit seiner Bescheidenheit (,,ich suche nicht meine eitele Ehre/ vnd mir für der Welt einen grossen Namen zumachen“), andererseits mit der Gefahr, in die er sich begäbe, würde sein Name bekannt (,wegen grosses Ansehens mein Leben in die schantze zuschlagen/ vnd den geitzigen Räubern feil zu biethen/ dazu auch mit prostituierung dieses grossen geheimnuß grosse Sünden auff mich zuladen"). ${ }^{22}$ Diese Beteuerung - dass die Veröffentlichung der Geheimnisse den Verfasser in größte Gefahr bringen würde - hat in der (Al)Chemie der Frühen Neuzeit dieselbe Präsenz und dieselbe Funktion wie im Roman des 18. Jahrhunderts die Fiktion eines Herausgebers. Es ist, genauso wie die Verrätselung der Namen, ein ironisches Spiel mit der Identität des Verfassers.

21 [Henricus Madathanus]: Aureum seculum redivivum. Das ist: Die vhralte entwichene Güldene Zeit. In: Dyas chymica (Anm. 16), S. 67-87, hier S. 72.

22 [Hermann Condeesynaus]: Vorrede. In: Dyas chymica (Anm. 16), S. 13-16, hier S. 14. 
Gerade im Fall der Dyas chymica liegt diese Erklärung nahe, denn dieser Text erscheint 1625 bei dem bereits genannten Lucas Jennis, einem Verleger, der mit rätselhaften (al)chemischen Texten geradezu sein Verlagsprogramm bestreitet. ${ }^{23}$ Jennis steht zudem in einer gewissen Beziehung zum Hof des Landgrafen Moritz von Hessen-Kassel („Moritz der Gelehrte“), seinerseits ein begeisterter, obsessiver chemischer Praktiker, der an seinem Hof - neben einer der berühmtesten Kunstkammern der Zeit - ein Labor unterhielt. ${ }^{24}$ Er gehörte genau zu der vermögenden, (Al)Chemie-begeisterten Käuferschicht, die vieles, wenn nicht alles gekauft hat, was Lucas Jennis an (al)chemischen Texten herausgebracht hat.

\section{Landgraf Moritz von Hessen-Kassel und Johannes Rhenanus}

Damit sind die chemischen Interessen - und hier handelt es sich tatsächlich um chemisch-praktische Interessen im Sinne der späteren Chemie, für Spekulation und Spiritualismus hatte der Landgraf kein Verständnis - des Landgrafen allerdings nur höchst ungenügend umrissen. ${ }^{25}$ Nicht nur finanzierte Moritz Labore und Personal (was gewaltige Summen verschlang), er holte auch berühmte (Al) Chemiker an seinen Hof oder ernannte sie zu Leibärzten. Mit Koryphäen der pa-

23 Einen Überblick über die Verlagsproduktion zumindest von 1616-1622 bietet Lucas Jennis: Catalogus omnium librorum, qui ab anno M.DC.XVI. maximae partis sumptibus Lucae Jennis [...] sunt editit. Frankfurt a. M. 1622. Vgl. außerdem Trenczak: Lucas Jennis (Anm. 15).

24 Zur architektonischen Verortung und Größe der Labore vgl. Heiner Borggrefe: Das alchemistische Laboratorium Moritz des Gelehrten im Kasseler Lusthaus. In: Landgraf Moritz der Gelehrte. Ein Kalvinist zwischen Politik und Wissenschaft. Hg. von Gerhard Menk. Marburg 2000, S. 229-252. Hartmut Broszinski bietet in der Einleitung zu seinem Katalog der alchemischen Handschriften an der Bibliothek Kassel einen Überblick über die alchemischen Interessen und die labortechnische Praxis des Landgrafen, vgl. Manuscripta chemica in quarto. Bearbeitet von Hartmut Broszinski. Wiesbaden 2011, S. XI-XXX. Der Katalog selbst ist ein wichtiges Instrument jeder Beschäftigung mit der frühneuzeitlichen Alchemie. Er ist-etwas versteckt - auch digital über den Katalog der Universitätsbibliothek Kassel zugänglich.

25 Bruce Moran hat die alchemischen Interessen und das Netzwerk von Moritz erschlossen und in grundlegenden Studien dargestellt, vgl. stellvertretend vor allem Bruce T. Moran: The Alchemical World of the German Court. Occult Philosophy and Chemical Medicine in the Circle of Moritz of Hessen (1572-1632). Stuttgart 1991, daneben auf ders.: Privilege, Communication and Chemiatry. The Hermetic Alchemical Circle of Moritz of Hessen-Kassel. In: Ambix 32 (1985), S. 110-126. Eine gekürzte, deutsche Fassung davon ist ders.: Der alchemistisch-paracelsische Kreis um den Landgrafen Moritz von Hessen-Kassel (1572-1632). In: Zeitschrift des Vereins für hessische Geschichte und Landeskunde 92 (1987), S. 131-148; ders.: The Kassel Court in European Context. Patronage Styles and Moritz the Learned als Alchemical Maecenas. In: Landgraf Moritz der Gelehrte. Ein Kalvinist zwischen Politik und Wissenschaft. Hg. von Gerhard Menk. Marburg 2000, S. 215-228 und ders.: Moritz der Gelehrte und die Alchemie. In: Moritz der Gelehrte. Ein Renaissancefürst in Europa. Hg. von Heiner Borggrefe und Vera Lüpkes. Eurasburg 1997, S. 357-384. Während Moran vor allem in seinen älteren Arbeiten die alchemischen Interessen des Landgrafen als "occult philosophy" charakterisiert hat, widerspricht in diesem Punkt Telle, der in Corpus Paracelsisticum (Anm. 18), Bd.3, S. 1153-1160 die (al)chemischen Interessen des Landgrafen als chemisch-praktische charakterisiert, vgl. v. a. ebd., S. 1156: „Im Zentrum der medizinisch-naturkundlichen Beschäftigungen des Landgrafen, so bekundet eine beträchtliche Zeugnisfülle, stand eine auf metallwandelnde Arkana und Heilmittel zielende Alchemia practica." 
racelsischen Chemiatrie wie Joseph Duchesne (Quercetanus), Leibarzt von Heinrich IV. in Paris, stand er in persönlichem Kontakt und lud sie nach Kassel ein. Der weltweit erste Lehrstuhl für Chemie an der Universität Marburg geht auf die Initiative des Landgrafen zurück und wurde von ihm finanziert. ${ }^{26}$ Ein weit ausgreifender Briefwechsel verband den Landgrafen mit chemisch interessierten Forschern in ganz Europa. Fünf Foliobände mit Hunderten von Briefen sind erhalten. ${ }^{27}$ Sein Kammerdiener Johann Eckel war nicht nur damit beauftragt, die chemischen Untersuchungen zu beaufsichtigen, die der Landgraf in seinen Laboren durchführen ließ, sondern auch mit der Abschrift (al)chemischer Texte. ${ }^{28}$ Wenn die darin beschriebenen Prozesse nichts taugten, notierte Moritz das handschriftlich am Rand: „da wirdt nichts auß", "darnach zum fenster hinauß", "geschwind wirdt windt" und "Lex im ars “. ${ }^{29}$ Diese Bemerkungen illustrieren nicht nur den Sarkasmus des Landgrafen, sondern vor allem die Tatsache, dass es sich um ein praktisches, technisches Interesse handelt, das der Landgraf an der Chemie hatte.

Vor allem aber verweist die implizite Verbindung von Lucas Jennis und Landgraf Moritz auf ein medienhistorisches Faktum: Wer in der Frühen Neuzeit (al) chemisch arbeiten wollte, brauchte Handschriften und Drucke, in denen die Prozesse beschrieben waren, die Erfolge versprachen und sich im Labor bewährt hatten. Oder er stellte Laboranten ein, die ihm diese Prozesse zeigen konnten, weil sie sie beherrschten (und dann nicht publizierten, weil damit ihr Wissen seinen Wert verloren hätte). Moritz tat beides. Der Landgraf war ein großer Sammler (al) chemischer Handschriften und Drucke. Dieselben ,Prozeßkrämer' und "Secreta“Verkäufer, die etwa Kaiser Rudolph II. in Prag mit Handschriften belieferten, schickten ihre Angebote auch nach Kassel. Die (al)chemische Bibliothek des Landgrafen gehörte sicherlich zu den größten ihrer Zeit. Die Handschriften sind annähernd vollständig erhalten und von Hartmut Broszinski eindrucksvoll erschlossen worden: „Im ganzen umfaßt die Sammlung heute 34 Bände in Folio (bei 25 Signaturen), 164 in Quarto (bei 108 Signaturen) und 61 in Octavo (bei 44

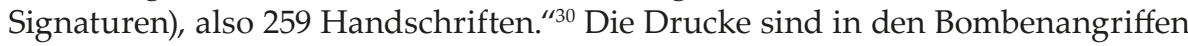
von 1941 verbrannt, aber ihre Zahl war ähnlich beeindruckend, Broszinski spricht von 202 Drucken. ${ }^{31}$

26 Detailliert dargestellt bei Bruce T. Moran: Court Authority and Chemical Medicine. Moritz of Hessen, Johannes Hartmann, and the Origin of Academic Chemiatria. In: Bulletin of the History of Medicine 63 (1989), S. 225-246 und ders.: Chemical Pharmacy Enters the University. Johannes Hartmann and the Didactic Care of "Chymiatria“ in the Early Seventeenth Century. Madison, WI 1991.

27 Broszinski: Manuscripta chemica (Anm. 24), S. XV.

$28 \mathrm{Zu}$ Johannes Eckel, Kammerdiener und Laborant von Moritz, vgl. Broszinski: Manuscripta chemica (Anm. 24), S. XXII.

29 Alle Zitate nach Broszinski: Manuscripta chemica (Anm. 24), S. XXXIII.

30 Broszinski: Manuscripta chemica (Anm. 24), S. XIII.

31 Broszinski: Manuscripta chemica (Anm. 24), S. XII; ebd., S. 403-446 bietet einen Rekonstruktionsversuch aufgrund eines alten Bibliothekskataloges. Eine ältere Skizze ist Hartmut Broszinski: Die alchemistische Bibliothek des Landgrafen Moritz. Der Landgraf und die Bücher. 
Selbstverständlich befand sich auch die Dyas chymica in der Bibliothek von Moritz, genauso wie die eingangs zitierte Thesaurinella des Benedict Figulus mit dem Alphidius. Unter den Manuskripten befindet sich eine Abschrift des Lamspring (in der lateinischen Übersetzung Barnauds) von der Hand Johannes Eckels, ${ }^{32}$ genauso wie eine Abschrift des Liber Alze, der ebenfalls in der Dyas chymica enthalten war. Letztere findet sich in einem Band aus dem Besitz von Johannes Rhenanus, einem der Leibärzte und (Al)Chemiker im Dienst des Landgrafen. ${ }^{33}$ Mit ziemlicher Sicherheit dürfte es sich bei ihm um „H.C.D.“ handeln, um „Hermannus Condeesyanus", den Herausgeber der Dyas chymica. ${ }^{34}$ Rhenanus war Leibarzt und enger Vertrauter von Moritz, unter anderem organisierte er 1627 den Umzug der alchemischen Bibliothek nach Melsungen, das Moritz als Alterssitz auserkoren hatte und das neben der von Rhenanus geleiteten Apotheke selbstverständlich auch ein (al)chemisches Labor beherbergte. Rhenanus hatte 1610 in Marburg bei Johannes Hartmann, Inhaber des bereits erwähnten, ersten Lehrstuhls für Chemie, promoviert. Schon 1613 war er am Hof des Landgrafen als Dichter mit einem (handschriftlich erhaltenen) Speculum aistheticum hervorgetreten. Aus dessen Vorrede spricht dasselbe sprach- und kulturpatriotische Interesse wie aus der Vorrede zur Dyas chymica. ${ }^{35}$ Zudem hatte Rhenanus enge Kontakte zu Fürst Ludwig von Anhalt (dem bereits erwähnten Gründer der „Fruchtbringenden Gesellschaft“), an dessen Hof er sich 1623 für längere Zeit aufhielt. ${ }^{36}$ Er dürfte dort Christian I. von Anhalt-Bernburg, den Widmungsträger der Dyas chymica, persönlich kennen gelernt haben, wofür

In: Landgraf Moritz der Gelehrte. Ein Kalvinist zwischen Politik und Wissenschaft. Hg. von Gerhard Menk. Marburg 2000, S. 253-262.

32 Vgl. Universitätsbibliothek Kassel, Sign. $2^{\circ}$ Ms. chem. 11 [4 („Alchemisches Handbuch“). Zugänglich unter URL: https://orka.bibliothek.uni-kassel.de/viewer/image/1448883442932/390/.

33 Der Band $4^{\circ}$ Ms. chem. 4 der Kasseler Bibliothek enthält eine Abschrift des Liber Alze, das ebenfalls Teil der Dyas chymica war. Der Band befand sich im Besitz von Rhenanus, vgl. Broszinski: Manuscripta chemica (Anm. 24), S. 10. Zu Rhenanus vgl. vor allem Moran: The Alchemical World (Anm. 25), S. 75-79, der dort auch einen wichtigen Einblick in die konkreten chemischen Prozesse bietet, an denen Rhenanus im Auftrag von Moritz gearbeitet hat, sowie zur Biographie Sabine Salloch: Das hessische Medizinalwesen unter den Landgrafen Wilhelm IV. und Moritz dem Gelehrten. Rolle und Wirken der fürstlichen Leibärzte. Marburg 2006, S. 53-60.

34 Alternativ wurde Johann Grasse (Grasshoff) als Herausgeber angenommen, vgl. in diesem Sinne Claus Priesner: [Art.] Grashof(f)/Graßhof(f), Johannes (Synonyme: Grasseus, Chortolasseus, Hermann Condeesyanus). In: Alchemie. Lexikon einer hermetischen Wissenschaft. Hg. von Claus Priesner und Karin Figala. München 1998, was wohl zurückgeht auf John Ferguson: Bibliotheca chemica. A catalogue of alchemical, chemical, and pharmaceutical books. Bd.1.2. Glasgow 1906, S.338ff. Aufgrund dieser Identifikation wird die Dyas chymica bis jetzt in zahlreichen Bibliothekskatalogen unter dem Namen von Johann Grasse/Grasshoff geführt. Thomas Lederer: Der Kölner Kurfürst Herzog Ernst von Bayern (1554-1612) und sein Rat Johann Grasse (um 1560-1618) als Alchemiker der Frühen Neuzeit. Ein Beitrag zur Geschichte des Paracelsismus. Heidelberg 1992, S. 207-210 hat diese Identifikation bereits 1992 widerlegt.

35 Johannes Rhenanus: Speculum Aistheticum. Hdschrft. in Kassel: Theatr. $4^{\circ}$. Dedication vom 30. Januar 1613. Vorrede abgedruckt in Wilhelm Creizenach: Die Schauspiele der englischen Komödianten. Berlin 1889, S. 327-329.

$36 \mathrm{Zu}$ seinem Aufenthalt bei Fürst Ludwig vgl. Salloch: Das hessische Medizinalwesen (Anm. 33), S. 54 . 
die ebenfalls Christian I. gewidmete Harmonia inperscrutabilis chymico-philosophicae (Frankfurt a. M. 1625, allerdings nicht bei Jennis erschienen, sondern bei Konrad Eifrid) spricht, in der sich "Condeesyanus" für die "vielen Wohltaten" bedankt, die Christian I. ihm erwiesen habe. ${ }^{37}$ Während auf dem ersten Band dieser Harmonia "Condeesyanus" als Herausgeber angegeben wird, ist es auf dem zweiten Band Johannes Rhenanus („Collecta studio et industria Ioannis Rhenani M.D.“). Einen deutlicheren Befund für die Identifikation von „Condeesyanus“ mit Rhenanus wird man wohl kaum finden. ${ }^{38}$

Rhenanus ist nicht die erste personelle Verbindung zwischen dem Kasseler Hof und dem Frankfurter Verlag von Lucas Jennis. Auch Johannes Daniel Mylius, der in Marburg Medizin und Chemie studierte (Johannes Hartmann, der Professor für Chemiatrie, ist zudem sein Schwager), publiziert bei Jennis medizinische und alchemische Werke (Opus medico-chymicum, 1618; Philosophia reformata, 1621), mit Kupfern illustriert. Zudem hat er für Jennis als Lektor gearbeitet. Um 1620 arbeitet er für Moritz als Laborant. ${ }^{39}$

Noch signifikanter ist allerdings die Verbindung zu einem anderen (Al)Chemiker, der für einige Jahre Leibarzt und "Chymicus" von Moritz war, nämlich Michael Maier. ${ }^{40} 1618$ hatte Moritz diesen - der zuvor bei Rudolph II. in Prag gewesen war - an seinen Hof geholt, nachdem er im selben Jahr in Frankfurt bei Theodor de Bry - dem Vorgänger und Schwiegervater von Lucas Jennis - seine Atalanta fugiens publiziert hatte, das ohne Zweifel kunstvollste und rätselhafteste aller (al) chemischen Emblembücher. ${ }^{41}$ Die Kupferstiche waren auch hier in der Werkstatt Merians entstanden. Zumindest eines der Embleme der Atalanta entstammt unmittelbar dem Lamspring (Emblem 47: Löwe und Wolf; der schwitzende König und der Ouroboros sind weitere Parallelen).

37 Harmonia inperscrutabilis chymico-philosophicae. [...] Collectae ab H.C.D. Frankfurt a. M. 1625, S. 4.

38 So bereits Carlos Gilly: Adam Haslmayr. Der erste Verkünder der Manifeste der Rosenkreuzer. Amsterdam 1994, S. 150.

$39 \mathrm{Zu}$ Mylius vgl. die grundlegende Studie von Oliver Humberg: Johann Daniel Mylius. Arzt, Musiker und Alchemist aus Wetter in Hessen. Elberfeld 2012, S. 123-125 die Transkription eines „Elixir auf des Lamsprings Figuren“, vor allem aber ebd., S. 126-147 der Briefwechsel zwischen Mylius und Moritz, der einen unschätzbaren Einblick in die Laborarbeiten vermittelt.

$40 \mathrm{Zu}$ Maier vgl. stellvertretend für die ältere Forschung Erik Leibenguth: Hermetische Poesie des Frühbarock. Michael Maier (1586-1622): Cantilenae intellectuales. Tübingen 2002.

41 Der Verlag de Bry war in der zweiten Hälfte des 16. Jahrhunderts vor allem mit seiner India Occidentalis-Sammlung berühmt geworden, also höchst kunstvoll illustrierten Reiseberichten aus der Neuen Welt. Verlagsgeschichtlich könnten die illustrierten Alchemica-Drucke damit der Versuch sein, an den ökonomischen Erfolg der India Occidentalis-Sammlung anzuknüpfen. Vgl. zuletzt Helge Perplies: Inventio et repraesentatio Americae. Die India Occidentalis-Sammlung aus der Werkstatt de Bry. Heidelberg 2017. 


\section{Lucas Jennis und seine Kupferstiche}

Eine ganze Reihe weiterer Werke Maiers erscheinen bei Jennis selbst, darunter 1617 die Symbola aureae mensae und 1618 der Tripus aureus. Bei diesem Tripus aureus handelt es sich um einen weiteren Sammelband mit (al)chemischen Schriften, unter ihnen die lateinische Fassung der Zwölf Schlüssel des Basilius Valentinus, mit denselben Kupferstichen, die 1625 dann auch in der Dyas chymica für die deutsche Fassung verwendet werden. 1619 erscheint bei Jennis im Übrigen auch das Verum inventum Maiers, dessen Untertitel in der deutschen Fassung lautet: Von den hochnützlichen, herrlichen Erfindungen ond Künsten, welche von der löblichen Teutschen Nation, auß sonderbarem hohen Verstande ond Scharpffsinnigkeit erstlich erfunden, ond der Welt communiciert worden - eine Schrift, die damit sehr gut zur Vorrede der Dyas chymica und dem kulturpatriotischen Impuls der „Fruchtbringenden Gesellschaft“ passt.

Die Dyas chymica steht 1625 mit den beeindruckenden Kupferstichen und ihrem kulturpatriotischen Vorwort also nicht alleine, sondern ist Teil eines künstlerisch und buchgestalterisch äußerst ambitionierten Verlagsprogramms. Die (al)chemischen Emblembücher, die de Bry und Jennis veröffentlichten, gehörten von ihrer Ausstattung her zum teuersten und anspruchsvollsten, was in puncto Buchgestaltung zu diesem Zeitpunkt möglich war. Es handelt sich um Buchkunstwerke im höchsten Sinne des Wortes - und das wiederum musste finanziert werden. Vor allem die Kupferstiche Merians (oder aus seiner Werkstatt) waren so teuer und aufwändig, dass Jennis sie so häufig wie möglich verwenden musste. Genau aus diesem Grund findet sich schon im Anhang der Dyas chymica ein HermeticoSpagyrisches Lustgärtlein, in dem Jennis die hundertsechzig kleinformatigen Embleme, die 1622 Johann Daniel Mylius in seiner Philosophia reformata verwendet hatte, noch einmal abdruckt. ${ }^{42} 1627$ druckt Jennis diese Kupferplatten ein drittes Mal unter dem Titel Hortulus hermeticus, diesmal begleitet mit lateinischen Versen von Daniel Stolz von Stolzenberg, auf den gleich zurückzukommen sein wird. ${ }^{43}$

Einen Teil der Kupferplatten aus der Dyas chymica verwendet Jennis dann 1625 wiederum in Herbrandt Jamsthalers Viatorium spagyricum, das ist: Ein Gebenedeyter Spagyrischer Wegweiser/ in den edlen Sonnengarten der Hesperidum zu kommen/ onnd daselbst den Güldenen TincturZweig des vniversals (sonsten Lapis Philosophorum genandt.) zu erlangen. Die Kupferstiche stehen in keinerlei inhaltlicher Beziehung zum Text und sie sind willkürlich in dem Buch verteilt:

Geschäftstüchtigkeit hat Jennis diesfalls Rücksichten auf inhaltliche Momente hintanstellen lassen, und es verwundert nicht weiter, wenn bei der Textdeutung die systemlos inserierten Kupferstiche keine Hilfe leisten, da zwischen den Bildern und dem Inhalt der ihnen benachbarten Textpartien keine oder kaum mehr als nur sehr lose gehaltene ,Konkordanzen' feststellbar sind. ${ }^{44}$

42 Nachdruck mit Übersetzung in Humberg: Mylius (Anm. 39), S. 155-175.

43 Hortulus hermeticus flosculis philosophorum cupro incisis conformatus et brevissimis versiculis explicatus [...] Authore M. Daniele Stolcio de Stolcenberg. Frankfurt a. M. 1627.

44 Joachim Telle: Bemerkungen zum Viatorium spagyricum von Herbrandt Jamsthaler und seinen 
Auch bei diesem Viatorium handelt es sich um den dunklen, narrativen Bericht eines Ich-Erzählers, der mit dem Rätsel als literarischer Form spielt. In den Text sind nicht-alchemische Rätsel - teilweise sehr bekannte, wie das „Eva“-Rätsel - aufgenommen worden, allerdings ohne ihre Lösung, offensichtlich mit der Absicht, den Text so unverständlich wie möglich zu machen:

Die Verlarvung [der ursprünglich nichtalchemischen Rätsel in alchemischen Texten] ist kaum noch kenntlich, da man die Texte um ihre Lösung beschnitt und ihnen ihre genuine von Frage und Antwort bestimmte Tektonik genommen hat. Man erkannte, daß sich ihre dadurch intensivierte Dunkelheit unschwer der neuen arkansprachlichen Umwelt fügte: Die ihm eigene obscuritas bewirkte offenbar nicht nur, daß man das Rätsel vor anderen literarischen Formen bei Dichteralchemisten gepflegt findet, - ebenso hat sie in einer Literatur, deren Schreibart von den Polen Exoterik / Esoterik bzw. „aperte / tecte“ bestimmt wurde, die Assimilation alchemiefremder Rätsel in maßgeblicher Weise begünstigt. ${ }^{45}$

„Intensivierung der Dunkelheit“ ist ein schöner Begriff für das Prinzip dieser Texte, Rätselhaftigkeit mit allen Mitteln herzustellen. Was Telle für das Viatorium beschrieben hat, entspricht im Grunde genau dem, was eingangs schon für die Übernahme des Alphidius in den Lamspring beobachtet wurde: Ein Rätsel wird unverständlich, dunkel, geheimnisvoll, wenn man es ohne die Lösung abdruckt. Noch rätselhafter wird der Text, wenn man nicht einmal deutlich macht, dass es sich um ein Rätsel handelt.

Einen ganz ähnlichen Befund erlaubt schließlich auch die Druckgeschichte des Viridarium chymicum, das - so könnte man sagen - ausschließlich einer Vermarktung der Rätselhaftigkeit diente. 1624, ein Jahr vor der Dyas chymica mit ihrem Hermetico-Spagyrischen Lustgärtlein, hatte Jennis nämlich schon einmal ein Chymisches Lustgärtlein publiziert, gleichzeitig in deutscher und lateinischer Fassung. ${ }^{46}$ Der Herausgeber ist Daniel Stolz von Stolzenberg (Stolzius, Stoltzius), der in seiner Vorrede ausführlich berichtet, wie dieses Lustgärtlein zustande kam. ${ }^{47}$ Auf der Su-

Quellen. In: Geist und Zeichen. Festschrift für Arthur Henkel. Hg. von Herbert Anton, Bernhard Gajek und Peter Pfaff. Heidelberg 1977, S. 427-442, hier S. 430. In diesem Aufsatz auch schon wichtige Hinweise für die gesamte alchemische Verlagsproduktion von Jennis.

45 Telle: Bemerkungen zum Viatorium spagyricum (Anm. 44), S. 440f.

46 Viridarium chymicum figuris cupro in cisis adornatum, et poeticis picturis illustratum. [...] Authore M. Daniele Stolcio de Stolcenberg. Frankfurt a. M. 1624. Für die deutschsprachige Fassung wurden die Verse von Stolz von Daniel Meißner ins Deutsche übertragen: Chymisches Lustgärtlein/ Mit schönen in Kupffer geschnittenen Figuren gezieret/ auch mit Poetischen Gemälden illustrirt vnd erleutert. Also daß es nicht allein Augen vnd Gemüt erquicket/ sondern zugleich eine sehr tieffe betrachtung der natürlichen dinge erwecket/ so in dieser ablengs Form zu einem Stammbuch guter Freund sehr dienlich vnd bequem kann gebracht werden. Beschrieben von M. Daniele Stoltzio de Stoltzenberg [...] Nunmehr aber auß dem Lateinischen transferirt vnd in gewönliche teutsche Rhythmos bracht/ Durch Danielem Meißnern [...]. Frankfurt a. M. 1624.

47 Heike Hild: Das Stammbuch des Medicus, Alchemisten und Poeten Daniel Stolcius als Manuskript des Emblembuches Viridarium Chymicum (1624) und als Zeugnis seiner Peregrinatio 
che nach Illustrationen für sein Stammbuch sei er auf „diese ins Kupffer geschnittene Figuren zu Franckfurt am Mayn/ bey Herrn Luca Iennisio“" gestoßen und da diese ihm sehr gefallen hätten, hätte er Jennis den Vorschlag gemacht, sie für sein Stammbuch zu verwenden - im Grunde also als bloße Illustrationen eines ansonsten leeren Buches, in das sich die Professoren (oder sonstige Berühmtheiten oder auch nur Freunde) eintragen konnten, bei denen er auf seiner peregrinatio academica studieren würde. ${ }^{48}$

Jennis tat ihm den Gefallen, machte gleichzeitig aber Stolz den Vorschlag, seinerseits die Kupferstiche mit Versen zu versehen und sie mit den Abbildungen als eigenes Buch herauszubringen. Das wiederum brachte Stolz in größte Gewissensnöte, wie er schreibt, denn abschlagen wollte er Jennis seinen Wunsch nicht. Einzuwilligen aber schien ihm eine große „Kühnheit“, denn er verstand gar nicht, was die Kupferstiche bedeuten sollten. Also verständigte er sich mit Jennis darauf, dass er zwar die begleitenden Verse schreiben würde, diese Verse aber nicht die "geheimnuß“ der „Figuren“" „expliciren vnd außlegen“ würden, sondern nur das, was in den (ursprünglich die Bilder begleitenden) Texten stünde, in Verse bringen würden. ${ }^{49}$ Auch diese reduzierte Variante erwies sich in der Durchsetzung aber als äußerst problematisch:

Da ich nun das Werck angefangen/ vnd fast bis auffs halbe theil desselben kommen/ als ward ich innen vnd gewar/ daß die Beschreibungen mit den Figuren nicht vberein stimmeten/ ich auch jhre Außlegungen niergend finden kunde/ da erkennete ich allererst/ daß ich mich in grosse angst vnd vnaufflößliche Labyrinth gestecket hatte/ wuste auch kein mittel zufinden/ dardurch ich mich auß dieser seltzamen krümmen hette herauß wickeln/ vnd erretten können. ${ }^{50}$

Stolz schreibt weiter, er hätte die alchemischen Schriften „gegeneinander gehalten/ vnd endlich derselbigen Figuren illustration vnd erleuterung herbey gebracht“.

Academica. München 1991. Dort S. 57 ein genauer Nachweis der Herkunft der einzelnen Kupferstiche. Vgl. auch Wilhelm Kühlmann: Poet, Chymicus, Mathematicus. Das Stammbuch des böhmischen Paracelsisten Daniel Stoltzius. In: Parega Paracelsica. Paracelsus in Vergangenheit und Gegenwart. Hg. von Joachim Telle. Stuttgart 1991, S. 275-300. Zur Entstehungsgeschichte des Stammbuchs vgl. auch Joachim Telle: Sol und Luna (Anm. 7), S. 64-66.

48 Es finden sich hier unter anderem Johannes Rhenanus, Johannes Daniel Mylius und einer der Söhne von Landgraf Moritz, vgl. das Verzeichnis bei Hild: Stammbuch Stolcius (Anm. 47), S. 242-272.

49 Stolz: Vorrede zum Chymischen Lustgärtlein (Anm. 46), fol. A4v f.: „Was solte ich thun? Abschlagen vnd nicht thun war ein Vndanckbarkeit vnd Faulheit: Thun vnd drein willigen/ war ein eygene Lieb [im Sinne von Eitelkeit] vnd Kühnheit. Nichts desto weniger/ so wolte ich lieber für freundlich/als vndanckbar gehalten/ auch mehrer der Künheit als Mißgust bezüchtiget werden. Darauff habe ich es versprochen vnd zugesagt: Vnd zwar/ daß ich nicht also die geheimnuß/ wie die Figuren expliciren vnd außlegen/ auch nicht etwas von den meinen eygenes gefallens hin zusetzen/ sondern nur allein/ was im rechten vnnd vngezwungenen text begrieffen/ auffs aller kürtzeste in gewisse Verß vbersetzen/ auch dasselbige/ was ich auß den Beschreibungen nehmen würde/ der zeit nach/ leichtlich praestiren vnnd ins Werck richten wollte."

50 Stolz: Vorrede zum Chymischen Lustgärtlein (Anm. 46), fol. A ${ }^{\mathrm{vr}}$. 
Wie auch immer es damit bestellt ist - das Interessanteste an dieser Geschichte ist eigentlich der Einblick, den sie in das Verlagsgeschäft des Lucas Jennis erlaubt. Hier hatte jemand die Rätselhaftigkeit der Alchemie als ökonomisches Potential erkannt. Egal, ob man verstanden hatte, was mit den rätselhaften Bildern gemeint war oder nicht: Sie konnten ein hübsches Buch abgeben. An erster Stelle steht das ökonomische Interesse, an zweiter Stelle (wenn überhaupt) das (alchemische) Verständnis. (Al)Chemie um 1600 ist ein Käuferinteresse, das bedient werden will.

Auch im Falle des Lamspring hat Jennis die Kupferplatten zweimal verwendet. Im selben Jahr 1625, in dem die Dyas chymica erschien, hatte Jennis den Lamspring auch in der lateinischen Übersetzung von Nicolas Barnaud veröffentlicht, innerhalb des Musaeum hermeticum. Wie im Falle der Dyas chymica handelt es sich um einen äußerst aufwändig gestalteten Sammelband mit (al)chemischen Schriften, allerdings wesentlich umfangreicher und eben auf Latein. Das Musaeum hermeticum übernimmt auch drei andere Traktate aus der Dyas chymica, ergänzt um eine ganze Reihe weiterer (al)chemischer Texte und kommt damit auf ca. 500 Seiten, vom Umfang her also fast doppelt so groß wie die Dyas chymica. Mit der lateinischen Sprache ist auch klar, dass dieser Sammelband sich an ein anderes Publikum, eine andere Käuferschicht wendet, nämlich die internationale res publica alchemica.

Mit dem lateinischen Musaeum hermeticum steht Jennis in einer anderen Texttradition als mit der deutschen Dyas chymica. Diese Tradition beginnt mit dem Band De alchemia (10 Texte, Nürnberg 1541), führt über den Band Verae alchemiae artisque metallicae, citra aenigmata, doctrina (53 Texte, Basel 1561), das Aureum vellus (1598-1604, 5 Bände) und über Pietro Pernas Sammelbände zum vorläufigen Höhepunkt dieser (al)chemischen Sammelpublikationen, Zetzners Theatrum chemicum (ab 1602, über 200 Texte in 6 Bänden). ${ }^{51}$ Im weiteren Verlauf gehört in diese Tradition etwa die Bibliotheca Chemica Curiosa (1702) von Jean-Jacques Manget und das Theatrum Chemicum (1728-1732) von Friedrich Roth-Scholtz. Diese Texttradition illustriert nicht nur die wachsende Bedeutung der (Al)Chemie in der Frühen Neuzeit, sondern auch die Tatsache, dass dieses wachsende Interesse für Verlage und Herausgeber ökonomisch interessant war. Sammelbände wie diese versprachen dem zahlungskräftigen Liebhaber der (Al)Chemie (wie etwa Moritz von HessenKassel) ein Ende ihres mühseligen Sammelns von Handschriften und Einzeldrucken. Alle wichtigen (al)chemischen Texte in einer Ausgabe: Das war das Versprechen, das hinter diesen Sammelausgaben steht.

Insbesondere Zetzners Theatrum chemicum dürfte dabei das Modell von Jennis' Musaeum hermeticum gewesen sein. Nicht zuletzt war dort nämlich im dritten Band von 1602 bereits die lateinische Fassung des Lamspring erschienen, ebenfalls in der Übersetzung von Nicolas Barnaud. ${ }^{52}$ Jennis tut damit nur, was in der Frühen Neuzeit allgegenwärtige Praxis ist: Texte, die sich verkaufen (oder von denen man

51 Vgl. Carlos Gilly: On the Genesis of L. Zetzner's Theatrum Chemicum in Strasbourg. In: Magia, alchimia, scienza dal '400 al '700. L'influsso di Ermete Trismegisto. Hg. von C. Gilly und C. van Heertum. Florenz 2003, S. 451-467.

52 Theatrum chemicum. Straßburg 1602. Bd.3, S. 860-870. 
dies annimmt), noch einmal abzudrucken. Auch Zetzner hatte nichts Anderes gemacht, denn die im Theatrum chemicum gesammelten Texte waren zumeist bereits anderen Orts erschienen. Barnaud selbst hatte seine Übersetzung des Lamspring bereits 1599 in der Triga chemica veröffentlicht. ${ }^{53}$ Von hier dürfte sie der anonyme Verfasser des Livres des figures hieroglyphiques (Paris 1612) kennen, einem weiteren, höchst rätselhaften und ins 14. Jahrhundert zurückdatierten Buchs. Dieser anonyme Verfasser hat in der modernen Esoterik genauso wie in der populären Unterhaltungsliteratur einen Bekanntheitsgrad erreicht, der wohl nur mit dem von Christian Rosenkreuz vergleichbar ist: Nicolas Flamel. Dass gerade in diesem Buch die rätselhaften Verse des Lamspring zitiert werden, ${ }^{54}$ passt besonders gut zu den Beobachtungen, die schon anlässlich des Verlagsprogramms von Lucas Jennis gemacht wurden.

Der Calvinist Nicolas Barnaud, dessen Werk Didier Kahn erschlossen hat, ${ }^{55}$ war seinerseits ein großer Liebhaber alchemischer Rätsel. So druckte er 1597 die Alchemische Messe des Melchior de Sibiu (Melchior Cibiensis, Melchior aus Siebenbürgen) ab, einen aus der Mitte des 15. Jahrhunderts stammenden Text, der (al) chemisches Wissen in die Form einer Messe gebracht hatte. ${ }^{56}$ Das ist mindestens genauso spektakulär und rätselhaft wie das Gleichnis des Alphidius und die Bilder des Lamspring. Barnaud druckt diese Messe zudem im Anhang eines weiteren, ebenso höchst rätselvollen Textes ab, nämlich der angeblichen Grabinschrift einer Aelia Laelia Crispis, in Bologna gefunden:

D. M. Aelia Laelia Crispis. Weder Mann, noch Frau, noch Zwitterwesen. Weder Kind, noch Jugendlicher, noch alt. Weder züchtig, noch ausschweifend, noch schüchtern, sondern alles. Weder getötet durch Hunger, Schwert noch Gift, sondern von allen zusammen. Weder im Himmel, im Wasser oder der Erde, sondern überall ruhend. Lucius Agatho Priscius. Weder verheiratet, noch Liebhaber, noch verwandt. Weder Trauerklage, noch Freude oder Tränen. [Errichtet] keinen Grabhügel, noch eine Pyramide oder ein Grabmal, sondern alles. Er weiß und weiß nicht, wem es gewidmet ist. ${ }^{57}$

53 Triga chemica. Hg. von Nicolas Barnaud. Leiden 1599, S.11-24. Die Rekonstruktion dieser Druckgeschichte bereits bei Telle: Lamspring (Anm. 7).

54 [Nicolas Flamel:] Livre des figures hieroglyphiques. Paris 1612, S.74. Vgl. auch die Ausgabe von Didier Kahn und Nicolas Flamel: Écrits alchimiques. Textes établis et présentés par Didier Kahn. Paris 1993, S. 56. Kahn rekonstruiert in seinem Nachwort die Entstehungsgeschichte der Figur „Flamel“ und des ihr zugesprochenen Textkorpus.

55 Didier Kahn: Between Alchemy and Antitrinitarianism. Nicolas Barnaud (ca. 1539-1604?). In: Socinianism and Arminianism. Antitrinitarians, Calvinists, and Cultural Exchange in Seventeenth-Century Europe. Leiden 2005, S.79-96. Aus der Perspektive eines Jungschen Verständnisses von Alchemie und für die historische Kontextualisierung weniger hilfreich ist Thomas Willard: The Enigma of Nicolas Barnaud. In: Ésotérisme, gnoses \& imaginaire symbolique. Mélanges offrets à Antoine Faivre. Hg. von Richard Caron u. a. Leuven 2005, S. 199-213.

56 Vgl. La Messe alchimique attribuée à Melchior de Sibiu. Édition critique par Didier Kahn. Avec le concours d'Alena Hadravova et Jean-Baptiste Lebique. Paris 2015.

57 Zitiert nach der anonymen Übersetzung im Art. „Aelia Laelia Crispis“ der deutschen Wikipedia, URL: https://de.wikipedia.org/wiki/Aelia_Laelia_Crispis (4.7.2020) Vgl. den lateinischen 
Auch Barnauds (al)chemische Deutung dieser Inschrift wurde, wie seine Übersetzung des Lamspring, 1602 in den dritten Teil des Theatrum Chemicum übernommen. ${ }^{58}$ In seiner Quadriga aurifera (Leiden 1599) hatte Barnaud dann noch (unter anderem) zwei alchemische Texte Georg Ripleys (1415-1490) veröffentlicht, die sich ebenfalls durch ein hohes Maß an Rätselhaftigkeit auszeichnen.

Diese Liste ließe sich unschwer erweitern. Schon hier dürfte allerdings deutlich geworden sein, dass die Rätselhaftigkeit (al)chemischer Texte ein Kriterium war, das um 1600 genügen konnte, um einen Sammelband wie die Dyas chymica des Rhenanus oder die Triga chemica Barnauds zusammenzustellen. Wenn das zutrifft, dann kontrastiert dieser Kontext erheblich mit dem Kontext, in dem 1608 Benedict Figulus den - eingangs zitierten - Alphidius abgedruckt hatte, nämlich der Thesaurinella Olympica.

\section{Benedict Figulus: Rätselhaftigkeit im Paracelsismus}

Benedict Figulus (Hafner, Hefner) ist eine äußert interessante Gestalt, über die wir - auch hier dank der Arbeiten Joachim Telles ${ }^{59}$ - relativ gut Bescheid wissen. 1567 in Uttenhofen/Franken geboren als Sohn eines Pfarrers, humanistisch erzogen, 1590/91 in Wittenberg immatrikuliert, später dann aus seiner Pfarre in Lipprichhausen durch die scharf gegenreformatorische Politik des Fürstbischofs von Würzburg vertrieben, beginnt Figulus 1601 sein Wanderleben, das bis zu seinem Tod (nach 1624) anhalten sollte. Den entscheidenden Impuls bildet dabei sein Bekenntnis zum Paracelsismus:

Zur Zeit seiner Vertreibung aus Franken sagte Figulus dann der ,Schulphilosophie' zugunsten einer die ,Astronomia', ,Alchymia', ,Magia' und ,Cabala' einbeschließenden ,Hermetischen Philosophey' endgültig ab. Er will sich seit 1601 als ein hermetischer ,Indagator' der Natur verstanden haben und vollzog an unbekanntem Ort einen Akt, der angesichts des mächtigen Widerstandes der aristotelisch-galenistischen Schulmedizin und orthodoxen Theologie wider den magico-hermetischen Paracelsismus [...] noch immer und auch weiterhin ernsthafte Gefahren barg: Figulus erklärte sich nach eigenem Bekunden im Jahre 1604 ,offentlich für einen Discipulum Paracelsi. ${ }^{\prime 60}$

Sein anschließendes, „unstet-landräumiges Leben“ (Telle) führt ihn durch den gesamten süddeutschen Raum bis nach Tirol und Kärnten. 1607 behauptet er, er sei „2000 oder noch 3000 Meil“ gereist. Immer wieder gerät er dabei mit den Obrigkei-

Text bei Nicolas Barnaud: Commentariolum in aenigmaticum quoddam epitaphium, Bononiae studiorum, ante multa secula marmoreo lapidi inculptum. Leiden 1597. Die Marmorinschrift wird heute im Museo Civico Medievale di Palazzo Ghisilardi-Fava aufbewahrt.

58 Vgl. Theatrum Chemicum 1602, Bd.3, S. 836-848.

59 Vgl. Joachim Telle: Benedictus Figulus. Zu Leben und Werk eines deutschen Paracelsisten. In: Medizinhistorisches Journal 22 (1987), S.303-326, dazu die Korrekturen und Erweiterungen im Corpus Paracelsisticum (Anm. 18), Bd.3, S. 1062-1077, von denen die folgenden Ausführungen abhängig sind.

60 Telle in Corpus Paracelsisticum (Anm. 18), Bd 3, S. 1063. 
ten in Konflikt. 1612 trifft er in Augsburg den Paracelsisten Karl Widemann, der wie Figulus selbst - mit alchemischen und paracelsischen Handschriften handelt. Zur selben Zeit begegnet er dem Tiroler Dorfschulmeister Adam Haslmayr, einem weiteren glühenden Paracelsisten und Rosenkreuzer. ${ }^{61}$ Als dieser kurz darauf festgenommen, zu einer Galeerenstrafe verurteilt und nach Genua geschafft wurde, geriet auch Figulus ins Visier der Behörden und wurde per Haftbefehl gesucht. 1612 wird er im vorderösterreichischen Ensisheim/Elsaß bis 1617 gefangengesetzt. Danach verlieren sich seine Lebensspuren.

„Ein von manchen Nöten geprägtes Geschick tut sich kund, ein umgetriebenleidvolles Leben“, ${ }^{\prime 62}$ das Figulus selbst zu einer ,Pilgrimschaft” in der Nachfolge des Paracelsus überhöht. In den Vorworten und Widmungen der von ihm herausgegebenen Schriften ist die Polemik gegen die "Gemeine Aristotelische Platonisch/ \& nostri temporis Philosophia“ als "Phantasey“ und "lähres todtes geschwätz" allgegenwärtig. ${ }^{63}$ Nicht die „heydnischen Büchern vnd Scripten“ solle man lesen, sondern das Buch der Natur und die Bibel. Neben der Polemik gegen die Schulgelehrsamkeit und universitäre Philosophie steht die Polemik gegen die protestantischen „Maul/ Schein vnd HeuchelChristen", den "Antichristischen hauffen" der lutherischen Amtskirche und die "Gottlosen verruchten/ vom Teuffel verblendten vnd verführten Weltkinder vnnd Bauchdiener". Seine Polemik gegen die "gottlose blinde Welt" bekundet - noch einmal in den Worten Telles - eine „tiefgreifende Frömmigkeitskrise, zu deren Überwindung Figulus nach einer christozentrischen, in ,wercken' sich bewährenden ,Theologia sana' verlangt und eine Natur- und Gotteserkenntnis verschränkende Theoalchemie verficht. Unverkennbar gehörte Figulus zu den Herolden eines einst reich schattierten chymischen Christentums, das einer Zweiten Reformation den Weg zu bahnen suchte ${ }^{\prime \prime 64}$ und von Universitätstheologen als „Fanatismus“ verdammt wurde.

Zumindest einen Teil seines Lebensunterhalts bestritt Figulus - „Poeta L. C. Theologus, Theosophus, Philosophus, Medicus, Eremita, etc. ${ }^{65}{ }^{6}$ wie er sich selbst nennt - mit dem Verkauf (al)chemischer Handschriften und Prozessbeschreibungen. Einen unschätzbaren Einblick in diese Tätigkeit vermittelt ein Brief an Landgraf Moritz aus dem Jahr 1611, in dem er diesem eine Reihe von solchen Handschriften und Prozessen anbietet. ${ }^{66}$ Gleichzeitig bittet er um Beihilfen zur Sicherung seines Lebensunterhaltes und Unterstützung bei seinem Versuch, das Wormser Bürgerrecht zu erlangen, um dort mit seiner „Sponsa“ und „zwei Kinderlein" "privatam Eremiticam Vitam [zu] instituieren“. ${ }^{67}$

61 Vgl. zur Rekonstruktion von dessen nicht weniger abenteuerlichen Leben Gilly: Adam Haslmayr (Anm. 38).

62 Telle in Corpus Paracelsisticum (Anm. 18), Bd 3, S. 1073.

63 Alle Zitate nach Corpus Paracelsisticum (Anm. 18), Bd 3, S. 1073.

64 Telle in Corpus Paracelsisticum (Anm. 18), Bd 3, S. 1074.

65 Figulus: Widmung der Thesaurinella in Corpus Paracelsisticum (Anm. 18), Bd 3, S. 1083.

66 Brief von Benedict Figulus an Landgraf Moritz vom 6. 7. 1611. Ich zitiere nach der kritischen Edition des Briefes im Corpus Paracelsisticum (Anm. 18), Bd. 3, S. 1153-1194.

67 Figulus: Brief an Landgraf Moritz (Anm. 66), S. 1169. 
Was er Moritz anzubieten hat, ist das Lux lucens in tenebris, ein Schlüssel zu den Archidoxa des Paracelsus, für den der Bischoff von Passau angeblich 1500 Kronen und Herzog Friedrich von Württemberg 6000 Florinen geboten hätten. Vor 18 Jahren sei dieses Manuskript dem spanischen König für 5000 Kronen verkauft worden, wäre dann aber - „villeicht auß Gottes verhengkniß“ - in Tirol verblieben, versetzt für 1000 Gulden. Zweitens hätte er „das Gehyme Büechlein Theophrasti, Arcanorum scilicet Mercuriorum Alchymiae“ anzubieten, „darinnen wunderbarliche, kurtze, vndt leichte künsten vndt Handtgriff In Metallurgia dargethan vndt gewiesen werden", ",so noch In gantz Teutschlandt vnbekandt ${ }^{\prime 6}{ }^{68}$ Drittens schließlich ein "Stattliches Hohes Particular Stück“, an dem Raimundus Lullus „sampt seinen Mitconsorten“ 60 Tage lang „laborirt“ hätten, bis sie schließlich „den Hohen Tinctur Stein“ erlangt hätten. „Warhafftig vndt gewiß“ sei das deshalb, weil ein adliger Alchemiker in Tirol auf dem Sterbebett das Sakrament darauf genommen habe, von dessen Gattin er es - „neben Anderen Hohen Secretis“ - bekommen habe. Mit den richtigen Öfen ließen sich damit im Jahr 24000 Gulden machen, wenn nicht mehr. ${ }^{69}$ Außerdem im Angebot habe er fünf "Particular Tincturen", auf Birkenrinde geschrieben und zwischen zwei blutrote Glastafeln gelegt, mit Gold eingefasst, die einige hundert Jahre in einer Mauer verborgen gelegen hätten und dem Verfasser von einem Engel mitgeteilt worden seien. ${ }^{70}$

Dieser Brief vermittelt einen unschätzbaren Einblick in das Leben eines ,Prozeßkrämers' und wandernden Alchemikers, der seine Dienste und sein (al)chemisches Sachwissen denjenigen anbietet, die dafür bezahlen können. Die Preise, die Figulus für seine Handschriften nennt, zusammen mit den abenteuerlichen Geschichten ihrer Provenienz, machen deutlich, in welchem Markt sich Lucas Jennis mit seinen Sammelausgaben (in denen genau solche Manuskripte teilweise zum ersten Mal gedruckt werden) bewegt - sei dies bei ihm nun ebenfalls ernst gemeint oder ein ironisches Zitat genau dieser phantastischen Provenienzen.

$\mathrm{Ob}$ Moritz Figulus eine dieser Handschriften abgekauft hat, wissen wir nicht, in einigen anderen Fällen hat er es getan. ${ }^{71}$ Oft schlug er solche Angebote aber auch aus und zeigte sich bei solcher Gelegenheit an spekulativer Alchemie höchst desinteressiert. Auf das Angebot des schon erwähnten Paracelsisten und Spiritualisten Karl Widemann reagiert er 1630 mit der Bemerkung, er hätte "gerne gesehen, dass er [Widemann] dermahleins etwas nutzliches und wurckliches in Chymicis communiciret", womit er Texte meint, nach denen man "alhie zu laboriren und zu perficiren" vermöge. ${ }^{72}$

Auch die Thesaurinella mit dem Abdruck des Alphidius fand sich in der Bibliothek von Moritz. Thesaurinella Olympica aurea tripartita. Das ist: Ein himmlisch güldenes Schatzkämmerlein/ von vielen außerlesenen Cle[i]nodien zugerüstet/ darinn der vhralte

68 Figulus: Brief an Landgraf Moritz (Anm. 66), S. 1167.

69 Figulus: Brief an Landgraf Moritz (Anm. 66), S. 1167.

70 Figulus: Brief an Landgraf Moritz (Anm. 66), S. 1167.

71 Vgl. die Nachweise im Corpus Paracelsisticum (Anm. 18), Bd 3, S. 1067.

72 Zitiert nach Gilly: Adam Haslmayr (Anm. 38), S. 115. 
grosse vnd hochgebenedyte Carfunckelstein vnd Tincturschatz verborgen lautet der vollständige Titel des Bandes. Er ist Rudolph II. gewidmet, also genau jenem Kaiser, dessen Prager Hof ein weiterer Mittelpunkt des Hermetismus und der Alchemie war. Aus der Widmung des Figulus weht allerdings ein ganz anderer Wind als aus der Vorrede zur Dyas chymica: Die Deutschsprachigkeit der Alchemie interessiert Figulus nicht, im Gegenteil: seine Widmungsgedichte schreibt er auf Latein. Keine Spur von einem Kulturpatriotismus, keine ironischen Spielereien mit seiner Identität durch Verrätselung seines Namens. Im Gegensatz zur Dyas chymica enthält die Thesaurinella keinerlei Illustrationen, geschweige denn Kupferstiche. Von einem buchgestalterischen Impuls wie bei Jennis kann keine Rede sein.

Stattdessen ist die gesamte Widmung von einer scharfen Polemik gegen die „Galenisten" geprägt, die Krankheiten für unheilbar hielten, die doch durch „,künstliche spagyrische Bereitungen/ Extracta vnd Oleiteten, auß des Menschen Cörper außgetreiben/ vnd radicitus können profligirt werden“, was auch keines Beweises bedürfe, „sondern die täglich Experientz stellets offentlich an hellen Tag. ${ }^{73}$ Das paracelsistische Wissen, das solche Krankheiten heilbar mache, sei auf einen unmittelbaren göttlichen Eingriff zurückzuführen, denn Gott erwecke „trefflichere Heroische Ingenia, die solchem hohen Gnadenschatz in der Forcht deß Herrn nachgehen“, „damit solche thewre Kunst vor dem jüngsten Tag nur desto heller vnd klärer widerumb an tag gebracht werde/ vnnd die Gottlose/ verruchte/ blinde/ lunatische/ tolle Welt dort an jenem tag jrer verachtung vnd Vnwissenheit halben keine Entschuldigung bey zu bringen vermöge.. ${ }^{174}$ Die Widmung kulminiert in der Prophezeiung der unmittelbar bevorstehenden Ankunft eines „Elias Artista“, der ,als ein rechter vngezweiffelter Vorbott vnd Praecursor Christi Iesu“ nicht nur das letzte Gericht ankündige, sondern auch die Schriften des Paracelsus ,elucidirn vnnd declarirn“ werde. Mit seinem Auftreten als „Mysteriarcha vnnd Interpres“ "der Göttlichen/ vberhimmlischen Magnalium vnd Geheimnussen Gottes" werde

die Gottlose/ verruchte/ blinde/ vnd in allerhand Sünd/ Schand/ Lastern vnd Untugenden ersoffene vnd ertrunckene Welt erschrecken/ vnd verstummen müssen/ das kleine Häufflein aber der Nachfolger/ vnd Liebhaber der edlen Kunst Alchymiae, als der himmlischen Warheit/ wird sich von hertzen darob erfrewen/ vnd Gott für solche gnädige Offenbarung dancken. ${ }^{75}$

Er, Figulus, trage deshalb „ein hertzlich sehnlich Verlangen nach dieses zukünfftigen/ ja vielleicht schon gegenwertigen Eliae Ankunfft vnd Offenbarung“, damit „die arge Lunatische Lust vnd geldtliebende Welt/ die die Finsternuß mehr dann das Liecht liebet" vor diesem "himmlischen Gnadenliecht" „vollendts erblindte/

73 Zitate nach der Edition im Corpus Paracelsisticum (Anm. 18), Bd.3, S. 1077-1088, hier S. 1080.

74 Figulus: Widmung (Anm. 65), S. 1080.

75 Figulus: Widmung (Anm. 65), S. 1081. 
zu spott vnd schanden werde/ vnd in ihres Hertzen vnbußfertiger Verstockung ihren verdienten Lohn dahin nemme ${ }^{\text {". }}{ }^{76}$

Diesem Zweck einer Vorbereitung der Rückkehr Christi dient nicht nur die Thesaurinella, sondern auch die anderen Textsammlungen, die Figulus herausgegeben hat: Sie sind Teil einer Offenbarung alchemischen Wissens, in der sich nichts Geringeres als die Apokalypse ankündigt. Unterzeichnet ist die Widmung der Thesaurinella denn auch nicht mit einer normalen Datumsangabe, sondern "sub regimine vero Gubernatoris Olympici, Angeli Hagith, anno centesimo XCVII. ${ }^{\prime{ }^{\prime 7}}$ Damit zitiert Figulus das Arbatel, ein magisches Werk, das die Beschwörung von Dämonen lehrte und deshalb auch nach seinem Druck 1575 sofort verboten wurde. „Hagith“ ist der Engel oder Dämon, der die Jahre von 1411 bis 1900 regiert, mit Venus korrespondiert und unter dessen Regentschaft Kupfer in Gold und Gold in Kupfer verändert wird. ${ }^{78}$

Wenn Figulus den Alphidius in einem solchen Sammelband abdruckt, hat die Rätselhaftigkeit offensichtlich eine ganz andere Funktion. Für einen Paracelsisten wie Figulus ist die Natur selbst eine Manifestation des göttlichen Geistes, des in Christus inkarnierten Wortes. Die Rätselhaftigkeit der Schöpfung resultiert aus der Präsenz dieses göttlichen Wortes in der Natur, das aus menschlicher Perspektive immer nur stückweise und fragmentarisch sichtbar wird. Der paracelsistische Alchemiker arbeitet niemals nur an der Natur als unbelebter Materie, sondern an der Enthüllung und Offenbarung des göttlichen Geistes in dieser Natur. Magie ist diese paracelsistische Alchemie, indem es einer göttlichen Erleuchtung bedarf, um die Präsenz des göttlichen Geistes in den Kreaturen zu entschlüsseln. ${ }^{79}$ Deshalb kann Figulus seine Editionen alchemischer Texte, wie in der Thesaurinella, auch zurecht in einen eschatologischen Horizont stellen.

Damit noch einmal zurück zum Alphidius, den Figulus innerhalb dieser Thesaurinella abdruckt. Der Abdruck des Alphidius in einem solchen Sammelband impliziert offensichtlich eine andere Funktion der Rätselhaftigkeit als die Publikation dieses Traktats (als Teil des Lamspring) in der Dyas chymica des Rhenanus - obwohl beide Veröffentlichungen nur durch wenige Jahre getrennt sind und beide Herausgeber sich im unmittelbaren Umfeld des Landgrafen Moritz bewegen.

Der entscheidende Unterschied zwischen den Vorworten von Rhenanus und Figulus ist dabei das Fehlen einer religiösen Deutung bei Rhenanus. Diese religiöse Dimension ist ein, vielleicht das entscheidende Element des Paracelsismus: Die (Al) Chemie des Paracelsismus ist religiös aufgeladen, sie ist - wie Telle das genannt hat - eine Theoalchemie. Und das ist nicht selbstverständlich. Im Grunde nämlich gibt es in der mittelalterlichen (Al)Chemie, bis hin zu Paracelsus, keine im engeren Sinne spiritualistische Alchemie, genauso wenig wie es eine Verbindung zur

76 Figulus: Widmung (Anm. 65), S. 1081.

77 Figulus: Widmung (Anm. 65), S. 1083.

78 Vgl. den Kommentar von Telle in Corpus Paracelsisticum (Anm. 18), Bd 3, S. $1087 f$.

79 Vgl. zu dem Komplex Alchemie, Magie und Mystik demnächst Simon Brandl: Mystik und Magie im Frühparacelsismus. Erkundungen um Alexander von Suchtens Traktat De tribus facultatibus. 
Magie gibt. ${ }^{80}$ Didier Kahn hat diesen wirklich wichtigen Punkt bereits in einigen Publikationen hervorgehoben, zuletzt im Kommentar zu einem Text, der mit dem Alphidius und dem Lamspring einige Gemeinsamkeiten hat, nämlich der (bereits erwähnten) Alchemischen Messe. Wie Kahn in aller Deutlichkeit zeigt, handelt es sich nicht um eine alchemische, irgendwie ,mystische' Interpretation der Messe oder gar um Blasphemie, sondern um ein literarisches Spiel. ${ }^{81}$ Der Begriff des „literarischen Spiels“ ist dabei nicht im Sinne einer bedeutungslosen Spielerei zu verstehen, sondern im Sinne einer allegorischen Deutung (al)chemischer Prozesse.

Interessant ist dieser Befund gerade deshalb, weil die Alchemische Messe sich ebenfalls 1608 in der Thesaurinella des Figulus findet, ${ }^{82}$ genauso wie im Anhang von Barnauds bereits zitierter Edition des alchemischen Rätsels aus Bologna aus dem Jahr 1597,83 von wo aus sie dann 1602 in Zetzners Theatrum chemicum gelangt war. Auch Michael Maier, der in seine Atalanta fugiens 1617 eines der Bilder aus dem Alphidius / Lamspring übernommen hatte, zitiert im selben Jahr in seinen Symbola aureae mensae die Alchemische Messe. ${ }^{84}$ Noch einmal acht Jahre später erscheint dann 1625 die Dyas chymica mit dem Lamspring bei Jennis, herausgegeben von Rhenanus. Es sind also dieselben Protagonisten und dasselbe historische Umfeld, in dem diese (al)chemischen Texte aus dem 15. Jahrhundert um 1600 gedruckt werden - und doch, so meine These, ist der religionshistorische Kontext, in dem sie durch ihr Publikationsumfeld jeweils stehen, ein höchst unterschiedlicher. Während wir es bei Figulus mit einem religiösen Separatisten, Paracelsisten und Spiritualisten zu tun haben (also mit dem, was die Theologen der Zeit einen „Fanatiker" und „Enthusiasten“ nennen), ist der Hof von Moritz von Hessen-Kassel eines der Zentren der "calvinistischen Internationale“, die sich in der zweiten Hälfte des 16. Jahrhunderts formiert und um 1620 auf dem Höhepunkt ihrer Bedeutung ist.

\section{Moritz von Hessen-Kassel und die calvinistische Internationale}

Moritz war 1605 zum Calvinismus übergetreten - ein Schritt, der sich bereits lange vorher angekündigt hatte, denn schon mit der Aufnahme sächsischer Kryptocalvinisten in der zweiten Hälfte des 16. Jahrhunderts war Kassel zunehmend zu

80 Vgl. die präzise Zusammenfassung der Verbindungen zwischen Alchemie und Religion im Mittelalter von Didier Kahn in: La Messe alchimique attribuée (Anm. 56), S. 11-23. Zur Verbindung von Magie und Alchemie vgl. meine Argumentation in Volkhard Wels: Magie und (Al) Chemie im 16. Jahrhundert. Thesen zu ihrer Begründung im Neuplatonismus, bei Paracelsus und im Paracelsismus. In: Der Begriff der Magie in Mittelalter und Früher Neuzeit. Hg. von Jutta Eming und Volkhard Wels. Wiesbaden 2020, S. 157-201.

81 Kahn: Messe alchimique (Anm. 56), S. 126: „L'intention initiale est certainement ludique, et non blasphématoire: il s'agit d'un jeu litteraire".

82 Vgl. Thesaurinella, S. 57-60, als „Corollarium“ zum ersten Teil. Der Titel dort lautet: Processus universalis viae, tincturae rubedinis et albidinis, alchymicae artis: Magistri Nicolai Melchioris Gibiniensis, Transsylvani etc. sub formam missae. Der Text folgt dort unmittelbar auf den Alphidius.

83 Nicolas Barnaud: Commentariolum in Aenigmatum quoddam epitaphium, Bononiae studiorum. Leiden 1597, S. 37-41.

84 Michael Maier: Symbola aureae mensae duodecim nationum. Frankfurt a. M. 1617, S. 509. 
einem „Knotenpunkt im Netzwerk des internationalen Calvinismus“ geworden. ${ }^{85}$ Dass mit Joseph Duchesne (Quercetanus), ausgerechnet ein Leibarzt Heinrichs IV. in Kassel zu Gast ist, ist kein Zufall, genauso wenig wie die engen Verbindungen, die Moritz zum englischen Hof unterhält. Genau auf dieses „Netzwerk des internationalen Calvinismus" verweist auch die Tatsache, dass Johannes Rhenanus, der Leibarzt von Moritz, enge Kontakte zu Fürst Ludwig von Anhalt hat. Christian I. von Anhalt-Bernburg, dem die Dyas chymica gewidmet ist, war - wie Moritz - 1605 zum Calvinismus konvertiert und im deutschen Raum so etwas wie die graue Eminenz dieses Calvinismus. Er war es, der die Ehe Friedrichs V., des pfälzischen Kurfürsten und späteren ,Winterkönigs', mit Elisabeth, der Tochter des englischen Königs eingefädelt und die Übernahme der böhmischen Königskrone durch Friedrich V. wesentlich vorangetrieben hatte: eine Übernahme, die dem protestantischen Lager eine Stimmenmehrheit bei der Wahl des nächsten Kaisers gesichert hätte. Zumindest für kurze Zeit schien damit am Horizont die Vision eines protestantischen Kaisers auf. Die „Fruchtbringende Gesellschaft“, die von Christians Halbbruder Fürst Ludwig gegründet worden war, war so etwas wie der kulturpolitische Arm dieses Calvinismus. ${ }^{86}$ Gerade der kultur- und sprachpolitische Impuls, der zur Gründung dieser Gesellschaft geführt hatte, war ein genuin reformiertes Anliegen. Martin Opitz - seit 1629 Mitglied der „Fruchtbringenden Gesellschaft", aber schon Jahre vorher mit Ludwig in Kontakt - ist als Dichter der prominenteste Vertreter dieser calvinistischen Internationale.

Wenn Rhenanus die Verse des Lamspring 1623 in moderne Form bringt, ein Jahr vor dem Erscheinen der Deutschen Poeterey, dann ist genau derselbe kulturpatriotische Impuls am Werk. Mit den Versen von Michael Maier wird das noch weitaus deutlicher, denn Maier bedient sich in seiner Atalanta (1617) einer aus dem Französischen übernommenen Variante des Alexandriners, die für sehr kurze Zeit - bis zum Erscheinen der Poeterey 1624 - das avancierteste Modell der Versgestaltung war. $^{87}$ Nur eine Handvoll Dichter hatten sich dieser avantgardistischen Technik bedient, darunter vor allem Dietrich von dem Werder (Absolvent der Kasseler Hofschule) und Tobias Hübner, beide aus dem engsten Umfeld von Fürst Ludwig, früheste Mitglieder der „Fruchtbringenden Gesellschaft“. Moritz selbst war seit 1623

85 Holger Thomas Gräf: Konfession und internationales System. Die Außenpolitik HessenKassels im konfessionellen Zeitalter. Darmstadt u. a. 1993, S. 226. Stellvertretend für die ältere Forschung vgl. zudem Gerhard Menk: Die Konfessionspolitik des Landgrafen Moritz. In: Landgraf Moritz der Gelehrte. Ein Kalvinist zwischen Politik und Wissenschaft. Hg. von Gerhard Menk. Marburg 2000, S. 95-138.

86 Zum konfessionellen Gepräge der „Fruchtbringenden Gesellschaft“ vgl. Klaus Conermann: Die Fruchtbringende Gesellschaft und ihr Köthener Gesellschaftsbuch. Eine Einleitung. In: Der Fruchtbringenden Gesellschaft Geöffneter Erzschrein. Das Köthener Gesellschaftsbuch Fürst Ludwigs I. von Anhalt-Köthen 1617-1650. Hg. von dems. Bd. 2. Leipzig 1985, S. 21-127, der dort zeigt, dass die reformierte Konfession überproportional stark vertreten war.

87 Zur Versgeschichte und ihren kulturpolitischen Implikationen vgl. Volkhard Wels: Kunstvolle Verse. Stil- und Versreformen um 1600 und die Entstehung einer deutschsprachigen ,Kunstdichtung'. Wiesbaden 2018. Dort S. 89-105 zur französischen Technik des Alexandriners. 
Mitglied. Rhenanus war nicht nur Leibarzt und Chemiker von Moritz, sondern schon 1613 mit einem Speculum aistheticum hervorgetreten, in dem er sich an einer Reform deutschsprachiger Dichtung versucht hatte ${ }^{88}$ Francis Segar, ein englischer Kammerjunker am Kasseler Hof, gehört $1610 \mathrm{zu}$ den ersten, die die neue Form des Sonetts - und damit den Petrarkismus - in die deutsche Sprache einführen. ${ }^{89}$ Der Hof von Moritz ist - neben dem Hof von Ludwig - eines der Zentren jener kulturpatriotischen Bewegung, die nach dem Vorbild Italiens und Frankreichs dem Ideal der ,Höflichkeit' nachstrebt, das heißt einer höfischen Kultur, die sich nicht nur an ,ritterlichen' Tugenden (Turnieren, Fechten usw.), sondern auch an im weitesten Sinne kulturellen Werten orientiert. Die Hofschule nach französischem Vorbild, das „Collegium Mauritianum“, das Moritz in Kassel einrichtet, kann vielleicht nicht geradezu als eine Kaderschmiede bezeichnet werden, zumindest aber als „personaler Knotenpunkt“ des internationalen Calvinismus. ${ }^{90}$

Moritz ist nicht nur von der Chemie als einer neuen Form des Naturwissens besessen, sondern genauso von der Astronomie. Er tritt als Reformator des Schulwesens auf, unterhält eine der größten Kunstkammern seiner Zeit, interessiert sich für Architektur und spielt nicht nur mehrere Instrumente (bevorzugt die Laute), sondern komponiert selbst und leistet sich ein anspruchsvolles Hoforchester. John Dowland, den berühmtesten Lautenisten und Sänger seiner Zeit, versucht er an den Kasseler Hof zu holen, um Heinrich Schütz streitet er lange mit dem Dresdner Hof. ${ }^{91}$ Mit dem „Ottoneum“ in Kassel ließ Moritz den ersten eigenständigen Theaterbau im deutschsprachigen Raum errichten. Von maßlosem Alkoholkonsum als klassischer Freizeitbeschäftigung des deutschen Adels distanzierte er sich, indem er einen „Orden Temperantiae“ gründete, der seinen Mitgliedern Mäßigkeit abforderte. Seine älteste Tochter Elisabeth war eine begabte Lautenistin und verfasste zweihundert Madrigale in italienischer Sprache. ${ }^{92}$

Dieser Mann ist kein religiöser Separatist, der auf die Wiederkehr eines „Elias Artista“" wartet. Als 1619 Heinrich Philipp Homagius und Georg Zimmermann, zwei Lehrer am Marburger Pädagogium, Werke der „Heiden-Götzen“ Vergil und Cicero zerschnitten, die Fetzen aus den Schulfenstern geworfen und Paracelsus und Valentin Weigel zu den „Kern-Theologi“" ihrer Zeit erklärt hatten, setzte Moritz

88 Rhenanus: Speculum Aistheticum (Anm. 35), S. 328.

89 Francis Segar: Die erst Probe Francisci Segar Angli In der teutshen Poeterey (1610). Hg. von Martin Spies. Kassel 2016.

90 Holger Thomas Gräf: Die Kasseler Hofschule als Schnittstelle zwischen Gelehrtenrepublik und internationalem Calvinismus. Ein Beitrag zu den institutionen- und sozialgeschichtlichen Grundlagen frühneuzeitlicher Diplomatie. In: Zeitschrift des Vereins für Hessische Geschichte und Landeskunde 105 (2000), S. 17-32, hier S. 20.

91 Vgl. Claudius Sittig: Kulturelle Konkurrenzen. Studien zu Semiotik und Ästhetik adligen Wetteifers um 1600. Berlin, Boston 2011, S. 159-176.

92 Dieter Merzbacher: „Literarum et literatorum summus Patronus“. Europäische Dichtung und Sprachen am Hofe Moritz des Gelehrten. In: Moritz der Gelehrte. Ein Renaissancefürst in Europa. Hg. von Heiner Borggrefe u. a. Lemgo, Kassel 1997, S. 323-329. 
diesem Treiben sofort ein Ende und ließ beiden den Prozess machen.$^{93}$ An dem abschließenden Befund, wie er im Corpus Paracelsisticum für Moritz formuliert wird, kann deshalb kaum ein Zweifel bestehen: „Allenthalben präsent ist ein calvinistischer Humanist. ${ }^{\prime 94}$ Als ein solcher wird Moritz von den Weltuntergangsprophetien eines Figulus nicht viel gehalten haben. Eine Stellung an seinem Hof hat er ihm jedenfalls - im Unterschied zu Rhenanus, Mylius und Maier - nicht gegeben.

Der calvinistischen Internationale gehört schließlich auch Nicolas Barnaud an und auch er ist von der Rätselhaftigkeit alchemischer Texte fasziniert, ohne deshalb ein Spiritualist zu sein. Im Gegenteil: Später wird er zum Antitrinitarier, also zu dem, was man als eine Art Extremform des Calvinismus bezeichnen könnte, eine höchst elitäre Form der Frömmigkeit, voraus verweisend auf den Deismus des 18. Jahrhunderts. Calvinistische Flüchtlinge aus den Niederlanden sind die Frankfurter Verleger de Bry und Jennis, wie überhaupt Frankfurt am Main in der zweiten Hälfte des 16. Jahrhunderts zum Mittelpunkt des französischen und niederländischen Refuge geworden war und insbesondere viele Hugenotten aufgenommen hatte. Mylius veröffentlicht eine Christliche reformierte Theologia, in der er seine Hoffnung zum Ausdruck bringt, Lutheraner und Calvinisten wieder zu vereinigen. ${ }^{95}$ Seine Philosophia reformata hatte er ursprünglich dem ,Winterkönig' gewidmet, was dazu führte, dass sich der Kaiser sofort beim Rat der Stadt Frankfurt gemeldet und die Verhaftung von Mylius gefordert hatte. Dieser entzog sich dem durch die Flucht an den Hof von Moritz. ${ }^{96}$ Dort scheint ihm die Widmung nicht geschadet zu haben.

Vor allem aber gehört Michael Maier zu dieser calvinistischen Internationale und zwar unabhängig von der Frage, ob wir es tatsächlich mit einem Calvinisten oder mit einem Lutheraner als Kryptocalvinisten zu tun haben. Die Stationen seines Studiums sind die Universitäten Rostock und Frankfurt an der Oder, beides Zentren einer melanchthonisch geprägten Frömmigkeit und Philosophie, mithin des Kryptocalvinismus verdächtig. Seine Promotion schließlich erfolgt in Basel. Es folgen Aufenthalte in Prag am Hof Rudolfs II. und in Kassel am Hof von Moritz als Leibarzt, ganz wie Rhenanus. Wie dieser stand auch er mit Christian I. von Anhalt-Bernburg in Kontakt. ${ }^{97}$ Vier Jahre verbringt er in England, zumindest in Kontakt mit Jacob I. und seinem Hof, was auch immer er dort sonst gemacht hat.

93 Vgl. Karl Wilhelm Hermann Hochhuth: Mittheilungen aus der protestantischen Secten-Geschichte in der hessischen Kirche. 5. Theil: Im Zeitalter der Reformation. Vierte Abth.: Die Weigelianer und Rosenkreuzer. In: Zeitschrift für die historische Theologie 32 (1862), S. 86159; Carlos Gilly: „Theophrastia Sancta“. Der Paracelsismus als Religion im Streit mit den offiziellen Kirchen. In: Analecta Paracelsica. Studien zum Nachleben Theophrast von Hohenheims im deutschen Kulturgebiet der frühen Neuzeit. Hg. von Joachim Telle. Stuttgart 1994, S. 425-488, hier S. 469-471 und Bruce T. Moran: Paracelsus, Religion, and Dissent. The Case of Philipp Homagius and Georg Zimmermann. In: Ambix 43 (1996), S. 65-79. Im selben Sinne auch Telle im Corpus Paracelsisticum (Anm. 18), Bd.3, S. 1158.

94 Telle in Corpus Paracelsisticum (Anm. 18), Bd 3, S. 1153.

95 Vgl. Humberg: Mylius (Anm. 39), S. 45-47.

96 Vgl. Humberg: Mylius (Anm. 39), S. 53-56.

97 Vgl. Leibenguth: Maiers Cantilenae (Anm. 36), S. 44 u. ö. 
Es ist nicht nötig, an diesen Aufenthalt in England bizarre Verschwörungstheorien zu knüpfen, wie dies Frances Yates getan hat. ${ }^{98}$ Die Verbindungen als solche, das calvinistische Netzwerk, in das Maier eingebettet erscheint, genügen völlig.

Die Atalanta fugiens ist Ausdruck genau dessen, was Opitz in seiner Poeterey die „verborgene Theologie“ der Dichtung genannt hat, mithin eine poetisch verschlüsselte Darstellung, die - als poetische - in Kontrast zu der ,unverschlüsselten', begrifflich-abstrakten Theologie der Konfessionen steht. ${ }^{99}$ Wo diese begrifflich-abstrakte Darstellung zu konfessionellen Streitereien und Kriegen führt, da dient die „verborgene Theologie“ der Dichtung einem irenischen Impuls, weil sie gerade das herausstellt, was allen Konfessionen gemeinsam ist. Der französische Calvinist Philippe Duplessis-Mornay (einer der wichtigsten Führer der Hugenotten und enger Berater von Heinrich IV.) hatte 1581 in seinem Traktat De la vérité de la religion chrestienne contre les athées, epicuriens, payens, juifs, mahumédistes, et autres infidèles (in zahlreichen Ausgaben und Übersetzungen, darunter mehrere deutsche, über Europa verbreitet) den Anfang gemacht, Hugo Grotius war ihm 1622 mit seinem Beweis der wahren Religion (Bewijs van den waren godsdienst, lateinisch unter dem Titel De veritate religionis christianae, bis zum Ende des Jahrhunderts weit über hundert Ausgaben) gefolgt. ${ }^{100}$ Opitz hatte das Werk 1631 ins Deutsche übersetzt. Unter dem Vorwand, die wesentlichen Inhalte des Christentums zusammenzufassen, um sie den Atheisten, Heiden, Juden und Moslems entgegenzustellen, werden hier gerade die Inhalte herausgestellt, die alle christlichen Konfessionen verbinden. De veritate religionis formuliert den allgemeinen und grundlegenden Konsens, jenseits der konfessionellen Streitpunkte, so dass das ganze Buch eine Art Grundlegung der christlichen Religion darstellt, deren innere Einheit und Gemeinsamkeit gerade in der Abgrenzung nach außen deutlich werden soll. Das ist das Glaubensbekenntnis der irenisch gesinnten, calvinistischen Internationale am Vorabend des Dreißigjährigen Krieges.

Genau als eine solche "verborgene Theologie" im Sinne einer Reduktion auf die essentiellen Wahrheiten der Religion kann man auch die Atalanta fugiens lesen, in deren Mittelpunkt mit dem 26. Emblem die als Frau personifizierte Weisheit steht, neben dem Baum des Lebens, dem Wort Gottes. Mit einem Zitat von Salomo (Sprüche Salomo 3.18) heißt es von dieser Weisheit: „Sie ist der Baum des Lebens

98 Frances A. Yates: The Rosicrucian Enlightenment. London, Boston 1972. Widerlegung etwa bei Leibenguth: Maiers Cantilenae (Anm. 40), passim.

99 Martin Opitz: Buch von der Deutschen Poeterey. Studienausgabe. Hg. von Herbert Jaumann. Stuttgart 2002, S. 14. Vgl. den ausführlichen Rekonstruktionsversuch in Volkhard Wels: ,Verborgene Theologie', Enthusiasmus und Andacht bei Martin Opitz. In: Daphnis 36 (2007), S. 223-294.

100 Vgl. Hugo Grotius: De veritate religionis christianae. In: ders.: Opera omnia theologica. Faksimile-Neudruck der Ausgabe Amsterdam 1679. Stuttgart-Bad Cannstatt 1972, Bd.3, S. 3-96. Vgl. dazu Jan-Paul Heering: Hugo Grotius as Apologist for the Christian Religion. A Study of his Work De veritate religionis christianae (1640). Leiden, Boston 2004. 
allen die sie greifen; und selig sind die sie halten. ${ }^{\prime 101}$ Allein diese Weisheit als Erkenntnis Gottes verschaffe ein langes Leben, Gesundheit und Reichtum. Und das heißt (zumindest implizit): Es gibt kein alchemisch zu gewinnendes „Elixier des Lebens", das alle Krankheiten heilen würde. Allein der Glaube an das Wort Gottes ist es, der das verschaffen kann. Das ist eine Absage an alle die Dinge, die Figulus in der Widmung seiner Thesaurinella von der paracelsistischen Medizin versprochen hatte. Es verwundert deshalb auch nicht, dass Maier für diesen Paracelsismus nichts übrighat. Im Gegenteil, mit Thomas Erastus zitiert er zustimmend den schärfsten Gegner der Paracelsisten. Ganz wie Landgraf Moritz oder Daniel Sennert akzeptiert er die medizinisch-chemischen Innovationen des Paracelsus, hatte aber für deren theologische Ausdeutung nichts übrig. ${ }^{102}$

\section{Zusammenfassung}

Ausgehend von der Rezeptionsgeschichte des Alphidius und des Lamspring habe ich zu zeigen versucht, dass die Rätselhaftigkeit dieser (al)chemischen Texte um 1620 ein entscheidendes Element ihrer Wirkung darstellt: Diese Texte werden nicht trotz ihrer Rätselhaftigkeit abgedruckt, sondern wegen ihrer Rätselhaftigkeit. Dabei kann diese Rätselhaftigkeit verschiedene Funktionen erfüllen. In der Dyas chymica des Johannes Rhenanus ist der Lamspring Ausdruck einer spielerischen Vergegenwärtigung biochemischer Beobachtungen, die den natürlichen Kreislauf von Zersetzungsprozessen und der Entstehung neuen Lebens betreffen. Aufgrund dieser biochemischen Einsichten genauso wie aufgrund seiner Deutschsprachigkeit ist der Lamspring ein Argument und Beleg für die wissenschaftlichen und literarischen Interessen des Mittelalters, das damit zu Unrecht gegenüber der Antike abgewertet wird. Dieser Kulturpatriotismus entspricht den Impulsen der „Fruchtbringenden Gesellschaft“ genauso wie Opitz' Buch von der deutschen Poeterey. Die buchkünstlerisch aufwändige Gestaltung des Lamspring im Verlag von Lucas Jennis ist ein weiteres Argument in diesem Sinne.

In der Thesaurinella olympica des Benedict Figulus sind dieselben Texte dagegen Zeugen einer zunehmenden Offenbarung eines göttlichen Wissens, das in der Person des Paracelsus seinen großen Verkünder gefunden hat und dessen vollständige Offenbarung (vgl. 1. Kor. 13: „Wir sehen jetzt durch einen Spiegel in einem dunklen Bild; dann aber von Angesicht zu Angesicht.") mit der Wiederkehr eines „Elias Artista“ und der Apokalypse identisch ist. Ihre Rätselhaftigkeit ist Ausdruck einer sich zunehmend enthüllenden Präsenz des göttlichen Geistes, die sich vor allem in der Entdeckung lebensverlängernder Medikamente vollzieht.

Beide Rezeptionsformen können nicht streng getrennt werden, schon deshalb, weil sie sich im selben historischen Kontext vollziehen, in diesem Fall am Hof des Landgrafen Moritz von Hessen-Kassel. Sie existieren nebeneinander: Figulus

101 Michael Maier: Atalanta fugiens. Oppenheim 1618, S. 113. Vgl. dazu die ausführliche Argumentation in Volkhard Wels: Manifestationen des Geistes. Frömmigkeit, Spiritualismus und Dichtung in der Frühen Neuzeit. Göttingen 2014, S. 189-232.

102 Vgl. in diesem Sinne bereits Leibenguth: Maiers Cantilenae (Anm. 40), S. $72 \mathrm{f}$. 
verkauft dem Landgrafen alchemische Handschriften, Rhenanus überwacht seine chemischen Labore. Es sind dieselben (al)chemischen Prozesse, an denen Figulus und Rhenanus arbeiten. Dennoch verläuft eine frömmigkeitsgeschichtliche Trennlinie zwischen beiden, die man nicht unterschätzen sollte. Die calvinistische Konfession und Frömmigkeit des Landgrafen macht sich gerade darin bemerkbar, dass dem chemischen Wissen als einem Naturwissen keine religiöse Bedeutung beigemessen wird. Ein, wenn nicht das entscheidende Indiz dafür ist die Einstellung zu Paracelsus und zum Paracelsismus. Anders als für Figulus ist die (Al) Chemie für Moritz, Rhenanus und Maier nirgendwo mit irgendwelchen religiösen Heilserwartungen verbunden. Paracelsus wird als Reformer der Medizin wahrgenommen, nicht als „Gesandter vnnd zeuge Gottes", der im Paradies am Tisch Jesu Christi Engelbrot isst. ${ }^{103}$

103 So wiederum Figulus, vgl. Corpus Paracelsisticum (Anm. 18), Bd 3, S. 1072. 


\title{
Wer weckt mich?
}

\section{Die Geheimnishaftigkeit der Wächterstimme im geistlichen Wecklied Jch wachter (RSM PeterA/3/1h)}

\author{
Susanne Reichlin
}

Bergmanns Das siebente Siegel von 1957 ist in einer Zeit der Pest und der Kreuzzüge angesiedelt. Der Ritter Antonius Block kommt aus dem Heiligen Land zurück und trifft am Strand auf den personifizierten Tod, der ihm sagt, dass seine Zeit abgelaufen ist. Block schlägt dem Tod eine Partie Schach vor, bei der er, solange sie spielen, am Leben bleibt. Nachdem die Schachpartie für Block ganz gut verläuft, beginnt er in einer Kirche spontan, einem Mönch zu beichten. Allerdings spricht er nicht von seinen Sünden, sondern von seinen Glaubenszweifeln. Während Block nur die schwarze Kutte des Beichtnehmers sieht, gibt die Kamera bald schon den Blick auf dessen Gesicht frei. Die Zuschauer erkennen, dass er mit dem Tod spricht. Block erzählt im Verlauf der Beichte auch von seinem Schachspiel und plaudert auf Nachfrage seine Strategie und die Fehler seines Gegners aus. Der Beichtnehmer bedankt sich für den Hinweis und zeigt sein Gesicht.

In dieser Szene werden mehrere Arten von Verbergen und Enthüllen, Geheimnis und Enträtselung miteinander verknüpft. Am Ausgangspunkt des Beichtgesprächs steht die Verborgenheit Gottes. Diese ist - in diesem von den modernen Fragen des Protestanten Bergmann geprägten Film - nicht Grundlage des Glaubens, sondern Ursprung der Glaubenszweifel. Block beschreibt Gott als eine „gaukelnde Wirklichkeit, die ich nicht loswerden kann". ${ }^{1}$ Vor seinem Tod möchte er einzig noch wissen, ob es Gott als verborgenen gibt oder ob dieser bloß eine Projektion seiner eigenen Ängste und Wünsche ist. Die Unergründbarkeit Gottes und die Unergründbarkeit des Ich werden so aufs engste miteinander verknüpft. Filmisch wird die Unzugänglichkeit des menschlichen Innens durch die Großaufnahme des Gesichts von Block (Hans von Sydow) dargestellt. Je näher die Kamera an die Figur heranfährt, umso unlesbarer wird sie. Der Tod ist dabei Verbergender und Enthüllender zugleich. ${ }^{2}$ Er bringt Block dazu, Gott und sein eigenes Innen zu ergründen, entzieht ihm aber jede letztgültige Sicherheit. Nur für das Publikum hebt sich aus den vielen unklaren Zeichen und Unsicherheiten eine Gewissheit

1 Ingmar Bergman: Das siebente Siegel. Drehbuch. Hg. von Enno Patalas. Hamburg 1963, S. 22.

2 Christian Kiening: Ingmar Bergman: Das siebente Siegel (1957) und Die Jungfrauenquelle (1960). In: Mittelalter im Film. Hg. von dems. und Heinrich Adolf. Berlin 2006, S. 249-281, hier S. 259; vgl. auch Christian Kiening: Das andere Selbst. Figuren des Todes an der Schwelle zur Neuzeit. München 2003, S. 7-69. 
hervor: Blocks Begehren nach Wissen. Dieses treibt ihn dazu an, immer von Neuem nach Antworten zu suchen. Darstellungstechnisch betrachtet werden so die Unergründbarkeit von Gott und Ich mit Hilfe von Blocks Begehren nach Wissen dargestellt.

Gemäß der eigenwilligen Darstellung von Jolles gründen Rätsel und Mythe ${ }^{3}$ auf der "Wißbegierde": ${ }^{4}$ Erst dadurch, dass es ein Begehren nach Wissen gibt oder dieses durch Fragen und andere ,Geheimnistuerei' geschürt wird, wird aus dem Unbekannten ein Geheimnis. ${ }^{5}$ Es ist deshalb zwischen dem semantischen Gehalt des Geheimnisses und der Performanz des Geheimnishaften (wie etwas zum Geheimnis stilisiert wird) zu unterscheiden. ${ }^{6}$

In der geschilderten Szene werden Geheimnisse (semantischer Gehalt) und die Performanz der Geheimnishaftigkeit auf mehreren Ebenen miteinander verknüpft. Auf der Ebene der Diegese treffen zwei Wissbegierige (der Tod und Block) aufeinander. Sie wollen je ein ganz anderes Geheimnis (Schachspielstrategie und Existenz Gottes) enthüllen. Auf der Ebene der filmischen Präsentation wird die Verkleidung des Todes den Rezipienten zwar früh als diabolische Strategie enthüllt, doch wissen sie dadurch auch, dass Blocks Gegner das Gespräch lenkt. Die großen Sinnfragen, die Block stellt, sind so immer auch durch den Tod hervorgelockt, allenfalls Teil seiner ,Gaukelei'. Auch auf der Ebene der filmischen Präsentation wird somit verhüllt und enthüllt. Die Existenz Gottes und das eigene Ich werden zu den großen, nie zu klärenden Unergründbarkeiten stilisiert, die durch das Faktum des Todes aufeinander bezogen, aber nicht geklärt werden können. Ob die Geheimnishaftigkeit Gottes auch einen semantischen Gehalt hat, bleibt dabei offen.

Von dieser dezidiert modernen Aneignung des Spätmittelalters ausgehend möchte ich den Blick auf Texte des 15. Jahrhunderts richten und untersuchen, inwiefern hier das eigene Ich befragt und zu einem Geheimnis gemacht wird?

3 André Jolles: Einfache Formen. Legende, Sage, Mythe, Rätsel, Spruch, Kasus, Memorabile, Märchen, Witz. 6. unveränderte Aufl. Tübingen 1982. Unter „Mythe“ versteht er eine „Offenbarung" durch eine nicht-menschliche Instanz, die Antwort auf eine menschliche Frage zur Beschaffenheit der Welt gibt, wie z. B. ein Orakel (S. 97-99).

4 Jolles: Einfache Formen (Anm. 3), S. 129.

5 Beim Rätsel ist es nach Jolles: Einfache Formen (Anm.3), S.134-139, so, dass einer, der im „Besitze des Wissens" ist, andere testet, ob sie dieses Wissen auch haben und ihm damit „ebenbürtig“ sind. Dieses Wissen ist Bedingung, um zu einer Gruppe von „Eingeweihten" zu gehören. Häufig beinhaltet aber die Antwort eines Rätsels auch ein neues, weiteres Rätsel (ebd., S. 146). Zur Unterscheidung von Geheimnis und Rätsel vgl. die Einleitung der Herausgeber*innen. Wie in diesem Beitrag zu zeigen sein wird, sind die performativen Sprechgesten, d.h. die Art und Weise, wie etwas zu einem Geheimnis oder einem Rätsel stilisiert wird, bei Geheimnis und Rätsel ähnliche (unten Anm. 23). Die damit verknüpften sozialen Praktiken sowie der epistemologische Status sind jedoch meist unterschiedlich.

6 Andrew Johnston sprach in seinem Vortrag (der leider nicht in diesem Band publiziert werden kann) von einem Paradox: Das Geheimnis verbirgt etwas. Doch ohne den performativen Hinweis darauf, dass es ein Geheimnis gibt, nimmt man es nicht wahr, bleibt es etwas Unbekanntes. 
Um dieser Frage nachzugehen, möchte ich ein geistliches Tagelied in seinem Überlieferungskontext genauer untersuchen. Diese Lieder haben ihren Namen dadurch erhalten, dass eine häufig als „wahter“ bezeichnete Stimme einen schlafenden Sünder weckt, ihm das Nahen des Tages ankündigt und ihn zu Umkehr, Reue und Buße mahnt. ${ }^{7}$ Es handelt sich um eine sehr heterogene Textgruppe, deren Gemeinsamkeit sich häufig auf das Wächtermotiv und den refrainartigen Ruf „wach uff" beschränkt. ${ }^{8}$ Da die bisherige Forschung sich vor allem auf die Umbesetzung von Motiven weltlicher Tagelieder sowie auf Gattungsfragen konzentriert hat, ${ }^{9}$ kamen viele andere Aspekte der Lieder nicht in den Blick. Insbesondere die Wächterfigur wurde bis jetzt kaum untersucht.

Die weckende und rufende Stimme wird gewöhnlich nicht näher eingeführt, sie charakterisiert sich nur durch ihre eigenen Aussagen, die sich von Strophe zu Strophe ändern. Sie ist also notorisch unterbestimmt und dadurch wandelbar. Auch in dem hier untersuchten Lied ist das so, wie im ersten Abschnitt genauer zu zeigen sein wird. Allerdings gibt es von dem mehrheitlich dreistrophig überlieferten Lied eine Fassung mit drei Zusatzstrophen, die die Unbestimmtheit der Wächterfigur zum Thema machen. In diesen Zusatzstrophen, die im zweiten Teil untersucht werden, fragt der Sünder, wer denn hier spricht, weckt und mahnt. Die Wächterfigur wird so plötzlich zu etwas Geheimnisvollem, der Sünder vermutet, es handle sich um den Tod. Als die Stimme dann antwortet, ist die Erklärung auf den ersten Blick erstaunlich modern. Die Wächterstimme sei Teil des Sünders, sein "gaist", also eine innere Wächterinstanz. Ähnlich wie bei Bergmann wird so die Frage nach einer äußeren, transzendenten Instanz umgelenkt in die Frage nach dem Innern des Menschen. Doch anders als bei Bergmann wird das menschli-

7 Die geistlichen Wecklieder wurden von Theodor Kochs: Das deutsche geistliche Tagelied. Münster 1928 als geistliche Tagelieder benannt und von André Schnyder: Das geistliche Tagelied des späten Mittelalters und der frühen Neuzeit. Textsammlung, Kommentar und Umrisse einer Gattungsgeschichte. Tübingen u. a. 2004 kürzlich neu herausgegeben und kommentiert. Meines Erachtens ist die Textgruppe zu heterogen, um von einer Gattung sprechen zu können; so auch Uwe Ruberg: Gattungsgeschichtliche Probleme des ,geistlichen Tagelieds' - Dominanz der Wächter- und Weckmotivik bis zu Hans Sachs. In: Traditionen der Lyrik. Festschrift für Hans-Henrik Krummacher. Hg. von Wolfgang Düsing. Tübingen 1997, S. 15-29, hier S. 18-20; anders jedoch Schnyder: Tagelied (Anm. 7), S. 541-636.

8 Kochs: Das geistliche Tagelied (Anm.7) und Ruberg: Gattungsgeschichtliche Probleme (Anm. 7), S. 18-20, zeigen, dass die Weckrufe bereits die lateinische Hymnendichtung prägen, später finden sie sich auch in Erzählungen und Spielen vom Jüngsten Gericht; vgl. Belege bei Petra Hörner: Das Tagelied von Gott unter besonderer Berücksichtigung der Revaler Fassung. In: Begegnung mit Literaturen. Festschrift für Carola L. Gottzmann zum 65. Geburtstag. Hg. von ders. Berlin 2008, S. 215-250, hier S. 239-241. Zum Motiv des Sündenschlafs s. u. Anm. 13.

9 Martina Probst: Nu wache ûf, sünder traege. Geistliche Tagelieder des 13. bis 16. Jahrhunderts. Analysen und Begriffsbestimmung. Frankfurt a. M. u. a. 1999, insb. S. 81-90; zu den Tageliedern von Hugo von Montfort Jan Mohr: Textreihe und Gattungsstrukturen. Zur Tageliedrezeption in Hugos von Montfort cpg 329. In: Beiträge zur Geschichte der deutschen Sprache und Literatur 138 (2016), S. 76-106; Sylvie Stanovská: Geistliches Tagelied - eine Gattung der Spätzeit. Eine vergleichende Darstellung anhand zweier Textbelege. In: Brünner Beiträge zur Germanistik und Nordistik 22 (2008), S. 27-36. 
che Innere nicht zu etwas Unergründbarem, sondern das Innere soll transparent werden. Im dritten Teil ist deshalb ausgehend von den handschriftlichen Kotexten nach dem diskursiven Kontext solcher Selbstbeobachtungen und ihrer Ergründoder Unergründbarkeit zu fragen. Wann und weshalb wird das Innere des Sünders oder die Instanz der imaginierten Fremdbeobachtung zu etwas Geheimnisvollem?

\section{Allegorische Unbestimmtheit und raumzeitliche Überdetermination}

Das hier zu untersuchende Lied Jch wachter, ich solt wecken (RSM PeterA/3/1) ${ }^{10}$ ist in neun Handschriften überliefert, wobei die Strophenfolge der ersten drei Strophen in allen Handschriften identisch ist, nur zwei Handschriften bieten darüber hinaus Zusatzstrophen (siehe Abs. III). Ich folge dem von Schnyder edierten Text der Augsburger Handschrift UB III.1.4 37,11 der beginnt:

Jch wachter, ich solt wecken den sunder, der da rüsset ser, daz er sich tët erschrecken von seiner sunde schein.
Ich Wächter, ich sollte den Sünder wecken, der da (so) sehr schnarcht, damit er aufgrund des Scheins seiner Sünde aufschreckt. ${ }^{12}$ $(1,1-4)$

10 Repertorium der Sangsprüche und Meisterlieder des 12. bis 18. Jahrhunderts (RSM). Hg. von Horst Brunner und Burghart Wachinger. Bd.4. Tübingen 1988, S. 486-488. Zusätzlich zu den im RSM erwähnten Handschriften hat Michael Baldzuhn noch auf eine weitere dreistrophige Fassung in der Handschrift mgf 634 der Staatsbibliothek Berlin aufmerksam gemacht (fol. 123v); vgl. Michael Baldzuhn: Teichnerreden und Meisterlieder in einer Handschrift des Erfurter Kanonikers und Universitätsrektors Tilomann Ziegler (+1479). In: Zeitschrift für deutsches Altertum und deutsche Literatur 133 (2004), S. 151-176. In der Kolmarer Liederhandschrift (Cgm 4997, 826r; vgl. dazu Anm. 38), die nach Tonautoren geordnet ist, heißt es in der Überschrift: Ein ander tagwyss graff peters von arberg. In allen anderen Handschriften ist das Lied anonym überliefert. Volker Mertens: [Art.] Peter von Arberg. In: Verfasserlexikon. 2. Aufl. Bd. 7. Hg. von Kurt Ruh u. a. Berlin u. a. 1989, Sp. 426-429, hier Sp. 428, vermutet als Tonautor den Solothurner Graf Peter II. von Aarburg. Vgl. zu dieser Frage auch Volker Mertens: Peter von Aarberg, Minnesänger. In: Zeitschrift für deutsches Altertum und deutsche Literatur 101 (1972), S. 344-357; Walter Röll: Oswald von Wolkenstein und Graf Peter von Arberg. In: Zeitschrift für deutsches Altertum und deutsche Literatur 97 (1968), S. 219-234, hier S. 223-225; Karl Bartsch: Die romanischen und deutschen Tagelieder. In: Gesammelte Vorträge und Aufsätze. Hg. von dems. Freiburg i. Br. u. a. 1883, S. 250-317, hier S. 305f.

11 Schnyder: Tagelied (Anm. 7), S. 21f.; zur Hs. siehe unten Anm. 49. Vgl. die Edition von den drei Handschriften mit Noten in: Geistliche Gesänge des deutschen Mittelalters (GGdM). Melodien und Texte handschriftlicher Überlieferung bis um 1530. Bd. 3: Gesänge I-M (Nr. 331-536). Hg. von Max Lütolf. Kassel u. a. 2009, Nr. 370, S. 65-67 sowie die Paralleledition von fünf Handschriften bei Thomas Cramer: Die kleineren Liederdichter des 14. und 15. Jahrhunderts. Bd. 2. München 1979, S. 434-442.

12 Übers. hier und im Folgenden von der Verfasserin. Vgl. auch die Übersetzung der Fassung der Mondsee-Wiener Liederhandschrift (vgl. dazu Anm. 41) bei Eva Willms und Hansjürgen Kiepe: Gedichte 1300-1500. München 1972, S. 100f. 
Die Sprechinstanz benennt sich selbst und erklärt ihre Aufgabe: den nicht näher charakterisierten, schlafenden Sünder zu wecken. ${ }^{13}$ Anders als in vielen anderen Liedern wird der Sünder somit nicht direkt angesprochen, sondern der Wächter kündigt sein Tun zuerst an. Der "schein“ der Sünde ruft die Hell-Dunkel-Metaphorik auf, die das gesamte Lied prägen wird, jedoch in je anderen Ausgestaltungen. Hier ist es das gleißende Licht der Sünde, das den Sünder erschreckt. Konträr zum Topos des sündenreinigenden Lichts geht es hier um ein Licht, das von der Sünde ausgeht und das den Sünder blendet. ${ }^{14}$

Im zweiten Stollen wird das gleißende Licht der Sünde dann zum Licht des Tagesanbruchs: „Es nahet gen dem morgen, / das got, der hochgelopte her, / günd switzen vnde sorgen / vff seines todes pein“ (1,5-8; „Es naht der Morgen, als Gott, der hochgelobte Herr, zu schwitzen und sich wegen seiner Todesqual Sorgen zu machen begann"). In einem stärker erzählenden Duktus wird das Gebet Jesu im Garten Gethsemane (Mt 26,36-46; Mk 14,32-42; Lk 22,39-46) mit dem Tagesanbruch verknüpft: ${ }^{15}$ Anstelle der Jünger wird im Lied jedoch der Sünder angesprochen: "Ach sunder, daz dü nicht enmacht / ein wilin mit im wachen" (1,9f.; "Ach Sünder, dass du nicht eine kurze Weile mit ihm zu wachen vermagst"). Der Sünder wird in der Gethsemane-Szene verortet, um so die Dramatik des Verschlafens zu steigern: Der Sünder schläft nicht irgendwann, sondern zu der Zeit, als Gott für ihn leidet. Auf der Bildebene werden mindestens drei Bildbereiche, das gleißende Licht der Sünde, das Verschlafen (Gethsemane) und der Tagesanbruch, miteinander fusioniert. Auf der hermeneutischen Ebene wird die abstrakte SündenschlafAllegorie durch den Bezug zur Passionsgeschichte historisch und raumzeitlich konkretisiert - zugleich wird die biblische Szene mit anderen Rollen (Sünder statt Jünger) vergegenwärtigt. Deshalb ist vom Passionsgeschehen in der ersten Strophe sowohl von einem gleichzeitigen $(1,5-8)$ als auch von einem früheren, bereits vollbrachten die Rede: Vom Tod, „den Ef dir het gemacht“ $(1,15)$, ist der Sünder

13 Das Motiv des Sündenschlafs geht auf eschatologische Vorstellungen zurück, in denen das Wachen wichtig ist, um das Kommen des Herrn nicht zu verpassen; vgl. Mt 24,42-44; Mk 13,33-36; Lk 12,35-48; Röm 13,11; 1 Thess 5,6; Eph 5,14; vgl. Erika Dinkler-von Schubert: [Art.] Schlaf. In: Lexikon der christlichen Ikonographie. Bd. 4. Hg. von Engelbert Kirschbaum u. a. Rom u. a. 1972, Sp. 72-75. In der späteren Tradition wird daraus das Motiv des Schlafs als Heilsversäumnis (vgl. auch Mk 14,38), das auch in der Volkssprache gut verankert ist (u. a. Anton E. Schönbach: Altdeutsche Predigten. Bd.2. Graz 1888, Nr. 5; 1 Rumelant, 11/2; Ps. Frauenlob, Langer Ton, k 81-83).

14 Zum sündenreinigenden Licht: Meinolf Schumacher: Sündenschmutz und Herzensreinheit. Studien zur Metaphorik der Sünde in lateinischer und deutscher Literatur des Mittelalters. München 1996, S. 343. Denkbar sind an der zitierten Stelle jedoch Bezüge zur Metapher des ,Zunders der Sünde' (fomes peccati); vgl. dazu Friedrich Ohly: Metaphern für die Sündenstufen und die Gegenwirkungen der Gnade. Opladen 1990, S. 41-45.

15 Jesus fürchtet sich und bittet die Jünger, mit ihm zu wachen („vigilate mecum“ Mt 26,38), findet sie aber schlafend. Nicht nur in geistlichen Liedern, sondern auch ikonographisch hat dieses Motiv im Spätmittelalter Hochkonjunktur; vgl J. Thüner: [Art.] Ölberg. In: Lexikon der christlichen Ikonographie. Bd. 3. Hg. von Engelbert Kirschbaum u. a. Rom u. a. 1971, Sp. 342 349, hier Sp. 344. Im biblischen Text ist vom Tagesanbruch nicht die Rede, auch die ikonographische Tradition stellt die Szene tendenziell als „Nachtstück“ dar (ebd., Sp. 348). 
bereits erlöst. Deshalb ist, wie später betont wird, bei rechtzeitiger Umkehr Sündenvergebung möglich (3,12-15).

Der in der ersten Strophe angekündigte Weckruf $(1,1)$ erfolgt am Beginn der zweiten Strophe:

Nü wach auff, sunder trege, gedencka hinder dich vnd für, wie hert es dir nü lege, ob er dich slaffent fünde.
Nun wach auf, träger Sünder, bedenke sorgfältig, wie schlimm es für dich wäre, wenn er dich schlafend finden würde.

$(2,1-4)$

Der Sünder wird geweckt, jedoch nicht zum Aufstehen oder Wachen aufgefordert, sondern zur Reflexion (,gedencka“) ermahnt. Die Bildlichkeit der ersten Strophe wird dabei pointiert verschoben, wie anhand des Pronomens "er" deutlich wird: Anaphorisch verweist das „er" auf Jesus im Garten Gethsemane, der für den Sünder gestorben ist und ihn von der Erbsünde erlöst hat. ${ }^{16}$ Wenn es in der zweiten Strophe heißt: „wie hert es dir nü lege, / ob er dich slaffent fünde“ (2,3f.), wird darauf erneut angespielt, aber nur, um sogleich mit dieser Kontextualisierung zu brechen: Das „,er“ wird nämlich kataphorisch ganz anders bestimmt:

Der dein so dick laget, den got ein lat durch beslossen tür $[\ldots]$ wann dü nit waist die stünd, Wann du waist leider nit wie ald wa dein leben hat ein ende. ${ }^{17}$
[D]er dir so häufig auflauert, den Gott durch verschlossene Türen hereinlässt. [...] Denn du kennst die Stunde nicht, du weißt leider nicht, wie oder wo dein Leben ein Ende nimmt.

$(2,5-10)$

,[E]r" ist nicht mehr Jesus, sondern der Tod, der den Sünder jederzeit heimsuchen kann. Das Herannahen ist nun unabhängig von der Tageszeit.

Die raumzeitliche Verortung des Sündenschlafs hat sich somit unter der Hand verändert. Der Schlaf wird nicht mehr mit der Passionsgeschichte, sondern mit dem individuellen Lebensverlauf parallelisiert. Der Tod, der diesem Leben ein Ende setzt, wird als unaufhaltbare und undurchschaubare Instanz beschrieben. Diese Undurchschaubarkeit interessiert vorerst allerdings nicht in ihrer Geheimnishaftigkeit, sondern sie wird sogleich funktionalisiert: „riht dich hie“ $(2,11)$, tue Beichte und Buße, damit du ins Himmelreich kommst (2,12f.).

16 ,[D]er durch dich ein so lange nacht / vor angst müest dick erkrachen, / den sterbens durch dich nÿe verdroß, / vnd der dich tet des todes ploz, den Ef dir het gemacht.“ (1,11-15; ,,der um deinetwillen eine ganze Nacht in Angst zitterte, dem es nicht zu viel war, für dich zu sterben, und der dich vom Tod, den Eva dir eingehandelt hat, erlöst hat").

17 Textrekonstruktion von Schnyder, in der Hs. steht „wann du waist leider wa ald wie dein leben [...]" (fol. 292v). 
Die Strophe endet mit der direkten Ansprache an den Sünder: „weder slaffst oder hastü mich vernomen? / das laß mich wissen hie“ (2,14f.; "Schläfst du oder hast du mich gehört, das tue mir jetzt kund"). Spielerisch wird so erneut die davor entworfene Szene aufgehoben: Nun ist es nicht mehr der Tod, der den Sünder schlafend vorfindet, sondern die Sprechinstanz, die an die Aufmerksamkeit des Sünders appelliert. Zugleich werden damit auch die Rezipienten angesprochen und gefragt, ob sie zuhören. Aufführungssituation und Sündenschlaf-Allegorie werden so effektvoll überblendet. Denn sobald sich die Rezipienten angesprochen fühlen, werden sie zu Sündern, die noch nicht aus dem Sündenschlaf aufgewacht sind.

„Ach waffen, ymmer waffen, / sunder, wie sol ich wecken dich" (3,1f.; "Ach Hilfe, und immer wieder Hilfe, Sünder, wie soll ich dich wecken“?). Die Wächterstimme klagt, dass es ihr nicht gelingt, den Sünder zu wecken. Wie in den anderen Strophen kommt hier eine neue raumzeitliche Kontextualisierung dazu: Der Sünder darf nicht schlafend vorgefunden werden, denn er soll dem "here“ $(3,3)$ wach begegnen. Dann werde er von Gott „schon[e]“ empfangen (3,15). Dieses Versprechen wird zugleich mit Drohungen verknüpft. Kommt der Schlafende "ze spat" $(3,10)$, dann erhält er keinen Lohn $(3,11)$ und wird es bereuen $(3,4)$ : „Derschell aber ich meinz horns dön, / mein warnug chumpt ze spat“ (3,9f.; "Lasse ich aber den Ton meines Horns erklingen, kommt meine Warnung zu spät“). Mit dem Klang des Horns und der Rede von der Ankunft des Herrn wird der Sündenschlaf durch das Endgericht kontextualisiert. ${ }^{18}$ Wenn der Schlafende erst mit den Toten beim Jüngsten Gericht wach wird, ist es zu spät, die Umkehr muss davor bzw. noch im Leben statthaben. ${ }^{19}$ Die eschatologischen Motive dienen als Drohkulisse, um den Sünder zur Umkehr zu bewegen. Das Ende der Strophe und der dreistrophigen Fassungen ist jedoch eine Verheißung: Der Sünder wird von Gott empfangen, die Sünden werden ihm vergeben und es erwartet ihn der himmlische Lohn. ${ }^{20}$

In den ersten drei Strophen wird die Unbestimmtheit der Sündenschlaf-Allegorie somit von Strophe zu Strophe neu kontextualisiert. Im Verlauf des Liedes

18 Belege zu ausführlichen spätmittelalterlichen Beschreibungen des Endgerichts bei Hörner: Das Tagelied von Gott (Anm. 8), S. 239-241. Vgl. zudem Reinhard Schwarz: Die spätmittelalterliche Vorstellung vom richtenden Christus - ein Ausdruck religiöser Mentalität. In: Geschichte in Wissenschaft und Unterricht 32 (1981), S. 526-553, hier S. 537; Egon Brandenburger u. a.: [Art.] Gericht Gottes. In: Theologische Realenzyklopädie. Bd.12. Hg. von Gerhard Müller u. a. Berlin u. a. 1984, S. 459-497, hier S. 483-488.

19 Schwarz: Vorstellung vom richtenden Christus (Anm. 18), S. 539-541.

20 Kolmarer Liederhandschrift zitiert nach GGdM (Anm. 11), S. 67 [dort Sigle C], III,13-15,,vnd wach üff, es ist an der zit! / Got dir dine sünde vergit: / kom, er enphahet dich schone!“. Ganz ähnlich wird der Lohn des Herrn auch in der Mondsee-Wiener Liederhandschrift versprochen (GGdM Sigle B): „stand auf vnd wach, es ist an der czeit, / wenn dir der herr den lon geit, / er kumpt vnd enphacht dich schon“" (III,13-15). Vgl. die ähnlichen Formulierungen in folgenden Fassungen (jeweils 3,14): Liederbuch der Clara Hätzlerin (Cramer [Anm. 11], Sigle D), Nürnberg GNM 3910 (Cramer, Sigle C) und das Eghenvelder Liederbuch (GGdM, Sigle A). Zu den einzelnen Handschriften siehe unten Anm. 38-43. Dieses Versprechen der Sündenvergebung fehlt in der hier untersuchten sechsstrophigen Fassung der UB Augsburg (vgl. dazu Anm. 49). 
ergibt sich so ein Bogen von der Passionsgeschichte zum individuellen Sterben bis hin zum Jüngsten Gericht und der Aufführungssituation. ${ }^{21}$ Die Dringlichkeit aufzuwachen ist deshalb so groß, weil der Sündenschlaf nicht nur in einer dieser Zeiten, sondern in allen zugleich statthat. Die Wachsamkeit, die vom Sünder erwartet wird, ist eine je unterschiedliche: In der ersten Strophe geht es um die Aufmerksamkeit für das Leiden des Herrn (und dessen Vergegenwärtigung), in der zweiten Strophe um Aufmerksamkeit für die eigene Sündhaftigkeit und das Nahen des Todes und in der dritten Strophe um die Aufmerksamkeit für die Ankunft des Herrn respektive für die Strafen und die Gnade des Richtenden.

Spätestens in der dritten Strophe betrifft diese je neue raumzeitliche Kontextualisierung des Sündenschlafs auch die Wächterinstanz. Sie ist nicht nur irdische Warn- und Mahn- und allenfalls Sängerinstanz, sondern sie präsentiert sich auch als Hornbläser am Ende der Zeit. Damit erscheint der Wächter als eine sowohl irdische als auch überirdische Instanz, die den zeitlichen Bogen, der in den drei Strophen aufgespannt wird, zu überdauern vermag und die allen Zeiten sowie der Aufführungssituation angehört.

Insgesamt wird also die Unbestimmtheit von Sündenschlaf und Wächter genutzt, um sie immer wieder anders zu kontextualisieren. Strophenübergreifend handelt es sich in den ersten drei Strophen um eine Unbestimmtheit, die zwar moderne Rezipienten zu irritieren vermag, die aber vom Text nicht als geheimnishaft stilisiert wird. Es ist nun zu beobachten, wie sich das in der sechsstrophigen Fassung von 1481 ändert.

\section{Die allegorische Unbestimmtheit wird geheimnishaft}

Wer wecket mich so hart vnd gicht, ich welle sprechen nicht?

ich lig doch hie vnd wart seins weckens mich beuilt.
Wer weckt mich so heftig und behauptet, ich würde nicht sprechen?

Ich liege doch hier und achte verdrossen auf sein Wecken?

\section{$(4,1-4)$}

In der vierten Strophe ${ }^{22}$ der Augsburger Handschrift kommt es zu einem effektvollen Sprecher- und Perspektivenwechsel. Statt des Weckenden spricht nun der Geweckte. Er tritt jedoch nicht (bzw. noch nicht) als reuiger Sünder auf, sondern als einer, der sich ob des wiederholten Weckrufs ärgert. Er widerspricht den Aussagen des Wächters: Er sei keineswegs schläfrig, sondern bereit zu sprechen $(4,2)$ und aufmerksam $(4,3)$. Zudem fragt er zurück, wer denn hier eigentlich spricht. Er markiert so zum einen eine gewisse Ebenbürtigkeit, zum anderen äußert er ein

21 So auch Schnyder: Tagelied (Anm. 7), S. 201.

22 Nur zwei Handschriften haben mehr als drei Strophen und diese haben wiederum keinerlei Ähnlichkeiten miteinander (vgl. zur zweiten Hs. Anm. 40). Auch aus anderen Gründen spricht vieles dafür, dass es sich bei den Strophen 4-6 um Plusstrophen handelt. 
Begehren nach Wissen: Was bis jetzt vom Text unhinterfragt vorausgesetzt worden ist, die Unbestimmtheit und Wandelbarkeit der Wächterstimme, aber auch ihre Autorität und (transzendente) Allwissenheit, ruft nun die Wissbegierde des Angesprochenen hervor.

Mit der konkreten Frage, „Wer wecket mich“ $(4,1)$, verändert sich aber auch die Qualität der Unbestimmtheit der Wächterstimme. Wie bei einem Rätsel wird suggeriert, dass sich die Vieldeutigkeit in Eindeutigkeit, die Unbestimmtheit in Bestimmtheit auflösen lässt. ${ }^{23}$ Die Antwort bleibt im Text aber vorerst aus.

Dü, wachter, mir antwürte

des ich dich hie zesagen bitt: wer bistü, wann ich furchte, dü siest, der kurczeẅ zilt.
Du Wächter, beantworte mir, was ich dich nun bitte zu sagen. Wer bist du? Denn ich fürchte, du bist der, der es auf die Kürze abgesehen hat.

$(4,5-8)$

Der Sünder wiederholt seine Frage und bittet mit einer gewissen Dringlichkeit um Antwort. Die Dringlichkeit ergibt sich aus der Furcht vor dem Verborgenen. Der Sünder vermutet, der personifizierte Tod spreche zu ihm, so wie dies in der zweiten Strophe beschrieben worden ist. Auch in den spätmittelalterlichen Quellen tritt der Tod häufig in Verhüllungen auf, ${ }^{24}$ und die Begegnung mit dem Tod oder den Toten wird durch rätselhafte Zeichen vorbereitet, deren Mehrdeutigkeit durch das Auftreten des Todes oder der Toten aufgehoben und in Eindeutigkeit überführt wird. ${ }^{25}$ Allerdings sind Wächter und Tod in der zweiten Strophe zwei getrennte Instanzen. Indem der Sünder hier den Wächter als den Tod und damit als eine ihn bedrohende Instanz deutet, ${ }^{26}$ wird die Wächterfigur mehrdeutiger

23 Bei Jolles: Einfache Formen (Anm.3), S. 129, definiert sich das Rätsel dadurch, dass es zur Frage eine Antwort gibt, auch wenn der Ratende sie allenfalls nicht kennt. Damit rückt die Frage des Sünders in die Nähe eines Rätsels, doch wird die Frage in unserem Text nicht wie beim klassischen Rätsel vom Wissenden, sondern vom Unwissenden gestellt. Auf der Ebene der Performanz funktionieren Geheimnis und Rätsel ähnlich. Das Fragen sowie das Begehren nach Wissen stilisieren etwas zu einem Geheimnis oder einem Rätsel, erst die sozialen Praktiken und der epistemologische Status des Verborgenen unterscheiden sie dann wieder.

24 Kiening: Das andere Selbst (Anm. 2), S. 47-65; siehe zudem unten Anm. 47.

25 Vgl. u. a. Die Begegnung der drei Lebenden und der drei Toten. Eine Edition nach der maasländischen und ripuarischen Überlieferung. Hg. von Helmut Tervooren und Johannes Spicker. Berlin 2011, insbesondere V.60-88. Es gehört auch zur üblichen Aufgabe von sprechenden Toten, die Lebenden daran zu erinnern, dass der Tod jederzeit eintreten kann und sie deshalb ihre Sünden bereuen sollen; vgl. z. B. ebd., V. 156-198, oder Heinrich von Melk: Von des todes gehugde - Mahnrede über den Tod. Mhd./Nhd. Hg. von Thomas Bein und Susanne Kramarz-Bein. Stuttgart 1994, V. 877.

26 Ähnliches konnten wir bereits in der dritten Strophe beobachten. Die Wächterfigur war in dieser Strophe nicht mehr nur eine (von außen) beobachtende und warnende Instanz, sondern sie wurde als Hornbläser zu einem Teil des entworfenen Endzeitgeschehens. 
und geheimnisvoller, als sie es in der dreistrophigen Fassung war. ${ }^{27}$ Zugleich wird die Spannung auf die erhoffte Antwort durch die Furcht und die Mutmaßungen über die Identität des Wächters gesteigert:

Jch pin dein gaist, das sag ich dir. Ich bin dein Geist, das sage ich dir, dü hast zelang geslaffen; du hast zu lange geschlafen.

bereẅ dein sünde vnd volg

Bereue deine Sünde und tue, was ich sage, des mir

vnd hab in herczen straffen, und übe in deinem Herz Sühne. peicht vnd richt dich hie zü got Beichte und richte dich hier auf Gott hin oder dü wirst dort des teẅfels spot. aus oder du wirst dort zum Spott des Teufels.

Obwohl „gaist“ im Mittelhochdeutschen mehrdeutig ist (Seele, Gespenst, Geist Gottes) ${ }_{,}^{28}$ ist die Antwort des Wächters klar: Er erklärt, ein Teil des Sünders zu sein. Er wird damit zu einer inneren Beobachtungs-, Mahn- oder Gewissensinstanz. ${ }^{29}$ Der Wächter und das Wecken werden damit zu einem inneren Geschehen. Die Frage ,Wer bist $\mathrm{du}^{\prime}$ ist zur Frage ,Wer bin ich' geworden, die Fremdbeobachtung wird zur Selbstbeobachtung. Das Innere des Sünders wird zu einem vielstimmigen Innern, in dem unachtsame und wachende Instanzen miteinander sprechen. ${ }^{30}$ Verschläft der Sünder und verpasst er die Umkehr, so liegt dies auch an der mangelnden Selbstüberwachung.

27 Georg Simmel: Das Geheimnis. Eine sozialpsychologische Skizze. In: Aufsätze und Abhandlungen, 1901-1908. Hg. von Alessandro Cavalli und Volkhard Krech. Frankfurt a. M. 1993, S.317-323, hier S.319, beschreibt etwas Ähnliches, führt es jedoch auf psychologische oder sozialpsychologische Ursprünge zurück: „Der natürliche Idealisierungstrieb und die natürliche Furchtsamkeit des Menschen wirken dem Unbekannten gegenüber zu dem gleichen Ziele, es durch die Phantasie zu steigern und ihm einen Aufmerksamkeitston zuzuwenden, den die offenbarte Wirklichkeit meistens nicht gewonnen hätte."

28 Der „geist“ steht für die Seele bzw. stellt das dar, was beim Tod den Körper verlässt; vgl. Walther L 78,7. Er ist aber auch die körperlose Gestalt, der „unsihtic geist“ (Iwein, V. 1391). Vgl. URL: http://www.mhdwb-online.de/wb.php?buchstabe=G\&portion=980 (23.08.2019).

29 Zur Geschichte des Gewissens und des Gewissensbegriffs, der sich im Deutschen erst im Spätmittelalter langsam durchsetzt, vgl. Mirko Breitenstein: Vier Arten des Gewissens. Spuren eines Ordnungsschemas vom Mittelalter bis in die Moderne. Mit Edition des Traktats De quattuor modis conscientiarum. Regensburg 2017, S. 12-40; Edith Feistner: Zur Semantik des Individuums in der Beichtliteratur des Hoch- und Spätmittelalters. In: Zeitschrift für deutsche Philologie 115 (1996), S. 1-17, hier S. 4-14; Uta Störmer-Caysa: Gewissen und Buch. Über den Weg eines Begriffes in die deutsche Literatur des Mittelalters. Berlin u. a. 1998.

30 Bereits in der Millstätter Sündenklage klagt der eine Teil des Körpers den anderen an; vgl. Die Millstätter Sündenklage. In: Die religiösen Dichtungen des 11. und 12. Jahrhunderts. Nach ihren Formen besprochen und hg. von Friedrich Maurer. Bd. II. Tübingen 1965, V. 416-427 u. ö. 
Diskursgeschichtlich lassen sich hier Bezüge zu den Diskussionen im Beichtund Bußdiskurs erahnen: ${ }^{31}$ Seit Abaelard ist einerseits die innere, volle Reue für die Vergebung der Sündenschuld nötig. Andererseits wird die Selbstbeobachtung durch die Einführung der jährlichen Ohrenbeichte und die Aufwertung der priesterlichen Absolution auch verstärkt institutionell gefördert. Reue und Beichte erfolgen nicht nur aus spontanem Sündenbewusstsein, sondern der einzelne Gläubige wird ab 1215 jährlich danach befragt. ${ }^{32}$ Aus dieser Perspektive kann das besprochene geistliche Wecklied als handlungsleitende Konkretisierung der institutionell geforderten Selbstbeobachtung verstanden werden. In der volkssprachlichen Lyrik wird so eine (Sprach-)Bildlichkeit ausgebildet, die es erst möglich macht, über Selbstbeobachtung zu sprechen. Indem das Lied gezielt nach dem Status der Wächterfigur - innere oder äußere Beobachtungsinstanz? - fragt, wird Selbstbeobachtung darüber hinaus auch diskutiert und reflektiert.

Doch muss die vierte Strophe immer auch im Kontext der Strophen 1-6 betrachtet werden. Wie in den vorangehenden Strophen wird die Wächterstimme auch in der vierten Strophe neu entworfen: Statt des enttäuschten, leidenden Christus, des drohenden individuellen Todes oder des Hornbläsers, der die Toten zum Jüngsten Gericht ruft, erscheint sie nur in der vierten Strophe als eine innere Beobachtungsinstanz. Die Antwort der Wächterstimme suggeriert somit eine Eindeutigkeit, die bei der Betrachtung des gesamten Liedes nicht gegeben ist. Denn das Lied entwirft insgesamt eine Wächterfigur, die zwischen transzendenter Fremd- und irdischer Selbstbeobachtung, zwischen einer fürsorgenden und einer überwachenden, zwischen einer äußeren und einer inneren Instanz changiert. Diese zugleich unter- und überdeterminierte Wächterstimme wird genau in dem Moment zu etwas Geheimnisvollem, als sie von einer äußeren zu einer inneren Instanz wird. Das Innere des Ich erscheint so dunkler als die transzendenten Beobachtungs- und Überwachungsinstanzen. Es wird aber anders als bei Bergmann nicht zu einem unlösbaren Mysterium, ${ }^{33}$ sondern die Selbstbeobachtung und Selbstüberwachung werden zur zentralen Aufgabe des um sein Seelenheil besorgten Gläubigen. Die Wächterstimme ist somit (anders als das FrageAntwort-Schema suggeriert) kein Rätsel, das in die eine oder andere Richtung aufgelöst werden kann, sondern die Aura des Geheimnisvollen entsteht dadurch, dass sie scheinbar Gegensätzliches verbindet.

31 Solche Bezüge werden im Rahmen eines von der DFG geförderten Teilprojekts „Wachsamkeit und Achtsamkeit. Literarische Dynamiken von Selbstbeobachtung und Fremdbeobachtung in mittelalterlicher deutschsprachiger Lyrik“ im SFB 1369 „Vigilanzkulturen“ untersucht (die Vf. leitet das Teilprojekt gemeinsam mit Beate Kellner).

32 Martin Ohst: Pflichtbeichte. Untersuchungen zum Bußwesen im Hohen und Späten Mittelalter. Tübingen 1995; Peter von Moos: „Herzensgeheimnisse“ (occulta cordis). Selbstbewahrung und Selbstentblößung im Mittelalter. In: Schleier und Schwelle. Bd. 1: Geheimnis und Öffentlichkeit. Hg. von Aleida Assmann und Jan Assmann. München 1997, S. 89-109, hier S. 97-105.

33 Vgl. auch Simmel: Geheimnis (Anm. 27), S. 322, der postuliert, „daß mit fortschreitender Kultur ursprünglich Offenbares geheim wird, ursprünglich Geheimes seine Verhüllung abwirft." 
Die Wächterstimme beantwortet die ,Wer bist du'-Frage zudem nicht nur semantisch, sondern auch performativ: Auf die kurze Antwort "Jch pin dein gaist" folgen Vorwürfe, Ermahnungen und Drohungen. Die abschließenden Strophen 5 und 6 spricht dann wieder der Sünder. Er stellt keine Fragen mehr, sondern beschreibt seine Reaktion auf die Mahnworte des Wächters: Jch sunder bin erwachet;
mein leib, der ist erschrocken ser;
mein hercz, das ist erkrachet
von deinen worten swer
Ich Sünder bin erwacht, mein Leib ist sehr erschrocken, mein Herz ist fast zerbrochen an deinen erdrückenden Worten.

$(5,1-4)$.

Indem der Geweckte sich nun als Sünder bezeichnet, offenbart er eine Selbsterkenntnis, die in der vierten Strophe noch gefehlt hat. Er führt sein Aufschrecken explizit auf „,deine[ ] worte[ ]“, also die Worte des Wächters, zurück, den er damit adressiert. Wächterstimme und Sünderstimme bleiben so einerseits unterscheidbar. Andererseits greifen die Aussagen des Sünders auffällig häufig die Worte des Wächters auf: Der Wächter kündigte an, den Sünder zu „erschrecken“ (1,3), und dieser beschreibt nun, wie er „erschrocken“ ist $(5,2)$. Der Wächter warf dem Sünder vor, „zelang geslaffen“ $(4,10)$ zu haben, der Sünder betont, er habe „gar verslaffen“ $(5,9){ }^{34}$ In der fünften Strophe mahnt der Sünder Gott, er solle daran "gedenck[en]", dass er ihn bereits durch großes Leid am Kreuz erlöst habe, und ihm deshalb erneut helfen (5,11-15). Damit benutzt er die Argumente des Wächters in 1,13f. Die Haltung und Sprechweise des Sünders haben sich somit im Übergang von der vierten zur fünften Strophe radikal geändert. Der Sünder ärgert sich nicht mehr über den Wächter, sondern macht sich dessen Argumente zu eigen und spricht zum und über den Wächter. Neben der nominellen gibt es so auch eine performative Antwort auf die ,Wer bist du'-Frage: Die internalisierte Wächterinstanz zeigt sich dann, wenn sie den Sünder zu bekehren vermag, wenn sie in ihm wirksam ist.

In der sechsten Strophe bittet das Ich Maria um Hilfe. Vom Gespräch mit dem Wächter ist als einem vergangenen und abgeschlossenen die Rede, das die Reue ermöglicht hat: „Mich hieß der wachter rë̈en [...] / ich hon em gancz getraẅen“ (6,5-7; „Der Wächter gebot mir Reue, ich bin ihm darin vollständig gefolgt“). Während am Beginn der Strophe Maria noch um Hilfe gebeten wird, ${ }^{35}$ ist das Ich am Ende der Strophe der Hilfe gewiss: „,vnd pin des fro / da sie mir chöm zü hilffe, [...] vnd laß mich nicht engelten, / das ich so lang verlsaffen hab" (6,9-13; ,[U]nd bin darüber froh, dass sie mir zu Hilfe kommt [...] und mich nicht dafür büßen lässt, dass ich so lange verschlafen habe“). Am Ende des Liedes ste-

34 Der Sünder betont, dass sein Herz vor Schreck „erkrachet“ sei, so wie der Wächter in der ersten Strophe beschrieben hat, dass Jesu Herz „,vor angst müest dick erkrachen“ $(1,12)$.

35 ,[D]as sie mir helffe slichten / das ich verslaffen hab" (6,3f.; ", sie soll mir helfen, wieder in Ordnung zu bringen, dass ich verschlafen habe"). 
hen wörtlich, aber auch im weiteren Sinne, der "trost ${ }^{\text {“36 }}$ und die Gewissheit, dass im Anschluss an die Reue die Verfehlungen vergeben werden. Die Wächterfigur verliert in dieser Strophe an Relevanz: Sie wird zu einer Episode im Prozess von Sündenerkenntnis, Reue und Erlösung von der Schuld und sie erscheint als eine Mittlerfigur neben Maria. Der Wächter geht nicht vollständig im Ich auf, sondern ist Mittler zwischen Mensch und Gott. Bleibt der Wächter also eine vom Ich getrennte Instanz und hat seine Antwort das Geheimnis seiner Identität nicht oder bloß partiell beantwortet?

Ausgehend von den beiden Schlussstrophen stellt sich auch die Frage, wie die Antwort der Wächterstimme und die Wissbegierde des Sünders zu werten sind? Entstammt die ,Wer bist du'-Frage der unwilligen, noch halb schlafenden Haltung des Sünders oder stellt die Frage den ersten Schritt der Umkehr dar? Zeigt sich die Wirksamkeit der Wächterstimme auch daran, dass der Sünder in den Schlussstrophen keine weiteren Fragen stellt? Damit ist grundsätzlicher die Frage verknüpft, wie weit die hier geforderte Selbstbeobachtung gehen soll: Hat sie sich nur auf sündige Regungen zu beziehen oder kann und soll auch die Selbstbeobachtung selbst beobachtet werden? Die Wissbegierde des Sünders kann dazu führen, dass auch die Rezipienten anfangen, die Wächterfigur genauer zu beobachten und nach der Funktion ihrer Unter- und Überdeterminiertheit zu fragen. Wenn sie dies tun, erkennen sie die Normiertheit der Wächterstimme. Sie erkennen, dass die Antwort „,dein gaist" nur eine Teilantwort ist und die Wächterstimme auch als verinnerlichte eine Vertreterin äußerer christlicher Normen ist. Mit der nominellen Antwort des Wächters ist somit die Unbestimmtheit der Wächterstimme nicht endgültig geklärt. Aber die Frage und die Antwort zusammen machen - anders als in den dreistrophigen Fassungen - die Identität der Wächterstimme zu etwas Geheimnisvollem. Sie rufen allenfalls ein Begehren der Rezipienten nach Wissen hervor, das auf kulturgeschichtliche Verschiebungen dessen hindeutet, was in einer Kultur als geheimnisvoll wahrgenommen wird. ${ }^{37}$

\section{Kotextuelle Konkretisierung der Wächterstimme}

Ein genauerer Blick in die Augsburger Handschrift, die die sechsstrophige Fassung überliefert, soll abschließend helfen, die in diesem Lied geforderte und vielleicht auch problematisierte Selbstbeobachtung diskursgeschichtlich nochmals etwas genauer zu verorten.

Wenn man die Kotexte der acht erhaltenen Überlieferungszeugen vergleicht, zeigt sich schnell, dass die dreistrophige Fassung im südostdeutschen Raum in Sammlungen von Meisterlieddichtungen (Kolmarer Liederhandschrift) ${ }^{38}$ sowie

36 ,[S]ist aller sunder trost“ (6,15; ,,sie [Maria, S. R.] ist der Trost aller Sünder“).

37 S. o. Anm. 33.

38 München, BSB, Cgm 4997 (vgl. das Digitalisat, URL: https://daten.digitale-sammlungen. de/ db/0010/bsb00105055/images/ [3.3.2021] ist eine der wichtigsten Sammlungen von Meisterlieddichtung (Entstehung wohl um 1460). Sie enthält gegen Ende drei Töne, die Peter von Arberg zugeschrieben und zu denen jeweils mehrere Lieder eingetragen sind. Es ist die 
innerhalb von Tageliedreihen in Liedsammlungen überliefert worden ist (Liederbuch der Clara Hätzlerin,, ${ }^{39}$ Eghenvelder Liederbuch, ${ }^{40}$ Mondsee-Wiener Liederhandschrift $\left.{ }^{41}\right)$. Daneben ist das Lied Teil von spezifischeren, nicht rein lyrischen

einzige Handschrift, die das Lied nicht anonym überliefert. Die Töne von Peter von Arberg stehen in einem der hintersten Teile, in dem wohl die bedeutenden Meister des späten 14. und frühen 15. Jahrhunderts gesammelt worden sind (u. a. Lesch und Harder). Allerdings handelt es sich bei den Liedern im Ton Peters von Arberg nicht um klassische meisterliche Liedkunst, sondern sie stehen vielmehr dafür, dass die Handschrift auch andere Traditionen aufgenommen hat. Vgl. Gisela Kornrumpf: Die Kolmarer Liederhandschrift. Bemerkungen zu Plan, Provenienz und Funktion. In dies.: Vom Codex Manesse zur Kolmarer Liederhandschrift. Tübingen 2008, S. 257-276, hier S. 258f.; Burghart Wachinger: [Art.] Kolmarer Liederhandschrift. In: Verfasserlexikon. 2. Aufl. Bd. 5. Hg. von Kurt Ruh u. a. Berlin u. a. 1985, Sp. 2739, hier Sp. 36; Georg Steer: Dat dagelyt von der heiligen passien. Die sogenannte Große Tageweise Graf Peters von Arberg. In: Beiträge zur weltlichen und geistlichen Lyrik des 13. bis 15. Jahrhunderts. Würzburger Colloquium 1970. Hg. von Kurt Ruh und Werner Schröder. Berlin 1973, S. 112-204, hier S. 158-160. Unser Lied (fol. 826r) gibt den Ton für die nachfolgenden Lieder an, es ist jedoch nur die Melodie des Aufgesangs eingetragen. Vgl. GGdM (Anm. 11), S. 65 und Eva Schumann: Stilwandel und Gestaltveränderung im Meistersang. Vergleichende Untersuchungen zur Musik der Meistersinger. Kassel 1972, S. 106 und 165.

39 Prag, Nat.mus. X A 12, fol. 277 (vgl. das Digitalisat, URL:https://imagines.manuscriptorium. com/loris/AIPDIG-NMP__X_A_12_____3XBZGT5-cs/ID0277r/full/full/0/default.jpg [3.3.2021]), hier fehlen in Str. 2 zwei Verse. Das Lied (Haltaus Nr. 26) ist Teil des Liederbuchteils der 1471 entstandenen Handschrift. Unser Lied steht am Ende einer Reihe von Tageliedern, die den Liederbuchteil eröffnen (Haltaus Nr. 1-27); vgl. Liederbuch der Clara Hätzlerin. Hg. von Carl Haltaus. Quedlinburg u. a. 1840; Ingeborg Glier: [Art.] Hätzlerin, Klara. In: Verfasserlexikon. 2. Aufl. Bd. 3. Hg. von Kurt Ruh u. a. Berlin u. a., Sp. 547-549; Burghart Wachinger: Liebe und Literatur im spätmittelalterlichen Schwaben und Franken. Zur Augsburger Sammelhandschrift der Clara Hätzlerin. In ders.: Lieder und Liederbücher. Gesammelte Aufsätze zur mittelhochdeutschen Lyrik. Berlin u. a. 2011, S.395-415, hier S. 403, vermutet, dass unser Lied zu einer „,sekundäre[n] Erweiterung“ des ,ursprünglichen' Tageliedteils (17 Lieder) gehört; zum Spektrum dieser Kernsammlung, in der geistliche Tagelieder fehlen, vgl. ebd., S. 403-408. Vgl. dazu auch Inta Knor: Das Liederbuch der Clara Hätzlerin als Dokument urbaner Kultur im ausgehenden 15. Jahrhundert. Philologische Untersuchung zum Textbestand in den Handschriften Prag Nationalmuseum, X A 12, der Bechsteinschen Handschrift (Halle a. d. S. 14 A 39) und Streuüberlieferung. Halle a. d. S. 2008, S. 199-201.

40 Wien, ÖNB, Cod. ser. nova 3344, fol. $100^{\mathrm{v}}-115^{\mathrm{r}}$ (vgl. das Digitalisat, URL: http://www. cantusplanus.at/OENBsn03344 [28.8.2019]). Die Fassung unseres Liedes im Eghenvelder Liederbuch ist fünfstrophig, vgl. GGdM (Anm.11), S.65f. In den Strophen IV-V wird der allmächtige Gott angesprochen und gebeten, dass er einen Sünder mit "ganczer reue" $(4,4)$ und „raine[m] gewissen“ $(4,6)$ erhört. Der Sünder wird ermahnt, nach Gottes „speiss" $(4,15) \mathrm{zu}$ streben und Maria anzubeten $(5,5)$, damit er vom Weg der Hölle abkommt $(5,14)$. Auch in dieser Liederbuchsammlung erscheint das Lied (Egh 7, fol. $103^{r-v}$ ) als Teil einer Sammlung von Tageliedern, die auf die an erster Stelle stehenden Marienlieder folgen; vgl. die Aufstellung bei Marc Lewon: Die Liedersammlung des Liebhard Eghenvelder: im Ganzen mehr als die Summe ihrer Teile. In: Musikalische Repertoires in Zentraleuropa (1420-1450) Prozesse \& Praktiken. Hg. von Alexander Rausch und Björn Tammen. Wien u. a. 2014, S. 299-343, hier S. 340-343. Die Sammlung besteht aus 31 Liedern. Neben dem Neidhartcorpus (Wiener Neidharths. w) dominieren Sangspruch, Tagelieder und geistliche Lieder. Die Sammlung wird auf 1431-1434 datiert und wurde in Hainburg verfasst (ebd., S. 306); vgl. auch Helmut Lomnitzer: Liebhard Eghenvelders Liederbuch. Neues zum lyrischen Teil der sog. Schratschen Handschrift. In: Zeitschrift für deutsche Philologie 90 (1971), S. 190-216.

41 Der Liederbuchteil (166 $-282^{\mathrm{v}}$, von 1454-1469), der später mit anderen Teilen der Handschrift 
Textensembles aus einem monastischen Umfeld geworden. So findet sich die dreistrophige Fassung in einer geistlichen Sammelhandschrift mit vorwiegend katechetischen Texten aus dem Nürnberger Katharinenkloster (GNM 877). ${ }^{42}$ Das Wächterlied findet sich aber auch zweimal im Kontext der Contemptus mundiThematik. In einer heute in Augsburg aufbewahrten Handschrift von $1457^{43}$ gehen unserem Lied (fol. $17^{v}$ ) ein Todsündentraktat ${ }^{44}\left(\right.$ fol. $\left.1^{r}-13^{r}\right)$ und eine Sterbelehre ${ }^{45}$ $\left(\right.$ fol. $\left.13^{\mathrm{v}}-17^{\mathrm{r}}\right)$ voran, gefolgt vom vierzeiligen oberdeutschen Totentan $\mathrm{z}^{46}$ (fol. $18^{\mathrm{r}}-$

Wien ÖNB Cod. 2856 zusammengebunden worden ist, stellt primär eine Sammlung der Lieder und insbesondere auch der weltlichen Lieder des Mönchs von Salzburg und seines Umkreises dar. Zwischen zwei sogenannten weltlichen Liedern des Mönchs von Salzburg (W38 und W39) findet sich auf fol. $214^{\mathrm{v}}-215^{\mathrm{r}}$ das dreistrophige Lied Ich wachter sol erwecken. Es folgt ein zweiter, evtl. später hinzugefügter Teil (Lage 8-10) mit Meisterlieddichtung. Vgl. Christoph März: Die weltlichen Lieder des Mönchs von Salzburg. Texte und Melodien. Tübingen 1999, S. 64-72, insb. S. 66f.; Burghart Wachinger: [Art.] Mondsee-Wiener Liederhandschrift. In: Verfasserlexikon. 2. Aufl. Bd. 6. Hg. von Kurt Ruh u. a. Berlin u. a. 1987, Sp. 672-674; Lorenz Welker: [Art.] Mondsee-Wiener Liederhandschrift. In: Die Musik in Geschichte und Gegenwart. Sachteil Bd. 6. 2. neubearbeitete Aufl. Kassel u. a. 1997, Sp. 441-445.

42 Nürnberg, GNM Hs. 877, die Hs. wird datiert auf 1421 (vgl. das Digitalisat, URL: http://dlib. gnm.de/item/Hs877/html [29.8.2019]). Die Handschrift enthält vor allem katechetische Texte (vgl. Lotte Kurras: Die deutschen mittelalterlichen Handschriften. Bd. 2. Wiesbaden 1980, S. 6-8), aber auch eine Katharinenlegende (fol. $2^{\mathrm{r}}-18^{\mathrm{v}}$ ) am Beginn sowie eine Sammlung von geistlichen Liedern (fol. 205 $-215^{v}$ ) in der Mitte. Es handelt sich fast ausschließlich um Marienlieder, darunter findet sich aber auch unser Wecklied (fol. 211 ${ }^{\mathrm{v}}-213^{\mathrm{r}}$ ). Allerdings fehlt hier der erste Stollen und an dessen Stelle sind 16 Reimpaarverse eingetragen, in denen Jesus den Sünder anspricht und ihm erklärt, dass er für ihn gelitten hat. Daran schließen die Verse 1,5-15 an (Transkription bei Cramer: Kleinere Liederdichter [Anm. 11], Bd. 2, S. 435, Sigle C).

43 Augsburg, Staats- und Stadtbib. Cod. 2, 157 (Vgl. das Digitalisat, URL: urn:nbn:de:bvb:37-dtl0000000261 [28.8.2019]). Die Sammelhandschrift in ostschwäbischer Diktion wird vom Schreiber auf 1457 datiert; gemäß dem Besitzvermerk war sie spätestens seit dem 17. Jahrhundert im Kloster Irsee. Vgl. Herrad Spilling: Die Handschriften der Staats- und Stadtbibliothek Augsburg $2^{\circ}$ Cod. 101-250. Wiesbaden 1984, S. 91-94; Wolf Gehrt: Nr. IV,13: $2^{\circ}$ Cod. 157. In: Von der Augsburger Bibelhandschrift zu Bertolt Brecht: Zeugnisse der deutschen Literatur aus der Staats- und Stadtbibliothek und der Universitätsbibliothek Augsburg. Ausstellung der Staatsund Stadtbibliothek Augsburg in Zusammenarbeit mit der Universität Augsburg anlässlich des Deutschen Germanistentags 1991, Augsburg, 4. Oktober bis 10. November 1991. Katalog. Hg. von Helmut Gier und Johannes Janota. Weissenhorn 1991, S. 100; RSM (Anm. 10), Bd. 1, S. 66.

44 Es handelt sich um die volkssprachliche Übersetzung des Etymachietraktats; vgl. Dietrich Schmidtke: [Art.] Etymachietraktat. In: Verfasserlexikon. 2. Aufl. Bd. 6. Hg. von Kurt Ruh u. a. Berlin u. a. 1980, Sp. 636-639.

45 Sie geht, wie eine ganze Gruppe dieser Texte, von Seuses Büchlein der ewigen Weisheit aus; vgl. dazu auch Mark Chinca: Innenraum des Selbst, Innenraum des anderen. Zur Ars moriendi im 15. Jahrhundert. In: Innenräume in der Literatur des deutschen Mittelalters. XIX. Anglo-German Colloquium Oxford 2005. Hg. von Burkhard Hasebrink u. a. Tübingen 2008, S. 355-381, hier S. 357-359; Nigel F. Palmer: Ars moriendi und Totentanz: Zur Verbildlichung des Todes im Spätmittelalter. In: Tod im Mittelalter. Hg. von Arno Borst u. a. Konstanz 1993, S. 313-334, hier S. 314-315.

46 Es handelt sich um die älteste Handschrift des vierzeiligen oberdeutschen Totentanzes; vgl. Christian Kiening: [Art.] Oberdeutscher vierzeiliger Totentanz. In: Verfasserlexikon. 2. Aufl. Bd. 11. Hg. von Burghart Wachinger. Berlin u. a. 2004, Sp. 1074-1079. 
$20^{\mathrm{r}}$ ) und einem De contemptu mundi Gedicht ${ }^{47}$ (fol. 20 ${ }^{\mathrm{r}}-21^{\mathrm{r}}$ ). In Letzterem versuchen unterschiedliche Instanzen, darunter auch der Tod und der Leichnam, einen mundanus zur Abkehr von der Welt zu überreden. Durch diese Kotexte liegt der Schwerpunkt des dreistrophigen Liedes auf der zweiten Strophe, in der der Wächter den Sünder vor dem plötzlich eintretenden Tod warnt. Auch die Sammelhandschrift des Erfurter Weltgeistlichen Tilomann Ziegler (Berlin mgf 643) hat einen Schwerpunkt auf Texten mit Vergänglichkeitsthematik, in die sich das Wächterlied (fol. $123^{\mathrm{v}}$ ) gut einbettet. ${ }^{48}$

Die Augsburger Handschrift, in der sich die untersuchte sechsstrophige Fassung findet, ist keine übliche spätmittelalterliche Liederhandschrift. Gemäß dem Schenkungseintrag am Ende der Handschrift wurde sie 1481 den acht Laienbrüdern des schwäbischen Birgittenklosters Maria Mai in Maihingen wohl zur Einweihungsfeier des Brüderkonvents vermacht. ${ }^{49}$ Es handelt sich um eine für Laienbrüder der Zeit ${ }^{50}$ nicht untypische Sammlung von Texten aus dem EckhartKontext, die das Thema der geistigen Armut umkreisen: die absolute Aufgabe des Eigenwillens, um das Hereinströmen Gottes zu ermöglichen. ${ }^{51}$ Konkret folgt auf den Traktat Vom Grund aller Bosheit ${ }^{52}$ das Buch von geistlicher Armut ${ }^{53}$ und sodann

47 Edition bei Christian Kiening: Contemptus mundi in Vers und Bild am Ende des Mittelalters. In: Zeitschrift für deutsches Altertum und deutsche Literatur 123 (1994), S. 409-457, hier S. 421f. Vgl. V. 130f.: „o sunder, gedenk, wes warten wir. / Wir warten des, den nyemant sicht“.

48 Die Hs. Berlin, Staatsbibliothek, mgf 643, enthält neben lateinischen Texten auch einen eigenen Abschnitt mit deutschsprachigen (und deutsch-lateinischen) Texten (fol.118 ${ }^{\mathrm{r}}-138^{\mathrm{v}}$ ), die formal sehr vielfältig sind (Reimpaarverse, Prosa, Lieder). Die Hs. wird durch Zieglers Tod auf vor 1479 datiert. Vgl. dazu Baldzuhn: Teichnerreden (Anm. 10), insb. S. 152-154 (Aufstellung der deutschen Texte) und 162f. zur Contemptus mundi-Thematik.

49 UB Augsburg, Cod. III 1.4³7; vgl. dazu Robert Steinke: Geistliches in Traktat-, Predigt- und Liedform in der Laienbrüderbibliothek des Birgittenklosters Maria Mai in Maihingen. In: Meister Eckhart in Augsburg. Deutsche Mystik des Mittelalters in Kloster, Stadt und Schule. Katalog zur Handschriftenausstellung in der Schatzkammer der Universitätsbibliothek Augsburg (18. Mai bis 29. Juli 2011). Hg. von Freimut Löser. Augsburg 2011, S. 178-183, hier S. 178; Dietrich Schmidtke: Harburger Liederfunde. In: Zeitschrift für deutsches Altertum und deutsche Literatur 105 (1976), S. 132-150, hier S. 132; Karin Schneider: Deutsche mittelalterliche Handschriften der Universitätsbibliothek Augsburg. Die Signaturengruppen Cod. I.3 und Cod. III.1. Wiesbaden 1988, S.347-349.

50 Freimut Löser: Meister Eckhart in Melk. Studien zum Redaktor Lienhart Peuger. Mit einer Edition des Traktats Von der sel wirdichait vnd aigenschafft. Tübingen 1999, S. 57-67, weist nach, dass zumindest die benediktinischen Laienbrüder im Reformkloster Melk im frühen 15. Jahrhundert sich täglich zur Lektüre trafen (ebd., S. 60); es gab eine eigene Bibliothek der Laienbrüder und deutsche Handschriften wurden extra für die Laienbrüder angefertigt, häufig mit gekürzten und z. T. vereinfachten Texten (ebd., S. 61-67). Auch inhaltlich beinhaltet unsere Augsburger Handschrift eine ähnliche aszetisch-mystische Textsammlung wie diejenigen von Peuger, die Löser untersucht hat. (Ich danke Stephan Müller für den Hinweis).

51 Steinke: Geistliches (Anm. 49), S. $179 f$.

52 Fassung B, vgl. Karl Heinz Witte: [Art.] Fundus omnis iniquitatis. In: Verfasserlexikon. 2. Aufl. Bd.11. Hg. von Burghart Wachinger. Berlin u. a. 2004, Sp. 471-472.

53 Johannes Auer: [Art.] Das Buch von geistlicher Armut. In: Verfasserlexikon. 2. Aufl. Bd.1. Hg. von Kurt Ruh u. a. Berlin u. a. 1978, Sp. 1082-1085; Kurt Ruh: Die Mystik des deutschen Predigerordens und ihre Grundlegung durch die Hochscholastik. München 1996, S. 517-528. 
eine Bearbeitung von Seuses Büchlein der Wahrheit ${ }^{54}$ sowie Auszüge aus Eckharts Predigtzyklus Von der ewigen Geburt (DW 103) ohne Nennung des Verfassers. ${ }^{55}$ Darauf folgen auf fol. $291^{\mathrm{r}}-294^{\mathrm{r}}$ vier Lieder. ${ }^{56}$ Das erste Lied leitet die adressierten ,[c]hinder" zur geistigen ,armüt“ und zum „enpinden“ (II,1-3) an, das zweite fordert sie zur „ordenung“ (I,1), also zu monastischem Gehorsam auf, das dritte ist unser sechsstrophiges Wecklied, gefolgt von einem kurzen Prosagebet, in dem ein Ich Gott anspricht und ihm "ernstlich pezzerung ${ }^{\prime 57}$ verspricht. Weiter bittet das Ich: „enpfilch mich vnd alle menschen in dein ewige grundlose trew [...] damit wir besiczen nach disem leben das ewig leben, amen“ („Nimm mich und alle Menschen in deine ewige, tiefe Treue auf [...], damit wir im Anschluss an dieses Leben das ewige Leben erhalten. Amen."). Im Anschluss an unser Lied, aber auch gegen Ende der Handschrift, wird somit den Rezipienten die Möglichkeit gegeben, die im Lied vorgeführte Reue zu ihrer eigenen zu machen. Die Liedgruppe und die Handschrift enden mit einem vierten, unikal überlieferten Lied, in dem ein Ich seine Liebe zu einem fernen ",er“ ausdrückt, ${ }^{58}$ dem es gerade dann nah ist, wenn dieser sich abwendet (II,1; III,1-5) und dem Ich „vngemach“ zufügt (III,8). Schmidtke bezeichnet das Lied behelfsmäßig als „weltliche[s] Gesellschaftslied [...]“. ${ }^{59}$ Allerdings ist das formal sperrige, sprachlich schlichte Lied, das sich keiner der gängigen Gattungen zuordnen lässt, schwer einzuordnen. Wohl ist der Text vordergründig auf eine weltliche Liebe bezogen (vgl. II,7f.), doch die Betonung des Leidens (,"kein leyden durch in myden“, II,6) und des Ausharrens (II,9) macht es auch möglich, darin eine geistliche Liebessehnsucht zu verstehen: „vmb das mein hercze will bey im sein / in lieber peyn" (III,10f.).

Diese Kotexte präsentieren die Internalisierung der Wächterinstanz nochmals in einem anderen Licht als der oben erwähnte Beicht- und Bußdiskurs: Das im ersten Lied thematisierte mystische Streben nach ",armüt“, also danach, den Eigenwillen vollständig aufzugeben, sich von allem Wissen und Wollen frei zu machen, um das Einströmen Gottes zu ermöglichen, ist ohne Selbstbeobachtung nicht zu haben - auch wenn die mystischen Texte darauf zielen, das Selbst am Ende hinter sich zu lassen. Das zweite Lied, das den monastischen Gehorsam lobt, verweist auf die nötige Disziplin, die dazu erforderlich ist und die nicht nur intrinsisch,

54 Heinrich Seuse: Das Buch der Wahrheit. Mittelhochdeutsch - Deutsch. Hg. von Loris Sturlese und Rüdiger Blumrich. Hamburg 1993. Zu den Bearbeitungstendenzen in der Augsburger Hs. vgl. Schneider: Deutsche mittelalterliche Handschriften der Universitätsbibliothek Augsburg. Die Signaturengruppen Cod. I.3 und Cod. III.1 (Anm.49), S. 348; Steinke: Geistliches (Anm. 49), S. 179.

55 Meister Eckharts Predigten. Hg. von Georg Steer. Stuttgart 2003, Nr. 103, S. 474-492.

56 Die Lieder sind mit Ausnahme von Jch wachter nach der Augsburger Handschrift ediert bei Schmidtke: Liederfunde (Anm. 49) (im Folgenden zitiert).

57 Transkription des Gebets bei Schnyder: Tagelied (Anm. 7), S. 199 Anm. 8.

58 ,Jch was dort vnd pin nü hie / vnd waizz auch nie, das er mich lie, / vnd will in ewiglichen in trewen han" (I,1-3).

59 Schmidtke: Liederfunde (Anm. 49), S. 137. 
sondern auch extrinsisch motiviert ist. ${ }^{60}$ Von den Kotexten her perspektiviert erscheint die internalisierte Wächterinstanz nicht mehr nur als eine, die sündhafte Regungen überwacht, sondern sie steht für eine viel umfassendere Wachsamkeit, die auf den einströmenden Gott ausgerichtet ist. Dass eine solche Wachsamkeit wieder neue Fragen aufwirft, deutet die erste Strophe des ersten mystischen Liedes Auff mit bekennen an: ${ }^{61}$

wir sullen bekennen was wir sein: Wir müssen erkennen, was wir sind, von auszen vnd von jnnen gaist natur in wesenlicheit. dem Wesen nach sind wir äußerlich und do ist da chein vnderscheid, innerlich Geist [und] Natur.

da natur ir liecht da vindet Da, wo die Natur ihr Licht findet, da ist kein Unterschied. ${ }^{2}$

Der Mensch ist in „wesenlicheit“, also von seinem Wesen her, "gaist“ und „natur ${ }^{\prime \prime}{ }^{63}$ Diese sind jedoch nicht als Gegensätze zu verstehen, sondern wenn der Mensch den göttlichen Anteil seiner „natur“ erkennt und die (intellektive) „natur" ihr Licht, also Gott, findet, dann hebt sich nicht nur die Unterscheidung von "gaist" und "natur", Außen und Innen auf, sondern das Selbst wird auf Gott hin überwunden: Es „,blibet ainualt aynicheit“ $(\mathrm{I}, 8)$.

Damit sind nun aber auch die Unterschiede zwischen den Kotexten sichtbar geworden. Den Komplexitätsgrad, mit dem das mystische Lied das Verhältnis von Außen und Innen konzipiert, erreicht das sechsstrophige Wecklied nicht. Anders als im mystischen Lied steht im Wecklied nicht die ,geistige Armut' oder Einheit mit Gott im Vordergrund, sondern die Wirksamkeit der Wächterinstanz, die den Sünder erfolgreich zum Umdenken bewegt. Es geht um eine Selbstbeobachtung, bei der das Selbst transparent werden, aber nicht überwunden werden muss. Dass die mystische Achtsamkeit für den einströmenden Gott und die durch den Reueund Bußdiskurs geprägte Selbstbeobachtung des eigenen Innen aber gleichwohl enge Bezüge aufweisen, wird selten so deutlich wie hier.

\section{Fazit}

Sowohl bei Bergmann als auch in unserem Wecklied wird die ,Wer bist du'-Frage, die an eine transzendente Instanz gerichtet ist, zurückgespielt zur Frage ,Wer bin ich'. Bei Bergmann wird dabei das eigene Ich zum großen Geheimnis, zum Myste-

60 Refrain des Liedes: „Ordnung tüt dein Leben wol behüt“.

61 Vgl. dazu Judith Theben: Die mystische Lyrik des 14. und 15. Jahrhunderts. Untersuchungen - Texte - Repertorium. Berlin u. a. 2010, S. 424 f.

62 Schmidtke: Liederfunde (Anm. 49), S. 133.

63 Im Hintergrund könnte hier Eckharts Konzept der "natura intellectualis“ stehen; vgl. u. a. Meister Eckhart, Sermo XIV,2 n. 152, LW IV,144,6f. (ich danke Fabian Prechtl für den Hinweis), daneben womöglich auch die gegenseitige Bedingtheit von "geist" und "natur", wie sie Tauler in seinen Predigten entwickelt; vgl. Vetter Nr. 45, 63, 71. Vgl. zudem Theben: Die mystische Lyrik (Anm. 61), S. 424f. 
rium, das der Mensch beständig zu lüften begehrt, ohne dass seine Anstrengungen zu sicheren Gewissheiten führen. Auf den ersten Blick entsteht der Eindruck, im mittelalterlichen Wecklied werde dagegen das Rätsel nach dem eigenen Ich nur kurz aufgeworfen und sogleich funktionalisiert, um den Sünder und die Rezipienten zu Reue, Buße und Wachsamkeit zu ermahnen. Was also im modernen Blick auf das Mittelalter pathetisch und geheimnisvoll erscheint, würde in den mittelalterlichen Texten zur einfachen Frage, die didaktisch funktionalisiert ist.

Doch sowohl der Text als auch die Kotexte zeigen, dass es so einfach nicht ist: In der dreistrophigen Fassung ist der Wächter unbestimmt und überdeterminiert zugleich, doch wirkt er nicht geheimnishaft. Geheimnishaft wird er erst durch das Begehren des Sünders nach Wissen und dessen Rückfrage, wer denn der Wächter sei. Mit der Internalisierung der Wächterinstanz wird dieses Geheimnis nominell aufgelöst und die Unbestimmtheit in Bestimmtheit überführt. Allerdings gilt diese Eindeutigkeit nur für die vierte Strophe. Liedübergreifend lässt sich die Wächterstimme nicht auf eine innere Instanz reduzieren. Vielmehr changiert sie zwischen Innen- und Außen-, Fremd- und Selbstbeobachtung, christlichen Normen und neugieriger Selbstbefragung. Das Lied zeigt sie als eine Mittlerinstanz, deren Effektivität in ihrer Unterbestimmtheit gründet, die mehrfache Besetzungen und Deutungen zulässt. Die ,Wer bist du'-Frage verdeutlicht aber auch, dass es jenseits der Funktionalisierung der Wächterstimme ein Interesse an solchen inneren Instanzen gibt. Es verschiebt sich das, was in einer „Kultur [...] [o]ffenbar [...]" ist, und das, was "geheim" ist. ${ }^{64}$

Die mystischen Kotexte der Augsburger Handschrift (UB Cod. III 1.4³7) verdeutlichen wiederum, dass die Internalisierung der Wächterinstanz in der vierten Strophe auch durch mystische Praktiken der Selbstbeobachtung beeinflusst sein könnte. Diese mystischen Selbstbeobachtungspraktiken machen zwar das Selbst nicht zu einem pathetischen Geheimnis, wie das bei Bergmann der Fall ist, doch sie stimulieren die Achtsamkeit und Aufmerksamkeit für das Innere, um es zu überwinden. Dabei wird die paradoxe Verschränkung von Innen und Außen, Immanenz und Transzendenz immer auch als Mysterium dargestellt, das unergründbar bleiben muss.

In Anbetracht dieser Kotexte fällt es schwer zu entscheiden, ob die ,Wer bist $\mathrm{du}$ '-Frage des Sünders und sein Begehren nach Wissen seiner halb schlafenden, unwillig-sündhaften Haltung entstammen oder ob die Frage bereits den ersten Schritt der Umkehr darstellt. Dass der Text uns dieses Rätsel lässt, kann man gleichfalls als Ausdruck eines Begehrens nach Wissen lesen.

64 S. o. Anm. 33. 

Inszenierungen von Geheimnis und Rätsel 



\title{
Verrätseltes Erzählen vom Mysterium
}

\author{
Wer nimmt was auf Munsalvæsche wahr?
}

\author{
Maximilian Benz
}

\section{Die Geheimnisse des Grals}

Die Gralslehre wiederzugeben, ist fast unmöglich. Sie ist eine Mischung von christlichem Sektierertum verbrämt mit mystischem Unsinn und entzieht sich jeder Vernunft, so daß sie nur an ihren Wirkungen erkannt werden kann. Zum Beispiel an diesen: eine Anhängerin des Grals begehrte in Wien Scheidung von ihrem Mann, da sie ihn schon vor zweitausend Jahren erschlagen habe und ihre Schuld büßen müsse. Ein anderer Gralsritter, Lehrer im Elsaß, entdeckte, daß er vor drei Jahrtausenden als Agamemnon von seiner jetzigen Frau, die damals Klytemnästra hieß, ermordet worden war. Ein Zusammenleben mit ihr könne man ihm nicht zumuten, weshalb auch er die Scheidung begehrte. ${ }^{1}$

Mit diesen Sätzen, die ich einem 1955 in der Wochenzeitung Die Zeit erschienenen Beitrag entnommen habe, der über den Ausgang eines sogenannten Ehrenbeleidigungsprozesses im Umfeld einer Gralsekte berichtet, bewegen wir uns im so blütenreichen wie auch dornigen Feld der Mittelaltertransformationen, deren ganz unterschiedliche Zeugnisse stets mehr über die eigene Zeit als über das Mittelalter aussagen. Dies ist erst recht im Hinblick auf die hier in Rede stehende sogenannte Gralsbewegung der Fall, die auf Oskar Ernst Bernhardt (1875-1941) zurückgeht. ${ }^{2}$ Er verstand sich selbst auf höchst ambitiöse Weise als Nachfolger Christi, ja erweiterte die christlich gut verbürgte imitatio durch eine suspekte Variante der aemulatio. Bernhardt verstand sich als verheißener ,Menschensohn', der zu einem Ende bringt, was Jesus Christus angefangen hatte. Wie dem Zeitungsbericht bereits zu entnehmen ist, gehört auch die Wiedergeburtslehre zum ideologischen Drahtverhau der Gralsbewegung, weshalb sich Bernhardt übrigens auch Abd-ru-shin nannte - ,Sohn des Lichts'; er hatte diesen Namen in einem früheren Leben als persischer Königssohn in Ägypten getragen.

Und dennoch: Vollkommen willkürlich erfolgt der Anschluss an den ,Gral' nicht. Gemeinschaft, Christliches, Mysterium, Erlösungsbedürftigkeit und nicht

1 Roland Nitsche: Kreuzzug gegen Gralsritter. In: Die Zeit, Nr. 13 vom 31. März 1955.

2 Biographisches nach Andreas Plagge: [Art.] Oskar Ernst Bernhardt. In: Biographisch-Bibliographisches Kirchenlexikon. Bd.22. Hg. von Friedrich Wilhelm Bautz, fortgef. von Traugott Bautz. Nordhausen 2003, Sp. 120-122. 
zuletzt: krude Idiosynkrasien - diese Stichworte lassen sich auch mit genuin mittelalterlichen Entwürfen zum Gral in Verbindung bringen. Der Gral ist nicht nur in der Neuzeit, sondern auch im Mittelalter ein schwer fassbarer, geheimnisvoller Gegenstand, der im Schnittpunkt verschiedener Diskurse zu verorten ist - mal ist er eine preziose Schale, mal ein magischer Stein, der zunächst aber einfach nur als ,Ding' bezeichnet wird, dann aber auch (und sehr einflussreich) ein Gefäß, mit dem Joseph von Arimathia bei der Kreuzigung Jesu Blut auffing. Das Geheimnis, das von diesem Gegenstand programmatisch ausgeht, ist Ursache für das Faszinosum, das mit ihm verbunden ist.

Ein Geheimnis lässt sich nicht einfach repräsentieren, darstellen, erzählen, sondern muss erzeugt werden. Es bedarf subtiler Strategien des Verbergens und Enthüllens, die mehr suggerieren, als tatsächlich ausgesagt werden soll (oder möglicherweise auch: darf). Dies trifft in besonderem Maße auf Wolframs von Eschenbach Parzival zu. Mit Blick auf ihn lassen sich mindestens drei Ebenen unterscheiden, auf denen Wolfram das Gralmysterium inszeniert - die ersten beiden streife ich nur in äußerster Abbreviatur, der Vollständigkeit halber.

Zunächst und ganz grundsätzlich betrifft dieses Mysterium den Text als ganzen. Wolfram lässt seine Fassung nicht nur auf Chrétiens de Troyes Conte du Graal zurückgehen, sondern korrigiert diesen mit Blick auf eine ,Sternenschrift'. ${ }^{3}$ Ein gewisser Kyot habe in einer arabischen Handschrift von Flegetanis, einem heidnischen Nachkommen Salomons, dank der Tatsache, dass er getauft war, Kenntnis von der Geschichte des Grals erhalten, die Flegetanis seinerseits aus den Sternen gelesen habe. ${ }^{4}$ Nachdem die Forschung zunächst (und vergeblich) versucht hat, diese Quelle, den Text des ansonsten gänzlich unbekannten Kyot ausfindig zu machen, glaubt man mittlerweile überwiegend, dass es sich um eine Mystifikation Wolframs handelt. ${ }^{5}$ Aber nicht nur der Status der Quellenberufung erscheint fraglich, sondern auch ihre Funktion. Es ist durchaus offen, ob Wolfram seinen Text, indem er ihn auf eine ,Sternenschrift' zurückgehen lässt, auratisiert und sakralisiert oder ob er lediglich ,so tut als ob“. ${ }^{\prime \prime}$ Mit all diesen Uneindeutigkeiten passt die Quellenberufung indes ausgezeichnet zu Wolframs Gralerzählung selbst.

3 So heißt es programmatisch am Ende des Parzival: "Ob von Troys meister Cristjân / disem mære hât unreht getân, / daz mac wol zürnen Kyôt, / der uns diu rehten mære enbôt." (Pz. 827,1-4); vgl. Jan-Dirk Müller: Percevals Fragen - oder ein Parzival ohne Mitleidsfrage. In: Wolfram-Studien 23 (2014), S. 21-49, hier S. 48f. Text nach Wolfram von Eschenbach: Parzival. Studienausgabe. 2. Aufl. Mittelhochdeutscher Text nach der sechsten Ausgabe von Karl Lachmann. Übersetzung von Peter Knecht. Mit Einführungen zum Text der Lachmannschen Ausgabe und in Probleme der Parzival-Interpretation von Bernd Schirok. Berlin, New York 2003. Die im Fließtext beigegebenen Übersetzungen stammt von Wolfgang Spiewok; sie wurde gelegentlich stillschweigend modifiziert.

4 Vgl. Pz. 454,17-21: „,Flegetânîs der heiden sach, / dâ von er blûweclîche sprach, / im gestirn mit sînen ougen / verholenbæriu tougen. / er jach, ez hiez ein dinc der grâl“".

5 Ein Einspruch hierzu von Harald Haferland: Die Geheimnisse des Grals. Wolframs Parzival als Lesemysterium? In: Zeitschrift für deutsche Philologie 113 (1994), S. 23-51, hier S. 34.

6 Peter Strohschneider: Höfische Textgeschichten. Über Selbstentwürfe vormoderner Literatur. Heidelberg 2014, S. 54. 
Erst recht spät erfahren die Rezipienten (wie Parzival) in der Figurenrede des Einsiedlers Trevrizent - dies die zweite Ebene -, dass der Gral ein Stein ist mit dem - von der Forschung bis heute nicht überzeugend entschlüsselten, ${ }^{7}$ ja vielleicht programmatischerweise gar nicht entschlüsselbaren Namen - ,lapsit exillis', der auf der Burg Munsalvæsche von Gralrittern bewacht wird. Der Gral hat magische Fähigkeiten: Er liefert Speise und Trank, fungiert als Jungbrunnen. Diesen besonderen Stein kann man allerdings nicht einfach finden: Man muss zum Gral berufen werden. Namen und Herkunft dessen, der berufen ist, gibt der Gral selbst bekannt, indem auf ihm eine Schrift erscheint. Der Stein ist also ein übernatürlicher Gegenstand, der aber christlich aufgeladen ist. Denn die besondere Kraft des Steins resultiert aus einer botschaft. Immer am Karfreitag bringt eine Taube eine kleine weiße Oblate vom Himmel (vgl. Pz. 470,3;5). Dem Gral ist somit entschieden eine heilsgeschichtliche Signatur eingeschrieben: sub gratia findet hier alles statt, wie der Verweis auf den Karfreitag betont, was natürlich immer schon voraussetzt: post lapsum. In diesem Zusammenhang sind die neutralen Engel von Bedeutung, also die Engel, die sich beim Fall Luzifers neutral verhielten. ${ }^{8}$ Der Gral wird damit deutlich als ein ,Drittes' zwischen Himmel und Hölle gedacht, was weitreichende Konsequenzen für den Roman hat, in dessen Prolog programmatisch der Mensch profiliert wird, an dem „sint beidiu teil, / des himels und der helle." (Pz. 1,8f.) Der Gral vergegenständlicht Grundprobleme, narrativ-diskursive Knoten des Romans: Offenbarung und Geheimnis, Tat und Gnade, Erwählung und Bewährung. Und er tut dies auf besonders ambivalente Weise. Die Ambivalenz der Figurenrede Trevrizents wird gerade auch darin offenbar, dass die vom Himmel gesandte Hostie den Stein mit solchen Kräften ausstattet, dass die Wirkung dem wunsch von pardîse angenähert wird, Trevrizent aber sogleich nachschieben muss: „ich mein swaz d'erde mac gebern.“ (Pz. 470,15) Auch darüber hinaus bleibt vieles im Vagen, denn Trevrizent revoziert an wiederum späterer Stelle und auf durchaus kryptische Weise seine Aussagen über die neutralen Engel. ${ }^{9}$

Sowohl mit Blick auf die Inszenierung des Gesamttexts wie auch mit Blick auf die Figurenrede wird ein Gralmysterium entfaltet. Damit wird in beiderlei Hinsichten fortgeführt, was - dies die dritte Ebene - in Wolframs Erzählerbericht selbst bei der Einführung des Grals exponiert wird. Diese dritte Ebene soll mit Blick auf Wolframs verrätseltes Erzählen vom Mysterium im Folgenden im Zentrum stehen und textnah analysiert werden.

7 Eine Übersicht über die möglichen Deutungen bei Joachim Bumke: Wolfram von Eschenbach. 8., völlig neu bearb. Aufl. Stuttgart, Weimar 2004, S. 139f. Das Folgende zum Gral in Pz. 468,23-471,29.

8 Es ist eine grundsätzliche Frage, ob man zur Erklärung dieser Stelle auf Außerliterarisches, etwa auch die Häresie der Katharer, zurückgreifen möchte oder ob man eine poetologische Interpretation vorzieht; vgl. Cornelia Herberichs: Erzählen von den Engeln in Wolframs Parzival. Eine poetologische Lektüre von Trevrizents ,Lüge'. In: Beiträge der Geschichte der deutschen Sprache und Literatur 134 (2012), S. 39-72 (mit der weiteren Lit.).

9 Vgl. Pz.798,6-8: „ich louc durch ableitens list/ vome grâl, wiez umb in stüende. / gebt mir wandel für die süende“. 


\section{Die Leerstelle von Munsalvæsche}

Ich beginne mit der notorischen Nacherzählung, die aber - das sei vorweggeschickt - die Pointe von Wolframs ,verrätseltem' Erzählen genau nicht erfassen kann. Lange bevor Parzival (und mit ihm der Rezipient) von Trevrizent über die Umstände des Grals aufgeklärt und noch ehe unter Rekurs auf Kyot die Ursprungserzählung der Gralgeschichte geliefert wird, kommt Parzival abends an einen See, auf dem er ein Boot mit einem prächtig gekleideten Fischer sieht. Auf Parzivals Frage nach einer Herberge für die Nacht weist er ihm den Weg zu einer Burg, auf der er Parzival bewirten will. Auf der Burg angekommen, wird Parzival mit einem prächtigen Mantel der Königin Repanse de Schoye bekleidet und anschließend in einen palas, einen Festsaal, geführt, in dem auch vierhundert Ritter anwesend sind. Parzival soll sich beim Gastgeber niedersetzen, eben jenem Fischer, dem er zuvor begegnet war. Auf einmal springt ein Knappe zur Tür hinein mit einer blutenden Lanze in der Hand, was unter den Anwesenden zu exzessivem Weinen und Klagen führt; beides hört aber sofort wieder auf, sobald der Knappe den Saal verlässt. Anschließend folgt eine Speisezeremonie. Zwei Jungfrauen bringen Kerzenständer, eine Herzogin mit Gefährtin bringt elfenbeinerne Tischbeine. Daraufhin treten zweimal vier Damen auf; die einen bringen Kerzen, die anderen eine Tischplatte aus grünem Hyazinth: Vor dem König wird der Tisch aufgebaut. Zwei weitere Frauen bringen zwei äußerst scharfe Messer, vier bringen Kerzen. Nun betritt die Königin, Repanse de Schoye, den Saal:

ûf einem grüenen achmardî truoc si den wunsch von pardîs, bêde wurzeln unde rîs. daz was ein dinc, daz hiez der Grál, erden wunsches überwal.

(Pz. 235,20-24)
Auf grünem Seidentuche trug sie den Inbegriff paradiesischer Vollkommenheit, Anfang und Ende allen menschlichen Strebens! Dieser Gegenstand wurde ,Gral' genannt und übertraf alle Vorstellungen irdischer Glückseligkeit.

Anschließend wird aufgetischt; vor dem Gral erscheinen alle Speisen und Getränke - „allez von des grâles kraft.“ (Pz. 239,5) Der König übergibt schließlich Parzival ein Schwert, woraufhin alles, ein wenig überstürzt, wieder abgetragen wird. Parzival wird zur Bettstatt geleitet. Wenn er am nächsten Tag nach einer Nacht mit schlimmen Träumen aufwacht, ist die Burg verlassen; als er von der Burg reitet, verflucht ihn ein Knappe. Parzival hat einen schweren Fehler begangen, daran lässt der Text auch im Folgenden keinen Zweifel, wenn auch die Beurteilungen in ihrer Drastik variieren. Was Parzival (sowie der Rezipient) zu diesem Zeitpunkt nicht weiß: Es handelt sich bei dem König um den Gralkönig Anfortas, den ein schreckliches Leiden an seinen Genitalien quält. Parzival hätte ihn erlösen können, wenn er - von sich aus, also ohne durch die Gralgesellschaft darauf hingewiesen worden zu sein ${ }^{10}$ - nach dessen Leiden gefragt hätte.

Ein dinc ist nicht nur, über dessen Namen, transzendente Herkunft und irdische Verwahrung Flegetanis etwas aus den Sternen liest, ein dinc steht auch im 
Zentrum, wenn auf Munsalvæsche ein äußerst aufwendiges Ritual inszeniert wird. ${ }^{11}$ Was deutlich ist: Die Ereignisse auf Munsalvæsche ereignen sich um eine Leerstelle herum. Noch lange bevor Trevrizent präzisieren wird, dass der Gral ein Stein ist, finden sich in der früheren Gralerzählung nur folgende Aussagen. Der Gral sei der „wunsch von pardîs“ (Pz. 235,21) und damit notwendigerweise „erden wunsches überwal“ (Pz. 235,24); als ,paradiesische Vollkommenheit’ stellt der Gral die Überhöhung irdischer Vollkommenheit dar. Über den Gral selbst wird im Zusammenhang der Spendung aller möglichen Speisen noch gesagt, er sei „der sælden fruht" (Pz. 238,21) - ich würde das als ,hypostasierte Seligkeit' begreifen und zwar „der sælden fruht" im immanenten Zusammenhang. Als solche wird der Gral mit der Eigenschaft der süeze in Verbindung gebracht, ein Nomen, das im religiösen Kontext die sinnliche Erfahrbarkeit von Transzendenz meint.

Was der Gral genau ist, wie man ihn zu imaginieren hat, wird gleichwohl an dieser Stelle nicht deutlich gesagt. Dies ist ein erzähltechnisch wohlkalkulierter Kniff, ein impliziter Unsagbarkeitstopos: Wolfram betont nicht etwa, dass man die Pracht des Grals, seinen überirdisch-irdischen Glanz nicht beschreiben könne, sondern er lässt bewusst eine Leerstelle, um die herum nun allerdings der Abglanz des Ausgesparten mit einigem Aufwand beschrieben wird. Zusammengefasst wird das, was sich zeigt, mit einem Terminus, der ganz regelmäßig für Transzendenzeffekte in der Immanenz genutzt wird: das wunder. Dieser Terminus wird indes rückgebunden an die Wahrnehmung Parzivals, von der an zwei zentralen Stellen deutlich die Rede ist, allerdings nicht dort, wo man es am ehesten erwarten würde. Denn unmittelbar am Höhepunkt des Rituals, nachdem Repanse de Schoye den Gral in den Saal gebracht und vor Anfortas abgestellt hat, wird Folgendes erzählt:

dez mære giht daz Parzivâl

dicke an si sach unt dâhte,

diu den grâl dâ brâhte:

er het och ir mantel an.
In der Erzählung heißt es, Parzival habe die Trägerin des Grals eingehend betrachtet, mußte er doch daran denken, daß er ihren Mantel trug.

(Pz. 236,12-15)

Nicht etwa, dass Parzival über den Gral, der immerhin als wunsch von pardîs und erden wunsches überwal beschrieben wurde, staunen würde, nein: wiederholt blickt er auf Repanse. Hervorgehoben wird dabei, dass ihm auffällt, dass er ihren Mantel

10 Vgl. Pz. 483,25-28: „,daz in der frâge warnet iht, / sone solt diu frâge helfen niht, / wan daz der schade stüende als ê / und herzelîcher tæte wê."

11 Vgl. Corinna Dörrich: Poetik des Rituals. Konstruktion und Funktion politischen Handelns in mittelalterlicher Literatur. Darmstadt 2002, S. 44, die herausgestellt hat, dass bei Wolfram das Gralritual kein Erlösungsritual ist wie bei Chrétien, sondern ein Herrschaftsritual. Das gesamte Gralritual hat als Herrschaftsritual einiges mit der in der Schwertübergabe thematisierten Herrschaftsübergabe an Parzival zu tun, die mit Anfortas' Leiden zusammenhängt. Ja, das Gralritual wird gleichsam gerahmt durch die von ihm freilich prinzipiell zu trennenden Lanzen- und Schwertrituale (vgl. ebd., S.33). 
trägt. Mireille Schnyder spricht in diesem Zusammenhang von einer Art ,schielendem Staunen', das durch die Aufmerksamkeitsdifferenz zwischen Protagonist und Rezipient hervorgerufen werde. ${ }^{12}$ Man kann hier aber mit Jutta Eming auch „einen für diesen Erzähler typisch hintergründigen Hinweis auf eine offenkundige äußerliche Verbindung [erkennen], die eine geheime innere Verbindung - dass auch Parzival zum Gralgeschlecht gehört - schon andeutet. ${ }^{\prime 13}$

Parzival nimmt aber eben nicht nur Repanse wahr, seine Aufmerksamkeit scheint dem Gesamtzusammenhang zu gelten. Bevor Parzival schließlich von Anfortas das Schwert übergeben wird, hebt der Erzähler hervor:

wol gemarcte Parzivâl

die rîcheit unt daz wunder grôz: ${ }^{14}$

durch zuht in vrâgens doch verdrôz. er dâhte ,mir riet Gurnamanz mit grôzen triwen âne schranz, ich solte vil gevrâgen niht. [...] âne vrâge ich vernim wiez dirre massenîe stêt.'

(Pz. 239,8-17)
Parzival bemerkte wohl alle Pracht und das ganze wunderbare Geschehen, doch seine höfische Erziehung ließ ihn auf jede Frage verzichten. Er dachte bei sich: ,Gurnemanz [sein Erzieher, der ihm einige Lehren mitgab] hat mir wohlwollend und unzweideutig eingeschärft, keine unnützen Fragen zu stellen. Auch ohne Fragen werde ich schon erfahren, was es mit dieser Rittergesellschaft auf sich hat.'

Nicht zuletzt diese beiden Aussagen des Erzählers haben dazu geführt, dass es Forschungskonsens ist, dass „,die ganze Szene aus der Perspektive Parzivals erzählt ist",

12 Mireille Schnyder: Überlegungen zu einer Poetik des Staunens. In: Wie gebannt. Ästhetische Verfahren der affektiven Bindung von Aufmerksamkeit. Hg. von Martin Baisch, Andreas Degen und Jana Lüdtke. Freiburg 2013, S. 95-113, hier S. 108. Anders Cornelia Schu: Vom erzählten Abenteuer zum Abenteuer des Erzählens. Überlegungen zur Romanhaftigkeit von Wolframs Parzival. Frankfurt a. M. u. a. 2002, S. 268: „Der staunende Blick Parzivals, der ganz auf den szenischen Ablauf der prachtvollen Prozession gerichtet ist und die Trauer der Anwesenden dabei nicht registriert, wird durch die hervorklingende Stimme des Erzählers verdeutlicht, der immer wieder auf die Prachtentfaltung im Kontrast zu seiner eigenen Erfahrung verweist und dadurch das Staunen des Helden gleichsam humoristisch imitiert.“ Im Widerspruch hierzu steht Schus Beobachtung, dass Parzival nicht den Gral, sondern Repanse wahrnimmt, vgl. ebd., S. 269: „All dies entgeht jedoch Parzival, dessen Aufmerksamkeit sich auf die Trägerin des Grals richtet".

13 Jutta Eming: Aus den swarzen buochen. Zur Ästhetik der Verrätselung von Erkenntnis und Wissenstransfer im Parzival. In: Magia daemoniaca, magia naturalis, zouber. Schreibweisen von Magie und Alchemie in Mittelalter und Früher Neuzeit. Hg. von ders., Peter-André Alt, Tilo Renz und Volkhard Wels. Wiesbaden 2015, S. 75-99, hier S. 92.

14 Was unter den beiden Begriffen zu verstehen ist, wurde unterschiedlich beurteilt, vgl. hierzu Bernd Schirok: Die Inszenierung von Munsalvaesche. Parzivals erster Besuch auf der Gralburg. In: Literaturwissenschaftliches Jahrbuch 46 (2005), S. 39-78, hier S. 59. Jedenfalls ist die „rîcheit", wie sich auch im Gespräch mit Sigune zeigt, „Parzivals vorherrschender Eindruck“ (ebd., S. 65), wobei er auch die Kategorie des ,",grœzlîch wunder [...]“" (Pz. 251,26) anführt.

15 Bumke: Wolfram von Eschenbach (Anm. 7), S. 231. Northcotts, Bumkes und Kordts Meinung wurde gelegentlich diskussions- (und referenz)los in der Forschungsliteratur als Faktum behandelt - mit Konsequenzen für die Deutung, die auf diesem (diskutablen) Befund beruht, 
wie Joachim Bumke unter Berufung auf Kenneth Northcott meinte. ${ }^{16}$ Christa-Maria Kordt formulierte, ebenfalls einflussreich: „Der Erzähler nimmt die staunende Perspektive Parzivals ein. ${ }^{\prime 17}$ Die Fragen nach der Wahrnehmung Parzivals und ihrer Vermittlung im Erzählerbericht haben für das Mysterium des Grals aber größte Bedeutung, ja größere als der offensichtliche, eben herausgearbeitete implizite Unsagbarkeitseffekt. Meines Erachtens ist die zentrale Gralszene, so oft sie behandelt wird, zu häufig nach Maßgabe impliziter Präsuppositionen untersucht worden, die eine wesentliche Strategie der Verrätselung übersehen. ${ }^{18}$ Diese soll im Folgenden mit genauem Blick auf den Text herausgearbeitet werden, zu dessen Analyse ein modifiziertes narratologisches Instrumentarium benötigt wird.

\section{Die Fokalisierung in der Gralszene im Dienste der Verrätselung}

Die Passage nach dem Aufbruch von Pelrapeire wird eingeleitet, indem Wolfram die Rezipienten darauf hinweist, dass sie im Folgenden "grôziu wunder" (Pz. 224,3) wahrnehmen können. Insofern gegen Ende der Gralszene explizit hervorgehoben wird, dass Parzival „wunder grôz“ (Pz. 239,9) wahrnahm, könnte man davon ausgehen, dass das, was Parzival vor allem sieht, aber eben auch hört, riecht, schmeckt und fühlt, vom Erzähler wiedergegeben wird. Zunächst wird diese Annahme auch bestätigt: ,"er kom des âbnts an einen sê. [...] / einen er im schiffe sach [...]" (Pz. 225,2;8): Wolfram gibt wieder, wie Parzival an einen See kommt und was er dort sieht. Raum- und Zeitfilter erzeugen einen Fokalisierungseffekt. Im Weiteren allerdings verunklart sich die Situation. Denn nachdem Wolfram erzählt hat, dass Parzival nach einer Herberge fragte, fährt er fort: „,sus antwurte im der trûric man. / er sprach [...]" (Pz. 225,18f.). Gerade auch vor dem Hintergrund, dass der ,Fischer' Parzivals Gastgeber auf der Gralburg sein wird, den Parzival nach seinem Leiden zu fragen hat, ist es keineswegs nur narratologische Beckmesserei, wenn man sich fragt, ob die Attribuierung des Mannes als trûric eine Information des Erzählers ist oder ob es durchaus eine Eigenschaft ist, die Parzival auch wahrnimmt. ${ }^{19}$

vgl. etwa Susanne Knaeble: Höfisches Erzählen von Gott. Funktion und narrative Entfaltung des Religiösen in Wolframs Parzival. Berlin, New York 2011, S. 170 u. ö.

16 Vgl. Kenneth J. Northcott: Seeing and partly seeing. Parzival's encounters with the Grail. In: Spectrum medii aevi. Essays in early German literature. Festschrift für George Fenwick Jones. Hg. von William C. McDonald. Göppingen 1983, S.409-428, hier S. 413. Aber selbst wenn man vorsichtiger vorgeht, wie Dörrich: Poetik des Rituals (Anm. 11), S.77, scheint es mir nicht erwiesen, dass „die Außenperspektive der Rezipienten mit der Perspektive Parzivals, der zwar Teilnehmer, aber als Nicht-Eingeweihter auch Außenseiter des Rituals ist, zum Teil in Kongruenz gebracht" wird.

17 Christa-Maria Kordt: Parzival in Munsalvaesche. Kommentar zu Buch V/1 zu Wolframs Parzival (224,1-248,30). Herne 1997, S. 60.

18 Dies gilt selbst für den narratologisch informierten Beitrag von Astrid und Britta Bußmann: Die Fortsetzung als Bewältigung des Rätsels. Chrétiens graal und lance qui saine in Wolframs Parzival. In: Wolfram-Studien 23 (2014), S. 171-205.

19 Dass die Frage in diesem Fall kaum bzw. nicht entscheidbar ist, konstatieren auch Kordt: Parzival in Munsalvaesche (Anm. 17), S. 26, und Schirok: Die Inszenierung von Munsalvaesche (Anm. 14), S.49. Schirok zeigt aber durch Rekurs auf einige spätere Passagen (Parzival bei 
Narratologisch formuliert, greift hier eine von Gérard Genette zurecht als zentral herausgestellte Unterscheidung, die zwischen mode (Modus), also der Regulierung der narrativen Informationen, ${ }^{20}$ und voix (Stimme). Die Regulierung der narrativen Informationen hat Genette nach dem Aspekt der Distanz (also dem Grad der Mittelbarkeit des Erzählten) und dem der Wahrnehmung respektive Perspektive differenziert. Letzteres hatte Genette als Fokalisation bezeichnet und zunächst mit der Leitfrage qui voit?, später dann mit qui perçoit? belegt. Nun ist nicht nur aus narratologisch-systematischer Sicht die Genettesche Trias von Nullfokalisierung (der Erzähler weiß mehr als die Figur), interner (der Erzähler weiß so viel wie die Figur) und externer Fokalisierung (der Erzähler weiß weniger als die Figur) etwa von Wolf Schmid als reduktionistisch kritisiert worden. ${ }^{21}$ Darüber hinaus hat, auch mit Blick auf die mittelhochdeutsche Literatur, Gert Hübner in seiner wegweisenden Studie über Erzählformen im höfischen Roman ${ }^{22}$ nicht nur gezeigt, dass das Phänomen der Fokalisierung, also die Frage nach der Einschränkung der narrativen Informationen im Geflecht von Erzählstimme und intradiegetischen Figuren um einiges komplexer ist, als es die Genettesche Theorie im Besonderen, aber auch die in Handbüchern kondensierte Erzähltheorie im Allgemeinen nahelegen. Vielmehr hat Hübner im Zuge seiner Differenzierungen zugleich einige Kategorien Genettes kassiert, etwa dafür plädiert, dass man grundsätzlich nur zwischen fokalisiertem und auktorialem (also in keiner Weise eingeschränktem) Erzählen unterscheiden muss. Was nun die Art der Einschränkung betrifft, hat Hübner überzeugend für eine Zweiteilung argumentiert. Einerseits kann ein Fokalisierungseffekt erzielt werden durch eine Bewusstseinsdarstellung, andererseits durch die Einschränkung von Informationen auf den Wissensstand einer Figur, wiederum differenziert nach Wissenseinschränkungen mit Blick auf allgemeine Informationen oder aber die Zeit- bzw. Raumstruktur oder durch einen Innensichtfilter (das ist etwas anderes als Bewusstseinsdarstellung). Um es zusammenzufassen: Ein Text kann (makrostrukturell) mehr oder weniger fokalisiert erzählt sein und Fokalisierungseffekte können generell durch verschiedene Mechanismen erzeugt werden. Mikrostrukturell können neben der Bewusstseinsdarstellung unterschiedliche figurenbezogene Filter zum Einsatz kommen, die jeweils stricte zwischen Fokalisierung und Nichtfokalisierung unterscheiden lassen.

An Hübners Terminologie wurde durchaus angeschlossen: So hat Jutta Eming vorgeschlagen, mit Blick auf die Gralszene eine Psychonarration anzunehmen, Bußmann und Bußmann sprechen von relativer Filterung. ${ }^{23}$ In Hinsicht auf die

Sigune und bei Trevrizent), dass einiges dafür spricht, dass er Anfortas' Traurigkeit, sein Leiden weder auf dem See noch im palas wahrgenommen habe.

20 Vgl. Gérard Genette: Die Erzählung. 2. Aufl. München 1998, S. 115f.

21 Vgl. Wolf Schmid: [Art.] Perspektive. In: Handbuch Erzählliteratur. Theorie, Analyse, Geschichte. Hg. von Matías Martínez. Stuttgart, Weimar 2011, S. 138-145, hier S. 141.

22 Vgl. Gert Hübner: Erzählform im höfischen Roman. Studien zur Fokalisierung im Eneas, im Iwein und im Tristan. Tübingen, Basel 2003.

23 Vgl. Eming: Ästhetik der Verrätselung (Anm. 13), S.92, und Bußmann und Bußmann: Die Fortsetzung als Bewältigung des Rätsels (Anm. 18), S. 190, Anm. 60. 
Gesamtpassage muss man - so meine These - von „weniger fokalisiertem Erzählen“ ausgehen ${ }^{24} \mathrm{~d}$. h. dass der Erzählerbericht nicht durchgehend durch die Wahrnehmung und das Wissen Parzivals eingeschränkt wird. So erzählt Wolfram folgendermaßen von Parzivals Ankunft auf der Gralburg:

In die burc der küene reit, ûf einen hof wît unde breit. durch schimpf er niht zetretet was (dâ stuont al kurz grüene gras: dâ was bûhurdiern vermiten), mit baniern selten überriten, alsô der anger z'Abenberc. selten frœlîchiu werc was dâ gefrümt ze langer stunt: in was wol herzen jâmer kunt.
Der tapfere Parzival ritt in die Burg hinein und auf einen weiträumigen Hof, keine Spuren von Kampfspielen zeigte. Hier gab es offenbar keine Turnierkämpfe; über diesen Hof - wie über die Wiese von Abenberg - wurden nie die Banner turnierender Scharen getragen. Man kannte unterhaltsame Kampfspiele seit langem nicht mehr und die Burginsassen trugen tiefes Herzeleid.

(Pz. 227,7-16)

Zunächst bleibt offen, ob es Parzival selbst auffällt, dass der Zustand des Burghofs auf die Lethargie der Burgbewohner hindeutet oder nicht. Der Erzähler fügt dann folgenden Satz an, der nahelegt, dass eine Differenz zwischen dem Zustand des Hofs und Parzivals Erleben vorliegt: „wênc er des gein in enkalt“ (Pz. 227,17), also: Man ließ Parzival davon nichts - es handelt sich um eine Verneinung durch Untertreibung ${ }^{25}$ - merken. ${ }^{26}$ In jedem Fall zeigt der Vers, dass eine auktoriale Erzählerstimme spricht, die gerade durch keinen Innensichtfilter der Hauptfigur fokalisiert wird. Die Differenz zwischen dem tatsächlichen Zustand und dem, was Parzival wahrnehmen kann, bleibt auch im Fortgang der Passage bestehen, wenn er von den Rittern auf Munsalvæsche empfangen wird. Nachdem ihm der Mantel der Gralkönigin Repanse de Schoye angelegt worden ist, wird er gastfreundlich bewirtet: „man schancte im unde pflac sîn sô, / die trûregen wâren mit im vrô.“ (Pz. 228,25f.) Parzival kann gar nicht merken, dass er hier an einem freudlosen Hof ist, da sich dieser Hof nicht freudlos zeigt. Dies mag damit zusammenhängen, dass Parzival nicht zur Frage geführt werden darf, sondern von selbst auf sie kommen muss. Entscheidend für unseren Zusammenhang jedenfalls ist, dass hier das, was der Erzähler sagt, und das, was Parzival wahrnimmt, unterschieden werden müssen. Auch bei der Erzählung des sich anschließenden Rituals gibt Wolfram ganz überwiegend keinen Hinweis darauf, was Parzival wahrnimmt. Sein Bericht wird vielmehr auktorial eingeleitet. Die literarische Kommunikation findet zwischen dem Erzähler und seinen Rezipienten statt, die in das Geschehen durch die

24 Hübner: Erzählform im höfischen Roman (Anm. 22), S. 63.

25 Anders Eming: Ästhetik der Verrätselung (Anm. 13), S. 86 m. Anm. 48.

26 Anders Kordt: Parzival in Munsalvaesche (Anm. 17), S. 38: „Dieser Hinweis muß nicht bedeuten, daß Parzival von der seltsamen Atmosphäre nichts bemerkt“. Man wird hier zu keiner Gewissheit kommen, da Parzivals Wahrnehmung nicht mitgeteilt wird. 
detailgetreue, staunenswerte Erzählung involviert werden: Dies zeigt sich auch an weiteren Stellen, wenn der Erzähler eine Interjektion dezidiert mit einem unpersönlichen Ausdruck verbindet: „âvoy nu siht man [...]” (Pz. 235,8), oder wenn er die Rezipienten direkt anspricht: „nu hœrt ein ander mære.“ (Pz. 238,2) Man wird nun aber auch nicht annehmen können, dass Wolfram hier wie an anderen Stellen, etwa bei der Begegnung mit den Rittern im Wald von Soltane, auf eine kategoriale Differenz abhebt zwischen Parzivals Wahrnehmung und Gedanken und dem, was sich intradiegetisch abspielt. ${ }^{27}$

Es handelt sich vielmehr um eine Verrätselung. Die Strategie, die ich herausarbeiten möchte, besteht aus zwei gegenstrebigen Komponenten. Zum einen nimmt Wolfram alle Fokalisierungsindikatoren zurück, wie sie an anderen Stellen im Roman vorkommen, in denen durchaus auf die Wahrnehmung einer ankommenden Figur Wert gelegt wird. Neben der schon erwähnten Ankunft Parzivals am See ließen sich weitere Szenen anführen, etwa Gahmurets Ankunft in Patelamunt:

Swaz dâ was volkes inne, Mœre und Mœrinne was beidiu wîp unde man. der hêrre schouwen began manegen schilt zebrochen, mit spern gar durchstochen:

(Pz. 19,17-22)
Die gesamte Bevölkerung der Stadt, Frauen und Männer, bestand aus Mohren und Mohrinnen. Unser Edelmann sah viele zerborstene, von Lanzen arg durchstoßene Schilde hängen.

Deutlicher noch wird die Verschleierung der Perspektive aber im Abgleich mit Wolframs Vorlage, Chrétiens Text. ${ }^{28}$ Hier wird über das gesamte Gralritual hinweg immer wieder deutlich auf die Wahrnehmung gerade auch Percevals abgehoben. Ich habe die jeweiligen Sätze im Folgenden zusammengestellt, die explizit darauf hinweisen, dass Perceval etwas sieht. Dies beginnt beim Betreten des Saals:

Anmi la sale sor un lit

Un bel prodome seoir vit,

Qui estoit de chienes meslez; [...]
Inmitten des Saales sah er auf einer Lagerstatt einen schönen Edelmann sitzen, welcher teilweise ergraut war; $[\ldots]$

(V.3085-3087)

27 Esther Laufer: Anmerkungen zur Fokalisierung in Wolframs Parzival. In: Vielheit und Einheit der Germanistik weltweit. Hg. von Franciszek Grucza. Bd.5, Sektion 38: Vielheit und Einheit des Erzählens? Möglichkeiten einer historischen Narratologie. Hg. von Matías Martínez, Magdolna Orosz und Christopher Young. Frankfurt a. M. u. a. 2012, S. 221-225.

28 Chrétien de Troyes: Der Percevalroman (Le Conte du Graal). Übers. und eingel. von Monica Schöler-Beinhauer. München 1991. 
Ja, er erkennt etwa bei der Präsentation des Schwerts seine Produktionsstätte gut:

Et il l'a bien demie treite,

$\mathrm{Si}$ vit bien ou ele fu feite;

Car an l'espee estoit escrit.

Et avuec ce ancore i vit

Qu'ele estoit de si bon acier [...]
Und dieser hat es gut zur Hälfte gezogen, so sah er deutlich, wo es gemacht wurde; denn es stand auf dem Schwert geschrieben. Und außerdem sah er noch, daß es aus so gutem Stahl war, [...]

(V.3135-3139)

Es sind nicht nur einzelne Dinge, die Perceval wahrnimmt, vielmehr registriert er umfassend, was sich im Saal und um ihn herum ereignet:

Derriers lui vit vaslez ester

Antor le feu qui cler ardoit;

Celui qui ses armes gardoit

I vit $[\ldots]$
Hinter sich sah er einen Knappen am Feuer stehen, welches hell brannte; den, der seine Rüstung aufbewahrte, sah er dort $[\ldots]$

(V.3180-3183)

Bei Chrétien erscheint, wie bei der Präsentation der Lanze deutlich wird, der gesamte Raum von gesteigerter Aufmerksamkeit zu sein:

Et tuit cil de leanz veoient

La lance blanche et le fer blanc,

S'issoit une gote de sanc

Del fer de la lance an somet,

Et jusqu'a la main au vaslet

Coloit cele gote vermoille.

Li vaslez vit cele mervoille

Qui leanz ert la nuit venuz,

Si s'est del demander tenuz

Comant cele chose avenoit; [...]
Und alle dort drinnen sehen die helle Lanze und das blanke Eisen, und ein Blutstropfen löste sich von dem Eisen an der Lanzenspitze, und dieser rote Tropfen rann herab auf die Hand des Knappen. Der Bursche, der am Abend dort hereingekommen war, sah dieses Wunder, doch er hat sich davon zurückgehalten zu fragen, wie diese Sache zustande kam; $[\ldots]$

\section{(V.3196-3205)}

Dies gilt schließlich auch für die sich mehrfach wiederholende Gralprozession; Percevals kontinuierliche Aufmerksamkeit wird deutlich hervorgehoben:

Et li vaslez les vit passer

Et n'osa mie demander

Del graal cui l'an an servoit, [...]
Und der Bursche sah sie vorbeigehen und wagte keinesfalls danach $\mathrm{zu}$ fragen, wen man mit dem Gral speiste, [...]

(V.3243-3245) 
Mes plus se test qu'il ne covient, Qu'a chascun més don l'an servoit Par devant lui trespasser voit Le graal trestot descovert, [...]
Aber er schweigt mehr als es sich geziemt, denn bei jedem Gericht, mit dem man ihn bediente, sieht er vor sich vorüberschreiten den Gral (völlig sichtbar/ unbedeckt) $[\ldots]$

(V.3298-3301)

Die romanistische Diskussion, wie die Wendung ,trestot descovert' genau zu verstehen ist, spielt keine Rolle für unsere Fragestellung. ${ }^{29}$ Wichtig ist, dass Percevals Wahrnehmung deutlich und kontinuierlich von Chrétien hervorgehoben wird. Vor diesem Hintergrund spricht einiges dafür, dass Wolfram hier bewusst anders verfährt. ${ }^{30}$

Die Strategie der Verrätselung besteht nun darin, dass neben der grundsätzlichen Zurücknahme von Fokalisationsindikatoren andererseits durchaus punktuell auf Parzivals Wahrnehmung rekurriert wird, und zwar in einer Weise, die ihn als Fokalisator erscheinen lässt. Eben diese Widersprüchlichkeit zeigt sich, in Ergänzung zu den schon behandelten Passagen, bereits beim Betreten des palas, des Festsaals, in dem die Lanzenszene, das Mahl und die Schwertübergabe stattfinden. Der Erzähler berichtet: „[S]i giengen ûf ein palas“ (Pz. 229,23) - für mich handelt es sich um eine Richtungsangabe -, um direkt darauf den Raum zu beschreiben. In die descriptio aber streut er Parzival als Wahrnehmungsinstanz punktuell ein:

hundert krône dâ gehangen was,

vil kerzen drûf gestôzen,

ob den hûsgenôzen,

kleine kerzen umbe an der want. hundert pette er ligen vant [...]. der wirt sich selben setzen bat gein der mitteln fiwerstat ûf ein spanbette.
Über den Versammelten hingen hundert Kronleuchter mit vielen Kerzen, während ringsum an den Wänden kleinere Kerzenhalter befestigt waren. Im Saal fand er hundert Ruhelager. In der Nähe des mittleren Kamins hatte sich der Burgherr auf einem Ruhelager niedergelassen.

(Pz. 229,24-28; 230,15-17)

Mit Blick auf den Vers „hundert pette er ligen vant“ erscheint Parzival als Fokalisator. Angesichts des Pronominagebrauchs im Mittelhochdeutschen - das Pronomen referiert auf die Figur, die die Passage ,regiert' - ist es unumgänglich, den erratischen Vers im Sinne eines Fokalisierungseffekts zu begreifen. Aber ist die descriptio wirklich deckungsgleich mit Parzivals Wahrnehmung? Erst an ihrem Ende heißt es explizit: „,in [in G: Uf] den palas kom gegangen / der dâ wart wol enpfangen, / Parzivâl der lieht gevar, / von im der in sante dar." (Pz. 230,21-24) Nun kann

29 Schöler-Beinhauer folgt hier der Deutung von Jean Frappier: Le graal trestot descovert. In: Romania 71 (1950), S. 240-245.

30 Vgl. Kordt: Parzival in Munsalvaesche (Anm. 17), S. 117. 
man das Präteritum anstelle des umschriebenen Plusquamperfekt im Sinne eines vorvergangenen Geschehens betrachten: Dann würde Wolfram das Betreten des Festsaals zunächst nicht explizit nennen, sondern in einem eher zeitdehnenden Verfahren Parzivals Wahrnehmung beim Betreten des Saals beschreiben und erst dann nachtragen, dass Parzival den Festsaal bereits betreten hatte. In die Beschreibung von Parzivals Wahrnehmung wären auch Erzählerkommentare integriert, die Parzivals Bewusstsein dezidiert entzogen sind ${ }^{31}$ und so deutlich den Eindruck einer kaum fokalisierten Passage erzeugen. Oder man begreift den inmitten der descriptio erratisch gesetzten Vers als Prolepse - angesichts der fehlenden Indikatoren eher eine technische Lösung zum Verständnis des lakonischen Ausdrucks.

Man kann es drehen und wenden, wie man will: Insgesamt hat die Passage den Charakter eines nicht-fokalisierten Erzählerberichts, durch den der Raum und auch Anfortas in seinem Leid beschrieben werden. Das Geschehen läuft beobachterunabhängig ab. Dem widersprechende, punktuell eingesetzte Indikatoren einer Fokalisation durch Parzival erzeugen aber eine Wahrnehmungsdiffusion, die den gerichteten Blick unterminiert. Die Verrätselung, die figurenbezogene Aspekte buchstäblich im Dunkeln lässt, erscheint dabei insofern funktional, als sie es ermöglicht, den Kern des Rituals, auf den alles hinausläuft, wahrnehmungstranszendent als Mysterium zu evozieren, also eher zu verbergen als zu enthüllen.

Dabei ist es nicht so, dass Wolfram suggerieren möchte, dass Parzival den Gral in dieser Situation nicht gesehen hat. ${ }^{32}$ So heißt es schon bei der Erzählung der Geschehnisse am Morgen nach dem skurrilen Gralabend:

umbe den wurf der sorgen wart getoppelt, do er den grâl vant, mit sînen ougen, âne hant und âne würfels ecke.
Als Parzival zum Gral kam, wurde um sein Lebensglück gewürfelt, und dies nur mit seinen Augen, ohne daß seine Hand einen Würfel berührt hätte.

(Pz. 248,10-13)

Die etwas kryptische Aussage - man mag an Gottfrieds Verdikt der „,bickelworte" (ja doch wohl ,Würfelworte') denken - stellt deutlich aus, dass Parzival den

31 Vgl. Pz. 230,4f.; 12f. und 18-20: „,fil li roy Frimutel / mohte wol geleisten daz. / [...] / sô grôziu fiwer sît noch ê / sach niemen hie ze Wildenberc: / [...] / ez was worden wette / zwischen im und der vröude: / er lebte niht wan töude." Da der Gral jugendliches Aussehen verleiht, gibt es, wie Bernd Schirok zurecht betont hat, keinen Grund dafür, anzunehmen, dass Parzival etwas von dem Leiden des Anfortas wahrnimmt; vgl. Schirok: Die Inszenierung von Munsalvaesche (Anm. 14), S. 55.

32 Bußmann und Bußmann: Die Fortsetzung als Bewältigung des Rätsels (Anm. 18), S. 191, listen folgende Möglichkeiten auf, dem Resultat stimme ich uneingeschränkt zu: „Vielleicht sieht Parzival den Gral tatsächlich nicht, weil er zu sehr auf die Gralträgerin Repanse de Schoye fixiert ist (236,12-15); vielleicht ist er auch zu tump, um den Gral begreifen zu können; vielleicht entzieht sich der Gral in seiner Inkommensurabilität ohnehin jeder Bezeichnung. Unabhängig davon, welcher dieser Deutungen man zuneigt, provoziert das Schweigen des Textes immer auch die Neugier des uneingeweihten Publikums und trägt so zum ostentativen Geheimnischarakter des deutschen Grals bei." 
Gral gesehen hat. Dies wird auch am Ende des Romans nochmals betont, wenn im Zusammenhang der zweiten Gralzeremonie die frühere nochmals aufgerufen wird - ,zeiner zît dô Parzivâl / ouch dâ für sach tragn den grâl.“ (Pz. 808,15f.)

Im Kontext dieser zweiten Gralzeremonie, die am Ende des Romans erzählt wird und in der die Lanze fehlt, wird in inverser Bezugnahme auf die erste Gralszene mit einer Begründung davon erzählt, wie der Gral nicht gesehen wird. Dort sitzt nämlich sein Halbbruder Feirefiz neben Anfortas. Da dieser nicht getauft ist, kann er (anders als Parzival) den Gral nicht sehen, seine Aufmerksamkeit gilt vielmehr (ebenfalls) Repanse, zu der er in heftiger minne entbrennt. Feirefiz, der Heide, der den Gral als Ungetaufter gar nicht sehen kann, fragt nach der Ursache des Speisewunders:

der heiden vrâgte mære, wâ von diu goltvaz lære vor der tafeln wurden vol. daz wundr im tet ze sehen wol. dô sprach der clâre Anfortas, der im ze geselln gegeben was, ,hêr, seht ir vor iu ligen den grâl?’ dô sprach der heiden vêch gemâl ,ich ensihe niht wan ein achmardî: daz truoc mîn juncfrouwe uns bî, diu dort mit krône vor uns stêt. ir blic mir inz herze gêt. [...]

(Pz. 810,3-14)
Der Heide erkundigte sich, wie es kam, daß sich die Goldschalen vor der Speisetafel stets von selbst füllten; dieses wunderbare Geschehen beeindruckte ihn sehr. Da fragte sein Tischgenosse Anfortas: ,Herr, seht Ihr denn nicht den Gral vor Euch liegen?' Der schwarz und weiß gefleckte Heide erwiderte: ,Ich sehe nur ein grünes Seidentuch. Das trug die Jungfrau zu uns herein, die dort gekrönten Hauptes vor uns steht. Der Glanz ihrer Schönheit geht tief in mein Herz.'

\section{Wolframs artifizielles Kryptogramm}

Was nun lässt sich aus diesen Beobachtungen schließen? Wolfram schildert ein formvollendetes Ritual ${ }^{33}$ und er tut dies so detailliert, dass die Rezipienten dem blendenden Vorgang unter Nutzung ihrer Imaginationskraft gebannt folgen können; ausgespart bleibt dabei das dinc, das im Zentrum steht. In dem Maße, in dem sich kein Reflektor ausmachen lässt, wird verrätselt, was genau wahrgenommen werden kann. Dadurch wird an dieser Stelle die Notwendigkeit der Erzählung ei-

33 Vgl. Dörrich: Poetik des Rituals (Anm. 11), S. 33: „Wolframs Gralsritual bietet alles, was ein Ritual an formaler Regulierung überhaupt bieten kann: Es zeigt einen streng festgelegten, wiederholbaren Ablauf mehrerer analog strukturierter, in sich aber auch variierter Handlungssequenzen. Die Bewegungen der geschlechtlich, ständisch und vestimentär exklusiven Akteure sind ebenso festgelegt wie ihre Positionen im Raum und ihre Gesten. Bestandteile des Rituals sind neben mehreren rituellen Gegenständen zahlreiche visuelle und olfaktorische Reize. Es findet in einem repräsentativen Raum statt, der nicht zuletzt auch über die für das gesamte Ritual wichtige Zahlensymbolik in den Ordo des Rituals einbezogen ist." Die Bedeutung der Wahnehmung betont Kordt: Parzival in Munsalvaesche (Anm.17), S. 138f: Der „Grund für Parzivals Schweigen muß in seiner Wahrnehmung gesucht werden." 
nes gerichteten Blicks unterbunden, was Bedingung der Möglichkeit ist, das Gralmysterium narrativ zu entfalten, ohne dass aber bestritten würde, dass Parzival den Gral gesehen hat. Die Gralszene schildert ein Ritual, das um ein mysteriöses Ding kreist; figurenbezogene Fragen werden hintangestellt.

Anders als figurenbezogene Lektüren es nahelegen, ${ }^{34}$ steht somit hier nicht Parzival im Fokus, sondern der Gral, der nicht als leeres, aber mysteriöses Zentrum des Geschehens figuriert. ${ }^{35}$ Erst an späterer Stelle, in der Blutstropfenszene, werden Parzivals Wahrnehmung und vor allem die Verarbeitung des Wahrgenommenen im Zentrum stehen. ${ }^{36}$ Und erst nach dem Frageversäumnis entwickelt Parzival, wie Katharina Mertens Fleury herausgestellt hat, „,sukzessive einen leid- und personenbezogenen affectus compassionis, eine Form partieller Angleichung und Leidenspartizipation, die auf das Leiden des Anfortas und Christi Passion ausgerichtet ist". ${ }^{37}$

Harald Haferland hat dafür argumentiert, dass es sich beim Parzival um ein ,Lesemysterium' handle. ${ }^{38}$ Es geht mir nun nicht um die hermetischen Traditionen, die möglicherweise hinter dem Text stehen, wohl aber darum, darauf hinzuweisen, dass durch die wohlkalkulierte und aufwendige Erzählweise hier ein Geheimnis verborgen und enthüllt wird: Parzival wird zur Nebenfigur vor dem Hintergrund eines Erzählens, das die größere Wahrheit hinter dem Pergament und inter lineas als Mysterium inszeniert. Das Erzählen stellt sich ganz in den Dienst eines Erzählten, das durch das Erzählen selbst kaum eingefangen, allenfalls suggeriert werden kann. Man könnte diese Linie für eine Gesamtdeutung des Texts ausbauen: Denn es ist offensichtlich, dass mit Blick auf die Figur Bewertungen im Umfeld des jungen Parzival von der Rede (und Deutung des Geschehens) durch Trevrizent abgekoppelt werden müssen. ${ }^{39}$ Ein Kontinuum über den Gesamttext hinweg ist hingegen das Mysterium, zu dessen Evokation verschiedene Strategien der Verrätselung eingesetzt werden.

34 Nach dem Muster: Der junge Parzival sei stark von höfischer Prachtentfaltung fasziniert - eine Pracht, die ihm in den einfachen Verhältnisses des Waldes von Soltane vorenthalten wurde, in denen er aufgewachsen ist. Freilich sind es Aspekte von "rîcheit" und großem „wunder", die Parzival in der Gralszene bannen, in der Erzählung selbst spielen aber sowohl Wahrnehmung als auch Mitleid keine Rolle. Vgl. Northcott: Seeing and partly seeing (Anm. 16), bes. S. 413.

35 Vgl. Bußmann und Bußmann: Die Fortsetzung als Bewältigung des Rätsels (Anm. 18), S. $187 f$. Gegenüber Chrétien nimmt Wolfram die Lanze in ihrer Bedeutung zurück.

36 Vgl. Joachim Bumke: Die Blutstropfen im Schnee. Über Wahrnehmung und Erkenntnis im Parzival Wolframs von Eschenbach. Tübingen 2001.

37 Katharina Mertens Fleury: Leiden lesen. Bedeutungen von compassio um 1200 und die Poetik des Mit-Leidens im Parzival Wolframs von Eschenbach. Berlin, New York 2006, S. 195.

38 Vgl. Haferland: Die Geheimnisse des Grals (Anm. 5), S.34f.: „In wenigen Worten: Parzival wird am Pfingstsonntag zur Gralherrschaft berufen - dies errechnet man, indem man drei Zeitangaben Wolframs miteinander verrechnet. Damit greift (nach Apg. 2) der Heilige Geist ins Geschehen ein - dies erkennt man zusätzlich an der wiederholten Erwähnung seines Symbols, der Taube, auf dem Gralwappen. Damit vollendet aber gleichzeitig die Trinität ihr Heilswerk [...]. Von nun an erlangen Gral und Gralherrschaft ihre geheime Heilsbedeutung bis in Wolframs Gegenwart hinein und gar darüber hinaus".

39 Vgl. Walter Blank: Mittelalterliche Dichtung oder Theologie? Zur Schuld Parzivals. In: Zeitschrift für deutsches Altertum und deutsche Literatur 100 (1971), S. 133-148, hier S. 134-139. 
Künstlerweihe

Wir wandern stumm, verschüchtert, bang gebückt

Und bergen scheu, was wir im Herzen hegen

Und reden Worte, die uns nicht bewegen,

Und todte Dinge preisen wir entzückt.

Die Seele ist vergraben und erstickt ..

Verfaultes leuchtet fahl auf nächt'gen Wegen ..

Und sind wir müde, soll uns Kunst erregen,

Bis wir im Rausch der leeren Qual entrückt ...

Jüngst fiel mein Aug' auf Meister Wolframs Buch

Vom Parcival, und vor mir stand der Fluch,

Der vom verlor'nen Gral herniederklagt:

,Unseliger, was hast du nicht gefragt?!

In Mitleid ahnend stumme Qual befreie:

Das ist einzig-eine Künstlerweihe! .. ${ }^{40}$

Dieses Sonett des - natürlich - frühen Hofmannsthal setzt, so hat Volker Mertens zurecht hervorgehoben, ${ }^{41}$ Wolfram gegenüber Wagner wieder in sein Recht. Mir kommt es abschließend nicht auf die Entgegensetzung des „Rauschs der leeren Qual“ und der Emphase auf Wolframs Dichtung an. Vielmehr möchte ich auf die Pointe Hofmannsthals hinweisen, mit der er auf diametral andere Weise auf den Gral reagiert, als dies der eingangs erwähnte Oskar Ernst Bernhardt tut. Hofmannsthal kommt es nicht auf die Einweihung in ein religiöses Mysterium an, vielmehr hebt er auf die Artifizialität von Wolframs Roman ab. Und: Der Gral interessiert hier vor allem als verlorener. Die Mitleidsthematik wird nur kurz und kryptisch angesprochen; sie tritt hinter der Inspirationskraft des Kunstwerks, hinter Wolframs ,Erzählwunder` zurück. Es ist vielleicht Signum der Moderne, dass das, was bei Wolfram noch eine Einheit war, ein hochartizifielles Kryptogramm, nun zerfallen ist in ,christliches Sektierertum' auf der einen, Ästhetizismus auf der anderen Seite. Dies ist allerdings eine Alternative, die der , anders' komplexen und differenzierten Situation von Wolframs Entwurf kaum gerecht werden kann.

40 Hugo von Hofmannsthal: Sämtliche Werke II: Gedichte 2. Hg. von Andreas Thomasberger und Eugene Weber. Frankfurt a. M. 1988, S. 48.

41 Vgl. Volker Mertens: Der Gral. Mythos und Literatur. Stuttgart 2003, S. $214 f$. 


\title{
Rätsel und Geheimnis im Wartburgkrieg \\ Epistemologische und ästhetische Dimensionen des Rätselwettstreits
}

\author{
Beate Kellner
}

Peter Strohschneider zum 65. Geburtstag gewidmet

\section{Wartburgkrieg: Rezeption - mittelalterliche Überlieferung}

Das Interesse an der Sage vom sogenannten Wartburgkrieg erreichte im Zuge der Mittelalterbegeisterung des 19. Jahrhunderts seinen Höhepunkt. In seinem unvollendet gebliebenen, 1802 postum erschienenen Roman Heinrich von Ofterdingen stellte Novalis zu Beginn des 19. Jahrhunderts einen der mittelalterlichen Sänger des Wartburgkriegs ins Zentrum. E.T.A. Hoffmann widmete sich dem Sängerwettstreit in seiner Erzählung Der Kampf der Sänger von 1818 und Friedrich de la Motte Fouqué brachte 1828 das Dichterspiel Der Sängerkrieg auf der Wartburg heraus. Mit Richard Wagners 1845 am Königlich Sächsischen Hoftheater in Dresden uraufgeführter Oper Tannhäuser und der Sängerkrieg auf Wartburg wurden die Traditionen vom sogenannten Wartburgkrieg und der Sage vom Tannhäuser im Venusberg verbunden, was eine erhebliche Transformation beider Stoffe mit sich brachte. Obgleich das Thema des Sängerkriegs in Wagners Oper der Frage nach der Erlösung Tannhäusers untergeordnet wurde, gab diese auch der Vorstellung vom Sängerwettstreit neue Strahlkraft. Im Zuge der Wiederentdeckung der Wartburg als literarischem, geschichtlichem und politischem Erinnerungsort im 19. Jahrhundert und ihrer Restaurierung ab 1838 erteilte Großherzog Carl Alexander zwischen 1854 und 1856 Moritz von Schwind den Auftrag, mehrere Räume der Burg mit Fresken auszugestalten. Das größte Fresko stellt den Sängerstreit dar und vermittelt durch seine Aufschrift auch heutigen Betrachtern noch, dass man sich tatsächlich am Ort des historischen Geschehens des Sängerstreits befinde: „IN DIESEM SAALE WURDE DER SÆNGER= / STREIT GEHALTEN DEN 7ten JULI 1207 / DEM GEBURTSTAG DER HEIL. ELISABETH.“ Die Wartburgkrieg-Begeisterung blieb mit zunehmender nationalistischer Tendenz bis ins 20. Jahrhundert hinein ungebrochen. ${ }^{1}$

1 Vgl. Burghart Wachinger: Der Sängerstreit auf der Wartburg. Von der Manesseschen Handschrift bis zu Moritz von Schwind. Berlin, New York 2004; Herfried Münkler: Die Deutschen und ihre Mythen. 2. Aufl. Berlin 2009, S.301-327; Jan Hallmann: Studien zum mittelhochdeutschen Wartburgkrieg. Literaturgeschichtliche Stellung - Überlieferung-Rezeptionsgeschichte. Mit einer Edition der Wartburgkrieg-Texte. Berlin, Boston 2015, S. $9 f$. 
Blickt man auf die mittelalterliche Überlieferung, so zeigt sich, dass die Sage vom Sängerwettstreit auf der Wartburg in der spätmittelalterlichen Thüringer Historiographie ausgestaltet wurde. ${ }^{2}$ Zugrunde liegt die ältere literarische Tradition von Sangsprüchen in zwei Tönen, dem Thüringer Fürstenton und dem Schwarzen Ton. Wir haben es hier mit einer breiten Überlieferung vom 13. bis zum 15. Jahrhundert zu tun, in der die Spruchgedichte vom Wartburgkrieg immer neue Fortsetzungen und Weiterdichtungen erfuhren. Insgesamt ist das Textfeld in etwa 30 Codices und Fragmenten tradiert. ${ }^{3}$ Die Hauptüberlieferungszeugen stellen aus älterer Zeit die Große Heidelberger Liederhandschrift (C) und die Jenaer Liederhandschrift (J) dar, daneben ist die ins 15. Jahrhundert zurückgehende Meistersingerhandschrift, die Kolmarer Liederhandschrift (k), als eine dritte Corpushandschrift mit einem großen Bestand an Wartburgkriegstrophen zu betrachten. Die Zuordnungen zu Autoren und Tonurhebern divergieren in den Handschriften zwischen Heinrich von Ofterdingen, Wolfram von Eschenbach und Klingsor von Ungerlant. ${ }^{4}$

Auch die Meinungen darüber, welche Texte unter dem Begriff des Wartburgkriegs zu fassen sind, waren vom Beginn der Forschungsgeschichte an verschieden; im Sinne des Herausgebers Tom Albert Rompelman sind nur das Fürstenlob und das Rätselspiel, ${ }^{5}$ bei Burghart Wachinger zusätzlich noch Zabulons Buch ${ }^{6}$ darunter zu rechnen. Karl Simrock hat die sieben Spruchgedichte Fürstenlob, Rätselspiel, Totenfeier, Aurons Pfennig, Zabulons Buch, Sprechen ohne Meinen und An Zeitgenossen

2 Grundlegend zur Darstellung und Bewertung der historiographischen Quellen noch immer: Burghart Wachinger: Sängerkrieg. Untersuchungen zur Spruchdichtung des 13. Jahrhunderts. München 1973, S. 52-60.

3 Vgl. die umfassende Übersicht über die Texte und ihre Überlieferung in: Repertorium der Sangsprüche und Meisterlieder des 12. bis 18. Jahrhunderts. Hg. von Horst Brunner und Burghart Wachinger. Bd.5: Katalog der Texte. Älterer Teil, Q-Z. Bearb. von Frieder Schanze und Burghart Wachinger. Tübingen 1991, S. 492-538; der jüngste Handschriftenfund wurde publiziert von Klaus Klein und Helmut Lomnitzer: Ein wiederaufgefundenes Blatt aus dem Wartburgkrieg-Teil der Jenaer Liederhandschrift. In: Beiträge zur Geschichte der deutschen Sprache und Literatur 117 (1995), S. 381-403. Vgl. dazu Wachinger: Sängerkrieg (Anm. 2), S.7-24; Burghart Wachinger: [Art.] Der Wartburgkrieg. In: Verfasserlexikon. 2. Aufl. Bd.10. Hg. von Burghart Wachinger u. a. Berlin u. a. 1999, Sp. 740-766; vgl. Hallmann: Studien (Anm. 1), S. 22-96.

4 Die Jenaer Liederhandschrift weist das Fürstenlob dem „,von Ofterdingen“ (Bl.123ff.) zu, das Rätselspiel und die anderen Textteile erscheinen unter der Überschrift „Her Wolueram“ (Bl. 127ff.); vgl.: Die Jenaer Liederhandschrift. Bd. I: Getreuer Abdruck des Textes. Hg. von Georg Holz. Hildesheim 1966 (Nachdruck der Ausgabe Leipzig 1901), S. 214-235. In der Großen Heidelberger Liederhandschrift wird der Wartburgkrieg unter dem Autor „Klingesor von Vngerlant“ geführt (Bl. 219vff.); vgl. Die Große Heidelberger ,Manessische' Liederhandschrift. In Abbildung hg. von Ulrich Müller mit einem Geleitwort von Wilfried Werner. Göppingen 1971. In der Kolmarer Liederhandschrift werden die Textteile unter den Überschriften "In clingesores swarczem ton“ (Bl. 680rff.) und „In dem gekauften oder in dem fursten ton Heinrichs von Offterdingen. Von erst die zwene kriege“ (Bl. 756rff.) sortiert; vgl.: Die Kolmarer Liederhandschrift der Bayerischen Staatsbibliothek München (Cgm 4997). In Abbildung hg. von Ulrich Müller, Franz Viktor Spechtler und Horst Brunner. 2 Bde. Göppingen 1976.

5 Tom Albert Rompelman: Der Wartburgkrieg: Kritisch herausgegeben. Amsterdam, Paris 1939.

6 Vgl. Wachinger: Sängerkrieg (Anm. 2), S. 5-89. 
als Wartburgkrieg gefasst. ${ }^{7}$ Neben diesen altbezeugten Textstücken existieren (in k) weitere Strophenfolgen, die unter den Titeln der Höllenkrieg, der Hort von der Astronomie, der Stubenkrieg oder der Sonrat geführt werden und als Weiterdichtungen der ursprünglicheren Texte zu verstehen sind. Die neueste, 2015 erschienene Monographie zum Wartburgkrieg-Komplex von Jan Hallmann grenzt ein Textfeld ab, das sich aus Rätselspiel, Aurons Pfennig, Totenfeier, Fürstenlob, Zabulons Buch, Der Meister Lob, Stubenkrieg, Sonrat und Hort von der Astronomie zusammensetzt. ${ }^{8}$ Jenseits unterschiedlicher Kriterien der Auswahl und Festlegung im Rahmen divergierender Forschungsparadigmata wurde das sogenannte Rätselspiel, um das es im Folgenden gehen soll, seit jeher zum Kernbestand des Wartburgkriegs gerechnet.

\section{Kennzeichen der Wartburgkrieg-Überlieferung}

Bis in die jüngere Überlieferung hinein sind die Texte des Wartburgkriegs durch einen relativ festen Bestand an Figuren, durch Rekurrenzen auf das Singen vor dem Thüringer Hof und vor allem durch das Prinzip dialogisch strukturierter Rede bestimmt. Der Sängerwettstreit wird über weite Strecken als Kampf auf Leben und Tod inszeniert, was besonders durch das poetologisch bedeutsame Vokabular des kriegens zum Ausdruck gebracht wird. So heißt es etwa im unteren Teil des berühmten Doppelbildes der Heidelberger Liederhandschrift C: „Hie kriegent mit sange her Walther von der Vogilweide, her Wolfram von Eschilbach, her Reiman der Alte, der Tugendhafte Schriber, Heinrich von Oftertingen und Klingesor von Ungerlant“ (Bl. 219v). In k wird der Fürstenton eingeleitet mit den Worten „In dem gekauften oder in dem furstenton Heinrichs von Ofterdingen. Von erst die zwene kriege“ (Bl. 756 v), und korrespondierend damit wird an späterer Stelle wie folgt auf Zabulons Buch verwiesen: „Diß ist der Oberkrieg in dem kauften oder fürstenton" (Bl. 759v). ${ }^{9}$ Forschungstitel wie Rätselspiel oder Fürstenlob verdecken die wichtige Dimension des Agonalen zugunsten des Spielerischen und blenden damit die Ebene der poetologischen Selbstbeschreibung der Literatur aus dem Gegenstandsbereich der Literaturwissenschaft aus. Zusammenfassend kann man sagen: Im „kriegen“ versuchen die Sänger, sich gegenseitig zu übertreffen und die jeweils anderen bewusst herabzusetzen, zum Schweigen zu bringen und auszuschalten. Im Kontext der Wartburgkrieg-Texte erfolgt dies vor allem als Wettstreit im Loben (Fürstenlob), im Erzählen (Zabulons Buch) und im Stellen und Lösen von Rätseln (Rätselspiel).

7 Vgl. Der Wartburgkrieg. Hg., geordnet, übersetzt und erläutert von Karl Simrock. Stuttgart, Augsburg 1858.

8 Vgl. Hallmann: Studien (Anm. 1).

9 Vgl. dazu Beate Kellner und Peter Strohschneider: Die Geltung des Sanges. Überlegungen zum Wartburgkrieg C. In: Neue Wege der Mittelalter-Philologie. Landshuter Kolloquium 1996. Hg. von Joachim Heinzle, L. Peter Johnson und Gisela Vollmann-Profe. Berlin 1998, S. 143-167; Beate Kellner und Peter Strohschneider: Poetik des Krieges. Eine Skizze zum WartburgkriegKomplex. In: Das fremde Schöne. Dimensionen des Ästhetischen in der Literatur des Mittelalters. Hg. von Manuel Braun und Christopher Young. Berlin, New York 2007, S. 335-356, mit reichem Belegmaterial. 


\section{Rätselspiel- Überlieferungssituation und Grundstruktur}

Ein Syntagma des Rätselwettstreits ist in den drei Lohengrinhandschriften (gemeinsame Sigle: L) sowie in der Überlieferung nach der Heidelberger Liederhandschrift (C, B1. 222 $2^{\mathrm{r}}-226^{\mathrm{r}}$ ) erkennbar, dies gilt jedoch in nur sehr eingeschränktem Maße für die Jenaer Liederhandschrift (J, Bl. 127 $7^{\mathrm{v}}-128^{\mathrm{r}} ; 129^{\mathrm{v}}-135^{\mathrm{r}}$ und $136^{\mathrm{v}}$ mit Dillinger Blatt), ${ }^{10}$ obgleich auch sie alte Rätselüberlieferung aufweist, und es trifft noch weniger zu für die jüngere Kolmarer Liederhandschrift, die im sogenannten "Schwarzen Ton“ (k, Bl. $\left.680^{\mathrm{r}}-705^{\mathrm{v}}\right)$ neben den Rätselstrophen auch ganz andere Textteile wie den Stubenkrieg, den Hort von der Astronomie und den Lorengel präsentiert. ${ }^{11}$ Das Rätselspiel stellt zweifellos den von allen Abschnitten des Wartburgkriegs am schwierigsten zu fassenden, weil sehr stark zergliederten Teil dar. ${ }^{12} \mathrm{Da}$ es aussichtslos ist, einen Archetyp des Rätselspiels rekonstruieren zu wollen, müssen die Versuche der älteren Forschung, ein Urrätselspiel finden zu wollen, als gescheitert gelten. ${ }^{13}$

Schon die älteren Haupthandschriften unterscheiden sich nach Bestand und Reihenfolge der Rätselstrophen ganz erheblich, $\mathrm{k}$ stellt ohnehin einen Sonderfall dar. Zudem sind die einzelnen Rätsel unterschiedlich gut und unterschiedlich vollständig überliefert. Dementsprechend geraten die Erschließungsarbeiten dort an ihre Grenzen, wo die Überlieferung der Rätsel ausfranst, wo es also offensichtlich ist, dass Rätsel fragmentarisch sind, da Teile der Rätselstellung und Rätsellösung in den Handschriften fehlen. ${ }^{14}$ Bisweilen werden Rätsel kombiniert oder es wird auf mehrere Rätsel in einer Strophe summarisch Bezug genommen. Darüber hinaus bieten manche Strophen nur noch Splitter von Rätseln und Narrationen, deren Gesamtkontext verloren ist.

10 Misslich ist der Verlust von drei Blättern in J, von denen allerdings eines, wenn auch verstümmelt, wiederentdeckt wurde. Vgl. Klein, Lomnitzer: Ein wiederaufgefundenes Blatt (Anm.3), S. 381-403.

11 Vgl. Holger Runow: Wartburgkrieg? Klingsors Schwarzer Ton in der Kolmarer Liederhandschrift. In: Germanisch-romanische Monatsschrift N. F. 57 (2007), S. 151-168.

12 Die Überlieferungslage macht eine Edition außerordentlich schwierig. Burghart Wachinger votiert gegen eine Edition nach Handschriftenfassungen und entscheidet sich für wechselnde Leithandschriften je nach Rätselkomplex. Vgl. Burghart Wachinger: Überlegungen zu einer Neuausgabe des Wartburgkriegs. Mit Editionsproben zum Rätselstreit. In: Beiträge zur Geschichte der deutschen Sprache und Literatur 133 (2011), S. 57-99. Auf den Überlegungen von Wachinger basiert die Edition von Hallmann: Studien (Anm. 1), S. 350-415 (hier zitiert, Strophennummerierung nach Hallmann, falls keine anderen Hinweise gegeben werden).

13 Vgl. dazu Tomas Tomasek: Das deutsche Rätsel im Mittelalter. Tübingen 1994, S. 221-232 (mit Diskussion vorgängiger Positionen). Dagegen haben Wachinger: Sängerkrieg (Anm. 2), S. 83 89; Hedda Ragotzky: Studien zur Wolfram-Rezeption. Die Entstehung und Verwandlung der Wolfram-Rolle in der deutschen Literatur des 13. Jahrhunderts. Stuttgart, Berlin, Köln u. a. 1971, S. 45-91, hier S. 48-52; und Wachinger: Überlegungen zu einer Neuausgabe (Anm. 12), S. 61, für eine offene Textstruktur plädiert, die solche Rekonstruktionsversuche nicht erlaubt.

14 Vgl. z. B. das Rätsel von den verlockten Schafen. Siehe dazu Tobias Bulang und Holger Runow: Allegorie und Verrätselung in der mittelhochdeutschen Sangspruchdichtung. In: Verrätselung und Sinnzeugung in Spätmittelalter und Früher Neuzeit. Hg. von Beatrice Trînca. Würzburg 2016, S. 27-45, hier S. 33-45. 
Jenseits aller Zweifel zeichnet sich als Grundstruktur der Rätselspiel-Überlieferung ab, dass es sich um variable dialogische Partien handelt, in denen eine Hierarchisierung der Kontrahenten über das Stellen und Lösen von Rätseln erfolgt. ${ }^{15}$ Dabei wird deutlich, dass in den Rätseln bis in die jüngere Überlieferung hinein durchaus nicht selten auf den Rahmen des Fürstenlobs vor dem Landgrafenpaar und seinem Hof Bezug genommen wird. Auffallend ist auch, dass es eine ganze Reihe von Rätselstrophen gibt, die sich weniger auf die Rätselinhalte als auf die Herausstellung der eigenen Leistungen, das Wissen und die dichterischen Fähigkeiten der Meister sowie die entsprechende Polemik gegen die Kontrahenten beziehen.

\section{Klingsor und Wolfram als Antagonisten des Rätselspiels}

Verhandlungen über Grenzen des Wissens sind im sogenannten Rätselspiel-Teil des Wartburgkriegs besonders bedeutsam. Mit den Antagonisten Wolfram und Klingsor stehen sich der inspirierte Laie und der gelehrte „meisterpfaffe“ gegenüber, die im Stellen und Lösen von Rätseln die Grenzen zwischen klerikalem und laikalem, heidnischem und christlichem Wissen, weißer und schwarzer Zauberkunst und schließlich zwischen Heils- und Unheilsgeschichte verhandeln. ${ }^{16}$ Entscheidend ist es daher nicht nur, dass die Meister zeigen, über welche Wissensfülle sie verfügen, sondern auch, dass sie die Grenzen des zulässigen Wissens respektieren. Dementsprechend ist darauf zu achten, ob die Rätsel ganz oder nur zum Teil gelöst werden, welche Aspekte aus der Rätselstellung in der angebotenen Lösung berücksichtigt werden, aber auch, was bewusst unterdrückt und verschwiegen wird. Zudem kann, was im Gewand einer Lösung daherkommt, auch eine weitere Verrätselung darstellen, die neue epistemologische und ästhetische Überschüsse erzeugt.

Das Agonale des Rätselwettstreits liegt darin, dass es den Meistern niemals nur um das Stellen und Lösen von Rätseln geht, sondern auch darum, das jeweilige Gegenüber als Sänger polemisch zu deklassieren und umgekehrt die eigene Meis-

15 Zur Gattung Rätsel und ihren Kennzeichen im Mittelalter vgl. etwa Burghart Wachinger: Rätsel, Frage und Allegorie im Mittelalter. In: Werk - Typ - Situation. Studien zu poetologischen Bedingungen in der älteren deutschen Literatur. Hg. von Ingeborg Glier, Gerhard Hahn, Walter Haug u. a. Stuttgart 1969, S. 137-160; Tomasek: Rätsel (Anm. 13); Freimut Löser: Rätsel lösen. Zum Singûf-Rumelant-Rätselstreit. In: Neue Wege der Mittelalter-Philologie. Landshuter Kolloquium 1996. Hg. von Joachim Heinzle, L. Peter Johnson und Gisela Vollmann-Profe. Berlin 1998, S. 245-275; ders.: Mein liebster Feind. Zur Rolle des literarischen Gegners in der Sangspruchdichtung am Beispiel Rumelants. In: Literarische Leben. Rollenentwürfe in der Literatur des Hoch- und Spätmittelalters. Festschrift für Volker Mertens zum 65. Geburtstag. Hg. von Matthias Meyer und Hans-Jochen Schiewer. Tübingen 2002, S. 507-533; Volker Schupp: Rätsel. In: Kleine literarische Formen in Einzeldarstellungen. Stuttgart 2002, S. 191210; Bulang und Runow: Allegorie und Verrätselung (Anm. 14), S. 27-45.

16 Nach Wachinger: Sängerkrieg (Anm. 2), S. 88, war für das Rätselspiel „von Anfang an die Gegenüberstellung des frommen, ungelehrten, aber inspirierten Laien und des zwar nicht bösen, aber doch etwas zwielichtigen, zaubermächtigen Gelehrten“ konstitutiv; vgl. auch Tomasek: Rätsel (Anm. 13), S. 221; Ragotzky: Wolfram-Rezeption (Anm. 13), S. 54-64. In aller Regel werden im Wartburgkrieg die Rätsel von Klingsor gestellt und von Wolfram gelöst. In den Strophen C 41f. stellt allerdings Wolfram das Rätsel von den verlockten Schafen, das ohne Lösung und ohne Antwort von Seiten Klingsors bleibt. 
terschaft im "tihten“ dadurch zu unterstreichen. Insofern sind die epistemologische und die ästhetische Dimension des Rätselwettkampfs sehr eng miteinander verbunden, weshalb das Augenmerk stets auch auf den rhetorischen und poetischen Verfahren des Ver- und Enträtselns liegen muss. Von Interesse ist auch, welche Sinndimensionen im Stellen der Rätsel aufgemacht werden und ob es im Zuge der Lösungen zur Vereindeutigung von Sinn oder auch zu Verschiebungen und Verdichtungen der Semantiken kommt. Unter diesen Fragestellungen werden im Folgenden Rätsel aus dem altüberlieferten Rätselbestand untersucht. Ich orientiere mich dabei am Syntagma der drei Lohengrinhandschriften (L), die den Rätselwettkampf als Einleitung zur Wolfram in den Mund gelegten späteren Erzählung von Lohengrin bieten. ${ }^{17}$

\section{Das Rätsel vom schlafenden Kind}

Die Lohengrinhandschriften und die Heidelberger Liederhandschrift ${ }^{18}$ eröffnen den Rätselwettstreit mit dem sogenannten Rätsel vom schlafenden Kind. C bietet als Überleitung zwischen dem Fürstenlob und dem Rätselwettstreit folgenden Text: „hie ist Clinsor komen vnd singet er vnd der von Eschelbach wider ein ander. Vnd vahet das Clinsor an. Vnd singet disiu driu lieder diu hie nach geschriben stant" (Überschrift vor C 26, Bl.222 ${ }^{\mathrm{r}} .^{19}$ Nach L und C sind Klingsor drei, Wolfram vier Strophen zugewiesen. Es gibt zwar Abweichungen zwischen $C$ und L, der Textbestand ist jedoch recht stabil. Die Meistersingerhandschrift k erweitert auf elf Strophen, von denen fünf aus der Perspektive Klingsors, fünf aus jener Wolframs und eine aus der Perspektive eines Erzählers gesprochen sind. Darüber hinaus wird hier ein dreistrophiges Marienlob angefügt. Ich betrachte vor allem L und diskutiere davon ausgehend die Abweichungen in C, zugleich werfe ich Seitenblicke auf k. ${ }^{20}$

In zwei Strophen entwickelt Klingsor nach L und C folgendes Rätsel: Ein Kind liegt vor dem Damm eines Sees und schläft. Aus Fürsorge und Liebe versucht der Vater, es zu wecken. Als die zweimaligen Weckrufe „nu wache kint!“ (L 1, V.3) und „wacha, liebez kint!“ (L 1, V.5) nichts fruchten, greift er zu einem Mittel der Züchtigung und schlägt das Kind mit der Rute (,,mit der hant gap er im einen besemslac"; L 1, V.9), worauf ein dritter und noch eindringlicherer Weckruf ergeht: „nu wache, kint, ja wirt ez dir zu spete!“ (L 1, V. 10). Nach der Darstellung der ersten Strophe ist es für das Kind wahrlich an der Zeit aufzuwachen, denn es ist Nacht geworden, und der Wind treibt das Wasser gegen den Damm.

Klingsor macht in der zweiten Strophe deutlich, wie der Vater immer stärker durch gerechten Zorn bewegt wird: „Dem vater was von schulden zorn“ (L 2, V. 1).

17 Zur Relation zwischen dem Wartburgkrieg und der Erzählung von Lohengrin vgl. Thomas Cramer: Lohengrin. Edition und Untersuchungen. München 1971, S. 34-45.

18 Zum Zusammenhang mit der Konstellation des Fürstenlobs nach C siehe Kellner und Strohschneider: Geltung (Anm. 9), S. 157-165.

19 Explizite Rollenzuweisungen, die einen szenischen Rahmen wiedergeben, finden sich im Rätselspiel durchgängig nur in C.

20 Zur Deutung von k vgl. Runow: Wartburgkrieg? (Anm. 11), S. 158-163. 
Dementsprechend ändert sich auch die Anrede des Kindes im vierten Weckruf, das jetzt nicht mehr mit "liebez kint" (L 1, V.5), sondern mit "tummer tore“ (L 2, V.3) adressiert wird. Der Vater versucht das Kind mit einem laut schallenden Horn zu wecken (L 2, V.2), packt es bei den gelockten Haaren und gibt ihm dazu eine Ohrfeige (L 2, V.5f.). Nach $\mathrm{k}$ handelt es sich sogar um einen Schlag mit der Faust ans Ohr (k 2, V.6). Während L betont, dass der Vater bei allem Zorn aus Liebe straft (V.4), dominiert in C in dieser Strophe stärker der Aspekt des Zorns (C 2, V.4).

In $\mathrm{k}$ fragt der Rätselsteller demgegenüber danach, warum es dem Vater überhaupt zukam, das Kind so zu züchtigen: „Ich weiß nit, wes dem vater zam, I das er das kindlin bi sim reiden hare nam" (k 2, V. 8f.). Hier schimmert zum einen ein gewisses Unverständnis an der strafenden Haltung des Vaters durch, zum anderen könnte sich in der Diminutivform das Mitleid des Sprechers mit dem Kind ausdrücken. Fast ängstlich fragt der Vater nach k, ob sich das Kind ihm entziehen wolle (k 2, V.7). Nach L und C droht er dagegen damit, sich abzuwenden und das Kind seinem Schicksal zu überlassen, wenn sein Herz weiterhin verstockt (,vermost"; L 2, V.7) bleibe. Doch zugleich macht er auch hier deutlich, dass er ihm helfen wolle, wenn es dem Wasser denn doch noch entfliehen möchte: „noch hilf ich dir, wilt du dem wag enpfliehen“ (L 2, V. 10). Das „noch“ zeigt die Dramatisierung der Zeit an und signalisiert zugleich, dass die Bereitschaft des Vaters begrenzt ist. Wieder hebt sich k ab, indem Klingsor den Vater hier sagen lässt: „,ich hilf dir gern, wolstu dem wag enpfliehen" (k 2, V. 10), womit die tendenziell uneingeschränkte Bereitschaft des Vaters zur Hilfe betont wird.

Bemerkenswert ist, dass die dritte Strophe zwar die Rätselstellung durch Klingsor fortsetzt, aber dennoch nach $\mathrm{L}$ und $\mathrm{C}$ aus der Perspektive Wolframs, respektive nach $\mathrm{k}^{21}$ aus derjenigen eines Erzählers gesprochen wird: Die Rede Klingsors wird unterbrochen, indem Wolfram nach L und C erzählt, was Klingsor ihm bereits in der Vergangenheit gesagt habe: "Clingezor uz Ungerlant mir jach, I der vater wider zu dem lieben kinde sach" (L 3, V.1f.). ${ }^{22}$ Berichtet wird, dass der Vater im heftigen Zorn mit einem Schlegel nach dem Kind geworfen und mitgeteilt habe, er habe dem Kind schon vorher einen edlen Boten gesandt, das Tier Ezidemon, das es in seine Obhut nehmen sollte (L 3, V.4-7). Statt sich diesem anzuvertrauen, sei das Kind jedoch dem Rat eines Luchses gefolgt, der es in "falschen slaf gedrungen" (L 3, V. 9) habe. So fruchten all die Rettungsversuche des Vaters nichts, der Damm bricht und der See kommt mit Brausen daher: „do brach der tam und quam der se mit schalle“ (L 3, V. 10). Die Katastrophe wird in k abgeschwächt, indem es lediglich heißt, der Damm erwachte und geriet in Bewegung und der See brauste mit Getöse: „da wacht der tum, do ging der see mit schalle“ (k 3, V. 10). ${ }^{23}$

21 Im Licht der späteren Rätsellösung darf man in diesem Erzähler aber wohl auch Wolfram sehen.

22 Vgl. k 3, V. 1f.: „Klingsor uß Ungerlant verjach, I wie das der vater das kint so bermiclich an sach."

23 Man könnte auch an die Bedeutungsnuance denken, dass der Damm das Kind auch weiter bewachte und damit schützte. In jedem Falle wird die Semantik des Wachens und Erwachens, die sich in den Weckrufen des Vaters zum Ausdruck brachte, hier auf den Damm übertragen. 
In keiner Version erfährt man, ob und gegebenenfalls auf welche Weise das Kind im tosenden See umkommt. Zur allegorischen Verrätselung, bei der sich die Überlegenheit Wolframs nach L und C bereits darin andeutet, dass er die Rede Klingsors in seine eigene integrieren kann, gehört die Aufforderung zur Lösung des Rätsels, die in der Strophenabfolge nach L wieder Klingsor in den Mund gelegt ist. Die abweichende Parallelstrophe nach C findet sich erst im Anschluss an eine weitere Wolframstrophe, was weniger plausibel ist. Ich stelle beide Varianten gegenüber, erläutere zunächst L und diskutiere dann C.

Swer mir nu lœset disen haft,

der hat in sins herzen kunst gut meisterschaft

und mir den sin gar eben konde uz rihten,

Der müste wohl geleret sin.

er möhte sanfter vinden fürte über Rin,

er were ein meister und könd wol tihten.

Doch wer ich gern und möht ez sin, da ouch ein meister were:

Man saget von dem von Eschenbach

und git im pris, daz laien munt nie baz gesprach.

her Wolferam, der tihtet gute mere. ${ }^{24}$

Ja meister, lœse uns baz den haft,

daz git der werlte maniger selden hohe kraft:

swer ez merken wil, der lazet mange sünde.

Min sin was al der werlte ze tief,

e daz mir von Oftertingen Heinrich rief.

nu vindest du die hœhe und ouch die gründe.

Driutusent marc in Ungerlant, die han ich von den richen.

Welle ich die habe vor dir sparn,

wilt du mit mir gegen Sibenbürgen varn,

so müeze got an selden mir geswichen..$^{25}$

(C 5)

24 Übers. L 4: „Wer mir diesen Knoten löst, der verfügt in seinem Herzen über treffliche Meisterschaft und kann mir den Sinn gerade aufreihen, [dieser, der das kann], dürfte wohl gelehrt sein. Er könnte ziemlich leicht eine Furt durch den Rhein finden, er wäre ein Meister und könnte gut dichten. Doch ich wäre gerne dort, wo auch ein solcher Meister wäre: Man sagt von dem von Eschenbach und lobt ihn damit, dass der Mund eines Laien nie besser gesprochen hat [als der seine]. Herr Wolfram, der dichtet gute Geschichten."

25 Übers. C 5: „Ja Meister, löse uns den Knoten, das schenkt der Welt großes Heil: Wer das verstehen will, der unterlässt viele Sünden. Mein Verstand war zu unergründlich für die Welt, bevor mich Heinrich von Ofterdingen herrief. Jetzt findest Du die Höhe und die Gründe in der Tiefe. Wenn ich dir die dreitausend Mark, die ich von den Reichen in Ungarn bekommen habe, nicht gebe, wenn Du mit mir nach Siebenbürgen fahren willst, dann müsste ich mein Seelenheil verlieren." 
Nach L fasst Klingsor das Rätsel als Knoten, den nur derjenige lösen kann, der über entsprechende Meisterschaft im Dichten verfügt und gelehrt genug ist, die verworrenen Fäden auseinanderzulegen und glatt zu ziehen. Der Rätselsteller betont die Schwierigkeit der Aufgabe, indem er behauptet, derjenige, der das Rätsel lösen wird, könnte ziemlich leicht auch eine Furt durch den Rhein finden. ${ }^{26}$ Antizipierend verweist die L-Strophe auf Wolfram, der als bester Laiendichter eingeführt wird. In der Parallelstrophe nach k wendet sich Klingsor in der letzten Verszeile der Strophe dagegen direkt an Wolfram und fordert ihn auf, unter Beweis zu stellen, dass er dem Lob vom besten Laiendichter auch tatsächlich entspricht: „nu rat, Wolfram, ich hett sin gern urkünde“" (k 6, V. 10).

Abweichend von L und k stellt die Parallelstrophe nach C demgegenüber deutlicher einen Zusammenhang mit dem Rahmen des Fürstenlobs her und rekurriert darauf, dass Heinrich von Ofterdingen Klingsor aus Ungarn herbeigerufen habe, um sich nach seiner Niederlage im Lobwettstreit mit dessen Hilfe gegen die anderen Sänger wehren zu können. Klingsor stellt dem Rätsellöser zudem eine Summe von dreitausend Mark aus Ungarn in Aussicht, wenn dieser mit ihm nach Siebenbürgen komme. In einer Semantik der Höhe und der Tiefe, die im Verlauf des Rätselwettstreits eine wichtige Isotopieebene ausbildet, bescheinigt er dem Antagonisten die Kompetenz zur Rätsellösung, denn dieser sei in der Lage, ihm sowohl bei seinen intellektuellen Höhenflügen zu folgen, als auch die Abgründe seines Denkens zu erfassen (C 5, V.4-6). Handschrift k fügt noch zwei Strophen der Rätselstellung hinzu, in deren erster Klingsor die Rätselmetaphorik des Knotens passend um das Bild des Stranges aus Fäden ergänzt und sich entschlossen zeigt, Wolframs Kunst zu zerstören ( $\mathrm{k}$ 4), während er in der zweiten zusätzlichen Strophe (k 5) noch einmal detailliert nach den Rätselinhalten fragt.

Um wieder auf die Reihenfolge nach L zurückzukommen: Wolfram beginnt das Rätsel zu lösen (L 5; C 4; k 7), was in der Parallelstrophe der Meistersingerhandschrift mit der Überschrift „Wolframs vff rat" angezeigt wird. Er lässt sich auf Klingsors Metaphorik des Knotenentwirrens ein („,Clingezor ich lœese dir den knoten“; L 5, V. 1; vgl. ähnlich C und k) und bekundet, er würde die Schelte und das Hohnlachen seines Herausforderers hinnehmen, wenn er sich im Netz seines Rätsels verheddern sollte (L 5, V. 4-6). Darüber hinaus verbindet Wolfram die Metaphorik von Knoten und Netz mit jener von Wasser und Waten, die in der vorausgehenden Klingsor-Strophe ebenfalls schon angeklungen war. Er möchte nämlich seinen Konkurrenten überwinden, indem er aus dem Wasser (L 5, V.3; k 7, V.3) oder dem See (C 4, V.3) seines Sinnes schöpft.

Die Wassermetaphorik nimmt auf das Bild der vorhergehenden Strophe vom Vergleich des Rätsellösens mit dem Durchwaten des Rheins an einer Furt Bezug. In der Fluchtlinie dahinter darf man eine Stelle aus Wolframs Parzival vermuten, der beim Aufbruch ins Ritterleben von seiner Mutter den Rat bekommen hat, er

26 Abweichend heißt es nach k 6, V.5 „villicht sucht er den grunt und wüt auch durch den Rin.“ (,Vielleicht sucht er den Grund und würde auch durch den Rhein waten“). 
solle dunkle Furten meiden, um sich nicht in Gefahr zu bringen (Parzival 127,16). Ein Baustein aus Wolframs epischem Text wird hier aufgegriffen und auf die Vorstellung des Rätsellösens im Wartburgkrieg bezogen. Auf die Selbstinszenierung Wolframs im Parzival, „ine kan decheinen buochstap“ $(115,27)$ zielt nachgerade auch die Laienrolle, die Wolfram von Klingsor zugeschrieben wird (L 4, V. 9). In dessen eigenem Ausruf, man solle ihn für seine Torheit auslachen, wenn er bei der Rätsellösung versage (L 5, V.6), klingt schließlich die „tumpheit“ und die Narrenrolle seines Protagonisten Parzival an. ${ }^{27}$ Die auf den Parzival bezogene Wassermetaphorik steht damit in inter- und intratextuellem Zusammenhang mit den anderen Anklängen an Wolframs Roman. Auf diese Weise ergibt sich ein intrikates literarisches Spiel zwischen den Figuren Klingsor, der seinerseits auf eine Figur aus Wolframs Text zurückgeht, Wolfram als Autor des Romans und Sänger im Rätselwettstreit und Parzival als dem Protagonisten seines Romans sowie zwischen den Gattungen Spruchdichtung und höfische Epik.

Zugleich steht die Wassermetaphorik jedoch auch mit dem Rätsel selbst und dem Vorgang seiner Lösung in Verbindung: Geht es dort um das andrängende Wasser, welches das Kind hinter dem Damm bedroht, möchte Wolfram hier nicht nur aus dem Denkvermögen Klingsors schöpfen, sondern auch seine Arche auf dem See der Dichtkunst des anderen schweben lassen: „,sus swebt uf diner künste se min arke“ (L 5, V.10). Mit der Arche kommt der Vorstellungshorizont der Sintflut ins Spiel, bei der Gott nicht nur einen sündigen Menschen bestraft hat, sondern die ganze Menschheit auszurotten drohte. Über den Anklang an die Sintflut erhält das Rätsel einen heilsgeschichtlichen Bezug, was seine Bedeutung einmal mehr unterstreicht und die Dringlichkeit des Dargestellten im Nachhinein dramatisiert. Zudem wächst dem Rätsellöser die Rolle als Retter und Heilsbringer zu. Rätselstellung und Rätsellösung werden also über die Metaphorik des Wassers und die damit verbundenen Vorstellungen der Tiefe und des Grundes sowie des Schöpfens, aber auch des ,Obenseins' als des Fahrens oder Schwebens auf dem Wasser verbunden.

Wolfram triumphiert und präsentiert die allegorische Auflösung des Rätsels (L 5-7; C 4; C 6f.): Im Vater ist Gott zu sehen, das Kind steht für jeglichen Sünder, Gottes Horn für die Priester („,meisterpfaffen“; L 5, V.9; C 4, V. 9), Damm, Wind und Wasser verweisen auf die dem Menschen von Gott gegebene Lebenszeit. Der sündige Mensch werde von Gott getötet und sei ewiger Höllenqual ausgeliefert, wenn er sich nicht der von Gott verlangten Reue und Beichte unterziehe. In der Allegorese des Rätsels werden auch die beiden Mächte ausgelegt, die den Menschen zum Guten und zum Bösen führen können. Das aus dem Parzival bekannte Tier Ezidemon, in dem die ältere Forschung ein Hermelin gesehen hat, ${ }^{28}$ bedeute den Schutzengel,

27 Sie zeigt sich z. B. bei Parzivals erstem Zusammentreffen mit dem Artushof (143,21-161,30). Vgl. Wolfram von Eschenbach: Parzival. Studienausgabe. Mittelhochdeutscher Text nach der sechsten Ausgabe von Karl Lachmann. Übersetzung von Peter Knecht. Einführung zum Text von Bernd Schirok. Berlin, New York 1998.

28 Vgl. Johannes Siebert: Ecidemôn. In: Zeitschrift für deutsche Philologie 62 (1937), S. 248-264. 
der den Menschen leite und behüte. ${ }^{29}$ Der Luchs, der den Menschen verführen wolle, wird dagegen als Teufel kenntlich gemacht. Wolfram fasst (L 7, V. 10; ähnlich k 9, V. 10) ${ }^{30}$ zusammen, dass er mit dieser Lösung des Rätsels eine Furt im Rhein gefunden habe, und kommt so erneut auf die Metaphorik des Wassers, den tiefen Fluss und das Durchwaten seiner seichten Stellen für den Dichterwettstreit zurück. Er hat sich nicht nur im Sinne des Wissenswettstreits durch die Lösung des Rätsels bewährt, sondern auch als Meister der Dichtkunst mit der souveränen und Klingsor übertreffenden Handhabung der Allegorien durch Allegorese und der Metaphoriken, die er in immer weitere Transformationen getrieben hat.

In der Tendenz der Kolmarer Liederhandschrift hat sich bereits eine Abmilderung der Schrecknisse, auf die das Rätsel verweist, angedeutet. Sie setzt sich in einer überraschenden Wendung zum Positiven in den beiden angehängten Strophen nach k (k 10f.) fort. ${ }^{31}$ Die erste dieser Strophen zeigt den himmlischen Vater so sehr im Leid über den Verlust seines Kindes, dass sich schließlich die Mutter Gottes erbarmt, nachdem sie seine Klagen, nota bene nicht die Klagen des Kindes, im Himmel gehört hat (V.1-9). Als sie dem Kind daraufhin aus der Flut hilft, vergibt ihm Gott seine Sünden (V. 10). In der elften und letzten Strophe des Rätsels nach k zitiert Wolfram Jesus, der sagt, dass diejenigen zurecht in das Reich seines Vaters aufgenommen werden, die mit wahrer Reue beichten und die zehn Gebote einhalten (V.2-6). Wer dagegen ungerecht handele und sich weder der Reue noch der Beichte unterziehe, könne niemals Gottes Gnade erreichen (V. 7-9). Aus diesen Worten lässt sich folgern, dass dem Kind als dem Protagonisten des Rätsels in der Perspektive der Kolmarer Liederhandschrift Reue und Beichte unterstellt werden, obwohl nichts davon erzählt wird. Auch das Gottesbild scheint sich in der spätmittelalterlichen Meistersingerhandschrift gewandelt zu haben, denn Gott kämpft geradezu um den Sünder, er klagt und jammert, seine Liebe und sein Wille, den Sünder zu retten, stehen im Vordergrund, was sich auch in den vorhergehenden Strophen bereits punktuell gezeigt hat. Dabei fällt der Jungfrau Maria als mediatrix des Heils eine Schlüsselrolle zu. Insofern ist es nur konsequent, dass Wolfram sie in einem sich anschließenden dreistrophigen Marienlob preist (k 100-102), das sich nicht in der älteren Überlieferung findet.

\section{Das Quaterrätsel}

Mit dem Quaterrätsel, das in L (L 8-13), C (C 8-15) und J (J 2-6) überliefert ist, nimmt Klingsor einen neuen Anlauf und fordert Wolfram zum zweiten Mal heraus. Strophenzahl und Strophenreihenfolge divergieren auch hier zwischen den verschiedenen Textzeugen in einem Maße, das keine Vereinheitlichung erlaubt. Ich richte mich wiederum nach der Reihenfolge von $\mathrm{L}$ und ziehe $\mathrm{C}$ und J verglei-

29 Handschrift k verballhornt zu ",zedelman“ (k 9, V. 8). Vgl. dazu die Überlegungen von Runow: Wartburgkrieg? (Anm. 11), S. $162 \mathrm{f}$.

30 Abweichend heißt es in C 7, V.10: "sus wen ich, dine rime ich vinde“ („,So glaube ich, Deine Reime zu finden").

31 Vgl. dazu Runow: Wartburgkrieg? (Anm. 11), S. 158-163. 
chend heran. Die nach L erste Strophe (L 8), die in C (C 12) und in J (J 4) erst an späterer Stelle des Rätsels folgt und hier jeweils auf die sogenannte Nasionszene hinleitet, bringt noch keinerlei Rätselinhalt, sondern hat vielmehr den Streit als solchen zum Gegenstand:

Ich wil gelouben, daz den list

din engel vinde oder daz der tiufel in dir ist.

hœr an, getriuwer Dürgenfürste riche!

Ich wilz ouch allen pfaffen clagen,

daz sie dem bœesen geiste argen willen tragen.

her Sathanas, ob ich eu hie entwiche,

Daz kan so balde niht geschehen, swie gern ir mich wolt krenken!

Ir müzet rumen mir daz vaz.

wolt ir in minem wac iht waten fürebaz,

ich vinde eu noch, daz iuch zu grunde kan senken. ${ }^{32}$

Klingsor polemisiert gegen Wolfram, indem er die Rechtmäßigkeit seines Wissens in Zweifel zieht und behauptet, seine Klugheit könne nicht aus ihm selbst kommen, sondern müsse von einem Engel (seinem Schutzengel?) oder vom Teufel inspiriert sein (L 8, V. 1f.). Da er den Thüringer Fürsten zum Zeugen der Anklage Wolframs macht (L 8, V.3), kommt unvermittelt der performative Rahmen des Fürstenlobs ins Spiel, der in den Lohengrinhandschriften eigentlich nicht vorausgesetzt werden kann. Was eingangs der Strophe im Blick auf die Wissensquellen, aus denen Wolfram schöpft, noch in der Ambivalenz gehalten ist, wird in den Folgeversen vereindeutigt, indem Klingsor Wolfram durch die Anrede „her Sathanas" (L 8, V.6) unterstellt, er sei vom Teufel besessen. Offensichtlich geht er von der Vorstellung aus, der Teufel sitze wie in einem Fass in Wolfram und solle entweichen, womit er sich die Rolle eines Exorzisten zuschreibt (L 8, V.6f.). Erneut erfolgt eine Zuspitzung und Dramatisierung über die Metaphorik des Wassers und des Grundes, denn der Gegner soll, wie es heißt, versenkt werden, wenn er weiterhin versuchen wolle, im Wasser von Klingsors Denken und Wissen herum zu waten (L 8, V. 9f.).

Nach C 8 und J 1 (J= J 77n, fragmentarisch) eröffnet Klingsor das Rätsel dagegen mit einer nicht in L überlieferten Strophe, in welcher der Meister sein eigenes Wissen und Können über einen Vergleich mit Basiant von Babylon (Konstantinopel nach J) unterstreicht. Obgleich jener aufgrund seiner aus den Sternen

32 Übers. L 8: „Ich möchte glauben, dass Deine Klugheit Dein Engel findet oder dass der Teufel in Dir ist. Hör zu, treuer und mächtiger Thüringerfürst! Ich will es auch gegenüber allen Priestern beklagen, dass sie dem bösen Geist feindlich gesonnen sind. Herr Sathan, dass ich mich von Euch hier davonmache, das kann nicht so bald geschehen, wie sehr Ihr mich auch beleidigen wollt! Ihr müsst mir das Fass verlassen. Wenn Ihr noch weiter in meinem Wasser waten wollt, dann finde ich (für Euch) schon noch ein Mittel, um Euch bis auf den Grund versenken zu können." 
abgeleiteten Kunst, Kupfer in Gold verwandeln zu können, als kluger Astronom und Alchemist kenntlich gemacht wird, erscheint er im Verhältnis zu Klingsor als unterlegen. Indem dies über den Vergleich zweier Falken illustriert wird, erhält die schon im Rätsel vom schlafenden Kind eingeführte Metaphorik der Höhe eine neue Pointe (C 8, V.1-5). Wenn Klingsor zugibt, dass Gott einen Laien mit noch höherem Wissen begabt habe (C 8, V. 6f.), entwickelt er eine Klimax, die von Basiant über ihn selbst auf Wolfram führt. Die Schlussverse deuten kryptisch an, dass Klingsor mit Wolfram einen Kampf auf Leben und Tod ausfechten will (C 8, V. 8f.), und kommen erneut auf die Metaphorik von Höhe, Tiefe und Grund zurück, wenn es heißt, wer den Grund der Rätsel finde, durchwate das Meer: „swer vindet grunt, der ist ein merwatere" (C 8, V.10).

Eine Plusstrophe nach C (C 9), die nur diese Handschrift bietet, führt die Polemik in ähnlicher Richtung weiter. Klingsor maßt sich hier an, Wolfram wie einen Gefangenen zu halten, ihn beherrschen und vernichten zu können. So droht er, seinen Verstand mit dem ohrenbetäubenden Lärm seiner Kunst zu ruinieren, und will ihn zwingen, seinen Denkbewegungen überall hin, in die Höhe und die Tiefe zu folgen (C 9, V. 1-5). Es mutet auf den ersten Blick bizarr an, wenn er in den Folgeversen sowohl auf den Leviathan als Macht des Bösen, als auch auf Christus Bezug nimmt. Während er sich einerseits fast schon als Teufelsbündner zu erkennen gibt, der mit Hilfe von Leviathan und seinen Leuten erreichen könnte, dass Wolframs Wissen und dichterisches Vermögen zu einem "gougelspil“ (C 9, V.7), also zunichte gemacht würden, behauptet er andererseits, dass er im Glauben an Jesus Christus unerschütterlich sei (C 9, V. 10). Klingsor zeigt sich hier als Grenzgänger, der vorgibt, an beiden Sphären teilzuhaben, am Teuflischen und am Göttlichen. Dazu passt, dass der „meisterpfaffe“ nach seinen in anderen Strophen geäußerten eigenen Worten nicht nur in Paris und Konstantinopel den "kern von kunst us meisterpfaffen sinne" erlernt habe (C 40, V. 1-3), ${ }^{33}$ sondern auch in Babylon ausgebildet worden sei $^{34}$ und daher über heidnisch-astronomisches und alchemistisches Wissen verfüge. Gerade an der Klingsor-Figur lassen sich daher komplexe Überlagerungen der christlichen und heidnischen Wissenshorizonte beobachten: Er partizipiert nicht nur an heidnischem Wissen, sondern er schließt sich auch der Religion „Machemetes" an, ${ }^{35}$ bevor er sich wieder dem christlichen Glauben zuwendet. Die Figur lässt sich daher nicht so leicht einordnen, wie es dem ersten Eindruck nach aus der Gegenüberstellung von gelehrtem Meisterpfaffen und Laien scheinen mag. Klingsor wird zwar als Christ in den Wartburgkrieg eingeführt, doch er war auch Heide, er ist Kleriker, doch auch Magier sowie Alchimist und er steht mit den Teufeln im Bund. Sein Anspruch auf Überlegenheit gründet sich

33 In J 77o wird auch Rom als Ausbildungsort genannt. Strophen außerhalb der Rätsel werden nach den jeweiligen Handschriften gezählt.

34 C 40, V.4f.: "ze Baldac ich zeschuole kam, I wand ich ze Babylone hohe kunst vernam" (in J 77o stark fragmentiert).

35 C 40, V.6f.: „driu jar ich diende in Machemetes minne, I der kunde mir daz herze wol von rehten sinnen wisen" (Vgl. J 77o, V.6f.). 
vermutlich gerade in diesen Grenzüberschreitungen. Da er nur als Christ zum adäquaten Gegner Wolframs werden kann, muss er sein Christentum durch Rekurse auf heilsgeschichtliche Tatsachen immer wieder unter Beweis stellen und seinerseits Wolfram der Teufelsbündnerei anklagen. ${ }^{36}$

Das eigentliche Rätsel vom Quater folgt nach L und C auf diese Polemik mit ihren Reizreden:

Nu sage mir, meister, sunder haz:

wo windet gotes tougen? niemant fürebaz

gesuchen tar, swer bliben wil bi sinne!

Ein quater mit vier essen stat,

der iegelichez sine wirde sunder hat.

nu merke, wie ich dirz halbez sagen beginne:

Ein quater uf der drien stat, so heldet ez die drie.

Swer nu da fürbaz sinnen wil,

so mac der ham im reizen uf des hirnes zil

und belibet doch vor witzen gar der frie. ${ }^{37}$

Klingsor fordert Wolfram auf, diese Bilder zu erklären, und gibt doch zugleich zu bedenken, dass man nicht in Gottes Geheimnisse eindringen könne, ohne wahnsinnig zu werden. Indem er die mögliche Lösung des Rätsels mit einem Auslegungstabu belegt, verstärkt er die mit dem Rätselstellen ohnehin gegebene Hierarchie noch einmal zu seinen Gunsten und will es Wolfram auf diese Weise unmöglich machen, im Wettstreit zu bestehen. Doch er unterschätzt seinen Konkurrenten, der sich seiner Falle geschickt entzieht, indem er gar nicht erst versucht, ausgehend von der Vierzahl und der Dreizahl in das göttliche Geheimnis der Trinität vorzudringen, eine Lösung, zu der ihn Klingsor offensichtlich provozieren will. Wolfram deutet vielmehr konsequent die Hälfte des Rätsels aus und antwortet damit übrigens genau auf Klingsor, der ihm auch nur die Hälfte, ",halbez", sagen wollte (L 9, V.6), weshalb Rätselstellung und Lösung miteinander korrespondieren und Wolfram die Bewältigung der Aufgabe für sich in Anspruch nehmen kann. Wolfram legt Klingsors allegorische Vorgabe aus, indem er in seiner Allegorese dessen Metapher von den Augen auf dem Würfel auf die bekannten Allegorisierungen der Evangelisten bezieht: „den selben ohsen zu einem esse ich

36 Vgl. etwa C 40, V. 8-10 (dazu J 77o, V. 8-10).

37 Übers. L 9: „Nun sage mir Wolfram, ohne hasserfüllt zu sein: Bis wohin reichen Gottes Geheimnisse, wo enden sie? Niemand wagt es, weiter zu suchen, der bei Verstand bleiben will Ein Würfel steht auf der Vier und zeigt vier Augen, von denen jedes seine besondere Auszeichnung hat. Jetzt pass auf, wie ich dir dies zur Hälfte auszulegen beginne: Der Würfel steht auf der Vier und hat [auf der gegenüberliegenden Seite] eine Drei, so hält sie [die Vier] die Drei. Wer jetzt noch weiter mit seinem Verstand vordringen will, dem kann die Haut auf dem Hirn reißen und er kann gut und gern dabei verrückt werden." 
prise. I Das ander es ist ein lewe, vil eben du daz merke. I Daz dritte ein are, daz ist mir kunt. I daz vierde ein mensche“ (L 10, V. 6-9; „Eben den Ochsen preise ich als das eine Auge des Würfels. Das zweite ist ein Löwe, merk dir das genau. Das dritte ist ein Adler, das ist mir bekannt. Das vierte ist ein Mensch“; vgl. C 11, V. 6-9; J 3, V. 6-9). Die Folgerung, dass die vier Evangelisten die Geheimnisse der Trinität halten und enthalten, symbolisiert im Würfel, der mit vier Augen auf der Drei steht und diese hält, liegt auf der Fluchtlinie dieser Auslegung, doch Wolfram zeigt sich zurückhaltend. ${ }^{38}$ Damit erweist er sich der Inszenierung des Wettstreits nach als der Überlegene, was er selbst wiederum in den Metaphern von Höhe und Tiefe fasst: „,ich rüere an dines sees grunt I und schat doch gote nicht an siner sterke" (L 10, V. 9f.; "Ich berühre den Grund deines Sees und schade doch Gott nicht in seiner Stärke“; vgl. C 11, V. 9f.; J 3, V. 9f.). Wiederum wird auf das Wasser Bezug genommen, was die Rätsel vom schlafenden Kind und vom Quater auf der Metaebene verbindet.

In einem klugen Schachzug autorisiert Wolfram seine Deutung unter Rekurs auf das Buch des heiligen Brandan (L 10, V.3-5; vgl. C 11, V.3-5; J 3, V.3-5). Indem er postuliert, Brandan habe das Buch direkt von der Zunge des Lukasochsen erhalten, und indem er eine Verbindung zwischen sich, Brandan und dessen Buch herstellt, gelingt es ihm, sich unmittelbar in den Einzugsbereich des Offenbarungswissens zu stellen und damit höchste Legitimität für seine Worte abzuleiten. Hier und auch an anderen Stellen im Rätselwettstreit sowie in der Lohengrinerzählung blitzen Versatzstücke aus der Brandanlegende auf..$^{39}$ An dieser Stelle ist wohl nicht das Buch gemeint, das Brandan von einem Engel bekam und aus Unglauben über die darin enthaltenen Wunder der Welt vor Zorn ins Feuer warf, sondern das Buch, das er aufgrund der Erfahrung seiner Seefahrt schreiben musste, ${ }^{40}$ wie in der das Quaterrätsel abschließenden Lohengrinstrophe (L 13; vgl. C 15; J 6) von Klingsor angedeutet wird.

38 Man könnte auch an die vier Buchstaben des Tetragramms denken, deren Buchstabenkombinationen etwa nach dem Dialogus (Titulus VI) des Petrus Alfonsi auf Vater, Sohn und Heiligen Geist hinweisen. Petrus verbindet Vier- und Dreizahl, Tetragramm und Trinität, in besonderer Weise. Für diesen Hinweis bedanke ich mich bei Wilhelm Schmidt-Biggemann. Vgl. dazu Klaus-Peter Mieth: Der Dialog des Petrus Alfonsi. Seine Überlieferung im Druck und in den Handschriften. Berlin 1982.

39 Vgl. zu den Erwähnungen des heiligen Brandan im Wartburgkrieg Leopold Peeters: Brandanprobleme. In: Leuvense Bijdragen 59 (1970), S.3-27, zum Quaterrätsel, S. 19; Verena Linseis: Gotteskrieger und Gottesgeheimnisse. Legendarisches im Lohengrin. In: Gattungsinterferenzen. Der Artusroman im Dialog. Hg. von Cora Dietl, Christoph Schanze und Friedrich Wolfzettel. Berlin, Boston 2016, S. 117-153, hier besonders S. 117-129. Vgl. dazu auch Walter Haug: [Art.] Brandans Meerfahrt. In: Verfasserlexikon. 2. Aufl. Bd. 1. Hg. von Kurt Ruh u. a. Berlin u. a. 1978, Sp. $986-991$.

40 Die im Wartburgkrieg angedeutete Fassung der Brandanlegende entspricht am ehesten der sogenannten Reisefassung, vgl.: Brandan. Die mitteldeutsche Reise-Fassung. Hg. von Reinhard Hahn und Christoph Fasbender. Heidelberg 2002. Vgl. dazu etwa Peter Strohschneider: Logbuch und heilige Schriften. Zu einer Version der deutschen Brandan-,Reise'. In: Gutenberg und die Neue Welt. Hg. von Horst Wenzel in Zusammenarbeit mit Friedrich Kittler und Manfred Schneider. München 1994, S. 159-169; Christine Kühn: Heilige sind anders. Das Spiel mit 
Im Prozess der allegorischen Auslegung bedient Wolfram damit die Rolle des Prüflings. Die Kompetenz seiner Auslegung liegt nicht nur in der Lösung des Rätsels, sondern vielmehr im Umgang mit den Quellen des Wissens sowie in der Art und Weise seiner Deutung und der damit verbundenen klugen Selbstbeschränkung, was für die Figurenkonzeption und die poetische Verfasstheit der Rätselstrophen im Wartburgkrieg als grundlegend betrachtet werden kann. Als Dichter zeigt Wolfram zudem Selbstbewusstsein, wenn er behauptet, er könne Klingsors Metaphern beherrschen und dessen „wilde wort“ ,bezähmen' (L 10, V.1f.; vgl. C 11, V.1f.; J 3, V.1f.). Insgesamt kann man auch folgern, dass Klingsor es zwar versteht, ein allegorisches Rätsel zu stellen, Wolfram aber über die höhere Kunst der Allegorese verfügt.

\section{Nasion}

Klingsors Versuche, Wolfram als unwissend zu delegitimieren oder ihn zu Vorstößen in verbotene Wissensbezirke zu verlocken, sind gescheitert, während sein eigenes Ansinnen im Horizont von Wolframs Weisheit nun als illegitim erscheint. Klingsor wird als geschlagen dargestellt, er kann den Wettstreit nur noch fortführen, indem er auf seine nigromantischen Fähigkeiten zurückgreift und den Teufel als seinen Stellvertreter beschwört. ${ }^{41}$ Dies führt zur sogenannten „Nasion“-Szene (L 14-18; C 16-20; J 7-9 = 77k-77m), in deren Umfeld die Rolle Klingsors als Grenzgänger noch einmal besonders deutlich wird. Denn als er den Teufel beschwört, um den vermeintlich vom Teufel besessenen Wolfram endgültig zu vernichten, beruft er sich gleichzeitig auf Gott und stellt überdies in Abrede, dass Wolfram angesichts seines astronomischen Wissens ein bloßer Laie sein könne (L 11; vgl. C 13). Wolfram dagegen beharrt auf der Rechtmäßigkeit seiner Rätsellösung und führt eine Reihe von Zeugen und besonders wieder den heiligen Brandan an, dessen Buch er über Uranias (nach C Jeronimus, nach J Origines) in Schottland erhalten habe (L 12, V.7f.; vgl. C 14, V.7f.; J 5, V.7f.). ${ }^{42}$ Im weiteren Streit zwischen Wolfram und dem Teufel Nasion, der in L Nazarus heißt, stellt dieser die Fragen, doch der Laie lässt sich auch jetzt nicht verleiten, in illegitime astronomische Wissensbezirke vorzudringen (L 14f.; vgl. C 16f.; J 8). Vielmehr weist Wolfram die Fragen seines teuflischen Gegners von vornherein zurück und verweigert jede Antwort: „für war, ich waiz niht rehte, waz ir meinet“ (L 15, V.3); „Ich enruoch [...] I in weiz" (C 17, V.4f.; „Mich kümmert's nicht [...], ich weiß es nicht“; vgl. J 8, V.4f.). Die Wunder der Schöpfung, nach denen Nasion/Nazarus gefragt hat, liegen seiner Darstellung nach ganz in der Obhut Gottes (L 15, V.8-10; C 17, V. 8-10; J 8, V. 8-10)

religiösen Motiven in der mitteldeutschen Reise-Fassung des heiligen Brandan. In: Studien zu Literatur, Sprache und Geschichte in Europa. Wolfgang Haubrichs zum 65. Geburtstag gewidmet. Hg. von Albrecht Greule u. a. St. Ingbert 2008, S. 113-132.

41 Hier wird das im Wartburgkrieg öfter auftretende Muster bemüht, an den Stellen, an denen der Konflikt schon entschieden scheint, einen Stellvertreter herbeizurufen.

42 Die Namen der Zeugen sind nach L 12 Aristoteles, Daniel, Uranias, Brandan; nach C 14 Augustinus, Daniel, Jeronimus, Brandan; nach J 5 Aristoteles, Daniel, Origines, Brandan. 
und sind Geheimnisse, "tougen" (L 17, V.6; vgl. C 19, V.6), die nicht von einem Menschen wie ihm erforscht werden können und dürfen. Die erneuten und verschärften Drohungen des Teufels, der immer mehr in Zorn gerät (L 16; C 18; J 9), beantwortet Wolfram nicht nur durch gebetsartige Anrufungen des Schöpfergottes und Mariens (L 17; C 19), sondern er beendet das Ringen mit dem Teufel, indem er verstummt und die rituelle Handlung des Kreuzzeichens an die Stelle weiterer Rede setzt: „Wolfram daz criuze für sich reiz“ (L 18, V. 1; C 20, V. 1). ${ }^{43}$ Gerade durch das Verstummen im rechten Augenblick und den Wechsel von der Rede auf das religiöse Zeichen erweist sich Wolfram als Sieger. Zugleich legitimiert er durch das Schweigen sein vorheriges Sprechen, und diese religiöse Qualifizierung seiner Rolle erscheint als Voraussetzung seines Wissens wie auch seiner ästhetischen Kompetenz.

\section{Luziferrätsel, Lohengrin und Artus, „,des wirtes maget“, Buckel und Schild}

\subsection{Luziferrätsel}

Zeigt sich nach den Lohengrinhandschriften in der Partie des Rätsels vom schlafenden Kind bis einschließlich zur Nasionszene ein nachvollziehbares Arrangement der Dialogpassagen im Rätselstreit zwischen Klingsor, dem Teufel Nasion/Nazarus und Wolfram (L 1-18), so zerfasern Anordnung und Aufbau des weiteren Wettkampfs. Ein ähnliches Bild ergibt sich nach dem Codex Manesse, wo zwischen dem Rätsel vom schlafenden Kind und dem Quaterrätsel mit der sich anschließenden Nasionszene noch die Rätsel von den Königstöchtern und den verlockten Schafen eingeschoben sind (C 33-42). ${ }^{44}$ Die auf die Nasionszene folgenden Rätselpartien von L und C, die keine Parallelüberlieferung in k, wohl aber in J haben, sind sichtlich fragmentarisch überliefert und bleiben vielfach dunkel. Hallmann fasst sie vereinfachend unter der Überschrift „Luzifer und Lohengrin“45 zusammen. Die Forschung hat sich dieser Strophen bislang kaum angenommen, es mangelt an basalen Erschließungsarbeiten, meine Vorstöße stellen daher tastende Versuche dar. Ich orientiere mich weiter an der Überlieferung nach $\mathrm{L}$ und ziehe $\mathrm{C}$ und $\mathrm{J}$ vergleichend heran.

Nach dem Abgang des Teufels gibt sich Klingsor nicht zufrieden, sondern fordert Wolfram erneut heraus (L 19; vgl. C 21; J 10). Die innere Gespaltenheit dieser Sängerfigur zeigt sich wiederum darin, dass er auch nach der Teufelsbeschwörung sowohl nigromantisches und astronomisches Wissen für sich beansprucht als auch behauptet, er würde in einer Art und Weise singen und sprechen, dass es „allen meisterpfaffen“ (L 19, V.5; „pfaffen, meistern“; C 21, V.5; „meisterpfaffen“; J 10, V.5) zusagen müsste. Darüber hinaus passt es zu Klingsor als Grenzgänger,

43 Nasion gesteht seine Niederlage gegenüber Klingsor ein (L 18, V.4-10; C 20, V. 4-10). Auch in den Prosakommentaren der Handschrift C zeigt sich eine Zäsur. Das nächste Rätsel findet danach erst wieder am nächsten Tag statt: „Do si an de‘m〉 andern morgen ze hove kamen“ (Überleitung zu C 56, Zählung hier nach der Handschrift).

44 Zählung hier nach der Handschrift und nicht nach Hallmann.

45 Hallmann: Studien (Anm. 1), S. 373. 
dass er im folgenden Rätsel über die Frage, wie Gott Luzifer gemacht habe, die Sphäre des Göttlichen und Diabolischen auch auf der Objektebene eng zusammenrückt (L 19, V. 6-10; C 21, V.6-10; J 10, V. 6-10). Die korrespondierende Strophe der Rätsellösung bietet in C die sich unmittelbar anschließende Strophe (C 22), während diese sich in L und J in weiter Entfernung zur Ausgangsstrophe findet (L 27; J 18), wodurch Rätselstellung und Rätsellösung in zwei der drei Überlieferungen auseinandergerissen sind. Dazu kommt, dass sich die Lösung Wolframs in der entsprechenden Strophe ausschließlich im Abgesang auf das Luziferrätsel bezieht (C 22, V.7-10; L 27, V.7-10; J 18, V.7-10), während sich der Aufgesang in kryptischer Weise der Lohengrin-Thematik widmet. Es ist deutlich, dass hier (C 22; L 27; J 18) verschiedene Rätsel, um die es in anderen Strophen geht (L 24-26), kombiniert und in einer Strophe beantwortet werden sollen. ${ }^{46}$ Im Blick auf Luzifer gibt Wolfram die Antwort, dass Gott ihn aus vier Winden gemacht habe. Er sei hochmütig geworden, weil der Anteil des Nordwindes Aquilo in ihm überwogen habe. Wolfram dominiert und macht deutlich, dass er für die Wunder, die Klingsor anspricht, Lösungen finden kann.

\section{2 "Des wirtes maget"}

Folgt man der Strophenreihenfolge von L, schließen sich zwei Strophen an das Luziferrätsel an, die in der Forschung unter dem Titel „Des wirtes maget“ geführt werden und sehr dunkel bleiben (L 20f.; C 23f.; J 11f.). Wenn man von einem Zusammenhang mit dem Vorausgehenden ausgehen darf, dann räsoniert Klingsor in der ersten dieser Strophen darüber, dass die Lösung des Luziferrätsels nur wenigen Meistern bekannt sei. Dabei erwähnt er einen Meister in Paris, der ihm wohl an Wissen und Kompetenz - gleichgestellt sei (L 20, V. 1-6; C 23, V.1-6; J 11, V.1-6, hier „phaffe“, V.6). Dessen Boten habe er, Klingsor, aus Gründen, die nicht erwähnt werden, fünf Tage lang mit Worten bei einem Mädchen festgehalten (L 20, V. 7f.; C 23, V. 7f.; J 11, V. 7f.). Das Mädchen, das einem Hausherrn zugeordnet ist („des wirtes maget“; L 20, V.7; C 23, V.7; J 11, V.7), wird durch kunstvollen Gesang und kunstvolle Rede charakterisiert (nach L 20, V. 9 und J 11, V. 9; vgl. dazu C 23, V.9). Darüber hinaus erfährt man nur noch, dass es dem durch den Zauber Gebundenen nun erlaubt sei, davonzuziehen, und dass auch das Mädchen dadurch seine Notsituation überwinden könne (L 20, V.10; C 23, V.10; J 11, V.10). Ganz offensichtlich handelt es sich um Partikel einer Geschichte, die nicht auserzählt wird und deren Rahmen daher nicht zu erhellen ist. Aus den kryptischen Andeutungen kann man allenfalls folgern, dass eine Zauberhandlung Klingsors im Zentrum steht.

In der Folgestrophe (L 21; C 24; J 12) wird deutlich, dass die Präsenz des Thüringer Fürstenhofes beim Rätselwettstreit offensichtlich auch in den Lohengrinhand-

46 Insofern ist auch die Reihenfolge nach C nicht stimmig, da C 22 zwar das Luziferrätsel beantwortet, aber die anderen Themen antizipiert, bevor sie von Klingsor überhaupt angesprochen sind. 
schriften durchgängig vorausgesetzt wird, obwohl der mit dem Fürstenlob gegebene Rahmen hier fehlt. Man erfährt, dass der Thüringer Fürst und seine Frau mit ihrer Gefolgschaft die Absicht haben, die Worte Klingsors persönlich zu überprüfen. Sie wollen sich nicht auf Boten verlassen, sondern sich selbst zu Pferde aufmachen, um zu sehen, ob „des wirtes maget“ so weise und verständig („sinnic“; L 21, V.4; C 24, V.4; J 12, V.4) sei, wie Klingsor es behauptet hat. Der Landgraf stellt für den einen Fall in Aussicht, Klingsors Reden von wunderlichen Dingen zuzustimmen („dar wider [...] nimmer wort gestriten“; L 21, V. 6; J 12 und 6; C 24, V. 6: „niemer tag da wider striten“), die Landgräfin gibt zu erkennen, dass sie im anderen Fall gewaltigen Zorn gegen Klingsor hegen würde (L 21, V.5-9; ähnlich C 24, V.5-9 und J 12, V.5-9).

Summa summarum: Der Hauptpunkt der vermutlich hinter den beiden Strophen liegenden Geschichte scheint die Frage zu sein, ob die wunderschön singende und als weise gekennzeichnete „maget“ durch die Vorfälle im Zusammenhang mit dem Boten des Meisters, den Klingsor magisch bei ihr gebunden hat, tatsächlich (noch) weise ist oder vielleicht den Verstand verloren hat. Eben dies soll überprüft werden, das Ergebnis soll die weitere Einstellung des Landgrafenpaares zu Klingsor bestimmen. Die überlieferten ,Sprengsel' der Geschichte stellen kein Rätsel im eigentlichen Sinne dar, in dem etwa nach der Identität des Mädchens oder des durch Zauber Gebundenen gefragt würde, vielmehr handelt sich um eine geheimnisvolle Rätselrede Klingsors und eines Erzählers, die nicht aufgelöst wird.

\subsection{Buckel und Schild}

Die zwei folgenden Strophen nach L (L 22f.; vgl. C 25; C 27; J 13f.) lassen sich, verbunden mit einer weiteren Strophe (L 28; C 28; J 15), unter der Thematik ,Buckel und Schild' zusammenfassen. Klingsor rühmt sich erneut, „Von hoher kunst ein meisterpfaffe“ (L 22, V. 2; vgl. C 25, V.2; J 13, V. 2) zu sein, doch gleichzeitig beklagt er, dass die Klugheit eines Laien seine Fragen austrockne und er ihm unterlegen sei (L 22, V. 6; C 25, V. 6; abweichend: J 13, V.6). Klingt bereits hier über das Verb ,austrocknen' wiederum die Isotopieebene des Wassers als Metaphorik für Verstand und Verstandeskräfte an, so setzt sich dies in Klingsors Drohung fort, er wolle nun seinerseits den Verstand aller („ir aller sinnes wac“; L 22, V. 7; vgl. C 25, V.7; J 13, V.7) mit seiner Meisterkunst ausschöpfen („mit miner kunst erschepfen“, ebd.). Erkennbar zieht sich selbst durch diese dunklen Partien des Rätselwettstreits die Metaphorik des Wassers für die Ebene des Agon durch. Im Folgenden geht Klingsor auf Buckel und Schild ein, indem er sagt, er habe einen, der den Buckelschild statt des Schildes gewählt habe, "sigelos“ (L 22, V. 8; vgl. C 25, V. 8; J 13, V. 8) im Kampf gesehen, obgleich sein Schwert Köpfe hätte abschlagen können (L 22, V. 8-10; vgl. C 25, V. 8-10; J 13, V. 8-10).

In der Anschlussstrophe (L 23; C 27;7 J 14) löst Klingsor diese verrätselte Rede selbst zumindest zum Teil auf: So bezeichnet er sich als Schutz und Schild für

47 Als C 26 ist eine Strophe des Erzählers eingeschoben. 
Heinrich von Ofterdingen und macht deutlich, dass diejenigen, die mit dem Buckelschild dastehen, ein Risiko eingehen und leicht eine Niederlage im Kampf kassieren können: „Heinrich von Oftertingen hat I den schilt an mir. swer mit dem buggelere stat, I der mac doch eine schanze wol versnellen" (C 27, V.1-3). ${ }^{48}$ Klingsor bezieht sich hier auf die nach $\mathrm{C}$ und $\mathrm{J}$ im Fürstenton gegebene und offensichtlich implizit auch im Lohengrin vorausgesetzte Personenkonstellation des Fürstenlobs zurück: Heinrich von Ofterdingen war dort den anderen Sängern im Lobwettstreit unterlegen gewesen und hatte sich in Klingsor einen Stellvertreter erwählt. Insofern kann sich dieser als dessen Schutz und Schild bezeichnen. Im Verlauf der Strophe, in dem Klingsor mit dem Schreiber, Biterolf, Walther und Wolfram weitere Personen aus dem Fürstenlob ins Spiel bringt, wird überdies deutlich, dass in Wolfram der Buckelschild der anderen Sänger zu sehen ist, der sie vor den Schwertschlägen des Gegners schützen soll: „Wolferam von Eschenbach, der ist ir pukelere I Der schirmet wol für swertes snit“" (L 23, V. 7f.; C 27, V. 7f.; J 14, V.7f.). Damit ergibt sich folgende ,Aufstellung' im Wettkampf: Klingsor schützt Heinrich von Ofterdingen mit dem Schild, Wolfram seine Kämpfer und Sänger mit dem Buckelschild.

Die Provokation Klingsors besteht nun darin, dass er voraussagt, diejenigen, die auf den Buckelschild vertrauen, würden unvermeidlich im Kampf verlieren, da er eine Kampftechnik kenne, gegen die man mit dem Buckelschild machtlos sei: „so kan ich kunst, da varent riutelinge mit I und ist ir smalez schirmen in zu swere" (L 23, V.9f.); "so weiz ich kunst, da fliegent riutelinge mit I und ist ir smalem schirmen gar ze swere" (C 27, V. 9f.; vgl. L 14, V. 9f.). ${ }^{49}$ Mit dieser Drohung provoziert Klingsor Wolfram erneut und stellt dessen Überlegenheit, die er in der vorausgehenden Strophe bereits eingeräumt hatte, wiederum in Frage.

In den gleichen Kontext gehört die sich in C und J anschließende Strophe (C 28 und J 15), die in L disloziert ist (L 28), aber hierher geordnet werden muss. Jetzt spricht Wolfram und pariert die Angriffe Klingsors, die auf der Ebene der Kampfmetaphorik über Schild, Schwert und Stechmesser erfolgen. Den Sinn der äußerst schwierigen Strophe möchte ich folgendermaßen zusammenfassen: Obwohl Klingsor scharfe Wurfmesser auf ihn, Wolfram, geworfen habe, stehe er dennoch unversehrt und nicht zerschnitten auf dem Kampfplatz und trete mit seiner Kunst gegen Klingsor an, um ihn seinerseits zurückzudrängen oder sich zumindest selbst nicht zurückdrängen zu lassen (L 28 V. 1-6; J 15, V. 1-6; C 28, V. 6). Stolz äußert Wolfram: Wenn das mit der Kunst eines Laien oder durch den Mund eines Laien möglich sei, dann gerate ein Pfaffe dadurch in Schande (ebd., V.7). Doch zugleich räumt er ein, dass seine Absichten zwar hochfliegend waren, er sich aber um der

48 Ich zitiere den am besten verständlichen C-Text. Vgl. dazu die noch schwierigeren Lesarten nach L und J: L 23, V. 1-3: „Heinrich von Ofterdingen hat I den schilt an mir. swer nu mit pukeleren stat I - daz er im eine schanze wol übersehe!“; J 14, V. 1-3: „Heinrich von Ofterdingen hat I an mir den schilt. swer mit dem bukelere gat, I der mac doch eine scanz wol vursehe."

49 Gemeint ist wohl die Technik, mit kleinen Speeren oder Stechmessern auf den Buckelschild zu werfen, gegen die man sich mit diesem offensichtlich nur schwer abschirmen konnte. 
deutschen Priester willen zügeln wolle („Ich wilz durch diutsche prister lan. I min sin was hoch entsprungen, der muz leise gan“; L 28, V. 9f.; vgl. J 15, V. 8f.; C 28, V. 8f.).

Die verrätselte Rede dieser drei Strophen dringt nicht zu einer Rätselstellung im eigentlichen Sinne vor, sie bezieht sich ganz auf den Wettstreit selbst, der konsequent als Kampf der Meister auf Leben und Tod metaphorisiert wird. Während Klingsor sich weit vorwagt und mit scharfen „riutelingen“ auf Wolfram zu werfen droht, beschränkt sich dieser darauf zu parieren, und muss sich am Ende in kluger Selbstbeschränkung als Laie zügeln. Eindrucksvoll ist, wie in diesen hermetischen Strophen deutlich wird, dass hier zwei Kämpfer stellvertretend für andere um die Vorherrschaft im Kampf konkurrieren, der metaphorisch für die Auseinandersetzung im Wissen und Dichten steht. Letztlich wird die Metaphorik so weit getrieben, dass die beiden Kämpfer metonymisch mit den Waffen verschmelzen. Keineswegs steht der Laie am Ende „sigelos“ dar, was Klingsor zu Beginn dieser Strophen postuliert hatte. Es entspricht der Überlegenheit Wolframs, dass er auch in dieser Partie das letzte Wort behält.

\subsection{Artus, Brandan, Lohengrin}

Die folgenden Strophen, auf die ich im Rahmen dieses Beitrags nur noch ganz summarisch eingehen kann, leiten in L zur Erzählung von Lohengrin über. Klingsor spricht und berichtet in L 24f. (J 16f.), dass Artus nach seinem Tod in Fleisch und Blut mit seinen Helden und seinem Gefolge in einem Gebirge weiterlebe. Aus Artus' Gefolge werden das Mädchen Felicia, darüber hinaus aus der Mythologie bekannte Gestalten wie Sibille und Juno genannt sowie ein berühmter Abt, dessen Name von Klingsor verschwiegen wird. In der nur in L überlieferten Folgestrophe (L 26) wird deutlich, dass Artus nach seinem Tod aus dem Jenseitsraum des Gebirges Kämpfer in die Christenheit sendet (L 26, V.1f.). Noch ohne den Namen zu nennen, deutet Klingsor bereits die Geschichte von Lohengrin an (V.3-10), indem er erzählt, dass eine Glocke von sehr weit her einen ohrenbetäubenden Lärm in der Artusgesellschaft erzeugt habe, was zur Folge gehabt habe, dass ein hoher Graf im Kampf gestorben sei.

Klingsor fordert Wolfram nicht zur Auflösung der geheimnisvollen Rede auf, die eher eine Erzählung darstellt, als dass sie ein Rätsel formulieren würde, doch dieser schaltet sich ungefragt ein (L 27; J 18) und erläutert zunächst nur, dass es sich bei dem ungenannten Abt um den heiligen Brandan handele. ${ }^{50}$ Nach der schon besprochenen Strophe aus dem Kontext des Komplexes um Schild und Buckel (L 28) bewegt sich der Rätselwettstreit in L dann immer mehr auf den Lohengrin-Roman zu. Der Thüringerfürst fordert Wolfram zum Erzählen auf und möchte dazu den Hof und vor allem die Damen versammeln: „wilt uns die mere künden fürebaz, I wir müzen nach den frowen allen senden“ (L 29, V.1f.). Klingsors Zorn auf Wolfram legt sich, er überlässt diesem das Feld und will nun selbst sehr gerne zuhören:

50 Es folgt in dieser Strophe noch die Antwort auf das Luziferrätsel (V.7-10), auf deren Zusammengehörigkeit mit Strophe L 19 (J 10 und C 21) oben schon hingewiesen wurde. 
„so hœrt ich selber singen nie so gerne“ (L 29, V. 10) und „nu singet, meister wise!“ (L 30, V. 10). Ein Erzähler erläutert, dass Wolfram vor dem versammelten Hof auf der Wartburg auftritt, und parallelisiert das Verhältnis dieses Sängers zur Landgräfin mit jenem von Horant vor Hilde aus der Kudrun. Der Rätselwettstreit ist zu Ende, Klingsor hat sich unvermittelt untergeordnet, und Wolfram füllt die leeren Stellen aus Klingsors fragmentarischer Rätselrede bereits in den ersten beiden Strophen seiner Rede aus:

Elsam von Prabant, die pflac, swen sie durch gebet an blozen knien lac, daz sie ein schellen got zu eren hete.

Nu merket, wie siez angevienc: swen der ougen saf von irem herzen gienc, do liute sie die schellen, die vil stete.

Da von Artus und sin massenie wart betoubet

Und Lohengrin wart uz gesant

durch einen kampf der edeln, claren in Prabant. der ez niht weiz, dem si noch frage erloubet. ${ }^{51}$

In Strophe L 32 erfährt man darüber hinaus noch, dass Gott für das wundersame Erklingen der Glocke Elsas am Artushof verantwortlich war, was wiederum Brandan niedergeschrieben haben soll. Damit ist die Erzählwelt, um die es im Lohengrin-Roman gehen wird, in Umrissen aufgebaut. Wolfram beansprucht gegenüber Klingsor „ich kan die rehten warheit singen“ (L 32, V. 10), und bleibt im weiteren Fortgang der unangefochtene Erzähler, dem auch Klingsor diese Rolle nicht mehr abspenstig machen will. Der Rätselwettstreit bleibt in den Lohengrinhandschriften eine Exposition zur Geschichte des Gralsgesandten, ein Vorspann, auf den am Ende nicht mehr verwiesen wird.

\section{Fazit}

Immer wieder bekämpfen sich die Kontrahenten in den Rätselpartien des Wartburgkriegs mit scharfer Polemik, mit Todesdrohungen und Ankündigungen harter gegenseitiger Bestrafungen. Insofern wird der Rätselwettstreit, der literarischen Inszenierung nach, über weite Strecken auf Leben und Tod geführt. Hier kommt es darauf an, den anderen durch verschiedene Taktiken und Techniken der Verrätselung, Allegorisierung und Allegorese in die Bredouille zu bringen und sich selbst als Dichter zu ermächtigen und zu autorisieren. Vielfach greifen die Sän-

51 Übers. L 31: „Elsa von Brabant, die hatte, wenn sie auf nackten Knien zu Gott betete, Gott zu Ehren eine Glocke bei sich. Jetzt passt auf, was sie tat: Wenn ihr die Tränen aus dem Herzen in die Augen stiegen, da läutete die standhafte Frau die Glocke. Dadurch wurden Artus und sein Gefolge taub und Lohengrin wurde ausgesandt, um einen Kampf für die Edle, Reine in Brabant zu kämpfen. Wer es nicht weiß, dem sei es erlaubt nachzufragen." 
ger dabei auf die Metaphorik des Schürzens und Lösens eines Knotens oder des Verwirrens und Entwirrens von Fäden zurück, aber auch auf jene des Deckens eines Hauses und Daches. Besonders oft wird die Metaphorik der Höhe und Tiefe bemüht, die sich auf vielfache Weise mit der Vorstellung des Wassers verbindet. Neben der Objektebene der Rätselinhalte spielt die poetologische Auseinandersetzung der Sänger, für die verschiedene Bildfelder bemüht werden, die entscheidende Rolle. Es geht um die Vormachtstellung im Dichten, die in den erläuterten Partien des Wettstreits stets Wolfram von Eschenbach zugesprochen wird. Insofern sind die Wartburgkrieg-Texte bedeutende Dokumente der Wolframrezeption. Daher habe ich zu zeigen versucht, wie Partikel und Versatzstücke aus Wolframs Romanen, insbesondere dem Parzival, aufgegriffen werden, was Sangspruchdichtung und höfische Epik in einer ganz besonderen Weise verbindet.

Im engen Zusammenhang mit dieser poetologisch und literaturgeschichtlich relevanten Ebene steht die epistemologische, denn es geht stets um die Frage, über welche Kenntnisse die Sänger verfügen und wo die Grenzen des legitimen Wissens liegen. Der Laie Wolfram bespielt diese Ebene auf vielfache Weise durch Überbietung und Mehrwissen, aber auch durch Respektieren der Geheimnisse Gottes und durch kluge Zurückhaltung in der Rede, die bis zum Verstummen und zum Rückzug auf das Schlagen eines Kreuzzeichens im entscheidenden Moment gehen kann. Der Meisterpfaffe Klingsor gerät immer wieder ins Zwielicht, was sein Werdegang deutlich macht, aber auch seine Praktiken des Zauberns, der Nigromantie und Teufelsbeschwörung. Wenn die Grenzen von legitimem und illegitimem Wissen in den Rätseln ausgehandelt werden, geht es auch um die Quellen des Wissens (wie die göttliche Offenbarung) und die Inspiration durch höhere Mächte (wie Engel oder Teufel). Die Sänger überwachen sich hier gegenseitig und halten sich in Schach, doch an vielen Stellen gibt es nicht einfach eine Scharzweißzeichnung, sondern die Grenzen zwischen Erlaubtem und Unerlaubtem beginnen zu schillern. Ein Bewusstsein von der Schwierigkeit, diese Grenzen zu beobachten und zu wahren, soll auf diese Weise gewiss auch den Rezipienten vermittelt werden.

Was die Rätselinhalte betrifft, so zeigt sich, dass Allegorisierung als Verrätselung und Allegorese als Enträtselung (Schlafendes Kind, Quaterrätsel) im Vordergrund stehen. Es wurde sichtbar, dass das Lösen der Rätsel keineswegs immer eine vollständige Enträtselung bedeutet, oft ergeben sich ungelöste Reste, die wiederum als poetische Überschüsse für neue Verrätselungen dienen können. Manchmal fehlt die Lösung ganz („Des wirtes maget“) oder sie findet sich disloziert von der Rätselstellung (Luziferrätsel), was mit der Spezifik und Fragmentarizität der Überlieferung zu tun hat. Manche Rätselrede scheint in einen größeren Kontext zu gehören, der uns nicht überliefert ist und von daher dunkel bleiben muss („Des wirtes maget“). Gelegentlich wird die Rede verrätselt, ohne dass ein förmliches Rätsel gestellt wird (Schild und Buckel). Das Ziel dieses Beitrags war es, das Spektrum der verschiedenen Formen der Verrätselung und Enträtselung im Wartburgkrieg durch die Diversität der Beispiele möglichst breit abzubilden. 
Darüber hinaus wird deutlich, dass in den Rätseln, welche etwa die Themen legitimes und illegitimes Wissen, göttliche Geheimnisse, Sünde und Tod, Wachen und Schlafen, Gnade und Strafe Gottes, Reue, Beichte und Buße betreffen, auch die Rezipienten angesprochen sind. Dies kann mittelbar der Fall sein, indem der Thüringer Hof an verschiedenen Stellen als Publikum und Rezipientenkreis des Streits präsent gehalten wird, aber auch unmittelbar, indem über Aufrufe wie „merke“ oder Generalisierungen wie „hier geht es um jeden Sünder" deutlich wird, dass jedermann gemeint ist. Insofern dienen die allegorischen Rätsel und ihre Allegoresen auch als Aufrufe an die Rezipienten zu geistlicher Umkehr sowie insbesondere als Mahnung an ein Laienpublikum, nicht allzu weit in die Geheimnisse Gottes einzudringen, sondern sich vorzusehen und selbst in den legitimen Grenzen des Wissens zu bleiben. 


\section{Gattung \& Geheimnis \\ Zum Begriff des Mysterienspiels}

Glenn Ehrstine

Gab es im deutschen Mittelalter Mysterienspiele? Die Antwort, wie vieles in der Wissenschaft, kommt auf die Definition an. Nach dem heutigen Sprachgebrauch zu urteilen, gab es sie ohne Zweifel: Wie uns der Duden verbürgt, war ein Mysterienspiel ein „auf biblischen Erzählungen beruhendes geistliches Spiel des Mittelalters ", 1 und eine solche Definition lässt sich problemlos auf fast alle Gattungen des mittelalterlichen religiösen Schauspiels beziehen, mit Ausnahme der im deutschen Sprachbereich nur vereinzelt überlieferten nachbiblischen Heiligen- und Legendenspiele. ${ }^{2}$ Mysterienspiele gibt es sogar noch: Eine Google-Suche zum Begriff lieferte im Mai 2019 etwa 54000 Treffer, mit Zeugen einer lebendigen Theaterpraxis wie etwa "Akte Zwingli - Ein Mysterienspiel“ und „500 Jahre Reformation - Das Jüterboger Mysterienspiel“, beide im Lutherjahr 2017 aufgeführt, oder gar die alljährlichen Aufführungen des Vereins "Lüfthildis-Mysterienspiele“ in Meckenheim-Lüftelberg bei Bonn sowie der Arbeitsgemeinschaft „Mysterienspiel“ am Albertus-Magnus-Gymnasium Rottweil, welche bewusst an mittelalterliche Traditionen anknüpfen und jeweils seit 1981 und 1991 aktiv sind. ${ }^{3}$ Der Begriff scheint in heutigen populären Vorstellungen des Mittelalters fest etabliert zu sein, vor allem als beliebte Bezeichnung für Laieninszenierungen neu geschaffener

1 Eintrag „Mysterienspiel, das.“ In: Duden Online, URL: https://www.duden.de/rechtschreibung/ Mysterienspiel (29.5.2019).

2 Siehe u. a. Die deutschen Mirakelspiele des Spätmittelalters. 2. Teil: Texte. Hg. von Elke Ukena. Bern, Frankfurt a. M. 1975; Heinrich Biermann: Die deutschsprachigen Legendenspiele des späten Mittelalters und der frühen Neuzeit. Köln 1977; Sibylle Jefferis: Ein spätmittelalterliches Katharinenspiel aus dem Cod. Ger. 4 der University of Pennsylvania. Text und Studien zu seiner legendengeschichtlichen Einordnung. Göppingen 2007; Das mittelniederdeutsche Theophilus-Spiel. Text - Übersetzung - Stellenkommentar. Hg. von André Schnyder. Berlin, New York 2009.

3 „Akte Zwingli - Ein Mysterienspiel“, von Christoph Sigrist (Text) und Hans-Jürgen Hufeisen (Musik), uraufgeführt im Zürcher Großmünster am 16. Juni 2017, URL: https://aktezwingli.ch/ (29.5.2019); ,500 Jahre Reformation - Das Jüterboger Mysterienspiel“, aufgeführt unter der Leitung von Pfarrer Bernhard Gutsche September-Oktober 2017: Iris Krüger: „Mysterienspiele zur Reformation", Märkische Allgemeine, (08.06.2017), URL: https://www.maz-online.de/ Lokales/Dahme-Spreewald/Mysterienspiele-zur-Reformation (29.5.2019); , ,500 Jahre Reformation: Das Jüterboger Mysterienspiel“, URL: https://www.youtube.com/watch?v=0e18So1mU1I (29.5.2019); Markus Schmitz: „Über uns“, Lüfthildis-Mysterienspiele e. V., URL: http:// mysterienspiele.de/?page_id=8 (29.05.2019); Veronika Heckmann-Hageloch: „Die Geschichte unserer Mysterienspiele“, URL: http://www.mysterienspiel.de/was-bisher-war.html (29.5.2019). 
Spieltexte, die sich an mittelalterliche Stoff- oder Aufführungstraditionen anlehnen oder diese evozieren wollen. ${ }^{4}$

Und dennoch: Vor 1800 sucht man vergeblich nach Belegen für diesen Gattungsbegriff im Deutschen, obwohl misterie im Englischen und vor allem mystère bzw. misterio in den romanischen Sprachen geläufige Spielbezeichnungen waren. ${ }^{5}$ Weder das Deutsche Wörterbuch noch das Grammatisch-Kritische Wörterbuch der hochdeutschen Mundart von Johann Christoph Adelung kennen ,Mysterienspiel' als Lemma; lediglich ,Mysterium' taucht bei Adelung als Synonym für ,Geheimniß` auf. ${ }^{6}$ Zieht man vor allem die „Übersicht über überlieferte Spielbezeichnungen" aus dem Katalog der deutschsprachigen geistlichen Spiele und Marienklagen des Mittelalters von Rolf Bergmann zu Rate, dann steht eindeutig fest: Während Begriffe wie osterspil oder passio bereits im 15. Jahrhundert kursierten, findet man mysterium oder etwa ein konjiziertes mysterienspil als Gattungsbezeichnung nirgends. ${ }^{7}$ Dass der Begriff im Laufe des 19. Jahrhunderts den Weg ins Deutsche gefunden hat, verdanken wir u. a. dem Theaterregisseur Eduard Devrient, der in seiner einflussreichen Geschichte der deutschen Schauspielkunst (1848) den „Aufschwung des dramatischen Lebens“ im deutschen Mittelalter auf die Einwirkung der „Mysterienspiele in Frankreich“ zurückführte. ${ }^{8}$ In der heutigen deutschsprachigen Spielforschung

4 Das neuzeitliche Interesse am mittelalterlichen Theater lässt sich außerdem seit dem späten 19. Jahrhundert an der Inszenierung mittelalterlicher Spieltexte beobachten. Diese bewahren aber in der Regel den etablierten Titel des mittelalterlichen Spieltexts, in dem gewöhnlich der Ursprungsort bzw. der Aufbewahrungsort der Spielhandschrift sowie die jeweilige mittelalterliche Spielgattung benannt werden. Vgl. die Liste der untersuchten Spiele bei Hansjürgen Linke: Mittelalter-Renaissance auf der Bühne. Wiederaufleben des mittelalterlichen Dramas und Theaters in der Neuzeit. Wiesbaden 2013, S.11f., die mit dem Alsfelder Passionsspiel beginnt und der Wolfenbüttler Marienklage endet. In Linkes Studie eingebunden sind auBerdem „fünf neuzeitliche Texte, die vermöge eklektizistischer Kompilation mittelalterlicher Spiele neu gestaltet wurden“ (ebd., S. 12), u. a. zwei ,Mysterienspiele' von Richard Kralik: Das Mysterium von der Geburt des Heilands. Ein Weihnachtsspiel (1894) und Das Mysterium von Leben und Leiden des Heilands (1895).

5 Emma Maggie Solberg: A History of ,The Mysteries'. In: Early Theatre 19 (2016), H. 1, S. 9-36; Graham A. Runnalls: Mystère ,Représentation théâtrale'. Histoire d'un mot. In: Revue de Linguistique Romane 64 (2000), H. 255f., S. 321-345; Rainer Hess: [Art.] Mysterienspiel. In: Literaturwissenschaftliches Wörterbuch für Romanisten. Hg. von Rainer Hess, Gustav Siebenmann und Tilbert Stegmann. 4. Aufl. Tübingen 2003, S. $205 f$.

6 Das Deutsche Wörterbuch kennt nur ,mystisch': Das deutsche Wörterbuch. Bd. 6: L-M. Bearb. von Moriz Heyne. Leipzig 1885, Sp. 2848. Adelung dagegen verzeichnet nur ,Mystik': Johann Christoph Adelung: Grammatisch-kritisches Wörterbuch der hochdeutschen Mundart. Bd.3. Wien 1808, S. 351. Für ,Mysterium' im Eintrag zu ,Geheimniß’ bei Adelung, siehe Bd. 2, Sp. 493.

7 Rolf Bergmann: Katalog der deutschsprachigen geistlichen Spiele und Marienklagen des Mittelalters. München 1986, S. 504f.

8 Eduard Devrient: Die Geschichte der deutschen Schauspielkunst. Bd.1. Leipzig 1848, S. 26. Devrient macht außerdem ausgiebig Gebrauch von „Mysterium" und „Mysterienbühne“: vgl. S. 15 und 57. Das Oberammergauer Passionsspiel galt um diese Zeit auch als Mysterienspiel: „Weithin aber durch ganz Deutschland verbreitete sich der Ruhm des Ammergauer Passionsspieles, als der Einen Reliquie der alten Mysterienspiele." Martin von Deutinger: Das Passionsspiel in Oberammergau. Berichte und Urtheile über dasselbe, gesammelt von dem Herausgeber. In: Beiträge zur Geschichte, Topographie und Statistik des Erzbistums 
jedoch, die sich für das Geistliche Spiel des deutschen Sprachbereichs möglichst eng an die im Bergmann'schen Spielkatalog etablierten Spielbezeichnungen und -gattungen hält, ${ }^{9}$ ist „Mysterienspiel“ als wissenschaftlicher Terminus verpönt: Er taucht allenfalls in älteren Untersuchungen oder in Studien aus der Anglistik oder Romanistik auf. ${ }^{10}$

Wie sollen wir diesen Befund deuten? Aus mittelalterlicher Perspektive scheint der Fall ganz einfach eine Frage von anders gelagerter Terminologie zu sein, denn im deutschen Sprachbereich sollte kein Mysterienspiel, sondern eine figur (bzw. - lateinisch - figura) die Geheimnisse des katholischen Kults theatral vermitteln. Nach einem ersten Abschnitt über die Semantik von mystère/misterie in Frankreich und England geht der zweite Teil meines Beitrags der engen Verwandtschaft von mystère und figur als szenischem Begriff nach, der nicht nur den allegorisch-typologischen Sinn biblischer Spielstoffe bezeichnen sollte, sondern, wie Niklaus Largier und Jutta Eming jüngst betont haben, auch eine zeichenhaft-plastische Ebene besitzt, die letztlich von der Allegorie zu unterscheiden ist und die jeweilige szenische Figur zu einem lebendigen Instrument der Erkenntnis werden lässt. ${ }^{11}$ Zwar hat die theatrale Zeichenhaftigkeit von figurae mich schon 2001 beschäftigt, ${ }^{12}$ doch im Gegensatz zu dieser früheren Arbeit geht es hier um die Nähe des Begriffs zu den ,Mysterien' französisch- und englischsprachiger Spiele bzw. zu den Mysterien des Kults an sich, die über die Figur wahrgenommen wurden. Am Ende kehre ich wieder zum Begriff, „Mysterienspiel' zurück und stelle Überlegungen zu seiner Semantik innerhalb der heutigen Theaterpraxis an. Im Unterschied zum wissenschaftlich neutralen ,Geistlichen Spiel’ scheint ,Mysterienspiel` zumindest im po-

München und Freysing. Hg. von Martin von Deutinger. Bd. 2. München 1851, S.397-570, hier S. 465. Vermutlich gibt es noch ältere Belege für den Begriff, die sich aber im Rahmen dieser Arbeit nicht finden ließen. Ich möchte mich an dieser Stelle bei Prof. em. Dr. Hansjürgen Linke, Universität zu Köln, für seine freundlich per Mail mitgeteilten Auskünfte zu möglichen ,Mysterienspiel'-Belegen vor Devrient bedanken.

9 Bergmann orientierte sich wiederum an der Liste von Spieltiteln, die Hansjürgen Linke für die zweite Auflage des Verfasserlexikons zusammengestellt hatte. Bergmann: Katalog (Anm. 7), S. 14.

10 Vgl. Anton Dorrer: Mittelalterliche Mysterienspiele in Tirol. In: Archiv für das Studium der neueren Sprachen 164 (1933), S. 161-177 und 165 (1934), S. 6-10; Heinz Kindermann. Theatergeschichte Europas. Bd.1. Salzburg 1957, S. 314 und 351; Hans-Jürgen Diller: Redeformen des englischen Misterienspiels. München 1973; Klaus Peter Steiger: Vom Misterienspiel zum Stuart-Drama. Theatralische Vielfalt aus heutiger Sicht. Berlin 1984. Die Form ,Misterienspiel' soll in diesem Fall die Ableitung des Wortes von ,ministerium' statt von ,mysterium' kennzeichnen: Solberg: History (Anm. 5), S. 17f.

11 Niklaus Largier: Zwischen Ereignis und Medium. Sinnlichkeit, Rhetorik und Hermeneutik in Auerbachs Konzept der figura. In: Figura. Dynamiken der Zeiten und Zeichen im Mittelalter. Hg. von Christian Kiening und Katharina Mertens Fleury. Würzburg 2013, S. 51-70, hier S. 52f.; Jutta Eming: Ambivalenz und figura. Überlegungen am Beispiel der Maria Magdalena. In: Die Ambivalenzen des geistlichen Spiels. Revisionen von Texten und Methoden. Hg. von Jörn Bockmann und Regina Toepfer. Göttingen 2018, S. 223-239, hier S. 226 und 232f.

12 Glenn Ehrstine: Das figurierte Gedächtnis: Figura, Memoria und die Simultanbühne des deutschen Mittelalters. In: Text und Kultur. Mittelalterliche Literatur, 1150-1450. Hg. von Ursula Peters. Stuttgart 2001, S. 414-437. 
pulären Verständnis viel eher in der Lage zu sein, die Essenz religiöser Spiele des Mittelalters zu kennzeichnen.

Stecken wir zunächst das semantische Feld des Mysterienspiels in anderen europäischen Spieltraditionen ab, um uns dann vergleichend der Figura zuzuwenden. Als Gattungsterminus ist mystère vor allem im französischen Mittelalter belegt, wo es die am häufigsten bezeugte Spielbezeichnung überhaupt bildet, vertreten nach Auskunft des britischen Romanisten Graham Runnalls durch 31 der insgesamt 74 zeitgenössischen französischsprachigen Spielhandschriften und -drucke, die mit Incipits bzw. Titeln versehen sind..$^{13}$ Darüber hinaus gab es in der Zählung Louis de Petit de Julevilles mindestens 64 Aufführungen von Mystères, für die kein Spieltext erhalten ist. ${ }^{14}$ Der Begriff begegnet vor allem bei Passionsund Heiligenspielen des 15. und frühen 16. Jahrhunderts, ${ }^{15}$ deren bekanntestes Beispiel, Le mystère de la passion von Arnoul Gréban, über vier Tage den Gang der Heilsgeschichte von der Schöpfung bis zur Auferstehung dramatisierte und zwischen 1455 und 1473 mindestens vier Mal aufgeführt wurde. ${ }^{16}$ Mit 34574 Versen übertrifft Grébans Mystère die Länge vergleichbarer deutschsprachiger Passionsspiele um das Zwei- bis Dreifache. Das Passionsgeschehen wird hier durch den „Paradiesprozess“ umrahmt, den Rechtsstreit der vier Töchter Gottes um die Erlösung der Menschheit. ${ }^{17}$ Die göttliche Vorsehung, die im „procés de paradis“ zum Ausdruck kommt, ließ sich allerdings nicht nur auf die Passion oder den Märtyrertod früher Heiliger beziehen: Auch zeitgenössische Geschehnisse konnten als Mystère inszeniert werden, wenn sie Gottes Wirken auf Erden bezeugten, wie etwa bei Jeanne d'Arcs wundersamer Errettung der Stadt Orleans vor der englischen Belagerungsmacht, dem Thema von Le Mistère du siège d'Orléans, das vermutlich zwischen 1450 und 1460 verfasst wurde und womöglich als Teil von Feierlichkeiten zur Aufhebung der Belagerung an einigen Originalschauplätzen

13 Graham A. Runnalls: When Is a ,Mystère' not a ,Mystère'? Titles and Genres in Medieval French Religious Drama. In: Treteaux 2 (1980), S. 23-28, hier S. 26.

14 Darwin Smith: About French Vernacular Traditions. Medieval Roots of Modern Theatre Practices. In: Journal of Early Modern Studies 8 (2019), S. 33-67, hier S. 33, Anm. 1.

15 Runnalls: When Is a ,Mystère' not a ,Mystère’? (Anm. 13), S. 24.

16 Le Mystère de la Passion d’Arnoul Gréban. Hg. von Omer Jodogne. Bruxelles 1965; Cornelia Herberichs: Die "Zwieschlächtigkeit der Aufführung" und die „double diffusion" von Arnoul Grébans Le Mystère de la Passion. Zu Rainer Warnings Thesen der Ambivalenz des Passionsspiels aus überlieferungsgeschichtlicher Perspektive. In: Ambivalenzen des Geistlichen Spiels (Anm. 11), S. 195-219, hier S. 200; Darwin Smith: [Art.] Greban, Arnoul. In: Die Musik in Geschichte und Gegenwart. Allgemeine Enzyklopädie der Musik. Personenteil. Bd. 7. Kassel 2002, Sp. 1541-1545.

17 Dieser „procés de paradis“ wird von den allegorischen Tugenden Barmherzigkeit, Gerechtigkeit, Wahrheit und Frieden vor Gottvater geführt: Le Mystère de la Passion d'Arnoul Gréban. Hg. von Gaston Paris und Gaston Raynaud. Paris 1878, V. 2072-3394. Vgl. Jacques Verger: Le ,Procès de Paradis' dans le Mystère de la Passion d'Arnold Gréban. In: Justice et Miséricorde. Discours et pratique dans l'Occident médiéval. Hg. von Catherine Vincent. Limoges 2015; Waltraud Timmermann: [Art.] Streit der vier Töchter Gottes. In: Die deutsche Literatur des Mittelalters. Verfasserlexikon. Bd.9. Hg. von Burghart Wachinger et al. Berlin 1995, Sp. 396-402. 
der Kämpfe in und um Orléans aufgeführt wurde..$^{18}$ Die Mysterienspiele anderer europäischer Traditionen sind indes nicht so lang wie die großen französischen Spiele und auch nicht so zahlreich vertreten: Im katalanischen Sprachbereich etwa kommt der Begriff seltener vor als die vergleichbaren Spielbezeichnungen representació oder consueta (Regiebuch). ${ }^{19}$

Misterie begegnet auch in englischen Quellen des 15. und 16. Jahrhunderts. Der unter Anglisten lang anhaltende Streit darüber, ob das Wort schon im Mittelalter im Sinne von ,dramatische Darbietung' oder gar als Gattungsbezeichnung kursierte, rückt weitere Vergleichsmomente für die Verwandtschaft von mystery und figura in den Fokus. In ihrem neuerlichen Plädoyer für die Rehabilitierung des Begriffs geht Emma Maggie Solberg zunächst der Rezeptionsgeschichte von mystery in der anglistischen Spielforschung nach, um sich dann einer kritischen Analyse des Wortes auf etymologischer Basis zuzuwenden, und zwar über die zwei Traditionsstränge, die Anglisten (und auch Romanisten) für die Erklärung des Begriffs bemüht haben. Einmal leitet man den Begriff von mysterium ab, im ursprünglichen Sinne des griechischen musterion als Ritus oder Gottesdienst. Das war allerdings ein Ritus, der nur Eingeweihten zugänglich war, wie Jesus betont, als die Jünger ihn fragen, warum er in Gleichnissen spricht, hier in der Vulgata-Fassung: „,vobis datum est nosse mysteria regni caelorum; illis autem non est datum“ („Euch ist's gegeben, zu wissen die Geheimnisse des Himmelreichs, diesen aber ist's nicht gegeben." Matthäus 13,11) Solberg verfolgt, wie der Begriff im Christentum mit Einweihungsritualen wie Taufe und Eucharistie in Verbindung gebracht, von Tertullian als sacramentum übersetzt und schließlich zur Bezeichnung von performativen Vorgängen während der Liturgie eingesetzt wurde, wie etwa der visitatio sepulchri zu Ostern. ${ }^{20}$ Von hier ist es nur noch ein kleiner Schritt bis hin zu der Bedeutung „,szenische Darstellung biblischen Inhalts“ im außerliturgischen Bereich. Um die Skeptiker vom Fach zu beschwichtigen, die mystery in der Bedeutung ,dramatische Darbietung' erst nach 1744 gelten lassen wollen, bringt Solberg etliche neue Belege, in denen misterie bzw. mystery eindeutig im Sinne einer dramatischen Darbietung von (katholischen) Glaubenswahrheiten fungiert, u. a. aus den Werken John Lydgates (ca. 1371-1449), dem N-Town-Spiel (2. Hälfte des 15. Jahrhunderts), anti-katholischer Polemik des 16. Jahrhunderts und schließlich aus Henry VIII von

18 Barbara M. Craig: The Staging and Dating of the Mystère du Siège d'Orléans. In: Res publica litterarum 5 (1982), S. 75-83, hier S. 81f.; Vicki Hamblin: The Mistère du siège d'Orléans as a Representational Drama. In: Rocky Mountain Review of Language and Literature 42 (1988), S. 61-68, hier S. 66.

19 Für die Übermittlung dieser Informationen danke ich Dr. Lenke Kovács, Universitat de les Illes Balears. Der früheste entsprechende Beleg ist das 1407 im Zusammenhang mit der örtlichen Fronleichnamsprozession in Valencia aufgeführte Spiel „E la corona d'espines e alguns dels oprobis i misteris de la Sagrada Passió del Fill de Déu“" Vgl. N. D. Shergold: A History of the Spanish Stage from Medieval Times to the End of the Seventeenth Century. Oxford 1967, S. 54f.

20 Solberg: History (Anm. 5), S. 16f. 
Shakespeare (uraufgeführt 1613). ${ }^{21}$ Diese Skeptiker, u. a. der einflussreiche Spielforscher E. K. Chambers (1866-1954), hatten allerdings auch eine zweite, nicht minder gültige Etymologie bemüht, in der sich mystery nicht von mysterium, sondern von ministerium ableitet, wie schon vom französischen Theaterhistoriker Louis Petit de Julleville vorgeschlagen. ${ }^{22}$ Als neulateinische Wortschöpfung bedeutete das Wort ursprünglich „Amt des Ministranten“, hat aber später die Bedeutung von Arbeit oder Handwerk im Allgemeinen angenommen. Weil viele Spiele in England wie anderswo von Zünften getragen wurden, hat man den spätmittelalterlichen Theaterbetrieb in England auch als Handwerk verstanden, und man findet ohne Mühe zahlreiche spätmittelalterliche Belege für misterie in der Bedeutung von Zunft oder Gilde, was auch beim verwandten métier im Französischen greifbar wird. Solberg kann allerdings zeigen, wie beide semantischen Ebenen des Begriffs - mysteriummystery und ministerium-mystery - sich gerade in der Aufführung religiöser Spiele treffen:

The convergence of mysterium and ministerium in the English ,misterie' cognates and variations seems ,to reflect the convergence of the text of sacred mysteries and the players from the craft-mysteries' in early English dramatic practice. ${ }^{23}$

Anstatt diese Bedeutungsebenen streng auseinander zu halten, plädiert Solberg dafür, die in den Quellen greifbare Mehrdeutigkeit des Begriffs als Wesensmerkmal des geistlichen Schauspiels an sich zu verstehen. Gerade die schillernde Semantik von mystery play macht für Solberg die Stärke des Begriffs aus: Wie keine andere Gattungsbezeichnung bringt er die Rolle des religiös Verborgenen bei theatralen Aufführungen der Zeit zum Ausdruck und ist somit Teil einer Spielforschung, die ihr begriffliches Instrumentarium nicht vom modernen Theaterbetrieb, sondern von der spätmittelalterlichen Theaterpraxis herleitet, einer Praxis also, die auch rituelle Performanzen mit einschloss, die für die Zeitgenossen an der Hervorbringung des Sakralen teilhatten.

Über die theatrale Mehrdeutigkeit lässt sich nun die Brücke zu ,Figur/Figura' schlagen. Spielte dieser "schillernde Begriff“ eine zentrale hermeneutische Rolle in der „Erfassung des ,mysterium“" in der mittelalterlichen Theologie, so hat Matthias Schulz bereits 1998 nachweisen können, dass er im Umfeld des deutschsprachigen Geistlichen Spiels eine vergleichbar schillernde Semantik besitzt. ${ }^{24}$ Schulz wertet in seiner Studie zu den Eigenbezeichnungen des mittelalterlichen deutschsprachigen geistlichen Spiels insgesamt 1270 Belege aus 68 verschiedenen Spieltexten aus

21 Solberg: History (Anm. 5), S. 21-26.

22 Solberg: History (Anm.5), S.16; Literaturwissenschaftliches Wörterbuch für Romanisten (Anm. 5), S. 205.

23 Solberg: History (Anm. 5), S. 19.

24 Matthias Schulz: Die Eigenbezeichnungen des mittelalterlichen deutschsprachigen geistlichen Spiels. Heidelberg 1998, S. 234-247. Zur "figurativen Hermeneutik“ vgl. Kirstin FaupelDrevs: Vom rechten Gebrauch der Bilder im liturgischen Raum. Mittelalterliche Funktionsbestimmungen bildender Kunst im Rationale Divinorum Officiorum des Durandus von Mende (1230/1-1296). Leiden 2000, S. 178-201, hier S. 178. 
und kommt in Bezug auf die typologisch-präfigurativen Aspekte des Begriffs zum folgenden Schluss:

Innerhalb dieser Beleggruppe ist oft nur schwer zu unterscheiden, ob figur/figura in den einzelnen Belegen die Vorausdeutung oder aber die szenische Darstellung dieser Vorausdeutung bezeichnet. Die Schwierigkeit ineinander übergehender und nur begrenzt gegeneinander abgrenzbarer Verwendungsweisen liegt dabei im Belegmaterial selbst begründet. ${ }^{25}$

Neben Bedeutungen wie ,Zeichen', ,Beispiel', ,Gestalt' oder gar ,Darsteller' verzeichnet Schulz drei Hauptverwendungen von figur im szenischen Bereich, einmal als Spielabschnitt (z. T. gleichbedeutend mit ,Szene' oder ,Akt' im heutigen Verständnis), einmal als lebendes Bild und einmal als ganzes Spiel. ${ }^{26}$

Auch wenn Schulz seine Ergebnisse nicht nach Spielstoff oder Perioden sortiert, sind sie dennoch in ihren Hauptkategorien auf verblüffende Weise nahezu deckungsgleich mit der theatralen Semantik von mystère, die Graham Runnalls bei seiner Untersuchung zur Geschichte des Worts in folgende Bedeutungen unterteilt:

(1a) ,pièce de théâtre, dont le sujet est tiré de l'Écriture, de la vie des saints ou des miracles de la Vierge'; depuis l'extrême fin du XIVe siècle jusqu'au deuxième tiers du XVIe siècle;

(1b) ,représentation théâtrale d'un mystère au sens (1a)';

(1c) ,épisode d'un mystère au sens (1a)';

(2) ,tableau vivant (p. ex. lors d'une entrée princiére)'; du début du XVe siècle jusqu'au premier tiers du XVIe siècle;

(3) $\quad$ pièce de théâtre religieuse du moyen âge'; depuis le XVIIIe siècle. ${ }^{27}$

Auch der französische Begriff mystère konnte also ein ganzes Spiel, einen Spielabschnitt oder auch ein lebendes Bild bezeichnen. Dass Runnalls bei mystère im Sinne eines Tableau vivant prozessional veranstaltete Fürsteneinzüge hervorhebt, heißt in diesem Fall nicht, dass etwa weltliche Tableaux als Teil dieser Einzüge zur Aufführung kamen, wie es oft bei späteren Renaissance-Einzügen der Fall war. Ein als mystère bezeichnetes lebendes Bild war religiösen Inhalts. Neben einem

25 Schulz: Eigenbezeichnungen (Anm. 24), S. 234f. Siehe auch Ehrstine: Das figurierte Gedächtnis (Anm. 12), S. 417.

26 In der Bedeutung ,Spielabschnitt' verzeichnet Schulz 97 Belege in 19 Texten; für ,lebendes Bild' 1083 Belege in 18 Texten (zum größten Teil Mehrfachbelege durch die 15 Spielhandschriften des Zerbster Fronleichnamsspiels); für ,eigenständiges Spiel' 22 Belege in 18 Texten. Schulz: Eigenbezeichnungen (Anm. 24), S. 237ff.

27 Runnalls: Mystère (Anm. 5), S.342. Auf Deutsch: „(1a) ,ein Schauspiel, dessen Thema aus der Heiligen Schrift, einem Heiligenleben oder den Mirakeln der Jungfrau gezogen wird'; vom äußersten Ende des 14. Jahrhunderts bis zum zweiten Drittel des 16. Jahrhunderts; (1b), theatralische Darbietung eines ,mystère' in der Bedeutung (1a)'; (1c) ,Spielabschnitt eines ,mystère' in der Bedeutung (1a)'; (2) ,lebendes Bild (z. B. bei einem fürstlichen Einzug)'; vom Anfang des 15. Jahrhunderts bis zum ersten Drittel des 16. Jahrhunderts; (3) ,ein religiöses Schauspiel des Mittelalters'; seit dem 18. Jahrhundert“. Falls nicht anders gekennzeichnet, stammen alle Übersetzungen ins Deutsche von mir. 
Tableau vivant des Alten und Neuen Testaments und einem mit der Flucht nach Ägypten kann Runnalls mit der Beschreibung eines als Tableau konzipierten Mistere de la Passion de Nostre Seigneur aufwarten, der am 1. Dezember 1420 als Teil des Einzugs von Charles VII. „figuriert" wurde, wie es im Journal d'un Bourgeois de Paris heißt. ${ }^{28}$

Trotz dieser Übereinstimmungen sind mystère und figur/figura als theatrale Begriffe nicht bedeutungsgleich. Sie verhalten sich zueinander eher wie Stoff und Medium: Durch die Figur wird das Mysterium erkannt. Wenn wir noch die restlichen von Matthias Schulz ausgemachten Bedeutungsnuancen hinzuziehen, die keinen unmittelbaren szenischen Bezug besitzen - also ,Zeichen', ,Beispiel', oder ,Gestalt' - dann wird klar, dass dem Begriff figura auch im Umfeld des Geistlichen Spiels immer ein verweisendes Moment innewohnt. Er zeigt stets auf etwas, was außerhalb des unmittelbaren Wahrnehmungshorizonts bzw. irdisch Erfahrbaren des Betrachters liegt. ${ }^{29}$ Manchmal ist der figürliche Bezugspunkt, der jenseits des Wahrnehmbaren liegt, das Mysterium selbst, vor allem wenn die Verwandlung der Hostie in den Körper Christi in der Eucharistie ,figuriert' wird. Manchmal besteht das Mysterium allerdings eher im eigentlichen Moment der Verweisung, d. h., in der zu entschlüsselnden Verbindung zweier ungleichzeitiger Ereignisse oder Begebenheiten, die dem menschlichen Verstand widerstrebt. Gerade hier dient die Figur zur Erhellung der typologischen Bezüge zwischen Altem und Neuem Testament: Die Gegenüberstellung von zwei Momenten der Heilsgeschichte in der Figur soll die irdische Zeit überwinden und die zeitlos göttliche Vorsehung erfahrbar machen, wie schon Erich Auerbach betont hat. ${ }^{30}$ Die Figur

28 „Et fut fait en la rue de la Kalende devant le Palais ung moult grant piteux mistere de la Passion Nostre Seigneur au vif, selon que elle est figuree autour du cueur de Nostre Dame de Paris, et duroient les eschafaux environ cent pas de long venant de la rue de la Kalende jusques aux murs du Palais, et n'estoit homme qui veist le mistere a qui le cueur n'apiteast." Runnalls: Mystère (Anm. 5), S. 337. Zu den Spielgattungen des französischen Mittelalters allgemein siehe Alan E. Knight: Aspects of Genre in Late Medieval French Drama. Manchester 1983.

29 Ähnlich Kirsten Faupel-Drevs: Vom rechten Gebrauch der Bilder (Anm. 24), S. 184: „Die ,figurae', ob als biblische Metaphern, in ihrer Übertragung auf sakramentale Zeichen und Formeln oder als großangelegte Malereien[,] stellen gemeinsam den der Liturgie zugrundeliegenden ,historischen' Metatext dar und werden stets in Bezug zum ,mysterium' gesetzt. Insofern fungieren sie auch als Schwelle von Sichtbarem und Unsichtbarem."

30 ,Jenes zukünftige Urbild, obgleich noch als Geschehen unvollendet, ist bereits in Gott vollständig erfüllt und war es in seiner Vorsehung von Ewigkeit her. Die Figuren, in denen er es verhüllte, und die Inkarnation, in denen [sic] er seinen Sinn enthüllte, sind daher Prophetien eines jederzeit Bestehenden, welches nur die Menschen noch verhüllt sehen, bis der Tag kommt, an dem sie den Erlöser, revelata facie' geistig und sinnlich schauen werden. Die Figuren sind also nicht nur vorläufig; sie sind zugleich auch die vorläufige Gestalt eines Ewigen und Jederzeitlichen; sie deuten nicht nur auf die praktische Zukunft; sondern auf die Ewigkeit und Jederzeitlichkeit von Anbeginn an; sie weisen auf etwas zu Deutendes, das zwar in der praktischen Zukunft erfüllt werden wird, aber in der Vorsehung Gottes, in der kein Unterschied der Zeiten ist, stets schon erfüllt vorliegt; dies Ewige ist schon in ihnen figuriert, und so sind sie sowohl vorläufig-fragmentarische als auch verhüllte jederzeitliche Wirklichkeit. Das wird besonders augenfällig im Sakrament des Opfers, im Abendmahl [...]." 
entschlüsselt, was für die Gläubigen sonst verschleiert bzw. aus der menschlichen Zeiterfahrung unüberschaubar wäre, nämlich Gottes Plan für die Menschheit und das Angebot der Erlösung. Aber Figur ist nicht bloß Allegorese, wie Niklaus Largier in der neuerlichen Auseinandersetzung mit Auerbachs Figura-Begriff betont:

Das Figurale ist zunächst keine tiefere Bedeutung, kein spiritueller Schriftsinn, sondern Teil der plastischen und körperlichen Gestalt historischer Vorgänge, das diese in der Sprachwirklichkeit und damit auf der Ausdrucksebene bildhaft-konkret - und durchaus versehen mit einem satten Bedeutungspotential miteinander verbindet. [...] Für ,figura' kann denn auch ,ambages', ,effegies', ,exemplum', ,imago', ,similtudo', ,species', ,umbra' und Ähnliches stehen, was bildhafte Verbindungspotentiale zum Ausdruck bringt. ${ }^{31}$

Was Largier hier für die Ausdrucksebene des Begriffs festhält, lässt sich um so mehr für die figurae des mittelalterlichen Geistlichen Spiels sagen, die die „plastische und körperliche Gestalt historischer Vorgänge" in mediale Präsenz verwandeln. ${ }^{32}$

Ähnliche Beziehungen zwischen figure und mystère gibt es bei französischen Spielen, ${ }^{33}$ aber es ist vor allem das von Solberg herangezogene englischsprachige Belegmaterial, in dem figurae als theatrale Medien für die Enthüllung von neutestamentlichen Mysterien klar hervortreten. Auch im englischen Schauspiel des

Erich Auerbach: Figura. In: Gesammelte Aufsätze zur romanischen Philologie. Hg. von Fritz Schalk. Bern 1967, S. 55-92, hier S. 81; nachgedruckt in Figura (Anm. 11), S. 263-300, hier S. 289.

31 Largier: Zwischen Ereignis und Medium (Anm. 11), S.59. Zu diesen mit ,figura' verwandten Begriffen vgl. auch Auerbach: Figura (Anm. 30), S. 74.

32 In der Aufführung entfaltet die Figur die mediale Potenz, die ihr nach Niklaus Largier begrifflich innewohnt: „Die Figur [steht] zwischen Ereignis und Medium. Sie ist nicht das Ereignis selbst, sondern die sinnlich-konkrete Ausdrucksform, in der sich dieses in der Erzählung in Ähnlichkeits- und Unähnlichkeitsbeziehungen niederschlägt, welche die Wahrnehmung bestimmen. Die Figur ist zunächst kein Medium, obwohl sie immer dazu werden mag, da sie - als Wahrnehmungsereignis - noch ganz im Partikularen steckt.“ Largier: Zwischen Ereignis und Medium (Anm. 11), S. 67. Vgl. Heike Schlie: Der Klosterneuburger Ambo des Nikolaus von Verdun. Das Kunstwerk als ,figura' zwischen Inkarnation und Wiederkunft des Logos. In: Figura. Dynamiken der Zeiten und Zeichen im Mittelalter (Anm. 11), S. 246, wo „,figurae' und ihre Manifestationen in der Typologie“ als „visuelles Phänomen und eine mediale Technik" fungieren.

33 Am vierten Tag von Grébans Mystère de la Passion weist der Evangelist Lukas im Gespräch mit den anderen Aposteln auf die alttestamentlichen Propheten Jesaja, Jeremia, Daniel und Ezechiël hin, die alle über typologische Figuren Zeugenschaft von Christus ablegten: „La exposoit ses escriptures, raportoit ses belles figurres: / comment tout estoit acomply / en Jhesus“. Le Mystère de la Passion (Anm. 16), V.31142-31145. Außerdem verknüpft Gréban „mistere" und "figuraument", also eine figürliche Darstellungsweise, in den ersten Versen seines Prolog. Allerdings macht die Mehrdeutigkeit des Begriffs es an dieser Stelle schwierig, eine spezifisch typologische Bedeutung festzustellen, so dass das Wort hier eher mit "bildhaft" zu übersetzen wäre: „Nostre especïale matiere / est d'insister au hault mistere de Jhesus et sa passion[.] / [...] / Mais la crëacion du monde / est ung mistere en quoy se fonde / tout ce qui deppend en aprés: / si monstrerons les motz exprés; /car la maniere du produire / ne se peut monstrer ne deduire / par effect sinon seulement / grossement et figuraument" (V.13f. und 16-24). Für seine Hilfe bei der Beschaffung der Jodogne-Ausgabe von Grébans Passion möchte ich mich bei Prof. Dr. Klaus Ridder, Universität Tübingen, allerherzlichst bedanken. 
Mittelalters begegnet figure häufig im Sinne einer präfigurativen szenischen Einheit bzw. als statisches, plastisches Tableau, mal mit, mal ohne Schauspieler. Im Fronleichnamsspiel von John Lydgate, A Procession of Corpus Christi, sind es gerade die figürlich konzipierten Tableaux der prozessionalen Aufführung, die die Mysterien des Spiels erhellen:

For now this day al derkenesse t'enlumyne

In youre presence fette out of fygure,

Schal beo declared by many unkouthe signe

Gracyous mysteryes grounded in scripture. ${ }^{34}$

Lydgate charakterisiert Figuren hier als unbekannte oder geheime Zeichen („unkouthe signe"). Geheim sind diese Zeichen allerdings nur den Uneingeweihten, den Nicht-Christen. Durch das Spiel werden die Zuschauer dagegen in die gnadenspendenden Mysterien des Sakraments eingeweiht. Es folgt eine Reihe von 26 Figuren, von alttestamentlichen Propheten über die Evangelisten bis hin zu den Kirchenvätern, die alle durch die kommentierenden Verse des Spielrektors zu Christus bzw. zur Eucharistie in Verbindung gesetzt werden. Dass man mit dem inneren Auge schauen muss, um die Figuren als sakramentale Zeichen richtig zu deuten, kommt vor allem in der Moses-Figur Lydgates zum Ausdruck, in der sich die Israeliten in der Wüste durch das himmlische Manna ernähren:

Figure and liknesse, who so look aright,

This goostly manna being here present,

To us figurethe in oure inwarde sight

A symilitude of the sacrament. ${ }^{35}$

Durch die kontinuierlich fortschreitende Vorführung von Figuren aus dem Alten Testament sollen die Zuschauer darin geübt werden, das Neue Testament als Erfüllung des im Alten Testament Verheißenen zu deuten, damit sie umso besser in der Lage sind, sämtliche Ereignisse der Heilsgeschichte zu deren Mittelpunkt in Verbindung zu setzen, nämlich zum Leben und heilspendenden Opfertod Christi. Im Abendmahlspiel der N-Town-Handschrift aus der 2. Hälfte des 15. Jahrhunderts, früher auch als Coventry Play bekannt, ist es folglich Christus selbst, der das figurierte Zeichen des durch das Abendmahl instituierten neuen Bunds für die Jünger im Spiel und somit auch für die Zuschauer erläutert:

34 John Lydgate: A Procession of Corpus Christi. In: John Lydgate: Mummings and Entertainments. Hg. von Claire Sponsler. Kalamazoo, MI 2010, S.75-81, hier V.5-8; Solberg: History (Anm. 5), S. 22. Übers.: Denn heute, um die Finsternis zu erhellen, / werden in Eurer Gegenwart, geschaffen aus Figuren, / gnadenreiche Mysterien aus der Heiligen Schrift / durch etliche geheime Zeichen verkündet.

35 Lydgate: A Procession of Corpus Christi (Anm. 34), S. 77, V. 53-56. Übers.: Figur und Ebenbild, wer richtig zu schauen versteht, / dieses geistliche Manna, hier gegenwärtig, / figuriert für uns in innerer Schau / ein Gleichnis des Sakraments. 
This fygure shal sesse; anothyr shal folwe therby

Weche shal be of my body that am youre hed,

Weche shal be shewyd to yow be a mystery

Of my flesch and blood in forme of bred. ${ }^{36}$

Hier dient eine Figur als Schlüssel zu gleich zwei Mysterien, einmal dem ,Corpus Christi verum', also der Eucharistie, und einmal dem ,Corpus Christi mysticum', dem mystischen Leib Christi, Sinnbild für die Kirche selbst, deren Glieder durch den wahren Leib Christi genährt werden. ${ }^{37}$ Die Zuschauer werden hier als Gemeinde, als Mitglieder der leiblich versinnbildlichten Kirche angesprochen: Sie sind Teil dieses unsichtbaren mystischen Leibs und nehmen durch das Sakrament am Mysterium des unsichtbar ins Fleisch verwandelten Brots des Lebens teil. ${ }^{38}$

Über die Figur werden die Mysterien des Glaubens nicht nur medial vergegenwärtigt, sie können zuweilen auch dinghaft werden. Dies betrifft in erster Linie die Hostie, die in zahlreichen Fronleichnamsprozessionen und -spielen des Mittelalters ausgestellt und verehrt wurde. Solberg weist in ihrem Aufsatz zu den englischen mysteries darauf hin, dass es Tertullian war, der zum ersten Mal das griechische musterion als sacrament übersetzte. Für das Zusammenspiel von Figur und Mysterium scheint es daher kein Zufall zu sein, dass Tertullian ebenfalls eine Schlüsselrolle bei der Neudefinition von figura für die christliche Theologie spielte und somit den Figura-Begriff bei Erich Auerbach grundlegend prägte, worauf Niklaus Largier aufmerksam macht. Sowohl Auerbach als auch Largier bringen ein längeres Zitat aus Tertullians Schrift Adversus Marcionem, in der die Eucharistie selbst als figura bezeichnet wird:

36 Play 27, Last Supper; Conspiracy with Judas. In: The N-Town Plays. Hg. von Douglas Sugano. Kalamazoo, MI 2007, V.361-364 (zitiert nach der parallel erschienenen Online-Ausgabe: https:/d.lib.rochester.edu/teams/text/sugano-n-town-plays-play-27-last-supper-conspiracywith-judas). Übers.: Diese Figur (des alten Bunds) endet nun; eine andere folgt hiernach, / die meinen mystischen Leib bezeichnet, dessen Haupt ich bin. / Das wird euch offenbart durch ein Mysterium / von meinem Fleisch und Blut in Gestalt des Brots.

Vgl. auch The N-Town Play. Cotton MS Vespasian D.8. Hg. von Stephen Spector. Bd. 1. Oxford 1991, V.361-364; Solberg: History (Anm. 5), S. 23; Theresa Coletti: Sacrament and Sacrifice in the N-Town Passion. In: Mediaevalia 7 (1981), S. 239-264, hier S. 242-249. Die Begegnung von Lukas und Kleopas mit dem auferstandenen, aber nicht erkannten Christus auf dem Weg nach Emmaus, die später im N-Town-Spiel gehandelt wird, dient Richard Emmerson zum Nachweis der Grenzen der Figuraldeutung im strengeren Auerbach'schen Sinne: Richard K. Emmerson: ,Figura' and the Medieval Typological Imagination. In: Typology and Medieval English Literature. Hg. von Hugh T. Keenan. New York 1992, S. 7-42, hier S. 27-30.

37 Vgl. den Abschnitt „Corpus ecclesiae mysticum“ in: Ernst Hartwig Kantorowicz: The King's Two Bodies. A Study in Medieval Political Theology. Princeton 1957, S. 194-206.

$38 \mathrm{Zu}$ Zuschauern als Gemeinde siehe Jan-Dirk Müller: Symbolische Kommunikation zwischen Liturgie, Spiel und Fest. In: Alles nur symbolisch? Bilanz und Perspektiven der Erforschung symbolischer Kommunikation. Köln 2013, S. 331-355, hier S. 332-335. 
Acceptum panem et distributum discipulis corpus suum illum fecit, Hoc est corpus meum dicendo, id est figura corporis mei. Figura autem non fuisset nisi veritatis esset corpus: ceterum vacua res, quod est phantasma, figuram capere non posset. ${ }^{39}$

Er nahm das Brot, verteilte es seinen Jüngern, und machte es zu seinem Leib, während er sagte, „Dies ist mein Leib“, das heißt, die Figur [,figura'] meines Körpers. Es wäre keine Figur gewesen, wäre es nicht in Wahrheit der Körper gewesen. Ein hohles Ding, also ein Phantasma, kann nicht Figur sein. ${ }^{40}$

Wie schon am Fronleichnamsspiel von Lydgate beobachtet, können Christen erst über die Figur den wahren Leib Christi wahrnehmen, der nach der Verwandlung der Hostie im Sakrament ,realiter' präsent ist. Uneingeweihten bzw. Nicht-Christen erscheint das heilspendende Corpus Christi als bloßes Objekt, ein "hohles Ding“, wie es Tertullian ausdrückt. Mit anderen Worten: Gerade über das Figuralverständnis der Eucharistie nimmt man am Hauptmysterium des Christentums teil. Die figurierte Wahrnehmung ist daher eine zweifache Wahrnehmung, in der man neben der bloßen Spezies des Brots die Realpräsenz Christi in der konsekrierten Hostie zu erschauen vermag. Durch die Paarung der ausgestellten Hostie mit den figuralen Lebenden Bildern deutscher Fronleichnamsspiele soll bei den Zuschauern dieses zweifache Schauen als Teil eines ,figurierten Gedächtnisses erweckt und geübt werden. In ihrem Verweisungscharakter verstärken die leiblich dargestellten Figuren die Fähigkeit der Zuschauer, während der Spielprozession die Gegenwart Christi in der mitgetragenen, zur Schau gestellten Hostie zu erkennen. ${ }^{41}$ Die Publikumsrezeption deutschsprachiger Fronleichnamsspiele besteht grundsätzlich in diesem Akt des zweifachen Zuschauens, so dass sämtliche figurae der Spiele, nicht nur alttestamentliche, sondern auch die nachbiblischen Figuren der Heiligen, auf den heilspendenden Leib des Salvators verweisen. ${ }^{42}$

Die Tendenz zum Dinghaften, zur gegenständlichen Darstellung der plastischbildhaften Anlage einer Figur, führt schließlich dazu, dass auch Reliquien und andere auratische Gegenstände im deutschen Fronleichnamsspiel zur Figurierung weiterer Momente der Heilsgeschichte dienen konnten. Sowohl im Künzelsauer als auch im Zerbster Fronleichnamsspiel wurde die Kreuzigung nicht etwa durch ein durch Schauspieler dargebotenes lebendes Bild figuriert, sondern jeweils durch die Weisung eines auratischen Kreuzes, das die Kreuzigung in anderen

39 Largier: Zwischen Ereignis und Medium (Anm. 11), S. 56. Bei Auerbach beginnt das Zitat mit „,corpus suum illum fecit", Auerbach: Figura (Anm. 30), S. 66. Vgl. auch Durandus von Mende: „Altaris igitur sacramentum est ueritas et figura.“ („Das Sakrament des Altars ist daher Wahrheit und Figur"). Faupel-Drevs: Vom rechten Gebrauch der Bilder (Anm. 24), S. 163.

40 Hier in der Übersetzung Largiers in Largier: Zwischen Ereignis und Medium (Anm. 11), S. 56.

41 Vgl. Ehrstine: Das figurierte Gedächtnis (Anm. 12), S. 429-432, dort allerdings ohne Überlegungen zur zweifachen figuralen Wahrnehmung.

42 „Dysze figuren thun Iesum beweysen. / Er wil uns mit seynem leichnam speysen. / Gyb lob und dang, o cristenheit“. Das Zerbster Fronleichnamsspiel. Hg. von Willm Reupke. Berlin 1930, S. 45, V.389-391. 
kultischen Zusammenhängen repräsentierte. Im Falle Künzelsaus war dies ein Kreuzreliquiar der örtlichen Sankt-Johannes-Pfarrei, das neben drei anderen passionsbezogenen Reliquien eine Partikel des Kreuzes enthielt, an dem Jesus vermeintlich gestorben war. ${ }^{43}$ Wie bei der Hostie war die dem Kreuz innewohnende Gegenwart Christi für den uneingeweihten Betrachter unsichtbar; über die Figur jedoch, die in der Reliquie zeichenhaft enthalten war, wurde der Erlösungsakt Jesu als Mysterium für die wahrhaft Gläubigen wahrnehmbar. Die Weisung dieses Kreuzreliquiars war höchstwahrscheinlich schon Teil der Kreuzverehrung der Karfreitagsliturgie in der örtlichen Johanneskirche: Die entsprechende adoratio crucis, von einem Priester geleitet und von liturgischem Gesang begleitet, wurde komplett in das Fronleichnamsspiel aufgenommen, wo es die mimetische Repräsentation der Kreuzigung ersetzte. Drei vermutlich in der Spielprozession mitgetragene Reliquienbüsten sind sogar noch erhalten, die die auratische Gegenständlichkeit der Aufführung ergänzten, und zwar von Heiligen, die sich einer besonderen Beliebtheit vor Ort erfreuten: Margarethe, Maria Magdalena und der Stadtpatron Johannes der Täufer. ${ }^{44}$

Im Zerbster Fronleichnamsspiel wurde dagegen keine Reliquie, sondern das sogenannte Ablasskreuz gewiesen, die zentrale Devotionalie päpstlicher Ablasskampagnen zwischen 1488 und 1503 unter dem Kardinal und päpstlichen Legaten Raimund Peraudi. ${ }^{45}$ Dieses blutrote hölzerne Kreuz fand noch 1517 beim Verkauf des Petersablasses Verwendung: Johann Tetzels Gleichstellung des Ablasskreuzes mit dem wahren Kreuz Christi rief unter anderem Luthers Kritik in der 79. These hervor. ${ }^{46}$ Die zentrale figura des Zerbster Spiels bestand in der erectio crucis, der Aufrichtung des Kreuzes, die über die Figur auch hier eine zweifache Schau ermöglichte: Im Moment der Aufrichtung sollte nämlich das wahre Kreuz Christi in der crux erecta ,realiter ${ }^{\prime}$ präsent werden.$^{47}$ Wie bei der Hostie diente die figürlich wahrzunehmende Realpräsenz Christi, hier am Kreuz, als Grundlage

43 Glenn Ehrstine: ,Crux interpretationis'. Die Heiltumsweisung im Künzelsauer Fronleichnamsspiel. In: Das Theater des Spätmittelalters und der Frühen Neuzeit. Kulturelle Verhandlungen in einer Zeit des Wandels. Hg. von Elke Huwiler. Heidelberg 2015, S. 215-228.

44 Ehrstine: Crux interpretationis (Anm. 43), S. 225-228.

45 Glenn Ehrstine: Raymond Peraudi in Zerbst. Corpus Christi Theater, Material Devotion, and the Indulgence Microeconomy on the Eve of the Reformation. In: Speculum 93 (2018), S. 319-356; Glenn Ehrstine: Ablass, Almosen, Andacht. Die Inszenierung der nahen Gnade im Zerbster Fronleichnamsspiel. In: Literaturwissenschaftliches Jahrbuch 56 (2015), S. 81-118, hier S.98. Bei der Identifizierung der Zerbster Stadtgeistlichkeit im deutschsprachigen Aufsatz sind mir bedauerlicherweise zwei Fehler unterlaufen: der „plebanus“ ist selbstverständlich der Leutpriester (ebd, S. 110), die „custodes“ sind Küster (ebd., S. 94 und 112). Ich danke Prof. em. Dr. Johannes Janota, Universität Augsburg, für diese freundlichen Hinweise.

46 „Dicere, Crucem armis papalibus insigniter erectam cruci Christi equivalere, blasphemia est." Martin Luther. Disputatio pro declaratione virtutis indulgentiarum. In: D. Martin Luthers Werke. Bd. 1, Abt. 1. Weimar 1883, S. 229-238, hier S. 237, Z. 15f.

47 „Genau genommen behauptete die Jubiläumsverkündigung eines Peraudi oder Paltz oder Tetzel nicht nur, dass das Jubiläumskreuz ,den gleichen Wert habe' [...] wie das Kreuz Christi, sondern dass in der Kreuzaufrichtung das Kreuz Christi selbst gegenwärtig werde." Berndt Hamm: Ablass und Reformation. Erstaunliche Kohärenzen. Tübingen 2016, S. 202. 
für die Heilspotenz des Gegenstands, so dass in der Aufrichtung des Kreuzes der „einzigartige Einfluss“ des himmlischen Gnadenschatzes der Kirche auf die Erde herabströmen konnte. ${ }^{48}$ Der figürlich dargestellte Moment der Kreuzigung im Zerbster Spiel sollte also die Ablasswirksamkeit der Peraudi'schen crux erecta als auratischen Gegenstand gewährleisten. Für den Besuch der alljährlichen Aufführungen konnte der Zerbster Stadtrat mit insgesamt vier Ablässen werben, und das käuflich zu erwerbende Heilsangebot des Spiels erfreute sich eines regen Zuspruchs, wie die von Willm Reupke edierten Spielrechnungen aus den Jahren 1511-13 und 1520-22 deutlich machen. ${ }^{49}$ Als Teil des spätmittelalterlichen Ablassbetriebs zahlten sich die figürlich dargestellten Mysterien des Kults offensichtlich auch in barer Münze aus.

Zwar ist die Figuralrezeption des Geistlichen Spiels hauptsächlich in der gegenständlichen Figurierung des Heils im deutschen Fronleichnamsspiel wirksam. Als exegetisches Prinzip fungierte sie dennoch zuweilen auch bei anderen Spielgattungen, wo sie eine eigene Dynamik entfaltete. ${ }^{50}$ Der erste Spieltag vom Luzerner Passionsspiel besteht ausschließlich aus ,Figuren', in diesem Fall szenischen Spieleinheiten aus dem Alten Testament, und auch die Verkündigung des Herrn an Maria wird als Figur gekennzeichnet. In den Texten des Fronleichnamsspiels gibt es keine Rezeptionsanleitungen oder metatheatrale Kommentare, die die Figuren der Spiele als Darstellungsmodus betreffen. Anders jedoch im Passionsspiel, wo die figurale Darstellung oft zum leitenden Prinzip erhoben wird. Das Donaueschinger Passionsspiel zum Beispiel verspricht den Zuschauern: „das werdent ir alles schowen / in figuren vnd ernstlicher geschicht", oder im Luzerner Osterspiel heißt es: „figürlich mans üch wirdtt gen zverstan“. ${ }^{51}$,Figurieren' kursierte im Spielkontext schließlich als Verb, wie wir schon im Französischen anhand des Mistere de la Passion de Nostre Seigneur aus dem Jahre 1420 gesehen haben. ${ }^{52}$ Diese Belege weisen die Figuraldeutung im Spielkontext als eine allgemeine Rezeptionshaltung aus, einen Code sogar, der dem Publikum geläufig sein soll. Wollen die Zuschauer die als figuren verpackten Heilswahrheiten erkennen und gar Heilserfahrung, beispielsweise im Ablass, aus dem Spiel ziehen, dann müssen auch sie diesen Code beherrschen, durch den man die Mysterien der dargestellten Figuren entschlüsseln kann.

48 „Est enim pie credendum, quod, interim quod talis crux sit erecta, stat auctoritate apostolica cum armis apostolicis, quod singularis influentia de celo in istam ecclesiam descendat ex meritis et orationibus illorum omnium unde indulgentie traxerunt originem." Johannes von Paltz: Werke. Bd. 2: Supplementum Coelifodinae. Hg. von Berndt Hamm. Berlin 1983, S. 7, Z. 15-18.

49 Zerbster Fronleichnamsspiel (Anm. 42), S. 10-16.

50 Vgl. hierzu Jutta Eming: ,Figura' im Heidelberger Passionsspiel. In: Transformationen religiösen Wissens im mittelalterlichen Schauspiel. Hg. von Klaus Ridder, Beatrice von Lüpke und Michael Neumaier. Basel (voraussichtlich 2021).

51 Das Donaueschinger Passionsspiel. Hg. von Anthonius H. Touber. Stuttgart 1985, V. 61f.; Das Luzerner Osterspiel. Hg. von Heinz Wyss. Bd. 1. Bern 1967, V. 83. Ehrstine: Das figurierte Gedächtnis (Anm. 12), S. 417.

52 Schulz: Eigenbezeichnungen (Anm. 24), S. $240 \mathrm{f}$. 
Ich kehre zu meiner Anfangsfrage zurück, ob es im deutschen Mittelalter Mysterienspiele gab, und möchte nun wie folgt antworten: Dem Namen nach gab es sie nicht, aber dem Inhalt nach offenbar schon. Der Opfertod Christi und seine Präsenz in dem vom Priester verwandelten Sakrament: das waren die Mysterien des Christentums schlechthin, und die Figuren des Geistlichen Spiels waren dazu da, diese Mysterien plastisch und physisch erfahrbar zu machen, nicht nur intellektuell, sondern auch spirituell. Mit anderen Worten: Es ging bei der Rezeption figürlich konzipierter Spiele nicht so sehr um Didaxe oder moralische Lehre, sondern um die Aneignung einer exegetischen Rezeptionshaltung, die es auch Laien ermöglichen sollte, die irdischen Zeichen und Ereignisse der Heilsgeschichte richtig zu deuten und durch sie hindurch die Mysterien des katholischen Kults ,realiter' zu erfahren.

Ob man heutzutage beim Wort ,Mysterienspiel' auch an den Ablass denkt? Wohl kaum: moderne Formen des Theaters, auch wenn sie mittelalterlichen Spielen nachempfunden sind, erheben keinerlei Anspruch auf eine unmittelbare Heilswirksamkeit, eine rituelle „efficacy“ im Sinne der Performanztheorie Richard Schechners. ${ }^{53}$ Dennoch gibt es keinen vergleichbaren Begriff, der die grundsätzliche Alterität des mittelalterlichen geistlichen Spiels so prägnant auf den Punkt bringt. ${ }^{54}$ Solberg weist auf namhafte mediävistische Spielforscher wie Karl Young hin, die die Semantik von mystery play „instruktiv“ gefunden haben, auch wenn sie den Begriff für eine moderne Wortschöpfung hielten. ${ }^{55}$ Ein besonders instruktives Beispiel für die modernen Konnotationen des Wortes im Deutschen ist jedenfalls Goethes Faust, für dessen Interpretation das Mysterienspiel immer wieder bemüht wird. So wie Eduard Devrient an der Etablierung von ,Mysterienspiel' als Lexem beteiligt war, so hat sein Sohn Otto Devrient als Regisseur am Weimarer Hoftheater zwölf Stunden lang über zwei Spieltage im Mai 1876 die beiden Teile von Faust auf einer dreistöckigen „Mysterienbühne“ inszeniert, auf der Himmel und Hölle das irdische Treiben Fausts umrahmten. Zwar betonen die Herausgeber des Faust-Handbuchs, dass Devrients Bezugnahme auf das mittelalterliche Mysterienspiel „historisch unzutreffend“ war, aber seine Inszenierung, die erste Gesamtaufführung von Faust I-II in seinen beiden Teilen überhaupt, fand dennoch große Beachtung in der Presse und wurde vielerorts nachgeahmt. ${ }^{56}$ Außerdem konnte Devrient auf die Struktur von Goethes Tragödie als Begründung für seine Büh-

53 Vgl. Schechners Situierung des Geistlichen Spiels beim Wirksamkeit-Pol seines „Wirksamkeit-Unterhaltung-Geflechts“: „From Ritual to Theater and Back: The Efficacy-Entertainment Braid" in: Richard Schechner: Performance Theory. 2. Aufl. London, New York 2003, S. 112-169, hier S. 133f. Im Ablass wird die Heilswirksamkeit des Geistlichen Spiels besonders greifbar.

54 Zur Alterität des Geistlichen Spiels vgl. Jan-Dirk Müller: Präsenz des Heils und Repräsentation. Zur Alterität des Geistlichen Spiels. In: Alterität als Leitkonzept für historisches Interpretieren. Hg. von Anja Becker und Jan Mohr. Berlin 2012, S. 263-284.

55 Solberg: History (Anm. 5), S. 11; Karl Young: The Drama of the Medieval Church. Bd. 2. Oxford 1933, S. 409.

56 Faust-Handbuch. Konstellationen - Diskurse - Medien. Hg. von Carsten Rohde, Thorsten Valk und Matthias Mayer. Stuttgart 2018, S. 284. 
nengestaltung hinweisen: So wie Arnoul Gréban Le Mystère de la Passion mit dem "Paradiesprozess" eröffnete, hat Goethe seinem Spiel einen „Prolog im Himmel“ vorangestellt. Diese Rahmenhandlung, das unablässige Bemühen von Mephistopheles, Faust auf ewig für die Hölle zu gewinnen, gilt heute immer noch als besonders mysterienspielhafter Zug und wird $u$. a. auch in Lehrmaterialien für den Schulunterricht hervorgehoben. ${ }^{57}$ Der Begriff kann also nicht nur eine besondere Nutzung des Spielraums in (meist phantasievoller) Anlehnung an die mittelalterliche Simultanbühne implizieren, sondern vor allem eine religiöse oder ethische Sinngebung des Bühnengeschehens, die das irdische Handeln des Menschen in Bezug zu himmlischen und - bei Bedarf - auch höllischen Mächten setzt.

Bei seinen Faust-Inszenierungen führte Otto Devrient allerdings eine professionelle Schauspieltruppe an. Heute sind es vor allem Laiendarsteller, die sich das Wort ,Mysterienspiel' zu eigen gemacht haben, und zwar als Teil eines gemeinschaftlichen Theaterschaffens, das durchaus Ähnlichkeiten zum Theaterbetrieb des Mittelalters aufweist. Wie Darwin Smith jüngst am Beispiel des Mystère de Trois Doms (1509) aus Romans gezeigt hat, war die Theaterpraxis, aus der die Mystères entstanden, ein kollektiver Prozess, an dem zahlreiche Spielschaffende beteiligt waren. ${ }^{58}$ Dies betraf nicht nur die materielle Bewerkstelligung der Aufführung (Kostüme, Requisiten, szenischer Apparat), sondern gerade die fast einjährige Erarbeitung des endgültigen Spieltextes, für den das Theaterkollektiv als Ganzes (mit obrigkeitlicher Beteiligung) verantwortlich zeichnete. Nach einem ersten Entwurf durch den ursprünglichen Spielautor erfuhr der Text mindestens zwei durchgreifende Neubearbeitungen, um Verbesserungen und kreative Einfälle aus den Proben aufzunehmen sowie Emendationen durch die mit der Zensur des Spiels beauftragten Kommissare des Stadtrats zu berücksichtigen, die alle in sukzessiven Reinschriften des Gesamttextes und revidierten Rollenauszügen für die Darsteller festgehalten wurden. Für ihre Mühen wurden die Schreiber entlohnt - es sind gerade die Spielrechnungen, die Auskunft über ihre Arbeit geben - doch die Darsteller in Romans mussten wohl, wie andernorts belegt, ${ }^{59}$ die Kosten für ihre Kostüme selber tragen. Durch das eigene Rollenspiel haben Laien ihre Zugehörigkeit zur Sakralgemeinschaft des Wohnorts unter Beweis gestellt und den gesellschaftlichen Zusammenhalt innerhalb anderer am Spiel teilnehmenden Institutionen der städtischen Gemeinschaft gestärkt, etwa der Zünfte und Spielbruderschaften, die die Verantwortung und unter Umständen auch die Kosten

57 Das Mysterienspiel als Bezugsgröße für Goethes Faust ist dermaßen etabliert, dass es auch zu Schulunterrichtsmaterialien gehört: „Zum Werkaufbau“, Teil 4 von Walter Schafarschik. Lektüreschlüssel. Johann Wolfgang Goethe: Faust II. Stuttgart o. J., o. Pag. (da nur als E-Book erhältlich).

58 Smith: About French Vernacular Traditions (Anm. 14), S. 50ff. und 54f.

59 Heidy Greco-Kaufmann: „Zuo der Eere Gottes, vfferbuwung dess mentschen vnd der statt Lucern lob“. Theater und szenische Vorgänge in der Stadt Luzern im Spätmittelalter und in der Frühen Neuzeit. Zürich 2009, S. 187. 
für Teile der Aufführung trugen. ${ }^{60}$ Über das Mysterienspiel eröffneten sich für die Bewohner eines Ortes Formen der Partizipation am Kult der Kirche, die bei der Messe nicht möglich waren.

Diese Tradition wird heute durch die Festspiele einiger katholischer Mysterienspielvereine gepflegt, oft unter bewusster Anknüpfung an örtliche Frömmigkeitstraditionen. Dies gilt für die anfangs erwähnten „Lüfthildis-Mysterienspiele e. V.“ aus Lüftelberg (Meckenheim) sowie die seit 2001 stattfindenden Kleinenberger Mysterienspiele aus Kleinenberg, einem Stadtteil von Lichtenau in NordrheinWestfalen. Beide Orte sind von alters her Wallfahrtsorte: Lüftelberg ist nach der Heiligen Lüfthildis benannt, die um 900 gelebt haben soll und in der örtlichen Pfarrkirche St. Petrus begraben ist, ${ }^{61}$ während Kleinenberg in der Wallfahrtskirche Mariä Heimsuchung ein wohl um 1400 entstandenes wundertätiges Gnadenbild behütet, Maria, Helferin vom Kleinen Berg. ${ }^{62}$ Ausgesprochenes Ziel von beiden Gruppen ist die Stärkung der örtlichen Wallfahrtstradition zur Ehre der jeweiligen Ortsheiligen. Die Kleinenberger Aufführungen z. B. finden immer Anfang Juli zum Fest Mariä Heimsuchung statt, dem Patronatsfest der barocken Wallfahrtskirche, während die Lüftelberger Spiele immer in der Fronleichnamsoktav aufgeführt werden. ${ }^{63}$ Zwar mag es bei diesem geistlichen Laientheater bescheidener zugehen als bei den Passionsspielen in Oberammergau, aber man hat es auch nicht nötig, den Ansprüchen von internationalen Gästen zu genügen: Die Aufführungen sind für ein regionales Publikum gedacht und werden regelmäßig von einigen Hundert Zuschauern im Rhein-Sieg-Kreis und im Hochstift Paderborn als fester Bestandteil des liturgischen Kalenders neben anderen Festen des Kirchenjahres angenommen. Wie beim Geistlichen Spiel treten Publikum und Darsteller gleichermaßen als Gemeinde zusammen. Auch wenn hier die Kulturanthropologie von Edith und Victor Turner nicht voll zutrifft, leisten die Spiele dennoch

60 Während in Friedberg die Zünfte für die Ausstattung der von ihnen betreuten Figuren der örtlichen Fronleichnamsprozession aufkamen, wurden die Kosten der Figuren in Zerbst offenbar durch Ablasseinkünfte gedeckt. Dorothea Freise: Geistliche Spiele in der Stadt des ausgehenden Mittelalters. Frankfurt - Friedberg - Alsfeld. Göttingen 2002, S. 238; Ehrstine: Raymond Peraudi in Zerbst (Anm. 45), S.331-337; Ehrstine: Ablass, Almosen, Andacht (Anm. 45), S. 91-95.

61 Magdalene Frank: Die Volksheilige Lüfthildis von Lüftelberg und ihre Attribute. Düsseldorf 1959. Vgl. dieInternetpräsenz der Lüfthildis-Mysterienspiele e. V., URL:http://mysterienspiele. de/ (10.6.2019).

62 https://www.wallfahrt-kleinenberg.de/ (10.06.2019). Vgl. auch den Eintrag zu Kleinenberg in: Georg Dehio: Handbuch der Deutschen Kunstdenkmäler. Nordrhein-Westfalen. II. Westfalen. Bearb. von Dorothea Kluge und Wilfried Hansmann. München, Berlin 1969, S. 268.

63 Die Spiele wurden 2001 gegründet und fanden bis 2013 alle drei Jahre statt; beteiligt waren vor allem junge Darsteller vom Kleinenberger Jugendtheater. Die 6. Kleinenberger Mysterienspiele sind für Juli 2020 geplant. Zu den 5. Kleinenberger Mysterienspielen siehe Bernhard Hagelüken: Religiöses Theater in Kleinenberg. Mysterienspiel ,Maria' lockt Gläubige aus dem ganzen Hochstift an. In: Neue Westfälische Zeitung, 07.07.2013, URL: https://www. nw.de/lokal/kreis_paderborn/lichtenau/8833857_Religioeses-Theater-in-Kleinenberg.html (11.6.2019). 
einen Beitrag zur religiösen communitas des Ortes: Sie ebnen Rangunterschiede ein und stärken die sozialen Beziehungen unter den Beteiligten. ${ }^{64}$

Unter ,Mysterienspiel' versteht man also in diesem Kontext nicht nur alt-neue alternative Bühnenformen oder eine religiöse Sinngebung des betreffenden Bühnenstücks, sondern eine besondere Art des Theaterspielens, die nicht nur Rollenspiel ist, sondern auch Ausdruck der eigenen Spiritualität, eine gelebte Frömmigkeit, die man über das Spiel mit Gleichgesinnten teilt. Gerade der „Lüfthildis-Mysterienspiele e. V.", ein eingetragener Verein mit eigener Satzung, ${ }^{65}$ ist eine „freiwillige Vereinigung“ im Sinne der Soziologie:

ein freiwilliger Zusammenschluss um ein gruppengeistig bestimmtes Anliegen, der einen persönlichen Kontakt unter den Mitgliedern voraussetzt und sich [...] durch regelmäßige Veranstaltungen eine eigene Lebensform gegeben hat. ${ }^{66}$

Beachtenswert in unserem Kontext ist, dass das neben den Aufführungen stattfindende Lüftelberger Vereinsleben sich durchaus mit den geselligen Aktivitäten und Funktionen einer spätmittelalterlichen Spielbruderschaft vergleichen lässt, u. a. in der Gedächtnispflege verstorbener Mitglieder.$^{67}$ Ihren Inhalten nach las-

64 „Es gibt keine Grüppchen, ganz unabhängig vom Alter bilden wir eine Gemeinschaft und haben Spaß": Anita Borhau-Karsten: Theater in Lüftelberg zeigt Clara Feys Leben in 26 Szenen. General-Anzeiger Bonn, 19.05.2018, URL: http://www.general-anzeiger-bonn.de/region/ vorgebirge-voreifel/meckenheim/Theater-in-L\%C3\%BCftelberg-zeigt-Clara-Feys-Leben-in26-Szenen-article3856653.html (11.6.2019). Edith Turner: Communitas. The Anthropology of Collective Joy. New York 2012; Schechner: Performance Theory (Anm. 53), S. 128. Gerade die Wallfahrt als eine liminale Zwischenzeit außerhalb der alltäglichen Gesellschaftsordnung spielt bei der Anthropologie der Turners eine große Rolle. Vgl. Victor und Edith Turner: Image and Pilgrimage in Christian Culture. Anthropological Perspectives. New York 1978, S. 4, sowie die Beiträge zu "Contemporary Pilgrimage and Communitas" in: Victor Turner and Contemporary Cultural Performance. Hg. von Graham St. John. New York 2008, S. 209-272.

65 Siehe „Über uns“, URL: http://mysterienspiele.de/?page_id=8 (10.06.2019). Ich bedanke mich bei Markus Schmitz, Schriftführer des Vereins, für seine freundlich mitgeteilten Informationen sowie für das bereitgestellte Exemplar von „Theatergeflüster", dem Newsletter des Vereins, zum 25. Jubiläum im Jahre 2006.

66 Walther Müller-Jentsch: Der Verein - ein blinder Fleck der Organisationssoziologie. In: Berliner Journal für Soziologie 18 (2008), S. 476-502, hier S. 479.

67 Eine frühere Fassung dieses Beitrags ging ausführlicher auf Einzelheiten des Lüftelberger Vereinslebens ein, die im Newsletter "Theatergeflüster" greifbar sind. Ich habe diese Passagen gestrichen - in denen alles anonym blieb - um die Privatsphäre der Vereinsmitglieder möglichst zu respektieren und weil es vermutlich ohnehin für sie etwas befremdlich ist, sich unter einer wissenschaftlichen Lupe zu finden. Mit ihnen möchte ich jedoch ihres Vereinsgründers Kurt Faßbender gedenken, der der Gruppe über zwanzig Jahre lang als Autor und Regisseur vorgestanden hat. Die überwiegende Mehrheit der Vereinsspieltexte stammt aus seiner Feder. Für seine Verdienste hat Faßbender 2005 die Verdienstmedaille des Verdienstordens der Bundesrepublik Deutschland erhalten. Vgl. den Nachruf auf Faßbender vom 15.2.2016 im General-Anzeiger Bonn (nicht online verfügbar) sowie den Artikel zum 20-jährigen Jubiläum des Vereins: Birgit Roßmöller, Martin Lehnert: Und ich dachte zuerst, es kommt keiner. General-Anzeiger Bonn, 18.06.2001, URL: http://www.general-anzeiger-bonn. de/news/kultur-und-medien/bonn/Und-ich-dachte-zuerst-es-kommt-keiner-article91412. html (11.6.2019). 
sen sich die Spiele darüber hinaus im engeren Sinne als Mystères bezeichnen: Unter den wechselnden Titeln der inzwischen 49 Aufführungen - in besonderen Jubiläumsjahren wurden 2-3 Spiele dargeboten - begegnen immer wieder Heiligenvitae, nicht nur die von Lüfthildis, sondern beispielsweise auch von Elisabeth von Thüringen, Franz von Assisi, Hildegard von Bingen, Bernhard von Clairvaux, Teresa von Avila, Nikolaus von Flüe und Bruno von Köln. Sind die Heiligenspiele des deutschen Mittelalters nur spärlich belegt: Hier entsteht ein ganzes Textcorpus theatraler Hagiographie. ${ }^{68}$ Es ist dies zumindest eine weit authentischere, sich selbst genügende Form des zeitgenössischen religiösen Theaters als die jüngeren, zu Sensationalismus und Missionierung neigenden Spielinitiativen fundamentalevangelischer Kreise in den USA, denen die Passionsgeschichte Christi als bevorzugter Spielstoff dient. ${ }^{69}$

Auf der anderen Seite: Dass dem mittelalterlichen Geistlichen Spiel Sensationalismus und Missionierung fremd geblieben wären, kann man auch nicht behaupten. ${ }^{70}$ Und auch das Laientheater dient zuweilen, mal explizit, mal implizit, gewissen politischen und gesellschaftlichen Zielen, selbst wenn es um Brauchtum und Traditionspflege geht. ${ }^{71}$ Es dürfte zumindest klar geworden sein, dass die Gattung des Mysterienspiels heute ein überaus vitales Nachleben genießt: Ein Begriff, der im deutschen Mittelalter so nie existierte und erst in der Neuzeit aus dem Französischen entlehnt wurde, wird seit dem 19. Jahrhundert neuen Bedeutungen zugeführt, in denen populäre, aber auch professionelle Vorstellungen des mittelalterlichen Theaters greifbar werden. Er dient nicht nur zur Charakterisierung von Goethes Faust als Teil des deutschen Kulturerbes, sondern wird mit Vorliebe für Formen des Theaters herangezogen, die sich bewusst von der modernen kommerziellen Theaterpraxis abgrenzen.

68 Vgl. „Stücke“, URL: http://mysterienspiele.de/?page_id=6 (10.06.2019). Die Lüftelberger stehen hier auch in guter Tradition: Bereits zu Anfang des 17. Jahrhunderts dienten die Vitae von Niklaus von Flüe und Bruno von Köln als Grundlage für gegenreformatorische Spiele, einmal beim Sarner Bruderklausenspiel von 1601, und wieder bei dem 1602 vollendeten Cenodoxus von Jakob Bidermann, dem Paradebeispiel des jesuitischen Theaters schlechthin, das die Ereignisse hinter der Gründung des Karthäuserordens durch Bruno auf die Bühne bringt. Vgl. Das Saarner Bruderklausenspiel von Johann Zurflüe (1601). Hg. von Heidy Greco-Kaufmann und Elke Huwiler. Chronos 2017; Jakob Bidermann: Cenodoxus. Comico-Tragoedia. Übers. und komm. von Christian Sinn. Konstanz 2004.

69 Jill Stevenson: Sensational Devotion. Evangelical Performance in Twenty-First Century America. Ann Arbor, MI 2013, S. 70-127. Um Spielinitiativen im Vereinsrahmen wieder aus soziologischer Perspektive zu charakterisieren: „Der Verein genügt sich selbst.“ Müller-Jentsch: Der Verein (Anm. 66), S. 480.

70 Vgl. u. a. John Spalding Gatton: „There Must Be Blood“. Mutilation and Martyrdom on the Medieval Stage. In: Violence in Drama. Hg. von James Redmond. Cambridge 1991, S. 79-91.

71 Mit den politischen Aspekten des Laientheaters beschäftigt sich bis Oktober 2021 ein vom Schweizer Nationalfonds finanziertes Forschungsprojekt unter der Leitung von PD Dr. Heidy Greco-Kaufmann (Universität Bern) zu „,Oskar Eberle (1902-1956): Identitätsdiskurs, Theaterpolitik und Laienspielreform", URL: https://www.theaterhistoriographie.net/en/third-partyfunded-projects/oskar-eberle-1902-1956/ (12.6.2019). 
Inwiefern heutige Mysterienspiele, von gläubigen Katholiken aufgeführt, nicht nur ethische Vorbilder durch dramatisch dargebotene Heiligenleben bereitstellen, sondern auch die gleichen Mysterien zur Veranschaulichung bringen, die in den dramatischen figurae des deutschsprachigen Geistlichen Spiels augenscheinlich werden sollten, lässt sich im Rahmen dieses Beitrags nicht sagen. Bei den 6. Kleinenberger Mysterienspielen, deren Aufführung ursprünglich im Juli 2020 stattfinden sollte, auf Grund der herrschenden Coronavirus-Pandemie jedoch auf den 2. und 3. Juli 2021 verlegt wurde, ist die Integrierung des dortigen Marienspiels zur Zeit in einen größeren Komplex kultischer Handlungen anlässlich des Fests Mariä Heimsuchung angekündigt: eine abendliche Lichterprozession am Vorabend des Festes, zwei Festhochämter in oder vor der Wallfahrtskirche, eine eucharistische Prozession mit Kreuzwegandachten auf dem Wallfahrtsgelände und eine abschließende Marienfeier vor dem Hochaltar der Wallfahrtskirche, in dessen Mitte das wundertätige Bild der „,auxiliatrix de monte“ steht. $^{72}$ Im Kontext der jüngeren mediävistischen Spielforschung, die das mittelalterliche Schauspiel in der Spannung zwischen Ritual und Theater untersucht und Etappen einer allmählichen Herausbildung eines säkularen, ästhetisch genossenen Theaterbetriebs ohne rituelle Ansprüche näher zu bestimmen sucht, lässt sich zumindest festhalten, dass das Geistliche Spiel, hier als neuzeitliches Mysterienspiel, sich auch in den Kult neu einbinden lässt. ${ }^{73}$

72 Vgl. die Informationen zum Fest Mariä Heimsuchung bei der Internetpräsenz der Wallfahrt Kleinenberg, URL: https://wallfahrt-kleinenberg.de/pilgerinfos/wallfahrtstage/ (20.4.2021) Nähere Details zur Geschichte der Wallfahrt und der örtlichen Marienverehrung entnimmt man der folgenden archivierten Webseite der Kleinenberger Pfarrgemeinde St. Cyriakus, URL: https://archive.fo/20130206174618/http://www2.kleinenberg.de/local/index.php?report= 41 (20.4.2021).

73 Vgl. Bruno Quast: Vom Kult zur Kunst. Öffnungen des rituellen Textes in Mittelalter und Früher Neuzeit. Tübingen, Basel 2005; Christoph Petersen: Ritual und Theater. Meßallegorese, Osterfeier und Osterspiel im Mittelalter. Tübingen 2004; Jan-Dirk Müller: Kulturwissenschaft historisch. Zum Verhältnis von Ritual und Theater im späten Mittelalter. In: Lesbarkeit der Kultur. Literaturwissenschaften zwischen Kulturtechnik und Ethnographie. Hg. von Gerhard Neumann und Sigrid Weigel. München 2000, S. 53-77. 


\title{
Der Buchstabe ist die Botschaft
}

\author{
Praktiken des Verbergens und Offenbarens \\ in mittelalterlichen ,Geheimschriften' - und wie sie im Kontext \\ von Herrschaft und Mystik benutzt werden
}

\author{
Stephan Müller
}

\section{Das Projekt und seine Ergebnisse}

Die Grundlage der folgenden Überlegungen ist ein abgeschlossenes DFG-Projekt, ${ }^{1}$ dessen Ergebnisse derzeit für die Publikation vorbereitet werden. Es ging in dem Projekt um eine Sammlung und Analyse von geheimschriftlichen Glossen und Texten des Mittelalters in deutscher Sprache. Als Untersuchungszeitraum ergab sich dabei die Zeit von 800 bis 1500 . Davor war nichts zu finden, danach ändert sich die geheimschriftliche Praxis enorm und wird so elaboriert, dass wir als Philologen die Segel streichen mussten. Zeugnisse der früheren Zeit jedoch konnten wir so gut wie alle entschlüsseln - und das nicht mit Hilfe des Computers, sondern einfach mit etwas Phantasie, ein wenig Zeit und viel Kaffee. Das allein schon ist ein Ergebnis des Projekts: Als sichere Form der Geheimhaltung von Sprachinhalten sind die meisten Zeugnisse nicht anzusehen. ,Geheimschrift' im Sinne einer effektiven Methode, Schriftinhalte vor ungewollten Zugriffen zu schützen, - so könnte man den Befund pointieren - ist für die Verschlüsselungspraktiken und die erfundenen Alphabete des Mittelalters eine anachronistische Bezeichnung, vor allem, wenn es sich um nichtdiplomatische Geheimschriften handelt. ${ }^{2}$ Der Grund dafür ist allein schon das Fehlen der kommunikationssoziologischen Voraussetzungen. Schrift ist gerade im früheren Mittelalter kein Verbreitungsmedium, das unkontrolliert zirkuliert. Auf das Medium der Schrift haben nur Wenige Zugriff, und Schrift ist gebunden an feste institutionelle Zusammenhänge. Für die Meisten war Schrift an sich also schon ein Geheimnis, ein arcanum, und wenn man etwas schriftlich Fixiertes geheim halten wollte, dann ging das am einfachsten durch die Geheimhaltung des Schriftträgers, der vor dem Buchdruck ja jeweils ein einzigartiger war. Aus einer anderen Perspektive lässt sich dieser Befund durch

1 Handbuch der deutschen Glossen und Texte des Mittelalters in Geheimschrift (8.-15. Jahrhundert) (Projektnummer 59532369).

2 Vgl. Bernhard Bischoff: Übersicht über die nichtdiplomatischen Geheimschriften des Mittelalters. In: Mittelalterliche Studien. Ausgewählte Aufsätze zur Schriftkunde und Literaturgeschichte. Hg. von dems. Bd. 3. Stuttgart 1981, S. 120-148. Diplomatische Geheimschriften in deutscher Sprache sind uns aus dem Untersuchungszeitraum nicht bekannt geworden. 
einen Blick auf die Gegenwart verdeutlichen: Im Internet kursierende Daten, die irgendwie vertraulich sein sollen, müssen alle aufwändig verschlüsselt werden, denn jeder kann potentiell zu jeder Zeit und von jedem Ort darauf zugreifen. Die Kryptographie ist deshalb ein notwendiger und immer wichtiger werdender Teil der Informatik; Datensicherheit ist ein absolut notwendiger Aufwand, den die Verfügbarkeit von Daten mit sich bringt. Kurz: Je unkontrollierter Daten zirkulieren, desto größer ist die Notwendigkeit ihrer Geheimhaltung. Dieser Befund erklärt, warum ,geheimschriftliche' Codes im Mittelalter vergleichsweise einfach sind. Es handelt sich um Praktiken des Ersetzens und Vertauschens oder um erfundene Alphabete, die simpel zu encodieren sind, da etwa die Häufigkeitsverteilung der verwendeten Buchstaben nicht berührt wird. Darüber hinaus beschränkt man sich auf wenige Techniken und gibt den Handschriften oft ihre eigenen Schlüssel bei. ${ }^{3}$

Wenn es also nicht um Geheimhaltung geht, worum dann? Eine ebenso phantasie- wie funktionslose Erklärung ist, dass es sich um ,Spielerei' handle. Aber das ist nicht nur zu einfach, sondern greift auch zu kurz und erklärt nichts. Ferner würde sich dann auch die Frage stellen, wie man den Begriff des ,Spiels' angemessen historisieren kann. Ich will, als Ergebnis des Projekts, dafür argumentieren, dass es sich bei den ,Geheimschriften' um eine besondere Form der Schrift handelt, die den Rezeptionsvorgang medial beeinflusst. Diese recht allgemeine Grundannahme kann sich in vielfältigen pragmatischen Funktionen realisieren, wie der Unterscheidung zwischen Text und Paratext oder der Markierung der geheimschriftlichen Einträge, die sich - so unsere Projekterfahrung - optisch von der umgebenden Schrift absetzt, also den Eintrag mehr hervorhebt denn verbirgt. Durch die Verschlüsselung ergibt sich aber auch so etwas wie ein ,Lesewiderstand', der zwar nicht dazu führt, dass man den Text gar nicht, aber doch nicht auf den ersten Blick lesen kann. Auch das kann rein pragmatische Funktionen haben, etwa dass man im Schulunterricht zwischen den Zeilen stehende Glossen nicht sofort entziffern können soll. Doch die Veränderung der Lektürepraxis durch den ,Lesewiderstand' kann auch eine weiterführende Bedeutung freisetzen. Der Text wird nicht einfach gelesen, sondern ,offenbart' sich in der Form des langsamen, konzentrierten Entschlüsselns - so einfach dieses auch sein mag. So wird nicht nur verhindert, dass ein Text versehentlich gelesen wird, sondern die fremde Form der Buchstaben stattet - so meine These - den Text mit einer Bedeutungsdimension aus, die über den reinen Wortsinn hinausgeht. Die Aspekte dieser Bedeutungsdimension, die Medium und Message verschaltet, die Buchstaben und Botschaft in der Performanz ihrer Verwendung ineinander rückt, kann ich hier nur anhand von zwei Beispielfeldern andeuten.

3 Vgl. dazu ausführlicher Stephan Müller: Warum mittelalterliche Geheimschriften keine Geheimschriften sind - am Beispiel des Trierer Teufelsspruches (Trier Stadtbibliothek Hs. 564/ $8068^{\circ}$ ). In: Schriftträger - Textträger. Zur materiellen Präsenz des Geschriebenen in frühen Gesellschaften. Hg. von Annette Kehnel und Diamantis Panagiotopoulos. Berlin, München, Boston 2015, S. 169-178. 


\section{Die Schrift der Herrscher}

Gregor von Tours berichtet über den merowingischen König Chilperich I. (um 535-584), dass er das lateinische Alphabet erweitert habe. ${ }^{4}$ Die Forschung hat diesen Buchstaben schon früh große Aufmerksamkeit geschenkt. ${ }^{5}$ Genauer heißt es bei Gregor:

Er fügte auch unserem Alphabet einige Buchstaben hinzu, nämlich $\omega$, wie es die Griechen haben, ae, the, wi wofür die Schriftzeichen folgende sind: [hier folgt die Abbildung der Zeichen] und sandte Schreiben in alle Städte seines Reichs, daß die Knaben so unterrichtet und die alten Büchern mit Bimsstein radiert und umgeschrieben werden sollten. ${ }^{6}$

Es kommt nun nicht darauf an, ob diese Geschichte so stattgefunden hat oder welche Funktionen diese Erfindung gehabt haben sollte. Sicher haben wir es nämlich mit einer Herrscheranekdote zu tun, in der die Wichtigkeit des Chilperich betont wird und die Tatsache, dass er mit der Modifikation der lateinischen Schrift in der Merowingerzeit für die Integration einer fremden Kulturtechnik in seine Herrschaft steht. Die Forschung hat die Geschichte in der Tradition der Claudiusvita des Sueton gesehen (cap. 41,3), in der es heißt, dass Claudius das lateinische Alphabet durch drei Buchstaben erweitert habe und dabei auf griechische Buchstaben, die er kannte, zurückgriff. Dagegen wurde zu Recht eingewandt, dass Sueton im frühen Mittelalter nicht verbreitet und kaum bekannt war. Besser sollte man wohl von einer etablierten Topik ausgehen, die sich dann auch bei Isidor von Sevilla greifen lässt, der unter den Schrifterfindern auch Herrscher wie die ägyptische Königin Isis oder Kadmos nennt (Etymologiae I,3). Schrifterfindung erscheint hier als Herrschaftsgestus, als eine Form, über die Welt zu verfügen. In den meisten Fällen werden wir es dabei mit ,Behauptungen' zu tun haben, wie ein kurioses Beispiel zeigt, das durch die Handbücher geistert: Das Alphabet Karls des Großen, von dem etwa Herbert W. Franke ${ }^{7}$ oder Friedrich L. Bauer ${ }^{8}$ berichten. Dabei handelt es sich um eine reine Erfindung des Johannes Trithemius in seiner Schrift Polygraphia, die 1508 vollendet und Kaiser Maximilian überreicht, aber erst 1518 gedruckt wurde. Dort heißt es: „Constat autem teste Otfrido Carolum propria plura excogitasse alphabeta, quibus per latissimum regnum secure uteretur in archanis cum singulis praefectis“. („Es steht aber, wie Otfrid bezeugt, fest, dass sich Karl mehrere eigene Alphabete ausgedacht hatte, die er im Gebiet seines sehr ausgedehnten Reiches sicher für geheime Kommunikation mit einzelnen Grafen

4 Vgl. Gregor von Tours: Zehn Bücher Geschichten. Historiarum libri decem. 5. Aufl. Bd. 1. Hg. von Rudolf Buchner. Darmstadt 1977, Buch V, S.364f.

5 Vgl. Wilhelm Grimm: Über deutsche Runen. Göttingen 1821, S. 52-60.

6 Die Übersetzung und die Literatur nach Willy Sanders: Die Buchstaben des Königs Chilperich. In: Zeitschrift für deutsches Altertum und deutsche Literatur 101 (1972), S. 54-84, hier S. 54.

7 Vgl. Herbert W. Franke: Die geheime Nachricht. Methoden und Technik der Kryptologie. Die Geschichte um den unknackbaren Code. Frankfurt a. M. 1982, S. 16.

8 Vgl. Friedrich L. Bauer: Entzifferte Geheimnisse. Methoden und Maximen der Kryptologie. 3. Aufl. Berlin u. a. 2000, S. 47. 
benutzte"). ${ }^{9}$ Trithemius fügt dem noch eine Abbildung hinzu und als Faksimile dieser Form findet es sich in den genannten modernen Darstellungen - und nicht nur in diesen. Aber allein die Behauptung des Trithemius zeigt, wie lebendig der Topos vom Herrscher als Schrifterfinder noch in der Frühen Neuzeit war. Und in diesem Kontext haben wir dann tatsächlich weitere Schrifterfindungen von Herrschern vor uns, wobei die Habsburger eine dominante Rolle spielen.

Kaiser Friedrich III. bezeichnet sich im Codex 2674 der Österreichischen Nationalbibliothek in Wien, also in seinem berühmten Notizbuch, in dem sich mehrere Verschlüsselungssysteme und fremde Alphabete finden, selbst als Erfinder einer Geheimschrift (Abb. 1). Unter einem Schlüssel steht dort nämlich am unteren Rand des Blattes: „hab ich selbs gedacht".

$\mathrm{Ob}$ das zutrifft, ist nicht zu klären, jedenfalls handelt es sich um einen originellen Schlüssel: In der unteren Zeile steht ein Alphabet mit 23 Buchstaben, also ohne $\mathrm{j}$, u und w. Dem Alphabet folgen Zeichen für et, us und (t)ur, was darauf hindeutet, dass mit dem Alphabet (zumindest auch) Latein geschrieben werden sollte. Über dieser Zeile stehen nun die Zeichen, die statt der Klarschrift geschrieben werden sollen. Die ersten vier Vokale werden vertauscht: $a=e, e=a, i=0$ und $o=i$. Das $\mathrm{v}$-Zeichen ist davon nicht betroffen. Die Konsonanten (und dabei auch das v) werden dann in Zweierpaaren kreuzweise vertauscht, wobei die Vokale ausgelassen werden: $b=c, c=b, d=f, f=d$, etc. Da die Buchstabenzahl ungerade ist, werden auch die drei Zusatzzeichen in das Spiel mit einbezogen: $z=e t$, et $=z$, us $=(t) u r, ~(t) u r=u s$. „Friedrich“ würde nach diesem System also als „Dsoafsobg“ geschrieben.

Auch in den Gedenkbüchern Kaiser Maximilians finden sich solche Versuche, die sehr wahrscheinlich von Trithemius inspiriert wurden, der immerhin am 8. Juni 1508 seine Polygraphia (u. a. mit dem Alphabet Karls des Großen) dem Kaiser überreichte. ${ }^{10}$ Diese Versuche Maximilians stehen technisch gesehen auf der Schwelle zur Neuzeit. Dabei kann als sicher gelten, dass diese Geheimschrift über die im Mittelalter üblichen Techniken des einfachen Ersetzens und/oder Vertauschens hinausgeht, sodass die bis dahin gewohnten Encodierungsversuche, die etwa auf den Prinzipien der Häufigkeitsverteilung von Buchstaben beruhen, nicht funktionieren. Ein Beispiel für dieses noch nicht systematisch untersuchte Phänomen ist etwa der Codex 2900 der Österreichischen Nationalbibliothek Wien. Dieses Gedenkbuch Kaiser Maximilians stammt von der Hand des Marx Treitzsaurwein, wurde also in direktem Kontakt zu Maximilian geschrieben - und das auf mehreren Blättern in einer Geheimschrift. ${ }^{11}$

9 Polygraphiae libri sex. Ionannis Trithemii abbatis Peapolitani quondam Spanheimensis ad Maximilian caesarem. Basel 1518 (VD16 T 1994), o. S. (Folgeseite nach Lagenzeichen q II).

10 Vgl. Klaus Arnold: Johannes Trithemius (1462-1516). Würzburg 1971, S. 191.

11 Vgl. Die Handschriften der K. K. Hofbibliothek in Wien im Interesse der Geschichte, besonders der österreichischen. Verzeichnet und excerpirt von Joseph Chmel. Bd.2. Wien 1841, S. 459. Ein Digitalisat der Handschrift findet sich unter dieser Adresse, URL: http://data.onb. ac.at/rep/100B810E (5.11.2019). 


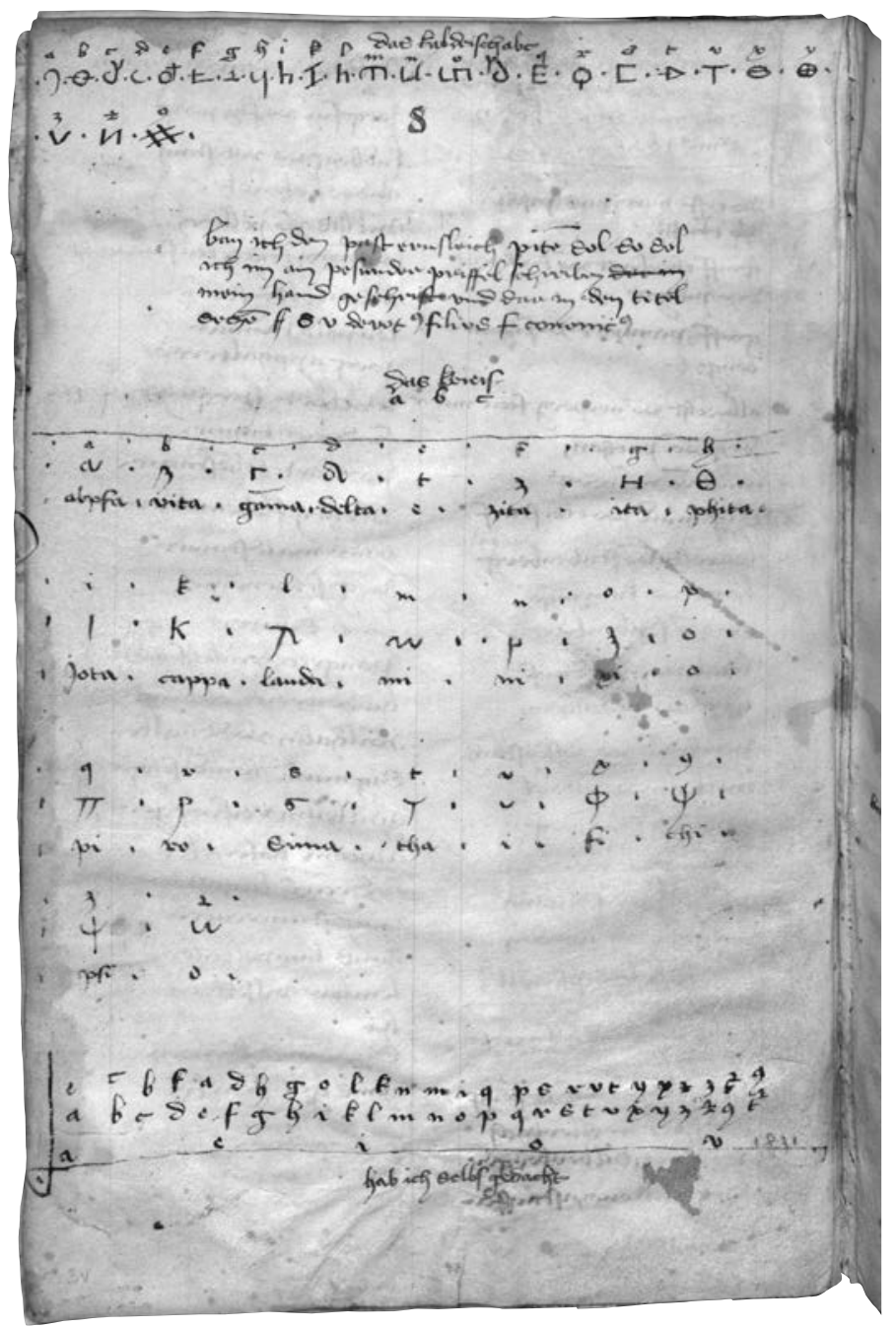

Abb. 1: Die Geheimschrift von der Hand Kaiser Friedrichs III. (Wien, Österr. Nationalbibl. Cod. 2674, fol. $3^{\mathrm{v}}$ ).

Etwas genauer soll auf die Schrifterfindung eines dritten Habsburgers eingegangen werden, auf die Geheimschrift Rudolfs des Stifters. ${ }^{12}$ Unter den wenigen persönlichen Eigenschaften, die die Österreichische Chronik von den 95 Herrschaf-

12 Dazu ausführlich Stephan Müller: Der Herrscher und sein Alphabet. Zur Geheimschrift Rudolfs des Stifters. In: Wien 1365. Eine Universität entsteht. Hg. von Heidrun Rosenberg und Michael Viktor Schwarz. Wien 2015, S. 42-53. 
ten am Ende des 14. Jahrhunderts über Rudolf den Stifter berichtet, sticht besonders die Erfindung dieser Geheimschrift hervor: „Wan er machte new figuren und půchstaben, die vormals nie chain auge het gesehen; mit den schraib er seinen gehaimen seine grosse und haimleich sache, so si nicht bey im waren.“ („Denn er fertigte neue Schriftzeichen und Buchstaben an, die zuvor kein Auge je gesehen hatte. Mit diesen schrieb er seinen Vertrauten - wenn sie nicht bei ihm waren wichtige und geheime Sachen" ${ }^{\prime \prime}{ }^{13}$ Die Chronik schreibt der Schrift also eine diplomatische Funktion zu. In dieser Funktion ist allerdings nichts erhalten. Tatsächlich sind uns aus dem Umkreis Rudolfs mindestens drei Zeugnisse der Geheimschrift überliefert, die einen anderen Zweck gehabt haben müssen. ${ }^{14}$ Es handelt sich dabei um eine Grabinschrift, die heute in das Bischofstor des Wiener Stephansdoms eingelassen ist, um ein Gebet, das wie ein Ornament eine Urkunde umrahmt, und um die fragmentarische Inschrift auf einem Sigel, die allerdings so weit zerstört ist, dass eine Deutung kaum möglich ist.

1772 wurde in der Taphographia Principum Austriae eine Auflösung des Alphabets und des Epitaphs abgedruckt, ${ }^{15}$ doch diese Auflösung, die in der Ausgabe fast wie die Lösung eines Kriminalfalls gefeiert wird, war eigentlich überflüssig, denn Petrus Apianus und Bartholomaeus Amantius hatten sie bereits 1534 veröffentlicht, ${ }^{16}$ auch wenn ihnen kleinere Lesefehler dabei unterliefen (Abb. 2).

Sie lesen „Hic est Sepultus dominus dux Rudolfus fundator", wobei das „DENS“, das als „,dominus dux“ gelesen wird, jedoch gar kein e enthält. Inzwischen versteht man das eher als „de nobili stirpe“, also „,aus edlem Geschlecht“; wenn auch dafür keine Sicherheit besteht. ${ }^{17}$ Wichtig für den vorliegenden Zusammenhang ist, dass der Abdruck bei Apianus und Amantius wie selbstverständlich geschieht, eine ,Geheimschrift' also wurde die Schrift erst durch das Vergessen der Neuzeit. Im 16. Jahrhundert war sie keine und das nicht nur bei Apianus und Amantius, denn es sind zahlreiche Zeugnisse einer Entschlüsselung des Alphabets bekannt, wobei keine Rudolf als Erfinder nennt, aber auch keine vor die Zeit Rudolfs zu datieren

13 Österreichische Chronik von den 95 Herrschaften. Hg. von Joseph Seemüller. Hannover, Leipzig 1909, S. 207.

14 Franz Kürschner: Herzog Rudolph's IV. Schriftdenkmale. In: Mittheilungen der K. K. CentralCommission zur Erforschung und Erhaltung der Baudenkmale 17 (1872), S. 71-80.

15 Martin Gerbert: Taphographia Principum Austriae. St. Blasien 1772, Teil II, Tafel XV. Eine gute Dokumentation mit Abbildungen bietet, URL: https://de.wikipedia.org/wiki/Kenotaph_für_ Herzog_Rudolf_IV. (5.11.2019).

16 Vgl. Petrus Apianus und Bartholomaeus Amantius: Inscriptiones Sacrosanctae Vetvstatis. Ingolstadt 1534, S. 403. Vgl. dazu: Stephan Müller: Digitalisierung in der Frühen Neuzeit. Rudolf der Stifter, Conrad Celtis und Titius Finitus in den Inscriptiones Sacrosanctae Vetvstatis des Petrus Apianus und Bartholomaeus Amantius (1534). In: Materialität und Formation. Studien zum Buchdruck des 15. bis 17. Jahrhunderts. Festschrift für Monika Unzeitig. Hg. von Karin Cieslik, Helge Perplies und Florian Schmid. Bremen 2016, S. 135-147.

$17 \mathrm{Zu}$ den möglichen Lesungen Müller: Zur Geheimschrift Rudolfs des Stifters (Anm. 12), S. 42 und 45 . 


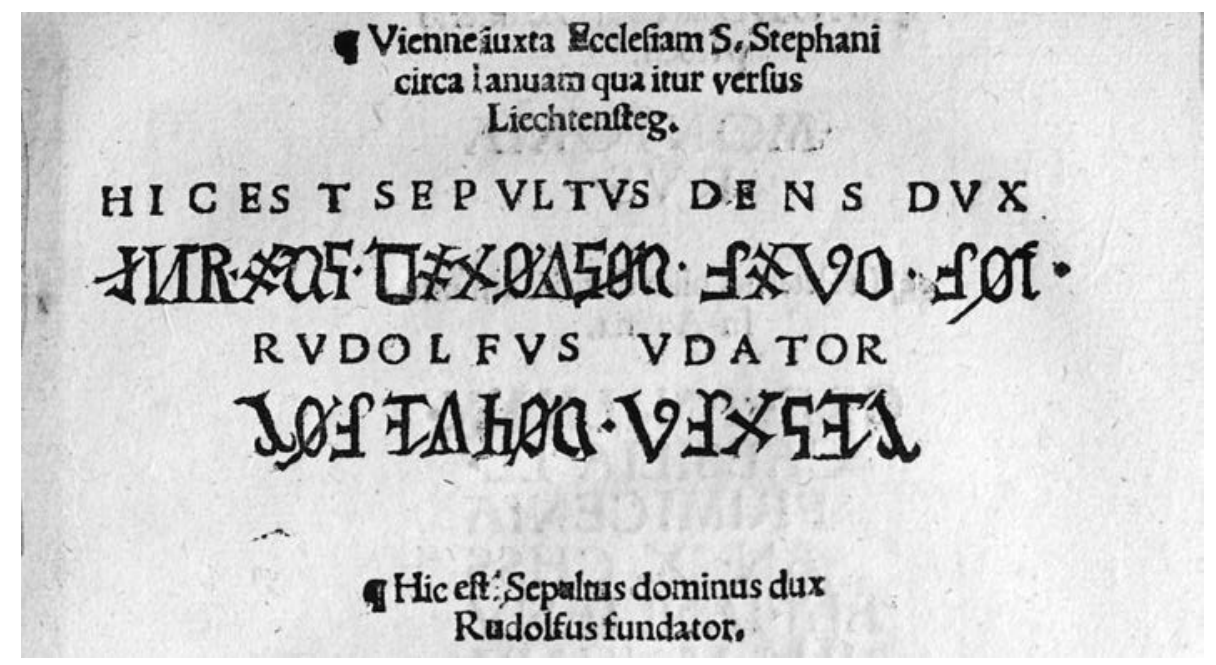

Abb. 2: Das Epitaph Rudolfs des Stifters in Petrus Apianus und Bartholomaeus Amantius: Inscriptiones Sacrosanctae Vetustatis. Ingolstadt 1534, S. 403.

ist. ${ }^{18}$ Wie wenig es um Geheimhaltung geht und welche Aura der Schrift zukommt, zeigt - um nur ein Beispiel zu nennen - die Verwendung der Schrift auf dem Hofer Altar des Hanns Pleydenwurff von 1465 als Teil der dreisprachigen Kreuzinschrift, wo die Rudolf-Schrift die griechischen Schriftzeichen ersetzt und damit öffentlich encodiert werden kann, denn man weiß ja, was auf der Kreuzinschrift steht. ${ }^{19}$

Ein weiteres Zeugnis ist eine Urkunde vom 4. Juni $1360,{ }^{20}$ mit der Rudolf dem Stephansdom die Reliquien des hl. Trophinus, der hl. Sophia, des heiligen Papstes und Märtyrers Urban sowie des heiligen Soldaten und Märtyrers Theodor überlässt. Diese Urkunde bestätigt Rudolf selbst mit der Unterschrift: „Wir der vorgenant Herzog Ruodolf sterken disen prief mit dir underschrift unser selbs hant“. Diese Urkunde ist ornamenthaft umrahmt mit einem Gebetstext in der Geheimschrift Rudolfs, mit der das Reliquiengeschenk als Opfergabe bezeichnet wird, für das die Tröstung Gottes für den Herrscher und seine Familie samt seiner Geschwister eingefordert wird. ${ }^{21}$ Eine non-invasive Röntgenfluoreszenzuntersuchung der Urkunde hat ergeben, dass die Tinte der Geheimschrift mit jener der legitimierenden Unterschrift Rudolfs identisch ist. Sie stammt also von der Hand Rudolfs und ist

18 Belege dafür, die im Kontext des Projekts vermehrt wurden, finden sich bei Bischoff: Übersicht (Anm. 2), S. 132f., Nr. 62.

19 Eine Abbildung der Kreuzinschrift bei Müller: Zur Geheimschrift Rudolfs des Stifters (Anm. 12), S. 52.

20 Diözesanarchiv Wien, Urkundenreihe 1360, Juni 4, Wien.

21 Eine Abbildung der Urkunde bei Müller: Zur Geheimschrift Rudolfs des Stifters (Anm. 12), S. 44 . 
damit eine Körperspur des Herrschers. Die Urkunde wurde und wird im Kontext des Stephansdoms aufbewahrt, also jenes Kirchenbaus, den Rudolf intensiv betrieb und der auch Ort seiner Grablege - und so auch der Ort für das geheimschriftliche Epitaph - werden sollte. Auch das berühmte Individualportrait Rudolfs des Stifters gehört zu diesem Komplex der medialen Gegenwärtigkeit des Herrschers. ${ }^{22}$

Der Herrscher macht sich in seiner Schrift präsent. Auch wenn unsicher bleiben muss, ob die Schrift seine eigene Erfindung war (die Überlieferungslage falsifiziert das jedenfalls nicht). Der Herrscher legt Hand an, ist in der Schrift der Urkunde spurhaft präsent, wie auch im Portrait und im Epitaph, das ihn im Kontext seines Grabmals also nochmals sehr konkret körperlich anwesend macht. Das geheim zu halten, wäre geradezu kontraproduktiv. Produktiv ist in diesem Konzept aber die Bindung von Zeichenkörper an den Körper des Herrschers insofern, als man mit ihm in direkten Kontakt kommt, wenn man die Schrift entschlüsselt oder sie sich entschlüsseln lässt (im Kontext des Stephansdoms war die Anwesenheit von Personen, die diese Schrift lesen konnten, sicher gewährleistet). In der Performanz der Entschlüsselung setzt man sich mit der ,Erfindung' des Herrschers auseinander und der Effekt ist eine besondere und besonders intensive Form der Memoria. In der singulären Relation von Zeichen und Zeichenerfinder performiert man aber auch eine Innovationsbehauptung. Mittelalterliche Memoria und humanistische Herrscherweisheit greifen ineinander.

Es geht dabei um eine ganz spezifische Weltaneignung und Geltungsansprüche durch die Herrscher, die über die Relation von Signifikat und Signifikant hinaus dort eingreifen, wo man sonst nur Außenstehender ist: Sie verfügen über den Code.

\section{Die Schrift der Mystik}

Wie bringt man das mystische Erlebnis einer unmittelbaren göttlichen Offenbarung in die vermittelte Form der Schrift? Das - um es einmal ganz abstrakt zu formulieren - mussten sich die Mystikerinnen und Mystiker des Mittelalters fragen. Dass diese Frage eine brisante war, zeigen uns jene Schreib- und Schriftkonstellationen der Mystik, die als komplexe Antwortentwürfe auf diese Frage gelesen werden können. Es sind Antwortentwürfe, die man als Prophylaxe gegen Häresievorwürfe lesen kann, aber auch als eine komplexe Form der Plausibilisierung und Legitimierung des Unerhörten. Dieses weite Feld eines mystischen Schriftdiskurses ist für die vorliegende Argumentation immer dann interessant, wenn Schrift und Schriftkörper selbst Gegenstand der Reflexion werden. Diese Reflexion setzt wie die Schrifterfindungen der Herrscher auf der Ebene des Codes an und kann - wie zu zeigen sein wird - auch Formen von ,Geheimschriften' hervorbringen.

Caroline Emmelius hat diese Problematik grundsätzlich herausgearbeitet und am Beispiel The Book of Margery Kempe vorgestellt. ${ }^{23}$ Dort wird erzählt, dass die

22 Zum Portrait Rudolfs vgl. Michael Viktor Schwarz: Magnifizenz und Innovation. Rudolf IV. im Bild. In: Wien 1365 (Anm. 12), S. 28-41.

23 Caroline Emmelius: Verborgene Wahrheiten offenbaren. Verschriftlichungsprozesse in frauenmystischen Texten zwischen Subversion und Autorisierung. In: Offen und Verborgen. 
Mystikerin in ihren Visionen aufgefordert wurde, dieselben aufschreiben zu lassen. Nach 20 Jahren - um 1433 - veranlasst sie das auf einen weiteren göttlichen Auftrag hin, doch der Schreiber stirbt bei der Arbeit. Ein ,Überarbeiter' und Fortsetzer kann die Schrift des Vorgängers jedoch nicht lesen und verstehen, weder die Sprache noch die Buchstaben (,lettyr") seien irgendwie bekannt. Trotzdem versucht sich der Schreiber an dem Text, gibt aber nach vier Jahren auf und empfiehlt einen anderen Schreiber, der mit dem ersten Schreiber bekannt war und vielleicht deshalb mit der Sprache und Schrift zurechtkommen könne. Als auch dieser dritte Schreiber scheitert, versucht sich der zweite Schreiber nochmals und kommt voran. Doch bei der Arbeit schwindet seine Sehkraft. Erst als ihm Margery erklärt, dass dahinter der Teufel stecke, der die Reinschrift vereiteln möchte, arbeitet er weiter, bis endlich das Buch in einer lesbaren Form vorliegt. Einfach aufschreiben lässt sich die mystische Offenbarung nicht! Über dieses Beispiel hinaus will ich nur folgende Fälle nennen: Margarethe Ebner, die über ihren Schreibprozess berichtet, dass er „zunächst wider Willen und mit ,forht und schrekken' [...] im Advent begonnen hat ${ }^{\prime \prime 24}$, und der nur mit Unterstützung einer vertrauten Schwester stattfinden konnte, die einen ihrer Träume aufzeichnet, womit Offenbarungssituation und Schreibsituation getrennt werden. Aber Margarethe Ebner schreibt auch selbst, und ihr Schreiben ist dann, wie Peters zusammenfasst, „Movens der Rekapitulation [...] und zugleich verstärkendes Medium der Begnadung “. ${ }^{25}$ Die Offenbarung widerstrebt dabei ganz grundsätzlich einem sukzessiven Bericht. Margarethe Ebner betont, "daz ich ainz kum vor dem andern gescriben moht“. ${ }^{26}$ Adelheid Langmann schreibt erst nach dem Schreibbefehl eines Dominikaners, der ihre Texte prüfte „und vant daz, daz ez allez gereht was und sterket sie dor an . ${ }^{27}$ Überhaupt sind Schreiber, die für Mystikerinnen arbeiten, nicht selten, und in Christine Ebners Offenbarungen sprechen solche Instanzen auch in der IchForm im Text; teils mit Namen versehen, teils als anonymer ",frund“ ${ }^{28}$ Das gilt nicht nur für Mystikerinnen. Die Geschichte der Verschriftlichung von Seuses Vita steht dafür. Seuse selbst wollte die Schrift nicht in Umlauf bringen und verbrennen, aber die Dominikanerin Elsbeth Stagel sorgte für den Erhalt des Textes der Vita. ${ }^{29}$

Bei diesen Beispielen handelt es sich kaum um solche realen Schrifterhaltungsgeschichten wie jene von Max Brod und Franz Kafka. Gearbeitet wird hier an der eingangs genannten Frage, die man noch abstrakter formulieren kann: Wie kann eine mediale Form für die Kodifikation der Erfahrung des Göttlichen überhaupt aussehen? Die vorliegenden Geschichten zeigen, dass man dabei an die etablier-

Vorstellungen und Praktiken des Öffentlichen und Privaten in Mittelalter und Früher Neuzeit. Hg. von ders. u. a. Göttingen 2004, S. 47-65.

24 Ursula Peters: Religiöse Erfahrung als literarisches Faktum. Zur Vorgeschichte und Genese frauenmystischer Texte des 13. und 14. Jahrhunderts. Tübingen 1988, S. 146.

25 Ebd.

26 Ebd.

27 Peters: Religiöse Erfahrung (Anm. 24), S. 178.

28 Peters: Religiöse Erfahrung (Anm. 24), S. 165.

29 Vgl. Peters: Religiöse Erfahrung (Anm. 24), S. 135-142. 


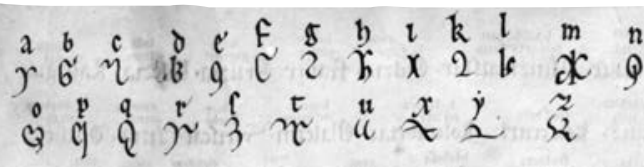

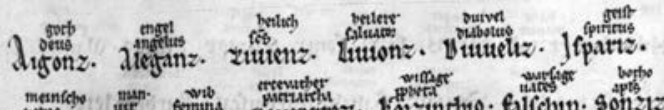

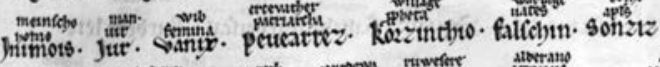

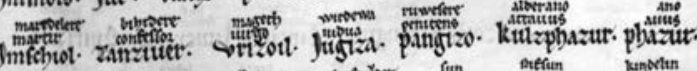

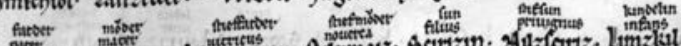

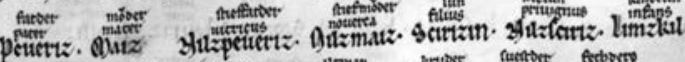

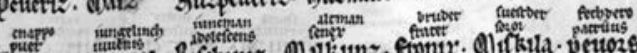

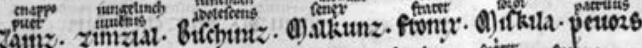

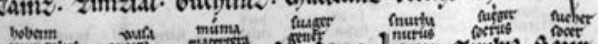

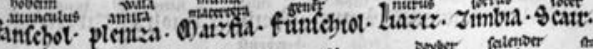

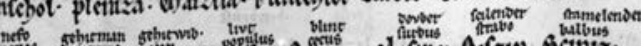

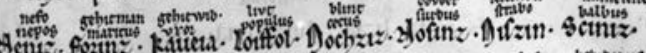

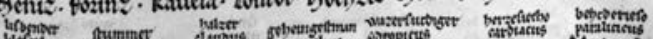

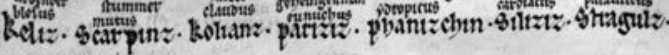
muatguthougr

patizio.

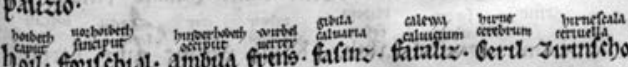

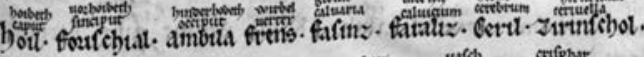

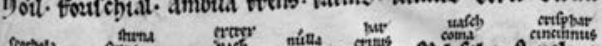

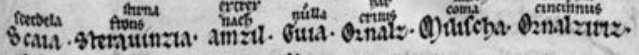

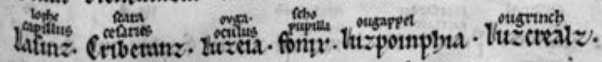

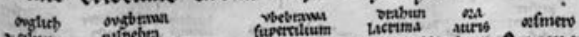

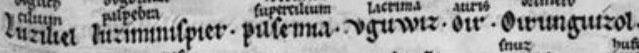

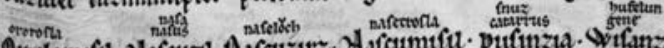

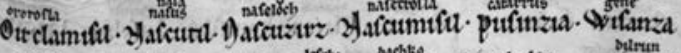

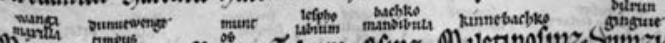

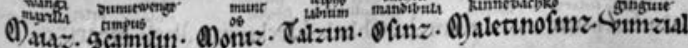

Abb. 3: Die litterae ignotae und die lingua ignota der Hildegard von Bingen (Berlin, Staatsbibl., Ms. lat. qu. 674, fol. 58 r).

te Schrifttradition anschließt, aber diese modifiziert: Man schreibt nicht selbst, schreibt gegen Widerstände, sucht nach Instanzen der Legitimierung, etc. In diesen Kontext will ich eine mystische ,Geheimschrift' aus dem 12. Jahrhundert stellen.

Von der Heiligen Hildegard von Bingen (1098-1179) ist uns ein eigenes Alphabet und eine eigene Sprache überliefert, die von der Forschung als litterae ignotae und 


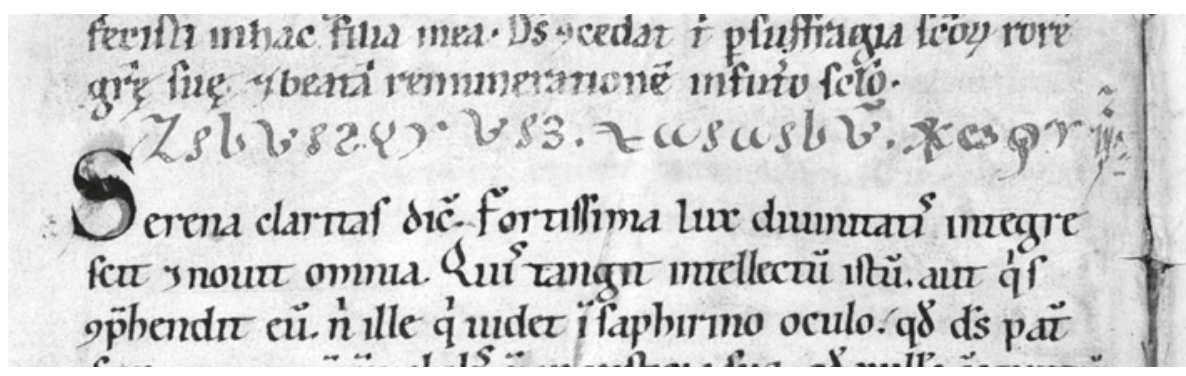

Abb. 4: Die litterae ignotae in der Zwiefaltener Briefhandschrift. (Stuttgart, Landesbibl., Cod. theol. et phil. $4^{\circ} 253$, fol. $75^{v}$, Zeile 5).

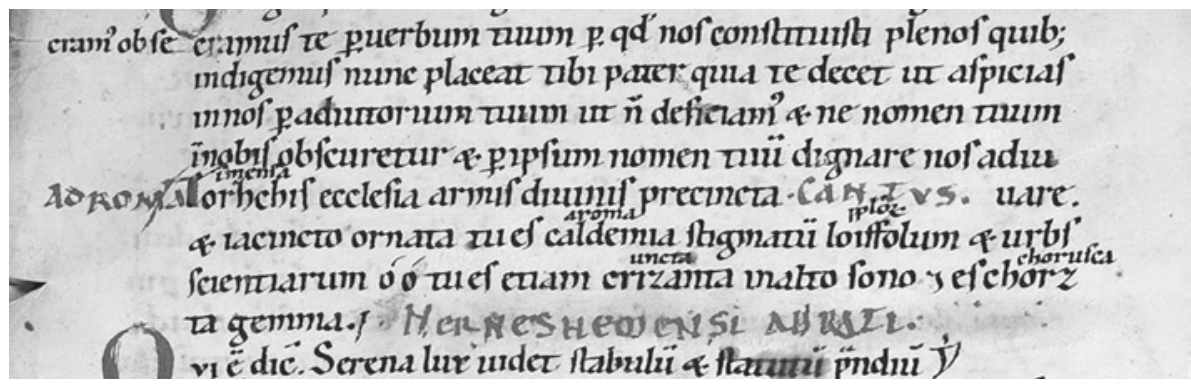

Abb. 5: Eine Antiphon mit Wörtern der lingua ignota in der Zwiefaltener Briefhandschrift. (Stuttgart, Landesbibl., Cod. theol. et phil. $4^{\circ} 253$, fol. $28^{r}$ ).

lingua ignota bezeichnet werden (Abb. 3). ${ }^{30}$ Dass beide aufeinander zu beziehen sind, zeigt schon die Überlieferung, in der die lingua immer von den litterae begleitet werden. Michael Embach fasst beides unter dem Titel „sprachlichkundlichexperimentelle[] Schriften ${ }^{\prime \prime 31}$ zusammen. Während die lingua ignota in zwei noch vorhandenen Textzeugen $(\mathrm{R}=$ Rupertsberger Riesencodex, Wiesbaden, Landesbibl., Hs. 2, fol. $461^{\text {ra }}-464^{\text {ra }}$ und B = Berlin, Staatsbibl., Ms. lat. qu. 674 , fol. $58^{\mathrm{r}}-62^{\mathrm{r}}$ ) und in ei-

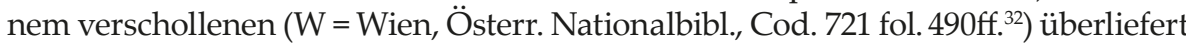
ist, sind die litterae ignotae in vier Handschriften bezeugt $(\mathrm{R}, \mathrm{B}, \mathrm{F}=$ Florenz, Bibl. Medicea Laurenziana, Plut. 22, dex. 4, fol. $143^{\mathrm{r}}$ und WR = Wien, Österr. Nationalbibl., Cod. 1016, fol. 119') und in der bereits genannten verschollenen Handschrift W.

30 Die lingua und die litterae wurden jüngst ediert von Hildegardis Bingensis: Lingua ignota. Hg. von Kurt Gärtner und Michael Embach. In dies.: Opera minora II. Hg. von Jeroen Deploige u. a. Turnhout 2016, S. 237-366.

31 Michael Embach: Die Schriften Hildegards von Bingen. Studien zu ihrer Überlieferung und Rezeption im Mittelalter und in der Frühen Neuzeit. Berlin 2003, S. 252.

32 Michael Embach und Martina Wallner: Conspectus der Handschriften Hildegards von Bingen. Münster 2013, S. 287f., Nr. 323. 
Wirklich benutzt wurden weder die neue Sprache noch die Schrift. Der einzige Textzeuge, in dem die litterae ignotae aktiv verwendet werden, ist die Zwiefaltener Briefhandschrift (Abb. 4). Dort wird ein Brief eingeleitet mit: „Hildigardis . xuiuild . monachis", also „Hildegard an die Mönche von Zwiefalten".

Die Anwendung der lingua ignota findet sich in einer Antiphon der Hildegard, die ebenfalls im Zwiefaltener Briefcodex überliefert ist (Abb. 5):

O orzchis (Glosse: imensa) ecclesia armis divinis precincta

et iacincto ornata

tu es caldemia (Glosse: aroma) stigmatum loifolum (Glosse: populorum)

et urbs scientiarum

ó, ó, tu es etiam cr[i]rzanta (Glosse: uncta)

in alto sono

et es chorzta (Glosse: chorusca) gemma. ${ }^{33}$

Damit fand die lingua immerhin im selben Codex wie die litterae Anwendung, wobei sich die Wörter der Antiphon mit nur einer Ausnahme („loifolum“ für „populorum") nicht in den überlieferten Fassungen der lingua ignota finden. Dort wird „loiffol“ als „populus“ (in B zusätzlich als „liut", ,Leute“ übersetzt), was auch zeigt, dass Hildegard die Wörter ihrer lingua flektiert, hier also den Genitiv Plural verwendete. Die in B und R nicht enthaltenen Wörter könnten darauf hinweisen, dass weitere, umfangreichere Glossare verloren sind, oder auch, dass Hildegard solche Wörter spontan erdachte und die überlieferten Glossare eine sekundäre Sammlung darstellen. Die Antiphon ist dann auch noch in R (fol. 405 va , ohne Neumen und fol. $466^{\mathrm{rab}}$, hier mit Neumen) und in der Handschrift Wien, Österr. Nationalbibl., Cod. 963 (fol. 156 ${ }^{\text {ra }}$, ohne Neumen) überliefert. Ursprünglich aber ist sie wohl als Anhang zu dem Brief an die Zwiefaltener Schwestern gedacht gewesen, der der Antiphon vorangeht. ${ }^{34}$

Christel Meier hat dieses Projekt der Heiligen Hildegard jüngst vorbildlich dokumentiert und bewertet. Sie stellt es in den Kontext der Verwendung des Griechischen und Hebräischen in lateinischer geistlicher Lyrik und stellt eine Verbindung zum Problem der "adamitische[n] oder angelische[n] Sprache“ - also zur Sprache des ersten Menschen und zur Sprache der Engel - her. ${ }^{35}$ Die lingua und die litterae sind jedoch ein Projekt, das keine breitere Verwendung fand, wie die wenigen Zeugnisse dokumentieren. Doch das Projekt steht auch im Kontext des

33 Hildegard von Bingen: Symphonia. Gedichte und Gesänge. Lat./Dt. von Walter Berschin und Heinrich Schipperges. Gerlingen 1995, S. 126f.: „O Kirche, unermeßlich weit, umgürtet mit göttlicher Rüstung, mit Hyazinthen geschmückt - O wohltuender Duft, der strömt aus den Wunden der Völker. Du Stadt aller Wissenschaft - Oh, oh - auch du bist gesalbt beim mächtigen Klange - o du funkelnde Gemme! "

34 Embach: Die Schriften Hildegards von Bingen (Anm. 31), S. 256.

35 Christel Meier: ,Fremde Wörter' in geistlicher Lyrik des Mittelalters: obscuritas und revelatio. In: wildekeit. Spielräume literarischer obscuritas im Mittelalter. Zürcher Kolloquium 2016. In Verbindung mit Ricarda Bauschke-Hartung und Franz-Josef Holznagel hg. von Susanne Köbele und Julia Frick. Berlin 2018, S. 91-118, hier S. 111. 
mystischen Vertextungsdilemmas, das ich oben zu beschreiben versuchte. Es ist eine Antwort auf die Frage nach der Kodifizierbarkeit mystischen Erlebens. Wir besitzen dafür ein Zeugnis von Hildegard selbst, das diese Lesung nahelegt. Sie schreibt an Papst Anastasius IV. um 1153/54 Folgendes:

Und es wurde ihr [der Inspirierten, C.M.] gesagt: Was du in der Sprache, die dir von oben gezeigt wurde, nicht in Form gewöhnlicher menschlicher Sprache hervorbringen kannst, da diese normale Fähigkeit dir nicht gegeben ist, soll der, der die Feile hat, zu glätten sich anstrengen zu einer für die Menschen verständlichen Rede. ${ }^{36}$

Explizit gesagt wird hier, dass das von Gott Gegebene nicht einfach analog abbildbar ist. Es bedarf einer Transformation in eine Form der Rede, die den Menschen verständlich ist, ein ,Feilen'. In diesem Fall wissen wir, wer die Feile in der Hand gehalten haben sollte: Es ist Volmar von Disibodenberg, der Lehrer und Schreiber Hildegards. In den Autorilluminationen der Hildegardschen Werke ist dieser Prozess der Transformation mystischer Offenbarung in verständliche Rede öfter abgebildet, am schönsten vielleicht im verschollenen Exemplar des Liber Scivias aus dem Rupertsberger Codex, in dem die Rolle Volmars auch im Prolog thematisiert wird (Abb. 6).

Die Rekonstruktion des Bildes zeigt, wie die Flammen des Heiligen Geistes direkt auf Hildegard einwirken, die räumlich von der Außenwelt getrennt ist. Sie schreibt das Diktat der Flammen auf Wachstafeln mit, und diese ephemere Form der Schrift wird dann von einem männlichen Schreibermönch, eben von Volmar, in einen Codex überführt. Zwischen Autorin und Codex schiebt sich der Prozess der genannten Transformation, und dabei werden der Codex und die Autorin der Texte, die er enthält, voneinander dissoziiert. Die Trennung zwischen Ursprung der Botschaft und ihrer medialen Vermittlungsform ist ein Mechanismus der Legitimierung und Autorisierung derselben, sie verbindet die Offenbarung mit Hildegard und trennt sie zugleich von ihr und behauptet für sie den paradoxen Status einer ,Autorin göttlicher Rede'.

Vielleicht ist die Erfindung einer fremden Sprache und einer fremden Schrift nichts anderes als der Versuch, für die Offenbarung im Zustand ihrer Transformation eine ganz eigene Form zu behaupten, und sei es nur als Zeichen dafür, dass es in diesem Prozess um nichts Menschengemachtes geht. Eine solche Sprache und Schrift würde man dann genau genommen nicht einfach lesen, also nicht einfach arbiträre Zeichen in Sprache rückübersetzen, sondern sie würde sich im Encodieren offenbaren und so die Offenbarung und mystische Schau sozusagen für Dritte wiederholbar machen.

Wir wissen, was und wie es im Codex steht, nämlich der, der von der Illumination eingeleitet wird. Wir sehen allerdings nicht, was Hildegard mit ihrem

36 Zitiert in der Übersetzung von Meier mit deren Ergänzung, Meier: ,Fremde Wörter' (Anm. 35), S. 92. 
Stylus in die Wachstafeln ritzt, und noch weniger wissen wir, was und in welcher Form die Flammen mit ihr kommunizieren. Der Brief an Anastasius IV. sagt uns aber, dass das nicht dasselbe sein kann wie das, was im Codex steht. Es ist vielmehr Produkt einer Transformation in eine verständliche Sprache. Zumindest implizit sagt der Brief an Anastasius IV., dass die Offenbarung in einer uns fremden, unverständlichen Form stattfand, dass Hildegard ihre Visionen in einer unbekannten Sprache erhielt, einer Sprache, zu der auch eine unbekannte Form gehört. Dass dabei Sprache und Schrift von der Antike bis ins hohe Mittelalter in eins gedacht werden, bezeugen die genannten Schrifterfindungsgeschichten in Isidors Etymologien. Das Schreiben in der deutschen Sprache (und auch anderen europäischen Volkssprachen) schert da aus. Ich verstehe die lingua ignota und die litterae ignotae als Versuche, für den göttlichen Offenbarungsakt eine angemessene Form zu finden.

Pragmatisch gesehen aber waren lingua und litterae kaum verwendbar, auch wenn sich die Sprache „sehr stark am Wortbestand des Glossarium Heinrici“ ${ }^{\prime 37}$ orientiert. Für einen wirklichen Gebrauch fehlt eine Grammatik, fehlen Strukturwörter, etc. Man könnte daran denken, dass der punktuelle Gebrauch der unbekannten Wörter - wie in der genannten Antiphon - eine Grenze zwischen Wissenden und Unwissenden zieht, also eine Form von Inklusion (bzw. Exklusion der NichtWissenden) darstellt oder dass die Einmaligkeit der sprachlichen Form mit der Einmaligkeit eines Ereignisses, im Kontext dessen sie realisiert wird, korreliert. Bei der Antiphon dachte man etwa an eine Verbindung mit der Weihe von Hildegards Klosterkirche auf dem Rupertsberg am 1. Mai 1152. ${ }^{38}$ Zentral scheint mir indes zu sein, dass die Dokumentation der lingua und der litterae das belegen, was wir nicht sehen können. Die Sprache und Schrift der direkten Offenbarung - ein Geheimnis, das aber gerade nicht geheim gehalten werden sollte.

\section{Schluss}

Neben den kryptographischen Techniken des Ersetzens, Verschiebens oder Vertauschens von Buchstaben zählt man erfundene Alphabete zu den ,Geheimschriften' des Mittelalters. Doch Alphabete waren im Mittelalter etwas Besonderes. Man sammelte sie und erfreute sich an der Kenntnis wenig bekannter und fremd gewordener Alphabete. ${ }^{39}$ Roland Marti fasst das unter den Begriff der ,Xenographie', ${ }^{40}$

37 Embach: Die Schriften Hildegards von Bingen (Anm. 31), S. 285.

38 Vgl. Honey Meconi: Hildegards Lingua ignota and Music. In: Musik des Mittelalters und der Renaissance. Festschrift für Klaus-Jürgen Sachs zum 80. Geburtstag. Hg. von Rainer Kleinertz, Christoph Flamm und Wolf Frobenius. Hildesheim, Zürich, New York 2010, S. 59-79, hier S. 66.

39 Vgl. Elmar Seebold: Die Iren und die Runen. Die Überlieferung fremder Schriften im 8. Jahrhundert als Hintergrund zum ersten Auftreten von Manuskript-Runen. In: Theodisca. Beiträge zur althochdeutschen und altniederdeutschen Sprache und Literatur in der Kultur des frühen Mittelalters. Hg. von Wolfgang Haubrichs u. a. Berlin, New York 2000, S. 10-37.

40 Vgl. Roland Marti: Fremde Schriften in einem lateinischen Codex (Zu den Bamberger Hss. Patr. 130/1 und 130/2). In: Scriptorium 45 (1991), S. 47-83. 


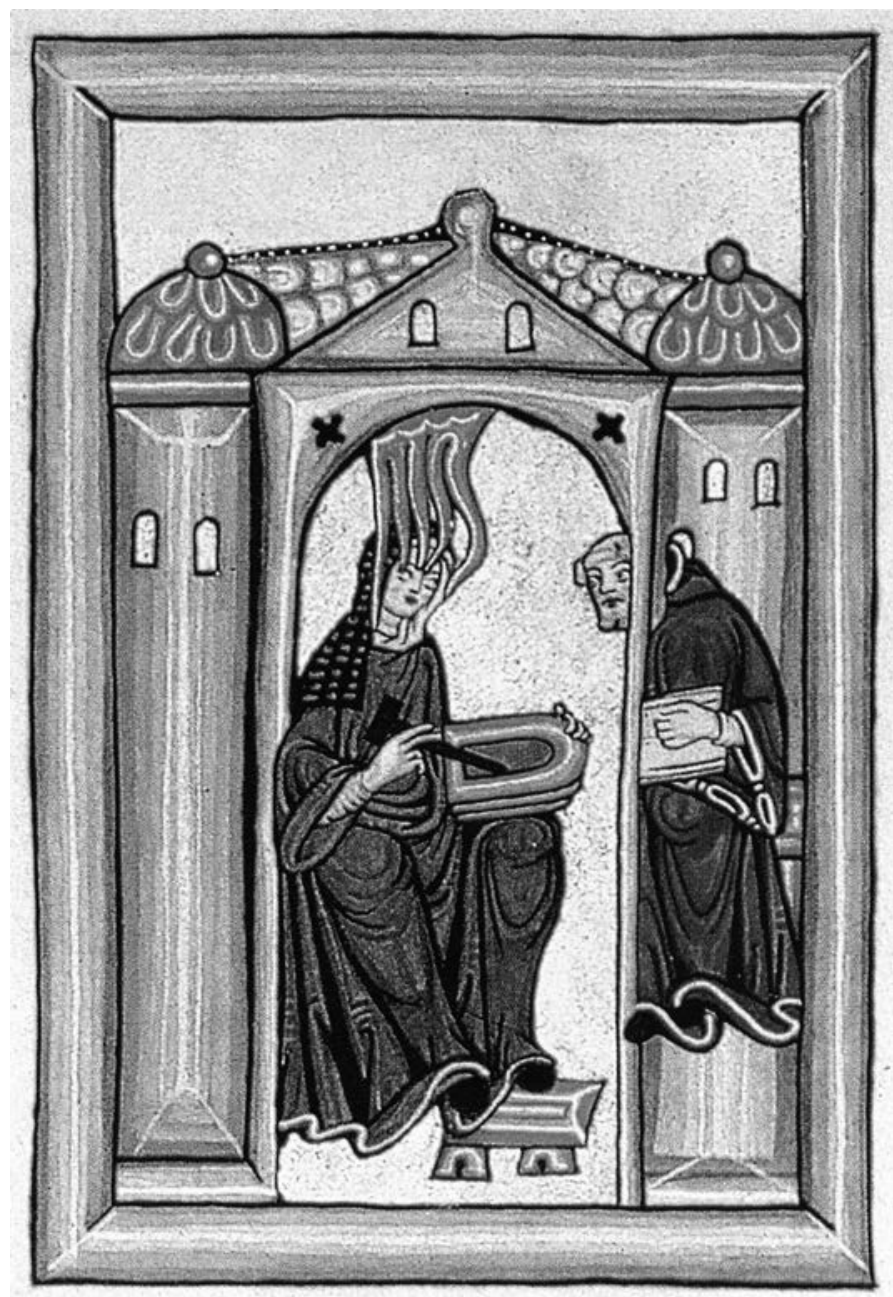

Abb. 6: Rekonstruktion der Autorinnenminiatur im Rupertsberger Codex des Liber Scivias (Wiesbaden, Hessische Landesbibl., Hs. 1, fol. 1'; , verschollen)

wobei das Phänomen nicht besonders häufig ist, und erfundene Alphabete, gerade im frühen und hohen Mittelalter, nicht oft begegnen. ${ }^{41}$ Die Erfindung von Alphabeten schätzt man dabei als eine hervorragende Leistung großer Persönlichkeiten - und das bis weit hinein in die Neuzeit, wie das die Abbildung der

41 Vgl. Bischoff: Übersicht (Anm. 2), S. 131-135, wobei die wenigsten dieser Alphabete dezidiert Erfindern zugeschrieben werden; bis zum 12. Jahrhundert nennt er nur vier vorwiegend frei erfundene Alphabete. 
Alphabeterfinder im Salone Sistino der Vatikanischen Bibliothek vielleicht am eindrücklichsten vor Augen führt. Die Aura der Schrift und die Bedeutsamkeit ihrer Erfindung alleine schon sind ein Signum mittelalterlicher Schriftpraxis, das für das Verständnis mittelalterlicher ,Geheimschriften' nicht hoch genug einzuschätzen ist. Diesen Eigenschaften kommen in exklusiven Kommunikationssituationen wichtige Funktionen zu, als Geste von Herrschaft, als Medium unmittelbarer Gotteserfahrung, als Mittel der Legitimierung von Texten. Doch das nicht nur symbolisch, sondern auch als Grundlage einer ganz eigenen performativen Dialektik von Verbergen und Offenbaren: Die Macht der Schrift besteht darin, die Welt abbilden zu können und dieses Bild der Welt dauerhaft verfügbar zu machen. Die Erfindung einer Schrift greift hier auf der Ebene des Codes ein. Wer eine Schrift erfindet, stellt eine neue Möglichkeit der Weltbeschreibung und Weltaneignung zur Verfügung, die von den normalen Praktiken abweicht. Wer die erfundene Schrift benutzt, tritt im Prozess des Encodierens in die Spur jener Instanz, die die Schrift erfand. Das Verbergen in Form einer Geheimschrift führt zu einer Form des Offenbarens, die einen Pakt zwischen der schreibenden und der lesenden Instanz voraussetzt. Diesem Pakt ist eine Asymmetrie des Gebens und Nehmens eingeschrieben. Es ist jene Asymmetrie, die hinter den hier vorgestellten Kommunikationspraktiken in Mystik und Herrschaft steckt, die uns zwar geheimnisvoll erscheinen mögen, aber letztlich vor allem ein Spiegel einer uns fremd gewordenen Schriftpraxis sind. Im Kontext dieser Schriftpraxis erwiesen sich die Buchstaben selbst als die Botschaft, die ihre Wirkung nicht nur im Entschlüsseln ihres wortwörtlichen Verständnisses entfalteten. 


\title{
Geheime Allianzen und soziale Mobilität im Iwein Hartmanns von Aue
}

\author{
Johannes Traulsen
}

\section{Geheimnis und soziale Mobilität}

Im zweiten Film der 007-Reihe mit dem Titel From Russia with Love von 1963 führt James Bond mehrfach folgenden Dialog:

Bond: Pardon me, do you have a match?

Gegenüber: I use a lighter.

Bond: Better still.

Gegenüber: Until they go wrong.

Bond: Exactly.

Die vermeintlich harmlosen Worte bergen ein Geheimnis. Die exakten („,exactly“) Fragen und Antworten weisen die beiden Sprecher als Angehörige derselben Geheimorganisation aus, während Nichteingeweihte das Gespräch für einen ganz gewöhnlichen Dialog zwischen Fremden halten müssen. Damit erstreckt sich die Geheimhaltung auf zwei Ebenen, denn erstens verbirgt der Dialog die Identität der Geheimagenten und zweitens verbirgt er seinen eigenen Status als Geheimkommunikation, indem doppeldeutige Begriffe verwendet werden. So kann das Wort „match" sowohl ein Zündholz als auch eine Übereinstimmung bezeichnen. Bonds Frage, die den Dialog eröffnet, kann also sowohl „Haben Sie ein Zündholz?“ als auch "Gehören wir zusammen?" bedeuten. Erst die richtige Antwort auf diese Frage, die natürlich ebenfalls codiert ist, stellt ein Vertrauensverhältnis zwischen den Agenten her. Der geheime Code eröffnet Bond den Zugang zur Gruppe der örtlichen Geheimagenten, die mit dem MI6 zusammenarbeiten und auf deren Unterstützung er im Folgenden setzen kann. Freilich ist dieses Geheimnis nicht undurchschaubar. In From Russia with Love gibt sich später ein Gegenspieler Bonds als dessen Partner aus, indem er den exakten Wortlaut ebenfalls benutzt, erwirbt sich damit das Vertrauen des Agenten und vermag ihm dadurch Schaden zuzufügen.

Die Angehörigen einer bestimmten Gruppe sind durch die Kenntnis eines Geheimnisses miteinander verbunden, Nichteingeweihte bleiben ausgeschlossen. Dieser Zusammenhang von Geheimnis und Gruppe existiert nicht nur im Genre des Agentenfilms, sondern prägt auf vielfältige Weise soziale Ordnungen und Prozesse. Schon im Kinderspiel wird die soziale Logik von Inklusion und Exklusion durch Geheimhaltung in Minimalkonstellationen greifbar, wenn das 
Geheimnis eine Gruppe zweier Wissender gegenüber einem Dritten konstituiert. Dabei kommt es nicht unbedingt auf das Geheime selbst an, sondern nur auf den performativen Akt der Gruppenbildung: ,Wir haben ein Geheimnis miteinander und gehören zusammen, Du kennst es nicht und bist deshalb ausgeschlossen.'

Im sozialen Zusammenhang kann durch Geheimnisse also Differenz hergestellt werden. Das Geheimnis scheidet die Wissenden von den Unwissenden, es inkludiert diejenigen, die es kennen, und exkludiert diejenigen, denen es verschlossen ist. Entsprechend führt Alois Hahn aus: „Ein Geheimnis charakterisiert die Personen, die es teilen, als eine Gruppe. Die Außengrenze zur Gruppe fällt dann mit der Differenz zwischen Geheimnisträgern und Nichteingeweihten zusammen. "1 Jan und Aleida Assmann hingegen erkennen nicht nur im Teilen eines Geheimnisses eine soziale Operation, sondern auch in der Verständigung einer Gruppe über etwas gemeinsam nicht Gewusstes, über ein Geheimnis jenseits ihrer selbst:

Der kulturstiftende und Gesellschaft ermöglichende Akt schlechthin ist die Ausbildung einer Wissensform, die im Hinausdenken über ihre Grenzen zugleich Formen einer Respektierung des Unwißbaren oder Vorenthaltenen ausbildet und auf diese Weise in der Dimension des Wissens einen gemeinschaftlich bewohnbaren sozialen Raum konstituiert. ${ }^{2}$

Damit ist das Geheimnis nicht nur als eine Möglichkeit der Gruppenbildung benannt, sondern als deren konstitutives Moment. Der ,gemeinschaftlich bewohnte Raum' vermag erst durch das Geheimnis zu entstehen, das die Grenzen desselben markiert, wobei das Geheime sowohl diesseits als auch jenseits dieser Grenzen liegen kann.

Die Thesen von Assmann/Assmann und Hahn implizieren, dass soziale Mobilität, das heißt die Möglichkeit der Bewegung zwischen sozialen Gruppen, durch Geheimnisse limitiert wird. Doch kann ein Geheimnis soziale Mobilität auch ermöglichen, weil sich einzelne Subjekte oder Gruppen einer festgefügten öffentlichen Ordnung durch Geheimhaltung zu entziehen vermögen. Geheimnisse können in dieser Hinsicht Freiräume schaffen. Insofern ist geheimes Handeln beziehungsweise das Agieren unter Ausschluss zwar ein „Komplement " zur Öffentlichkeit, aber Geheimnisse und Geheimhaltung können relevante Instrumente der Entwicklung und auch der Behebung von Problemen beziehungsweise Systemfehlern sein, die sich aus der jeweiligen öffentlichen ${ }^{4}$ Ordnung ergeben. Sie

1 Alois Hahn: Soziologische Aspekte von Geheimnissen und ihren Äquivalenten. In: Schleier und Schwelle. Bd. 1: Geheimnis und Öffentlichkeit. Hg. von Aleida und Jan Assmann in Verbindung mit dems. und Hans-Jürgen Lüsebrink. München 1997, S. 23-39, hier S. 27.

2 Aleida und Jan Assmann: Das Geheimnis und die Archäologie der literarischen Kommunikation. Einführende Bemerkungen. In: Schleier und Schwelle (Anm. 1), Bd. 1, S. 7-16, hier S. 7.

3 Jan-Dirk Müller: Höfische Kompromisse. Acht Kapitel zur höfischen Epik. Tübingen 2007, S. 272.

4 Diese Gegenüberstellung von öffentlicher Ordnung und Geheimnis kongruiert nicht mit dem Gegensatz von Öffentlichem und Privatem. Vgl. dazu Peter von Moos: Das Öffentliche 
können daher eine relevante Ergänzung und ein Gegenstück zu dieser darstellen, und zwar besonders dort, wo restriktive öffentliche Ordnungen herrschen, wie in der höfischen Kultur, der die volkssprachige Literatur des Mittelalters angehört. Das Geheimnis ${ }^{5}$ eröffnet Möglichkeiten, soziale Beschränkungen zu umgehen, und so können etwa im Geheimen Hierarchien oder Tabus ignoriert, Allianzen über soziale oder kulturelle Grenzen hinweg geschlossen oder alternative Lebensmodelle verfolgt werden. Die mittelalterliche Literatur inszeniert nicht selten solche geheimen Übertretungen, durch die es Figuren möglich wird, sich zwischen religiösen und weltlichen, christlichen und nichtchristlichen oder mehreren familiären Gruppierungen zu bewegen. ${ }^{6}$

In geradezu exemplarischer Weise stellt der Iwein ${ }^{7}$ Hartmanns von Aue Konstellationen dar, in denen Geheimnisse zur sozialen Mobilität beitragen. Der Text erzählt gleich mehrfach, wie Geheimnisse Handlungsspielräume eröffnen und Figuren, insbesondere dem Protagonisten des Romans, Zugang zu neuen sozialen Zusammenhängen ermöglichen. Im Folgenden werde ich drei entsprechende Konstellationen in den Blick nehmen, nämlich den heimlichen Aufbruch Iweins vom Artushof, die Gefangenschaft im Torraum, während derer Iwein sich im Geheimen mit Lunete verbindet und das Minneverhältnis mit Laudine seinen Anfang nimmt, und Iweins Geheimidentität als Löwenritter. In allen drei Fällen erweist sich das Geheimnis nicht nur als sozialer Mechanismus der In- und Exklusion, sondern eröffnet zugleich Möglichkeiten der Bewegung zwischen unterschiedlichen sozialen Gruppen.

und Private im Mittelalter. Für einen kontrollierten Anachronismus. In: Das Öffentliche und Private in der Vormoderne. Hg. von Gerd Melville und dems. Köln, Weimar, Wien 1998, S.3-83, hier S. 27-29, sowie dessen Definition ebd., S. 29 (Hervorhebung i. Orig.): „Das Öffentliche ist demnach das allgemein und unbegrenzt Erfahrbare, Zugängliche, Verbindliche oder Nützliche; das Private ist das nur begrenzt oder eingeschränkt Erfahrbare, Zugängliche, Verbindliche oder Nützliche."

5 Ich verstehe den Begriff des Geheimnisses im literarischen Text als spezifische Konstellation von Wissen und Erkennen, die sowohl auf der Handlungs- als auch auf der Erzählebene angesiedelt sein kann. Anders als das Rätsel generiert das Geheimnis aber keine eigene literarische Kleinform. Vgl. Heike Bismark und Thomas Tomasek: [Art.] Rätsel. In: Reallexikon der deutschen Literaturwissenschaft. 3. Aufl. Bd.3. Hg. von Jan-Dirk Müller. Berlin, New York 2007, S. 212-214; sowie im Hinblick auf die mittelalterliche Literatur Günter Bernt u. a.: [Art.] Rätsel. In: Lexikon des Mittelalters Online. Bd. 7. (26.07.2019), Sp. 463-468.

6 Vgl. in Abgrenzung dazu auch die Ausführungen zur List bei Claudia Lauer: Die Kunst der Intrige. Spielarten strategischer Täuschung in den Artusromanen Hartmanns von Aue. In: Aktuelle Tendenzen der Artusforschung. Hg. von Brigitte Burrichter u. a. Berlin, Boston 2013, S. 17-38, hier bes. S. 17-22. Lauer fokussiert im Anschluss an Peter von Matt insbesondere die poetische Dimension der Intrige, die sie als ,spezifisches Erzählmuster in ihren jeweils changierenden Mustern, Variationen und Transformationen in Augenschein" (ebd., S. 22) nimmt.

7 Hartmann von Aue: Iwein. 4., überarbeitete Aufl. Text der siebenten Ausgabe von Georg Friedrich Benecke, Karl Lachmann und Ludwig Wolff. Übersetzung und Nachwort von Thomas Cramer. Berlin, New York 2001. 


\section{Geheimnisse im Iwein}

Bereits die Haupthandlung des Iwein Hartmanns von Aue beginnt mit einem Akt der Geheimhaltung, durch den die herrschende öffentliche Ordnung unterlaufen wird. Auf die Erzählung seines Verwandten Kalogrenant hin bricht Iwein heimlich vom Artushof auf, um die Brunnenaventiure, von der Kalogrenant erzählt hat, zu bestehen, ehe andere berufenere Ritter ihm dies streitig machen können (vgl. V.911-932). ${ }^{8}$ Er bedient sich dabei der Hilfe eines Knappen, den er im Geheimen („vil stille“, V.952) mit den Vorbereitungen betraut ${ }^{9}$ und mit dem er sich in „Vriuntschaft“ (V. 962) ${ }^{10}$ für das Unterfangen verbindet. Durch die Geheimhaltung kann Iwein vor Artus und seinem Gefolge an den Ort der Aventiure gelangen und den anstehenden Kampf für sich entscheiden.

Iweins heimlicher Aufbruch vom Artushof offenbart ein Problem der dort herrschenden öffentlichen Ordnung. Junge Ritter können sich nicht bewähren, solange erfahrene Kämpfer wie Gawein in der Nähe sind, da diese schon aufgrund ihres Rufes jeden Kampf für sich beanspruchen müssen. Die Geheimhaltung erweist sich nun als probates Mittel, dieses Problem zu umgehen. Für Iwein eröffnet das Geheimnis die Möglichkeit, von den in der Öffentlichkeit geltenden Regeln vom Vorrang Gaweins - abzuweichen, um sich Handlungsräume zu erschließen. Die Geheimhaltung des Handelns gegen die Ordnung wird dabei in dieser ersten Geheimnisepisode des Iwein durch zwei Aspekte bestimmt. Einerseits durch die exklusive Verbindung mit dem hilfreichen Knappen, der Iwein bei seinem Unterfangen unterstützt. Andererseits durch die Gedankenrede, mit der sich Iwein seines Planes versichert: ${ }^{11}$ Er erörtert im Stillen die Möglichkeiten und Gefahren der Situation und trifft den Entschluss, allein aufzubrechen, womit die Öffentlichkeit ausgeschlossen und das Geheimnis begründet wird. Iweins Motive und Pläne bleiben für seine Umgebung im Dunkeln, bis er aus der Aventiure als Sieger hervorgegangen ist und dem Artushof nun selbst als Hüter des Brunnens wieder gegenübertritt. Wie sich dann zeigt, wird Iweins Verstoß gegen die Ordnung, den er mit dem heimlichen Aufbruch begangen hat, nicht geahndet. Im Gegenteil freut sich gerade Gawein ganz außerordentlich über Iweins Erfolg (vgl. V. 2618f.) und beklagt keineswegs, übergangen worden zu sein. Damit hat sich Iweins geheimes Handeln als eine Ermächtigungsstrategie erwiesen, durch welche die Ordnung des Artushofs, die so restriktiv ist, dass nur wenige Ritter überhaupt als Akteure

8 Im Gegensatz zu Lauer begreife ich diese Handlungsweise nicht als per se problematisch. Vgl. Lauer: Die Kunst der Intrige (Anm. 6), S. 27f.

9 Diese Konstellation eines geheimen Verbundes von zwei Figuren mit ungleichem sozialem Status wird sich später in der Verbindung von Iwein und Lunete wiederholen.

10 Vgl. Jutta Eming: unsippiu geselleschaft. Paradigmen von Freundschaft und Konkurrenz in Hartmanns Iwein. In: Freundschaftszeichen. Gesten, Gaben und Symbole von Freundschaft im Mittelalter. Hg. von Marina Münkler, Antje Sablotny und Matthias Standke. Heidelberg 2015, S. 103-123, hier S. 111f.

11 Vgl. dazu Brigitte Burrichter: Perspektive bei Chrétien de Troyes. In: Narratologie und mittelalterliches Erzählen. Autor, Erzähler, Perspektive, Zeit und Raum. Hg. von Eva von Contzen und Florian Kragl. Berlin, Boston 2018, S. 43-60, hier S. 58f. 
in Frage kommen, dynamisiert wird. Das Geheimnis ermöglicht Iwein die Bewährung in der Aventiure und den damit verbundenen Aufstieg zum Herrscher.

Auch innerhalb von Iweins Brunnenaventiure spielen Geheimnis und Geheimhaltung eine zentrale Rolle. Nachdem Iwein im Kampf gegen Ascalon, den Hüter des verzauberten Brunnens, gesiegt hat, verfolgt er ihn. Beim Einreiten in dessen Burg kann er sich nur knapp vor dem herabfallenden Tor retten, doch ein zweites Tor vor ihm ist bereits geschlossen und Iwein ist nun zwischen zwei Toren in einem Torraum gefangen. Er kann weder weiter in die Burg vordringen noch wieder hinaus, und die Lage ist für ihn ausweglos. Der Raum, in dem Iwein eingeschlossen ist, verfügt über undurchschaubare Schließsysteme und wird deshalb für Iwein zum Gefängnis. Für den Burgherrn stellt er die vorläufige Rettung dar, denn dieser kann mithilfe des Raums Iwein entkommen. Dabei ist das Wissen um die verborgene Mechanik von zentraler Bedeutung: Ascalon hat „die kunst und

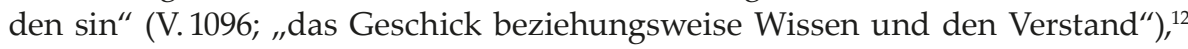
sodass er noch hindurchreiten kann, der ihn verfolgende Iwein aber gefangen wird. Ascalons Erfolg ist allerdings nur von kurzer Dauer, da er gleich darauf seinen Verletzungen erliegt. Der eingeschlossene Iwein findet sich nun in einem Raum wieder, der zwar so prachtvoll ausgestattet ist (vgl. V. 1135-1144), dass selbst König Artus nie Schöneres gesehen hat, doch weil ihm das Wissen um die verborgenen Funktionen fehlt, kann er keinen Ausgang erkennen: „[D]ô suochter wider unde vür / und envant venster noch tür“ (V.1145f.; „Nun suchte er allenthalben und fand weder Fenster noch Tür $\left.{ }^{\prime \prime 13}\right) \cdot{ }^{14}$ Iwein sitzt fest, und doch gibt es, wie sich zeigt, durchaus Türen. Durch eine solche nämlich schlüpft Laudines Kammerfrau Lunete zu Iwein hinein (vgl. V. 1150f.). ${ }^{15}$

Die Angehörigen des Laudinereichs, zu denen Ascalon und Lunete gehören, verfügen über die Kenntnis um die geheimen Ein- und Ausgänge des Torraums, die Iwein fehlen, was den Raum für ihn zum Gefängnis macht. Iwein bleibt darin stecken und gerät in eine prekäre Lage, aus der er sich nicht selbst befreien kann, da er alle Handlungsmöglichkeiten verloren hat. Dabei rückt Wissen beziehungsweise Nichtwissen in den Mittelpunkt: Der unwissende Iwein kann suchen, solange er will, er findet keinen Ausgang, während der Burgherr und Lunete um die Eigenarten des Raums wissen und ihn verlassen bzw. betreten können.

12 Im Gegensatz zur Kampffähigkeit, für die „,kunst unde kraft“ (V. 7003; „Geschicklichkeit und Stärke") zusammenkommen müssen.

13 Hier und im Folgenden entsprechen die direkten Übersetzungen der o. g. Ausgabe Hartmann von Aue: Iwein (Anm. 7).

14 Hier ergibt sich eine Differenz zwischen Hartmanns Iwein und dem Yvain Chrétiens de Troyes. Während Iwein die Mauern absucht und keinen Durchgang finden kann, kommt Lunete Yvain nicht durch eine verborgene, sondern durch eine verschlossene Tür zu Hilfe, die sie hinter sich wieder zuriegelt. Vgl. Chrestien de Troyes: Yvain. Übersetzt und eingeleitet von Ilse Nolting-Hauff. Hg. von Hans Robert Jauss und Erich Köhler. München 1962, V. 970-975.

15 Vgl. zur Besonderheit des Torraums und der entsprechenden Forschungsdiskussion Silvan Wagner: Erzählen im Raum. Die Erzeugung virtueller Räume im Erzählakt höfischer Epik. Berlin, Boston 2015, S. 1-24, hier bes. S. 18-21. 
Die physische Gefangenschaft und Immobilität Iweins wird durch eine geheime Allianz von Lunete und Iwein aufgehoben: Lunete schließt mit Iwein einen Bund, weil sie bei einem früheren Besuch am Artushof ausgegrenzt, aber von Iwein, der ihr seinen Gruß gewährte, in die Artusgesellschaft integriert wurde (vgl. V.1181-1196). Iwein erhält von Lunete einen magischen Ring, der, wird er in der nackten Hand gehalten, den Träger unsichtbar macht. Durch die Gabe ermöglicht Lunete es Iwein, ${ }^{16}$ wieder handlungsfähig zu werden: Indem er sich unsichtbar macht, entzieht er sich zunächst der Verfolgung und wird seinerseits nun zum Geheimnis für die Gefolgsleute Laudines, der Witwe Ascalons. Sie können nur noch sein halbes Pferd, sicheres Zeichen seiner Anwesenheit, nicht aber ihn selbst finden. Entsprechend nehmen die Suchenden von vornherein nicht nur die Möglichkeit an, dass Iwein geflohen ist, sondern auch, dass er ihre Sinne beeinträchtigt haben könnte: „,[W]arst der man komen, / ode wer hât uns benomen / diu ougen und die sinne?“ (V. 1273-1275; „Wo ist der Mann geblieben, oder wer hat uns der Augen und des Verstandes beraubt?"). Nichts anderes als Magie („zouberliste“, V. 1284) kann ihrer Auffassung nach dafür verantwortlich sein, dass sich Iwein ihnen entzogen hat. Noch nachdrücklicher wird diese Vermutung formuliert, wenn die Wunden des toten Burgherrn zu bluten beginnen, als er an dem unsichtbaren Iwein vorbeigetragen wird (Bahrprobe) und sich dadurch dessen Anwesenheit enthüllt, ohne dass er zu fassen wäre. Diesmal ist es Laudine, die laut ausruft: „[Er] hât uns der sinne / mit zouber âne getân“ (V.1368f.; „,[Er] hat uns die Sinne mit Zauber verblendet") und ihn im Folgenden bezichtigt, ein unsichtbares Gespenst („,unsihtic geist“, V. 1391) und ein Magier („,zouberære“, V. 1394) zu sein. Man weiß um Iweins Anwesenheit, kann ihn aber nicht sehen oder ihn, der eine Bedrohung darstellt, entfernen, weil er sich aktiv entzieht. Iwein ist also auch in den Augen seiner Verfolger und Laudines durch das Geheimnis wieder zum Handelnden geworden. Wie schon nach Kalogrenants Erzählung hat sich Iwein einer Situation, in der er keine Möglichkeit der Bewegung vor der Öffentlichkeit hat, durch Geheimhaltung entzogen und dadurch Spielräume gewonnen. Diese nutzt er jedoch nicht nur für die Flucht vor den Verfolgern. Nachdem sich Iwein und Lunete verbündet haben und er von ihr den Ring erhalten hat, ändert sich sein Status. Er wird vom Gefangenen zum Verborgenen, die verschlossene Kammer wird vom Gefängnis zum Versteck und Schutzraum, der Iwein nicht nur einschränkt, sondern ihm auch Möglichkeiten und neue Perspektiven eröffnet. Mit Lunetes Hilfe verschafft sich Iwein einen Ausblick aus einem Fenster - das nun plötzlich doch vorhanden ist (vgl. V. 1450f.) -, von dem aus er das Begräbnis des getöteten Burgherrn beobachten kann. Dort sieht er auch Laudine, die große Qualen wegen ihres Kummers leidet (vgl. V. 1453), und verliebt sich in sie. ${ }^{17}$ Der Blick, der unbemerkt, im Geheimen, von einer Figur auf die andere geworfen wird, hat gerade in der

16 Vgl. zu Lunete die Zusammenfassung bei Lauer: Die Kunst der Intrige (Anm. 6), S. 32f.

17 Zur eingehenden Analyse der Szene im Hinblick auf den Zusammenhang von compassio und Minne vgl. Andreas Kraß: Die Mitleidfähigkeit des Helden. Zum Motiv der compassio im höfischen Roman des 12. Jahrhunderts (Eneit - Erec - Iwein). In: Aspekte des 12. Jahrhunderts. 
visuell ${ }^{18}$ orientierten Gesellschaft des Hofes einen konstruktiven Charakter, denn er stellt, wie Judith Klinger hervorhebt, ${ }^{19}$ durch seine Unidirektionalität hierarchische Beziehungen her. Iwein wechselt durch den geheimen Blick auf Laudine aus der Position des immobilen Gefangenen endgültig in die Position des Handelnden. Dabei geht es hier nicht darum, geheime Blicke als vormoderne Form der Inszenierung von Subjektivität zu begreifen, wie Christiane Witthöft das getan hat, ${ }^{20}$ sondern um die Bewegung im sozialen Gefüge, die durch Iweins heimlichen Blick in Gang kommt und zunächst eine Asymmetrie erzeugt: Iwein wird von der Minne zu Laudine überwältigt, sie möchte ihn tot sehen.

Es ist in der Forschung verschiedentlich vermerkt worden, dass die Laudinefigur und der Konflikt zwischen Iwein und Laudine mit einer Verhandlung feudalrechtlicher Fragen kaum hinreichend begründet ist. ${ }^{21}$ Hinzu kommt, dass sich gerade die Torraumszene in ihrer Komplexität kaum in die Aventiurestruktur des Artusromans ${ }^{22}$ fügen will. Haiko Wandhoff deutet Iweins Eintritt in die Laudineburg als "Allegorie der topischen inventio “23, indem er Sehen und Erzählen zusammenbindet und den in Gefangenschaft auf dem Bett sitzenden Iwein als mise en abyme begreift:

Im Iwein sitzt [...] nicht nur unser liebender Held auf diesem Bett, sondern auch der ,unsichtbare Geist' des Dichters, der vom Gedanken an die Liebe inspiriert, über die ungeahnten Möglichkeiten nachsinnt, Minne und Ritterschaft in seinem neuen âventiure-Roman zur Freude des Hofes trefflich zu verbinden. ${ }^{24}$

Doch mir scheint es hier weniger um die literarischen Entwürfe von Minne und Ritterschaft, denn um Möglichkeiten geheimen Handelns bei der Initiierung und Gestaltung sozialer Beziehungen zu gehen. In der Torraumszene erweist das Ge-

Freisinger Kolloquium 1998. Hg. von Wolfgang Haubrichs, Eckart C. Lutz und Gisela Vollmann-Profe. Berlin 2000, S. 282-304, hier S. 299-301.

18 Vgl. allgemein Horst Wenzel: Spiegelungen. Zur Kultur der Visualität im Mittelalter. Berlin 2009.

19 Vgl. Judith Klinger: Die Macht der Blicke. Augenlust und Geschlechter-Repräsentation bei Hartmann von Aue. In: Im Zeichen des Geschlechts. Repräsentationen, Konstruktionen, Interventionen. Hg. von Celine Camus u. a. Frankfurt a. M. 2008, S. 28-45, hier S. $29 f$.

20 Vgl. Christiane Witthöft: Schlüssel(loch)szenen. Von der Theatralität räumlicher Perspektiven in der Literatur des Mittelalters und der Frühen Neuzeit (Der arme Heinrich, Tristan, Melusine). In: Imaginative Theatralität. Szenische Verfahren und kulturelle Potenziale in mittelalterlicher Dichtung, Kunst und Historiographie. Hg. von Manfred Kern. Heidelberg 2013, S. 275-295, hier S. 280.

21 Vgl. Wolfgang Achnitz: Deutschsprachige Artusdichtung des Mittelalters. Eine Einführung. Berlin, Boston 2012, S. 74f.

22 Vgl. Achnitz: Deutschsprachige Artusdichtung des Mittelalters (Anm. 21), S. 81-86.

23 Haiko Wandhoff: Imaginäre Kopfreisen in die Wunderwelt der âventiure, oder: Wenn das Sehen zur Allegorie des Lesens wird. Neue Überlegungen zu Hartmanns Erec und Iwein. In: Sehen und Sichtbarkeit in der Literatur des deutschen Mittelalters. 21. Anglo-German Colloquium London 2009. Hg. von Ricarda Bauschke, Sebastian Coxon und Martin H. Jones. Berlin 2011, S. 141-159, hier S. 154.

24 Wandhoff: Imaginäre Kopfreisen (Anm. 23), S. 157. 
heimnis sein konstruktives Potential. Der eigentlich vollständig immobile Iwein im Gefängnis kann sich durch die geheime Verbindung mit Lunete nicht nur der Verfolgung entziehen, sondern sich außerdem mit dem geheimen Blick die Grundlage für den späteren Ehe- und Minnebund mit Laudine verschaffen. Das Problem zunächst fehlender Reziprozität ${ }^{25}$ im Verhältnis von Iwein und Laudine kann schließlich durch die Verbindung des Geheimnisses um Iwein mit dem äußerst geschickten rhetorischen Agieren von Lunete gelöst werden, die auch der Burgherrin gegenüber eine besondere Rolle einnimmt, weil sie mit dieser ihre Geheimnisse teilt („,swaz si tougens weste“, V. 1791). ${ }^{26}$ Mit der Überredung Laudines wird dem Geheimnis auch noch eine rhetorische Komponente hinzugefügt und Lunete kann als ,Geheimagentin' beider Beteiligter zwischen den Welten wandeln und den neuen sozialen Verbund zwischen Iwein und Laudine stiften. Mit dem Erzählen von Geheimnissen wird hier also mehr als nur Abwechslung und Spannung erreicht. ${ }^{27}$ Der Text entfaltet die sozialen Funktionen des Geheimnisses als Instrument des Wandels und der sozialen Mobilität. Geheimnisse erscheinen dabei zwar als potentiell bedrohlich für die bestehenden Sozietäten, wirken aber gleichzeitig als Katalysator für neue Gruppenbildungen und Konstellationen. So ermöglicht erst die geheime Handlung abseits der öffentlichen Sphäre die neue Verbindung zwischen Iwein und Laudine.

Iweins Aufenthalt in der Laudinegesellschaft ist bekanntermaßen nur von kurzer Dauer, weil er sich durch wiederholte Verspätungen den Zorn seiner Ehefrau zuzieht und daraufhin in die Wildnis flieht. Die Botschaft Laudines, in welcher Iwein die „triuwe“ (V.3180) abgesprochen und das Eheverhältnis aufgekündigt (vgl. V.3190f.) wird, überbringt Lunete, die in diesem Zusammenhang auch ihre eigene Verbindung mit Iwein beendet: „[D]az ich ez ie undervienc, / daz iuwer ende niht ergienc, / des wil ich iemer riuwec sîn: / wan diu schult ist älliu mîn" (V.3147-3150; „Daß ich je abwendete, daß Ihr Euer Ende fandet, das soll mir immer leid tun, denn ich allein bin schuld daran" $).{ }^{28}$ Die Aufkündigung der beiden Beziehungen raubt Iwein die „vreude und den sin“ (V.3215; „Frohsinn und Verstand“) und jegliche Möglichkeit innerhalb der Gesellschaft zu agieren. Er will fliehen, so "daz man noch wîp enweste wâ / und niemer gehôrte mære / war er komen wære" (V.3218-3220; „daß kein Mensch wüßte, wo, und auch niemals hörte, wohin er geraten sei“). Das folgende Waldleben kennzeichnet eine räumliche Distanz zur Artus- und zur Laudinegesellschaft (vgl. V.3216-3220), doch Iwein bleibt für alle anderen Figuren als Vermisster präsent (vgl. V.3372-3374), weshalb er schließlich

25 Vgl. Harald Haferland: Höfische Interaktion. Interpretationen zur höfischen Epik und Didaktik um 1200. München 1989, S. 179-191.

26 Vgl. zur sozialen Symmetrie, die in der Kommunikation zwischen Laudine und Lunete hergestellt wird, Caroline Emmelius: Gesellige Ordnung. Literarische Konzeptionen von geselliger Kommunikation in Mittelalter und Früher Neuzeit. Berlin, New York 2010, S. 31.

27 Wie Burrichter: Perspektive bei Chrétien de Troyes (Anm. 11), S. 60 annimmt.

28 Eine entsprechende Bezugnahme Lunetes auf ihr eigenes Verhältnis zu Yvain fehlt bei Chrétien. Vgl. Chrestien de Troyes: Yvain (Anm. 14), V. 2722-2773. 
wiedererkannt werden kann. Die fehlende Erinnerung Iweins an seine höfische Vergangenheit versetzt ihn allerdings seinerseits in einen Zustand der sozialen Depravation und Stillstellung, aus dem er sich nicht befreien kann und der andauert, bis er mithilfe der magischen Salbe der Dame von Narison (vgl. V.3475ff.) wieder geheilt werden kann.

Im Gegensatz zum passiven Dasein während des Waldlebens hält Iwein bei seinen folgenden Taten als Löwenritter seine Herkunft zwar geheim, begibt sich aber in seiner Geheimidentität in die Öffentlichkeit und handelt dort als Ritter. Damit trägt das Geheimnis hier zunächst nicht, wie im Fall von Iwein und Lunete, zur Konstitution eines neuen Verbundes bei, sondern hält im Gegenteil die Differenz zwischen dem Protagonisten und den Gesellschaften, denen er angehört hat, aufrecht. Die Geheimhaltung seiner eigentlichen Identität eröffnet Iwein aber Handlungsspielräume, denn in der Maske des Löwenritters hat er Zugang zu der höfischen Öffentlichkeit, aus der er eigentlich verstoßen ist, und kann sich bewähren. Inzwischen ist nicht mehr nur er selbst, sondern auch Lunete exkludiert, da man sie wegen ihrer Verbindung mit Iwein anklagt. Mit ihr geht er erneut ein geheimes Bündnis ein. Wieder kennt Lunete als einzige Akteurin am Laudine- und am Artushof seine wahre Identität: „Noch erkand in dâ wîp noch man [...] niuwan eine vrou Lûnete.“ (V.5451-5453; „Es erkannte ihn derzeit dort kein Mensch [...], [n]ur allein Frau Lunete kannte ihn“). Wie beim heimlichen Aufbruch zur Brunnenaventiure eröffnet die Geheimhaltung seiner Identität nach seiner Genesung Iwein einen Handlungsspielraum, der ihm die Bewährung und schließlich die gewünschte Restitution des Minneverbundes mit Laudine im Einklang mit dem Artushof ermöglicht.

Iwein ist bei seinen Unternehmungen als Löwenritter nicht allein, wird er doch von seinem namengebenden animalischen Begleiter unterstützt. Es ist dabei der Löwe, der den Verbund zwischen den beiden herstellt. Er macht seine Zuneigung zu Iwein deutlich (vgl. V.3873) und schließt sich ihm an (,,antwurt sich in sîne pflege“, V. 3877), sodass Mensch und Tier nun eine Gemeinschaft bilden. Der Löwe fungiert dabei als Begleiter und als ,leeres` Wappen, das Teil einer Geheimidentität wird: Er stellt zwar einerseits als Wappentier und Symbol mit kultureller Bedeutung Iweins Zeichen dar, verweist aber nicht auf dessen Zugehörigkeit zu einer bestimmten Gruppe, sondern markiert vielmehr eine Differenz, weil der Löwe als wildes Tier den kultivierten Gesellschaften der Menschen gegenübersteht.

Die Enthüllungen des Geheimnisses um den Protagonisten vor den beiden Gesellschaften, dem Artus- und dem Laudinehof, werden voneinander getrennt erzählt, sind aber miteinander verschränkt. ${ }^{29}$ Iwein tritt zunächst als Löwenritter für die Belange der jüngeren Schwarzdorn-Tochter gegen Gawein an und gibt sich nach diesem Kampf zu erkennen, dann zieht er wieder ins Laudinereich, wo

29 Vgl. zur Handlungsverschränkung im zweiten Teil des Iwein Hartmut Kugler: Fenster zum Hof. Die Binnenerzählung der Entführung der Königin in Hartmanns Iwein. In: Erzählungen in Erzählungen. Phänomene der Narration in Mittelalter und Früher Neuzeit. Hg. von Harald Haferland und Michael Mecklenburg. München 1996, S. 115-124, hier bes. S. 118-120. 
Lunete mit einer neuen List die Wiedervereinigung mit Laudine möglich macht. Bemerkenswerterweise geht der Entdeckung der Identität $t^{30}$ Iweins am Artushof eine weitere geheime Handlung voraus, denn auch Gawein maskiert sich vor dem Kampf:

[H]er Gâwein, der sich helen bat, Herr Gawein, der gebeten hatte, ihn nicht zu entdecken, der hete sich selben sô verholn hatte sich selbst verborgen und hete sich vor enwec gestoln, und hôrten in des alle jehen, und hatte sich vorher fortgestohlen, und alle hatten ihn sagen hören, ern möhte den kampf niht gesehen er könne dem Kampfe nicht beiwohnen von ander unmüezekheit. wegen anderer Beschäftigungen.

(V. 6884-6889)

Handlungslogisch hat die Verheimlichung der Identität hier die Funktion, einen Kampf zwischen Gawein und Iwein möglich zu machen, der sich aufgrund der Freundschaft beider ansonsten verbieten würde (vgl. V. 7486-7490). ${ }^{31}$ Zugleich bietet die Geheimhaltung Gawein Gelegenheit zu einem Kampf, der nicht unter den Vorzeichen seines Rufs steht und nicht von vornherein als entschieden gilt. Auch ihm eröffnet das Geheimnis so einen größeren Handlungsspielraum. Durch die Geheimhaltung kommt es zu einem Kampf zwischen den Freunden Iwein und Gawein, der nach der öffentlichen Ordnung eigentlich unmöglich ist und der unentschieden ausgehen muss. Gerade die fehlende Entscheidungsfunktion des Kampfes aber erweist sich als Lösungsmöglichkeit in einer schwierigen gesellschaftlichen Situation. ${ }^{32}$ Der Konflikt der Schwarzdorn-Töchter, welcher den Zweikampf zwischen Iwein und Gawein begründet, stellt am Artushof eine problematische Konstellation dar, weil die ältere Tochter, die im Unrecht ist (vgl. V.5635-5637), sich durch ihr früheres Erscheinen am Artushof mit Gawein den vermeintlich besten Ritter gesichert hat (vgl. V.5666-5674). Nachdem der Kampf keinen Sieger hervorgebracht hat, die beiden Kämpfer ihre jeweilige Identität entdeckt (vgl. V. 7470ff.) und gegenüber Artus ihre Freundschaft beteuert haben (vgl. V.7609), kann dieser den Mechanismus des Gottesurteils durch Zweikampf aussetzen und ein salomonisches Urteil (vgl. V. 7655-7702) fällen, das den Frieden und die Einheit in seinem Herrschaftsbereich wiederherstellt. Wiederum erscheint das

$30 \mathrm{Zu}$ Identität als Aspekt der höfischen Literatur und Forschungsparadigma in der germanistischen Mediävistik vgl. Jan Mohr: Logisches Ich und epistemisches Ich. Noch einmal: Identitätsprobleme in Hartmanns Iwein. In: Alterität als Leitkonzept für historisches Interpretieren. Hg. von Anja Becker und dems. Berlin 2012, S. 141-169, hier bes. S. 141-145.

31 Vgl. zur besonderen Konstellation von Iwein und Gawein als Freunde und als Konkurrenten auch Eming: unsippiu geselleschaft (Anm. 10), die die Konfrontation der beiden als „Ernstfall“ des höfischen Romans bezeichnet (ebd., S. 108).

32 Anders argumentiert Lauer, welche die Gleichheit von Iwein und Gawein als Störung der Ordnung deutet. Vgl. Lauer: Die Kunst der Intrige (Anm. 6), S. $23 f$. 
Geheimnis als essentielles Instrument zur Regelung von Problemen, die in der Öffentlichkeit nicht zu lösen sind.

Als ebenso wirksam für die Wiederherstellung der Ordnung erweist sich das Geheimnis am Laudinehof. Als Iwein dort als Löwenritter auftritt, um Lunete zu unterstützen (vgl. V.5175ff.), macht er die Geheimhaltung seiner Identität gegenüber Lunete explizit zum Teil seiner Strategie: „[D]iz sol allez ergân / daz sî [Laudine] niht wizze wer ich sî" (V.4238f.; „Dies soll aber alles geschehen, ohne daß sie weiß, wer ich bin“). Nur durch die Wahrung des Geheimnisses bis zum letzten Moment, in dem Laudine ein Schutz- und Hilfeversprechen für den Ritter mit dem Löwen abgibt (vgl. V. 8071-8074) und dann zu ihrem gegebenen Wort stehen muss, wird der Minneverbund von Iwein und Laudine wiederhergestellt. So ist es letztlich wiederum die Geheimhaltung, die Iwein erneut den Zugang zu Laudine und die endgültige Aneignung der Herrschaft erlaubt.

\section{Geheimnis als Ermöglichung}

Wenn eine Erzählung nicht einfach nur berichtet, dass bestimmte Umstände ein Geheimnis sind, sondern das Geheimnis mit ihren eigenen Mitteln inszeniert, tut sie das häufig über die Erzählperspektive. ${ }^{33}$ So geschieht es auch in meinem 007-Beispiel: Wenn Bond das erste Mal einen vermeintlichen Kollegen mit „Do you have a match?" anspricht, wissen die Rezipienten nichts von dem Geheimcode und werden so in die Rolle der Außenstehenden versetzt, die denken, Bond ginge es tatsächlich nur um Feuer für seine Zigarette. Wenn der Dialog jedoch zum zweiten Mal geführt wird, haben die Zuschauer die Seite gewechselt und sind Teil der geheimen Verbindung geworden, denn nun kennen sie den Code. Diese Möglichkeit, die Rezipienten bei der narrativen Inszenierung von Geheimnissen einzubeziehen, nutzt auch der Iwein. Solange Iwein keinen Ausweg aus dem Torraum sieht, kennen auch der Erzähler und die Rezipienten keinen. Wie dem Helden fehlt ihnen das Wissen um die Mechanismen des Raums. ${ }^{34}$ Ebenso kennt die Erzäh-

33 Ich greife bei diesen Überlegungen auf das narratologische Konzept der Erzählperspektive von Wolf Schmid zurück. Schmid unterscheidet heuristisch fünf Aspekte der Perspektive im erzählten Text: 1) Perzeption, 2) Ideologie, 3) Raum, 4) Zeit, 5) Sprache. Perzeption bezeichnet die Instanz, d. h. die Figur oder den Erzähler, durch die das Geschehen wahrgenommen wird. Unter Ideologie versteht Schmid das Wissen, das zur spezifischen Erfassung eines Geschehens führt. Der Raum bezeichnet den räumlichen point of view der Erzählung. Zeit meint dasselbe im Hinblick auf die Chronologie, und mit Sprache erfasst Schmid Markierungen der Perspektive durch sprachliche Eigenheiten. Diese fünf Aspekte dienen innerhalb der Erzählung zur Modellierung einer narrationalen oder einer figuralen Perspektive. Die von Schmid vorgeschlagenen Aspekte haben den Vorteil, Phänomene der Erzählperspektive genauer beschreiben zu können, als dies mit dem Genette'schen Konzept der Fokalisierung möglich ist, auf die etwa Burrichter: Perspektive bei Chrétien de Troyes (Anm. 11) zurückgreift. Vgl. zur Kritik und Erweiterung von Gérard Genettes' Konzept der Fokalisierung auch Tilmann Köppe und Tom Kindt: Erzähltheorie. Eine Einführung. Stuttgart 2014, S. 208-236.

34 Gert Hübner fasst diese Inszenierungsform als „Informations-“ beziehungsweise „Innensichtfilter". Ders.: Erzählform im höfischen Roman. Studien zur Fokalisierung im Eneas, im Iwein und im Tristan. Tübingen, Basel 2003, S. 132. 
lung die Namen der beiden Frauenfiguren Lunete und Laudine nicht (vgl. V. 1301), solange Iwein sie nicht weiß. ${ }^{35}$ Dann gibt die Erzählung die Einschränkung auf und folgt den Burgbewohnern, die Iwein vor dem Burgtor suchen ${ }^{36}$ und mit dem toten Burgherrn zum Münster ziehen, was Iwein keinesfalls sehen kann. Wiederum mit Iwein blickt die Erzählung durch das Fenster auf die klagende Laudine. Die Konzentration der Erzählung auf einen Raum wird mit der sich nun entwickelnden Intrigenhandlung zwischen Lunete und Laudine endgültig aufgegeben. Sie beschränkt sich auf die Torraumpassage. Damit wird der Zusammenhang von Geheimnis, Handlungsfähigkeit und Wissen beziehungsweise Wahrnehmung als Mittel der Inklusion oder Exklusion nicht nur dargestellt, sondern auch narrativ vollzogen und für die Rezipienten als Prinzip offengelegt. Solange Iwein durch den geheimen Mechanismus des Torraums stillgestellt ist, bleibt die Erzählung an ihn gebunden. Sobald er durch das Bündnis mit Lunete wieder in eine aktive Position versetzt wird, löst sich auch die Erzählung von der Figur.

Besonderes Gewicht liegt in Hartmanns Iwein auf der Befähigung zum Han-

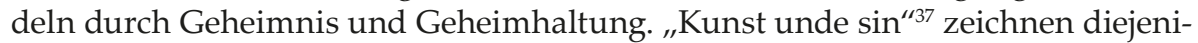
gen aus, die ein Geheimnis kennen und im Geheimen handeln können. Das ist nur schwer ins Neuhochdeutsche zu übersetzen. Gemeint sind Wissen und Wahrnehmungsvermögen, die gemeinsam Handlungsfähigkeit und Geschick hervorbringen. Durch das geschickte geheime Agieren können fest gefügte Regeln der Öffentlichkeit übergangen und Veränderungen ermöglicht werden. Das ist gerade dort besonders produktiv, wo sich aus der Ordnung selbst Probleme ergeben, etwa im Fall der verfolgten Lunete oder im Konflikt der Schwarzdorn-Töchter. Nicht zuletzt erzählt der gesamte Roman die Geschichte eines Helden, der am Ende nur durch Geheimhaltung seine Minnedame und seine Herrschaft gewinnen kann.

35 Vgl. Hübner: Erzählform im höfischen Roman (Anm. 34), S. 128.

36 Den Fokalisierungswechsel bemerkt auch Hübner, deutet ihn aber anders. Er versteht die auffällige Fokalisierung in der Brunnenraumepisode als narrativen Trick, um zunächst die arthurische Aventiurestruktur einhalten zu können, die später problematisiert wird. Vgl. Hübner: Erzählform im höfischen Roman (Anm. 34), S. 123, 185 und 189.

37 Diese Formel taucht auch im Gregorius als Beschreibung desjenigen auf, der ein Geheimnis kennt. Vgl. Hartmann von Aue: Gregorius. Hg. von Hermann Paul, neu bearbeitet von Burghart Wachinger. 14., durchgesehene Aufl. Tübingen 1992, V. 1420. 
Geheimnis und Offenbarung 



\title{
Geheimnisse in Übersetzung \\ Zu den Stigmata in deutschen Franziskus-Viten
}

\author{
Beatrice Trînca
}

Die Popularität des Armutsvirtuosen und Passionsmystikers Franziskus von Assisi lässt sich auch daran ablesen, dass im 13. Jahrhundert zwei voneinander unabhängige deutsche Viten entstanden: Lamprechts von Regensburg um 1237/1239 verfasstes Sanct Francisken Leben ${ }^{1}$ und das Franziskus-Kapitel aus dem anonymen Passional, das auf das letzte Viertel des 13. Jahrhunderts datiert wird. ${ }^{2}$ Die Faszination für den neuen Heiligen, sanctus novus, geht nicht zuletzt auf sein Aufsehen erregendes Geheimnis zurück: eine Vision, die sich in den Körper einprägte, der Gipfelpunkt seiner imitatio Christi. Bekanntlich wurden ihm dabei die fünf Passionswunden verliehen, welche die lateinischen Viten im Anschluss an eine paulinische Formulierung $(\mathrm{Gal} 6,17)^{3}$ als ",stigmata“ bezeichnen. ${ }^{4}$ Sie wurden nach seinem Tod, nunmehr für alle zugänglich, zur singulären Erscheinung proklamiert ${ }^{5}$ und avancierten zum Attribut des Heiligen.

1 Lamprecht von Regensburg: Sanct Francisken Leben und Tochter Syon. Hg. von Karl Weinhold. Paderborn 1880. Zur Datierung vgl. Joachim Heinzle: [Art.] Lamprecht von Regensburg. In: Die deutsche Literatur des Mittelalters. Verfasserlexikon. 2. Aufl. Bd. 5. Hg. von Kurt Ruh u. a. Berlin, New York 1985, Sp. 520-524, hier Sp. 521.

2 Vgl. Passional. Buch I: Marienleben. Hg. von Annegret Haase, Martin Schubert und Jürgen Wolf. Berlin 2013, S. XXX. Die Franziskus-Vita wird zitiert nach: Das Passional. Eine LegendenSammlung des 13. Jahrhunderts. Hg. von Fr[iedrich] Karl Köpke. Quedlinburg, Leipzig 1852. Zur Ausgabe vgl. Andreas Hammer: Inszenierung und Vergegenwärtigung im ersten Buch des Passional. In: Imaginative Theatralität. Szenische Verfahren und kulturelle Potenziale in mittelalterlicher Dichtung, Kunst und Historiographie. Hg. von Manfred Kern. Heidelberg 2013, S. 345-366, hier S. 349.

3 Die Bibel wird zitiert nach der Ausgabe: Biblia Sacra Vulgata. Editio quinta. Hg. von Robert Weber und Roger Gryson. Stuttgart 2007, URL: http://www.bibelwissenschaft.de/online-bibeln/ biblia-sacra-vulgata/lesen-im-bibeltext/ (15.05.2019).

4 Vgl. Christian Kiening und Ulrich Johannes Beil: Urszenen des Medialen. Von Moses zu Caligari. Göttingen 2012, S.161. „Provozierend wirkt auf die Kritiker die übergroße ChristusNähe, laut wird auch der Vorwurf der Simulation und Idolatrie. Papstbullen müssen die Echtheit der Wundmale verteidigen.“ Urban Küsters: Spuren der Heiligkeit. Formen der Körperwahrnehmung in mittelhochdeutschen Franziskus-Legenden. In: Akten des X. Internationalen Germanistenkongresses Wien 2000. Hg. von Peter Wiesinger. Bd.5: Mediävistik und Kulturwissenschaften - Mediävistik und Neue Philologie. Bern u. a. 2002, S. 57-61, hier S. 60. Vgl. auch (zu Thomas von Celano) Niklaus Largier: Die Kunst des Begehrens. Dekadenz, Sinnlichkeit und Askese. München 2007, S. 111f.

5 Vgl. Richard C. Trexler: The Stigmatized Body of Francis of Assisi. Conceived, Processed, Disappeared. In: Frömmigkeit im Mittelalter. Politisch-soziale Kontexte, visuelle Praxis, kör- 
Lateinische Hagiographen, allen voran Bonaventura, dessen Legenda maior von 1262/1263 als kanonische Vita intendiert war, und der allererste Biograph, Thomas von Celano, ${ }^{6}$ der Bonaventura einen Großteil des Materials lieferte, sprechen von einem zweifachen Geheimnis: „,secretum “ und „sacramentum". Im Folgenden soll in einem ersten Schritt das Bedeutungsspektrum der zwei lateinischen Termini rekonstruiert werden, um im Anschluss präzise verfolgen zu können, wie sie ins Deutsche übertragen wurden bzw. welche Begriffsverwendungen sich der Übersetzung verweigerten. Zeichnet sich hier eine Einschränkung im Deutschen ab, so gilt es andererseits, Aspekte der narrativen Auseinandersetzung mit dem Geheimnis in den Blick zu nehmen, die nicht in den lateinischen Prätexten vorgegeben sind und die (nicht unbedingt als Kompensation für den Verzicht auf theologische Fachtermini) von einer für deutsche Vers-Adaptationen spezifischen Eigenständigkeit zeugen.

Die Seraph-Vision und die Wundmale repräsentieren bei Thomas von Celano das „secretum“ (Vita prima 96) des bescheidenen Franziskus, ein persönliches Erlebnis und eine private Markierung am Körper, die erst nach seinem Tod öffentlich werden sollen. Mit dem bereits im 12. Jahrhundert brautmystisch umgemünzten Jesaja-Zitat (Jes 24,16):" "Secretum meum mihi“" (,mein Geheimnis gehört mir" ${ }^{8}$ signalisiert Bonaventuras Franziskus (Legenda maior XIII,4) ebenfalls Aversion ge-

perliche Ausdrucksformen. Hg. von Klaus Schreiner und Marc Müntz. München 2002, S. $463-$ 497. Allerdings sind schon aus der Zeit vor Franziskus' Tod ähnliche Phänomene überliefert. Vgl. ebd., S. 480 und Kiening und Beil: Urszenen (Anm. 4), S. 161. - Es waren „zehn Männer und 44 Frauen unter den Stigmatisierten des 13. und 14. Jahrhunderts.“ Bettine Menke: Evidenz (der Stigmata). In: Religion und Rhetorik. Hg. von Holt Meyer und Dirk Uffelmann. Stuttgart 2007, S. 134-151, hier S. 142.

6 Beide schrieben in päpstlichem Auftrag. Celanos Vita prima stammt von 1228/1229, die Vita secunda von 1246/1247. Die Texte werden zitiert nach: Thomas de Celano: Vita prima sancti Francisci. In: Fontes franciscani. Hg. von Enrico Menestò und Stefano Brufani. Assisi 1995, S. 273-424; Thomas de Celano: Vita secunda sancti Francisci. Ebd., S. 441-639; Thomas de Celano: Tractatus de miraculis beati Francisci. Ebd., S. 641-754; Bonaventura de Balneoregio: Legenda maior sancti Francisci. Ebd., S.775-911. Übersetzungen in: Franziskus-Quellen. Die Schriften des heiligen Franziskus, Lebensbeschreibungen, Chroniken und Zeugnisse über ihn und seinen Orden. Hg. von Dieter Berg und Leonhard Lehmann. Kevelaer 2009; insbes. Thomas von Celano: Erste Lebensbeschreibung oder Vita des hl. Franziskus. Auf der Grundlage der Übersetzung von Engelbert Grau OFM überarbeitet und kommentiert von Johannes-Baptist Freyer OFM. Ebd., S. 195-288; Bonaventura von Bagnoregio: Legenda Maior - das Große Franziskusleben. Auf der Grundlage der Übersetzung von Sophronius Clasen OFM neu bearbeitet von Marianne Schlosser und eingeleitet von Paul Zahner OFM. Ebd., S. 686-778. Vgl. zu den Datierungen ebd., S. 187 und 686f.

7 Vgl. Hildegard Elisabeth Keller: My Secret is Mine. Studies on Religion and Eros in the German Middle Ages. Leuven 2000. Jesajas „prophetic calling originated in his vision of the seraphim standing on the throne of Jehovah (Isaiah 6.1-7).“ Jeffrey F. Hamburger: The Visual and the Visionary. Art and Female Spirituality in Late Medieval Germany. New York 1998, S. 258. Zur Analogie zwischen Jesaja und Franziskus vgl. auch Arnold I. Davidson: Miracles of Bodily Transformation, or How St. Francis Received the Stigmata. In: Critical Inquiry 35 (2009), H. 3, S. 451-480, hier S. 460f. Brautmystische Anklänge finden sich auch bei Celano.

8 Übersetzungen stammen, falls nicht anders angemerkt, von der Verfasserin. 
gen das Publikwerden seiner erotisch konnotierten Auszeichnung: der Vision und der Stigmata. ${ }^{9}$

Gleichzeitig berichten beide Autoren von der graduellen Offenbarung des „secretum" noch zu Franziskus' Lebzeiten: ${ }^{10}$ oft ohne das Zutun des Heiligen und gegen seinen Willen, ${ }^{11}$ anhand von Blutspuren, ${ }^{12}$ Mirakeln, Andeutungen und vertraulichen Mitteilungen - bevor sich die Stigmata im Tod allen darbieten, die sie sehen, küssen oder ungläubig berühren wollen. Vertraute, denen Franziskus von der Vision berichtet hatte, machen diese öffentlich.

„Meum mihi“ formuliert einen emphatischen Besitzanspruch, der von der Gesetzmäßigkeit des Wunders konterkariert wird. ${ }^{13}$ Gott, die uneinholbare Transzendenz, vollbringt physikalisch Unerklärliches, damit es an die Öffentlichkeit gerät und seine Allmacht bezeugt. ${ }^{14}$ Authentisch wirkt es aber nur in Relation mit der Demut des Protagonisten, welche die Geheimhaltung („,secretum“) motiviert.

Autorität gewinnt der hagiographische Bericht indes nicht nur in der Berufung auf Augen- und Hörzeugen oder in der Inszenierung von Authentizität. Celano und Bonaventura führen - ausgerechnet über diesen „atheoretische[n] ${ }^{“ 15}$ Heiligen - einen Expertendiskurs, ${ }^{16}$ der das Geschehen theologisch aufwertet. Sie führen Bibelzitate an und entwickeln im Rückgriff auf die Tradition ein eigenes

9 Zum Eros vgl. Barbara Vinken: Via crucis, via amoris. In: Stigmata. Poetiken der Körperinschrift. Hg. von Bettine Menke und ders. München 2004, S.11-23. - Der franziskanische ,Bestseller' Meditaciones vite Christi erinnert später an die Verschwiegenheit des Franziskus und hält mit Blick auf den Urheber des Geheimnisses fest: „,contemplatiuus secretum Domini reuelare non debet“ („,Der Kontemplierende soll das Geheimnis Gottes nicht offenbaren“). Iohannis de Cavlibvs: Meditaciones vite Christi. Hg. von M[ary] Stallings-Taney. Turnhout 1997, Kap. LXXIII,246.

10 Ein ,reflexives Geheimnis' (dessen Existenz unbekannt ist) wird zu einem ,einfachen' (dessen Inhalt man als Vertrauter wissend verschweigt), oder auch zum Gerücht. Vgl. zu den Geheimnis-Formen Alois Hahn: [Art.] Geheimnis. In: Vom Menschen. Handbuch Historische Anthropologie. Hg. von Christoph Wulf. Weinheim, Basel 1997, S. 1105-1118, hier S. 1108f.; Daniel Jütte: Das Zeitalter des Geheimnisses. Juden, Christen und die Ökonomie des Geheimen (1400-1800). Göttingen 2011, S. 23.

11 Außerdem und gegen den Willen der Franziskaner teilt sich Franziskus das Geheimnis, die Auszeichnung, mit vielen anderen religiösen Ausnahmetalenten, die Stigmata empfangen. Vgl. Anm. 5.

12 Vgl. dazu Menke: Evidenz (Anm. 5), S. 148; Kiening und Beil: Urszenen (Anm. 4), S. 162 und 175.

13 Zum Wunder vgl. etwa Hartmut Bleumer: ,Historische Narratologie'? Metalegendarisches Erzählen im Silvester Konrads von Würzburg. In: Historische Narratologie. Mediävistische Perspektiven. Hg. von Harald Haferland und Matthias Meyer. Berlin, New York 2010, S. 231-261; Nine Miedema: Wunder sehen - Wunder erkennen - Wunder erzählen. In: Sehen und Sichtbarkeit in der Literatur des deutschen Mittelalters. XXI. Anglo-German Colloquium London 2009. Hg. von Ricarda Bauschke, Sebastian Coxon und Martin H. Jones. Berlin 2011, S.331-347; Elke Koch: Zeigen und Deuten im Medium Spiel. Zur visuellen Präsentation des Wunders in den Blindenheilungsszenen des Donaueschinger Passionsspiels. Ebd., S. 348-363.

14 Dies formuliert auch Bonaventura in der Legenda maior XIII,4.

15 Uta Störmer-Caysa: Einführung in die mittelalterliche Mystik. Stuttgart 2004, S. 34.

$16 \mathrm{Zu}$ diesem Expertendiskurs zählen Begriffe wie „imago", „visio“, "effigies“, "figura“, vgl. zu Bonaventura Kiening und Beil: Urszenen (Anm.4), die zeigen, dass sich die Termini zu einem vielschichtigen Stigmata-Konzept formieren mit dem Effekt, dass in den Wundmalen 
Vokabular für das, was sie als beispielloses Novum behaupten: für die Schau einer Überblendung von Passionschristus und Seraph ${ }^{17}$ sowie für die im Fleisch sichtbar gewordene "Spiritualisierung des Fleisches" ${ }^{18}$ Die Wundmale, aus denen an Händen und Füßen fleischgewordene Nägel, Nägel aus Fleisch, herausragen, vergegenwärtigen $^{19}$ - aufgefasst als detailgetreu nachahmende Zeichen - permanent den Moment der Kreuzigung und den Körper Christi in Franziskus.

Zum von beiden Autoren etablierten Begriffsinstrumentarium zählt der vielschichtige Terminus "sacramentum“, ${ }^{20}$ dessen unterschiedliche semantische Valenzen zum Tragen kommen. Diese beziehen sich nicht immer auf die Stigmata und die Seraph-Vision. Am Körper des Franziskus sei, schreibt Bonaventura, die Seitenwunde Christi erneut erfahrbar, in der das "sacramentum" der Eucharistie bzw. der Taufe seinen Ursprung habe (Legenda maior XV,2). Oder der Begriff bezeichnet von Franziskus geschaute göttliche Geheimnisse (Legenda maior XIII,4). Durch ein Tobit-Zitat (Tob 12,7) werden die Wundmale zum "sacramentum", Geheimnis des (nunmehr himmlischen) Königs, das es zu bewahren gilt (Legenda maior XIII,5, vgl. auch XIII,4). Jede Begriffsverwendung assoziiert die jeweils anderen, wodurch sich eine Affinität zwischen Stigmata und Eucharistie abzeichnet. ${ }^{21}$

Dass Franziskus gezeichnet (,,signatus“) ist, als hätte er mit Christus am Kreuz gehangen, repräsentiert für Thomas von Celano ein "sacramentum magnum“. Celano bedient sich in dieser Formulierung eines Epheser-Zitats (Vita prima 90; Eph 5,32). Das paulinische „sacramentum magnum“ repräsentiert dort die Verbindung zwischen Christus und Gemeinde, die der Apostel mit dem ehelichen EinsSein im Fleische gleichsetzt. Diese wird bei Celano zum brautmystisch aufgeladenen Eins-Sein am Kreuz - ein großes Geheimnis, das die Erhabenheit der Liebe offenlege. Zugleich verberge es (,in eo latet“, Vita prima 90) einen geheimen Ratschluss („,arcanum [...] consilium“) und ein ehrwürdiges Mysterium (,reverendum [...] mysterium"), das Franziskus nur unvollständig offenbarte. (Bei Bonaventura sind es „arcana“, die der Seraph Franziskus mitteilt und die kein Mensch aussprechen darf, Legenda maior XIII,4. $)^{22}$

Körperlichkeit und Geistigkeit, Evidenz und Entzogenheit, Figürlichkeit, Repräsentation und Präsenz zusammenfallen. Vgl. auch Menke: Evidenz (Anm. 5).

17 Die Überblendung des Unsterblichen „mit dem Sterblichen - [...] das ist es, was Zeitgenossen als das eigentlich Skandalöse der Situation empfanden." Kiening und Beil: Urszenen (Anm. 4), S. 173. Ein Reflex dieses Gedankens findet sich bei Lamprecht in Sanct Francisken Leben, V.3391-3395, s. u.

18 Vinken: Via crucis (Anm. 9), S. 14.

19 Vgl. Kiening und Beil: Urszenen (Anm. 4), S. 162.

20 Dazu vgl. Reinhart Meßner: [Art.] Sakrament/Sakramentalien. I. Westen. In: Lexikon des Mittelalters. Bd. 7. Hg. von Norbert Angermann u. a. München 1995, Sp. 1267-1272; Odo Casel: Zum Worte sacramentum. In: Jahrbuch für Liturgiewissenschaft 8 (1928), S. 225-232.

21 Vgl. dazu auch Kiening und Beil: Urszenen (Anm. 4), S.170f. und 173f.; Vinken: Via crucis (Anm. 9), S. 20; Menke: Evidenz (Anm. 5), S. 141f.

22 Vgl. dazu Kiening und Beil: Urszenen (Anm. 4), S. 176. Dass Franziskus bzw. Bonaventura die „arcana“ erwähnt, gerade als sich der Heilige gezwungen sieht, sich seinen Gefährten mit- 
"Mysterium" bezeichnet in den Viten transzendentes Wissen oder die unzugängliche Dimension heilsgeschichtlicher Ereignisse, jedoch in keinem Text die Seraph-Vision oder die Stigmata. Letztere werden, wie sich zeigte, als „sacramentum" aufgewertet. Als Geheimnis des Königs gilt es, wie es heißt, sie zu verbergen. Im semiotischen Diskurs des Mittelalters wurde andererseits und im Anschluss an Augustin ",sacramentum" als sichtbares Zeichen für eine heilige Sache (und als Gnadenmittel) aufgefasst, ${ }^{23}$ und Celano und Bonaventura heben die Zeichenqualität der Stigmata mehrfach hervor, indem sie diese als ",signa", „, signacula“ oder als „signacula sacra“ (etwa Vita prima 95, 113, 115 und 118; Legenda maior XII,12; XIII,3,5 und 7) bezeichnen. So bewegt sich das "sacramentum“ zwischen Zeigen und Verbergen, während die Stigmata in der Handlung zwischen Verheimlichung und Sichtbarwerdung oszillieren. ${ }^{24}$

Mit Blick auf die deutschen Viten stellt sich vor diesem Hintergrund die Frage, wie sich das doppelte Geheimnis des Franziskus - „sacramentum“ und ",secretum" - für Laien retextualisieren ließ. Christian Kiening und Ulrich Johannes Beil haben bereits auf Bonaventuras begrifflich-theologische Ambitionen hingewiesen und treffend beobachtet, dass der gelehrte Diskurs den "geheimnisvolle[n] Charakter ${ }^{\prime 25}$ der Stigmatisierung bewahrt. Allerdings diskutieren sie nicht die Termini „secretum“ und „sacramentum", und sie verzichten - trotz ihres mediologischen Interesses für Mittler und Vermittlungsformen - auf eine übersetzungshistorische Perspektive.

Lamprechts von Regensburg Sanct Francisken Leben repräsentiert eine Übertragung der Vita prima von Thomas von Celano. ${ }^{26}$ Die Franziskus-Biographie im Passional richtet sich nach der Legenda aurea des Dominikaners Jacobus de Voragine ${ }^{27}$ sowie abschnittsweise nach franziskanischen Quellen, der Vita secunda von Tho-

zuteilen, vermittelt den Eindruck, zumindest ein Aspekt des Geheimnisses werde zur ,Privatsache' erklärt: das emphatisch Unaussprechliche.

23 Vgl. Meßner: Sakrament (Anm. 20); San Isidoro de Sevilla: Etimologías. Edición bilingüe. Bd. 1. Hg. von José Oroz Reta und Manuel A[ntonio] Marcos Casquero. Madrid 1982, VI,19-42.

24 In der Diskussion um das Phänomen ,Geheimnis' richtet sich ein signifikanter Teil der Forschung nach Kants Dreiteilung: „arcana (Geheimnisse, die (noch) nicht bekannt sind, z. B. die Verborgenheit der Natur), secreta (Geheimnisse, die nicht bekannt sein sollen, z. B. die Geheimhaltung der Politik) und mysteria (heilige Geheimnisse der Religion)“. Doren Wohlleben: Enigmatik. Das Rätsel als hermeneutische Grenzfigur in Mythos, Philosophie und Literatur. Antike - Frühe Neuzeit - Moderne. Heidelberg 2014, S. 157. Franziskus' „,secretum“ zählt zur gleichnamigen Kategorie, das „sacramentum“ zu den mysteria.

25 Kiening und Beil: Urszenen (Anm. 4), S. 176.

26 Vgl. Heinzle: Lamprecht von Regensburg (Anm. 1), Sp. 521.

27 Jacobus de Voragine: Legenda aurea. Goldene Legende. Einleitung, Edition, Übersetzung und Kommentar von Bruno W. Häuptli. Freiburg, Basel, Wien 2014. „Den tatsächlichen Durchbruch in der Verbreitung der Kenntnis von Francesco d'Assisi im deutschen Mittelalter schaffte [...] erst der Dominikaner Jacobus de Voragine mit seiner Legenda Aurea." Manfred Zips: Franziskus von Assisi, vitae via. Beiträge zur Erforschung des Geschichtsbewusstseins in den deutschen Franziskusviten des Mittelalters mit besonderer Berücksichtigung der deutschsprachigen Werke. Wien 2006, S. 106. 
mas von Celano und Bonaventuras Legenda maior. ${ }^{28}$ Das Legenda aurea-Kapitel geht wiederum auf Celanos Vita secunda, auf sein Mirakelbuch und auf Bonaventuras Legenda maior zurück. ${ }^{29}$ Für den religiösen Gebrauch verfasst, sollen die lateinischen Prosa- und deutschen Vers-Fassungen überzeugend informieren und affizieren, gerade indem sie das Geheimnis offenbaren und verschleiern. So gilt es im Folgenden, die Dynamik des doppelten Geheimnisses „secretum“-,,sacramentum“ auf einem narrativen Terrain zu verfolgen, das sich in der Volkssprache aus präzisen Übersetzungen, Verzicht auf Übertragung, Paraphrasen, amplificatio und abbreviatio, Quellenkombination, lexikalischen Übernahmen mit semantischen Verschiebungen konstituiert.

\section{1 "Sacramentum"}

Außer im Mirakelbuch kommt der Begriff „sacramentum“ in allen genannten Texten von Celano und Bonaventura im Zusammenhang mit den Stigmata vor. Jacobus de Voragine wiederum, der eine komprimierte Version der Franziskus-Legende einem weniger prätentiösen Publikum zur Verfügung stellt, verzichtet auf den Begriff, und wenngleich der Passional-Autor weitere Quellen kennt, sucht man dort ein deutsches Äquivalent vergeblich. Lamprecht von Regensburg übergeht stillschweigend Celanos Rekurs auf das paulinische „sacramentum magnum“ aus dem Epheser-Brief, aber er reagiert auf ein anderes „sacramentum“, das in der Vita prima im Stigmata-Kontext gebraucht wird.

Lamprecht präsentiert sich in der Rolle eines von Jugendsünden Bekehrten, der in den Franziskaner-Orden Aufnahme finden will. ${ }^{30}$ Er schwankt zwischen den Stilisierungsformen der Armut im Geiste und der Gelehrsamkeit. Insbesondere stellt er im Text seine Allegorese-Kenntnisse unter Beweis. Zweimal beteuert er, dass es Franziskus nicht gelingt, die Bedeutung (das „bîzeichen[]“, V.3398f.) der Seraph-Vision zu erkennen. Der Begnadete findet keine Erklärung für die Erscheinung des gekreuzigten, geflügelten Mannes, der einem Seraph gleicht (und später im Narrativ als Seraph bezeichnet wird) und der ihn eindringlich ansieht. Der Berichterstatter Lamprecht hingegen überführt die geschauten sechs Flügel (wie Celano) in einen ethischen Diskurs: „nu wil ich ${ }^{31}$ sagen waz bediutet / der man, den sant Francisk sach" (V. 4147f.). Die nach oben gerichteten Flügel würden reine Absicht und gute Tat bedeuten und sich aus den Federn der Gottesfurcht und der Liebe zusammensetzen etc.

28 Vgl. Edith Feistner: Historische Typologie der deutschen Heiligenlegende des Mittelalters von der Mitte des 12. Jahrhunderts bis zur Reformation. Wiesbaden 1995, S. 231; Andreas Hammer: Erzählen vom Heiligen. Narrative Inszenierungsformen von Heiligkeit im Passional. Berlin, Boston 2015, S. 33-68 und 247-257.

29 Vgl. Jacques Le Goff: Franz von Assisi. Stuttgart 2006 [1999], S. 115.

30 Zum Passional lässt sich festhalten: „Letztendlich zeigt das Passional Entsprechungen zur Denkwelt des Deutschen Ordens sowie zu derjenigen der Franziskaner." Passional (Anm. 2), S. XLIII.

31 Vgl. auch Sanct Francisken Leben, V. 4164. 
Nachdem er die Vision fachkundig ausgelegt hat, merkt aber das Sprecher-Ich im Zusammenhang mit der besonderen Verehrung seines Protagonisten für den gekreuzigten Christus Folgendes an:

des hât er [Christus] in [Franziskus] besunderlich

gezeichent alsô hêrlich

mit sînes selbes bilde

under des wâfens schilde,

dârunder er den tiuvel sluoc,

daz nie ritter mêr getruoc

wan dirre ritter eine.

swer mich frâget waz daz meine,

dâzuo ist mînes sins gedanc,

daz ichz bescheide, al ze kranc.

doch mac man wol kiesen dran,

daz diser heiliger man

dem künege von himelrîche

liep ist besunderlîche,

wand er daz selbe wâfen treit,

dâmit er al die kristenheit

an dem kriuze erlôste. ${ }^{32}$

(Sanct Francisken Leben, V. 4242-4258)

Die Stigmata formieren sich zu einem Panzer in Entsprechung zu den Siegeswunden des Erlösers. Im Sinne der christlichen Umwertung der Werte figurieren die Verletzungen als Schutzhülle. Angespielt wird auf die Vorstellung der geistlichen Ritterschaft aus der Väter- und Mönchstradition. ${ }^{33}$ Die metaphorische Formulierung repräsentiert kein Musterbeispiel für Klarheit, perspicuitas, aber sie ist nicht unverständlich. Ihre Redundanz belegt zudem, dass dem Sprecher-Ich der Literalsinn doch keine Schwierigkeiten bereitet, und zumindest die Quelle sieht hier keine allegorische Auslegung vor, an der das Ich scheitern könnte. In der gespielten Ahnungslosigkeit gewinnt Lamprechts sancta simplicitas an Kontur. Oder aber: Sie drückt seine Ratlosigkeit angesichts des physikalisch Unerklärlichen aus.

32 Übers. Sanct Francisken Leben, V. 4242-4258: „Deshalb hat er [Christus] ihn [Franziskus] besonders [und] so herrlich mit Zeichen versehen, mit seinem eigenen Bild unter dem Kampfschild, unter dem er den Teufel besiegte, [mit der Ausrüstung: „wâfen“], die kein Ritter später trug bis auf diesen Ritter allein. Wer mich fragt, was das meint, um es zu erklären, dafür ist der Gedanke meines Verstandes viel zu schwach. Doch kann man daran wohl sehen, dass dieser heilige Mann dem König des Himmelreichs besonders lieb ist, denn er trägt die gleiche Ausrüstung, mit der er [Christus] die ganze Christenheit am Kreuz erlöste."

33 Vgl. Werner Williams-Krapp: „Nucleus totius perfectionis“. Die Altväterspiritualität in der Vita Heinrich Seuses. In: Festschrift Walter Haug und Burghart Wachinger. Hg. von Johannes Janota u. a. Tübingen 1992, Bd. 1, S. 407-421, hier S. 414. 
Der Vergleich mit der Quelle legt im Deutschen eine Lücke offen, die auf Ignoranz oder aber auf freie Entscheidung zurückgeht. Thomas von Celano schreibt:

O singulare donum et praerogativae dilectionis indicium, iisdem gloriae armis militem adornari quae soli Regi excellentissima dignitate conveniunt! O aeterna memoria dignum miraculum, et sine omni intermissione [cfr. Ps 111,7; Rom 1,9] admirabili reverentia memorabile sacramentum, quod oculata fide illud mysterium repraesentat, in quo Agni immaculati sanguis [cfr. 1 Pet 1,19], per quinque foramina ${ }^{34}$ copiosissime manans, lavit crimina mundi [cfr. Apoc 1,5]!

(Vita prima IX,114)

O einzigartiges Geschenk und Zeichen [,,indicium“] einer außerordentlichen Liebe! Mit der gleichen Ausrüstung des Ruhmes wird der Ritter ausgestattet, wie sie nur der allerhöchsten Majestät des Königs zukommt! O ewig denkwürdiges Wunder, erinnerungswürdiges Geheimnis [„,sacramentum“], dessen man ohne jeden Unterlass mit staunender Ehrfurcht gedenken sollte, weil es dem Auge des Glaubens jenes Mysterium [„,mysterium“] zeigt [„repraesentat“], in dem das Blut des unbefleckten Lammes, das aus fünf Wunden überströmend sich ergoss, die Verbrechen der Welt abgewaschen hat ${ }^{135}$

Das Geschenk, das Liebeszeichen, die Ausrüstung und das Wunder werden kongruent gesetzt und bilden das „sacramentum“, welches seinerseits das Passionsmysterium zur Schau stellt und repräsentiert. Der größere Kontext legt nahe, dass mit dem "sacramentum" hier die Stigmata gemeint sind. Das martialische Bild aktualisiert eine semantische Valenz des Begriffes, die im patristischen Kontext Relevanz besaß. „Sacramentum“, in der spätantiken Bedeutung ,Fahneneid', auch ,Mysterieneid', bezeichnet etwa bei Tertullian die Taufe als Eintritt in die christliche Miliz. ${ }^{36}$ Wohl im Anschluss an diese Begriffsverwendung spricht Celano an anderer Stelle von „sacramentum“ als ,Eid ${ }^{37}$ (Vita secunda V,9). In unserer Passage aktualisiert der militärische Zusammenhang die Wortgeschichte. Aber in erster Linie meint "sacramentum“ hier ein Zeichen und die Schauseite des Erlösungsmysteriums. Sie verweist ihrerseits auf Zusammenhänge, die sich entziehen, vor allem auf das Signifikat Gott und die Wirkungsweise seiner Gnade.

34 Vgl. dazu Beatrice Trînca: The Bride and the Wounds - „columba mea in foraminibus petrae" (Ct. 2.14). In: Interfaces. A Journal of Medieval European Literatures 5 (2018). Special issue: Biblical Creatures. The Animal as an Object of Interpretation in Pre-Modern Jewish and Christian Hermeneutic Traditions. Hg. von Astrid Lembke, S. 16-30.

35 Übersetzung von Grau und Freyer: Erste Lebensbeschreibung (Anm.6), modifiziert. Vgl. auch Eph 6,11-13.

36 Vgl. Casel: Zum Worte sacramentum (Anm. 20), S. 226f. Allerdings war ",der Sinn ,Fahneneid“ nur eine mitschwingende Note in dem großen Akkord ,Mysterium “". Ebd., S. 227. Zur mittelalterlichen Arbeit am Begriff vgl. auch Meßner: Sakrament (Anm. 20).

37 Vgl. Casel: Zum Worte sacramentum (Anm. 20), S. 232. 
Lamprecht verzichtet auf beide Geheimnis-Termini, „sacramentum“ und „mysterium“, und setzt stattdessen sein Scheitern an der martialischen Metapher in Szene. Für gebildete Rezipienten, die die Vita prima konsultieren können, fungiert sein Unwissen als Indiz für eine Leerstelle. Sie erweist sich beim näheren Hinsehen als ein Charakteristikum der beiden volkssprachlichen Viten, das sich - je nach Quellenlage - auch der simplifizierenden Legenda aurea verdankt: Das "sacramentum" wird getilgt $\mathrm{t}^{38}$ - obwohl es entsprechende Begriffe gegeben hätte, auch wenn der "geistliche Wortschatz" im Deutschen „über Jahrhunderte hinweg nicht festgelegt ${ }^{\text {“39 }}$ blieb.

\section{2 "Secretum"}

Dass Vision und Stigmata von Franziskus verheimlicht werden, unterstreicht sowohl das Passional-Kapitel als auch Sanct Francisken Leben. Explizit als „heimlicheit" (V.3443) wird die singuläre Gnade aber nur von Lamprecht bezeichnet, der Celanos „secretum“ (Vita prima 96) übersetzt. Die Legenda aurea kommt ohne den Begriff aus, und der Passional-Autor greift nicht ergänzend etwa auf Bonaventuras „Secretum meum mihi“ zurück. "Sacramentum" stellt ein terminologisches Experiment von theologischer Reichweite dar, an dem sich die deutschen Verfasser nicht beteiligen. Das semantisch weniger komplexe „secretum“ bezeichnet indes eine narrative Konstellation der Verheimlichung, welche die volkssprachlichen Hagiographen nicht überspringen können, auch wenn sie den Begriff ignorieren.

Die zwei deutschen Berichte darüber geraten - im Einklang mit ihren primären Quellen - unterschiedlich ausführlich. Dabei bieten sie im Anschluss an die lateinischen Texte dem Publikum beinahe uneingeschränkten Zugang zu dem, worauf Franziskus alle Mühe anwendet, um es (intradiegetisch) zu verbergen. Das göttliche Wunder muss bekanntlich öffentlich werden. Auch Franziskus' Strategien der Geheimhaltung werden narrativ dokumentiert. Wie er sich von Brüdern und Gläubigen abschottet, schildern die Autoren ohne - in Korrespondenz zur Handlung - sich um Diskretion zu bemühen. Die Texte setzen dabei unterschiedliche Schwerpunkte. In den Viten gewinnt auf Grund dieser Differenzen, die im Folgenden vor der Folie der Vorlagen kurz skizziert werden sollen, ein heterogenes Bild des weltabgewandten Protagonisten und seines „secretum", d. h. der Vision und der Stigmatisierung, an Kontur. Gemeinsam haben alle Texte die auktoriale Perspektive, die fast keine Abweichungen aufweist. ${ }^{40}$

38 Anders verhält es sich mit der (nach 1276) entstandenen, für Utrechter Franziskaner verfassten niederländischen Versübertragung von Bonaventuras Legenda maior. Vgl. Jacob van Maerlant: Sinte Franciscus leven. Hg. von Maximilianus O.F.M. Cap. Zwolle 1954. Zum Text vgl. Feistner: Historische Typologie (Anm. 28), S. 200-211.

39 Dieter Kartschoke: Geschichte der deutschen Literatur im frühen Mittelalter. 2. Aufl. München 1994 [1990], S. 28.

40 Zur Narratologie der nicht-fiktionalen Gattung Legende vgl. Bleumer: ,Historische Narratologie' (Anm. 13); Armin Schulz: Erzähltheorie in mediävistischer Perspektive. Hg. von Manuel Braun, Alexandra Dunkel und Jan-Dirk Müller. Berlin, Boston 2012. 
Das Extraordinäre (die Erscheinung und die Stigmatisierung) ereignet sich in der Einsamkeit, auf einem Berg: La Verna. ${ }^{41}$ Berichte über die Absonderung zu Beginn und die Geheimhaltung im Anschluss umrahmen das narrativ offengelegte "secretum", dessen intradiegetische Einhaltung die Zurückgezogenheit des Protagonisten begünstigt. Vom Geist Gottes auf den Berg gejagt (mhd. „iagen“, 529,82), wie es im Passional heißt, praktiziert der Heilige vierzig Tage lang strengste Askese. Auf den Rückzug folgt die Entrückung als Bedingung für die singuläre Gnade. Franziskus' Herz wird weit in den Bereich des Göttlichen „geworfen“ (529,90), sein heiliger Sinn bricht sich (,sich [...] brach“, 529,93) von der Welt.

Lamprecht von Regensburg legt größeren Wert auf Ortsangaben:42 Franziskus empfängt die Vision in einer Einsiedelei, „in einem einhûs“ (V.3373), im „eremitorio [...] Alverne“ (V.3377f.). Anders als das Passional setzt sein Text räumliche Segregation und Ablösung vom Diesseits nicht explizit analog, und er interessiert sich auch nicht für die Vehemenz der Kontemplation. Gerade darin weicht wiederum das Passional von seiner Primärquelle, der Legenda aurea, ab, indem es sich Bonaventura anschließt, während Lamprecht Thomas von Celano hier und auch sonst fast überall in der Episode genau folgt.

Nachdem sich das visionär Gesehene ins Fleisch einprägt, schützt Franziskus seinen ausgezeichneten ${ }^{43}$ Körper vor fremden Blicken, um ihn erst im Tod allen uneingeschränkt preiszugeben. Lamprecht stellt einen expliziten Kontrast her zwischen „het ir grôze hæle“ (V.3436; „,verheimlichte sie [die Wundmale] sorgfältig“) und dann, als die Gläubigen den Verstorbenen verehren: „sus lac er / unverborgen schînbærlîche“ (V.4067f.; ",so lag er unverborgen vor aller Augen“ oder „unverborgen strahlend").

Über die intradiegetische Geheimhaltung berichtet Sanct Francisken Leben (im Anschluss an Celano), anders als das Passional, in extenso. In seinem Wunsch, die Gnadenerfahrung und insbesondere ihre körperlichen Spuren für sich zu behalten, fühlt sich Franziskus von einem Psalmvers bestärkt. Für die Hagiographen repräsentiert dieser Vers einen (für Celano erneuten) Versuch, das Phänomen ohne Präzedenz, die Stigmata, konzeptuell zu fassen und diskursiv einzuordnen. Lamprecht zitiert (mit Quellenangabe: „salter“, V.3463) zunächst auf Latein, dann auf Deutsch:

41 Zum Berg-Motiv vgl. Davidson: Miracles (Anm. 7), S. 463.

42 Vgl. dazu bei Bonaventura Kiening und Beil: Urszenen (Anm. 4), S. 170.

43 ,Der Aspekt von Leid und Martyrium spielt zwar in die Franziskus-Legende hinein; noch bedeutsamer aber ist die Funktion der Auszeichnung. Sie gewinnt gerade für Bonaventura, dessen Geschichtsbild joachimitisch geprägt ist, eine eschatologische Dimension: Franziskus ist der ,engelsch man', ja der Engel des sechsten Siegels der Apokalypse, den man an seinen Zeichen erkennt. Daher bringt man seinen Körper schon vor Alverna mit dem Kreuzzeichen in Verbindung." Küsters: Spuren (Anm. 4), S. 59. Franziskus versuchte zweimal, in den Orient zu reisen, um für Christus zu sterben, aber das Martyrium gelang ihm nicht: Er kam nicht an bzw. gewann dort Anerkennung. Dafür gilt in der Hagiographie seine Stigmatisierung als Überbietung eines jeglichen Martyriums. Sie ereignet sich ohne Arena, Zuschauer oder Glaubenskrieg. Für die meisten Verehrer werden die Gewaltspuren erst nach seinem Tod sichtbar. 
In corde meo abscondi eloquia tua ut non peccem tibi. [Ps 118,11]

nu hoert waz diz entiutschen sî:

ich hân dîn rede verborgen

in mînem herzen durh die sorgen,

her, daz ich iht sünde dir. ${ }^{44}$

(Sanct Francisken Leben, V.3464-3468)

Den Wundmalen, die im Text "mâl“ und "zeichen" (Sanct Francisken Leben, V. 3404, 3435, 4053, 4060, 4092, 4197 und 4396; vgl. auch Passional 530,67) genannt werden, weist das Zitat nun die sakrale Wertigkeit sprachlicher Zeichen zu, die aus der Transzendenz stammen: „dîn rede“, Gottes Rede. Die Stigmata stellen ein NachAußen-Treten des auf Christus fixierten Inneren des Heiligen dar ${ }^{45}$ sowie dessen, was er in der Vision vielleicht nur vor seinem inneren Auge sieht. ${ }^{46}$ Nun werden die gezeichneten äußeren Körperschichten selbst wieder zum verborgenen Inneren des Herzens ${ }^{47}$ in dem göttliche Worte, als Metapher für die Wundmale, aufbewahrt werden. Textilien - auf deren Funktion, die Stigmata zu verbergen, die Viten häufig referieren - figurieren nun als Schutzhüllen dieser neuen Innerlichkeit an der Hautoberfläche.

Der Psalmvers dient darüber hinaus der alläglichen Kommunikation; zwischen Diskretion und Abschottung besteht eine Kontiguitätsrelation. Franziskus und seine Brüder verabreden einen Geheimcode, der den Heiligen vor einer allzu zeitintensiven Nähe zu seinen Laien-Besuchern (",aller liute heimelîch", V.3478) schützen soll. Seine Begleiter haben die Gäste (,werltlîche liute“, V.3473) zu verabschieden, wenn der Protagonist den genannten Psalmvers zitiert, der für Eingeweihte als Signal für den gewünschten Rückzug figuriert.

Im Zentrum der Absonderungsbewegungen steht, wie bereits angedeutet, das Mirakel. Während Lamprecht (wie seine Vorlage) von der Erscheinung eines gekreuzigten, geflügelten Mannes erzählt, der einem Seraph gleicht und später inkonsequent - weil man Manifestationen des Transzendenten kaum gerecht werden kann - einfach als Seraph bezeichnet wird, hängt im Passional, wie in der Legenda aurea, von Beginn an ein Seraph am Kreuz. Bonaventuras terminologische

44 Übers. Sanct Francisken Leben, V.3464-3468: „In corde meo abscondi eloquia tua ut non peccem tibi. Hört nun, was das auf Deutsch bedeutet: Ich habe deine Rede in meinem Herzen verborgen, Herr, aus Sorge, dass ich sündige."

45 Vgl. Vinken: Via crucis (Anm. 9), S. 14.

46 Zum visionären Sehen vgl. etwa Barbara Newman: What Did It Mean to Say „I Saw“? The Clash between Theory and Practice in Medieval Visionary Culture. In: Speculum 80 (2005), S. 1-43; David Ganz: [Art.] Visio depicta. Zur Medialität mittelalterlicher Visionsdarstellungen. In: Handbuch der Bildtheologie. Bd.3: Zwischen Zeichen und Präsenz. Hg. von Reinhard Hoeps. Paderborn 2014, S. 145-182; Davidson: Miracles (Anm. 7).

47 Vgl. dazu Peter von Moos: Herzensgeheimnisse (occulta cordis). Selbstbewahrung und Selbstentblößung im Mittelalter. In: Schleier und Schwelle. Bd. 1: Geheimnis und Öffentlichkeit. Hg. von Aleida und Jan Assmann. München 1997, S. 89-109. 
Angebote, etwa als er eucharistisch formuliert und von „Christo sub specie Se-

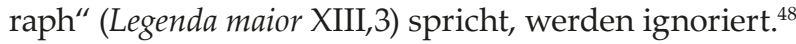

Die Stigmata treten zu unterschiedlichen Zeitpunkten auf: bei Lamprecht (und Celano), als Franziskus ratlos über die Vision nachdenkt. Im Passional, dessen Verfasser eine Anregung Bonaventuras aufgreift (Legenda maior XIII,5), ${ }^{49}$ wird der Protagonist von der „minne“ $(530,62)$ verletzt, ${ }^{50}$ als er den Engel innig ansieht. Die Wunden an Händen und Füßen tragen in beiden Texten die aus Fleisch nachgebildeten Nägel in sich, die Seitenwunde blutet vor den Augen des extradiegetischen Publikums. Dass die anderen Wunden definitiv nicht bluten, steht nur im Passional, das zugleich in stärkerem Ausmaß für ihre Sichtbarkeit Sorge trägt - und signifikant von den Quellen abweicht. Es heißt:

im was rechte als einem man,

dem uf vrischen wunden

were ein vel gebunden,

dunne unde luter gar,

durch daz man sehe aloffenbar

die stat enbinnen sin verwunt. ${ }^{51}$

(Passional 530,72-77)

Die ungewöhnliche Wundversorgung - Haut anstelle von Bandagen - im Vergleichsmodus, die, wie es scheint, das Bluten verhindert, veranlasst Franziskus natürlich dazu, seine deutlich sichtbaren Verletzungen zu verbergen. Für die Erzählung gilt: „Je unwahrscheinlicher, um so präziser muss man werden". ${ }^{52}$ Die Gleichzeitigkeit von versuchter Hauttransplantation und Offenlegung der Wunden erzeugt eine Artifizialität, welche das Exorbitante am Mirakel akzentuiert, an Reliquien erinnert und die Glorifizierung des Heiligen vorwegnimmt. ${ }^{53}$ In dieser

48 Bonaventura behauptet zudem, dem Heiligen hätte sich ein Seraph bzw. eine Ähnlichkeit („,similitudo“) mit dem Seraph und ein Abbild des Gekreuzigten („effigies“, XIII,10) gezeigt - wobei der Terminus ",effigies“ „Momente einer magischen Realpräsenz" transportiert. Kiening und Beil: Urszenen (Anm. 4), S. 174. Außerdem ist, wie gesagt, von „Christo sub specie Seraph“ (XIII,3) die Rede.

49 Vgl. dazu Davidson: Miracles (Anm. 7), S. 467.

50 Die Stigmata „,sind keine Wunden zum Tod, sondern Zeichen einer Liebe, die stärker ist als der Tod." Vinken: Via crucis (Anm. 9), S. 19.

51 Übers. Passional 530,72-77: „Er war genau wie ein Mann, dessen frische Wunde mit Haut verbunden war, dünn und ganz durchsichtig/glänzend, damit man sehr deutlich das Innere der Verletzung sehen konnte."

52 Diese Beobachtung von Susanne Köbele zu Heinrich Seuses Christus-Monogramm auf der Brust trifft ebenso auf das Passional zu. Susanne Köbele: heilicheit durchbrechen. Grenzfälle von Heiligkeit in der mittelalterlichen Mystik. In: Sakralität zwischen Antike und Neuzeit. Hg. von Berndt Hamm, Klaus Herbers und Heidrun Stein-Kecks. Stuttgart 2007, S. 147-169, hier S. 162.

$53 \mathrm{Zu}$ den Stigmata als „Vorgriff auf die Auferstehung des Fleisches“ vgl. Menke: Evidenz (Anm. 5), S. 136. Zum leuchtend-kristallinen glorifizierten Körper vgl. Beatrice Trînca: Schriftliche Berührung - gedruckte Süße. Zum bot der gotlichen mildigkeit. In: Zeitschrift für deutsche Philologie 135 (2016), H. 3, S. 349-366. 
wohl singulären Phantasie findet sich eine Geste des Verbergens aus Celanos Vita secunda wieder. ${ }^{54}$ Dort trägt Franziskus Wollsocken, um seine Wunden an den Füßen geheim zu halten. Die Verletzungen schützt er gegen die Rauheit der Textilie mit einem Stück Fell („pelle supra vulneribus posita“, Vita secunda 136), das im Deutschen als „vel“, jetzt Haut, an Transparenz und Leuchtkraft gewinnt. Dass Glanz traditionell Anmut assoziiert, fügt sich in das bereits in den lateinischen Viten geprägte Bild der schönen Wundmale, ${ }^{55}$ auf die die Schönheit der Erlösung abfärbt. Franziskus” „secretum“ lässt sich in der Erzählung beinahe bedingungslos zur Schau stellen.

\section{3 (Un)sagbarkeit}

Im Wunder - auch im verheimlichten (,secretum“) Geheimnis (,sacramentum“) des Franziskus - manifestiert sich aber sprachlich uneinholbare Transzendenz. Daran gemessen gilt, wie Peter Strohschneider mit Bezug auf Konrads von Würzburg Alexius ausgeführt hat, legendarisches Schreiben prinzipiell als prekär. ${ }^{56}$

54 Vgl. Feistner: Historische Typologie (Anm. 28), S. 232.

55 Über den verstorbenen Franziskus heißt es: „Membra ipsius adeo mollia et tractabilia se praebebant palpantibus, ut conversa viderentur in teneritudinem puerilis aetatis et quibusdam cernerentur evidentibus signis innocentiae decorata. Cum igitur in candidissima carne clavi nigrescerent, plaga vero lateris ut vernans roseus flos [cfr. Sir 50,8] ruberet, mirandum non est, si tam formosa et miraculosa varietas iucunditatem et admirationem contuentibus ingerebat." (Bonaventura: Legenda maior XV,3; „Seine Glieder fühlten sich so weich und geschmeidig an, als hätten sie die Zartheit des Kindesalters zurückerlangt; manchen erschienen sie, als sei die Unschuld an ihnen sichtbar. Da von seinem strahlend weißen Fleisch die Nägel schwarz abstachen, die Seitenwunde sich aber wie eine rosarote Frühlingsblume rötete, braucht sich niemand zu wundern, dass diese schöne und übernatürliche Buntheit die Betrachter mit Freude und Bewunderung erfüllte.") Übersetzung von Clasen, Schlosser: Legenda Maior (Anm. 6), stark modifiziert. - „Non incutiebant horrorem mentibus intuentium signa martyrii, sed decorem multum conferebant et gratiam sicut in pavimento albo nigri lapilli solent.“ (Thomas von Celano: Vita prima, IX,113; „Die Zeichen des Martyriums flößten den Seelen keinen Schauder ein, sondern verliehen großen Liebreiz und Anmut, wie es schwarze Steinchen in weißem Fußboden zu tun pflegen.") Übersetzung von Grau und Freyer: Erste Lebensbeschreibung (Anm.6), modifiziert. Der Hinweis auf den "horror" setzt sich in der lateinischen Tradition nicht durch, wird von Lamprecht ausgeklammert und geht für den Verfasser des Passionals verloren - wenngleich das ",secretum“ (und „sacramentum“) schaurig-schön bleibt. Bei Lamprecht schmücken die Stigmata den im Tod weiß und weich gewordenen Körper des Franziskus, "sam von dem wîzen esterîche / glîzent swarziu steinelîn” (V. 4095f.; „,wie von weißem Fußboden schwarze Steinchen glänzen“). Der Vergleich nimmt die anorganische Beschaffenheit des glorifizierten Körpers vorweg.

56 Vgl. Peter Strohschneider: Textheiligung. Geltungsstrategien legendarischen Erzählens im Mittelalter am Beispiel von Konrads von Würzburg Alexius. In: Geltungsgeschichten. Über die Stabilisierung und Legitimierung institutioneller Ordnungen. Hg. von Gert Melville und Hans Vorländer. Köln, Weimar, Wien 2002, S. 109-147, hier S. 117. Hartmut Bleumer spricht von einem „Kompetenzgefälle zwischen dem Erzähler und dem heiligen Gegenstand“. Bleumer: ,Historische Narratologie' (Anm. 13), S. 246. Kritisch zu Strohschneider, aber ohne ein prinzipielles Defizit der Sprache in der Konfrontation mit der Transzendenz auszuschließen: Cornelia Herberichs: „Der Erzähler ist uns keineswegs durchaus gegenwärtig“. Zu Benjamins Aura-Konzept in narratologischer Perspektive und zur Auratisierung legendarischen Erzählens im Väterbuch. In: Aura und Auratisierung. Mediologische Perspektiven im An- 
Dass sie auf Grund des Unsagbaren an ihre Grenzen geraten, thematisieren allerdings Franziskus-Hagiographen in ihrem Bestreben, das Mirakel evident in Worte zu fassen, äußerst selten. Dass etwas ungesagt bleibt, suggerieren sie im Lateinischen etwa durch die Verwendung des Begriffs „sacramentum", durch die unaussprechlichen „arcana“ oder in beiden Sprachen durch Inkonsistenzen im Bericht über den Visionsinhalt.

Komplementär dazu macht sich gerade im Deutschen eine „Zudringlichkeit der Erzählerstimme ${ }^{\prime 57}$ bemerkbar, die sich den metaphysisch bedingten Einschränkungen widersetzt (ohne sie aufzuheben). Während lateinische Berichte mitunter sogar teilnahmslos wirken, greifen die Übersetzer auf eine gattungsübergreifende Eigenart der mittelhochdeutschen Reimpaardichtungen zurück. Edith Feistner beobachtet, dass Lamprecht „fast konsequent unpersönliche Konstruktionen“ aus

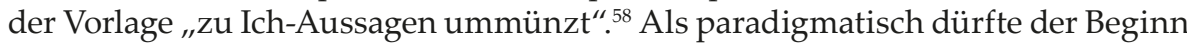
der Stigmatisierungsepisode in Sanct Francisken Leben gelten, wo es heißt: „Ich wil iu ein grôz wunder sagen“ (V.3368). ${ }^{59}$ Ähnlich attestiert Andreas Hammer dem Passional im Vergleich zur Legenda aurea eine „Verlebendigung der Erzählweise“.60 In markanten Erzählereinwürfen - die sie nicht in den Quellen vorfinden - stellen die deutschen Verfasser ihr rhetorisches Können aus und dem Mirakel gegenüber.

Im Passional tritt ein souveräner Berichterstatter in Erscheinung, der an der Schwelle der Diegese ${ }^{61}$ als Instanz figuriert, welche das Handeln des Protagonisten auch in der Zweisamkeit mit der Transzendenz lenkt. Mitten in der Schilderung der sechs Seraph-Flügel fällt sich der Erzähler selbst ins Wort: „,ey, Francisce, vollentrib / und schowe diz gevugele!“ (530,20f.; „Ei, Franziskus, vollende [es] und betrachte diesen Vogel!“). Der Verfasser beschreibt den großen Engel, das vogelartige Wesen im Präteritum und wechselt - im Sinne der Evidenzsteigerung - ins Präsens, um Franziskus als sein Gegenüber aus Fleisch und Blut anzusprechen. Der Blick des Begnadeten führt die Vision weiter bzw. zu Ende. Oder - so kann man die Formulierung auch verstehen - er vervollständigt die Engelsgestalt selbst,

schluss an Walter Benjamin. Hg. von Ulrich Johannes Beil, ders. und Marcus Sandl. Zürich 2014, S. 85-115.

57 Sonja Glauch: Ich-Erzähler ohne Stimme. Zur Andersartigkeit mittelalterlichen Erzählens zwischen Narratologie und Mediengeschichte. In: Historische Narratologie (Anm. 13), S. 149 185, hier S. 176.

58 Feistner: Historische Typologie (Anm. 28), S. 206f.

59 Auch im Passional steht schon zu Beginn des Franziskus-Kapitels fest, dass Gott an ihm „ein nuwe wunder" $(514,26)$ vollbracht hat. „Dass das Erkennen von Wundern [...] theologisch prekär ist, wird in den Legenden narrativ in der Regel mit großer Autorität seitens der Erzählerfigur, die jedes Wunder explizit als solches bezeichnet, gelöst bzw. umgangen." Miedema: Wunder sehen (Anm. 13), S. 346. Gerade die Stigmata waren höchst umstritten. Dazu vgl. etwa Klaus Schreiner: Soziale, visuelle und körperliche Dimensionen mittelalterlicher Frömmigkeit. Fragen, Themen, Erträge einer Tagung. In: Frömmigkeit im Mittelalter (Anm.5), S. 9-38, hier S. 34 .

60 Hammer: Inszenierung (Anm. 2), S. 348.

61 Überschritten wird diese Grenze in einer Metalepse zu Beginn des Franziskus-Kapitels, als der Erzähler und Franziskus ein Gespräch führen. 
und zwar gesteuert vom Verfasser, dem man freilich kein Zögern angesichts des Unaussprechlichen anmerkt.

Lamprecht, der, wie sich zeigte, zwischen Gelehrsamkeit und Armut im Geiste schwankt, verzichtet ebenfalls auf Unsagbarkeitsbeteuerungen, verfügt aber nicht über lückenloses Wissen. In der Intimität der Vision gerät Franziskus in einen emotionalen Zwiespalt:

daz in ansach der Seraphim,
des was er inneclîche frô:
daz er aber stuont gekriuzet sô,
dâvon er harte erschrac;
ich enweiz wederz vür daz ander wac. ${ }^{62}$

(Sanct Francisken Leben, V.3391-3395)

Lamprecht verweist pedantisch darauf, dass ihm präzisere Informationen zu den psychischen Vorgängen seines Protagonisten fehlen. Dadurch fällt aber umso mehr auf, dass das Wunder gerade kein Schweigen im detaillierten Erzählprozess erzwingt - wenngleich es die Kapazitäten der Sprache trotz (partieller) Sichtbarkeit prinzipiell übersteigt und sich Lamprecht (wie Celano) wohl deswegen nicht festlegt, ob Franziskus einen Mann oder einen Seraph schaut.

In beiden volkssprachlichen Texten platzt sozusagen die narrative Instanz in die persönliche Gnadenerfahrung des Heiligen hinein. Sie stellt dem Publikum das "secretum“ vor Augen, indem sie vor dem Numinosen gerade nicht zurückschreckt. Unsagbarkeit kann implizit reflektiert (bei Lamprecht), oder vorausgesetzt werden (im Passional). Theologische Begriffe, die das Bewusstsein der Ineffabilität transportieren („,sacramentum“, „mysterium“), werden nicht ins Deutsche übersetzt, der metaphysisch-,,geheimnisvolle[] Charakter "63 steht nicht im Vordergrund. Es etabliert sich kein äquivalenter Diskurs auf gleichem Abstraktionsniveau wie im Lateinischen.

Dafür haben die volkssprachlichen Verfasser im anschaulichen Erzählen über das verheimlichte Wunder die Zügel fest im Griff. Während (gerade in der franziskanischen Tradition) Gott am liebsten Ungebildete an seinen Mysterien teilhaben lässt, vermag das lateinunkundige, volkssprachliche Publikum, mit plastischen Darstellungen (Passional) und emphatischer Präzision (Sanct Francisken Leben) konfrontiert, Franziskus' Auszeichnung beinahe mit Händen zu greifen. Dass und wie Franziskus etwas verheimlicht, setzen alle Texte in Szene. Wie nachvollziehbar und in welcher Terminologie sich der (vom Heiligen geheim gehaltene) Eingriff der Transzendenz in die Immanenz versprachlichen lässt, variiert abhängig vom Rezipientenkreis.

62 Übers. Sanct Francisken Leben, V.3391-3395: „Dass ihn ansah der Seraph, darüber war er innerlich froh, dass er aber gekreuzigt war, darüber erschrak er sehr. Ich weiß nicht, was schwerer wog."

63 Kiening und Beil: Urszenen (Anm. 4), S. 176. 



\title{
Rhetorik und Parrhesia \\ Zum Offenbarungsmodus von Geheimlehren in Antike und Mittelalter
}

\author{
Yoshiki Koda
}

\begin{abstract}
Nû bite ich iuch, daz ir alsô sît, daz ir verstât dise rede; wan ich sage iu in der êwigen wârheit: ir ensît denne glîch dirre wârheit, von der wir nû sprechen wellen, sô enmuget ir mich niht verstân.

Nun bitte ich euch, ebenso (arm) zu sein, auf daß ihr diese Rede versteht: denn ich sage euch bei der ewigen Wahrheit: Wenn ihr dieser Wahrheit, von der wir nun sprechen wollen, nicht gleicht, so könnt ihr mich nicht verstehen. ${ }^{1}$
\end{abstract}

Dieses Wahrheitsgebot Meister Eckharts, ein Leitfaden für meine Untersuchungen zum Wahrheitswert der religiösen Sprache, klingt wie ein Paradox: Wer die Lehre der ewigen Wahrheit verstehen will, muss der Wahrheit gleich sein. Der Meister verlangt im Grunde sowohl von seinen Jüngern als auch von seinen Zuhörern, a priori seinesgleichen zu sein. Muss aber diese Forderung nicht so lange als widersprüchlich gelten, wie die Rezipienten noch gar nicht wissen, was die Wahrheit ist? Wie kann ein Mensch, bevor er belehrt wird, wahrheitsgleich sein? Man muss somit fragen: Was bedeutet die Wahrheit für ein Individuum, wenn es diese sein muss?

Die Religion verpflichtet die Gläubigen, wahrhaftig zu sein. Diese Pflicht mag auf einer individuellen Ebene, die allein auf die Gegenwart bezogen ist, erfüllbar sein; für die zeitübergreifende, ewige Wahrheit jedoch muss man stattdessen ,Wahrheitssager' wie Propheten, Sybillen und Priester anrufen. In der mythischen Zeit wurden Priester damit beauftragt, die wahre Zukunft und das wahre Schicksal zu verkündigen. Der Wahrheitsdiskurs hängt demnach eng mit dem wahrheitssprechenden Subjekt zusammen. Die ewige Wahrheit zu sagen, heißt, die Wahrheit über sich selbst zu sprechen. Michel Foucault hat neben den drei wahrheitssagenden Subjekten, nämlich dem Propheten, dem Weisen und dem Fachmann, noch ein viertes genannt: den Parrhesiasten, was im Altgriechischen der ,Freisprechende' be-

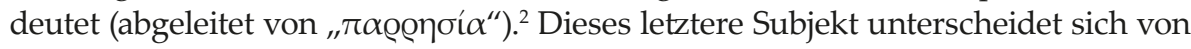

1 Meister Eckhart: Die deutschen Werke (DW). Bd. 2. Hg. und übersetzt von Josef Quint. Stuttgart 1971, S. 487, 5-7 und 727 (Übersetzung).

2 Michel Foucault: Der Mut zur Wahrheit. Die Regierung des Selbst und der anderen. Vorle- 
den vorherigen dreien hinsichtlich seines individuellen Charakters. Die Parrhesia ist also das ergänzende Charakteristikum historischer Wahrheitssprecher.

Diese vier Modalitäten des Wahrheitsprechens verbinden sich darüber hinaus, so Foucault, in verschiedenen Kulturen und Gesellschaften in vielfältiger Weise miteinander. Als bekanntester Parrhesiast im antiken Griechenland kann Sokrates gelten. Er war freier Sprecher und verstand es, die vier Modalitäten miteinander zu verknüpfen. Als die Athener das Orakel fragten, wer der weiseste Mensch Griechenlands sei, und der Delphische Gott antwortete, dass es Sokrates sei, begann dieser, als Parrhesiast die Leute zu belehren, um die Prophezeiung zu erfüllen. ${ }^{3}$ Er nahm dabei allerdings keine Autorität in Anspruch, sondern behauptete lediglich, dass er nichts wisse. Wegen seiner Unwissenheit musste er die Bürger selbst fragen und die Wahrheit gemeinsam mit ihnen suchen. Der Delphische Gott hatte ihm die Wahrheit anvertraut, Sokrates jedoch hat sie nicht priesterhaft verkündet, sondern leitete sie in einer parrhesiastischen Form an die Menschen weiter - in einer einfachen Volkssprache ohne Rhetorik. Seine freisprechende Dialektik säkularisiert also die göttliche Wahrheit und versinnbildlicht das Transzendente in sprachlich Begreifbarem.

Foucault untersucht nun, wie sich jene Formen des Handlungstyps manifestieren, gemäß welcher das Subjekt die Wahrheit sagt, d. h. wie der Mensch sich selbst als jemand vorstellt (bzw. von anderen als jemand erkannt wird), der die Wahrheit sagt. Das selbstbezogene Ich muss dafür durch ein Super-Ego aufgehoben werden.

Nach Foucault steht die sokratische Parrhesia historisch am Wendepunkt des Wahrheitssprechens vom staatlichen Akt zum Handeln, zum Verhalten und schließlich zum Sein des Individuums. Propheten, Sibyllen und Priester in der antiken Zeit haben für ihre Staaten wahrgesprochen, nicht für irgendein Individuum. Die Parrhesia hingegen stellt eine Individualisierung des staatlichen Aktes dar. Sie kann daher als Widerstand gegen die institutionalisierte Religiosität verstanden werden, die sich auch auf politischer Ebene legitimieren lässt und sich mit der Zeit in ein weltliches Herrschaftsmittel verwandelt. Die Parrhesia versucht, erstarrte religiöse Charismen wieder zu beleben. Sie setzt eine Zäsur im unbekümmert-routinehaften Glauben und beschwört die vergessenen Altgötter.

In den folgenden Abschnitten, in welchen die Offenbarungsmodi des hermetischen und religiösen Geheimnisses analysiert werden, soll der Poet als dritte wahrheitsbezogene Person an die Stelle des Fachmanns gesetzt werden, weil er seit der Antike als Verkünder der Wahrheit die Prophezeiung funktionell ergänzt hat. Beide haben, als Sprachrohr Gottes, nicht nur das religiöse und ethische Leben in der griechischen Polis oder dem römischen Imperium beeinflusst, sondern auch die Aktivitäten der mittelalterlichen Mystiker und Mystikerinnen im deutschsprachigen Raum vorbereitet.

sungen am Collège de France (1983/84). Frankfurt a. M. 2010, S. 42f.; ders.: Hermeneutik des Subjekts. Vorlesungen am Collège de France (1981/82). Frankfurt a. M. 2009, S. 453f.

3 Platon: Des Sokrates Apologie. In: Werke in acht Bänden. Griechisch und Deutsch. Bd. 2. Hg. von Heinz Hofmann. Darmstadt 1990, hier Kap. 6 f. 


\section{Der Dichterprophet als Figur der wahnsinnigen Gotteseingebung}

Die Inschrift an der Vorhalle des Delphischen Tempels "gnothi seauton“ (Erkenne dich selbst) wurde das ganze Mittelalter hindurch als Aufforderung zur vernünftigen Selbstreflexion verstanden. ${ }^{4}$ Tatsächlich aber wurde sie im griechischreligiösen Kontext eher als Mahnung zur Bescheidenheit aufgefasst, die Gott an den sterblichen Menschen richtete. Das Orakel erging zwar direkt an die Tempeldienerin Pythia (puthiā), das im geistigen Rausch geoffenbarte Geheimnis aber musste dann von einem eingeweihten Priester (prophetes) gedeutet werden. ${ }^{5}$ Das Delphische Motto befiehlt also dem Interpreten (mantis), nicht über die Grenze des menschlichen Vermögens hinauszugehen. Die göttliche Vorhersehung sollte somit unerreichbar bleiben. Das Geheimnis Gottes wird deshalb in Korrelation von einer über den Intellekt hinausgehenden Geisteslage und einer zur Überlegung bestimmten analytischen Fähigkeit verkündigt. ${ }^{6}$

Platon sieht als Quelle des visionären Vermögens der Sibylle den Körper (genauer: die Leber) und als jene des Traumdeutens den Verstand. ${ }^{7}$ Er nimmt aber eine ambivalente Haltung zum Grundkonzept von ,Seher' ${ }^{\prime}$ und ,Deuter' ein: Im Timaios wird betont, dass die Priester „Dolmetscher der rätselvollen Stimme und Erscheinung, nicht aber Seher sind, und mit dem größten Rechte wohl Verkünder von Wahrsagenden genannt werden dürften“ (Timaios, 72b). Im Phaidros bekräftigt Sokrates hingegen den Beitrag der Seherinnen zur Wahrheitsverkündung ganz ausdrücklich: „Denn die Prophetin zu Delphi und die Priesterinnen zu Dodone

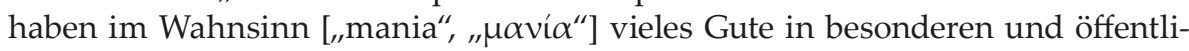
chen Angelegenheiten unserer Hellas zugewendet, bei Verstande aber Kümmerliches oder gar nichts ${ }^{\prime 8}$ Die Neueren hätten aber, so Sokrates, ungeschickterweise den Namen „Wahnsagekunst“ mit dem Konsonantenwechsel zwischen R und N

4 Alois M. Haas: Nim din selbes war. Studien zur Lehre von der Selbsterkenntnis bei Meister Eckhart, Johannes Tauler und Heinrich Seuse. Freiburg i. Ü. 1971.

5 Diese Doppelstruktur der Geheimnisverkündigung lässt sich z. B. in der Traum-Szene Kriemhilds am Beginn des Nibelungenliedes aufzeigen. Dort übernimmt Kriemhild die Rolle einer göttlich inspirierten Sibylle, ihre Mutter Ute die einer Traumdeuterin, welche die Vision in menschliche Sprache transformieren („,besceiden“) kann. Siehe: Das Nibelungenlied. Nach der Handschrift B hg. von Ursula Schulze, ins Neuhochdeutsche übersetzt und kommentiert von Siegfried Grosse. Stuttgart 2011, S. 8, Str. 12 (14).

6 Gregory Nagy: Ancient Greek Poetry, Prophecy, and Concepts of Theory. In: Poetry and Prophecy. The Beginnings of a Literary Tradition. Hg. von James L. Kugel. Ithaca, London 1990, S. 56-64, hier S. 61. „The prophètēs declares, formalizes as a speech-act, the words of the inspired mantis.“ Das griechische Wort „prophetes“, dessen Präfix ",pro-“ eigentlich ein Substitutionsverhältnis anzeigt und keinen zeitlichen Vorrang impliziert, wurde als ,Vorher-Sager' mit der Präfiguration des Neuen Testaments missverständlich verbunden. Dazu siehe Herbert Marks: Der Geist Samuels. Die biblische Kritik an prognostischer Prophetie. In: Prophetie und Prognostik. Hg. von Daniel Weidner und Stefan Willer. München 2013, S. 99-121, hier S. 102.

7 Platon: Timaios. In: ders.: Werke (Anm. 3), Bd. 7, S. 151, 72b.

8 Platon: Phaidros. In: ders.: Werke (Anm. 3), Bd. 5, S. 63, 244a-b. 
zur „Wahrsagekunst“ gemacht (Phaidros, 244c), so dass die bloß menschliche Verstandeskraft dem göttlichen Wahnsinn überlegen zu sein scheint. ${ }^{9}$

Die Relation zwischen „mania“ und „mantis“ ist in den platonischen Schriften also ganz unterschiedlich gestaltet. Gemeinhin aber gilt in der griechischen Antike die positive Ansicht vom Wahnsinn als kreativem dichterischem Vermögen. Pindar z. B. hält „mantis“ für den Wahnsinn, der den Poeten überfällt und den der Prophet in menschliche Sprache übersetzt. ${ }^{10}$ Beide werden im Phaidros funktionell eng zusammengedacht. Ein wahnsinnig gewordener Prophet kann einerseits seinem ",aus altem Zorn in Not stehenden Geschlecht", „zu Gebeten und Verehrungen der Götter fliehend und dadurch reinigende Gebräuche und Geheimnisse erlangend“, Erlösung bringen (Phaidros, 244d-e). Neben den Sibyllen und den Propheten wird noch "eine zarte und heilig geschonte Seele“ als dritte von den $\mathrm{Mu}$ sen aufgeregt und befeuert, die „in festlichen Gesängen und anderen Werken der Dichtkunst tausend Taten der Urväter" ausschmückt (Phaidros, 245a). Andererseits ist ein Dichter, der „ohne diesen Wahnsinn der Musen in den Vorhallen der Dichtkunst sich einfindet", „ungeweiht" (ebd.). Da die Schönheit dabei als Katalysator für die Erinnerung funktioniert, ist die Dichtkunst eigentlich an die Vergangenheit gerichtet. (Phaidros, 249d-250c).

Wackers Studie hat erhellt, dass Poeten als Sprachrohr der Götter bis in die Moderne ähnliche Funktionen innehaben wie die Propheten. ${ }^{11}$ Voneinander distanziert sind Wahr- und Wahnsager jedoch hinsichtlich ihrer gesellschaftlichen Positionen, ihrer Zielgruppen, ihrer stilistischen Eigenarten und ihrer Erscheinungsformen. Im Folgenden soll daher die innere Konstruktion des Seher-Dichter-Komplexes näher analysiert und schematisiert werden.

\section{Paradox des Geheimnisses}

Hier soll zuerst der Psychologie der Wahrheitssprecher Rechnung getragen werden, um zu verstehen, wie sie sich als Eingeweihte und Verkünder der ihnen anvertrauten Geheimnisse gegenüber ihren Gegenspielern verhalten.

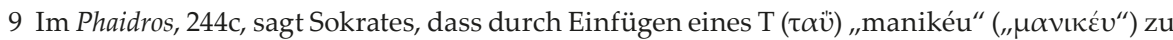

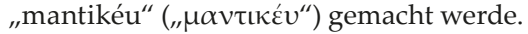

10 „Gib mir, Muse, ein Orakel und ich soll dein Prophet (Übersetzer) sein“. Pindar: Fragment 150. In: ders.: Nemean Odes, Isthmian Odes, Fragments. Hg. von William H. Race. Cambridge, MA, London 2006, S.378f.

11 Gabriela Wacker: Poetik des Prophetischen. Zum visionären Kunstverständnis in der klassischen Moderne. Berlin, Boston 2013. Natürlich stellt sich die Frage, ob der prophetische Charakter der altgriechischen Poeten noch bei den sog. Minnesängern im Mittelalter wirksam war. Ruh sieht die „Dichter im wahrsten Sinne des Wortes", wie Dante, Walther von der Vogelweide, Heinrich von Morungen usw., im Prinzip auf dem „Pfad der strengen und korrekten mittelalterlichen Dichtungslehre“, weist aber darauf hin, dass „zweckmäßige Gebrauchsliteratur unmittelbar in Poesie umschlagen“ kann. Kurt Ruh: Poesie und Gebrauchsliteratur. In: Poesie und Gebrauchsliteratur im deutschen Mittelalter. Hg. von Volker Honemann u. a. Tübingen 1979, S. 1-13, hier S. 5. 
Georg Simmel hat das Vertrauen ins Zentrum seiner Gesellschaftsanalyse gestellt. ${ }^{12}$ Durch Vertrauen und Diskretion baut man rechtlich feste Verhältnisse zu seinen Partnern auf. Simmel fügt jedoch hinzu, dass Vertrauen nicht die einzige Bedingung für die Möglichkeit von Beziehungen darstelle, denn

der ganze Verkehr der Menschen [ruht] darauf, daß jeder vom anderen etwas mehr weiß, als dieser ihm willentlich offenbart, und vielfach solches, dessen Erkanntwerden durch den andren, wenn jener es wüßte, ihm unerwünscht wäre. ${ }^{13}$

Dies könne im individuellen Sinne als Indiskretion gelten, im sozialen aber erforderlich sein. ${ }^{14}$ Wir bedürfen also nicht nur

[...] einer bestimmten Proportion von Wahrheit und Irrtum als Basis unsres Lebens [...], sondern auch einer solchen von Deutlichkeit und Undeutlichkeit im Bilde unsrer Lebenselemente. Was wir bis auf den letzten Grund deutlich durchschauen, zeigt uns eben damit die Grenze seines Reizes, und verbietet der Phantasie, ihre Möglichkeiten darein zu weben..$^{15}$

Die Lebenslust liegt im Spannungsfeld von Offensichtlichem und Verborgenem. Das Geheimnis ist deshalb attraktiv, weil es paradoxerweise für den Verrat bestimmt ist. ${ }^{16}$ „Das Geheimnis legt eine Schranke zwischen die Menschen, zugleich aber den verführerischen Anreiz, sie durch Ausplaudern oder Beichte zu durchbrechen. ${ }^{{ }^{17} 7}$ Diese Paradoxie bestimmt die Erzählwelt der Literatur. Sowohl die Geschichten im Alten und Neuen Testament als auch die profane Literatur im Mittelalter, wie Heldenepen, Kurzerzählungen, Fabeln, Märchen und Konfessionen, zeichnen sich durch diese widersprüchliche Struktur von Verstecken und Verraten aus. Zahlreiche Manipulationsmanöver der Ehebrecher im Tristanroman, die Entlarvung des Inzestgeheimnisses bei Gregorius, die Mordintrige von Hagen

12 Georg Simmel: Soziologie. Untersuchungen über die Formen der Vergesellschaftung. In: ders.: Gesammelte Werke Bd. 2. Berlin 1968.

13 Simmel: Soziologie (Anm. 12), S. 267.

14 Vgl. ebd.

15 Simmel: Soziologie (Anm. 12), S. 271.

16 Darbord unterscheidet mit Recht zwischen dem erzählerischen Geheimnis („,secret“) und dem religiösen Mysterium („mysterie“). In profanen Prosaerzählungen wie Tausendundeine Nacht gehören „la dissimulation d'un secret et sa révélation“ zusammen, während das Mysterium in den altgriechischen Kulten seinen Ort hat, die ihren Teilnehmern ein strenges Schweigegebot auflegten. Dazu siehe Bernard Darbord: Le secret dans les contes et exempla du Moyen Âge espagnol. In: Le partage du secret. Cultures de dévoilement et de l'occultation en Europe du Moyen Âge à l'époque moderne. Hg. von Bernard Darbord u. a. Paris 2013, S. 123-141, hier 125f.; R. Stupperich: [Art.] Mysterium. In: Historisches Wörterbuch der Philosophie. Bd. 6. Hg. von Joachim Ritter und Karlfried Gründer. Basel 1984, S. $263 f$.

17 Simmel: Soziologie (Anm. 12), S. 275. Simmel vergleicht das Geheimnis mit dem Geld: „das mit dem Geldbesitz gegebene Machtgefühl konzentriert sich für die Seele des Verschwenders am vollständigsten und lustvollsten in dem Augenblick, wo er diese Macht aus den Händen gibt" (ebd., S. 274). Von dieser Lust des Geheimnisbesitzers haben am meisten die mittelalterlichen Klosterfrauen profitiert, wenn sie schrieben. Dazu siehe Anm.39. 
und Gunther gegen Siegfried - die mittelalterlichen Leser und Hörer waren mit einer entsprechenden psychologischen Spannung vertraut.

Die Geheimnisstudie Simmels, deren Ziel eine soziologische Strukturanalyse arkaner Gesellschaften ist, konstatiert, dass Geheimbünde, wie die Pythagoräer, die Freimauer oder gallische Druiden, dem Aufnahme suchenden Jüngling Schweigen auferlegt haben, und dass letzterer durch das Einhalten der Schweigepflicht das Vertrauen anderer Mitglieder gewonnen habe. ${ }^{18}$ Schweigen ist zwar die Voraussetzung für den Eintritt in einen institutionalisierten religiösen Geheimbund, es verspricht einem Novizen aber nicht immer die persönliche Unio-Erfahrung. Gott legt sein Wort eher einem Wüsteneinsiedler in den Mund.

\section{Authentizität der Prophetie}

Die Art und Weise, in welcher die Aussage eines Propheten öffentlich als authentisch anerkannt wird, scheint abhängig von der Religionsstruktur eines Volkes zu

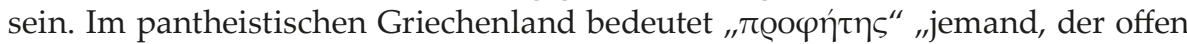
heraus erklärt, öffentlich bekannt macht, verkündet.." ${ }^{\prime 19}$ Wie später noch erläutert wird, ist er selbst kein Empfänger der göttlichen Eingebung, sondern jemand, der ratsuchenden Personen verkündete Orakelsprüche deutet. Im arabisch-hebräischen Kulturraum bedeutet „nābî" ,jemand, der etwas ausruft oder andere anruft. ${ }^{\prime 20}$ Er spielt also sowohl eine passive als auch eine aktive Rolle bei der Orakeldeutung; als ein von Jahwe erwählter Verkünder deutet er dem israelischen Volk die Gegenwart und sagt ihm die Zukunft vorher. Während die griechischen Orakeldeuter lediglich in engeren Kreisen tätig sind, übernimmt der "nābî" öffentliche Funktionen für ein monotheistisches Volk. Er ist einerseits unerbittlicher Gesellschaftskritiker und andererseits Berater seines Königs. ${ }^{21}$

Um sich den Volksmassen kritisch gegenüberzustellen, bedient er sich mit einer ausdifferenzierten Gestik performativer, persuasiver und provokativer Ausdrucksmittel, welche ihm die Authentizität verbürgen sollen. ${ }^{22}$ Der göttlich Inspirierte ist also nicht nur ein Sprachrohr Gottes, sondern er muss trotz vollkommener Passivität bei der Verinnerlichung seiner Erfahrungen zu einem aktiven Redner werden. Diese „Doppelnatur von Objekt- und Subjekt-Sein“23 des Propheten verleiht seinem Leben einen dramatischen Zug. Manche Propheten

18 Simmel: Soziologie (Anm. 12), S. 285.

19 Jan Dietrich: [Art.] Prophetenrede. In: Historisches Wörterbuch der Rhetorik. Bd.7. Hg. von Joachim Ritter und Karlfried Gründer. Basel 1989, S. 290-307, hier S. 290.

20 Dietrich: Prophetenrede (Anm. 19), S. 290.

21 Dietrich: Prophetenrede (Anm. 19), S. 291.

22 Wacker erläutert, sich auf eine Studie Malinowskis stützend, diese persuasive Struktur folgendermaßen: „,Diese typischen Invokations- und Berufungsdichtungen ,dienen der Rechtfertigung und Legitimation der herausragenden Position des Sehers innerhalb der Sozietät und liefern den nachhaltigen Beweis über die Authentizität und Objektivität des Offenbarten"“. Wacker: Poetik (Anm. 11), S. 29. Siehe noch: Bernadette Malinowski: Das Heilige sei mein Wort. Paradigmen prophetischer Dichtung von Klopstock bis Whitman. Würzburg 2002, S. 33f.

23 Wacker: Poetik (Anm. 11), S. 30. 
sträuben sich gegen den göttlichen Auftrag, fliehen davor und befolgen den Ruf erst, nachdem sie sich ihres Auftrags bewusst werden. Als solche ungehorsamen Gottesfreunde gelten Mose, Jesaja, Jeremia, Jona usw. ${ }^{24}$ Unter ihnen ist Jona die interessanteste Figur, die für den Wahrheitsdiskurs viele Anhaltspunkte liefert. Anders als normative Wahrsager im Alten Testament, deren Autorität mehr oder weniger gesichert ist, hadert Jona mit seinen menschlichen Schwächen. Als Gott ihm befiehlt, in die Hauptstadt von Assyrien, Ninive, zu gehen und gegen ihre Bewohner zu predigen, lehnt er sich dagegen auf; jedoch nicht aus Bescheidenheit, wie Jeremia (1,6: „Ach, mein Gott und Herr, ich kann doch nicht reden, ich bin ja noch so jung"), sondern aus Furcht: Eine Bußpredigt vor dem heidnischen Volk von Ninive würde ihn in Lebensgefahr bringen. ${ }^{25}$ Er flieht und begeht damit die Sünde des Ungehorsams, woraufhin Gott dafür sorgt, dass ihn ein großer Fisch verschluckt. Der biblische Autor markiert die innerliche Wende des ungehorsamen Mannes mit dem Wechsel seines Sprechaktes. Während seines dreitägigen Aufenthalts im Fisch wird Jona seines Irrtums gewahr und ,singt' ein psalmähnliches Danklied in Versform, welches - im Gegensatz zu den Götzenverehrern - seine Opferbereitschaft genau für das ausspricht, was er lobt: „Die Anhänger eitler Nichtse (Götzen)/ müssen ihre Liebe lassen./ Ich aber, mit lautem Lob/ will ich dir opfern,/ was ich gelobt,/ will ich erfüllen.“26

Die Nahtoderfahrung macht Jona zu einem gottnahen Propheten und schärft seine Sensibilität für die Bedeutung des Gebots. Als das Wort Jahwes zum zweiten Mal an ihn ergeht, nimmt er die konkrete Zeitangabe „Noch vierzig Tage, und Ninive ist zerstört!" wahr. ${ }^{27}$ Diese präzise Ankündigung stiftet unter dem Volk so große Unruhe, dass es mitsamt dem König sofort Buße tut. Dieser Umstand hält Gott letztlich davon ab, sein Strafgericht auszuführen, was wiederum Jona missfällt, da ihm die nicht verwirklichte Prophetie nichts Anderes zu sein scheint als der bloße Verrat eines Geheimnisses. Zwischen Gott und Prophet entsteht nun, auf anderer Ebene, ein erneuter Vertrauensbruch, denn Jona missversteht in diesem Moment die übernommene Aufgabe, sind Propheten doch „nicht Lehrer des Gesetzes, keine Wahrsager im strengen Sinn, sondern eher Mahner zur Gesetzobservanz, sofern Gegenwärtiges als unrecht, gewalttätig oder gesetzwidrig empfunden wird. ${ }^{228}$ Jahwe will den ungehorsamen Jona diesmal nicht bestrafen, sondern mit dem Gleichnis vom Rizinusstrauch belehren. Gottes Geheimnis wird den

24 Wacker: Poetik (Anm. 11), S. 24. Die betreffenden Stellen sind: Ex 4,10f.; Jes 1,6-13; Jer 1,4-10; Jon 1,3-16.

25 Der wahre Grund für die Befehlsverweigerung wird nicht ganz klar, erfährt man doch später, dass Jona nur befürchtet, dass Jahwe gegenüber den Heiden barmherzig sein könnte. Weiser versteht diese Geschichte als die einer Konversion Jonas' vom patriotischen Judaismus zum barmherzigen Kosmopoliten. Dazu siehe Artur Weiser: Das Alte Testament deutsch. Neues Göttinger Bibelwerk. Bd. 24. (Das Buch der zwölf Kleinen Propheten I), Göttingen 1979, S. 439.

26 Das Buch Jona 2,9-12. Übersetzung von Weiser (Anm. 24).

27 Pierre Boutang: Ontologie du secret. Paris 1973, S. 149.

28 Lukas Pallitsch: [Art.] Prophetie. In: Handbuch Literatur und Religion. Hg. von Daniel Weidner. Stuttgart 2016, S. 423-427, hier S. 423. 
ungehorsamen Menschen durch Unheilprophetie und Gleichnisrede vermittelt. Diese antworten ihrerseits mit Singen und Büßen. Im Folgenden soll entsprechend die Funktion der Dichterkunst in der Prophezeiung betrachtet werden.

\section{Kombination von Prosa und Vers in der Prophetie}

Die ursprünglich getrennten Funktionen von Seher/in und Prophet scheinen mit der Entstehung Israels zu einer einzigen verschmolzen zu sein. Der folgende Kommentar zum Begriff, Seher' aus dem Alten Testament macht diesen Prozess erkennbar: „Früher sagte man in Israel, wenn man hinging, um Gott zu befragen: Wir wollen zum Seher gehen. Denn wer heute Prophet genannt wird, hieß früher Seher" (I Sam 9,9).$^{29}$ Der Prophet des Alten Testaments hat also eine eher schamanistische Funktion übernommen; er hat Visionen gesehen und ist in dem Maße selbst in Verzückung geraten, wie er, anders als griechische Priester, ein Orakel nicht für den privaten Zweck interpretiert, sondern als staatliches Organ des Volkes Israel. ${ }^{30}$

Der schamanistische Charakter des Propheten ist an einer Stelle des ersten Buchs Samuel besonders gut erkennbar (I Sam 9,15). Samuel wurde von Gott beauftragt, einen Jungen namens Saul aus dem Gebiet Benjamins zum Fürsten des israelischen Volks zu salben. Samuel prophezeit, Saul werde eine Schar von Propheten treffen, die von der Kulthöhe herabkommen, und vor ihnen werde Harfe, Pauke, Flöte und Zither gespielt (I Sam 10,15). Die Musik bringt Saul derart in Verzückung, dass er selbst prophezeien kann, wodurch dieser musikalische Prophetenzug die enge Beziehung zwischen Dichtung und Geheimlehre andeutet. Die rauschhafte Wirkung der Musik lässt sich auch bei Elischa ersehen, der beim Harfenspiel sofort in Verzückung gerät und Visionen erhält (II Könige 3,15f.). Die Musik wird natürlich in einem bestimmten Rhythmus, nach einer bestimmten Metrik gespielt und kann insofern als "accounterment[s] of poetry“ (Kugel) am meisten zur Verkündigung göttlichen Mysteriums beitragen. ${ }^{31}$

Es ist umstritten, ob die alttestamentlichen Prophetenschriften in hebräischen Versen geschrieben wurden. Einige Hebraisten, wie Philip Sidney, George Puttenham und Thomas Lodge, haben in ihren historischen Studien betont, dass David, Salomon und andere Propheten zugleich Poeten gewesen seien und in metrischer

29 Neue Jerusalemer Bibel. Hg. von Alfons Deissler und Anton Vögtle. Freiburg i. Br. 1985. Die Doppelnatur der Schamanen und der Staatspropheten ist auch bei Jesaja (8,1-4) zu ersehen: Er erhält einen magischen Namen „Raubebald-Eilebeute“, verkündigt und deutet ihn dem Volk. Vgl. Reinhard Gregor Kratz: Prophetenstudien. Kleine Schriften II. Tübingen 2017, S. 24f. Das Konzept vom göttlich inspirierten Dichter wird nach Kugel von Alexander dem Großen aus Griechenland in die semitische Welt eingeführt. James L. Kugel: Poets and Prophets. An Overview. In: Poetry and Prophecy. The Beginnings of a Literary Tradition. Hg. von James L. Kugel. Ithaca, New York, London 1990, S. 1-25, hier S. 13f. Zur enthusiastischen Grundbedeutung vom hebräischen „nābîi” siehe Marks: Der Geist Samuels (Anm. 6), S. 102f.

30 Dies besagt jedoch nicht, dass er ein staatshöriger Hofprophet sei. Er hat als Einsiedler zum Staat eine gewisse Distanz gehabt und bei jeder Prophetie von den Befragten Geschenke verlangt. Vgl. Num 22,7; I Kön 14,3; II Kön 4,42; 5,15; 8,8 und Sam 9,8.

31 Kugel: Poets and Prophets (Anm. 28), S. 5. 
Sprache geschrieben hätten. ${ }^{32}$ Auch Max Wehrli glaubt, im biblischen Offenbarungswort selber Spuren metrischer Ordnung nachweisen zu können. ${ }^{33}$ Diese Thesen lassen sich jedoch kaum stichhaltig begründen, weil die Ausspracheregeln des Hebräischen nicht erhalten sind und sein metrisches System nicht rekonstruierbar ist. Anstatt die alttestamentarischen Dichtungen unter dem Gesichtspunkt griechischer Metrik und Reimstrukturen zu untersuchen, schlägt Kugel mit dem Parallelismus eine andere Verslehre vor:

Rather, the basic feature of biblical songs - and, for that matter, of most of the sayings, proverbs, laws, laments, blessings, curses, prayers, and speeches found in the Bible - is the recurrent use of a relatively short sentence-form that consists of two brief clauses. ${ }^{34}$

Diese Quasi-Metrik zeigt sich am deutlichsten in Psalm 94, in dem einzelne Teilsätze (clauses), z. B. „Gott der Vergeltung“ oder „Wie lange noch dürfen die Frevler", wiederholt werden. Dies erwecke „a feeling of correspondence between the two parts", worin Kugel eben jene hebräische Art der Satzverbindung sieht, die Robert Lowth , parallelismus membrorum' genannt hat. ${ }^{35}$

Abgesehen von der Debatte um die Existenz einer hebräischen Metrik stellt sich zumindest die Frage, ob die Dichterpropheten anhand ihrer rhetorischen Künste mit gewissen Effekten auf die Zuhörer rechnen konnten. Eine Prophetengeschichte aus dem 4. Buch Mose (Numeri) scheint das zu belegen:

Balak, der König von Moab, erschrak vor der wachsenden Kraft der Israeliten und flehte den Wahrsager Bileam an, dieses Volk zu verfluchen. Bileam ließ sieben Altäre herrichten und auf jedem Altar einen jungen Stier und einen Widder darbringen. Dann legte ihm Gott seine Worte in den Mund. Allerdings verbat er Bileam den Fluch und befahl ihm dreimal, nur zu tun, was er ihm gesagt hatte (Num 22,20; 35 und 23,12). Als Gott aber sah, dass Balak nicht aufgab und Bileam immer eindringlicher auf das Verfluchen drängte, gab er Bileam folgenden Orakelspruch ein:

32 Kugel: Poets and Prophets (Anm. 28), S. 21f. Es genügt, hier nur einen Autor zu zitieren. Georg Puttenham (1532-1590) schreibt: „King David also and Solomon his sonne and many other of the holy Prophets wrate in meeters, and used to sing them to the harpe, although to many of us, ignorant of the Hebrue language and phrase, and not observing [that is, scanning] it, the same seeme but a prose." Ders.: The Arte of English Poesie. In: English Literary Criticism. The Renaissance. Hg. von O. B. Hardison. New York 1963, S. 153.

33 Max Wehrli: Literatur im deutschen Mittelalter. Eine poetologische Einführung. Stuttgart 1984, S. 185: „Es gilt, gegenüber der Homerischen Dichtung das höhere Alter biblischer Poesie nachzuweisen. Nach einer Theorie des Flavius Josephus, die Hieronymus übernahm, liegen in den Mosaischen Büchern Hexameter vor, von den Versen der Psalmen ganz abgesehen."

34 James L. Kugel: The Idea of Biblical Poetry. Parallelism and Its History. Baltimore, London 1981/1996, S.1.

35 Robert Lowth: Lectures on the Sacred Poetry of the Hebrews. Hildesheim 1969 (Faksimileausgabe von 1753). Vgl. dazu Chiara Conterno: Die andere Tradition. Psalm-Gedichte im 20. Jahrhundert. Göttingen 2014, S. $23 f$. 
Aus Aram führte mich Balak her,/ der König von Moab vom Ostgebirge:/ ,Geh, verfluche mir Jakob!/ Geh, drohe Israel!'/ Doch wie soll ich verwünschen,/ wen Gott nicht verwünscht,/ wie soll ich drohen,/ wem Jahwe nicht droht? (Num 23,7f.)

Der in Versform gesungene Spruch stellt einen deutlichen Kontrast zur bisherigen Antwort dar. Bileam segnete sogar die Israeliten und wusste, dass es dem Herrn recht war. Der König gab aber nicht auf und bat den Propheten zum dritten Mal um Hilfe. Bileam suchte dann nicht „geheimnisvolle Zeichen, wie er sonst zu tun pflegte, sondern wandte sein Gesicht der Wüste zu“ (Num 24,1). Da kam der Geist Gottes über ihn und Bileam geriet in prophetische Ekstase.

Durch die Intensivierung der göttlichen Eingebung erfährt die prophetische Attitüde Bileams eine qualitative Veränderung: Er ist nicht mehr bloß Zeichenleser, sondern ein sibyllinischer Visionär. Seine epileptische Geisteslage („Er fällt, und seine Augen sind aufgetan", Num 24,4) kennzeichnet den Übergang im Sprachakt von der Prosa zur figurativen Sprache. Bileam verweigert Balak zum dritten Mal seine Bitte und sagt:

Gott hat sie [die Israeliten] aus Ägypten geführt./ Er hat Hörner wie ein Wildstier./ Zauberei wirkt nicht gegen Jakob./ Beschwörung hilft nicht gegen Israel./ [...] ein Volk wie ein Löwe, der aufsteht,/ wie ein Raubtier, das sich erhebt./ Es legt sich nicht hin,/ bevor es die Beute gefressen/ und das Blut der Erschlagenen getrunken hat. (Num 23,22-24)

Diese Aussage in Versform nimmt eine magische Wirkung in Anspruch, die gegenüber den Gegnern die Herrschaft und die Überlegenheit der Israeliten legitimiert. Bileam prophezeit dann den Untergang des Reichs von Moab: „Ein Stern geht in Jakob auf,/ ein Zepter erhebt sich in Israel./ Er zerschlägt Moab die Schläfen/ und allen Söhnen Sets den Schädel“ (Num 24,17).

Soweit Prophetie und Poesie aus derselben sibyllinischen Begabung entspringen, ist ihr Zweck nicht in erster Linie in der Ästhetik, sondern in der Offenbarung der Gewalt Gottes zu sehen. Die Poesie unterscheidet sich zudem in ihrer Beschwörungsart von der Prophetie: Während diese an die Zukunft gerichtet ist, beschwört jene die Vergangenheit. Die Propheten kritisieren die Korruption der Welt und verkündigen ein Unheil. Die Poeten hingegen erzählen von mythischen Zeiten und loben die glorreichen Taten der Helden. Ihr Lobgesang und ihre Hymnen verzweifeln keineswegs am Bestehen der Welt, denn die Welt ist Gottes Schöpfung, ein göttliches Ethos mithin, und insofern lobenswert.

\section{Poetische Geheimlehre}

Während der Prophet mit der Öffentlichkeit verbunden ist, tritt der Poet eher in einem relativ geschlossenen, privaten Anhängerkreis auf. Beide sind von Gott ,erwählt', und dieses Elitebewusstsein verkörpert sich beim Propheten im Charisma, das auf der Anerkennung eines ganzen Volks aufbaut; bei den Poeten hingegen kann es ein Stigma sein, das sich im schöpferischen Prozess als Weltschmerz aus- 
drückt. Wacker sieht die Grundkonstellation von Stigma und Charisma auf die Inszenierung von Dichter-Propheten oder deren literarische Propheten-Figurationen übertragbar. Charisma und Stigma gehören in der Form zusammen, dass das Stigma regelrecht zur dichterischen Karriere aufgewertet werden kann. ${ }^{36}$ Auch mittelalterliche Mystikerinnen eignen sich wegen ihrer schriftstellerischen Begabungen sowohl priesterliche Charismen als auch Stigmata im Sinne der Märtyrer an. Durch ihren speziellen Status in der Kirche ohnehin gesellschaftlich stigmatisiert, wenden sie eine merkwürdige, paradoxe Strategie an, um ihre soziale Integrität wiederzugewinnen: die Selbststigmatisierung. ${ }^{37}$ Für diesen Zweck aktivieren sie die traditionellen Sprechkünste in einer neuen Dimension.

Die geistliche Literatur des Mittelalters ist durch vielfältige Sprechakte charakterisiert. Sie kann in monologischer Sprachform (Gebet, Beichte, Rezitation usw.), in dialogischer Form (Lehrgespräch, geistliches Spiel usw.), in rhetorischer Form (Prophezeiung, Loblied, Gleichnisrede usw.), in sinnlich-ästhetischer Form (visionäre Literatur, ekstatische Zungenrede usw.) oder in intellektuell-kontemplativer Form (Theologie, Traktat, Predigt usw.) manifest werden. All diese Realisierungsweisen und Sprechakte zielen darauf, das Geheimnis Gottes in der gesellschaftlichen Kommunikation zum Ausdruck zu bringen, ohne dessen sakralen Charakter zu verlieren.

Die Sprache der Mystik aber ist keine Sprache der Eloquenz. Kaum, dass sie von Gott redet, stößt sie auf sprachlich Unfassbares und wird zum Schweigen gebracht. Der Herausgeber der deutschen Werke Meister Eckharts, Josef Quint, hat daher die Funktion der mystischen Sprache darin gesehen, dass sie die Grenze zwischen Gott und Mensch sprengt und dass sie insofern eine „Sich-überschreitende Sprache" sei.

Walter Haug hat dieses seit Quint in der Mystikforschung dominante Schema vom „Kampf der Sprache mit dem Unaussprechlichen“ in Frage gestellt:

Die Sprache wird nicht vom überwältigenden mystischen Erlebnis her gesprengt - bei dieser Meinung hat anachronistisch die moderne Sprachskepsis mit ihrem Antagonismus zwischen Leben und Wort Pate gestanden. ${ }^{38}$

36 Wacker: Poetik (Anm. 11), S. 85f.

37 Lipp erläutert die Mechanismen, in denen sich Stigmatisierte und Selbststigmatisierer stufenweise zu Charismatikern entwickeln, folgendermaßen: „Wenn der besondere normative Druck, der in Gesellschaften wirkt, Normenbrecher zwar primär erfasst, tendenziell aber verzweigte, auch umstehende Gruppen betrifft, springen Selbststigmatisierer, die sich dem Druck entgegenstellen, für andere in die Bresche. Sie können aufsteigen zur Leitfigur. Wenn sie schließlich von breiteren sozialen Bewegungen getragen werden, nimmt Selbststigmatisierung die Züge von Begnadung an, sie schlägt um in Charisma." Wolfgang Lipp: Außenseiter, Häretiker, Revolutionäre. Gesichtspunkte zur systematischen Analyse. In: Religiöse Devianz in christlich geprägten Gesellschaften. Vom hohen Mittelalter bis zur Frühaufklärung. Hg. von Dieter Fauth und Daniela Müller. Würzburg 1999, S. 13-26, hier S. 21; siehe auch ders.: Stigma und Charisma. Über soziales Grenzverhalten. Berlin 1985, S. 14 und 202.

38 Walter Haug: Das Gespräch mit dem unvergleichlichen Partner. Der mystische Dialog bei Mechthild von Magdeburg als Paradigma für eine personale Gesprächsstruktur. In: ders.: 
Die Sprache sei vielmehr, so Haug, mit ihren emphatischen Ausdrucksmöglichkeiten immer schon funktional in die Erfahrung einbezogen. Diese emphatische Ausdrucksmöglichkeit wird im folgenden Abschnitt aus einer Predigt Meister Eckharts besonders deutlich erkennbar:

Der vater gebirt sînen sun in der êwicheit im selber glîch [...]. Noch spriche ich mêr: er hât in geborn in mîner sêle [...] und gebirt der vater sînen sun in der sêle in der selben wîse, als er in der êwicheit gebirt [...] und ich spriche mêr: er gebirt mich sînen sun und den selben sun. Ich spriche mêr: er gebirt mich nicht aleine sînen sun, mêr: er gebirt mich sich und sich mich und mich sîn wesen und sîn natûre.

Der Vater gebiert seinen Sohn in der Ewigkeit sich selbst gleich. [...] Noch sage ich mehr: Er hat ihn in meiner Seele geboren [...] und der Vater gebiert seinen Sohn in der Seele in derselben Weise, wie er ihn in der Ewigkeit gebiert [...], und ich sage noch mehr: Er gebiert mich [als] seinen Sohn und [als] denselben Sohn. Ich sage noch mehr: Er gebiert mich nicht allein [als] seinen Sohn; noch mehr: Er gebiert mich [als] sich und sich [als] mich und mich [als] sein Sein und [als] seine Natur.

(DW I, S. 109, 2f.; Übersetzung von Verfasser)

Diese Stelle legt nahe, dass sich die Sprache des Mystikers durch die emphatische Redeweise zur grammatischen Vereinigung von Vater-Sohn-Ich steigert. Das Verb "gebërn", das eigentlich keine appositiven Doppelakkusative annimmt, verbindet die semantisch nicht miteinander identifizierbaren Objekte zu einem Wesen, zu einer Natur. Die Steigerung und die Apposition wechseln plötzlich den Ton der Predigt, erwecken einen musikalischen Eindruck bei den Zuhörern und heben eine objektive, prädikative Aussage wie "Gott und Mensch sind eins" oder "Gleichwerdung mit Gott“ zu einer subjektiven Erfahrung auf.

\section{Der Dialog als Grundlage für das Sprechen der Wahrheit}

So vertraut Gott auch einer Mystikerin sein Geheimnis an, das er von ihr als Botin verkünden und aufschreiben lässt. Er kann es nicht verbergen und muss es einer reinen, bescheidenen Seele offenbaren. Entsprechend lässt Mechthild von Magdeburg Gott im Prolog ihres Werks von seiner Absicht berichten: „Ich han es [daz buoch] gemachet an miner unmaht, wan ich mich an miner gabe nút enthalten mag." (Ich habe es gemacht in meinem Unvermögen, weil ich meine Gabe nicht zurückzuhalten vermag.) ${ }^{39}$ Durch dieses Anvertrauen gerät sie indes in eine Art Double-

Brechungen auf dem Weg zur Individualität. Kleine Schriften zur Literatur des Mittelalters. Tübingen 1995, S. 550-578, hier S. 570.

39 Mechthild von Magdeburg: Das fließende Licht der Gottheit (FLG). Hg. von Hans Neumann und Gisela Vollmann-Profe. Bd. 1. Tübingen 1990. Buch I, Prolog, S. 5. Bei der Untersuchung wird neben dieser Ausgabe auch die alte Morelsche Edition benutzt, weil sie den metrischen Verscharakter des Werkes gebührend berücksichtigt. Vgl. Offenbarungen der Schwester 
bind-Situation zwischen dem Zorn Gottes und dem Hass ihrer Nächsten: „Nu voerhte ich got, ob ich swige, und voerhte aber unbekannte (verständnislose) lúte, ob ich schribe" (FLG, III, 1, 37f.; ,IIch fürchte aber Gott, wenn ich schweige, und fürchte aber (auch) unverständige Menschen, wenn ich schreibe." Schmidt: Übersetzung, S. 78). Mechthild war sich der Bedeutung der ,Öffentlichkeit', d. h. der Leserschaft, voll bewusst. Sie hat ihre Schrift zuerst an die Magdeburger Beginen, dann an die Schwestern des Helftaer Klosters gerichtet. Sie hat sich die handschriftliche Verbreitung ihres Werkes gewünscht, und das ursprünglich niederdeutsch verfasste Fließende Licht der Gottheit wurde tatsächlich ins Südalemannische übertragen und im Umkreis der Basler ,Gottesfreunde' gelesen..$^{40}$ Es wurde sogar als Lux divinitatis ins Lateinische übersetzt und fand unter Geistlichen zahlreiche Leser.

Das Fließende Licht der Gottheit ist weder unvollkommener Lobgesang noch Niederlage der menschlichen Sprache, auch wenn die Autorin immer wieder ihre Unfähigkeit verzweifelt beklagt. Haug sieht im Fließenden Licht der Gottheit sogar verschiedene Sprachhandlungen strategisch eingebettet. Die Mystikerin bediene sich z. B. zweier unterschiedlicher Diskurstypen: des narrativen und des dialogischen. Die Narratio ist in präteritale Erfahrungen einbezogen und bringt daher das Geheimnis der Unio indirekt zum Ausdruck. Der narrative, explikative Bericht verdeutlicht die Distanziertheit zwischen der mystischen Reflexion und der aktuellen Gegenwart der Seherin, und die Mystikerin muss verstummen.

Der Dialog aber fungiert als Schaltstelle, über die das Jederzeitlich-Allgemeine konkret aktualisierbar wird, das Vergangene sich gegenwärtig gibt und das Gegenwärtige ins Vergangene als in etwas Überzeitliches eingeschrieben werden kann. ${ }^{41}$

Der Dialog aber realisiert keine innere Beziehung zwischen der Mystikerin und Gott, weil „der Dialog zwar diese Beziehung neu eröffnet, aber zugleich sein Ungenügen ihr gegenüber mit zum Ausdruck bringt, und dies mit dem Ziel, das Sprechen in jene übersprachliche Begegnung einmünden zu lassen“. ${ }^{42}$ Haug betont: „Das Gespräch und das Schweigen gehören funktional zusammen." ${ }^{143}$ Mit diesem widersprüchlichen Dialogmodell setzt sich Haug mit der Dialoganalyse Gerhard Bauers auseinander, weil das von Bauer definierte Gespräch „als mehr

Mechthild von Magdeburg oder Das fließende Licht der Gottheit (OSM). Hg. von Gall Morel. Darmstadt 1976. Neuhochdeutsche Übersetzung: Mechthild von Magdeburg. Das fließende Licht der Gottheit. 2., neubearbeitete Übersetzung mit Einführung und Kommentar von Margot Schmidt. Stuttgart-Bad Cannstatt 1995, S. 9.

40 „Eya herre, ich súfzen und gere und bitte fúr dine schribere, die das buoch na mir haben geschriben, das du in ovch wellist die gnade ze lone geben, [...]" (FLG [Anm. 38], II, 26, 34f.; „Eia, Herr, ich seufze und begehre und bitte dich für die Schreiber, die das Buch nach mir geschrieben haben. Du mögest auch ihnen zum Lohn die Gnade geben, [...].“ Schmidt: Übersetzung [Anm. 38], S. 72).

41 Haug: Gespräch (Anm. 37), S. 566.

42 Haug: Gespräch (Anm. 37), S. 573.

43 Haug: Gespräch (Anm. 37), S. 568. 
oder weniger illusionistische Bestätigung einer gesetzten und nicht weiter angetasteten Übereinstimmung abläuft" ${ }^{44}$ Dem mystischen Dialog hingegen liegt das Modell des Liebesgesprächs aus dem alttestamentlichen Hohelied zugrunde, in dem ausschließlich die Unerreichbarkeit bzw. Unvergleichlichkeit des Partners thematisiert und die Liebe letztlich jenseits des Wortes im Schweigen der Liebenden erfüllt wird. ${ }^{45}$ Die Seele Mechthilds muss nach dem entrückten Gespräch wieder in den Leib einkehren:

So swebent si [dú sele] fúrbas an ein wunnenriche stat, da ich nút von sprechen will noch mag. Es ist ze notlich, ich engetar, wan ich bin ein vil súndig moensche. Mer: wenne der endelose got die grundelosen sele bringet in die hoehin, so verlúret sú das ertrich von dem wunder und bevindet nút, das si ie in ertrich kam. Wenne das spil allerbest ist, so muos man es lassen. So sprichet der bluejende got: ,Juncfrou, ir muessent úch neigen.' So erschrikket si und beweinet ir ellende. So sprichet si: ,Herre, nu hast du mich hie so sere verzogen, das ich dich in minem lichamen mit keinem orden mag geloben, sunder das ich ellnde lide und gegen dem lichamen strite.' So sprichet er: ,Eya du liebú tube, din stimme ist ein seitenspil minen oren, dinú wort sind wurtzen minem munde, dine gerunge sint die miltekeit miner gabe.'

Dann schweben sie weiter an einen wonnenreichen Ort, von dem ich nicht viel sagen kann noch will. Es ist zu schwierig, ich wage es nicht, denn ich bin ein sehr sündiger Mensch. Aber wenn der endlose Gott die grundlose Seele in die Höhe reißt, dann vergißt sie die Erde über diesem Wunder und weiß nicht mehr, daß sie je auf Erden war. - Wenn das Spiel am allerschönsten ist, muß man es lassen. Dann spricht der blühende Gott: ,Jungfrau, Ihr müßt niedersteigen.' Da erschrickt sie und weint über ihre Verlassenheit. Sie sagt dann: ,Herr, nun hast Du mich so hoch entrückt, daß ich Dich in meinem Leibe auf keine Art mehr lobpreisen kann, ohne daß ich an der Verbannung leide und gegen meinen Leib kämpfe.' Da spricht er: ,Eia, du liebe Taube, deine Stimme ist ein Saitenspiel meinen Ohren; deine Worte sind wie Gewürze in meinem Munde, deine Sehnsüchte sind der Überfluß meiner Gnade.'

(FLG, I, 2, 17-27; Schmidt: Übersetzung, S. 11)

Nachdem die Unio zuerst in historisch-objektiver Perspektive erläutert wurde, geht die Handlung schließlich ins Gespräch über, in die Vergegenwärtigung der eigenen Unio-Erfahrung. An der Schnittstelle, an der die Seele dem Universellen begegnet und ihren Namen in das Pronomen der ersten Person (ich) ändert, wechselt die Modalität der Sprache von der Narratio zum Dialog. Ich möchte hier Haugs These mit der Sprechakttheorie ergänzen: Um die Frage zu beantworten,

44 Haug: Gespräch (Anm. 37), S. 573. Siehe auch Gerhard Bauer: Zur Poetik des Dialogs. Leistung und Formen der Gesprächsführung in der neueren deutschen Literatur. Darmstadt 1969.

45 Haug: Gespräch (Anm. 37), S. 574. 
mit welchen sprachlichen Handlungen das Geheimnis Gottes sich verhüllen lässt, verweise ich nochmals auf Foucaults Parrhesia-Konzept.

Auch Foucault hat dem dialogischen Charakter der Parrhesia Rechnung getragen. Die Parrhesia setzt sich in ihrer interaktiven Struktur mit der Rhetorik auseinander, weil diese als Redekunst „nicht durch die persönliche oder individuelle Beziehung oder auch durch die ,taktische Situation' dessen bestimmt [ist], der spricht, gegenüber dem, an den sich die Rede richtet" ${ }^{46}$ Die Rhetorik ist die Fähigkeit, das herauszufinden, was zum Überreden geeignet ist. ${ }^{47}$ Quintilian sagt auch: sie sei eine Kunst und eine Technik, die den Zuhörer von etwas Wahrem wie auch von etwas Unwahrem überzeugen kann. ${ }^{48}$ Die Rhetorik ist also nicht auf die Wahrheit des Gesagten bezogen, sondern sie kann im Sprechen selbst die Wahrheit ,herstellen'. Sie ist sogar regelrecht unmoralisch, wenn ein Redner mit wohlkalkulierter Bescheidenheitsgeste sein rhetorisches Unvermögen bekennt und damit das Mitleid des Richters zu erwecken sucht. ${ }^{49}$

Nicht nur in der Wahrheitsfrage, sondern auch im Souveränitätsverhältnis stellt sich die Parrhesia der technischen Redekunst entgegen. Der gute Rhetor beabsichtigt in erster Linie, mit seiner Rede auf die anderen einzuwirken, um sie in eine bestimmte Richtung zu lenken. Ein Wahrheitssprecher zielt hingegen darauf, nicht über die anderen, sondern für sich selbst die Souveränität herzustellen und freimütig über sich zu sprechen. Nicht durch Befehl, sondern durch seine eigene Wahrhaftigkeit lässt er die anderen "mit einer Öffnung des Herzens" auf seine Parrhesia antworten..$^{50}$ Diese Umkehrung des Souveränitätsverhältnisses zwischen Lehrer und Schüler erweitert sich dann im christlichen Gott-MenschVerhältnis zur Konfession.

Auf das wahre Wort, das mich die Wahrheit lehrt und mich folglich bei der Erlangung des Seelenheils unterstützt, muß ich - ich werde dazu angeregt, aufgefordert und verpflichtet - mit einer wahren Rede antworten, durch die ich dem anderen, den anderen die Wahrheit meiner eigenen Seele offenbare. ${ }^{51}$

46 Foucault: Hermeneutik (Anm. 2), S. 467.

47 Aristoteles: Rhetorik, 1.1, 1355b.

48 Marcus Fabius Quintilianus: Ausbildung des Redners. Hg. von Helmut Rahn. Teil 1. Darmstadt 1995, Buch 2, Kap. 17,26f. Quintilian misst der Rhetorik eine besondere Bedeutung für die Didaktik bei: „Ja, sogar die sittlichen Grundsätze der Lebensführung, mögen sie auch von Natur schon Achtung verdienen, haben doch eine stärkere Wirkung auf die Formung des Geistes, wenn die Schönheit ihres Gehaltes der helle Glanz der Rede überstrahlt: weshalb es, auch wenn die Waffen der Redefertigkeit zweischneidig sind, doch nicht billig ist, etwas für schlecht zu halten, das auch zum Guten zu gebrauchen ist" (Buch 2, Kap. 16,10).

49 Quintilian: Ausbildung (Anm. 48), Buch 4, 1,8f.: „Denn es gibt eine natürliche Vorliebe für die Schwachen, die sich abmühen, und ein gewissenhafter Richter hört am liebsten den Anwalt, bei dem er für die Sache der Gerechtigkeit am wenigsten zu befürchten hat." Zit. nach Thomas Zinsmaier: Wahrheit, Gerechtigkeit und Rhetorik in den Reden Antiphons. Zur Genese einiger Topoi der Gerichtsrede. In: Hermes 126 (1998), S. 398-422, hier S. 402.

50 Foucault: Hermeneutik (Anm. 2), S. 477.

51 Ebd. 
Foucault denkt, dass die stoische und christliche Parrhesia durch den Dialog zwischen Lehrer und Schüler oder zwischen Laien und Beichtvater aktiviert wird, diese Wahrheitsrede aber ist sehr prosaisch gedacht. In der mittelalterlichen geistlichen Literatur werden der Ausruf der liebenden Seele und die Antwort Gottes, wie es bei den alttestamentlichen Propheten der Fall war, durch die Versform getragen. Im Kapitel 34 des 5. Buches des Fließenden Lichts der Gottheit handelt es sich um eine endzeitliche Vision. Mechthild wundert sich über St. Elisabeth von Thüringen, die nach ihrem Tod sehr schnell heiliggesprochen wurde. Sie verheimlicht nicht ihren Ehrgeiz, ihr folgen zu wollen. Der Herr erklärt ihr entsprechend, dass er Elisabeth als Botin zu den unseligen höfischen Frauen gesandt habe, die in den Burgen saßen und von Unkeuschheit verzehrt waren. Er habe auch St. Dominikus, St. Franziskus und St. Peter wegen der Korruption der Kirche gesandt. Mechthild sagt, sie habe im Gebet auch die verdorbene Kirche in den Arm ihrer Seele genommen, um sie aufzurichten.

Ich armer mensche, ich wart in minem gebette also kuene, das ich freventlich tet und nam alzemale die verboesete cristanheit an miner sele arm, da borete ich mit jamere.

Ich armer Mensch war in meinem Gebete so kühn, daß ich sogleich verwegen die verdorbene Kirche in den Armen meiner Seele nahm. Da schleppte ich mit Seufzen, [...].

(FLG, V, 34, 21-23; Schmidt: Übersetzung, S. 204)

Wie kühn und verwegen ihre Tat auch erscheinen könnte, so muss sie doch so freimütig sprechen, um sich vor Gott der Heiligsprechung würdig zu zeigen. Die Bescheidenheit vor Gott und, um mit Foucault zu sprechen, die "Schmeichelei“ vor dem Mächtigen sind nicht genug für die Persuasion eines unvergleichlichen Partners. ${ }^{52}$ Von dieser ,frevelhaften' Ambition Mechthilds stimuliert, antwortet Gott ihr sofort. Der Dialog beginnt:

Do sprach únser herre: ,Las, si ist dir alze swere.' ,Eya nein, suesser herre, ich will si ufheben und fúr dine fuesse tragen mit din selbes armen, da du si mit an dem crúze truege.' Do gestattete mir armen got mines willen, uf das er mich moechte gestillen.
Unser Herr sprach: ,Laß, sie ist dir viel zu schwer!' ,Eia, nein, mein süßer Herr, ich will sie aufheben und dir zu Füßen legen mit deinen eigenen Armen, womit du sie am Kreuze getragen! Da ließ mir Armen Gott meinen Willen, um so mein Verlangen zu stillen.

(OSM, V, 34, 23-26; Schmidt: Übersetzung, S. 204) $)^{53}$

52 Foucault nennt neben der Rhetorik die Schmeichelei als Widersacherin der Parrhesia. Siehe ders.: Hermeneutik (Anm. 2), S. 455f. 
Hier wird das Gespräch unterbrochen, und der Sprachmodus wechselt zur Visualisierung der Unio-Erfahrung. Mechthild sieht dort die arme Kirche vor den Herrn treten, die sich in eine Jungfrau verwandelt. Sie sieht die Jungfrau an und zugleich, wie der Herr diese ansieht. Wegen dieses Blickwechsels schämt sie sich sehr, da der Blick die brautmystische Liebkosung der Kirche durch den Herrn signalisiert.

Do sprach únser herre: ,Nu sich! Gezimet mir disú jungfrowe wol in minem ewigen brútbette ane ende ze minnende und mit minen keyserlichen armen zuo mir ze nemende und mit minen goetlichen ougen an ze sehendét.

Unser Herr sprach: ,Siehe selbst, geziemt es mir wohl, diese Jungfrau in meinem ewigen Brautbett endlos zu lieben und sie mit meinen kaiserlichen Armen an mich zu ziehen und sie mit meinen göttlichen Augen anzuschauen [...]'.

(FLG, V, 34, 28-31; Schmidt: Übersetzung, S. 204f.)

Die apokalyptische Endzeit-Vision ist auf die erotische Vision der Vereinigung der kirchlichen Braut mit ihrem Liebhaber bezogen. Die atemberaubend wechselhaften Darstellungsmodi Mechthilds bewirken unter den Lesern eine Vielzahl stets neu zu konstruierender Rezeptionshaltungen. ${ }^{54}$ Selbst Gott muss darauf reagieren. Die Mystikerin bekennt sich vor Gott wahrhaftig zu ihrer sündigen Tat, oder sie schämt sich wegen ihrer Ohnmacht, oder sie fürchtet Gottes Allmacht, oder sie bittet ihn dreist um die Würdigung ihrer Tat. Als Gegenleistung zu ihrer Freimütigkeit offenbart sich Gott im Dialog. Zu bemerken ist, dass Gott das Geheimnis der Unio im liedhaften Gesang mit lyrisch-metrischem Takt von seinem Herzen einflößt.

Diese narrative Struktur ist im zweiten Kapitel des 4. Buches vom Fließenden Licht der Gottheit gut zu erkennen. In einem autobiographischen Kapitel erzählt Mechthild ihre qualvoll-sündhafte Kindheit, den ersten Gruß Gottes im zwölften Lebensjahr und den Umzug nach Magdeburg (FLG, 4-25). Nach den kurzen Visio-Erfahrungen, in denen Gott sie tröstlich liebkost, erscheinen zwei Teufel, mit denen sie heftige Streitgespräche führt (FLG, 40-62). Sie verteidigt sich schließlich mit einem Klagelied gegen den ersten Teufel, woraufhin er „Waffen úber deinen zouver, las mich nu von dir varen, ich wi dich niemer besweren“ („Wehe über deinen Zauber!/ Laß mich von dir fahren,/ ich werde dich nie mehr plagen.."; FLG, 69f.; Schmidt: Übersetzung, S. 122) schreit und wegfliegt. Der Teufel scheut sich vor dem ,Zauber' des Wortes, das in der Liedform mit Metrik und Reim gesungen wird. Dem zweiten Teufel, der sich "geistlicher lúte kamerer" (geistlicher Leute Kämmerer) nennt (FLG, 87), geht es nicht anders: Wieder singt sie ein Lied (FLG, 102-114), das den Teufel zu vertreiben scheint und schließlich Gott beschwört,

53 Um die Reime des Textes deutlich zu zeigen, folge ich hier der Morelschen Edition (OSM) (Anm. 38).

54 Walter Haug: Grundformen religiöser Erfahrung als epochale Positionen. Vom frühmittelalterlichen Analogiemodell zum hoch- und spätmittelalterlichen Differenzmodell. In: ders.: Brechungen (Anm. 37), S. 501-530, bes. S. 518-523. 
der mit ihr ein tröstendes Gespräch führt (FLG, 117-127). Sie erzählt dann ihrem Beichtvater die ganze Geschichte, und dieser empfiehlt ihr, ein Buch zu schreiben.

Mechthild hat bei der Darstellung ihrer mystischen Erfahrung vielfältige Sprachmodi verflochten. Der Wechsel der Sprechakte zwischen Rhetorik und Parrhesia prägt den Grundcharakter ihrer Offenbarungsliteratur. Beide vom altgriechischen Verbum "@é $\omega^{\prime \prime}$ (sprechen) abgeleiteten Begriffe konstruieren das Spannungsfeld, in dem die arme Seele der Mystikerin ihren geliebten Herrn evoziert, herausfordert, ihm zuhört und sich schließlich weinend von ihm verabschiedet.

\section{Schluss}

Religiöse Kommunikation beruht auf absolutem Vertrauen. Man glaubt an Gott nicht auf Grund eines Beweises für dessen Dasein. Simmel hat dieses „religiöse Vertrauen" daher "Grundkategorie des menschlichen Vertrauens" genannt. Es stehe jenseits von Wissen und Unwissenheit und sei deshalb "gefühlsmäßig", „unerklärbar" und „mystisch“ ${ }^{55}$ Die Ansicht Simmels wäre jedoch verfehlt, wenn sie im glaubenden Menschen bloß eine bedingungslose Zuneigung zum Absoluten sähe und sie mit dem übernatürlichen, unaussprechlichen Mysterium verbände. Glauben ist zwar ein unabdingbares Postulat religiösen Lebens, es muss jedoch, abgesehen von religiösem Fanatismus, im höchsten Grad sprachlich konstruiert werden. Das religiöse Vertrauen kommt durch literarische Handlungen, durch die diskursive Zusammenwirkung zwischen Gott und Mensch erst richtig zu Stande, wie Haug gezeigt hat. Die Parrhesia Foucaults ist auch kein Monolog, keine vertikale Verkündigung der Wahrheit, sondern sie bereitet den Boden, auf dem es „eine Reihe horizontaler Beziehungen, intensiver, enger und starker Beziehungen freundschaftlichen Charakters [gibt], die das Seelenheil gegenseitig befördern" . ${ }^{56}$ Das Wahrheitssprechen des Meisters veranlasst die Jünger dazu, sich ebenfalls wahrhaftig zu äußern, und die wahrhaftige Rede lässt dann unter den Jüngern die Freundschaft wachsen. Der Parrhesiast regt die anderen an, sich ihm gegenüber voller Zuneigung (,eunoia“) zu verhalten, „damit alle Elemente, alle Personen der Gruppe zur Erlangung des Seelenheils angeregt werden ${ }^{\prime 57}$ Damit stellt sich nun ein Bezug zur eingangs vorgestellten Forderung Meister Eckharts nach der Assimilierung durch die Wahrheit zur Wahrheit her. Beide Denker erhoffen sich von der Wahrheit, dass sie die sie suchenden Menschen vernetzt, diese aneinander angleicht und so für sie ein gemeinsames, freies Kommunikationsfeld öffnet.

55 Simmel: Soziologie (Anm. 12), S. 263.

56 Foucault: Hermeneutik (Anm. 2), S. 476.

57 Foucault: Hermeneutik (Anm. 2), S. 477. 


\title{
Das Mysterium der incarnatio verbi in Alexander von Suchtens frühparacelsistischem Traktat De tribus facultatibus (um 1565)
}

\author{
Simon Brandl
}

Von einem „literarisch hochstehenden Buch“, ja sogar von „einem der schönsten Bücher des 16. Jahrhunderts“ spricht Carlos Gilly mit Blick auf den kleinen Traktat De tribus facultatibus, ${ }^{2}$ der aus der Feder des Paracelsisten Alexander von Suchten stammt. ${ }^{3}$ Diese Einschätzung verdankt sich vor allem dem erzählerischen Tonfall, den Suchten anschlägt, indem er vom Ursprung eines paracelsisch tingierten, geheimen Schöpfungswissens berichtet. Dieses Wissen verweigere sich angesichts seines göttlichen Grundes einer Vermittlung im Modus der eigentlichen Rede. Vielmehr kleide es sich in Chiffren und Allegorien, die nur der von Gott erleuchtete Weise zu entschlüsseln wisse. Wer dagegen dem Literalsinn anhänge, die Botschaft der Gestirne ignoriere und die wahre Bedeutung der Pflanzenwelt missverstehe, bleibe von einer Unterweisung durch die ,Drei Fakultäten' der himmlischen Weisheit ausgeschlossen: Theologia, astronomia und medicina hätten demnach mit den gleichnamigen Wissenschaften des universitären Fächerkanons nichts gemein. Nach Suchten handelt es sich bei diesem Dreigestirn um Teilge-

1 Carlos Gilly: Vom ägyptischen Hermes zum Trismegistus Germanus. Wandlungen des Hermetismus in der paracelsischen und rosenkreuzerischen Literatur. In: Konzepte des Hermetismus in der Literatur der Frühen Neuzeit. Hg. von Peter-André Alt und Volkhard Wels. Göttingen 2010, S. 103.

2 Carlos Gilly: Zwischen Erfahrung und Spekulation. Theodor Zwinger und die religiöse und kulturelle Krise seiner Zeit. Teil 1. In: Basler Zeitschrift für Geschichte und Altertumskunde 77 (1977), S. 57-135, hier S. 77.

$3 \mathrm{Zu}$ den richtungsweisenden Beiträgen zu Leben und Werk Alexander von Suchtens zählen: Wilhelm Haberling: Alexander von Suchten, ein Danziger Arzt und Dichter des 16. Jahrhunderts. In: Zeitschrift des Westpreußischen Geschichtsvereins 59 (1929), S. 175-230; ders.: Neues aus dem Leben des Danziger Arztes und Dichters Alexander von Suchten. In: Sudhoffs Archiv 24 (1931), S. 117-123; Der Frühparacelsismus. Erster Teil. Corpus Paracelsisticum I: Dokumente frühneuzeitlicher Naturphilosophie in Deutschland. Hg. von Wilhelm Kühlmann und Joachim Telle. Tübingen 2001, S.545-584; Ralf Bröer: Friedenspolitik durch Verketzerung. Johannes Crato (1519-1585) und die Denunziation der Paracelsisten als Arianer. In: Medizinhistorisches Journal 37, Heft 2 (2002), S. 139-182, bes. S. 145-152; Oliver Humberg: Die Verlassenschaft des oberösterreichischen Landschaftsarztes Alexander von Suchten († 1575). In: Wolfenbütteler Renaissance-Mitteilungen 31 (2007), H. 1, S. 31-50. Eine Studie zu Suchtens Mystik- und Magie-Verständnis befindet sich im Erscheinen (Simon Brandl: Mystik und Magie im Frühparacelsismus. Erkundungen um Alexander von Suchtens Traktat De tribus facultatibus. Boston, Berlin 2021). 
biete einer urzeitlichen Weisheitslehre, in deren Zentrum das Mysterium der incarnatio verbi steht. Das Heilswissen der alten Weisen sei jedoch schon früh dem Vergessen anheimgefallen. In der Folge hätten die akademisch gebildeten Theologen, Astronomen und Mediziner ihre Irrlehren über die ganze Welt verbreitet. Doch Suchtens Traktat besitzt auch den Charakter eines Evangeliums: Wer sich zu der kürzlich wiederentdeckten Weisheitslehre bekenne, werde das Geheimnis der „Menschwerdung des Sohns Gottes“ lüften und im Angesicht des Allmächtigen ein seliges Leben führen. ${ }^{4}$

Suchten konnte zum Zeitpunkt der Entstehung von De tribus facultatibus bereits auf ein bewegtes Leben zurückblicken: Um 1520 als Sohn einer einflussreichen Danziger Familie geboren, hatte er schon früh Kontakt zu spiritualistischen Kreisen. So hörte er während seiner Gymnasialzeit Vorlesungen bei Wilhelm Gnaphaeus, der als Katholik mit dem Schwenckfeldianismus sympathisierte. ${ }^{5} \mathrm{Ab}$ 1541 stand er unter der Anklage der Häresie, nachdem bereits sein Onkel, der mit Copernicus befreundete Alexander Scultetus, aufgrund protestantischer Umtriebe geächtet worden war. Suchten wurde nach Rom zitiert, was zur Folge hatte, dass er im März 1545 sein Domkanonikat und seine ermländischen Güter verlor.

Suchtens paracelsistische Wende fällt auf den Zeitraum von 1549 bis 1553, als er zu Neuburg im Dienst des Pfalzgrafen Ottheinrichs von Weinheim stand. Zu seinen Aufgaben zählte die Verwahrung einer umfassenden Sammlung alchemischer "Kunstbueecher", die ihn mit der Ideenwelt des Paracelsus bekannt machte. Am Hofe des Pfalzgrafen befand er sich in der Gesellschaft der späteren Paracelsisten Michael Toxites, Wilhelm Rascalon und Christoph Pythopoaeus, die von ihm die „warhafftige separation“ erlernten. Im Jahr 1558 trat er in die Dienste des polnischen Königs Sigismund August, den er bis 1560 zunächst in Krakau und danach für ein Jahr in Wilna behandelte. ${ }^{8}$ Wie aus seiner Elegie Quid sit nihil hervorgeht, war er dort den Verleumdungen der galenisch geschulten Leibärzte ausgesetzt. Diese bezichtigten ihn der Verabreichung von aus ihrer Sicht giftigen Quecksilberpräparaten. ${ }^{9}$ Womöglich hatte dies die Entlassung Suchtens aus dem Fürstendienst zur Folge. Offenbar machte er sich sodann nach Italien auf, vielleicht um dort den Doktorgrad zu erwerben; ${ }^{10}$ allerdings kehrte er bereits 1563

4 Alexander von Suchten: De tribus facultatibus. In: ders.: Chymische Schrifften. Hg. von Ulrich C. Dagitza. Frankfurt a. M. 1680, S. 357-82, hier S. 379.

5 Vgl. Bröer: Friedenspolitik durch Verketzerung (Anm. 3), S. $145 f$.

6 Zur Bedeutung und Geschichte dieser Sammlung siehe Joachim Telle: Kurfürst Ottheinrich, Hans Kilian und Paracelsus. Zum pfälzischen Paracelsismus im 16. Jahrhundert. In: Von Paracelsus zu Goethe und Wilhelm von Humboldt. Hg. von Sepp Domandl. Wien 1981, S. 130-146.

7 Davon berichtet Toxites in der Vorrede zu dem von ihm edierten ersten Teil von Suchtens Antimonmonographie, siehe Alexander von Suchten: De secretis antimonij liber unus. Straßburg 1570, S. 18.

8 Kühlmann, Telle: Corpus Paracelsisticum I (Anm. 3), S. 545-547.

9 Vgl. hierzu einen an Herzog Albrecht von Preußen adressierten Brief Suchtens vom 2. Juli 1561, in welchem dieser sich gegen die genannten Anschuldigungen verteidigt, enthalten in: Kühlmann, Telle: Corpus Paracelsisticum I (Anm. 3), S. 553-555, hier 554.

10 Haberling: Alexander von Suchten (Anm. 3), S. 194. 
wieder nach Preußen zurück. Dort bemühte er sich um eine Bestallung am Hofe Herzog Albrechts. Dies war auch bitter nötig, zumal er unter fürstlicher Protektion vor der Verketzerungskampagne, die der kaiserliche Leibarzt Johannes Crato seit 1561 gegen ihn betrieb, ${ }^{11}$ sicher sein konnte. In der Nähe des Herzogs genoss Suchten zwar eine gewisse Immunität, eine in Aussicht gestellte Übernahme in den Fürstendienst kam jedoch nicht zustande. Im Jahr 1565 begab er sich nach Danzig, um die Erbschaft seines Bruders anzutreten, was jahrelange Rechtsstreitigkeiten nach sich zog. Drei Jahre später findet man ihn im Elsass und am Oberrhein in der Gemeinschaft seines alten Bekannten Michael Toxites. Lange Zeit galt ein an Suchten adressierter Brief des St. Gallener Handelsherrn Bartholomäus Schobinger als letztes Lebenszeichen. Oliver Humberg brachte allerdings 2007 eine Menge Dokumente ans Licht, die von Suchtens letztem Lebensjahr Kunde geben. Demnach fand dieser im Oktober 1574 eine Stelle als Landschaftsarzt in Linz, wo er im November 1575 starb. $^{12}$

Suchten gehörte zu den frühesten Vorkämpfern der geistigen Bewegung, die unter der Bezeichnung ,Paracelsismus' den frühneuzeitlichen Gelehrtendiskurs auf den Gebieten von Medizin, Naturphilosophie und Theologie maßgeblich mitbestimmen sollte. Als Erben der von Paracelsus begründeten Chemiatrie stehen die Paracelsisten im Ruf, Alchemie betrieben zu haben. Dies ist richtig, sofern man ihr spiritualistisch geprägtes Verständnis von Alchemie von den Praktiken der althergebrachten Scheidekunst abgrenzt, deren Hauptanliegen die Verwandlung unedler Metalle in Gold war. Tatsächlich hatte sich auch Suchten anfangs zu dieser trügerischen Spielart von Alchemie bekannt. Dies geht aus einer Schrift De secretis antimonij hervor, in der er diesbezüglich hart mit sich ins Gericht geht: „Die Alchymisten überreden sich selbst/ ( $\mathrm{O}$ wieviel Jahr bin ich in diesem Spital auch kranck gelegen) man kônne so ein subtil Feuer auch künstlich machen ${ }^{\prime \prime}{ }^{13}$ In seiner Elegie an den ,sophistischen Goldmacher' (Ad Chrysogonum Sophistam) schildert Suchten sein Erweckungserlebnis, das ihn von seiner Depression angesichts der Fruchtlosigkeit der herkömmlichen Alchemie befreite. Seine Bekehrung zu Paracelsus, so berichtet er mit dichterischem Pathos, habe ihn vor dem geplanten Freitod gerettet:

An diesem Punkt sah mich Gott, dem ich von früher Jugend an aus ganzem Herzen zugetan war, / schon vor dem See der Unterwelt stehen, / und er streckte mir seine Hand entgegen und entführte mich in die Höhen des Himmels, / und er sagte: Durch meine Fürsorge will ich dich vor dem Tod erretten. / Komm hierher, und wonach du verlangst, das nimm an als mein Geschenk: Niemand außer mir selbst kann dir meine Gaben verleihen. / Er sprach es und beschenkte

11 Zur Häretisierung Suchtens siehe Bröer: Friedenspolitik durch Verketzerung (Anm. 3), S. $145 f$.

12 Humberg: Die Verlassenschaft des oberösterreichischen Landschaftsarztes Alexander von Suchten (Anm. 3), S. 32.

13 Alexander von Suchten: Der dritte Tractat vom Antimonio. In: ders.: Chymische Schrifften. Hg. von Ulrich C. Dagitza. Frankfurt a. M. 1680, S. 229-266, hier S. 242. 
mich: Ich fand meinen Geist, frischen Mut und auch meine Stimme wieder, die so lange vor lauter Irrlehren verstummt war. ${ }^{14}$

In der Tat ist die Inkriminierung der mittelalterlichen Transmutationsalchemie Teil des paracelsischen Reformprogramms: Die ,reine und keusche Jungfrau Alchymia', welche Paracelsus und seine Nachfolger den betrügerischen Goldköchen entrissen hatten, war in ihren Augen eine göttliche Gnadengabe. ${ }^{15}$ Damit unterzogen die Paracelsisten die althergebrachte Scheidekunst einer Spiritualisierung, die über eine bloße Veranschaulichung von chemischen Prozessen durch religiöse Gleichnisse weit hinausging. Aus ihrer Sicht hatte die Alchemie Offenbarungsfunktion: Im ,Licht der Natur' konnte der gottergebene Adept zu einer Schau des göttlichen Angesichts gelangen, zumal sich dieses in der Herrlichkeit der Schöpfung zu spiegeln schien. Die (al)chemische Erkundung der Natur wurde somit zum Ausgangspunkt von mystischen Erfahrungen: Diese dienten allerdings weniger dem Erwerb innerer Seligkeit in der Einheit mit Christus, als vielmehr der Einweihung in göttliche Geheimnisse. Folglich waren die Paracelsisten sehr darum bemüht, ihren Erkenntnissen den Charakter des Mysteriösen zu verleihen: So bedienten sie sich - ganz in der Tradition der mittelalterlichen Alchemie - einer durch Chiffren und Allegorien verdunkelten Bildsprache, gepaart mit der anmaBenden Behauptung, dass es zu deren Verständnis einer Erleuchtung durch den Geist des Herrn bedürfe. Die göttlichen Geheimnisse mit Außenstehenden zu teilen, hieße gemäß Matthäus 7,6 „Perlen vor die Säue zu werfen“. Tatsächlich gab es für die paracelsistische Geheimhaltungspraxis mitunter gute Gründe: Mit ihrer spiritualistischen Auslegung der Heiligen Schrift standen die Paracelsisten nämlich in ständigem Konflikt mit der kirchlichen Theologie. So auch im Falle ihrer Deutung des Geheimnisses der incarnatio verbi, in welchem sie eine Präfiguration mystischer, naturphilosophischer und alchemischer Denkfiguren erblickten. Der paracelsistische Gestus der Geheimhaltung gründet sich auf die Heiligkeit der Natur, findet Rückhalt in der Arkansprache der althergebrachten Alchemie und dient bisweilen dem Schutz vor Häretisierung. Zugleich produziert er aber auch die Vision einer Elite von Begnadeten, denen es vergönnt ist, ausgehend von der Natur zu einer Erkenntnis des Schöpfers zu gelangen.

Naturwissen und Erwähltheit bilden in diesem Sinne den thematischen Schwerpunkt von De tribus facultatibus. Suchtens Ausführungen kreisen um die Begründung und Fortführung einer ehrwürdigen Weisheitslehre, über die Gott

14 Alexander von Suchten: Elegia ad chrysogonum sophistam. In: ders.: Chymische Schrifften. Hg. von Ulrich C. Dagitza. Frankfurt a. M. 1680, fol. Hh $4^{r-v}$, hier fol. Hh $4^{v}$ : Hic Deus, à teneris cujus delubra frequento, / Vidit auernalem me prope stare lacum. / Porrexitque manum, superasque reduxit ad auras, / Atque ait, ô curâ non periture meâ. / Huc ades, \& quod amas, hoc accipe munere nostro: / Nemo tibi præter me mea dona dabit; / Dixerat, et dederat: rediit mihi mensque colorque. / Linguaque tam longis obstupefacta malis.

15 Volkhard Wels: Manifestationen des Geistes. Frömmigkeit, Spiritualismus und Dichtung in der Frühen Neuzeit. Göttingen 2014, S. 167-169. 
auf mystische Weise erfahrbar wird. Zwar finden sich schon in der paracelsischen Laientheologie gelegentlich Elemente, die eine Nähe zur Mystik des Spätmittelalters erkennen lassen, darunter die spiritualistischen Topoi von Neugeburt und Christus-Nachfolge. ${ }^{16}$ Die Vorstellung einer unio mystica, welche ein völliges Aufgehen des Gläubigen in Gott impliziert, hat für Paracelsus jedoch nie eine Rolle gespielt. Es ginge daher zu weit, ihn als einen Mystiker zu bezeichnen. Umso größere Beachtung fanden mystische Konzepte im Paracelsismus, der sich in der zweiten Hälfte des 16. Jahrhunderts über den deutschsprachigen Raum hinaus ausbreitete.

Einen wesentlichen Faktor hierfür bildete der Einfluss der Theosophie Valentin Weigels (1533-1588). Wenngleich der Großteil von Weigels Werken erst postum zur Drucklegung gelangt, kursierten hiervon schon zu seinen Lebzeiten zahlreiche Abschriften in spiritualistisch versierten Kreisen, so auch unter den Paracelsisten. Weigel verarbeitete in seinem spätestens 1571 einsetzenden literarischen Schaffen neben paracelsischem auch introversionsmystisches Gedankengut. Letzteres schöpfte er aus dem von Luther wiederentdeckten, geistlichen Traktat Theologia Deutsch sowie aus der 1521 erschienenen Basler Sammelausgabe der Predigten Johannes Taulers, in die auch zahlreiche Predigten Meister Eckharts eingegangen waren. ${ }^{17}$ Durch Weigels Schrifttum, das etwa in Heinrich Khunrath, Oswald Crollius und Johann Arndt eifrige Rezipienten fand, ${ }^{18}$ drängten die mystischen - und vielfach häretisierten - Ideen des Spätmittelalters ins Bewusstsein der frühneuzeitlichen Gelehrtenwelt. Während die Bedeutung Weigels für den Spiritualismus um 1600 in der Forschung zu Recht große Beachtung gefunden hat, ist die Affinität zur Mystik, welche der Paracelsismus bereits in seinen frühsten Anfängen besaß, bislang kaum in den Blick geraten.

Tatsächlich besitzt das Geheimnis der incarnatio verbi in Suchtens Traktat nicht nur eine mystische, sondern, wie ich zeigen möchte, auch eine hermeneutische und eine alchemische Dimension. In allen drei Fällen aber erscheint die Menschwerdung Christi nicht nur als ein heilsgeschichtliches Ereignis, sondern - so lautet meine These, - vor allem als ein Paradigma, das die generelle Verschränkung der Bereiche von Transzendenz und Immanenz verdeutlicht. Demnach handelt es sich

16 Zur spiritualistischen Theologie Hohenheims siehe v. a. Ute Gause: Paracelsus (1493-1541). Genese und Entfaltung seiner frühen Theologie. Tübingen 1993. Zur Bedeutung von Neugeburt und Christus-Nachfolge siehe S. 96-104 u. ö.

17 Zu Weigels Rezeption der sog. ,Deutschen Mystik' immer noch Winfried Zeller: Meister Eckhart bei Valentin Weigel. Eine Untersuchung zur Frage nach der Bedeutung Meister Eckharts für die mystische Renaissance des 16. Jahrhunderts. In: Theologie und Frömmigkeit. Gesammelte Aufsätze. Bd. 2. Hg. von Bernd Jaspert. Marburg 1971, S. 55-88.

18 Vgl. Wilhelm Schmidt-Biggemann: Der Text der Bilder. Das ikonologische Programm von Khunraths Amphitheatrum sapientiae aeternae. In: Amphitheatrum sapientiae aeternae. Schauplatz der ewigen allein wahren Weisheit. Vollständiger Reprint des Erstdrucks von [Hamburg] 1595 und des zweiten und letzten Drucks Hanau 1609. Stuttgart-Bad Cannstatt 2014, S. 42; zu Croll Wilhelm Kühlmann: Oswald Crollius und seine Signaturenlehre. Zum Profil hermetischer Naturphilosophie in der Ära Rudolphs II. In: Die okkulten Wissenschaften der Renaissance. Hg. von August Buck. Wiesbaden 1992, S. 103-124, hier S. 111; zu Arndt Hans Schneider: Der fremde Arndt. Studien zu Leben, Werk und Wirkung Johann Arndts (1555-1621). Göttingen 2006, S. 23 u. ö. 
bei der Fleischwerdung des Wortes um eine Denkfigur, die auch außerhalb biblischer Zusammenhänge Gültigkeit besitzt. Da Suchtens diesbezügliche Gedankengänge stellenweise sehr komplex und äußerst voraussetzungsreich sind, möchte ich vorab kurz auf sein Welt- und Menschenbild eingehen. Zweitens werde ich seine Argumentationsgrundlage, die paracelsistische Logostheologie, skizzieren. Davon ausgehend werde ich mich drittens der mystischen, viertens der hermeneutischen und fünftens der alchemischen Dimension der incarnatio verbi zuwenden.

\section{Suchtens Kosmologie und Anthropologie}

Suchten war, wie Paracelsus, Anhänger einer physica mosaica: einer Naturphilosophie, die ihre Grundlagen beinahe ausschließlich aus dem mosaischen Schöpfungsbericht bezieht. Theologie und Naturkunde lassen sich daher nicht getrennt voneinander denken. ${ }^{19}$ Den Urstoff, aus welchem Gott die Welt erschuf, identifiziert Suchten mit dem Gewässer, über dem nach Gen 1,2 der Geist Gottes schwebte. Dieses bezeichnet er in Anlehnung an die Johannesapokalypse als ein „Crystallinisch Wasser ${ }^{\prime 20}{ }^{20}$ In einer Hinsicht unterscheidet er sich dabei von Paracelsus: Diesem zufolge verblieb der Geist des Herrn, der zu aller Anfang über den Wassern schwebte, nach dem Schöpfungsakt in allen natürlichen Erscheinungen. Suchten verortet den Geist hingegen allein in der prima materia des Menschen. Letzterer besitzt als Mikrokosmos analog zum Makrokosmos eine dreiteilige Struktur: Ebenso wie die große Welt aus Erde und Himmel besteht, verfügt auch die kleine Welt, der Mensch, über eine innere Erde und einen inneren Himmel. Erstere repräsentiert seinen Leib und sein sinnlich-affektives Vermögen, letzterer seine Vernunftwelt. Und ebenso wie der große Himmel über eine Sonne verfügt, befindet sich auch im menschlichen Gemüt so etwas wie eine Sonne, nämlich der Geist des Herrn.

In der Tat bringt Suchten den göttlichen spiritus mundi in seinem medizinischen Manifest, den XVIII Propositiones (1561), mit der Sonne in Zusammenhang. So bekundet er, dass die höheren und niederen Vitalkräfte, die alle himmlischen und irdischen Kreaturen mit Leben erfüllen, von der Sonne, welche gleichsam das Herz des Alls verkörpere (,„à Sole, tanquam Corde Cœli“ $),{ }^{21}$ ihren Ausgang nehmen. ${ }^{22}$ In

19 Wels: Manifestationen des Geistes (Anm. 15), S. 132.

20 Off 4,6; 15,2 und 22,1.

21 Alexander von Suchten: De vera medicina. In: ders.: Chymische Schrifften. Hg. von Ulrich C. Dagitza. Frankfurt a. M. 1680, S. 458-486, hier S. 467.

22 Suchten stimmt in dieser Einschätzung mit Nicolaus Copernicus überein, der nachweislich zu Suchtens Bekanntenkreis gehörte (siehe Kühlmann, Telle: Corpus Paracelsisticum I [Anm. 3], S. 545). Copernicus hatte im Jahr 1543 sein aufsehenerregendes Werk De revolutionibus orbium coelestium publiziert, in welchem er erstmals in der Geschichte der Astronomie für das heliozentrische Weltbild eintrat. Die spektakuläre Entdeckung, dass sich die Erde um die Sonne dreht, dürfte auf Suchten als Sympathisanten der neuplatonischen Kosmologie kaum verstörend gewirkt haben, und dies umso weniger, da Copernicus seinen Heliozentrismus in De revolutionibus mit Berufung auf Hermes Trismegistus, den Urahn der Alchemie, verteidigte (De revolutionibus. Nürnberg 1543, fol. $9^{v}$ ). Nicht zuletzt steht die Sonne in der traditionellen wie in der paracelsistischen Alchemie sinnbildlich für Gold, das wertvollste aller Metalle. Gleichwohl lässt sich die Frage, ob sich Suchten zum heliozentrischen Weltbild bekannte, 
dieser Überzeugung steht er unter dem Einfluss der Occulta philosophia des Agrippa von Nettesheim, aus der er beinahe wörtlich zitiert:

Die Sonne sitzt nämlich wie ein König inmitten der anderen Planeten, wobei sie diese jeweils an Stärke und Schönheit ihres Lichts übertrifft und ihnen allen Helligkeit verleiht. Auch gibt sie ihnen die Kraft, allen Dingen in den unteren Regionen ihren Ort zuzuweisen, und spendet aus sich selbst heraus überall Licht und Leben in Überfülle; und dies nicht nur im Himmel und in der Luft, sondern auch auf Erden und in den entlegensten Tiefen des Abyss. ${ }^{23}$

Gleichermaßen wie das Herz mitsamt dem darin wohnenden spiritus den Mittelpunkt des menschlichen Körpers repräsentiert, steht die Sonne als ,Herz des Himmels' im Zentrum des Weltalls. ${ }^{24}$

An die Stelle des solar vermittelten spiritus mundi tritt in De tribus facultatibus der Geist des Herrn. Diesen bezeichnet Suchten als einen „Stul deß Allmăchtigen“. ${ }^{25}$ Er entlehnt dieses Motiv der Offenbarung des Johannes (22,1), wonach das „Crystallinisch Wasser" dem Thron Gottes entströmt. Suchten erkennt hierin einen Emanationsprozess: Das kristalline Wasser war vor der Erschaffung der Welt von rein metaphysischer Natur. Es entsprach damit dem noch ungeschiedenen, unsichtbaren Himmelswasser, über dem zu aller Anfang der Geist des Herrn schwebte. Indem der Geist im Zuge des fiat lux in die Finsternis eindrang, nahm das kristalline Wasser, das ihn umhüllte, die Gestalt eines Dunstes an, der in den Tiefen des irdischen Diesseits zu einer Flüssigkeit von paradiesischer Qualität kondensierte. ${ }^{26}$ Nach Vorstellung der Paracelsisten ist dieses Wasser als quinta essentia nach wie vor aus bestimmten Substanzen extrahierbar. ${ }^{27}$

nicht abschließend klären: Dies gebietet der Umstand, dass Suchten der konventionellen Astronomie in De tribus facultatibus jeglichen Nutzen abspricht.

23 Alexander von Suchten: De vera medicina (Anm. 21), S. 469: „Sol enim tanquam Rex in meditullio sedet aliorum planetarum, luce magnitudine, pulchritudine omnes excellens, omnes illuminans, virtutemque illis ad inferiora quaeque disponenda; distribuens omnibus Lumen \& Vitam à se ipso copiosé largitur, non solum in Coelo et in Aere, sed etiam in terra et in intimis profundis Abyssi.“ (Übers. S. B.). Vgl. hierzu Cornelius Agrippa von Nettesheim: De occulta philosophia. Köln 1533, Buch II, S. 174: „Ipse tanquam rex sedet in meditullio aliorum planetarum, luce, magnitudine, pulchritudine omnes excellens, omnes illuminans, virtutemque illis ad inferiora quaeque disponenda distribuens, gressusque eorum regulans \& disponens, adeo, ut inde motus eorum diurni vel nocturni, meridionales vel aquionales, orientales aut occidentales, directi vel retrogradi [...]."

24 Indem der von Suchten zitierte Agrippa die Sonne als Herrscherin über die Planeten bezeichnet, greift er auf Ficinos Theologia platonica zurück, in der die Sonne als ein „rex in medio planetarum" und ein "rex in medio civitatis" bezeichnet wird; vgl. Marsilio Ficino: De immortalitate animorum Liber XVIII. In: ders.: Opera omnia Bd.1. Hg. von Paul Oskar Kristeller. Turin 1962, S. 397-414, hier S. 403.

25 Alexander von Suchten: De tribus facultatibus (Anm. 4), S. 377.

26 Martin Ruland: Quinta essentia. In: Lexicon alchemiae vel dictionarium alchemisticum. Frankfurt 1612. ND Hildesheim 1987, S. 401.

27 Lawrence M. Principe: The Secrets of Alchemy. Chicago 2013, S. 69-71; Karin Figala: [Art.] 
Vor dem Hintergrund, dass die große Welt aus dieser Flüssigkeit geschaffen wurde, kann auch der Mensch, der als Mikrokosmos seinerseits einen Auszug aus dem Makrokosmos repräsentiert, das kristalline Wasser als seine materia prima beanspruchen. Und doch unterscheidet sich die Urmaterie des Menschen von derjenigen der großen Welt: Sie ist nämlich angesichts ihrer - gleichsam destillatorisch vollzogenen - Scheidung vom kristallinen Wasser ungleich reiner und subtiler als dieses selbst. Suchten erkennt in jenem herrlichen Extrakt zugleich die Substanz, aus welcher der erwähnte ,Himmel des Menschen' gebildet ist. Weiterhin macht er dessen Reinheit und Ewigkeit zum Kriterium dafür, dass der Geist Gottes nach der Erschaffung der Welt im Mikrokosmos verblieben ist. Als geradezu dramatisch erweist sich nun der Umstand, dass sich der Mensch dieses Geistes - der ,Sonne' seines inneren Himmels - zu keinem Zeitpunkt bewusst ist, zumal sein innerer Blick von der undurchdringlichen Finsternis seines Verstandes (ratio) umfangen ist. Ein weiterer Grund, weshalb der Mensch außerstande ist, seines Geistes inne zu werden, besteht in seiner Faulheit:

[E]s ist viel leichter ein Stund in der Kirchen sitzen/ hơren was ein ander sagt/ daheim ein Buch nach dem andern durchlesen/ dann uns im Schweiß unsers Angesichts in so schröckliche Hăndel einlassen/ mit all unserm Vermògen Leibs und guts suchen den lebendigen Geist Gottes/ so er in den Erdenkloß/ darauß er Adam erschaffen/ bliß/ welcher uns die Augen aufthut/ und die Geheimnuß der Schriften/ Petri, Pauli, und der Apostel offenbahret/ dadurch wir Theologi werden/ der Welt nutz seyn/ unserm Nechsten helffen auß seinen Nöthen/ und den Geist deß HErrn/ der doch in uns zu finden/ von ihm Gesundheit und Fried haben/ von ihm lernen den Sohn des Menschen zu erkennen/ wie sein Fleisch unser Fleisch transmutiret in sein Fleisch/ ins ewige Leben. ${ }^{28}$

Die Auffindung des Geistes mündet in eine imitatio Christi, welche sich darüber realisiert, dass der Heiland in komplementärem Verhältnis zu seiner eigenen Fleischwerdung das Fleisch des Gottsuchenden in sein himmlisches Fleisch "transmutiret“. Indem Suchten das Verb ,transmutieren' mystisch überformt, nimmt er eine Neukontextualisierung des Vokabulars der traditionellen Alchemie vor: Er re-interpretiert damit die althergebrachte Transmutationskunst auf innovative Weise als eine alchemia mystica, welche in den Händen Christi, des höchsten Scheidekünstlers, die metaphysische Existenz des Adepten veredeln könne. Um eine solche Perfektionierung muss sich die gefallene Kreatur jedoch erst einmal verdient machen: Nach Suchten können allein eine alchemische Arbeit ,im Schweiße des Angesichts‘ und eine radikale Absage an die Verstandeserkenntnis den Allmächtigen vielleicht - aber eben nur vielleicht! - dazu bewegen, den Menschen innerlich zu erleuchten, auf dass dieser durch Christus seines innerhimmlischen Geistes teilhaftig werde:

Quinta essentia. In: Alchemie. Lexikon einer hermetischen Wissenschaft. Hg. von Claus Priesner und ders. München 1998, S. 302-304.

28 Alexander von Suchten: De tribus facultatibus (Anm. 4), S. 370f. 
Vielleicht einmal/ wann wir bekennen werden/ daß unser menschlicher Verstand nichts sey/ sondern daß wir durch denselben allen Jammer anrichten [...] und Gott umb Erleuchtung bitten nit mit Worten/ sondern mit Wercken/ so wird er sein Angesicht wieder zu uns wenden/ und an unserm Jammer und Unverstand ein Genugen haben/ und das Liecht der Natur wieder geben/ daß es in unserm Verstand leuchte/ wie die Sonne im Himmel/ die den Sternen alle Krafft gibt/ so ohne die Sonn kein Liecht haben. ${ }^{29}$

Erst wenn Gott Gnade walten lässt und die Finsternis des Verstandes auf den Geist hin transparent macht, steht der Mensch im Licht der Natur. Und erst dann vermag dieser das Antlitz des Allmächtigen innerhalb des Schöpfungsganzen zu schauen. Noch aber hält Gott sein Angesicht bedeckt. Mehr noch; er hat sich - wie sich dem Text entnehmen lässt - von der Menschheit abgewandt. Vor diesem Hintergrund liegt es ihm fern, sich auf seinem ,Stuhl' niederzulassen, mit anderen Worten: in den Geist des Menschen einzukehren. Vielmehr befindet er sich „in seinem Himmel weit von der Menschen Augen. ${ }^{\text {"30 }}$

Es wird mehr als deutlich, dass Suchtens Anthropologie keine prinzipielle inhabitatio dei in der Seele vorsieht. Der Allmächtige verharrt gegenüber der Schöpfung in Seklusion. ${ }^{31}$ Angesichts der Kluft, die zwischen Gott und der gefallenen Kreatur besteht, ist diese nicht in der Lage, eine unio mystica in Eigeninitiative herbeizuführen. Vielmehr ist es Gott anheimgestellt, in den Geist einzelner Erwählter einzukehren. Suchten distanziert sich damit vom Konzept eines Seelengrunds, wie man ihn in den mystischen Schriften Meister Eckharts, Johannes Taulers und später auch Valentin Weigels findet. ${ }^{32}$ Nicht einmal der Begriff ,Seele' ist für ihn noch von Bedeutung. ${ }^{33}$ Dies erweist sich als theologischer Problemfall, denn mit dem biblischen Begriff der Seele (anima) verbinden sich die Theologoumena von spiraculum vitae und imago dei.

29 Alexander von Suchten: De tribus facultatibus (Anm. 4), S. $361 f$.

30 Alexander von Suchten: De tribus facultatibus (Anm. 4), S. 357.

31 Hierin findet De tribus facultatibus Übereinstimmung mit dem spätmittelalterlichen Traktat Theologia Deutsch. Überhaupt bestehen zwischen den beiden Schriften zahlreiche inhaltliche Parallelen: Hier wie dort spielt der Eintritt in das Christusleben eine bedeutende Rolle. Ferner vollzieht sich die unio mystica in beiden Fällen über einen Raptus (vgl. Theologia Deutsch. Hg. von Wolfgang von Hinten. München 1982, S. 150,18). Vor allem aber dürfte die Theologia Deutsch auf Vertreter einer physica mosaica wie Suchten auch insofern großen Eindruck ausgeübt haben, als hier - für einen Text der Einigungsmystik ungewöhnlich - mehrmals der "geist gotis" zur Sprache kommt (ThD, S. 99,9f. und 16; S. 113,14). Zum unverkennbaren Einfluss der Theologia Deutsch auf die Formierung der paracelsistischen Theologie vgl. Brandl: Mystik und Magie im Frühparacelsismus (Anm. 3), Kap. 6.

32 Auch hierin entspricht Suchtens Traktat der Theologia Deutsch: Der Begriff , sêlengrund' findet sich hier kein einziges Mal, und wenn doch an einer Stelle vom ",grunde der sele“ die Rede ist (ThD, S. 101,9), so ist hiermit nur ein innerer Rückzugsraum gemeint, der es dem Menschen ermöglicht, sich von den sinnlichen Reizen der Außenwelt abzuschirmen.

33 Tatsächlich weist der Traktat nur eine einzige Stelle auf, an der Suchten von der ,Seele' spricht. Dies allerdings im Zusammenhang mit dem Seelenheil, also in jedem Fall fernab von mystischen Implikationen; vgl. Alexander von Suchten: De tribus facultatibus (Anm. 4), S. 366. 
In der Folge degradiert Suchten die theologische Relevanz der imago-Lehre auf geradezu skandalöse Weise: Demnach erschuf Gott den Menschen nur insoweit nach seinem Ebenbild, als dieser das Konterfei des Makrokosmos repräsentiert:

Da der Mensch durch die Erfahrenheit erkandte/ daß wie GOtt auß dem Wasser gemacht hatte die grosse Welt/ das ist/ Himmel und Erden/ und alles was darinnen ist/ und auß der grossen Welt den Menschen nach seinem Ebenbild/ welcher da war die kleine Welt/ daß alles/ so in der grossen Welt ist/ auch in der kleinen wăre [...]..$^{34}$

Mit seiner Relativierung respektive Brechung der bildlichen Gleichheit von Mensch und Gott, die sich angesichts der Kür des Makrokosmos zur eigentlichen imago dei ergibt, rezipiert Suchten vermutlich Agrippas Occulta philosophia. Dort heißt es:

Gott schuf den Menschen nach seinem Bilde, denn so wie die Welt das Ebenbild Gottes ist, so ist der Mensch das Ebenbild der Welt. Darüber erklären sich einige das Bibelwort, welches ja nicht besagt, dass der Mensch einfach als Bild Gottes geschaffen wurde, sondern nach dessen Bilde; also gewissermaßen als Bildnis des Bildnisses. Daher nennt man ihn Mikrokosmos, die kleinere Welt [...]. Der Mensch heißt die zweite Welt und zweites Ebenbild Gottes, denn er enthält in sich alles, was in der großen Welt ist, sodass es nichts gibt, was man nicht tatsächlich auch im Menschen selbst finden könnte [...]: In ihm ist das vegetative Leben der Pflanzenwelt, die Sinneswahrnehmung der Tiere, der himmlische Geist, die Vernunft der Engel und der göttliche Gedanke [...]. ${ }^{35}$

Führt man sich vor Augen, dass dieser himmlische Geist zugleich auch der göttliche Same ist, der von jeher die gesamte Schöpfung als Idee enthielt, erscheint er als das eigentliche und erste Urbild, welches sich im Makrokosmos auf sichtbare, im Mikrokosmos aber auf unsichtbare Weise manifestiert.

\section{Die paracelsistische Logostheologie}

Als theologisches Wagnis offenbart sich auch die Neukontextualisierung, die das Motiv des göttlichen Lebensatems erfährt. Letzteren identifiziert Suchten nämlich nicht mit jenem göttlichen Hauch, durch den der Allmächtige den Menschen am sechsten Schöpfungstag adelte (1 Gen 2,7), sondern abermals mit dem primordialen spiritus mundi, der zu aller Anfang in die Finsternis einging. Hierbei

34 Alexander von Suchten: De tribus facultatibus (Anm. 4), S. 362.

35 Cornelius Agrippa von Nettesheim: De occulta philosophia (Anm. 23), Buch III, S.284f.: „Creavit deus etiam hominem ad imaginem suam: nam sicuti imago dei mundus est, sic imago mundi homo est: hinc putant quidam dictum esse, quod homo non simpliciter imago dei creatus est, sed ad imaginem, quasi imaginis imago: idcirco microcosmus dictus est, hoc est, minor mundus [...]. Homo itaque alter mundus vocatus est, \& altera dei imago: quia in se habet totum quod in maiori mundo continetur, ut nihil relictum sit, quod ipsum non etiam vere \& realiter in ipso homine reperiatur [...].“ (Übers.: S. B.). 
kann er sich auf die Polysemie des Wortes spiritus berufen, welches nicht nur Geist, sondern auch ,Hauch' oder ,Atem' bedeutet.

Dass Suchten im schöpfungstheologischen Kontext das Theologoumenon der Seele suspendiert, liegt in seiner Rezeption der Weisheitsbücher des Alten Testaments begründet. Das kosmologische Konzept, das dort mit Bezug auf den Begriff spiritus entfaltet wird, ist für Suchtens weitere Ausführungen überaus aufschlussreich; es erhellt nämlich die religiösen und anthropologischen Hintergründe seines naturphilosophischen Weltbilds. Der Geist des Herrn steht demnach in engem Zusammenhang mit der himmlischen Weisheit (sapientia), welche an der Kosmogonie beteiligt war. Dies ergibt sich aus den biblischen Sprüchen Salomos $(8,22-30)$, in denen sich die Weisheit selbst zu Wort meldet:

Der HERR hat mich geschaffen als Anfang seines Weges, vor seinen Werken in der Urzeit; in frühester Zeit wurde ich gebildet, am Anfang, beim Ursprung der Erde. Als die Urmeere noch nicht waren, wurde ich geboren, als es die Quellen noch nicht gab, die wasserreichen. Ehe die Berge eingesenkt wurden, vor den Hügeln wurde ich geboren. Noch hatte er die Erde nicht gemacht und die Fluren und alle Schollen des Festlands. Als er den Himmel baute, war ich dabei, als er den Erdkreis abmaß über den Wassern, als er droben die Wolken befestigte und Quellen strömen ließ aus dem Urmeer, als er dem Meer sein Gesetz gab und die Wasser nicht seinen Befehl übertreten durften, als er die Fundamente der Erde abmaß, da war ich als geliebtes Kind bei ihm. Ich war seine Freude Tag für Tag und spielte vor ihm allezeit.

Auf diese Textstelle nimmt auch das vierundzwanzigste Kapitel von Jesus Sirach Bezug, da die Weisheit erneut ihre Stimme erhebt (24,3-9):

Ich ging aus dem Mund des Höchsten hervor und wie Nebel umhüllte ich die Erde. Ich schlug in den Höhen mein Zelt auf und mein Thron stand auf einer Wolkensäule. Den Kreis des Himmels umschritt ich allein und in der Tiefe der Abgründe ging ich umher. Auf den Wogen des Meeres und auf der ganzen Erde, in jedem Volk und in jeder Nation hatte ich Besitz. Bei all diesen suchte ich Ruhe und in wessen Erbteil ich verweilen kann. Da gebot mir der Schöpfer des Alls, der mich schuf, ließ mein Zelt einen Ruheplatz finden. Er sagte: In Jakob schlag dein Zelt auf und in Israel sei dein Erbteil! Vor der Ewigkeit, von Anfang an, hat er mich erschaffen und bis in Ewigkeit vergehe ich nicht.

Im ersten Kapitel desselben Buchs heißt es, dass das Wort Gottes die ,Quelle der Weisheit‘ sei $(1,7)$. Zu einer vollständigen Gleichsetzung von Verbum und Sapientia kommt es schließlich im Neuen Testament. Diese erweist sich als unausweichlich, wenn man auf den Prolog des Johannesevangeliums blickt („In principio erat Verbum, et Verbum erat apud Deum, et Deus erat Verbum“): Der göttliche Urgrund, 
durch den der Schöpfer alles Seiende gemacht hat, behauptet sich einmal als die Weisheit, ein andermal als der Logos, und beides ist in Gott eins. ${ }^{36}$

Der Frage, wie aus ebendieser, in Gott beschlossenen Einheit das Viele hervorging, widmet sich das neuplatonisch inspirierte ,Buch der XXIV Philosophen'; eine ursprünglich arabische Kompilation, die später Hermes Trismegistus zugeschrieben wurde. ${ }^{37}$ In der ersten der insgesamt vierundzwanzig Definitionen des göttlichen Wesens heißt es: „Gott ist die Monas, welches die Monas aus sich selbst

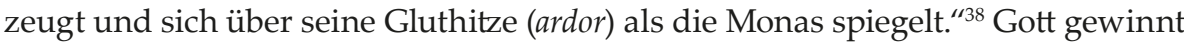
kraft seiner Selbstreflexion die Bestimmung seiner selbst als das Eine, oder anders formuliert: Er bringt das Eine, das er selbst ist, fortwährend aus sich selbst hervor. Das Spiegelbild aber, in dem sich Gott in seinem einheitlichen Wesen erblickt, lässt sich nicht in Worte fassen, es sei denn auf uneigentliche Weise: so etwa über das Bild von der Gluthitze der Monas. Gemäß ihrer Gottähnlichkeit offenbart sich diese als Spenderin einer allumfassenden Lebensglut oder - was dem Bedeutungsspektrum des Lexems ardor ebenfalls entspricht - eines feurigen Glanzes.

Die Entitäten von Licht und Leben, die Gott im Rahmen seiner Selbstobjektivierung erzeugt, entsprechen, übertragen auf den Johannes-Prolog, dem Gottessohn: jenem göttlichen Wort, welches dortselbst mit vita, lux hominum und lux vera kontextualisiert wird. Indem Gott sich als das Wort begreift, bringt er sich als Sohn seiner selbst hervor. ${ }^{39}$ Es kann kein Zweifel bestehen, dass Suchten mit diesem Konzept vertraut war; wahrscheinlich begegnete es ihm bei der Lektüre des dritten Buches von Agrippas Occulta philosophia. Agrippa identifiziert hier die Weisheit explizit mit dem Sohn Gottes. Er beruft sich dazu auf den Evangelisten Johannes sowie auf Hermes, Orpheus, Jamblich, Moses, Zarathustra, Heraklit, Platon, das ,Buch der XXIV Philosophen' und auf das oben zitierte, vierundzwanzigste Kapitel von Jesus Sirach:

[Gott] zeugt in sich selbst seinen eingeborenen Sohn, die vollkommene Weisheit, sein vollkommenes Ebenbild, ein vollkommenes Vorbild der Welt; dieses nennen unser Evangelist Johannes und Hermes das Wort oder die Rede. Platon bezeichnet es als den Sohn Gottvaters, Orpheus aber als die aus Jupiters Kopf

36 Vgl. Wilhelm Schmidt-Biggemann: Philosophia perennis. Historische Umrisse abendländischer Spiritualität in Antike, Mittelalter und Früher Neuzeit. Frankfurt a. M. 1998, S. 205 und 213.

37 Zur Rezeptionsgeschichte des ,Buchs der XXIV Philosophen' Kurt Ruh: Geschichte der abendländischen Mystik. Bd. 3. München 1996, S. 33.

38 Liber XXIV philosophorum. In: Hermes Latinus Abt. III. Bd. 1. Hg. von François Hudry. Turnhout 1997, S. 5-83, hier S. 5: „Deus est monos, monadem ex se gignens, in se vnum reflectens ardorem." (Übers. S. B.).

39 Diese Vorstellung wurde im Mystik-Diskurs des Spätmittelalters in Gestalt der Philosopheme von ,Gottgeburt' und ,Geburtenzyklus' rege rezipiert. So begreift etwa Meister Eckhart diese auf sich selbst gerichtete Dynamik Gottes als ein inneres Sprudeln (bullitio). Gott bringt den Seelengrund des Menschen ständig aus sich selbst hervor, wobei die Eingeburt Gottes in der Seele zugleich seinen Rückfluss in sein ureigenes Selbst impliziert. Die schöpferische, aus dem göttlichen Selbstbezug ausbrechende Wirkung Gottes bezeichnet Eckhart hingegen als ein Überquellen (ebullitio). 
geborene Pallas Athene, das heißt: als die Weisheit. Sie ist das höchste Ebenbild Gottvaters, und doch hat sie sich ihrer Herkunft und ihres inneren Wesens gewissermaßen entäußert; eben auf solche Weise, wie ein Gezeugtes stets von seinem Erzeuger verschieden ist. So heißt es bei Jesus Sirach: ,Ich bin aus dem Munde des Höchsten hervorgegangen, als eine Erstgeborene, die vor allem Geschöpflichen da war.' Des Weiteren ist dieses Kind Gottes nach dem Zeugnis des Jamblich mit dem Vater ganz eins und seinem Wesen nach Gott selbst: Er beschreibt Gott offenkundig als Vater und Sohn seiner selbst. Auch Hermes Trismegistus bezeugt im ,Asklepios' an verschiedenen Stellen die Existenz eines Gottessohns. Er sagt nämlich: ,Mein Gott und Vater hat aus sich ein anderes Lebewesen als Schöpfer hervorgebracht.' Und anderenorts heißt es: Die Monas zeugt eine weitere Monas und spiegelt sich in sich selbst in Gestalt eines feurigen Glanzes [...]. Auch liest man im Fünften Buch Mose: ,Gott ist ein verzehrendes Feuer', und darauf bezugnehmend sagt Zarathustra, alles sei durch ein Urfeuer entstanden. Zudem lehrte Heraklit von Ephesus, dass das Feuer der Ursprung aller Dinge sei. Davon ausgehend stellte der göttliche Platon die These auf, dass Gott in einem feurigen Wesen wohne, wobei er darunter freilich den unaussprechlichen Glanz und Liebreiz verstand, der Gott umgibt [...]. ${ }^{40}$

Indem sich Agrippa auf Platon beruft, nimmt er offenbar Bezug auf dessen Schrift über den Staat, in der Sokrates die Sonne zur behelfsmäßigen Bestimmung des Absoluten heranzieht: Die Idee des Guten ist, wie das Sonnenlicht an sich, weder sichtbar noch greifbar, und doch treten in diesem ,Licht' ${ }^{\prime}$ alle Dinge zu Tage. In demselben Sinne macht sich freilich auch der biblische Schöpfungsbericht die Lichtmetaphorik zu eigen: Gott schuf das All durch das fiat lux. Diese Formel wiederum wird im Johannesprolog indirekt mit dem Logos gleichgesetzt, zumal dieser ja ebenfalls ,im Anfang' (in principio) war: In dem Moment, da sich der Logos nach außen kehrte, wurde er zur primordialen lux in tenebris, die alle irdischen und himmlischen Dinge zum Vorschein bringt; und dies bereits vor seiner Fleischwerdung in Christus. ${ }^{41}$

40 Agrippa von Nettesheim: De occulta philosophia (Anm. 35), S. 221f.: „prolem \& filium in se progenerat, quae est plena intelligentia, plena sui imago, \& plenum mundi exemplar: quod Ioannes noster, \& Mercurius verbum nominant, siue sermonem: Plato dei patris filium: Orpheus vero Palladem ex Iouis capite natam, hoc est sapientiam. Haec est altissima dei parentis imago quadam tamen relatione, aut aliquo intrinseco absoluto, tamquam genita distincta generante, quae apud Ecclesiasticum ait: Ego ex ore altissimi prodii, primogénita ante omnem creaturam Filium autem hunc cum patre vnum \& eundem in essentia testat Iamblichus, deum videlicet sui ipsius patrem filiumque nominans. Mercurius quoque Trismegistus in Asclepio, dei filium diuersis in locis affirmat. Inquit enim: Deus meus atque pater mentem sibi aliam opificem peperit. Et alibi: monas gignit monadem, \& in se suum reflectit ardorem [...]. Et in Deuteromonio legitur: Deus ignis consumens est. De quo \& Zoroastes ait, omnia von ab igne genita esse. Et Heraclitus Ephesius cuncta ex igne genita esse docuit. Hinc divinus Plato, deum in ignea essentia habitare posuit, intelligens videlicet inenarrabilem dei in seipso splendorem, \& circa seipsum amorem [...].“ (Übers. S. B.).

41 Vgl. Schmidt-Biggemann: Philosophia perennis (Anm. 36), S. 206f. 
Auch die Weisheit fügt sich konzeptionell nahtlos in das Szenario ein, welches das ,Buch der XXIV Philosophen' zeichnet. Dies jedenfalls wird deutlich, wenn man folgendes Textzitat aus dem biblischen Liber sapientiae Salomonis ins Auge fasst (7,25f.):

[Die Weisheit] ist ein Hauch (,vapor'), der von dem allmächtigen Gott ausgeht, ein reiner Ausfluss seiner Herrlichkeit; deshalb kann nichts Unreines in sie eindringen. Sie ist der Abglanz des ewigen Lichtes, der ungetrübte Spiegel von Gottes Macht, das Abbild seiner Vollkommenheit.

Die primordiale Weisheit ist der ,Spiegel', an dem sich Gott im permanenten Akt seines dynamischen Selbstbezuges auf sich selbst hin reflektiert. ${ }^{42}$ Das Bild des göttlichen Angesichts selbst aber ist ein Abglanz des ewigen Lichtes, was an die johanneische lux in tenebris und somit an den Logos gemahnt. ${ }^{43}$ Ebenso wie letzterer verbindet sich die Weisheit mit einer Metaphorik, die sich zur Beschreibung des Einen eignet. So kommt sie dem Einen vor allem darin gleich, dass sie über alle Maßen schlicht und doch zugleich so allumfassend ist: Als ein reiner, makelloser Spiegel ist sie imstande, alles Sichtbare zum Vorschein zu bringen. Dennoch - oder gerade deswegen - hat sie, ebenso wie ein Spiegel, selbst kein konkretes Aussehen. Ihre Gestalt ist unbegreiflich: Sie ist weder über den Verstand noch mit Händen zu fassen. In letzterem Sinne entspricht die Weisheit denn auch besagtem „Hauch, der von dem allmächtigen Gott ausgeht.“ Indem der Autor des Weisheitsbuches, in welchem der Leser des 16. Jahrhunderts Salomo selbst zu erkennen glaubte, ${ }^{44}$ diesen Hauch fernerhin als eine Emanation der göttlichen Herrlichkeit beschreibt, drängt sich freilich dessen Identifikation mit dem spiritus mundi auf (Weish 7,22-23):

In ihr [sc. der Weisheit] ist nämlich ein Geist, vernunftvoll, heilig, einzigartig, mannigfaltig, zart, beweglich, durchdringend, unbefleckt, klar, unverletzlich, das Gute liebend, scharf, nicht zu hemmen, wohltätig, menschenfreundlich, fest, sicher, ohne Sorge, alles vermögend, alles überschauend und alle Geister durchdringend, die gedankenvollen, reinen und zartesten.

Es wird deutlich: Die Wortnatur Christi ist nichts anderes als der glühende Geisthauch der himmlischen Weisheit. Dem Konzept der Spiegelung trägt Suchten insofern Rechnung, als er in den Propositiones die Hypostase dieses Geisthauchs mit Berufung auf Pseudo-Dionysius als gottgleich beschreibt. ${ }^{45}$ Die Schöpfung reali-

42 Vgl. Schmidt-Biggemann: Philosophia perennis (Anm. 36), S. 214f.

43 Der Gedanke, dass der Logos als göttliches Spiegelbild fungiert, klingt indirekt auch im

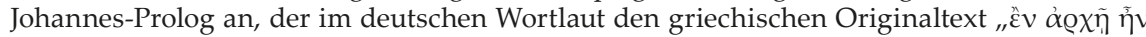

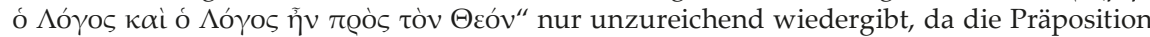
Tœó eine Richtung auf etwas hin beschreibt. Das Wort ist in diesem Sinne nicht ,bei' Gott: Vielmehr ist es - gleich einem Spiegel - dem göttlichen Antlitz zugewandt.

44 Schmidt-Biggemann: Philosophia perennis (Anm. 36), S. 213f.

45 Alexander von Suchten: Decem et octo propositiones, in quibus liquide demonstratur, quod medicus sit, quidque medicina ipsius. Item quibus remediis aegritudines a corporibus expel- 
siert sich demnach darüber, dass die Weisheit, welche ursprünglich innerhalb der zirkulären Bewegung der göttlichen Selbstobjektivierung vor dem Herrn ",spielte“ (Spr. 8,30), sich nach außen stülpt und den lichten Glanz des Logos in die Finsternis hineinspiegelt sowie ihren glühenden Geisthauch, als einen Ausfluss ihrer selbst, in die Tiefe entlässt. Sie erweist sich damit als eine Scharnierstelle zwischen dem Logos und dem Geist des Herrn: Weisheit, Wort und Geist bilden eine unauflösliche Einheit, innerhalb derer sich höchstens begriffliche Differenzierungen treffen lassen. Weiterhin wird deutlich, dass nicht nur der Logos, sondern auch der Geisthauch der Weisheit direkt auf das fiat lux referiert; ${ }^{46}$ denn als göttliche Verlautbarung ist das fiat zugleich das Wort und die Stimme des Allmächtigen - und in diesem Sinne zugleich der lauterzeugende Atem, der durch den Mund Gottes weht. ${ }^{47}$

Dieser wehende Atem verkörpert wiederum den spiritus mundi, dessen trübes Kleid in den Tiefen des Abyssus zu dem erwähnten kristallinen Wasser gerinnt. Da ebendieser Hauch zugleich den Spiegel des Allmächtigen darstellt, ist auch sein wässriges Kondensat vom Licht des göttlichen Angesichts erfüllt. Indem nun das kristalline Geistwasser ferner als materia prima des Makrokosmos fungiert, kann auch noch dieser selbst für sich Gottähnlichkeit behaupten. Diese similitudo äußert sich in Gestalt einer vom Geist gestifteten, metaphysischen Substruktur, die sich unter der Oberfläche der sichtbaren Natur verbirgt und das Lebenselixier aller Kreaturen darstellt. Dementsprechend lassen sich Weisheit, göttlicher Geist, das ewige Wort und letztlich auch Christus selbst an der äußeren Schöpfung ablesen. Dass dies bereits vor der incarnatio verbi möglich ist, bekräftigt Suchten mit Verweis auf Hermes Trismegistus: „Wer hat ihm Christum zu erkennen geben? Die Creaturen Gottes/ die Galeno so wol furr den Augen gelegen als Hermeti. ${ }^{\text {‘48 }}$ Hierbei denkt er wohl an das Paulus-Wort, wonach sich die unsichtbare Wirklichkeit Gottes auch dem intellectus der Heiden erschließt, zumal der Schöpfer stets an seinen Werken erkennbar ist. ${ }^{49}$ Zwar hält die äußere Schöpfung ihren göttlichen Grund zumeist vor den unwürdigen Augen der gefallenen Kreatur bedeckt; dem wahrhaft gläubigen Menschen ist es jedoch vergönnt, in diesen Grund Einblick zu gewinnen und daraus praktischen Nutzen zu ziehen. Damit ergibt sich ein

lant [...] Joannes de Suchten, Medicus regis Poloniae. In: Codex Palatinus Latinus der Bibliothe-

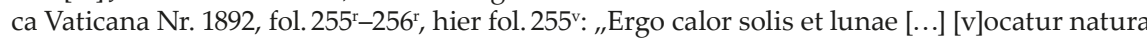
mundi, anima mentis nostrae, à Platone, Pythagorae philosophis prima mens, diuinus intellectus, imago diuinae intelligentiae, et conspicuus Dei filius dicitur. Orpheus antiquissimus theologus Jovem nuncupat. Dionysius beati Pauli discuipulus conspicuam Dei statuam nominat [...]. Calor enim ille est ens perfectissmum spirituale, maximè inter creaturas Dei [...]."

46 Schmidt-Biggemann: Philosophia perennis (Anm.36), S. 216.

47 Schmidt-Biggemann: Philosophia perennis (Anm. 36), S. 216f. Siehe hierzu auch folgendes Zitat Suchtens (Anm. 4, S. 379): ",Das Fiat/ dadurch die Welt erschaffen/ das ist der Saamen deß Himmels und der Erden/ der Athem Gottes/ den er in den todten Erdenkloß einbließ [...]."

48 Alexander von Suchten: Der dritte Tractat vom Antimonio (Anm. 13), S. 256.

49 Rom 1,20: „Invisibilia enim ipsius a creatura mundi, per ea, quae facta sunt intellecta conspiciuntur." 
erstaunlicher Befund: Die Logostheologie mündet, solcherart zu Ende gedacht, direkt in das naturphilosophische Weltbild der Paracelsisten.

\section{Die mystische Dimension der incarnatio verbi}

Vor dem Hintergrund der Logostheologie wird verständlich, weshalb eine Erfahrung des gütigen Wesens Christi zugleich eine Offenbarung der göttlichen Weisheit impliziert. Ferner zeigt sich, dass es hierfür einer Teilhabe am Geist des Herrn bedarf. Die Frage, wie sich dieser Geist greifbar machen lässt, steht daher im Zentrum von De tribus facultatibus. Suchten erörtert diese Frage anhand einer allegorischen Erzählung von einem gottergebenen Menschen, der in vormosaischer Zeit lebte. Dieser habe „nicht mehr gewust/ als daß er von seinem Vatter Adam gehơrt/ wie er von Gott geschaffen/ wie er ins Paradeiß gesetzt/ darinnen gesundiget/ und darumb verstossen in Arbeit/ Jammer und Noth dieser Welt. ${ }^{150}$ Die Kümmernisse seines postlapsaren Daseins und die Liebe zu Gott hätten ihn bewogen, sich auf die Suche nach seinem Schöpfer zu begeben. Indem Suchten den Blick derart weit in die Vergangenheit schweifen lässt, macht er indirekt deutlich, dass die folgenden Ausführungen keinen Anspruch auf Tatsächlichkeit erheben. Die Erzählung hat den Charakter einer heuristischen Rekonstruktion des Weges, auf dem die vermeintlichen Vorläufer der Paracelsisten ihres Geistes und somit der göttlichen Weisheit teilhaftig wurden.

Nach Suchten führte dieser Weg über eine Erfahrung der Natur: Der gottsuchende Adamssohn hegt die Überzeugung, „daß der Meister am besten zuerkennen wăre an seinem Meisterstůck [...]. ${ }^{\text {‘51 }}$ Da die Kreaturen allein noch keine Schau ihres Schöpfers gestatten, setzt er die Suche auf alchemischem Wege fort. Damit hat er die ideale Grundlage zur Ergründung der Wirklichkeit gefunden. Zunächst entdeckt er durch Destillation des kristallinen Wassers die sogenannten ,drei Prinzipien', die nach der paracelsischen Lehre allem Geschöpflichen zugrunde liegen: Es handelt sich dabei um "mercurius", "sulphur" und "sal". Suchten bevorzugt in diesem Kontext allerdings die Rede von "Wasser", "Sulphur" und "Saltz". ${ }^{52}$ Bei diesem Salz dürfte es sich um Eisenvitriol handeln. Auf die Fährte dieses Minerals führt die erste Druckfassung von De tribus facultatibus von 1608, denn hier ist mit Bezug auf das Salz von einem "Oleum Saltz" die Rede. ${ }^{33}$ "Oleum" ist die alchemische Bezeichnung für Schwefelsäure, und letztere wurde spätestens seit dem 13. Jahrhundert durch die Destillation von Eisenvitriol gewonnen. ${ }^{54} \mathrm{Nich}$ zuletzt verweist das Eisenvitriol aber auch anhand seines Namens, welcher sich von vitreolus oder vitriolus (glasartig) herleitet, auf seinen Ursprungsort zurück:

50 Alexander von Suchten: De tribus facultatibus (Anm. 4), S. 357.

51 Alexander von Suchten: De tribus facultatibus (Anm. 4), S. 358

52 Alexander von Suchten: De tribus facultatibus (Anm. 4), S. 362.

53 Benedict Figulus: Pandora magnalium naturalium [...]. Straßburg 1608, S. 118.

54 Claus Priesner: [Art.] Säuren. In: Alchemie. Lexikon einer hermetischen Wissenschaft. Hg. von dems. und Katrin Figala. München 1998, S. 314f., hier S. 314; Wolfgang Schneider: Lexikon alchemistisch-pharmazeutischer Symbole. Weinheim 1962, S. 82. 
das kristallgleiche, gläserne Meer („mare vitreum simile crystallo“), von dem in der Johannes-Apokalypse (Off 4,6) die Rede ist. Dieses Eisensalz bleibt im Folgenden von Bedeutung:

Nun aber als der Mensch dasselb erfuhr/ wie auß dem Wasser per corruptionem \& generationem die drey Substanzen gebohren sind/ doch hatte noch nicht seinen Schöpffer gefunden/ dessen Geist ob dem Wasser schwebete/ ut inquit Scriptura. Greiff darumb an die drey Corpora, durchgrubelt eins nach dem andern/ betrachtet/ wie Gott ein Geist ist/ konte mit leiblichen Augen nicht begriffen werden/ und dieweil er alles erschaffen hat/ müste er ein lebendige Krafft seyn/ nimbt derwegen das Wasser/ beschauet es/ findet nichts darinn/ dann die vier Element: Nimbt darnach den Schwefel/ findet auch nichts dann die vier Element/ das ist/ er findet nichts bestăndigs. Zu letzt nimbt er auch das Saltz/ sihet daß etwas mehr darbey ist/ dann bey dem Wasser und Sulphur: Ja findet darinn zwey Stück/ ein Wasser/ nichts anders/ dann das vorige/ ein Sulphur aber anderst/ dann der vorige war/ das ist ein Schwefel der nicht brennet [... ${ }^{55}$

Das extrahierte „Wasser" bezeichnet wohl das Hydratwasser des Eisenvitriols, das schon bei geringer Luft- und Wärmezufuhr entweicht. Vor dem Hintergrund, dass dieses aus dem kristallinen Wasser destilliert wurde, handelt es sich hierbei offenkundig um dieselbe quinta essentia, aus der der subtile ,Himmel des Menschen' geschaffen ist. Der unbrennbare Schwefel repräsentiert demnach das nunmehr dehydrierte Eisensulfat. Dieser Feststoff wird im Verlauf des Traktats nur noch als ,Erde' aufgerufen. Als solche steht der Schwefel wohl für die ,Erde des Menschen'. Nicht von ungefähr heißt es: „[D]er Mensch/ das ist die kleine Welt/ ein kleiner Himmel/ und ein kleine Erden. ${ }^{\prime 56}$ Indem der urzeitliche Naturforscher im Verlauf seines alchemischen Kunststücks die genannten Extrakte Schritt für Schritt nachvollzieht, eröffnet sich ihm seine eigene Anthropologie. Diese beansprucht für sich freilich noch ein Drittes: den Geist des Herrn. Suchten identifiziert diesen offensichtlich mit dem spiritus vitrioli, ${ }^{57}$ bei dem es sich um ein schwefeloxidhaltiges Gas handeln dürfte. Doch ebenso, wie es dem Adamssohn angesichts der Finsternis seines Verstandes missgönnt ist, selbigen Geist in seinem Inneren aufzufinden, misslingt es ihm auch, diesen nach erfolgter Extraktion festzuhalten:

[D]as dritte fand er nicht/ dann es verschwand vor seinen Augen. Was sollte er thun/ es war dahin/ wo sollte ers finden. Er besahe das Wasser, besahe den Sulphur, zwo feine weisse und reine Substantzen/ das dritte/ so darinnen gelegen $[\ldots]$ / war hinweg/ und war eben dasselbige/ das er suchte. ${ }^{58}$

55 Alexander von Suchten: De tribus facultatibus (Anm. 4), S. 362 f.

56 Alexander von Suchten: De tribus facultatibus (Anm. 4), S. 378.

57 Zum spiritus vitrioli siehe Schneider: Lexikon alchemistisch-pharmazeutischer Symbole (Anm. 54), S. 89.

58 Alexander von Suchten: De tribus facultatibus (Anm. 4), S. 363. 
Dem Gottsuchenden bleibt nun nichts weiter, als an die Gnade seines Schöpfers zu appellieren:

[Der Mensch war] nicht wenig traurig/ seufftzet und schrey Tag und Nacht zu dem HErren: Disrumpe Colos \& descende: Trieb es so lang/ biß er erhört wurde und das fand so er suchte/ wie aber das zu finden zugieng/ wer will das schreiben? oder/ wann mans gleich schrieb/ welche Ohren kônnten solch Mysterium anhören? Wahrlich in diesem Stück ist verborgen die Sapientia omnium Cœlestium \& Terrestrium rerum. Allhier ist das Mysterium, wie zu den letzten Zeiten das Wort sey Fleisch worden/ wird denen/ so Gott zu dieser Erkäntnuß erwehlet/ also offenbahr/ daß Sie mit Stephano den Himmel offen sehen/ und den Sohn deß Menschen sitzen zur rechten Hand Gottes/ und mit Paulo von der Erden auffahren biß in den dritten Himmel/ sehen darinnen/ das keinem erlaubt ist zu offenbahren. ${ }^{59}$

Was ist geschehen? Gott hat auf seinem Stuhl im Himmel des Menschen platzgenommen. Analog zur Theologia Deutsch greift der Allmächtige von außen auf die Kreatur aus, ${ }^{60}$ indem er kurzzeitig in sie einkehrt und sich seinem ,Sohn', dem Geist der Weisheit, vollkommen mitteilt. Den Geist zu erkennen bedeutet gemäß der von Suchten rezipierten, neuplatonischen Epistemologie nichts anderes, als diesem völlig gleich zu werden. ${ }^{61}$ Der getrübte innere Spiegel der gefallenen Kreatur erhält dadurch dieselbe Lauterkeit, welche dem präexistenten Spiegel der Weisheit eigen ist: Der Erleuchtete wird somit innerlich zum vollkommensten Ebenbild Gottes.

Führt man sich vor Augen, dass der Allmächtige sich im Moment des Raptus nicht nur im menschlichen Geist widerspiegelt, sondern sogar in diesem Wohnung bezieht, so ergibt sich damit eine Intensität an Gottesunmittelbarkeit, welche über eine bloße Ebenbildlichkeit weit hinausgeht: Die inhabitatio dei offenbart sich zugleich als eine unio mystica. Gemäß der paulinischen Devise „Wer dem Herrn anhängt, der wird ein Geist mit ihm“ (1 Kor 6,17) wird der menschliche Geist gänzlich von der Herrlichkeit Gottes durchdrungen. Das paulinische „Auffahren biß in den dritten Himmel“ erweist sich somit als eine Metapher für die Realisierung des Empyreums im Gottsuchenden: Über die Erleuchtung durch den Allmächtigen wird die gefallene Kreatur in ihren paradiesischen Urzustand zurückversetzt. In Absetzung von der traditionellen Konzeption der mystischen Erfahrung, der zufolge illuminatio und unio zwei voneinander getrennte Stadien

59 Alexander von Suchten: De tribus facultatibus (Anm. 4), S. 363f.

60 Vgl. hierzu v. a. Lydia Wegener: ,Der Frankfurter' / ,Theologia Deutsch'. Spielräume und Grenzen des Sagbaren. Berlin, Boston 2016, S. 141-188.

61 Vgl. Plotin: Enneade 1,6 § 43: „Man muß nämlich das Sehende dem Gesehenen verwandt und ähnlich machen, wenn man sich auf die Schau richtet; kein Auge kann je die Sonne sehen, das nicht sonnenhaft geworden ist; so sieht auch keine Seele das schöne, welche nicht schön geworden ist." Zitiert nach Plotin: Das Schöne ( $\pi \varepsilon \varrho i$ toṽ $\kappa \alpha \lambda$ 人ũ). In: ders.: Schriften Bd. 1. Hg. und übers. von Richard Harder. Leipzig 1930, S. 1-13, hier S. 13. 
darstellen, bedeutet dies, dass mit der Erleuchtung durch den Geist bereits die Vereinigung verwirklicht ist. Über die Auffindung des Geistes wird auch das verlorengeglaubte Licht der Natur aufs Neue entzündet. Darüber empfängt der Mensch seinen „geistlichen Verstand“.62 Dieser erlaubt es ihm, die geheimnisvollen Signaturen der Schöpfung im Licht der Natur zu entschlüsseln, auf dass ihm Christus in Wort und Wesen offenbar werde. Es wird deutlich: Die mystische Einheitserfahrung dient nicht - oder zumindest nicht primär - dem Selbstzweck. Ihr eigentlicher Mehrwert besteht darin, dass der Urmensch „das fand so er suchte": den Geist des Herrn. ${ }^{63}$ Dieser gibt dem Menschen die innersten Geheimnisse Gottes zu erkennen.

Indem sich das ,Wissen über alle himmlischen und irdischen Dinge' mit der Fleischwerdung des Wortes zu einem großen ,Mysterium' verbindet, verlagert sich der Diskurs erneut auf das Terrain der Schöpfungstheologie: Dies zeigt sich am Begriff ,Mysterium' selbst, denn nach der pseudo-paracelsischen Schrift Philosophia ad Athenienses ist es das Mysterium magnum, das eine präkreationale materia prima und somit die "Mutter aller Creaturen" darstellt. ${ }^{64}$ Der frühe Paracelsist Gerhard Dorn verteidigte diese Schrift gegen die Angriffe des Heidelberger Theologen Thomas Erastus, indem er erklärte, dass das besagte Mysterium nichts weiter als das mosaische principium darstelle, in welchem Gott die gesamte Schöpfung angelegt habe (,in principio creavit Deus caelum et terram ${ }^{\prime \prime} .{ }^{65}$ Mit anderen Worten: Das Mysterium magnum ist nichts anderes als das fiat lux, der göttliche Geisthauch und somit letztlich das Wort, das die gesamte Schöpfung durchhallt.

Dementsprechend wird der urzeitliche Adamssohn, indem er im Akt seiner Erleuchtung in die Sphäre seines Geistes vorstößt, in die göttliche Wortnatur Christi ,transmutiert'. Dies bedeutet im Umkehrschluss, dass Christus in ihm Menschengestalt annimmt. Der Schleier, der auf der incarnatio verbi liegt, wird gelüftet, sowie der Gottsuchende die Fleischwerdung des Gottessohns am eigenen Leibe erfährt. Hier ist denn auch der Punkt, an dem das Geheimnis, um das Suchtens Ausführungen kreisen, seine größte Offenbarkeit entfaltet. Die unio mystica, welche dem Urmenschen im Zuge seiner Exaltation zuteilwird, impliziert zugleich eine unio cum Christo. Diese ebnet seiner Christusnachfolge den Weg.

62 Alexander von Suchten: De tribus facultatibus (Anm. 4), S. 370.

63 Alexander von Suchten: De tribus facultatibus (Anm. 4), S. 363.

64 Paracelsus: Philosophia ad Athenienses. In: ders.: Sämtliche Werke Abt. I, Bd. 13. Hg. von Karl Sudhoff. München, Berlin 1931, S. 388-423, hier S. 390.

65 Vgl. Carlos Gilly: Das Bekenntnis zur Gnosis von Paracelsus bis auf die Schüler Jacob Böhmes. In: From Poimandres to Jacob Böhme. Gnosis Hermeticism and the Christian Tradition. Hg. von Roelof van den Broek und Cis van Heertum. Amsterdam 2000, S. 385-425, hier S. 395f. mit Bezug auf Gerhard Dorn: De naturae luce physica ex Genesi desumpta [...]. Frankfurt a. M. 1583, S. 32f. 


\section{Die hermeneutische Dimension der incarnatio verbi}

Auch wenn Suchtens Erzählung in erster Linie ein Experiment darstellt, welches sich darauf richtet, mit den Mitteln der Allegorie die Erfahrbarkeit der göttlichen Weisheit auszuloten, hat sie doch auch den Charakter eines Gründungsmythos. Dieser widmet sich der Frage, auf welchem Wege das paracelsische Wissen in die Welt kam. Die Antwort lautet: über das Urerlebnis einer göttlichen Selbstoffenbarung. Suchten stellt sich damit dem Problem, dass er und seine Mitstreiter keine Wissenstradition aufweisen konnten, die weiter als über die Schaffenszeit des Paracelsus zurückreichte. Im Bekenntnis zu einem solchen mythischen Urereignis aber war es ihnen möglich, ihre Theoalchemie und hermetisch-neuplatonische Naturphilosophie als Zeugnisse eines vormosaischen Schöpfungswissens zu beglaubigen.

Sowie das Fleisch Christi - beziehungsweise der Geisthauch Gottes - den urzeitlichen Adamssohn innerlich durchglühte, habe dieser um die „Trinitatem \& Incarnationem Verbi gewust/ und viel hundert Jahr vor Christi Geburt darvon geschrieben." ${ }^{\prime 66}$ Suchten sieht hierin die Geburtsstunde der magia, einer allumfassenden Weisheitslehre, welche in die ,drei Fakultäten' von theologia, astronomia und medicina unterteilt ist. Die Adepten der magia sind die natürlichen Nachkommen des urzeitlichen Scheidekünstlers. Als Bewahrer seines Vermächtnisses widmen sie sich der "Kunst, den HErrn zu finden in seinem Geschöpff." ${ }^{\prime 67}$ Mit dem „HErrn" ist nicht etwa Gottvater, sondern Christus gemeint. Indem Suchten den Gottessohn andernorts als „Heyland und Schöpffer [!]“ bezeichnet, ${ }^{68}$ bezieht er sich damit auf dessen Wortnatur. Die incarnatio verbi steht demnach nicht bloß für ein singuläres heilsgeschichtliches Ereignis. Vielmehr nimmt das Wort innerhalb der äußeren Natur fortwährend und auf vielfältige Weise leibliche Gestalt an. Demnach verweisen alle Kreaturen - Pflanzen, Tiere, Minerale und Gestirne - als verba creata auf das präkreationale Wort Gottes und somit auf Christus. Die magischen Disziplinen von medicina und astronomia besitzen in diesem Kontext hermeneutische Funktion: Indem der magus die äußere Natur auf das Wort hin auslegt, verständigt er sich damit zugleich über seine eigene Natur, und somit letztlich über die Wortnatur Christi, an der er über den Geist des Herrn partizipiert.

Der Geist ist nach Suchten der wahre medicus, der all jene Menschen, die seiner teilhaftig geworden sind, vor Krankheiten bewahrt. Die Heilpflanzen der Außenwelt hingegen seien vollkommen nutzlos. Wie sollte ihnen auch heilende Funktion zukommen: Schließlich ist der Geist des Herrn nach der Schöpfung allein in der prima materia des Menschen verblieben. ${ }^{69}$ Stattdessen inauguriert

66 Alexander von Suchten: De tribus facultatibus (Anm. 4), S. 364.

67 Alexander von Suchten: De tribus facultatibus (Anm. 4), S. 379.

68 Alexander von Suchten: De tribus facultatibus (Anm. 4), S. 366.

69 Indes vertraute Suchten auf Medikamente, die er aus Mineralien - besonders Antimon - und tierischen Essenzen gewann. Auch vertrat er unter diesen Vorzeichen offensichtlich eine ganz konventionelle Lesart der Signaturenlehre, wonach die Natur des Makrokosmos die 
Suchten eine „Erden/ die in mir ist. ${ }^{\text {" }}{ }^{70}$ Dieser inwendigen Erde entsprießen geistige ,Pflanzen':

Der Ebulus und Holunder/ so aus der Erden der großen Welt wachsen/ werden mir die Wassersucht nicht vertreiben. Die Hermodactyli das Podagram nicht. Die Erdbeer den Aussatz nicht. Aber der Ebulus, Hermodactylus, Erdbeeren/ so da wachsen auß der Erden/ die in mir ist/ in der kleinen Welt/ die thuns. ${ }^{71}$

Als Manifestationen des göttlichen Geistes aber referieren die inneren Pflanzen analog zu den äußeren verba creata auf die Wortnatur Christi. ${ }^{72}$ Auch die Sterne und Planeten besitzen, anders als einige paracelsische Schriften suggerieren, keine Influenz auf den menschlichen Geist. ${ }^{73}$ Sie bilden lediglich Signaturen für den Himmel des Menschen:

Die Sonn und Mond/ die ich ob mir sehe, influiren in mich nichts Böses/ noch Gutes; Aber die Sonne/ Mond und Planeten/ damit die Göttliche Fürsichtigkeit gezieret hat den Himmel/ der in mir ist [...]/ die haben Gewalt mich zu regiren/ reformiren/ nach ihrem Lauff/ wie denselben Gott geordnet hat. ${ }^{74}$

Vor dem Hintergrund, dass auch diese inneren Gestirne - allen voran die innere ,Sonne', beziehungsweise der Geist des Herrn - Exemplifikationen von Christi Wortnatur sind, wird ersichtlich, dass die wahre Reformation nicht von den Kirchenoberen, sondern von Christus selbst ausgeht. Dieser aber wohnt, dem Epheserbrief entsprechend (3,16-17), im Herzen des Gläubigen, der durch den Geist Gottes gestärkt ist. Katechismen und religionspolitische Edikte ringen dem Gläu-

,Apotheke' des paracelsistischen Arztes ist. Dieser verfährt hierbei nach der similia-similibusDoktrin, der sich auch Suchten verpflichtet fühlt: So bezeichnet er etwa in einem Brief an Herzog Albrecht, der an einem Geschwür am Unterschenkel litt, die (blut-)rote Koralle als probates Mittel zur Blutstillung; Kühlmann, Telle: Corpus Paracelsisticum I (Anm. 3), S. 565.

70 Alexander von Suchten: De tribus facultatibus (Anm. 4), S. 377.

71 Ebd.

72 Im Zusammenhang mit Suchtens Werk De secretis antimonij ergibt sich, dass mit dieser Pflanzenwelt das Leben des „greifflichen Leibs“ gemeint ist: „Diß kurtz Leben wird in der Medicina Balsam genant/ darumb/ daß es die Artzeney ist/ die den Leib erhălt für Făule/ daß er nicht zerbrochen/ das ist/ kranck werde: Und so er in Kranckheit kommen/ ist er auch die Artzeney/ die ihn wieder heilen sol. Nicht die Salbey/ Melissen oder Endivien: Sondern der Balsam muß es thun." (Anm. 13, S. 254). Die Fakultät der Medicina beschäftigt sich also mit dem unsichtbaren Balsam des Menschen, nicht mit der Zubereitung pflanzlicher Pharmaka.

73 Indes bekennt Suchten in De secretis antimonij, dass der Balsam ex impressione colesti verunreinigt werden könne (Anm. 13, S. 254). An anderer Stelle heißt es, dass der sulphur philosophorum „den Balsam des Bluts von dem bòsen Dampff des widerwărtigen Gestirns“ klarifiziere (Anm. 13, S. 259). Zudem spricht Suchten in seiner Schrift De vera medicina davon, dass die Sonne den Planeten durch ihr Licht die Kraft verleiht, über das Geschehen in den unteren Regionen zu bestimmen (Anm.21, S.469). Die Sonne selbst ist Spenderin des spiritus mundi, durch den die irdische Natur fortwährend influiert wird. Diese Unstimmigkeit lässt sich möglicherweise dadurch erklären, dass es sich bei De tribus facultatibus um einen dezidiert literarischen Text mit einem in sich geschlossenen Weltbild handelt.

74 Alexander von Suchten: De tribus facultatibus (Anm. 4), S. 377. 
bigen lediglich Lippenbekenntnisse ab, solange er nicht der Regentschaft seiner inwendigen Gestirne untersteht.

Auch die magische theologia lehrt im Grunde nichts anderes als die incarnatio verbi. Abermals ist es das Fleisch des magus, in welchem sich das verbum dem Diesseits mitteilt. War es im Falle der medicina und astronomia das ,Buch der Natur', welches als ein Zeichen für die innermenschliche Wortnatur fungierte, ist es nun die Heilige Schrift, die als bloßes signum das Wort Gottes repräsentiert. Dessen signatum aber lässt aufhorchen: „Wir seynd die Außlegung des A. und N. Testaments/ und der Apostolischen Schriften/ nicht dieser oder jener Bauer/ der erst vom Pfluge herlaufft/ euch ein neues Liedlein zu singen [...]. ${ }^{\prime \prime 5} \mathrm{Zu}$ der Gemeinschaft, die Suchten unter Verwendung des Personalpronomens „Wir“ apostrophiert, zählen all diejenigen, die über die magia den Geist des Herrn und somit die Wortnatur Christi innerlich ergründet und erfahren haben: die uralten magi, der anonyme Widmungsempfänger des Traktats sowie seine eigene Person.

Mit dieser anmaßenden Setzung grenzt sich Suchten zugleich scharf von einer Art der Bibelexegese ab, wie sie die reformatorischen Schultheologen an den Tag legen: Im Ausgang der lutherischen sola-scriptura-Doktrin orientieren sich diese nämlich vor allem am Literalsinn der Heiligen Schrift. Das ,äußere Wort' steht an erster Stelle, wohingegen sich das ,innere Wort', die Erleuchtung im Glauben, erst durch Vermittlung des Heiligen Geistes einstellt. ${ }^{76}$ Nach Luther entsprach es dem göttlichen Willen, „keinem Menschen die innerlichen Stuck zu geben ohn durch die äußerlichen Stucke. ${ }^{\prime 77}$ Für Suchten hingegen hat das äußere Wort nur insofern Geltung, als es das innere Wort, die geistige Präsenz Christi im Menschen, bestätigt. Dazu bedarf es einer Auslegung des Buchstabens durch den Geist. Luther hält dies freilich für eitle Schwärmerei: Die Heilige Schrift soll nicht durch den menschlichen Geist, sondern aus ihrem eigenen Geist gedeutet werden. ${ }^{78}$ Daher verwirft er auch das Prinzip der Allegorese: Jeder andere Schriftsinn als der buchstäbliche verfehlt das im Glauben erwerbbare Heil. ${ }^{79}$ Nach Suchten kann der Wortlaut der Heiligen Schrift jedoch per se nur allegorisch verstanden werden, da die magi - zu denen offenkundig auch Mose, die Propheten und die Evangelisten gehören, - den Sinn ihrer Schriften per allegorias $\mathcal{E}$ similitudines verdunkelt hätten. ${ }^{80}$ Daher bleibt für den ,gemeinen Mann' die "Arca deß Testaments [...] zu gedeckt." ${ }^{\text {" } 11}$

Mit dem Begriff, ,Arca', zu Deutsch ,Truhe', spielt Suchten auf das ,Arkanum' an; einen Terminus technicus der paracelsistischen alchemia medica. Der Begriff

75 Alexander von Suchten: De tribus facultatibus (Anm. 4), S. 373.

76 Wels: Manifestationen des Geistes (Anm. 15), S. $15 \mathrm{f}$.

77 Martin Luther: Wider die himmlischen Propheten, von den Bildern und Sakrament. In: ders.: Werke. Bd. 18. Hg. von Joachim Karl Friedrich Knaake. Weimar 1908, S. 37-214, hier S. 136.

78 Martin Luther: Assertio omnium articulorum M. Lutheri per bullam Leonis X. novissimam damnatorum. In: ders.: Werke. Bd. 7. Hg. von Joachim Karl Friedrich Knaake. Weimar 1897, S. 91-151, hier S. 98f.

79 Wels: Manifestationen des Geistes (Anm. 15), S. $14 \mathrm{f}$.

80 Alexander von Suchten: De tribus facultatibus (Anm. 4), S. 361.

81 Alexander von Suchten: De tribus facultatibus (Anm. 4), S. 372. 
,Arkanum' ist biblischen Ursprungs. Es beschreibt Geheimes und Verborgenes, doch im Gegensatz zum Begriff ,Mysterium' nichts Übernatürliches oder gar Unheimliches. ${ }^{82}$ Auch ist dieser Begriff nicht nur in der paracelsischen Heilkunde anzutreffen; man findet ihn unter anderem bei Jean François Fernel, Cornelius Gemma und Jean Bodin..$^{83}$ Nach Paracelsus ist das Arkanum eine vom magus konkretisierte und konzentrierte Astralkraft, welche dem jeweiligen Heilmittel überhaupt erst seine Wirkung verleiht, ${ }^{84}$ oder um mit Paracelsus selbst zu sprechen: „dan das wir sehen, ist nit die arznei sonder das corpus, darinnen sie ligt. dan die arcana der elementen sind unsichtbar [...]. das da sichtbar ist, ist das eußer, das nit darzu gehört. " ${ }^{185}$ Seine kurative Wirkung empfängt das Arkanum von den Gestirnen; daher finden die Begriffe arcanum und astrum in paracelsistischen Texten oft unterschiedslos Verwendung. ${ }^{86}$

Wenn die Heilige Schrift und das Buch der Natur jeweils Verborgenes bezeichnen, so erliegt der ,gemeine Mann' dennoch der irrigen Annahme, dass die Kenntnis der äußeren Welt bereits genüge, um Theologie, Astronomie und Medizin zu betreiben. Allein der magus weiß das Buch der Natur auf die polyglotten Manifestationen des göttlichen Geistes hin auszulegen. Paracelsus bezeichnet dieses hermeneutische Verfahren als eine magica inventrix. ${ }^{87}$ Diese bringt er in Zusammenhang mit den Magi ex oriente:

82 Vgl. Kurt Goldammer: Naturphilosophie und Theologie der Heilung und der Heilmittel des Paracelsus. In: Der göttliche Magier und die Magierin Natur. Religion, Naturmagie und die Anfänge der Naturwissenschaft vom Spätmittelalter bis zur Renaissance. Hg. von dems. Stuttgart 1991, S. 83.

83 Vgl. Martin Mulsow: Arcana naturae. Verborgene Ursachen und universelle Methode von Fernel bis Gemma und Bodin. In: Der Naturbegriff in der Frühen Neuzeit. Semantische Perspektiven zwischen 1500 und 1700. Hg. von Thomas Leinkauf. Tübingen 2005, S. 31-68.

84 So Goldammer: Naturphilosophie und Theologie (Anm. 82), S. 79.

85 Paracelsus: Paragranum. In: ders.: Sämtliche Werke Abt. I, Bd. 8. Hg. von Karl Sudhoff. München 1924, S. 133-221, hier S. 194.

86 Vgl. z. B. Oswald Crollius: Basilica Chymica oder Alchymistisch koniglich kleynod. Frankfurt a. M. 1622, S. 24: „Dannhero dann gnugsamb erscheinet/ das die Kranckheiten nicht durch jhr contrarium oder widerwertiges geheylet vnd vertrieben werden als solte die Hitz die Kălte austreiben/ oder als seyen die Elementa auß dem Menschen herauß zu jagen: Sonder durch die Arcana oder Astra [!], welche der Medicus durch Hülffe der Alchimy auß der letzten Matery in die erste bringen kann."

87 Unter den Beiträgen zur paracelsischen magia sind hervorzuheben: Volkhard Wels: Magie und (Al)Chemie im 16. Jahrhundert. Thesen zu ihrer Begründung im Neuplatonismus, bei Paracelsus und im Paracelsismus. In: Der Begriff der Magie in Mittelalter und Früher Neuzeit. Hg. von Jutta Eming und dems. Wiesbaden 2021, S. 157-202. Charles Webster: Paracelsus, Paracelsianism, and the Secularization of the Woldview. In: Science in Context 15 (2002), S. 9-27; Kurt Goldammer: Der göttliche Magier und die Magierin Natur. Religion, Naturmagie und die Anfänge der Naturwissenschaft vom Spätmittelalter bis zur Renaissance. Stuttgart 1991; Ders.: Magie bei Paracelsus. In: Paracelsus in neuen Horizonten. Gesammelte Aufsätze. Hg. von dems. Wien 1986, S. 321-342; Wolf-Dieter Müller-Jahncke: Astrologisch-magische Theorie und Praxis in der Heilkunde der Frühen Neuzeit. Wiesbaden 1985, S. 67-89; Arlene Miller Guinsburg: Die Ideenwelt des Paracelsus und seine Anhänger in Hinsicht auf das Thema des christlichen Magus und dessen Wirken. In: Von Paracelsus zu Goethe und Wilhelm von Humboldt. Hg. von Sepp Domandl. Wien 1981, S. 27-54; Dies.: Paracelsian Magic and Theo- 
vil hab ich gedacht und gemelt der magica, und noch oftermals der erfindung der heimlikeit der natur in disen büchern, auch in andern. darumb solt ir das wissen nach der kürze, das dis buch magica inventrix bei einem ietlichen arzt sol wol gelernet werden [...]. und wie die magi von orient durch diese [magicam] inventricem gefunden haben Christum im sterne, als das feuer im kisling gefunden wird, also werden auch gefunden die künst der natur, die leichter zu sehen ist, dan Christus zu suchen gewesen ist. und so Christus von weite ersucht ist worden von den königen aus Saba und Tharsis so wird der schatz der natur viel nehender gefunden. ${ }^{88}$

Indem die Weisen vom Morgenland den Stern von Bethlehem - die Signatur des verbum incarnatum! - zu deuten wussten, legten sie den Grundstein der magia. Nach Paracelsus beschreibt das zweite Matthäuskapitel hiermit einen Präzedenzfall magischer Hermeneutik. Demnach influierte der Stern von Bethlehem die diesseitige Welt mit der heiligsten aller Astralkräfte, mit der Wortnatur Christi. Diese ist denn auch das höchste Arkanum: Ebenso wie sich die energetische Kraft des Feuersteins in seinem Funken zeigt, erweist sich das johanneische Wort als die Heilkraft des Sterns, welche die Menschheit von allem Leid erlöst. Christus besitzt demzufolge nicht nur eine göttliche und eine irdische, sondern - analog zum gestirnten Himmel - auch eine mittlere Natur.

Diese Vorstellung fand Eingang in Suchtens medizinisches Manifest, die XVIII Propositiones (spätestens 1561), in denen er dem Heiland eine Mittlerrolle zuschrieb, ohne die Gott und Mensch nicht vereinigt werden könnten. ${ }^{89}$ In diesem Sinne hatte bereits Meister Eckhart den Gottessohn als die „mittelste persône“ bezeichnet, ${ }^{90}$ was Suchten angesichts seiner Kenntnis des Basler Taulerdrucks wahrscheinlich bekannt war. ${ }^{91}$ Allerdings gründet Suchten die Mittlerinstanz Christi in den Propo-

logy. A Case Study of the Matthew Commentaries. In: Kreatur und Kosmos. Internationale Beiträge zur Paracelsusforschung. Hg. von Rosemarie Dilg-Frank. Stuttgart, New York 1981, S. 125-139.

88 Paracelsus: Labyrinthus medicorum errantium. In: ders.: Sämtliche Werke Abt. I, Bd.11. Hg. von Karl Sudhoff. München, Berlin 1928, S. 161-221, hier S. 205-208.

89 Alexander von Suchten: Decem et octo propositiones (Anm. 45), fol. 255" : ,Sicut deus et homo vniri non possunt, nisi per medium, quod est Christus, saluator noster: ita calor solis \& lunae misceri non potest cum nutrimento nisi per medium."

90 Vgl. Meister Eckhart: Predigt 16 B. In: ders.: Werke Bd.1. Hg. und kommentiert von Niklaus Largier. Frankfurt a. M. 2008, S. 186-197, hier S. 188, 18-22: "[D]ie meister enlegent niht daz bilde in den heiligen geist, mêr: sie legent ez in die mittelste persône, wan der sun hât den ersten ûzbruch ûz der natûre; darumbe er heizet eigentlîche ein bilde des vaters, und daz entuot niht der heilige geist [...]."

91 Suchten verweist in seiner Elegie Quid sit nihil in einer Interlinearglosse auf Eckarts Predigt 71 (Surrexit autem Saulus de terra apertisque oculis nihil videbat), die im Basler Taulerdruck enthalten ist; und dies sogar unter namentlicher Nennung des „Echardus", den er im Verbund mit Nikolaus Cusanus und Augustinus als bedeutenden Interpreten des paulinischen Damaskuserlebnisses aufführt; siehe Alexander von Suchten: Ad Apollinem in Catharro [sic] pestilentiali, Elegia. Quid sit nihil. In: ders.: Chymische Schrifften. Hg. von Ulrich C. Dagitza. Frankfurt a. M. 1680, fol. Hh $5^{\mathrm{v}}-6^{\mathrm{v}}$, hier fol. $6^{\mathrm{v}}$. 
sitiones in erster Linie auf das neuplatonische Emanationsprinzip. Dies hat gravierende Konsequenzen, denn indem er zwischen den beiden Naturen des Erlösers einen fließenden Übergang konstatiert, sind diese nicht mehr klar voneinander abgrenzbar. Damit aber verstößt Suchten gegen das überkonfessionell gültige Dogma, wonach Christi Menschen- und Gottnatur zwar als ungetrennt (indivise), aber auch als unvermischt (inconfuse) anzusehen sind..$^{92}$ Der daraus resultierende Monophysitismus, den Suchten zusammen mit Paracelsus vertritt, ${ }^{93}$ wirft freilich auch ein vielsagendes Licht auf die paracelsistische Konzeption der incarnatio verbi: Christi Wortnatur ging nicht in einen menschlichen Körper ein, vielmehr ging sie in einen menschlichen Körper über. Hierbei bleibt jedoch die Koexistenz von göttlicher und leiblicher Natur ungebrochen. Der Heiland ist überall zugleich anzutreffen: in der terrestrischen Natur, in der mittleren Sphäre des Äthers und - wie anhand des geschilderten Raptus deutlich wird - „zur rechten Hand Gottes“ im Empyreum. ${ }^{94}$

In der Tat lösten die Propositiones, die der Danziger unter dem leicht durchschaubaren Pseudonym ,Joannes de Suchten' publizierte, unter seinen akademisch gebildeten Zeitgenossen einen Sturm der Entrüstung aus. ${ }^{95}$ Auch wurde Suchten der Häresie bezichtigt: dies zunächst in einem Brief des Züricher Stadtarztes Conrad Gessner an seinen Kollegen Johannes Crato, der ihm eine Abschrift der Propositiones übermittelt hatte. ${ }^{96}$ Allerdings richtete sich Gessners Kritik hierin nicht gegen Suchtens Monophysitismus, sondern allein gegen die Identifizierung der geistigen Natur Christi mit dem spiritus mundi. Hierin glaubte er eine Minderung der Göttlichkeit des Erlösers zu erkennen, was ihn zu der Behauptung bewog, Suchten vertrete einen Antitrinitarismus. ${ }^{97}$ Gessner verkannte offensichtlich die logostheologische Grundlegung des paracelsischen spiritus-Begriffs, sonst

92 Dieses Dogma wurde bereits auf dem Konzil von Chalkedon anno 451 verabschiedet: „[C]onsonanter omnes docemus [...] Christum, Filium, Dominum, unigenitum, in duabus naturis inconfuse, immutabiliter, indivise, inseparabiliter cognoscendum [...]."

93 Paracelsus lehrt, dass Christus auch zu seinen Erdentagen einen wenngleich physischen, so doch unsterblichen Leib von göttlicher Perfektion besaß. Wenn er ansonsten stark zwischen Seele und Körper differenziert, wobei er letzteren als defizitär und minderwertig beurteilt, so ist die Leiblichkeit Christi hiervon ausgenommen, da sie die physische Natur aller Kreaturen übersteigt. Diese Anschauung erweist sich abermals als theologischer Problemfall, zumal sie das konfessionsübergreifende Dogma, dass Christus als Mensch dem Leiden am Kreuz unterwarf, ignoriert. Tatsächlich bekennt sich auch Paracelsus zu Christi Leiden und Kreuzestod, er betont aber ausdrücklich, dass der Leib des Heilands auch während der Passion von göttlicher Natur war: ,,[A]llein das göttlich fleisch und das göttlich blut und kein tödlichs fleisch und kein tödlichs fleisch und blut hat darumb müessen leiden." Paracelsus: De sancta trinitate. In: ders.: Sämtliche Werke Abt. 2, Bd.3. Hg. von Kurt Goldammer. Wiesbaden u. a. 1986, S. 234-266, hier S. 250.

94 Alexander von Suchten: De tribus facultatibus (Anm. 4), S. 364.

95 Vgl. hierzu Didier Kahn: Le Fixe et le volatil. Chimie et alchimie, de Paracelse à Lavoisier. Paris 2016. S. 76f.; Ders.: Alchimie et Paracelsisme en France à la fin de la Renaissance (15671625). Genf 2007, S. 134-136.

96 Brief vom 16.8.1561. In: Conrad Gessner: Epistolarum medicinalium [...] Libri III. Zürich 1577, fol. $1^{\mathrm{r}}-2^{\mathrm{v}}$.

97 Vgl. Bröer: Friedenspolitik durch Verketzerung (Anm. 3), S. 160f. 
hätte er sogleich eingesehen, dass die Gleichsetzung des Heilands mit dem Geist des Herrn keine Minderung, sondern - im Gegenteil - eine Affirmation der Göttlichkeit Christi bedeutete.

Gessners Häretisierung von Suchten und Paracelsus befeuerten Cratos Bemühungen, sämtliche Adepten der ,theophrastischen' Lehre als Ketzer zu verteufeln. Nur wenige Monate, nachdem er den Brief des Züricher Stadtarztes erhalten hatte, erklärte er Paracelsus öffentlich zu einem „Meister der Enthusiasten“ und einem „frevlerischen Verräter seiner Religion “98 Außerdem spielte er dem ParacelsismusGegner Thomas Erastus für dessen Disputationes de medicina Paracelsi Dokumente zu, die Suchtens Antitrinitarismus belegen sollten. ${ }^{99}$ Auf anderem Wege gelangte Erastus auch in den Besitz der speziell gegen Suchten gerichteten Antitheses rationales des Augsburger Arztes Lukas Stenglin. Letztgenannte Schrift versteht sich als eine gnadenlose Abrechnung mit den Propositiones. In einer Beigabe zu Stenglins Antitheses, die sich als Iudicium et censura ausgibt, fordert der ebenfalls in Augsburg ansässige Universalgelehrte Achilles Pirmin Gasser für Suchten die Todesstrafe. ${ }^{100}$

Suchten selbst erhielt sehr bald Notiz von dem Wirbel um sein Manifest, zumal Gessner die Antitheses höchstpersönlich an ihn weiterleitete, um ihn davor zu warnen, den eingeschlagenen Weg auch nur einen Schritt weiter zu verfolgen. Bemerkenswerterweise wendet er sich in seinem Begleitschreiben aber nicht mehr gegen das Konzept der Mittlerinstanz Christi, sondern gegen Suchtens Bekenntnis zur magia:

Zürich, 8. Februar 1564

Unnachahmlicher, berüchtigter Johannes [sic] von Suchten,

sei es, dass Du am polnischen Königshof oder sonst wo Deinem ärztlichen Treiben nachgehst: Hiermit sende ich Deine Thesen zusammen mit den Antithesen und einer Zensur zweier ausgewiesener Augsburger Ärzte, wie von diesen erbeten, an Dich zurück. Es tut mir in der Seele weh, mitanzusehen, wie Du und Deinesgleichen mit der Medizin Schindluder treibt - und dies auf derart erbärmliche Weise, dass ihr es wagt, sie nach dem Vorbild eures Theophrastus mit Magie, Nekromantie und ähnlichem Gift sowie mit gottlosen Betrügereien in Verbindung zu bringen: Dies ist nicht nur eines Christen, sondern überhaupt eines jeden Menschen unwürdig. Über den Charakter und den Lebenswandel

98 Vgl. Cratos Vorrede zu Johannes Montanus' Werk In nonum librum Rhasis [...] lectiones. Basel 1562, S. $3^{r-v}$.

99 Bröer: Friedenspolitik durch Verketzerung (Anm. 3), S. 172f.

$100 \mathrm{Zu}$ Stenglins und Gassers Gegenschriften siehe Codex Palatinus Latinus Nr. 1892, fol. $256^{\mathrm{v}}$ 260v: „Antitheses rationales paradoxis Johannis à Suchtis medici regis Poloniae propositionibus adversariae [...] Lucas Stenglin Physicus Augustanus. / Iudicium et censura Achillis P. Gasseri L. medici Augstburgensis de irrationabilibus Joannis a Suchten Propositionibus: In quibus is se liquido demonstraturum promittit, Quid Medicus, Quidue Medicinia ipius, Item quibus remediis aegritudines a corporibus expellant: Hoc est perridicule vnicus chymistarum Quintae essentiae sotulari, ómnium morborum pedes inanus et caput uestiendus somniat [...]." 
eures Lehrers, der bei mir ganz in der Nähe geboren wurde, weiß ich nur allzu gut Bescheid. Inzwischen will ich gar nicht in Abrede stellen, dass dieser viele gute und - gerade auf dem Gebiet der Heilkunst - vorzügliche Rezepte kannte. Du aber leb wohl und komm zur Vernunft!

PS.: Falls Du die Nekromantie oder ähnliche Dinge weiterhin verteidigst, sehe ich keinen Grund, weshalb Du mir oder den erwähnten Augsburgern zurückschreiben solltest. Auch werden wir uns nicht dazu herablassen, Dir zu antworten, es sei denn, Gott habe Deinen Sinn zum Besseren gewendet. Du kannst deine Rückschrift an den Apotheker Paul Olinger zu Nürnberg schicken. ${ }^{101}$

Tatsächlich ließ Suchten es sich nicht nehmen, Gessner zu antworten, wenngleich er dies nicht auf brieflichem Wege tat. Seine Rechtfertigung erfolgte vielmehr über eine Interlinearglosse in einer dem Paracelsisten Karl Rauchenberg dedizierten Elegie, die später zusammen mit seinen Propositiones in den Traktat De vera medicina einging. Hier heißt es:

Ebenso wie es nicht drei Götter, sondern nur einen Gott gibt: so gibt es nicht drei Weisheitslehren, sondern nur eine Weisheitslehre, die in einer Dreiheit besteht: Diese nannten die Alten ,Magia'. Demzufolge ist nicht derjenige als ein Magus zu bezeichnen, der sich mit Dämonenbeschwörung beschäftigt - dies ist uns streng verboten! -, sondern derjenige, der sich auf die beste Weise in der Theologie, der Astronomie und in der Medizin auskennt. Ein solcher war Theophrastus, doch es gehörten auch jene dazu, die der Stern zu Christus, dem Sohn Gottes, unserem Erlöser führte: Darüber an anderer Stelle mehr. ${ }^{102}$

Der letzte Satz lässt sich als Ankündigung von De tribus facultatibus verstehen. Mit seiner Erwähnung der Magi ex oriente gibt Suchten bereits einen Hinweis darauf, dass es sich bei der magia um eine wenngleich nicht astrologische, so doch hermeneutische Kunst handelt. Als solche beschäftigt sie sich mit dem Mysterium der incarnatio verbi, dessen Enthüllung sie nicht am Beispiel Christi, sondern am Beispiel der magi vorexerziert, zumal diese in der Nachfolge Christi stehen. Theologia, astronomia und medicina fungieren hierbei als Teildisziplinen, derer sich der magus bedient, um sich das in ihm fleischgewordene Wort zu vergegenwärtigen.

101 Gdańsk, Biblioteka Gdańska Polskiej Akademii Nauk, Ms. Nr. 2318: „Singulari et famoso viro Ioanni de Suchten medicum agenti in Polonia in aula regis vel ubicum est. Mitto ad te theses tuas cum antithesibus et censura duorum Augustae medicorum excellentium quod illi ut facerem a me petiverunt. Mihi quidem dolet artem medicam tam misere prostitui ut Magiam, Necromantiam et huius modi non Christiano solum sed plane homine indignas et impias imposturas, tale et simile toxicum ea iungere audeatis Theophrasti exemplo. Cuius nos mores et vita in vicinia nostra nati optime novimus. Interim quidem multa bona et in arte medendi praeclara illum calluisse non negarim. Vale et resipisce. Tiguri Helvetiorum 1564 Febr. die 8. Necromantiam et similes artes si pergis defendere non est quod vel mihi vel Augustanis illis rescribas neque respondere te dignabimur, sin Deus meliorem mentem tibi dederit. Norimbergam literas tuas ad Paulum Olingerum destinare poteris." (Übers. S. B.).

102 Alexander von Suchten: De vera medicina (Anm. 21), S. 460. 


\section{Die alchemische Dimension der incarnatio verbi}

Auch wenn Suchten die Pflanzen und Gestirne des Makrokosmos in erster Linie als Symbole für die verschiedenen Modi des menschlichen Geistes auffasst und sich die Exaltation des Adamssohnes auf innerlich-mentale Weise realisiert, so ist Christi Wortnatur zumindest in einigen Substanzen der äußeren Natur aufzufinden: Schließlich war es dem urzeitlichen Adamssohn gelungen, den unsichtbaren Leib des Heilands in Gestalt des göttlichen Geistes aus dem Eisensalz zu extrahieren. Weiterhin heißt es in De tribus facultibus:

[I]hr habt Mosen und die Propheten/ Christum und die Aposteln/ hòret was die sagen/ sie reden nit allein mit dem Munde/ sondern mit Hănden und Füssen/ mit Feuer und Wasser/ mit Silber und Gold/ mit Saltz/ und Seiden/ mit Sammet/ mit Steinen/ mit Schwartz/ mit Weiß/ mit Roth/ mit Gelb/ mit Wachs und mit Oel/ und dergleichen hòret nicht allein/ was das Maul sagt/ hòret was das Wasser sagt/ was das Saltz sagt: Sie reden auch/ aber eine andere Sprach. ${ }^{103}$

Die Abfolge von Schwarz, Weiß, Gelb und Rot beschreibt den farblichen Wandel eines mineralischen Substrats, den dieses bei der Zeugung des lapis philosophorum phasenweise durchläuft. ${ }^{104}$ Feuer, Wasser, Silber, Gold, Salz: All dies gehört zum Gegenstandsbereich der Alchemie, und diesem sei nun ein tieferer Sinn eingeschrieben, der mit der Lehre höchster biblischer Autoritäten - darunter Moses, die Apostel und sogar Christus selbst - übereinstimme! In der Tat mangelt es in der paracelsistischen Literatur nicht an Gleichsetzungen des Steins der Weisen mit dem Gottessohn. Einen nachhaltigen Eindruck hiervon vermittelt das Amphitheatrum aeternae sapientiae Heinrich Khunraths. Dieser begründet die Konvergenz von Christus und lapis einerseits mit der klassischen Gleichsetzung Christi mit dem Eckstein des Tempels Salomos, ${ }^{105}$ andererseits über die Logostheologie: Da das Wort, das in Christus Fleisch geworden ist, zugleich die salomonische Weisheit repräsentiert, ist der Geisthauch der Weisheit, welcher im lapis materielle Gestalt annimmt, gewissermaßen der makrokosmische ,Bruder ' des Gottessohns:

Nun sieh und bewundere das bildhafte Mysterium; ich meine die Empfängnis des Retters und Erlösers der großen Welt und der kleinen Welt [...]. Von letzterer steht geschrieben: ,Das Wort ist Fleisch geworden.' Um die erstere wissen wir dank der jüdischen Weisheitslehre: Sie ist der leibgewordene Geist des Herrn. Und ebenso wie sich Gott in fleischlicher Gestalt zu erkennen gab, nahm der Spiritus Dei körperliche Gestalt an. Da ist zum einen der Sohn Gottes, er ist Gott und Mensch. Zum andern ist da Gott und das Schöpfungsganze. Der eine

103 Alexander von Suchten: De tribus facultatibus (Anm. 4), S. 372.

104 Christian Thiel: [Art.] Alchemie. In: Enzyklopädie Philosophie und Wissenschaftstheorie. Bd. 1. Hg. von Jürgen Mittelstraß. Mannheim u. a. 1980, S. 67-74, hier S. 71.

105 Vgl. Heinrich Khunrath: Amphitheatrum sapientiae aeternae. Hanau 1609, S. 459, ferner Heinrich Khunrath: Vom hylealischen/ das ist pri-materialischen, catholischen oder allgemeinem natürlichen Chaos. Magdeburg 1597, S. 282. 
wurde vom jungfräulichen Leibe der kleinen Welt empfangen, der andere vom jungfräulichen Leib der großen Welt. ${ }^{106}$

Ebenso wie Christus die mikrokosmische Frucht des unbefleckten Leibes Mariens darstellt, repräsentiert der lapis philosophorum seinem Wesen nach den Sohn der reinen, prälapsaren Natur des Makrokosmos. Die heilsgeschichtlich beglaubigte incarnatio verbi nährte somit die Hoffnung auf die lang ersehnte Zeugung des Steins der Weisen.

\section{Zusammenfassung}

Christi Wortnatur ist auf der Grundlage der Logostheologie mit dem glühenden Hauch der Weisheit und insofern mit dem Geist des Herrn zu identifizieren. Davon ausgehend lassen sich folgende Feststellungen treffen. Erstens: Das Theologoumenon der incarnatio verbi bezeichnet nicht allein das heilsgeschichtliche Ereignis der Menschwerdung Christi. Vielmehr fungiert es als ein Paradigma für die Realisierung der vita Christi im Menschen. Hierzu bedarf es einer inneren Erleuchtung, über die der Gottsuchende seiner Teilhabe an der geistigen Natur des Erlösers innewird. Dieser mystische Akt ist und bleibt ein Mysterium, da er sich jenseits des Verstandes und des sprachlich Mitteilbaren ereignet.

Zweitens: Die hermeneutische Dimension der incarnatio verbi besteht in der heilsgeschichtlich präfigurierten Kompetenz der magi, die zeichenhafte Außenwelt auf die Wortnatur Christi hin auszudeuten. Diese selbst manifestiert sich in einer unsichtbaren Substruktur der Natur. Die incarnatio verbi offenbart sich in De tribus facultatibus über eine Exegese der äußeren Natur, die auf die innere Natur des Menschen abhebt: Dessen unsichtbare Pflanzen und Gestirne referieren als Manifestationen des göttlichen Geistes allesamt auf das präexistente Wort, welches in der fleischlichen Hülle der Kreatur verborgen ist. Diese Lesart der incarnatio verbi findet darin Bestätigung, dass sich ,Gottes Wort' - die Heilige Schrift vollständig auf die geistige Existenz des magus auslegen lässt.

Drittens wurde deutlich, dass die Fleischwerdung des Wortes nach Suchtens Vorstellung das neuplatonische Emanationsprinzip in Anspruch nimmt. Auf dieser Grundlage offenbart sich ein analoges Verhältnis von Christus und dem Geist des Herrn: Beide gehören zugleich dem Empyreum, der mittleren Sphäre des Äthers sowie der terrestrischen Region an. Während der eine die Menschheit durch seinen Kreuzestod vor Gott rechtfertigt, beschenkt der andere sie in der Gestalt des Steins der Weisen mit Gesundheit, langem Leben, Reichtum und Seligkeit.

106 Khunrath: Amphitheatrum sapientiae aeternae (Anm. 104), S. 197: „Mysterium iam observa \& admirare typicum; conceptionem, inquam, Servatoris \& Saluatoris vtriusque \& Mundi maioris \& Mundi minoris, sive generis humani. De hoc, scriptum, legimus: Verbum caro factum est; de illo, Cabalâ, scimus: Rvach Elohim, corpus factus est. Et; Devs manifestatus in carne: Spiritvs Dei manifestatus in corpore. Hic, filius Mundi maioris, Deus \& creatura, catholicus: ille, filius Dei [...] Deus \& homo: Vnus, in vtero Mundi maioris; alter, in vtero Mundi minoris: vterque Virgineo, conceptus." (Übers. S. B.). 



\title{
Solve Coagulata! Verflüssige die Schöpfung!
}

\author{
Die pseudo-paracelsische Schrift Philosophia ad Athenienses \\ als Rätsel und Offenbarung
}

\author{
Ute Frietsch
}

\section{Einleitung}

Geheimnis und Rätsel, Lösung und Offenbarung gehen in der Alchemie der Frühen Neuzeit vielfältige Verbindungen ein. Schließlich wollten die alchemischen Theoretiker und Praktiker ihren Leserinnen und Lesern zwar mitteilen, dass sie über ein geheimes Wissen verfügten. Sie wollten es ihnen aber auch nicht zu leicht machen, sich dieses selbst anzueignen.

Die deutschsprachige Schrift Philosophia ad Athenienses („Philosophie an die Athener") ist ein typisches Beispiel für diese alchemische Texttradition. Sie wurde erstmals 1564 bei Arnold Birckmanns Erben in Köln gedruckt, zusammen mit zwei medizinischen paracelsischen Schriften, die sich der Epilepsie und der Kontraktur der Glieder (d.h. der Einschränkung der Beweglichkeit von Gelenken) widmen. Die Philosophia ad Athenienses wurde als kürzeste der drei Schriften an den Anfang gestellt. Ein unmittelbarer inhaltlicher Zusammenhang dieser pseudo-paracelsischen Schrift mit den anderen beiden Werken, die wohl von Paracelsus selbst stammen, ist nicht zu erkennen. ${ }^{1}$

Im Erscheinungsjahr des Druckes war der vermeintliche Autor, Theophrastus Bombastus von Hohenheim (1493/4-1541), der seine Schriften ab 1529 mit dem Na-

1 Die Arbeit an diesem Artikel wurde gefördert durch die Deutsche Forschungsgemeinschaft (DFG), Projektnummer 632428. In der folgenden Textanalyse beziehe ich mich auf die Erstausgabe: Des Hocherfarnen und Hochgelehrten Herrn Theophrasti Paracelsi von Hohenheim/ beider Artzney Doctoris, Philosophiae ad Athenienses, drey Bücher [...]. Köln 1564, fol. A2K4; die beiden einschlägigen Gesamtausgaben von Johann Huser und Karl Sudhoff weichen im Wortlaut passagenweise von dieser ab, vgl.: Theophrast von Hohenheim, genannt Paracelsus: Philosophia ad Athenienses. In: Bücher und Schrifften des edlen hochgelehrten und bewehrten Philosophi und Medici Philippi Theophrasti Bombast von Hohenheim, Paracelsi genannt. Jetzt auffs new auß den Originalien und Theophrasti eigner Handschrift durch Johannem Huserum, Teil 8, Basel 1590, fol. 1-47; ders.: Sämtliche Werke. Erste Abteilung. Medizinische, naturwissenschaftliche und philosophische Schriften. Hg. von Karl Sudhoff. 14 Bde. München, Berlin 1922-1933 (Reprint: Hildesheim, Zürich, New York 1996), Bd. 13, S. 387-423. Zu Provenienz und Bedeutung der Philosophia ad Athenienses vgl. ebd., S. XI-XIII; sowie Karl Sudhoff: Bibliographia Paracelsica. Besprechung der unter Hohenheims Namen 1527-1893 erschienenen Druckschriften. Berlin 1894 (Reprint: Graz 1958), S. 101-103. Siehe auch meine frühere Analyse der Philosophia ad Athenienses in Ute Frietsch: Häresie und Wissenschaft. Eine Genealogie der paracelsischen Alchemie. München 2013, S. 346-355. 
men Paracelsus signiert hatte, bereits seit 23 Jahren tot. Während es nach dem Tod des skandalträchtigen und charismatischen Schweizer Arzt-Alchemikers und Laientheologen zunächst etwas ruhiger um ihn geworden war, setzte ab den 1560er Jahren eine Bewegung ein, die man heute Paracelsismus nennt. Bereits die Zeitgenossen bezeichneten die Anhänger des Paracelsus als Theophrasten, Paracelser, Paracelsisten oder Paracelsiker. Die Paracelsisten edierten Schriften des verstorbenen Paracelsus und setzten sich für seine Überzeugungen, Lehren und Praktiken sowie für die Herstellung seiner Medikamente ein. Adam von Bodenstein (1528-1577), Sohn des protestantischen Theologen Andreas Bodenstein (genannt Karlstadt), der u. a. an der Universität Basel für die Etablierung des Paracelsismus agierte, war beispielsweise daran gelegen, dem Paracelsismus ein gelehrtes und internationales Image zu geben. Er gab daher einige seiner Paracelsus-Ausgaben in lateinischer Sprache heraus, stellte in seinen Vorworten und Einleitungen einen Zusammenhang mit Neuplatonismus und Hermetismus her und widmete die Editionen Vertretern des Hochadels wie etwa Kaiser Maximilian II., Erzherzog Ferdinand II. oder Herzog Cosimo I. de' Medici. ${ }^{2}$ Paracelsus' Lebenswerk authentisch zu tradieren war bei dieser Editionsarbeit zumindest bis zur Herausgabe der ersten naturkundlichen Gesamtausgabe paracelsischer Schriften durch Johann Huser, die in den Jahren 1589-1591 neue Standards setzte, nicht unbedingt das entscheidende Kriterium: Anhänger des Paracelsus überarbeiteten und ergänzten dessen Schriften oder gaben ihre eigenen Werke unter seinem Namen heraus, wobei sie wohl oftmals davon ausgingen, dass ihre eigenen Anliegen mit denen des Paracelsus konform seien und dass ihre Redaktionen einen verborgenen Textsinn zur Geltung brächten. Indem sie eine Flut von Paracelsica und Pseudo-Paracelsica sowie zudem eigene alchemische Medikamente auf den Markt brachten, machten sie den Paracelsismus zur dominierenden alchemischen Tradition der Frühen Neuzeit.

\section{Eine Arbeit an der symbolischen Ordnung}

Die Philosophia ad Athenienses ist eine offensichtlich fingierte, also pseudo-paracelsische Schrift. ${ }^{3}$ Die Aussagen dieses Werkes, das bis heute nicht historisch-kritisch ediert ist, waren entscheidend mit dafür verantwortlich, dass dem Paracelsismus

2 Adam von Bodensteins Dedikationen und Vorreden sind dokumentiert und mit biographischer Gesamtwürdigung kommentiert in: Corpus Paracelsisticum. Der Frühparacelsismus. Hg. von Wilhelm Kühlmann und Joachim Telle. Bd.1. Tübingen 2001, S. 104-544: Adam von Bodenstein, Nr. 6-30.

3 Als pseudo-paracelsische Schrift wird die Philosophia ad Athenienses in der Forschung zumeist nur kurz gestreift, wobei sich zwei Positionen abzeichnen: Walter Pagel betont, dass ihr Gedankengut dennoch echt paracelsisch und dass der Paracelsismus in der Folge von dem Neuplatonismus dieser Schrift stark geprägt worden sei, vgl. u. a. Walter Pagel: Paracelsus and the Neoplatonic and Gnostic Tradition. In: Ambix 8 (1960), S. 125-166, hier S.143. Kurt Goldammer hingegen bemerkt zwar den Versuch der Systematisierung des authentisch-parcelsischen Gedankengutes in dieser Schrift, betrachtet diesen jedoch als unzulänglich, vgl. Kurt Goldammer: Bemerkungen zur Struktur des Kosmos und der Materie bei Paracelsus. In: Paracelsus in neuen Horizonten. Gesammelte Aufsätze. Wien 1986, S. 263-287, hier S. $276-$ 278. Didier Kahn wiederum betont, dass das paracelsische Ideengut durch die Philosophia 
ab den 1560er Jahren ein Anti-Paracelsismus entgegen gesetzt wurde: Anhänger und Gegner verstanden, dass die verhandelte Schöpfung hier nicht in ihrer verbindlichen alttestamentarischen Form, sondern als alchemische Scheidung dargestellt wurde. Als Gegner traten insbesondere theologisch geschulte Ärzte auf: so der Zittauer Arzt Bartholomäus Reußner (1565-1629) und der Heidelberger Theologe und Medizinprofessor Thomas Erastus (1524-1583). Sie betrachteten diese Schrift als paradigmatisch für alles, was sie am Paracelsismus ablehnten. Reußner kritisierte die Vermengung von göttlicher Creatio und alchemischer Separatio als Gotteslästerung und veröffentlichte in Görlitz 1570 eine eigene Widerlegung, die lange Passagen aus der Philosophia ad Athenienses zitiert und sie mit entsprechenden Textstellen aus dem Alten Testament zu kontern versucht. ${ }^{4}$ Erastus wiederum, der als Anhänger der Reformkirche Zwinglis im Zuge der Konfessionswechsel der Pfalz in den 1560er Jahren selbst zwischen die Fronten der orthodoxen Lutheraner und der Calvinisten geriet und wegen seiner vermeintlichen atheistischen und arianischen Position mit Verketzerungen zu kämpfen hatte, ${ }^{5}$ nutzte die paracelsischen Schriften als Gelegenheit zu umfangreicheren Disputationes, ${ }^{6}$ die implizit seine eigene Rechtgläubigkeit dokumentieren sollten. Ins Zentrum seiner Kritik stellte er, dass das paracelsische Verständnis der Schöpfung platonisch geprägt sei und dem theologischen Konzept der Creatio ex nihilo widerspreche. ${ }^{7}$ Aus dieser

ad Athenienses korrumpiert worden sei, gerade weil diese populär war und zeitlich vor den Schriften, von denen sie Anleihen macht, in Umlauf kam: vgl. Didier Kahn: Paracelsus' Ideas on the Heavens, Stars and Comets. In: Unifying Heaven and Earth. Essays in the History of Early Modern Cosmology. Hg. von Miguel Á. Granada, Patrick J. Boner und Dario Tessicini. Barcelona 2016, S. 59-116, hier S. 114-115. Eine eigene Textinterpretation und einen Überblick zur bisherigen Forschung gibt: Georgiana Hedesan: The Mystery of Mysterium Magnum. Paracelsus's Alchemical Interpretation of Creation in Philosophia ad Atheniensis (sic) and its Early Modern Commentators. In: Hidden Truths from Eden. Esoteric Readings of Genesis 1-3. Hg. von Caroline Vander Stichele und Suzanne Scholz. Atlanta 2014, S. 141-162.

4 Bartholomaeus Reußner: Ein kurtze Erklerung und Christliche widerlegung/ Der unerhörten Gotteslesterungen und Lügen/ welche Paracelsus in den dreyen Büchern Philosophiae ad Athenienses hat wider Gott/ sein Wort/ und die löbliche Kunst der Artzney außgeschüttet. Zur Warnung aller fromen Christen geschrieben [...]. Görlitz 1570.

5 Vgl. Charles Gunnoe: Thomas Erastus and the Palatinate. A Renaissance Physician in the Second Reformation. Leiden 2011; Ruth Wesel-Roth: Thomas Erastus. Ein Beitrag zur Geschichte der reformierten Kirche und zur Lehre von der Staatssouveränität. Veröffentlichungen des Vereins für Kirchengeschichte in der evang. Landeskirche Badens. Bd. 15. Lahr 1954.

6 Thomas Erastus: Disputationum De medicina nova Philippi Paracelsi. Pars Prima: In Qua, Quae de Remediis Superstitiosis \& Magicis curationibus ille prodidit, praecipue examinantur. Basel 1571; Pars Altera: In qua Philosophiae Paracelsicae Principia \& Elementa explorantur; Pars Tertia: In Qua dilucida et solida Verae Medicina assertio \& falsae, vel Paracelsicae Confutatio continetur; Pars 4: In qua Epilepsia [...] \& colici doloris vera curandi ratio demonstratur, \& Paracelsica solidißimè confutatur. Basel 1572.

7 Vgl. Erastus: Disputationum, Pars Prima (Anm. 6), S. 4, S. 22f. Während Reußner die paracelsi(sti)schen Konzepte eher vage auf Hermes Trismegistos zurückführte, erkannte Erastus den platonischen Gehalt des Werkes. Der Platonismus bleibt sowohl in den paracelsischen wie in den pseudo-paracelsischen Schriften eher implizit, getreu der Aussage, Platon und Aristoteles seien „nichts“, vgl. Theophrast von Hohenheim, genannt Paracelsus: Philosophia Magna. In: ders.: Sämtliche Werke (Anm. 1), Bd. 14, S. 1-377, hier S.263. Gelegentlich werden Platon 
„falsa Astronomia \& Pseudophilosophia“8 sei die ketzerische Folgerung, dass Gott nicht alles geschaffen habe. Gott werde bei den Paracelsisten zu einem Alchemiker, der eine Materie, die angeblich schon da sei, nur noch trenne und bearbeite. Die Natur der Materie könne jedoch durch Alchemie und Magie nicht verändert werden. Magie, Kabbala, Alchemie und Astrologie seien mit dem Christentum ohnehin unvereinbar. Paracelsus habe sich zudem durchweg selbst widersprochen. Basis für die Vereinbarkeit von Theologie und Naturkunde sei Aristoteles. Erastus ging in seinen Disputationes, die später der katholischen Kirche zur Indizierung der paracelsischen und pseudo-paracelsischen Schriften dienten, so weit, die Todesstrafe für den bereits verstorbenen Paracelsus sowie die Paracelsisten zu fordern. ${ }^{9}$

Reußner und Erastus machten dabei keinen Unterschied zwischen Paracelsus und den Paracelsisten, da sie Paracelsus als den Begründer einer ketzerischen Sekte betrachteten. Dass sie die Philosophia ad Athenienses als Schrift des Paracelsus traktierten, obwohl ihnen durchaus klar war, dass dieses Buch in seiner veröffentlichten Form nicht von diesem selbst verfasst sein konnte, wäre zwar im Sinne einer historisch-kritischen Textexegese nicht ganz vorbildlich, inhaltlich hatten sie aber gewissermaßen recht: In dieser wie in anderen pseudo-paracelsischen Schriften wird oftmals nur stringenter und literarisch und philosophisch anspruchsvoller expliziert, was in authentisch-paracelsischen Schriften implizit schon angedeutet ist. ${ }^{10}$ Dass Paracelsus die göttliche Schöpfung als alchemische Scheidung betrachtet hat, lässt sich beispielsweise seinem naturphilosophischen Gebrauch des Begriffs Yliaster in der Schrift Philosophia de generationibus et fructibus quatuor elementorum ${ }^{11}$ und des Begriffs Matrix im vierten Buch des Opus Para-

allerdings sogar alchemische Äußerungen zugeschrieben: So habe er Mercurius als Mehl bezeichnet und aqua mercurius als Wasser; Luna calcinata habe er die Hilfe genannt, vgl. ders.: Manuale chemicum id est Thesaurus chemicorum particularium experimentorum. Bd.13, S. 451-539, hier S. 521.

8 Erastus: Disputationum, Pars Prima (Anm. 6), S. 24.

9 Zur Indizierung paracelsi(sti)scher Schriften seitens der katholischen Kirche vgl. die ausführliche Dokumentation und Analyse in: Catholic Church and Modern Science. Documents from the Archives of the Roman Congregations of the Holy Office and the Index. Hg. von Ugo Baldini und Leen Spruit. Bd. 1: Sixteenth-Century Documents. Bde. 1-4. Roma 2009. Bei dieser Veröffentlichung des Heiligen Stuhles handelt es sich um eine Aufbereitung der Dokumente aus dem Archivio della Congregazione per da Dottrina della Fede zur Arbeit der Römischen Index-Kongregationen des 16. Jahrhunderts. In dieser Dokumentation nimmt Paracelsus als Magier und Häretiker breiten Raum ein, vgl. die Einleitungen und die Darstellungen zu „Alchemy“, "Magic", "Medicine and Natural Philosophy" in Bd.1, S.1-664 sowie, speziell zur Verurteilung von Paracelsus durch die Römische Index-Kongregation, die Dokumentation in Bd. 3, S. 2166-2196.

10 Mit dieser Auffassung folge ich insofern der Argumentation von Pagel: Paracelsus and the Neoplatonic (Anm. 3), als mir der (korrumpierte) Paracelsismus philosophisch fast interessanter zu sein scheint als der authentische Paracelsus.

11 Theophrast von Hohenheim, genannt Paracelsus: Philosophia de generationibus et fructibus quatuor elementorum. In: ders.: Sämtliche Werke (Anm. 1), Bd. 13, S. 5-123. 
mirum entnehmen. ${ }^{12}$ Paracelsus' Neologismus Yliaster (gelegentlich auch Iliaster u. ä.) ist aus dem alt-griechischen Begriff hyle, der zunächst Holz oder Wald, bei Aristoteles jedoch ,Stoff' bedeutete, und dem lateinischen Wort aster, d. h. Stern, zusammengesetzt, und lässt sich demnach als ,Sternstoff' übersetzen. Die lateinische Übersetzung für hyle war materia; das davon abgeleitete Wort matrix war ein Synonym für uterus und bedeutet zunächst Gebärmutter. Paracelsus hatte den Matrix-Begriff insbesondere in seinem Opus Paramirum als kosmologisches Prinzip inszeniert und damit implizit der naturphilosophischen Konzeption des (aristotelischen) Hylemorphismus, welche die Interaktion von Form (morphé) und Materie bei der Schöpfung sowie bei Zeugung und Geburt reflektiert, ein eigenes Konzept entgegengesetzt. ${ }^{13}$ Die paracelsi(sti)sche Ablehnung des traditionellen Hylemorphismus und das naturphilosophische Bestreben einer Neukonzeptionalisierung der Schöpfungsprozesse erklären sich m. E. daraus, dass Paracelsus und die Paracelsisten - durchaus ambitioniert, wenngleich philosophiegeschichtlich nur bedingt erfolgreich - theoretische Grundlagen für die alchemische Praxis schaffen wollten. Darüber, ob die Häretisierung eher den Effekt einer Ausdifferenzierung des Gedankengutes oder eher den Effekt der Unterbindung seiner Artikulation hatte, lässt sich streiten. Ähnlich wie sich auch darüber diskutieren ließe, ob Paracelsus und die - sozusagen als Fälscher seiner Schriften aktiven - Paracelsisten sich in Hinblick auf Rechtgläubigkeit grundsätzlich voneinander unterschieden. Die religiös verfasste paracelsische und pseudo-paracelsische Kritik des Hylemorphismus lässt sich aus heutiger säkularer Perspektive jedoch durchaus als eine Arbeit an der symbolischen Ordnung betrachten: Diese Schriften richteten sich gegen ein relativ geschlossenes (u. a. patriarchales) System und gingen insofern mit einer Erweiterung oder Öffnung des Denkhorizontes einher. ${ }^{14}$

\section{Literarische Formgebung: Ein manieristisches sprachliches Kunstwerk}

Die Philosophia ad Athenienses, die auf der Kenntnis der naturphilosophischen paracelsischen Schriften beruht und deren Aussagen variiert, hat einen eigenwilligen, virtuosen Aufbau: Sie gliedert sich in drei Bücher, die der Autor - wohl in Anspielung auf das griechische Präfix para, das ja auch Teil des Namen Paracelsus

12 Theophrast von Hohenheim, genannt Paracelsus: Paramiri liber quartus de matrice. In: ders.: Sämtliche Werke (Anm. 1), Bd. 9, S. 177-230.

13 Vgl. Thomas Rentsch: [Art.] Matrix. In: Historisches Wörterbuch der Philosophie. Begründet von Joachim Ritter und Karlfried Gründer. Bd. 5. Basel, Stuttgart 1980, S. 939 (mit weiteren Hinweisen u. a. auf den Matrix-Begriff bei Jakob Böhme); sowie Heribert Maria Nobis: [Art.] Matrix. In: Ebd., S. 939-941 (mit weiteren Hinweisen u. a. auf den Matrix-Begriff bei Robert Fludd). Neben dem Begriff Matrix ist es insbesondere der Begriff Fiat, der bei Paracelsus und im Paracelsismus konzeptionalisiert und terminologisiert wurde, vgl. Kurt Goldammer: [Art.] Fiat. In: Historisches Wörterbuch der Philosophie. Begründet von Joachim Ritter und Karlfried Gründer. Bd. 2. Darmstadt 1972, S. 945-946.

$14 \mathrm{Zu}$ Paracelsus' alchemischer Neukonzeptionalisierung sowohl der alttestamentarischen Genesis wie des platonischen Modells der Schöpfung und des aristotelischen Hylemorphismus vgl. die Analyse in Frietsch: Häresie und Wissenschaft (Anm. 1). 
ist, d. h. gegen, wider, neben, außerhalb - als paras bezeichnet. Jeder paras wird durch eine Vorrede eingeleitet, zwei der paras enden mit einem Beschluss. Ein weiterer erster paras scheint $\mathrm{zu}$ fehlen, da das Ganze mit einer Vorrede zu einem andern (also zweiten) paras beginnt. Die drei paras sind in 24, 23 und 6 Texte bzw. Textabschnitte unterteilt, die als solche durchnummeriert sind. Der vierte paras ist fragmentarisch. Durch die Verwendung des Kunstwortes paras erscheint die Philosophia ad Athenienses als ein manieristisches sprachliches Kunstwerk, das die Ambition hat, den Para-celsismus als eigene Textgattung zu etablieren. ${ }^{15}$

Die Vorreden und Beschlüsse schreiben die paras - also den Haupttext - einem "fürst[en] Theophrastus" (fol. A2) zu, von dem sie in der dritten Person handeln. Sie leisten auf diese Weise eine Mystifizierung, denn Theophrastus Paracelsus war selbst kein Fürst, wenngleich er von seinen Anhängern, in gewollter Analogie zu dem ,dreimal großen' Hermes Trismegistos, als der erste der Philosophen, Naturkundler oder Alchemiker stilisiert wurde. Vorrede und Beschlüsse der Philosophia ad Athenienses taten auf diese Weise allerdings offen kund, dass sie nicht von Paracelsus selbst verfasst waren. Sie übernahmen die Funktion einer paratextuellen Rahmung und weckten zugleich den Verdacht, dass vielleicht auch der Haupttext nicht authentisch war: Zwar spricht der Haupttext nicht in der dritten Person von Paracelsus, doch sagt er auch nirgends ich; ein Wechsel im Sprachgestus ist nicht erkennbar. Gleich eingangs in der "Vorrede" sowie im "Beschluß" zum zweiten paras heißt es außerdem, dass sich der "fürst Theophrastus" hierin auf das „erste[n] Volumen[s] seiner Philosophiae“ (fol. A2) bzw. auf das „erste[n] Volumen der generation (sic) rerum" (fol. E) beziehe. ${ }^{16}$ Mit diesem stilistisch kryptischen Verweis wurde die Philosophia ad Athenienses offenbar als Paratext der paracelsischen Schrift Philosophia de generationibus et fructibus quatuor elementorum ausgewiesen, die sowohl naturkundlich wie laientheologisch vom Yliaster und der Erschaffung der Welt handelt, wobei sich das erste ihrer vier Bücher insbesondere dem Element Luft widmet. ${ }^{17}$ Demnach ließe sich der Haupttext der Philosophia ad

15 Wilhelm Schmidt-Biggemann hat mich in der Diskussion zu meinem Konferenz-Vortrag darauf hingewiesen, dass paras von dem hebräischen Verb פרש (parasch) abgeleitet sein könnte. Dieses bedeutet ein- oder abteilen, ist im Judentum vor allem in der Einteilung des ThoraTextes in wöchentliche Portionen präsent, und schwingt u.a. im Begriff "Pharisäer" mit. Eine Kenntnis dieses Begriffs ist für unseren Textzusammenhang nicht ausgeschlossen, da Figuren der christlichen - und möglicherweise auch der jüdischen - Kabbala in den Paracelsismus und damit auch in dessen fingierte Schriften eingegangen sind, siehe dazu ebenfalls Frietsch: Häresie und Wissenschaft (Anm. 1), S. 355-369.

16 Vgl. die Lesarten bei Huser und Sudhoff: Theophrast von Hohenheim, genannt Paracelsus: Philosophia ad Athenienses. In: Bücher und Schrifften (Anm. 1), Teil 8, fol. $8^{\mathrm{vi}}$, fol. 18; ders.: Sämtliche Werke (Anm. 1), Bd. 13, S. 389 und 402.

17 Vgl. Theophrast von Hohenheim, genannt Paracelsus: Sämtliche Werke (Anm.1), Bd.13, S. 5-123. Kurt Goldammer weist bereits auf Anleihen hin, welche die Philosophia ad Athenienses bei der authentischen Philosophia de generationibus et fructibus quatuor elementorum macht, vgl. Goldammer: Bemerkungen zur Struktur des Kosmos (Anm.3). Didier Kahn betont in diesem Zusammenhang die Korruption des paracelsischen Ideenguts durch die Philosophia ad Athenienses, da die Philosophia de generationibus et fructibus quatuor elementorum wohl zwi- 
Athenienses als Interpretation oder Variation eines vermutlich authentisch paracelsischen Textes - des „Liber primus, de elemento aëris“ aus der Philosophia de generationibus et fructibus quatuor elementorum ${ }^{18}$ - interpretieren: Dies wäre auch eine Erklärung dafür, dass die Philosophia ad Athenienses, wie gleich zu zeigen sein wird, eher von den himmlisch-luftigen als von den irdisch-wässerigen Aspekten der Schöpfung handelt.

Als eine an die Athener gerichtete Philosophie reflektiert die Philosophia ad Athenienses bereits auf terminologischer Ebene griechisches Gedankengut, indem sie Gott als „höchsten Künstler" (fol. A3) und Materie als „prima materia“ bezeichnet. Da sie von der Schöpfung handelt, bieten sich neben der hebräischen Bibel bzw. der alttestamentarischen Genesis und der paracelsischen Textvorlage (auf die ich noch zurückkomme) zwei griechische Vergleichstexte an, mit denen die Philosophia ad Athenienses möglicherweise über die Jahrhunderte hinweg korrespondierte: Platons berühmter naturphilosophischer Dialog Timaios, ${ }^{19}$ der von der Ordnung der Materie zum Kosmos durch einen Demiurgen-Gott handelt, und Aristoteles' Meteorologie, ${ }^{20}$ die u. a. die Prozesse der Kondensation, die Bildung von Wasserdampf, Rauch und Hagel sowie - im vermutlich pseudo-aristotelischen vierten Buch - die Entstehung der Mineralien und Metalle thematisiert.

Paracelsus, der philologisch wenig geschult war, wird Platons Schrift Timaios in ihrer griechischen Fassung unbekannt gewesen sein; auch die einschlägigen lateinischen Übersetzungen durch Calcidius sowie Marsilio Ficino dürfte er selbst nicht rezipiert haben, so dass ihm die platonische Naturphilosophie vermutlich nur in vermittelter Form bekannt war. Lateinkundige Paracelsisten wie Adam von Bodenstein hingegen werden mit Ficinos Übersetzung des Timaios (gedruckt 1484) sowie seinem Kommentar Compendium in Timaeum (gedruckt 1496) durchaus vertraut gewesen sein. Sie konnten das paracelsische Gedankengut daher ausbauen und mit der gelehrten Tradition vermitteln. Philosophie- und ideologiegeschichtlich betrachtet gleicht die Philosophia ad Athenienses die platonische Figur der Chõra (des Raumes) mit der paracelsischen Figur des Yliaster (des Sternstoffes) $a b$ und ersetzt beide durch die neologistische Figur eines Mysterium magnum

schen 1525 und 1530 geschrieben, jedoch erst 1590 veröffentlicht wurde, vgl. Didier Kahn: Paracelsus' Ideas on the Heavens (Anm. 3). Neben der Philosophia de generationibus et fructibus quatuor elementorum dürfte in der Philosophia ad Athenienses mit dem Verweis auf ein erstes Volumen auch das Volumen paramirum angesprochen sein, vgl. Udo Benzenhöfer: Studien zum Frühwerk des Paracelsus im Bereich Medizin und Naturkunde. Münster 2005, S. 30-40.

18 Theophrast von Hohenheim, genannt Paracelsus: Sämtliche Werke (Anm. 1), Bd. 13, S. 9-19.

19 Vgl. Platon: Timaios. In: ders.: Sämtliche Werke in zehn Bänden. Griechisch und deutsch. Nach der Übersetzung Friedrich Schleiermachers, ergänzt durch Übersetzungen von Franz Susemihl und anderen. Hg. von Karlheinz Hülser. Bd. 8, Frankfurt a. M., Leipzig 1991, S. 197425. Zur Überlieferung vgl. Le Timée de Platon. Contributions à l'Histoire de sa Réception. Platos Timaios. Beiträge zu seiner Rezeptionsgeschichte. Hg. von Ada Neschke-Hentschke. Paris 2000.

20 Aristoteles: Meteorologie. In: ders.: Werke in deutscher Übersetzung. Hg. von Ernst Grumach, fortgeführt von Hellmut Flashar. Bd. 12. Übersetzt von Hans Strohm. Berlin 1970, S. 9-235. 
(großen Mysteriums). ${ }^{21}$ Der Sprachgestus ist dabei keineswegs polemisch, wie es für authentisch-paracelsische Schriften typisch wäre, sondern eher kontemplativ: Im Text wird mit philosophischen sowie mit alchemischen Begriffen gearbeitet, wobei die Begriffe durch die Verbindung des Abstrakten mit dem Konkreten zu Prozess-Figuren hypostasiert werden.

\section{Der Inhalt: Die Schöpfung}

Der Haupttext der Philosophia ad Athenienses setzt bei der Erschaffung aller vergänglichen Dinge an und problematisiert deren Substantialisierung und Sichtbarwerdung als Separatio und Coagulatio sowie ihr jeweiliges Ende als ultima materia und erneute Separatio. So heißt es gleich zu Beginn:

Aller geschaffnen dinge die da in zergencklichem wesen stehen/ ist gewesen ein einiger anfang/ in welchem beschlossen gewest ist alles geschöpf so zwischen den Etheren [den Äthern] eingefangen und begriffen seind: und sol verstanden werden/ das alle geschöpff auß einer materien kommen/ und nit eim jeglichs ein eigens gegeben. Diese materia aller ding/ ist Mysterium magnum/ und nit ein begreifligkeit auf keinerley wesen gestelt: noch in kein bildnuß geformiert: auch mit keiner eigenschafft incliniert/ dergleichen ohn farben unn Elementische natur. So weit sich die Etheren [̈̈ther] eingeben haben/ so weit ist gewesen der kreiß Mysterii magni/ diß Mysterium magnum ist ein muter gewesen aller Elementen/ und gleich in solche auch ein großmuter aller Stern/ Bäumen/ und der Creaturen des fleisch: dann auß dem/ wie von einer Muter kinder geboren werde/ also auch vom Mysterio magno geboren seind alle geschöpf von empfindtlichen [tastbaren] und unentpfindtlichen: und aller andern gleichformig [bei allen anderen verhält es sich ebenso]/ und ist Mysterium magnum ein einige muter aller tödtlichen [sterblichen] ding. (fol. A3)

Zunächst wird also der Neologismus Mysterium magnum als Begriff für die Materie aller Dinge zitiert bzw. konzeptionalisiert: Mysterium magnum habe kein Wesen, kein Bild und keine Eigenschaft, es sei ohne Farben und ohne elementische Natur. Es sei eine Mutter der Elemente und eine Großmutter der Sterne, Bäume und Kreaturen sowie alles Sterblichen. In ihm, so heißt es weiter, habe der höchste Künstler (also der Demiurg, mit Platon gedacht) Substanz, Materie, Form, Wesen, Natur sowie Inklinierung (das heißt: die Neigung des Menschen, sich nach den Sternen zu richten) zubereitet. Das „Mysterium magnum“ selbst hingegen sei ungeschaffen (fol. A3-A3 $)$.

21 Der Neologismus „Mysterium magnum“ findet sich als „M. magnum” schon im paracelsischen Volumen paramirum, vgl. Benzenhöfer: Studien zum Frühwerk (Anm. 17), S. 33 und 39. Dies ist wiederum ein Beleg dafür, dass die pseudo-paracelsischen Schriften die impliziten Gehalte der paracelsischen Schriften entfalten. 
Diese Darstellung korrespondiert - von der ungewöhnlichen Erwähnung einer Großmutter einmal abgesehen - mit der platonischen Konzeption der "Chõra“:22 Das Mysterium magnum ist ungeschaffen und undarstellbar wie die platonische Chõra, es ist jedoch im Unterschied zu dieser vergänglich. Der offenkundig medizinisch geschulte Autor vergleicht das „Mysterium magnum" zudem mit Urin und Milch (fol. A3 ${ }^{v}$ ). In Platons Timaios wird Chõra u. a. mit einer Amme, mit Salbe, mit Gold und mit einem Sieb verglichen. Die Entstehung der Dinge aus dem Mysterium magnum wird in der Philosophia ad Athenienses als Geburt, als Scheidung, als Separatio und als Coagulatio bezeichnet und u. a. durch Beispiele aus Alchemie und Medizin anschaulich gemacht: Wie die Blumen des Silbers in der alchemischen Arbeit aufsteigen und sich scheiden - hiermit ist auf die Praxis der Stofftrennung durch Sublimation verwiesen -, so sei das Gestirn durch Scheidung von den Himmeln geboren worden (fol. B4). Der Rauch wiederum, der selbst nicht greifbar sei, enthalte coagulierten, also substantiell verfestigten oder verklumpten, Ruß. Von solchen Dingen zu philosophieren, sei zwar mehr als menschlich. Dennoch sei es ein Gegenstand der natürlichen Magie. Der Autor veranschaulicht die Rolle des Mysterium magnum zudem, indem er es mit der Verdauung (und modern betrachtet mit der Hydrolyse) vergleicht: Diese sei ebenfalls selbst nicht substantiell, bewirke jedoch eine Substantialisierung (fol. B2v).

Im Unterschied zu Platons Timaios reflektiert unser pseudonymer Autor im nächsten Schritt sogleich (am Beispiel der Fermentation) über das Ende der Dinge: Wie der Käse nicht mehr zu Milch werde, so würden auch die sterblichen Dinge bei ihrem Ende nicht mehr in das Mysterium magnum eingehen. Das Mysterium magnum sei wie eine Schreibtafel; der Tod komme ihrem Abwischen gleich (fol. $\mathrm{D}^{\mathrm{v}}$ D2). Das Ich und das Wir (hier als substantialisierte Pronomen) gehörten nicht zum Ewigen, sie würden von dieser Tafel abgewischt werden; die Tafel selbst sei ebenfalls vergänglich. Der Mensch sei die einzige Kreatur, die etwas Ewiges in sich habe, das bleibe und über das gerichtet werde (fol.D3-D3 ${ }^{v}$ ). Darüber, was nach dem Tod aus dem Ewigen werde, sei hingegen nicht zu spekulieren (fol. E). Damit endet das erste Buch. ${ }^{23}$

$\mathrm{Zu}$ Beginn des dritten paras oder zweiten Buches kommt es im Text zu einem gnostisch schöpfungsfeindlichen Umschwung, der dem Beginn der Schrift zu

22 Vgl. Platon: Timaios (Anm. 19). Das Konzept der "Chõra“ wird in der Textpassage 49a-53c geprägt.

23 Die Reflexion über das Ende der Dinge verdankt sich möglicherweise den Lehren des alexandrinischen Platonikers und christlichen Theologen Origenes (185-ca. 254 u. Z.). Origenes hatte die Auffassung vertreten, die Welt werde eines Tages in den Zustand vor dem Sündenfall zurückversetzt. Diese Position war posthum häretisiert worden und ist aus katholischer Perspektive bis heute umstritten. Auch die Reflexionen des Gelehrten und Philosophen Calcidius', der im Anschluss an Origenes ca. im 4. Jahrhundert u. Z. Platons Timaios aus dem Griechischen ins Lateinische übersetzte und in seinem Kommentar u. a. das Fatum (Schicksal) diskutierte, könnten - neben Marsilio Ficinos Schriften - zum Vorwissen der Philosophia ad Athenienses gehört haben. Calcidius' Timaios-Übersetzung und -Kommentar waren 1520 in Paris gedruckt worden. 
widersprechen scheint. Der Autor klagt nun, andere Schöpfer als jener, der das Ewige schuf, hätten das Vergängliche im Mysterium magnum gemacht: nicht Gott, sondern Götter seien hier tätig gewesen, zu einem Urteil (oder Unheil - hier gibt es unterschiedliche Lesarten) sowohl für sie selbst als auch für uns, d. h. die Menschen (fol. E2 ${ }^{\mathrm{v}}$ ). Das Mysterium magnum sei eine Einheit, die in den Elementen Feuer, Wasser, Erde und Luft Verschiedenes gebäre: In jedem Element werde Vernünftiges sowie Unvernünftiges geboren (fol. F3v ${ }^{v}$. Es sei töricht, Menschen für die edelsten der Geschöpfe zu halten, denn es gebe noch mehr Leute, die ebenfalls im bzw. aus dem Mysterium magnum geschaffen seien (fol. $G-G^{v}$ ). Damit sind die Nymphen im Wasser und die Geschöpfe in den Elementen Feuer, Erde und Luft gemeint sowie weitere Elementargeister, die wir (Menschen) nicht erkennen; diese Wesen werden in zahlreichen (pseudo-)paracelsischen Texten - in skurril anmutender Vertrautheit - als „leut(e)" bezeichnet. Zwar hätte lediglich der Mensch etwas Ewiges bzw. eine Seele, doch alles Geschaffene, so etwa auch die „blümeln" (Blümlein), habe ein Bildnis im Ewigen (fol. G2). Im Ende werde auch das Mysterium magnum erkannt, denn nicht der Anfang, sondern das Ende gebe den Philosophen, der die vollkommene Natur eines Dinges wisse. Vielleicht werde am Ende sogar ein neues Mysterium magnum gemacht (fol. G2v'). Letztlich komme alles Ewige von dem Arcanum und nicht von den Elementen. Die Elemente seien nur eine Herberge und Nahrung (fol. G3-G3v). Die Hunde (sic) und die Menschen stürben, aber ihr Arcanum bleibe im "Mysterium magnum ultimum", in dem alle Dinge erneuert und dabei doch nicht anders würden als sie gewesen seien (fol. G3 ${ }^{\mathrm{v}}-\mathrm{G} 4$ ).

In dieser neuerlichen textuellen Wendung wird dem Mysterium magnum also ein Mysterium magnum ultimum vorgeordnet und so das in Aussicht gestellte neue Mysterium magnum vom Autor selbst eingeführt oder gemacht. Zudem wird der Begriff Arcanum (Geheimnis) eingebracht: Aus dem Arcanum in diesem letzten großen Mysterium werde sich alles erneuern (fol. G4). Es gebe nur einen Gott, nur einen Richter und nur einen Glauben. Die Elemente bedeuteten Korruption, Vergänglichkeit und Fäulnis; durch sie sei das Ewige verkehrt und verlassen worden (fol. $\mathrm{H}^{\mathrm{v}}$ ). Während der Begriff „Mysterium“ hier als räumlich konzipiert ist und durch den Zusatz magnum zum Synonym für Materie sowie quasi zu einem Eigennamen hypostasiert wird, lässt Arcanum an alchemische Medikamente denken, da es in anderen paracelsischen Schriften, etwa in den Libri Archidoxae, so gebraucht wird. ${ }^{24}$

Die Schrift, der bis zu dieser Stelle trotz ihrer barocken Textelemente - etwa der Großmutter, den Blümchen und den Hunden - und ihrer Widersprüche zumindest formal gut zu folgen ist, geht nun sozusagen mit sich selbst durch, indem sie

24 Vgl. Theophrast von Hohenheim, genannt Paracelsus: Sämtliche Werke (Anm. 1), Bd. 3, S. 138. Die oben zitierte Textaussage korrespondiert mit der des Liber primus, de elemento aëris der Philosophia de generationibus et fructibus quatuor elementorum, wo es gleich eingangs heißt, dass es nach dem Tod der Elemente "ein ander welt" geben werde, die nicht sterblich sei, sondern wie die Seele erhalten bleibe, vgl. ebd., Bd.13, S. 9. Sie steht hingegen im Gegensatz etwa zur Philosophia Magna, in der gesagt wird, lediglich die Seele sei aus Gott und werde wieder zu Gott gehen, vgl. ebd., Bd. 14, S. 1-377, hier S. 221. 
als weiteren Begriff ein Evestrum (einen Schatten) einführt und hypostasiert, mit dem wohl in implizitem Anschluss an Platons Höhlengleichnis, die vergängliche Kreatur bezeichnet wird:

Evestrum ist ein ding wie ein schadt an der Wandt/ der schadt der wächst und kompt mit dem corpus/ und bleibt mit demselbigen/ und in sein letzte materien/ Evestern nimpt sein anfang mit der ersten gebierung eins jeglichen dings/ denn selisch und unselisch/ entpfindtlichs und unentpfindtlichs hat mit leuffig des Evestren/, unn alles das schatten gibt. (fol. H2)

Aus dem Schatten seien die Prophezeiungen entstanden und entständen sie weiterhin, weswegen es der höchsten Sophia (also der Weisheit bzw. gnostischen Gottheit Sophia) zustehe, aus dem Evestrum zu philosophieren. Der Prophet ,evestriere', das heißt, er rede aus dem Evestrum (fol. H2v). Der Autor konzipiert die Evestren als Daseinsformen der vergänglichen Geschöpfe, behandelt sie aber zugleich wie Geister oder Gespenster, denn sie wohnen seiner Darstellung zufolge in Spiegeln, Kristallen, polierten Flächen, Wassern, im Gesang und im Gemüt (fol. H4v). Allein durch unser Evestrum sei es uns möglich, uns selbst zu erkennen - demnach wohl unsere Vergänglichkeit oder unseren doppelten Charakter, vergänglich und zugleich unvergänglich zu sein.

Der vierte paras schließlich wird expliziter medizinisch alchemisch (chemiatrisch) und gibt weitere Auskunft über die Substantialisierung des Unkörperlichen. Der Autor erläutert, wie Körperliches aus Flüchtigem entstehe: Es werde aus einem spiritus fumosus (einem Rauch-Geist) geboren, der selbst weder körperlich, noch substantiell oder "greifflich" (d. h. tastbar) sei. Der jeweilige spiritus fumosus und der jeweilige Körper beständen nach ihrer Geburt oder Scheidung beide fort, der eine subtil und unsichtbar, der andere körperlich und sichtbar; so verhalte es sich beispielsweise mit dem - im Text nicht weiter traktierten - Arsen (fol. I3 $\left.3^{v}\right){ }^{25}$

Im Widerspruch zu den eingangs getroffenen Bestimmungen wird nun nahegelegt, dass das Mysterium magnum auch als ewig gedacht werden könne (fol. $3^{\mathrm{v}}$ ). Das hat seine Begründung vielleicht darin, dass inzwischen ja auch der Begriff Mysterium magnum ultimum und somit eine weitere Bestimmung eingeführt worden ist. Der Text kommt so jedenfalls mit der platonischen Unentschiedenheit überein, der zufolge Chõra sowohl ewig als auch vergänglich und zugleich keines von beidem sein soll.

Alle Dinge, so der Autor, seien ein coagulierter Rauch, sie kämen aus ihrer $M a-$ trix, also dem Mysterium magnum, an die Luft, an der sie coagulierten (fol. K). Das

25 In Aristoteles' Meteorologie sind es die Mineralien, die aus dem Rauch, und die Metalle, die aus dem Wasserdampf entstehen (Buch III, Kap. 6). In Pseudo-Paracelsus' „Rauch" ist zudem der ruach elohim, der Geist Gottes aus der hebräischen Bibel bzw. dem Alten Testament synkretistisch präsent, während das entsprechende Wasser, über dem dieser schwebt oder brütet, hier ausgeklammert bzw. (etwa im semantischen Gehalt des „Mysterium magnum“ als Wolke) etwas zurückgenommen ist. Zur Bedeutung der Genesis-Szene für die paracelsische Alchemie vgl. Frietsch: Häresie und Wissenschaft (Anm. 1), S. 182-191. 
Mysterium magnum sei wie eine Wolke und die Dinge seien wie der Hagel, der aus der Wolke coaguliere. Diese Bewegung werde jedoch jeweils wieder rückgängig gemacht: „die gantze Welt wirt zergehen wie ein schne/ und wirt widerumb kommen in dieselbige materien des spiritus fumi/ und sich vereinigen ohn alles greifflichs wesen". So sei es von dem höchsten Gut im Anfang aller Dinge verordnet worden (fol. I4 ${ }^{\mathrm{v}}$ ).

Hinter dieser Darstellung lassen sich die alchemischen prozessualen Figuren des Solve, also der Verflüssigung, und des Coagula, der Verfestigung, wahrnehmen. Im Text ist allerdings überwiegend von Separatio als Scheidung und von Coagulatio als Verfestigung die Rede. Das Solve wird nicht benannt. Die textuelle Verfestigung des Gesagten wird zudem durch den Gebrauch von Neologismen und fremdkörperhaften Latinismen vorangetrieben: So sei etwa "Stannar" (dies ist ein Neologismus, der sich nicht etabliert hat) die Mutter der Metalle; sie gebe aus ihrem Rauch eine Prima materia metallorum. Alle Metalle seien nichts anderes als ein coagulierter Rauch aus dem „Stannar“ (fol. $\mathrm{K}^{\mathrm{v}}$ ). Im Rauch eines jeden Dings sei dessen Prädestination enthalten. Durch das Leben werde alles Coagulierte transmutiert und verzehrt, bis es wieder zu Rauch werde. Das Mysterium magnum sei ohne Neigung und Gattung, wie die braune Farbe, die alle weiteren Farben in sich trage. Von dem obersten Werkmeister sei alles aus dem Mysterium magnum geschieden worden (fol. K3). Damit endet die Schrift.

\section{Philosophiegeschichtliche Einordnung}

Karl Sudhoff beurteilte die Philosophia ad Athenienses als „keineswegs unbedeutend[]“, wenngleich befremdlich. Er befand, diese "ganze Rauch- und DampfPhilosophie, ihre Selbstverzehrung des Lebens, ihre Fassung der Prädestination, auch ihre ganz religiöse Einstellung" sei jener des Paracelsus fremd. Der Titel der Schrift erschien ihm als unsinnig, da er keinen Bezug auf „die Athener" erkennen konnte. ${ }^{26}$ Als Athener kam für ihn nur das paracelsische Feindbild Aristoteles in Frage, das in der Schrift - ganz so wie Platon - nicht explizit erwähnt ist.

Auffallend an dieser ambitionierten Schrift ist jedenfalls, gerade im Vergleich zu Platons Timaios, das Fehlen von Ironie. Im Timaios wird die Entstehung der Welt als Mythos erzählt und wie alle Mythen stellt dieser in Platons Werk ein Diskussionsangebot bzw. eine Erzählung unter anderen, möglichen dar. In Aristoteles' Meteorologie wiederum wird sogar einige Male explizit darauf hingewiesen, dass Begriffe wie „Rauch" nicht spezifisch genug seien, um die sublunaren Prozesse des Entstehens und Vergehens wiederzugeben, und dass eine zutreffendere Begrifflichkeit - modern formuliert: eine eigene chemische Terminologie - fehle. ${ }^{27}$ In der Philosophia ad Athenienses hingegen verfestigt sich die Erzählung über die Erschaffung der Welt zu einer Darstellung mit Wahrheitsanspruch. Wie in weiteren

26 Karl Sudhoff: Vorwort. In: Theophrast von Hohenheim, genannt Paracelsus: Sämtliche Werke (Anm. 1), Bd. 13, S. V-XVI, hier S. XII-XIII.

27 Aristoteles: Meteorologie, Buch II, Kap. IV sowie Buch IV, Kap. 2. 
paracelsischen und pseudo-paracelsischen Schriften wird auch hier mit größter Sicherheit Faktizität benannt, wenngleich die Aussagen widersprüchlich bleiben.

Das überlieferte paracelsische Ideengut, u. a. das handschriftlich kursierende Ideengut aus dem ersten Buch der Philosophia de generationibus et fructibus quatuor elementorum, wurde in der Philosophia ad Athenienses reflektiert und variiert, indem ihr Autor dem Element Luft bei seiner Schöpfungserzählung den Vorzug gab. ${ }^{28}$ Auf diese Weise wurde im Verlauf des 16. Jahrhunderts ein chemiatrisches und zugleich theoretisches Modell von Schöpfung präsentiert, in welchem das Konzept der hebräischen Bibel bzw. des Alten Testaments etwas in den Hintergrund rückte, während sich die platonischen, aristotelischen sowie gnostischen, hermetischen $^{29}$ und neuplatonischen Überlieferungen synkretistisch mit Versatzstücken der paracelsischen Lehre verbanden.

Die Abweichung der Philosophia ad Athenienses vom alttestamentarischen Schöpfungsbericht und vom traditionellen Hylemorphismus zu erkennen, war dabei eher theologisch denn philosophisch verdienstreich. Weder Reußner noch Erastus stellen sich bei ihren Attacken auf Paracelsus die Frage, warum die Philosophia ad Athenienses das jüdisch-christliche Modell der Genesis transformierte, indem sie dieses mit materiell-naturkundlichen Termini kombinierte. Ähnliche Freiheiten hatte sich zwar bereits Marsilio Ficino in seinen drei Büchern De Vita im 15. Jahrhundert herausgenommen. In den Augen von Reußner und Erastus war diese Vorgehensweise dennoch schlicht kriminell. Es sollten sich allerdings bald schon weitere Naturkundler und Naturphilosophen - so etwa Oswald Croll, ${ }^{30} \mathrm{Ja}-$ kob Böhme und Robert Fludd - dieser Vorgehensweise anschließen und sich in die platonisierende Tradition der Renaissance einschreiben, die auf diese Weise im 17. Jahrhundert zu neuen Wendungen fand. Die genannten Autoren verbanden die anagogische Interpretation der biblischen Genesis mit einer hermetischen Spiritualisierung der Naturvorgänge sowie - dies kam durch Paracelsus und den

28 Neben den bereits genannten Übereinstimmungen zwischen der Philosophia ad Athenienses und der Philosophia de generationibus et fructibus quatuor elementorum finden sich etwa folgende: Im ersten Buch der Philosophia de generationibus et fructibus quatuor elementorum wird Gott beispielsweise als „fabricator" bezeichnet, vgl. Theophrast von Hohenheim, genannt Paracelsus: Sämtliche Werke (Anm. 1), Bd. 13, S.9-19, hier S. 13. Die platonische Naturphilosophie ist u. a. auch insofern präsent, als die Elemente geordnet (ebd., S. 13) oder geschnitzt (ebd., S. 14) und nicht eigentlich geschaffen werden. Auch von der Coagulatio ist die Rede: „, anfenglich ist der himel nichts als alein ein weißer sulphur, coagulirt mit dem salzgeist und clarificirt mit dem mercurio" (ebd., S. 18).

29 In der Philosophia ad Athenienses scheint u. a. das Gespräch des Hermes mit Asklepios und damit die mittelplatonische Tradition des Corpus hermeticum reflektiert und imitiert zu sein. $\mathrm{Zu}$ diesem Gespräch vgl.: Das Corpus hermeticum Deutsch. Übersetzung, Darstellung und Kommentierung in drei Teilen. Hg. von Carsten Colpe und Jens Holzhausen. Teil 1, StuttgartBad Cannstatt 1997, S. 28-36.

30 So ist beispielsweise der coagulierte Rauch als Teil der Schöpfung bei Croll topisch präsent; das Wasser der Genesis wird von Croll mit dem Mercurius analog gesetzt. Vgl. Oswald Croll [1609]: Basilica Chymica [...]. Frankfurt 1623, S. 16 (deutsche Ausgabe). 
Paracelsismus neu hinzu - mit konkreten alchemischen Versatzstücken. ${ }^{31}$ Die Nennung von alchemischen Prozessen und Substanzen (Blumen des Silbers, Coagulation von Rauch, Arsen etc.) in der Philosophia ad Athenienses verweist auf eine Analyse von Naturvorgängen, die der Schöpfungsgeschichte hier gleichsam injiziert wurde. ${ }^{32}$ Wissenschafts- und ideengeschichtlich führte dieses textuelle Verfahren in zwei Richtungen: Es ließ sich weiter zu einer Spiritualisierung der Natur nutzen, wie dies beispielsweise in der Theosophie von Jakob Böhme geschieht, der 1623 ein eigenes Werk mit dem Titel Mysterium Magnum verfasste. Es ließ sich jedoch auch praktisch naturkundlich nutzen, indem man versuchte, die Geheimnisse des Schöpfungsberichtes in alchemischen Praktiken aufzuklären.

\section{Das Rätsel: Der Titel und die Verfasserfrage}

Die offenkundig fingierte Philosophia ad Athenienses handelt nicht nur vom Geheimnis der Schöpfung der Welt. Letztlich spielt sie auch mit dem Rätsel ihrer eigenen Autorschaft (und insofern Schöpferkraft). Der obigen Interpretation zufolge adressierte sie die Athener Platon und Aristoteles, die sie mittels ihrer sowohl durch das Christentum wie durch die paracelsische Naturphilosophie geschulten Aussagen durchaus nicht feindlich zu bekämpfen, jedoch zu übertreffen trachtete. Der Autor zitierte mit seinem Titel rhetorisch Paulus' Rede an die Athener auf dem Areopag (Apg 17, 22-34) und identifizierte seine Position damit als christlich. ${ }^{33}$ Er zielte auf die Galenisten an den medizinischen Fakultäten und könnte darüber hinaus konkrete Personen im Blick gehabt haben. Hierauf weisen mehrere Schriftstücke aus dem Kontext des Werkes hin, in denen von Athenern die Rede ist. So veröffentlichte Adam von Bodenstein 1562 in seinen Editionen der Werke De Vita longa und Paramirum zwei Texte, in denen "Atheniensibus" bzw. "Stoicis" erwähnt sind: Diese hätten Paracelsus den ,großen' Paracelsus geheißen, da er so viele Bücher verfasst habe. ${ }^{34}$ Es handelt sich um einen Brief von einem Valentius de Retiis ${ }^{35}$

31 Zur weiteren Tradierung der Konzepte der Philosophia ad Athenienses bei Jakob Böhme, Robert Fludd u. a. vgl. Frietsch: Häresie und Wissenschaft (Anm. 1), S. 352-355; Hedesan: The Mystery (Anm.3); zu Fludds Konzepten und seinen Kontroversen mit Johann Kepler, Marin Mersenne und Pierre Gassendi vgl. die alchemiehistorisch einschlägige Darstellung von Allen G. Debus [1977]: The Chemical Philosophy. Paracelsian Science and Medicine in the Sixteenth and Seventeenth Centuries. New York 2002, S. 253-293; sowie Frietsch: Häresie und Wissenschaft (Anm. 1), S. 403-407 (u. a. zu Fludd, Mersenne und Gassendi); Wilhelm Schmidt-Biggemann: Robert Fludds Streit mit Johannes Kepler. In: Ideengeschichte um 1600. Konstellationen zwischen Schulmetaphysik, Konfessionalisierung und hermetischer Spekulation. Hg. von Wilhelm Schmidt-Biggemann und Friedrich Vollhardt. Stuttgart-Bad Cannstatt 2017, S. 143-171; sowie ders.: Geschichte der christlichen Kabbala. Bd. 2: 1600-1660. Stuttgart-Bad Cannstatt 2013, S. 144-186 (zu Fludd, Mersenne und Gassendi).

32 Zum Zusammenhang mit der Arbeit im Labor vgl. auch Hedesan: Mystery (Anm. 3), S. $151 f$.

33 So bereits Hedesan: Mystery (Anm. 3), S. 143.

34 Vgl. Karl Sudhoff: Paracelsus. Ein deutsches Lebensbild aus den Tagen der Renaissance. Leipzig 1936, S. 21, und Theophrast von Hohenheim, genannt Paracelsus: Sämtliche Werke (Anm. 1), Bd.3, S. 565-567.

35 Adam von Bodenstein veröffentlichte diesen Brief „Ad lectorem" in seiner Edition von Paracelsus' Schrift De vita longa 1562. Darin heißt es, auf Latein, von den "Stoicis“ sei Paracelsus 
und um einen Prolog von einem Valentius Anthrapassus Sileranus, beide Namen sind vermutlich wiederum fingiert. Im Prolog des Sileranus heißt es:

und so sein [Paracelsus'] schreiben [...] nicht bewert were [...], hetten i[h]n [Paracelsus] die Athenischen nit für einen destructorem aller irrung [...] (erkennet). [...] die Pessulanischen [die Ärzte in Montpellier] nennen i[h]n den teutschen Hippokratem und den neuen Aesculapium. Darumb [...] bezwingt das götliche gebot [...,] sie zu teutschen [seine Schriften ins Deutsche zu übersetzen], damit das der gemeine man, dem unbekant ist das latein, seiner [Paracelsus'] geschriften genießen müge. Doctor Ciperinus Flaenus hat $\mathrm{i}[\mathrm{h}] \mathrm{n}$ welscher und französischer zungen transferirt. Bebeus Ramdus hat alle seine bücher der arznei zu griechischer zungen verwandelt. Als i[h]n die griechischen erfaren, haben sie i[h]n geheißen monarcham perpetuum, aus kluger art seines trefflichen [...] schreiben[s], [...] dan in seiner philosophia werden alle aristotelischen ler verworfen, auch Platonis. ${ }^{36}$

Demnach wären Paracelsus' lateinische Schriften ins Deutsche, Griechische und Französische übersetzt worden und „die Athener" hätten daraufhin erkannt, dass Paracelsus die Irrtümer des Plato und Aristoteles' zurecht zerstöre. Diese Darstellung ist offensichtlich unzutreffend, da der historische Paracelsus die meisten seiner Schriften auf Deutsch verfasste. Er wurde zwar ab den 1560er Jahren ins Lateinische und bald auch schon ins Französische, Tschechische und Niederländische übersetzt; frühe Übersetzungen ins Griechische sind jedoch nicht belegt. Bei dem erwähnten „Bebeus Ramdus“ lässt sich zwar an den französischen Philosophen Petrus Ramus (1515-1572) denken, dessen pädagogische Aufbereitung von Wissensfeldern für den Paracelsismus eine Rolle spielte. Ramus war allerdings nur im übertragenen Sinne übersetzerisch tätig und hat nicht ins Griechische übersetzt.

Karl Sudhoff, als Editor der ersten modernen Paracelsus-Ausgabe, nahm an, dass der zitierte Prolog bereits zur Zeit von Paracelsus' Professur in Basel (also etwa 1527) von einem Studenten verfasst worden sei. Er bemerkt hierzu:

Die Namen der angeführten angeblichen Autoritäten muten fast so an, als wenn es Spitznamen wären, die sich die jungen Eiferer um die Lehren des Meisters in der Debatte beigelegt hatten, kenntlich untereinander im studentischen Kreise, kaum auf Personen außerhalb gemünzt. ${ }^{37}$

Wilhelm Kühlmann und Joachim Telle, die sich eingehend mit den paracelsistischen Netzwerken befasst und die Schriftstücke des Valentius de Retiis und Va-

der Große genannt worden, weil er so viele Bücher geschrieben habe. Valentius beziffert die Zahl der Bücher auf 364. Toxites übersetzte den Begriff "Stoicis" 1574 mit "Atheniensibus": „Philippus Theophrastus von Hohenheim [...] ist von den Atheniensibus der große Paracelsus genant worden", vgl. Theophrast von Hohenheim, genannt Paracelsus: Sämtliche Werke (Anm. 1), Bd. 3, S. 564.

36 Theophrast von Hohenheim, genannt Paracelsus: Sämtliche Werke (Anm. 1), Bd. 3, S. 565-566.

37 Theophrast von Hohenheim, genannt Paracelsus: Sämtliche Werke (Anm. 1), Bd. 3, S. 567. 
lentius Anthrapassus Sileranus historisch-kritisch ediert haben, ${ }^{38}$ schließen sich Sudhoffs Interpretation, dass es sich um Studenten-Sprache handele, nicht an. Sie diskutieren die zitierte Textstelle vielmehr mit Verweis auf den französischen Paracelsus-Übersetzer Pierre Hassard, der in einem Vorwort von 1566 schreibt, Paracelsus werde an Universitäten in Polen, Siebenbürgen, Mähren, Griechenland, Athen und Damaskus rezipiert. ${ }^{39}$ Kühlmann und Telle betrachten die Verfasser von Brief und Prolog als Paracelsisten, können sie jedoch nicht identifizieren, genauso wenig wie die weiteren namentlich genannten Personen. Für die Einschätzung von Kühlmann und Telle ist wohl ausschlaggebend, dass auch Adam von Bodenstein die Schriftstücke für authentisch hielt, und sie nach dessen Edition noch sehr oft ediert und übersetzt wurden.

Die Universitäten der Frühen Neuzeit waren jedenfalls auch in Hinblick auf die Mobilität der Studenten international. So studierten beispielsweise in Pisa in der Zeit von 1544 bis 1609 ca. 6200 junge Männer: Von diesen kamen 126 aus Deutschland, 77 aus Spanien, 39 aus Frankreich, 30 aus Portugal, 26 von Mallorca, 26 aus Bayern, 11 aus Flandern, sieben aus England, sechs aus Polen, drei aus Tirol, einer aus Belgien, einer aus Griechenland und der Rest aus der Toskana bzw. anderen Teilen Italiens. ${ }^{40}$

Wie auch immer man den zitierten Prolog also datieren und interpretieren mag: Auffällig ist, dass die Zuschreibung „die Athenischen“ hier eher positiv konnotiert ist. Als „Athener" könnte so auch der Autor der Philosophia ad Athenienses bestimmte zeitgenössische Gelehrte adressiert haben, die in der griechischen Tradition besonders bewandert und dennoch bereit waren, sich von Aristoteles und Galen zu distanzieren bzw. die aufgefordert werden sollten, dies zu tun.

Eindeutig geht aus der literarischen Verschachtelung der Philosophia ad Athenienses mit ihren paras und ihrem „fürst[en] Theophrastus“ und aus den genannten Pseudonymen jedenfalls hervor, dass die Paracelsisten in den 1560er Jahren ein Versteckspiel mit ihren Lesern spielten und ihre eigene Identität verrätselten. Während der Haupttext oder Textkern vom Geheimnis der Schöpfung handelt und es zu enthüllen scheint, als ob es ganz aktuell und der natürlichen Magie bzw. Naturforschung zugänglich wäre, scheint die literarische Rahmung mit diesem bedeutsamen Inhalt zu spielen und ihn, wie in einer Gelegenheitsschrift, hinter mehr oder weniger kontingenten Zuschreibungen zu verbergen. Dieser Widerspruch von bombastisch philosophischem Inhalt und kontingent literarischer Form führt schließlich die Ironie wieder ein, die mit Blick auf Platons Timaios zu vermissen war.

38 Vgl. Wilhelm Kühlmann und Joachim Telle: Corpus Paracelsisticum (Anm. 2), S. 585-620.

39 Kühlmann und Telle: Corpus Paracelsisticum (Anm. 2), S. 609.

40 Vgl. P. Paganini: Statistica degli studenti pisani del secolo XVI. In: Rivista critica della letteratura italiana 3 (1886-87), S. 125-126, zitiert nach Cristina Bellorini: The world of plants in Renaissance Tuscani. Medicine and Botany. Farnham u. a. 2016, S. 56. 


\section{Spielräume des Selbst \\ Zum Verhältnis von Darstellung und Geheimnis in der Bruderschaft der Freimaurer}

Kristiane Hasselmann

\section{Initialgemeinschaft als alternative Sozialisationsform}

Im frühen 18. Jahrhundert wandelt sich die Bruderschaft der Freimaurer auf den britischen Inseln zu einer angesehenen Sozialitätsform. Die Free and Accepted Masons entwickeln ein Modell der individuellen Selbstperfektionierung im Kontext einer Wertegemeinschaft, die einen performativen Aneignungs- und Verfestigungsprozess entlang von Symbolen, Mythen und Legenden entwirft, deren Bedeutung es im rituellen Vollzug zu erschließen gilt. Die Freimaurer-Bruderschaft ist eine Initiationsgemeinschaft, in der der Prozess der Erkenntnis und Vervollkommnung stufenweise über Rituale der Aufnahme und Beförderung erfolgt. Ansehen und Position eines Mitglieds bemessen sich unabhängig von Herkunft und Stand ausschließlich an dieser persönlichen Entwicklung und Bewährung innerhalb der Gemeinschaft, ${ }^{1}$ was sie letztendlich zu einer der Triebfedern einer neuen Bürgerlichkeit werden lässt. ${ }^{2}$

Grundgedanke der Freimaurerei ist die Erlangung tieferer Einsichten in die göttliche Schöpfung mit dem Ziel, aus den Funktionsweisen Prinzipien und Praktiken für die Formung der eigenen Person und die Gestaltung einer funktionierenden Gesellschaft abzuleiten. Die Arbeit am Selbst und dessen Erprobung im Rahmen einer schützenden Gemeinschaft soll langfristig zur Perfektionierung der Welt in einem größeren gesellschaftlichen Kontext beitragen. Metaphorisch steht hierfür die Baumetapher, die dazu auffordert, einen ursprünglichen göttlichen Bauplan zu durchdringen und aus ihm verbindliche Handlungsprinzipien abzuleiten.

The World's great Architect is our Supreme Master, and the unerring Rule he has given us, is that by which we Work. Religious Disputes are never suffered in the Lodge; for as Masons, we only pursue the universal Religion, or the Religion of Nature. This is the Cement which unites Men of the most different Principles

1 Die berühmten Ausnahmen bestätigen auch hier die Regel. So wurde beispielsweise der preußische Kronprinz Friedrich, der spätere Preußenkönig Friedrich II., 1738 in Braunschweig innerhalb einer Nacht in alle drei Johannisgrade aufgenommen.

2 Siehe hierzu ausführlich Monika Neugebauer-Wölk: Esoterische Bünde und bürgerliche Gesellschaft. Entwicklungslinien zur modernen Welt im Geheimbundwesen des 18. Jahrhunderts. Göttingen 1995. 
in one sacred Band, and brings together those who were the most distant from another. $^{3}$

Die Übersetzung des göttlichen Prinzips in einen Größten Baumeister aller Welten beinhaltet die Aufhebung jedes religiösen Determinismus' und stärkt zugleich die theistisch gedachte Grundlage des Seins und jeglichen Wissens.

Der Neuaufzunehmende tritt als ,Suchender' auf und wird von der Bruderschaft einem ihm vorher unbekannten Initiationsritual unterzogen, welches er von da an als gemeinschaftliches Erlebnis mit seinen Brüdern teilt, das dem Uneingeweihten jedoch stets verschlossen bleibe. Die Bruderschaft fordert von ihren Mitgliedern absolute Verschwiegenheit darüber, was in ihrem geschützten Innenraum vonstatten geht. Während der Aufnahmezeremonie leistet der Initiand einen martialisch anmutenden Geheimhaltungsschwur, der jedwede Form der spitzfindigen Umgehung des Gebotes ausschließt:

Ich gelobe und schwöre hiermit in Gegenwart des allmächtigen Gottes und dieser ehrwürdigsten Versammlung, daß ich die Heimlichkeiten, oder das Geheimniß der Maurer oder Maurerei, so man mir offenbaren wird, hehlen und verbergen, und niemals entdecken will, es sey denn einem treuen und rechtmäßigen Bruder, nach gehöriger Erforschung, oder in einer rechten und ehrwürdigen Loge von Brüdern und Gesellen. Ich verspreche und gelobe ferner, daß ich selbige nicht schreiben, nicht drucken, nicht zeichnen, nicht stechen oder eingraben, noch selbige schreiben, drucken, zeichnen, stechen oder eingraben lassen will, es sey in Holz oder Stein, dergestalt, dass die sichtbaren Zeichen oder der Eindruck eines Buchstaben erscheinen, wodurch solches auch immermehr auf unrechtmäßige Art erlanget werde. Alles dies unter keiner geringeren Strafe, als daß meine Gurgel abgeschnitten, meine Zunge aus dem Gaumen meines Mundes genommen, mein Herz unter meiner linken Brust heraus gerissen, so dann in dem Sande des Meeres, die Länge eines Cabeltaues weit von dem Ufer, wo die Ebbe und Flut in vier und zwanzig Stunden zweymal abwechselt, begraben, mein Körper zu Asche verbrannt, und meine Asche auf der Oberfläche des Erdbodens zerstreuet werde, damit also nicht das geringste Andenken von mir unter den Maurern übrig bliebe. So wahr mir Gott helfe! ${ }^{4}$

3 "Charge to new admitted Brethren" aus dem Pocket Companion (1734-35). Zitiert nach: The Early Masonic Catechisms. Hg. von Harry Carr. 2. Aufl. des überarbeiteten und ergänzten Reprints der von Douglas Knoop, G. P. Jones und Douglas Hamer transkribierten und kommentierten Edition aus dem Jahre 1943. London 1975, S. 23.

4 Samuel Prichard: Masonry Dissected (1730). In: The Early Masonic Catechisms (Anm.3), S. 161. Deutsche Übertragung zitiert nach Samuel Prichard: Die zergliederte Freymaurerey worin eine allgemeine und richtige Beschreibung aller ihrer Aeste vom Anfang bis auf gegenwärtige Zeit enthalten wie solche in den aufgerichteten regulmäßigen Logen sowohl in der Stadt als auf dem Lande nach den verschiedenen Stufen der Aufnehmung verordnet worden. Frankfurt, Leipzig 1788, S. 10f. 
Das als Erkennungszeichen im Lehrlingsgrad ausgeführte Kehlzeichen, bei dem die rechte flache Hand mit abgewinkeltem Daumen am Hals entlangfährt und die Trennung von Kopf und Rumpf andeutet, bezieht sich auf eben diese symbolische Todesandrohung bei Verletzung des Verschwiegenheitseides. Wer sich eines Verstoßes gegen den Schwur schuldig macht, dem verheißt der Verfluchungsteil den zweiten Tod und damit die denkbar härteste Strafe. Die symbolische Androhung einer Zerteilung und anschließenden Zerstreuung der Körperteile verweist auf eine im Mittelalter besonders unehrenhafte Form der Tötung, die dem Verräter die Wiederauferstehung unmöglich und die Bestrafung damit unumkehrbar macht. Der Vertrauensbruch hat den unwiderruflichen Ausschluss aus der Gemeinschaft zur Folge. In den Augen der Brüder ist der Eidbrüchige gestorben. Sie werden ihn fortan nicht mehr als einen der ihren wahrnehmen, geschweige denn sich seiner annehmen, sollte er in eine Notsituation geraten. Die Bestrafung beruht darin, in aller Radikalität aus der Wahrnehmung und dem Gedächtnis der Gemeinschaft gestrichen zu werden.

Das freimaurerische Geheimnis, die Formen seiner Darstellung, seine schrittweise rituelle Durchdringung sowie der Anspruch, es vor den Blicken ,Profaner' zu schützen, sind konstitutiv für die Bruderschaft, auch wenn bei der als Geheimgesellschaft bezeichneten Freimaurerei die Existenz der Vereinigung selbst zu keinem Zeitpunkt grundsätzlich in Frage steht. Dieser Beitrag widmet sich der frühen Formierungsphase der spekulativen Freimaurerei an der Schwelle zur Moderne. Er hebt dabei jedoch weniger auf die Popularisierung und Verbreitung ab, die die Freimaurerei seit den 1720er Jahren erfährt, sondern folgt einigen ideengeschichtlichen Spuren und Verflechtungen zwischen den ersten Gentleman Masons, der Gründung der Royal Society of London sowie Mitgliedern der Cambridge Platonists, die bereits in der zweiten Hälfte des 17. Jahrhunderts ihren Anfang nehmen und neues Licht auf das freimaurerische Darstellungsparadigma - vor allem das Verhältnis von Darstellung und Geheimnis - werfen.

Die frühe Phase der Ausbildung der spekulativen Freimaurerei koinzidiert mit einer grundlegenden erkenntnistheoretischen Umbruchsituation, in der wissenschaftliche Ansprüche und Arbeitsweisen eine Neudefinition erfahren. Das Motto der Royal Society Nullius in verba - Folge niemandes Wort - ist Ausdruck einer grundlegenden Distanzierung von dominanten Autoritäten oder Schulen zugunsten einer neuen, faktenbasierten und experimentellen Generierung von Wissen. ${ }^{5}$ Im Vordergrund soll nun nicht mehr stehen, die Annahmen historischer Geistesgrößen zu diskutieren, sie gegeneinander antreten zu lassen und diese zuletzt in der einen oder anderen Weise zu bestätigen oder zu widerlegen, sondern selbst neues Wissen über das naturwissenschaftliche Experiment hervorzubringen. Dazu gehört, die Ergebnisse wissenschaftlicher Beobachtungen unter Wis-

5 Quelle von Zitat und Erläuterung ist die Website der Royal Society, URL: https://royalsociety. org/about-us/history/ (29.12.2020). 
senschaftlern auszuwerten, sie zu diskutieren und durch Wiederholbarkeit nachprüfbar zu machen.

Die Infragestellung und Ablösung von traditionellen Autoritäten zugunsten des Primats eines kollektiven Empirismus' erfordert neue Verlässlichkeiten und ein Management von Vertrauenswürdigkeit zwischen den kooperierenden Wissenschaftlern. ${ }^{6}$ Schließlich gilt es, die gleichen Standards im Hinblick auf die Genauigkeit der Versuchsdurchführung, die Integrität und Verlässlichkeit empirischer Augenzeugenschaft verbindlich zu teilen. Im Zuge der Schaffung dieser sozialen Voraussetzungen für eine neue Form wissenschaftlicher Rationalität rücken daher ethische Standards und nicht zuletzt auch Fragen der Moral und der Erziehung in den Fokus, die es durch neue Kriterien des Ein- und Ausschlusses abzusichern gilt. Diese neuen Voraussetzungen des kollektiven Empirismus in der Wissenschaft Mitte des 17. Jahrhunderts führen nicht nur zu einer gewissen Hybridität von Natur- und Menschenkenntnis, sondern erfordern auch eine Konkretisierung dessen, was einen vertrauenswürdigen Gentleman ausmacht. Der Wissenschaftssoziologe Steven Shapin hat in seiner Social History of Truth auf eindrucksvolle Weise verdeutlicht, dass eine Begleiterscheinung - wenn nicht gar die Voraussetzung - des scientific turn im 17. Jahrhundert das „fashioning of a new and valued character of the experimental philosopher" ist. ${ }^{\text {" }}$

Die berühmte Royal Society of London for Improving Natural Knowledge hat selbst ihren Ursprung in einem kleinen Zusammenschluss gleichgesinnter Personen, in einer geheimen privaten Vereinigung (invisible college), die die naturwissenschaftliche Forschung von den Vorgaben philosophischer Schulen lösen und $\mathrm{zu}$ einer Praxis der experimentellen Faktengenerierung transformieren will. ${ }^{8}$ Dabei sieht sie sich rasch mit sehr grundsätzlichen ethischen und gesellschaftlichen Fragestellungen konfrontiert: Gibt es überhaupt so etwas wie universelle Wahrheit, die sich über das naturwissenschaftliche Experiment ergründen lässt? Wie lassen sich wissenschaftliche Beobachtungen verlässlich absichern und wie vermag ein auf diese Weise generiertes neues Wissen Geltung zu erlangen? Sind der Rationalitätsanspruch einer faktenbasierten Wissenschaft und die Annahme einer universell geltenden göttlichen Weisheit überhaupt miteinander vereinbar? Angesichts der Pluralität und des historischen Widerstreits verschiedener, um Wahrheitsanspruch ringender, religiöser Formen und Konfessionen scheint die Versöhnung von Theismus und Experimentalwissenschaft eine ernsthafte Herausforderung. In der politischen Theorie sendet das Aufkommen der neuen rationalistischen Philosophie, die Thomas Hobbes unter dem Eindruck des Englischen

6 Da es sich ausschließlich um männliche Personen handelt, ist die Verwendung der rein männlichen Form hier angebracht.

7 Steven Shapin: A Social History of Truth. Civility and Science in Seventeenth-Century England. Chicago 2011, S. xxviii.

8 Michael A. Peters und Tina Besley: The Royal Society, the making of ,science' and the social history of truth. In: Educational Philosophy and Theory 51 (2019). H. 3, S. 227-232, hier S. 228. 
Bürgerkriegs (1642-1649) vorlegt und die fortan bei den Zeitgenossen als Inbegriff atheistischer Doktrin gilt, Schockwellen aus. ${ }^{9}$

\section{2 "Publick“ and „arcane theology“. Die religio duplex bei Ralph Cudworth}

Ein Mitglied der Royal Society, das vehement gegen diese drohende Gefahr des Atheismus - verstanden als ein Monismus oder Materialismus, der nichts außer der sichtbaren Natur anerkennt - anschreibt, ist der in Cambridge lehrende Historiker und Hebräist Ralph Cudworth (1617-1688). In seinem 1678 erschienenen Hauptwerk The True Intellectual System of the Universe versucht das Mitglied der Royal Society, atheistische Tendenzen niederzuringen, indem er einen doppelten Nachweis führt

[erstens], daß alle bekannten Religionen, auch die des polytheistischen Heidentums, an einen einzigen Gott glauben und [zweitens], daß dieser Eine durchweg als geistiges Wesen, und nicht als Materie, verstanden worden sei. ${ }^{10}$

Cudworth rekonstruiert in seinem Buch aus unzähligen Quellen und in atemberaubender Dichte und Komplexität die Theologien der Alten Welt, um den Nachweis zu führen, dass all diese Religionen im Grunde auf eine gemeinsame Urreligion zurückgehen, die allen Menschen gemein und in den Mysterien verborgen liege. ${ }^{11}$ Er führt die je besonderen Religionen von Juden, Christen und Muslimen auf eine pantheistische, geistige All-Einheit zurück, die er ins alte Ägypten datiert, und tritt den Nachweis an, dass letztendlich jede der von ihm untersuchten antiken Theologien auf einen Monotheismus dieser All-Einheit hinauslaufe, der wie ein nicht versiegender Strom unter den verschiedenen Religionen liege. Cudworth insistiert, dass schon die ,altägyptische Theologie' in eine ,publick', also eine Volkstheologie für die Masse, und eine ,arcane theology', eine Geheimtheologie für die Elite, gespalten gewesen sei. Dieser modellhaften Urform der ,Doppelreligion' der alten Ägypter folgend, wiesen nun alle antiken Religionen eine Außenseite in Gestalt der offiziellen Religion und eine Innenseite auf, die ihre geheimen Mysterien birgt. Während das einfache Volk ausschließlich den Glauben des Landes praktiziere, gelänge es einem erleseneren Kreis, in diese tieferen, hermetischen Bedeutungsschichten vorzudringen und das All-Eine zu erkennen, mit dem er gleichsam die Idee einer universalen vernünftigen Menschheitsreligion verbindet. Cudworth trifft damit eine grundlegende Unterscheidung zwischen ei-

9 „It was atheism [...] which was the heart of the controversy about Hobbes“. Samuel Mintz vermittelt in seiner Untersuchung der Reaktionen auf den Hobbes'schen Rationalismus im 17. Jahrhundert einen Eindruck jener ideologischen Erschütterungen, die dieser seinerzeit verursacht. Samuel I. Mintz: The Hunting of Leviathan. Seventeenth-Century Reactions to the Materialism and Moral Philosophy of Thomas Hobbes. Cambridge 1962, S. 45.

10 Jan Assmann: Religio duplex. Ägyptische Mysterien und europäische Aufklärung. Berlin 2010, S. 73.

11 Ralph Cudworth: The True Intellectual System of the Universe: the First Part; Wherein, All the Reason and Philosophy of Atheism is Confuted; and Its Impossibility Demonstrated. London 1678 . 
ner pantheistisch gefassten Religion aller vernunftbegabten Menschen und allen sich später herausbildenden Konfessionen, die später in den Geheimbünden der europäischen Aufklärung eine ungeahnte Wirkmacht entfalten wird. ${ }^{12}$

Dass es sich bei dieser postulierten Spaltung in eine Volks- und Elitekultur um das Produkt einer historischen "gräko-ägyptischen Konfabulation" handelt und diese darüber hinaus im Zuge ihrer Rezeption im 17. und 18. Jahrhundert von zahlreichen Missverständnissen antiker Quellen durchzogen wurde, zeichnet der Ägyptologe Jan Assmann in seinem Buch Religio duplex - ̈̈gyptische Mysterien und europäische Aufklärung mit unvergleichlicher Expertise nach. ${ }^{13}$ Indem die ,Doppelreligion' das All-Eine als eine geistig-hermetische Quintessenz aller positiven ,praktischen' Religionen bestimmt, zu der jedoch nur besonders geschulte Menschen durch die Lektüre der Natur und ein Verständnis des Zusammenspiels ihrer Kräfte vorzudringen vermögen, kann Ralph Cudworths Schrift „als locus classicus der Vorstellung von der ägyptischen religio duplex [gelten], auch wenn der Ausdruck [uns] hier selbst nicht begegnet ${ }^{\prime \prime}{ }^{14}$ Diese aus den hermetischen Schriften abgeleitete philosophia perennis - als eine sich über Zeiten und Kulturen hinweg erhaltende Weisheit - steht weder mit den Zielen und Methoden naturwissenschaftlicher Forschung noch mit der christlichen Religion im Dissens, sondern bringe beides in Einklang. Das Eine (to hen), der unsichtbare Ursprung, manifestiere sich schließlich in Allem (to pan), ist allerdings wesenhaft nicht auf diese Erscheinungsformen zu reduzieren. In der Theologie des, to hen kai to pan' wird das grundsätzlich verhüllte geistige All-Eine über die versierte Erkundung seiner diversen Erscheinungsformen in der Natur lesbar.

\section{Das unabgegoltene Potential ",alten Wissens"}

Parallel zur Fokussierung althergebrachter Mysterien mit dem Ziel der Ergründung einer sich über Zeiten und Kulturen hinweg erhaltenden Weisheit entzündet sich Mitte des 17. Jahrhunderts ein besonderes Interesse an der Zunft der Steinmetze und ihren Zunftlegenden als potentielle Hüterinnen eines solchen , alten Wissens ${ }^{\prime 15}$ Etymologisch scheint dies verheißungsvoll, schließlich bezeichnet das

12 Assmann: Religio duplex (Anm. 10). Was die Unterscheidung von ,public' und , arcane theology' betrifft, ist Cudworth sicherlich nicht der Diskursgründer. Zu erinnern ist vor allem an Augustinus, der in seinem Hauptwerk De civitate dei drei Arten der Theologie unterschieden und sich hierbei auf Varro berufen hat: die mythische oder fabulierende (die Religion der Dichter), die natürliche bzw. physische im antiken Sinne (die Religion der Philosophen) und die staatliche (die Religion des bildungsfernen Volkes); die erste geeignet für das Theater, die zweite für die Welt, die dritte für die Stadt. Es scheint sich hier um einen weit zurückreichenden Topos zu handeln, der jeweils in veränderter Form fortlebt.

13 Assmann: Religio duplex (Anm 10), S. 27.

14 Assmann: Religio duplex (Anm. 10), S. 73.

15 Auch von William Stukeley (1687-1765), Altertumsforscher und Fellow der Royal Society, ist bezeugt, dass er sich der Bruderschaft anschloss, weil er von ihr Aufschluss über die alten Mysterien erwartete. In seinem Common Place Book behauptet er, er sei der Erste gewesen, der in London seit vielen Jahren zum Freimaurer gemacht worden sei. Ders.: The Commentarys, Diary, \& Common-place Book \& Selected Letters of William Stukeley. London 1980. 
mittelenglische Wort mistere, welches dem altfranzösischen mestier entlehnt ist, sowohl eine Handwerksgilde als auch eine nur Eingeweihten zugängliche Geheimlehre. ${ }^{16}$ Die King's Masterbuilder, die vom Mittelalter bis in die Frühe Neuzeit hinein imposante gotische Kathedralen erschaffen und damit einen Baustil realisieren, der noch bis in die Gegenwart hinein als erhabene Signatur des Glaubens und der Gelehrsamkeit gilt, genießen traditionell hohes Ansehen bei Hofe, teilen mit den Herrschenden die Tafel und gelten als prestigeträchtiger Umgang.

Seit dem 13. Jahrhundert ersuchen einzelne nicht-operative Maurer um Aufnahme in die Handwerkszunft. Als so genannte Masons of Redemption kaufen sie sich aus Interesse an den spekulativen Schichten der Freimaurerei in die Gemeinschaft ein. Der Sehnsucht folgend, die Freimaurer seien im Besitz besonderer Kenntnisse der Natur und hüteten ein besonderes mathematisches und mechanisches Wissen, interessieren sich Mitte des 17. Jahrhunderts verstärkt auch nicht handwerklich tätige Bürger und Personen von Stand für die Bauzunft und ersuchen sie um Aufnahme. Die ersten verlässlich belegten und bekanntesten Acceptions von Gentleman Masons sind die vielzitierten Aufnahmen von Robert Moray 1641 in Edinburgh und des Gelehrten Elias Ashmole 1646 in Warrington, Lancashire. ${ }^{17}$ In den 1680er Jahren findet die Society of Free-Masons bereits Erwähnung in verschiedenen Publikationen. Randle Holme the Third schreibt in seinem Buch Academie of Armory (1688) auf den Besuch eines Logentreffens in Chester bezugnehmend: „Ich kann diese Bruderschaft aufgrund ihrer Antiquität nur wertschätzen; dies umso mehr, als ich selbst ein Mitglied dieser Gesellschaft bin, die sich die Freimaurer nennt. ${ }^{" 18}$ Robert Plot beschreibt in seiner Natural History of Straffordshire (1686) die Aufnahme von „hervorragenden Männern“ (men of most eminent quality) in die Society of Free-Masons als eine im ganzen Land verbreite Praxis. ${ }^{19}$ John Aubreys Natural History of Wiltshire (1691) bestätigt die Bekanntheit der angenommenen Freimaurerei mit einem ergänzenden Hinweis auf die einsetzende internationale Verbreitung. ${ }^{20}$ Für die 90er Jahre des 17. Jahrhunderts häufen sich schließlich die

16 Dass der Begriff, wie bei Knoop und Jones zu lesen, zwei unterschiedliche Entwicklungsstufen implizieren soll, in denen die Geheimlehre der Handwerksgilde chronologisch nachgeordnet sei, ist noch der Gould'schen historischen Unterscheidung einer operativen und einer spekulativen Form der Freimaurerei geschuldet, die 1986 von John Hamill überzeugend widerlegt wurde. Douglas Knoop und G. P. Jones: The Genesis of Freemasonry. Manchester 1948, S. 41; John Hamill: The Craft. A History of English Freemasonry. Wellingborough 1986, S. $18 \mathrm{ff}$.

17 Siehe für Robert Moray David Stevenson: The Origins of Freemasonry. Scotland's Century 1590-1710. Cambridge 1988, S. 167 und für Elias Ashmole John Hamill: The Craft (Anm. 16), S. 30ff. sowie die abgedruckten Tagebucheinträge in den Early Masonic Pamphlets. Hg. von Douglas Knoop, G. P. Jones und Douglas Hamer. London 1978 (Reprint der Ausgabe London 1944), S. 40 und 42.

18 „I cannot but honour the Fellowship of the Masons because of its antiquity; and the more as being [myself] a member of that Society called Free-Masons.“ Zitiert nach Hamill: The Craft (Anm. 16), S. 33f.

19 Robert Plot: The Natural History of Staffordshire. Oxford 1686, S. 316.

20 Ebd., S.35f. Hamills Angaben sind insofern zu korrigieren, als dass er John Aubreys Buch mit dem Titel Natural History of Straffordshire angibt. Tatsächlich wurde das Manuskript 1691 
Nachweise nicht-operativer Logen. James Anderson nennt in seiner Neuauflage der Konstitutionen (1738) für das Jahr 1693 bereits acht in London arbeitende Logen, die sich nicht mehr allein aus Handwerkern der Zunft zusammensetzen. ${ }^{21}$

Ein Zunftmitglied, welches das Initiationsverhör besteht und den rituellen Schwur ablegt, verpflichtet sich zu einer Geheimhaltung, die dem operativen Handwerk zunächst einmal der Sicherung ganz pragmatischer Interessen diente. Im Fokus standen der urheberrechtliche Schutz bautechnischen Wissens, von Zeichnungen und Entwürfen, wirtschaftliche und arbeitsrechtliche Interessen, wie die Verlässlichkeit von Absprachen zwischen den Gewerken, sowie die soziale Absicherung der Mitglieder durch die Zunftgemeinschaft und eine gerechte Entlohnung von Arbeit. Knoop und Jones verweisen auf direkte Zusammenhänge zwischen englischen Versammlungen, Handwerksgilden und Compagnien sowie schottischen Lodges und Corporations und der Freimaurerei. Obschon differierende Organisationstypen mit unterschiedlichen Einflusssphären, teilen sie zentrale Eigenschaften und Zwecke: Sie dienen der Sicherung des Gewerbemonopols und der Vereinheitlichung der Geschäftsbedingungen bei Bauvorhaben, indem sie den Ausbildungsstandard anhand von Eignungsprüfungen kontrollieren und die entsprechenden Werkzeichen und Urkunden vergeben. Die gewerblichen Körperschaften der Maurer bemühen sich um die Erläuterung der Gewohnheitsrechte des Handwerks sowie ihre konstitutionelle Fixierung und Durchsetzung anhand spezifischer Sanktionsmaßnahmen. Sie regeln die Lehr- und Arbeitsverhältnisse, schlichten Streitigkeiten innerhalb der Zunft und bieten ihren Mitgliedern eine Art Sozialversicherung auf der Basis erhobener Gebühren und Geldbußen, welche zugunsten notleidender Genossen reinvestiert werden. Nicht zuletzt sind die handwerklichen Zusammenschlüsse Orte der geselligen Zusammenkunft, die einen fairen und kameradschaftlichen Umgang sowie den Gottesdienst unter den Mitgliedern fördern und auf Kosten neuer Bewerber gemeinschaftliche Feste ausrichten. Die alten Konstitutionspapiere, welche die Gewohnheitsrechte innerhalb der Zunft fixieren und seit spätestens dem 14. Jahrhundert in schriftlicher Form vorliegen, beinhalten einerseits einen Kodex des gewerblichen, andererseits aber auch des sittlichen Verhaltens. Neben den Besonderen Pflichten, einer gewerblichen Handwerksordnung der Steinmetzenzunft (mistery regulations), regeln Allgemeine Pflichten der Bruderschaft (fraternity regulations) die sozialen und religiösen Tätigkeiten der Gilde.

Tatsächlich besitzt die Zunft der Freestone Masons neben dem gemeinsamen Gebet, der Verlesung der Zunftgeschichte, den Pflichten ihrer Zunft und einer Vereidigungsformel im 14. Jahrhundert vermutlich keine weiteren Aufnahmezeremonien, die sich grundsätzlich von denen anderer Zünfte unterscheiden. Rituale und Initiationen, verbunden mit mythischen Erzählungen, die das Alter und das

zunächst unter dem Titel Memoirs of Naturall Remarques in the Count of Whiltshire veröffentlicht. Unter dem von Hamill genannten Namen wurde es erst 1847 publiziert. Siehe Early Masonic Pamphlets (Anm. 17), S. 41f.

21 Ebd., S. 37. 
spezifische Wissen der verschiedenen Berufsstände betonen und mit religiösen und moralischen Konzepten verbunden sind, sowie die Forderung der Geheimhaltung bestimmter Arbeitstechniken sind nahezu allen mittelalterlichen Zünften und Gilden gemein. Und dennoch weckt gerade die Bruderschaft der Steinmetze das Interesse von Männern, die selbst nicht im Bauhandwerk tätig sind, und wird zur Plattform für eine außergewöhnliche Erkenntnissuche sowie die Umgestaltung einer gewohnheitsrechtlichen bzw. konstitutionellen, gewerblichen Sittenlehre zu einer symbolgeleiteten, systematischen Einübung spezifischer ethischer Ansprüche an sich selbst.

Dafür scheint es mehrere Gründe zu geben: Wenn auch nicht einzigartig, so war doch bereits im Mittelalter die in den Alten Pflichten fixierte, mythische Herleitung der Steinmetzkunst außergewöhnlich umfangreich und ihre moralische Aufladung ausgeprägter als die anderer Zünfte..$^{22}$ Ihre Konstitutionsmanuskripte werden von einer Erzählung eingeleitet, welche die Freimaurerei als eine der sieben freien Künste vorstellt und sie der Geometrie als wichtigste dieser sieben Künste, da sie allen anderen zugrunde liege, gleichstellt. Die Bruderschaft wird in die biblische Geschichte eingewoben und Euklid zum Protagonisten ihres Herkunftsmythos' gemacht. ${ }^{23}$ Der Legende nach wurden alle Gewerke von den Söhnen Lamechs gegründet, welcher im Buch Genesis Erwähnung findet. Sein ältester Sohn Jabal erfand die Geometrie. Aus Angst, Gott würde seine und die Sünden seiner Brüder bestrafen, meißelten sie ihre Entdeckungen in zwei Steinsäulen, die Feuer und Wasser trotzen würden. Nach der Sintflut wurde eine dieser Säulen von einem Urenkel Noahs gefunden, dem ,großen Hermarius', besser bekannt als Hermes Trismegistos. Hermes Trismegistos lehrte die Menschen die Wissenschaften und sorgte für ihre Verbreitung. So fand die Geometrie Verwendung beim Bau des Turms zu Babel und König Nimrod selbst wurde Maurer und formulierte als ihr Patron erste verbindliche Pflichten für die Zunft.

In Ägypten verbreiteten Abraham und seine Frau Sarah das Wissen der sieben Wissenschaften. Euklid weihte als ihr begabtester Schüler viele weitere junge Männer in die Kunst der Geometrie ein, auf dass sie in die Welt ziehen und sich mit dem Entwurf und dem Bau von Gebäuden verdingen konnten. Euklid setzte zudem Geometrie und Bauhandwerk gleich und verfasste auf der Basis der Nimrod'schen Pflichten ein neues, ergänztes Buch für die ,Maissonrie‘. Im Heiligen Land rief König David 80.000 Handwerker für den Bau eines Tempels ins Land, welcher später unter seinem Sohn Salomon fertig gestellt wurde. Bauleute, die an der Errichtung des Salomonischen Tempels beteiligt waren, trugen die Maurerei nach Europa. Über Frankreich erreicht sie in Person St. Albans das englische Königreich, wo sie nach einigen Wirren von King Athelstan und später seinem Sohn Edwin Schutz und besondere Förderung erfuhr.

22 Stevenson: The Origins of Freemasonry (Anm. 17), S. 5f.

23 In dieser Zusammenstellung folge ich der exemplarischen Beschreibung der Inhalte dieser Old Charges aus dem Kilwinning Manuscripts aus der Mitte des 17. Jahrhunderts von David Stephenson. Ders.: The Origins of Freemasonry (Anm. 17), S. 19ff. 
Diese legendären Ursprünge, die in früheste biblische Zeiten zurückreichen und eine lückenlose Verbindung in die Gegenwart nachweisen sollen, haben den Zweck, die Antiquität der Handwerksvereinigung zu bezeugen und ähnlich den Freibriefen oder Privilegienurkunden anderer Handwerkszünfte und Gilden den erforderlichen Legitimitätsnachweis ihrer Zunft zu erbringen. Es gibt zahlreiche Fassungen und Revisionen dieser Geschichte, aus denen sich später die elaborierten, symbolischen Zeremonien und Rituale der angenommenen Freimaurer speisen werden. Die in den Zunftmythen enthaltenen Verweise auf die Existenz von Logen seit Anbeginn der Welt und die legendären Wurzeln der Zunft als Hüterin einer verlorenen adamitischen Sprache der Erkenntnis erwecken den Anschein einer Gemeinschaft, die im Besitz eines exklusiven ,ältesten Wissens‘ sein könnte.

Die Anzahl personeller Überschneidungen zwischen der Royal Society of London und der Bruderschaft der Free and Accepted Masons ist beeindruckend, darunter die bereits erwähnten frühesten Mitglieder Robert Moray (1608/1609-1673) und Elias Ashmole (1617-1692), die Mitgliedschaft Christopher Wrens (1632-1722) ist nicht ausreichend bezeugt, aber als wahrscheinlich anzusehen, Alexander Bruce, Second Earl of Kincardine (1629-1680), John Theophilus Desaguliers (1683-1744), William Stukeley (1687-1765), Martin Folkes (1690-1754), Martin Clare (1690-1751) und John Second Duke von Montagu (1690-1749), dem das Konstitutionenbuch der Free and Accepted Masons von 1723 gewidmet ist. Während Robert Moray und Elias Ashmole von der Freimaurerforschung als die ersten bekannten Gentleman Masons ins Feld geführt werden, gilt John Theophilus Desaguliers als einer der Gründungsväter der modernen Freimaurerei. Desaguliers hat zahlreiche alte freimaurerische Manuskripte und Old Charges gesammelt, bevor James Anderson von der Großloge beauftragt wurde, die Neuen Konstitutionen (1723) zusammenzustellen. ${ }^{24}$ Mit der Aufnahme der Gentleman Masons finden viele neue Elemente Eingang in die Freimaurerei, die Ausdruck eben dieser Suche nach tieferer mythischer Weisheit sind und zusätzliche spekulative Bedeutungsebenen hinzufügen, die ihren Interessen und Bedürfnissen angepasst sind.

\section{4 „Conscience“ and „freewill“. Cudworth's Umdeutung der göttlichen Vorsehung als limitierter Möglichkeitsraum verschiedener Zukünfte}

Im Hinblick auf eine kulturgeschichtliche Engführung einer neuen Wissenschaftskultur und deren Wirkung auf das kulturelle Leben des 17. und 18. Jahrhunderts, insbesondere auf die Ausbreitung und Strahlkraft der Bruderschaft der Freimaurer, lag in der Forschung bislang der Fokus auf Isaac Newton (1643-1727) und seinem 1686 fertiggestellten Hauptwerk, der Philosophiae Naturalis Principia Mathematica, welches durch die Freimaurer John Theophilus Desaguliers und

24 In ihrer Einleitung in die Early Masonic Catechisms (Anm.3) betonen Douglas Knoop, G. P. Jones und Douglas Hamer die langsame, über mehrere Generationen andauernde Transition der Freimaurerei von einer operativen Zunft zu einer spekulativen Vereinigung. Desaguliers sei mit Verweis auf Murray Lyon weniger der Erfinder als ein wichtiger „co-fabricator and pioneer of the system of symbolical masonry" (ebd., S. 22). 
William Stukeley eine enorme Popularisierung erfuhr und Eingang in unzählige Logenreden fand..$^{25}$ Der vorliegende Beitrag nimmt die wissensgeschichtlichen Fäden an anderer, mit dem späteren Einfluss Newtons aber durchaus vereinbarer, Stelle auf. So dokumentieren Newtons Notizen Quaestiones quaedam philosophicae, die er während seines Studiums anfertigte, seine Beschäftigung mit den platonisch-hermetischen Positionen Henry Mores. Das ist nicht so erstaunlich, denn zu Studienzeiten Newtons an der Universität Cambridge hatten die Cambridge Platonists im wissenschaftlichen Diskurs der Zeit ein gewisses Gewicht. Newton, der mit Spencer hebräische Studien trieb und Maimonides las, nahm in diesem Kontext auch Cudworths Schriften eingehend zur Kenntnis und legte zu dessen True Intellectual System umfangreiche Exzerpte an. ${ }^{26}$ Ob Ralph Cudworth jemals selbst Interesse an der Bruderschaft der Maurer gezeigt oder sich bei Mitgliedern der Royal Society über sie informiert hat, ist nicht belegt. Die ideengeschichtlichen Linien, die sich zwischen seinen Schriften und der Formierung der Gemeinschaft der Freien und Angenommenen Freimaurer auftun, lassen in der hier beschriebenen Konstellation die Vermutung zu, dass seine Gedanken zur religio duplex und zur praktischen Ethik den Free and Accepted Masons in mehrerlei Hinsicht als Inspirationsquelle dienten. ${ }^{27}$

1662, im Jahre seiner Aufnahme in die Royal Society, nimmt Ralph Cudworth die Arbeit an seinem Treatise Concerning Eternal and Immutable Morality auf. Obwohl das Werk erst 1731, also lange nach Cudworths Tod, auf Veranlassung seines Enkels Francis Cudworth Masham im Druck erscheint, ist davon auszugehen, dass es wie auch das Treatise of Freewill und andere seiner unveröffentlichten Schriften zu Lebzeiten unter Kollegen und Schülern in Manuskriptform kursierte. ${ }^{28}$ Darin verortet Cudworth den Ursprung der Moral, die er als das unendliche, vom menschlichen Geist und der physischen Welt unabhängig existierende ,Gute' de-

25 Siehe hierzu Margaret C. Jacobs Publikationen: The Radical Enlightenment. Pantheists, Freemasons and Republicans. London 1981; Living the Enlightenment. Freemasonry and Politics in Eighteenth-Century Europe. New York 1991 und gem. mit Stewart Larry: Practical Matter. Newton's Science in the Service of Industry and Empire, 1687-1851. Cambridge, MA 2004, bes. S. 22-24; Paul Elliott und Stephen Daniels: The ,school of true, useful and universal science'? Freemasonry, natural philosophy and scientific culture in eighteenth-century England. In: The British Journal for the History of Science 39 (2006). H. 2, S. $207-229$.

26 Assmann: Religio duplex (Anm. 10), S. $72 \mathrm{f}$.

27 Die Cambridge Plantonists und ihre Rolle im Rahmen der europäischen Aufklärung rückt derzeit verstärkt in den Fokus der Forschung. Insa Kringler untersucht in ihrer Dissertationsschrift die Funktion, die den Argumenten der Cambridge Platonists angesichts des erstarkenden Weltbeschreibungsparadigmas des Mechanismus und der gefürchteten Konsequenz des Atheismus zukam. Die Studie macht deutlich, wie ertragreich Topik und Konstellationsforschung auch für die Untersuchung des komplexen Transfergeschehens zwischen den im vorliegenden Beitrag verhandelten Gruppen und ihren Denkfiguren eingesetzt werden könnten. Dies.: Die gerettete Welt. Zur Rezeption des Cambridger Platonismus in der europäischen Aufklärung des 18. Jahrhunderts. Berlin, Boston 2013.

28 Ralph Cudworth: A Treatise Concerning Eternal and Immutable Morality. With a Treatise of Freewill. Cambridge Texts in the History of Philosophy. Hg. und mit einer Einleitung versehen von Sarah Hutton. Cambridge 1996, S. xii und xxviii. 
finiert, in der absolut gesetzten göttlichen Wahrheit und Weisheit. Diese göttlichen Prinzipien der Tugend seien in der menschlichen Seele von Geburt angelegt und der Mensch folge dieser Tendenz in natürlicher Weise. Er sei deshalb nicht darauf angewiesen, sein Handeln ausschließlich an Regeln auszurichten, die ihm von außen auferlegt werden, und Pflicht und Gehorsam zum einzig akzeptablen Maßstab moralischen Handelns zu machen. Grundlegend für diese einschneidende Aufwertung menschlicher Handlungs- und Entscheidungskompetenz gegenüber der seinerzeit dominanten calvinistischen Prädestinationslehre ist die Verlagerung zentraler Grundlagen und Maßstäbe individueller Handlungsentscheidungen in das Innere des Individuums. Für die Beschreibung der kognitiven Prozesse, die mit der freien Willensbildung verbunden sind, und im Versuch, „den freien menschlichen Willen mit der göttlichen Omnipotenz und Omnipräsenz in Einklang zu bringen“, verwendet Ralph Cudworth erstmals den Begriff conscience. ${ }^{29}$

Als Voraussetzungen dafür, den eigenen freien Willen als koordinierende Fakultät des Selbst einzusetzen und als moralischer Akteur selbstverantwortlich zu handeln, zählt Cudworth, zum einen, die grundlegende Fähigkeit des Menschen, seine Handlungen über das, was er , animal sense' nennt, zu erheben, die eigene Position in der Welt bewusst zu reflektieren und auf dieser Basis eigenständige Handlungsentscheidungen zu treffen. ${ }^{30}$ Zum anderen bedarf es des Freiraums, aus einer gewissen Bandbreite möglicher Spielformen der göttlichen Vorsehung über den Verlauf zukünftiger Ereignisse (mit)entscheiden zu können. ${ }^{31}$ Cudworth generiert diesen notwendigen Handlungsspielraum für selbstverantwortliches Handeln durch die Umdefinition der göttlichen Vorsehung zu einer Vorsehung nicht nur einer, sondern verschiedener möglicher Zukünfte, die Cudworth als „bewegliche Vorsehung" (moveable providence) einführt. ${ }^{32}$ Zur anschaulichen Vermittlung dieser platonischen Vorstellung, dass die göttliche Vorsehung zwar die Weltordnung überwacht, aber nicht das Einzelschicksal lenkt, wählt er - Platons Theaterskepsis zum Trotz - die Theatermetapher:

The Dramaticall Poem of the world is wonderfull and extraordinary for it is such as if we should suppose the Histrionick Actors to pronounce something of their own besides what the Poet hath written down the Poem itself being

29 "At the heart of Cudworth's rejection of Calvinism is the dilemma over whether God is understood primarily in terms of will or justice. In this fleshing-out of the power of consciousness Cudworth moves from an instrumental account of the working of the human mind towards an account of human consciousness that is intrinsic to his definition of human agency. [...] although Cudworth's initial account of consciousness appears to be applying and softening aspects of Cartesian dualism against the limitations of Hobbist material determinism, it is in reality part of a much larger and longer debate seeking to reconcile the freewill of humankind with the omnipotent and omnipresent power of God." Benjamin Carter: Ralph Cudworth and the theological origins of consciousness. In: History of the Human Sciences 23 (2010). H. 3, S. 29-47, hier S. 29.

30 Cudworth: True Intellectual System of the Universe (Anm. 11), S. 137.

31 Carter: Ralph Cudworth (Anm. 29), S. 31.

32 Ebd. 
incompleat and having certain void Spaces left in it here and there purposly by the Poet for the Actors themselves to Supply and fill up to which the Poet forknowing what every one will utter or accommodating what he adds thereunto afterwards makes up one coherent and intire Plot of all, so that the Actors are not meer actors of Parts \& Speakers of words given them but partiall Poets themselves, the grand Poet or Dramatist allways fore knowing what every Actor will here and there interpose of himself and still accomodating that that follows which is his own so that it shall aptly agree with what was interpreted by them thereby connecting all into one inntire Plot one coherent dramatical Poem. ${ }^{33}$

Cudworth illustriert hier das menschliche Handeln unter göttlicher Vorsehung als gemeinsame Hervorbringung eines dramatischen Werkes im kunstvollen Wechselspiel zwischen einem Autor und den am Stück beteiligten Akteuren auf der Bühne. Der Dramatiker habe das Stück zwar gescripted, belasse den Spielern aber bewusst Freiräume im Hinblick auf die konkrete Ausgestaltung ihrer Rollen. Da der Autor als auktorialer Erzähler sämtliche mögliche Formen der Rollengestaltung durch die Schauspieler vorhersieht, werden diese - egal welche Entscheidungen sie selbst treffen oder welche der zur Verfügung stehenden Handlungsoptionen sie wählen werden - stets zur Kohärenz des Gesamtplots beitragen.

Dieser Individualisierungsschub eines nach freiem Willen agierenden Menschen, der nach Maßgabe seines Gewissens eigene Entscheidungen zu treffen vermag, ohne dabei notwendigerweise gegen die göttliche Vorsehung zu verstoßen, eröffnet gleichsam die Möglichkeit, die eigene Person, welche sich in seinen Handlungsweisen und seiner Lebensführung ausdrücke, ${ }^{34} \mathrm{zu}$ konturieren:

$[T]$ here is a contingent liberty, and [...] man have something in their own power, add something of their own, and so they can change themselves and determine themselves, and all things are not linked and tied in a fatal adamantine chain of causes. ${ }^{35}$

In dieser Willens- und Gewissensfreiheit lägen die Spielräume eines „,self-promoting, self-improving power, in good, and also a self-conserving power “36 sowie die Möglichkeit der Perfektionierung der Seele durch eine gute Lebensführung.

Aus den gedruckten Werken und unveröffentlichten Manuskripten destilliert der australische Philosoph John Passmore die von Cudworth sehr verstreut entwickelten Maßgaben für die Gestaltung eines solchen "guten Lebens“:37 (1) ein

33 Cudworth: Additional MS 4980, fol. 206. Zitiert nach Carter: Ralph Cudworth (Anm. 29), S. 42.

$34,[\mathrm{I}] \mathrm{t}$ is ,Action that gives denomination to a Persone ".. Cudworth: Additional MS 4981, fol. 16. Zitiert nach Sarah Hutton, die in ihrer Einführung zum Treatise Concerning Eternal and Immutable Morality auf den hohen Stellenwert der unpublizierten Schriften für die praktischen und sozialen Aspekte Cudworths ethischer Überlegungen verweist (Anm. 28), S. xxvii.

35 Cudworth: A Treatise of Freewill (Anm. 28), Kap. III, S. 160-163, hier S. 163.

36 Ebd., S. 185.

37 John A. Passmore: Ralph Cudworth. Cambridge 2013, Kap. VI „The Good Life“, S. 68-78. Passmore bezieht in seine Interpretation eine unter der Nr. 4983 verzeichnete Manuskriptsamm- 
von Spontaneität, Freiheit und Freiwilligkeit geprägtes selbstbewusstes Handeln ohne Unterwürfigkeit auf der Grundlage eines von göttlicher Tugend geprägten Handlungsdispositivs, (2) Rationalität, verstanden als praktische Weisheit und Fähigkeit, eine Situation richtig einschätzen und in ihr angemessen zu agieren, (3) Unparteilichkeit und Gemeinwohl (impartiality and disinterestedness) als Überwindung der reinen Selbstbezogenheit zugunsten einer Inblicknahme des gesellschaftlichen Ganzen aus dem Wissen heraus, dass eine Gesellschaft auf der Basis eines vitalen Egoismus von Einzelakteuren auf lange Sicht nicht lebensfähig wäre, (4) Ordnungsliebe, als ein der juridischen Absicherung des gesellschaftlichen Lebens komplementär zur Seite gestelltes System sich wechselseitig bekräftigender Tugenden, (5) Schönheit oder Harmonie, die sich in Proportion, Symmetrie und Angemessenheit ausdrücken und damit auf die Unendlichkeit verweisen und - nicht zuletzt (6) Kreativität im Sinne einer bewussten Gestaltung der eigenen Lebensführung, als Weg zu diesseitigem Glück und zu Zufriedenheit.

\section{John Locke und seine Schülerin Lady Damaris Masham, Cudworth's Tochter}

Zeitsprung: Im September 1753 publiziert das Gentleman's Magazine ein bis dahin unbekanntes, auf den 6. Mai 1696 datiertes Schreiben des englischen Philosophen John Locke (1632-1704), das nicht nur in Freimaurerkreisen Aufsehen erregt. Es ist an seinen Freund und Förderer Thomas Earl of Pembroke gerichtet, welchem er sieben Jahre zuvor bereits sein berühmtes erkenntnis- und wissenschaftstheoretisches Werk An Essay Concerning Human Understanding (1689) gewidmet hatte. Darin präsentiert er eine Kopie der Abschrift einer 260 Jahre alten Handschrift König Heinrichs VI., welche einen frühen freimaurerischen Katechismus enthält. ${ }^{38}$ Locke verleiht in einem Begleitschreiben der Vermutung Ausdruck, dass es sich bei dem Text mit dem Titel Certayne Questyons, with Awnsweres to the same, concernyne the Mystery of Maconye um ein freimaurerisches Prüfungsgespräch handelt, welchem - möglicherweise in Anwesenheit des Königs, von dem es hieß, er sei selbst Mitglied und Protektor der Bruderschaft der Maurer gewesen - ein neues Mitglied unterzogen wurde. Die erste Abschrift des Originals sei von John Leyland, einem Antiquar Heinrichs Vlll., um 1536 angefertigt worden, welcher im

lung aus der British Library ein, deren Zuschreibung Sarah Hutton in ihrer Einleitung zum Treatise Concerning Eternal and Immutable Morality anzweifelt (Anm. 28, S. x). Auch im Research Portal forScholarship on CambridgePlatonism, URL:https:/cprg.hypotheses.org/bibliography/ ralph-cudworth (08.01.2021) wird die Manuskriptsammlung gemeinsam mit zwei anderen, also alle drei British Library Additional MSS 4983-5, als „Works formerly attributed to Cudworth, including notes on the idea of eternal torments, and extracts from various authors" ausgewiesen. Dieser korrigierten Zuschreibung wurde bei der Verwendung von Passmores Zusammenfassung für den vorliegenden Beitrag Rechnung getragen.

38 Die Zeitschrift gibt an, ein 1748 in Frankfurt gedrucktes, kleines Pamphlet von 12 Seiten in Oktavfomat mit dem Titel Ein Brief Von dem Beruehmten Herrn [sic!] Herrn Johann Locke, betreffend die Frey-Maurerey. So auf einem Schrieb-Tisch eines verstorbnen Bruders ist gefunden worden, abzudrucken. Gentleman's Magazine xxiii, September 1753, S. 417-421 (anonym veröffentlicht). 
Zuge der Klosterauflösungen mit der Aufgabe betraut war, wertvolle Bücher und Aufzeichnungen herauszusuchen und für die Nachwelt zu retten. Dieses Manuskript wiederum habe er, John Locke, auf Wunsch des Lord of Pembroke in der Bodleian Library aufgespürt und mit zahlreichen erläuternden und kritischen Anmerkungen versehen.

Durch diese Beschäftigung habe er nicht nur seine Schülerin Lady Masham, der er mit seinen Annotationen die Lektüre erleichtern wollte, in Aufruhr versetzt - sie sei „für die Freimaurerei so eingenommen [...], dass sie sich nun mehr denn je wünschte, ein Mann zu sein, um in die Bruderschaft aufgenommen werden zu können“. Locke behauptet, das Manuskript habe auch sein eigenes Interesse an der Vereinigung und ihren Mysterien geweckt. Er schließt seinen Brief mit den Worten, er wisse nicht, welche Auswirkungen die Durchsicht dieses alten Dokuments auf seine Lordschaft habe; er aber könne seinethalben nicht verleumden, dass es seine Neugier in solch einem Maße geweckt habe, dass er nun überzeugt sei, selbst der Vereinigung beitreten zu wollen. Er sei fest entschlossen, die Bruderschaft im Laufe seines nächsten Aufenthaltes in London - und er fügt hinzu, dass dies bald sein würde - um Aufnahme zu ersuchen. Ein tatsächlicher Logenbeitritt John Lockes ist jedoch nicht belegt.

Das Leland-Locke-Manuskript, dessen Authentizität mittlerweile hinlänglich angezweifelt und sicherlich als ein Ringen um Prestige und Ansehen einzustufen ist ${ }^{39}$ stellt den Versuch dar, eine philosophiegeschichtliche Verbindung sowohl zur Royal Society als auch zu den Cambridge Platonists herzustellen. Nicht ganz zufällig setzt es eine enthusiasmierte Lady Damaris Cudworth Masham (16591708) in Szene. Die philosophisch gebildete Tochter Ralph Cudworths verbindet eine enge Freundschaft und ein langjähriger philosophischer Austausch mit John Locke, in ihrem Haus verkehrt auch Isaac Newton. Sie gilt nicht nur als ausgewiesene Kennerin und hartnäckige Verteidigerin der Schriften ihres Vaters, sondern widmet sich selbst intensiv Fragen der praktischen Ethik. ${ }^{40}$ Ihrer Überzeugung nach gälte es (auch für Frauen), das ,,autoritäre Handbuch-Wissen für tugendhaftes Handeln“ gegen ein Verständnis der grundlegenden Prinzipien der Vernunft und eine vernunftbegleitete, nicht-dogmatische Religiosität auszutauschen und so eine tiefere Einsicht und Verankerung moralischer Grundsätze zu erlangen. Nur über die Fähigkeit zu solch einer tieferen Einsicht gelänge es einer Person auf

39 James Halliwell-Phillipps moniert in seiner Geschichte der Freimaurerei, dass das Manuskript seit seiner Publikation im Gentleman's Magazine immer wieder kritiklos abgedruckt wurde, obgleich es so leicht als Fälschung auszumachen sei. (James Orchard Halliwell-Phillipps: Early History of Freemasonry in England. London 1840). Mackey ordnet das Manuskript nach genauer Prüfung aus gleichem Grund den freimaurerischen Legenden zu, die das Ansehen der Bruderschaft steigern und historische Wurzeln kräftigen sollen. Albert G. Mackey: The History of Freemasonry. Bd.1: Prehistoric Masonry. Chapter XLIV „The Leland Manuscript". New York 1898.

40 Sarah Hutton: Damaris Cudworth, Lady Masham. Between Platonism and Enlightenment. In: The British Journal for the History of Philosophy 1 (1993), S. 29-54; Kringler: Die gerettete Welt (Anm. 27), S. 120-128. 
lange Sicht, selbstständig moralisch zu handeln. ${ }^{41}$ Der auf das Jahr 1696 dokumentierte Fund des vermeintlich von John Locke kommentierten historischen Manuskripts soll zum einen die historischen Wurzeln der Bruderschaft kräftigen, zum anderen liest es sich zum Zeitpunkt seiner Publikation in der Mitte des 18. Jahrhunderts bereits wie eine Werbeannonce für die ,moderne' Freimauerei und ein Loblied auf die gelungene praktische Umsetzung einer vernunftbasierten Theologie im Sinne Cudworths sowie eine praktische Ethik, die bei Locke schließlich ihre Fortsetzung gefunden hat.

\section{Exoterische Freimütigkeit und esoterische Codierungen als performatives Paradoxon}

[F]rom the mysterious knowledge of the Egyptians that philosopher [Iamblicus] drew the system of his symbolical learning and instructive tenets, seeing that the principles and wise doctrines of his nation were ever kept secret among themselves, [...] that every disciple admitted to their wise and scientific mysteries, was bound in the same solemn manner to conceal much mysteries from the vulgar, or those whose ideas were not sufficiently exalted to receive them. ${ }^{42}$

In freimaurerischen Magazinen werden Ende des 18. Jahrhunderts regelmäßig Verteidigungen der freimaurerischen Geheimhaltungspraxis publiziert, die stets mit einer ungebrochenen Traditionslinie zu altägyptischen Mysterienkulten argumentieren. Die Inhalte dieser Mysterien seien seit jeher dem unwürdigen ,profanen' Auge entzogen. Derselben hermetischen Tradition verpflichtet unterscheidet Cudworth in seinem True Intellectual System of the Universe zwei Ebenen menschlicher Erkenntnis und Handlungskompetenz - zum einen die, die er als ,animal sense' bezeichnet (s. o.), und zum anderen die Fähigkeit zur Führung eines ,conscious or self-perceptive life'. ${ }^{43}$ Während er unter dem , animal sense' alle basaleren Bedürfnisse und Triebe des Menschen subsummiert, fungiert das Bewusstsein in dieser dualistischen Einteilung als zentraler Mechanismus, der es dem Menschen ermöglicht, sich selbst als Träger einer höheren Bewusstseinsstufe wahrzunehmen und ein selbstreflektiertes Leben zu führen. ${ }^{44}$ Die Welt sei das Werk eines intelligenten Schöpfers, welcher den menschlichen Geist mit den Konzepten (noemata) ausgestattet hat, um ihre Struktur zu durchdringen und die eigene Rolle darin zu reflektieren und mitzubestimmen. Dazu sei jedoch nicht jeder Mensch gleichermaßen berufen. Cudworth illustriert diese Trennlinie im Treatise Concerning Eternal and Immutable Morality anhand der Fähigkeit zur Durchdringung verschiedener Darstellungsformen wie beispielsweise der Schrift, die der illiterate Geist lediglich als Tinte auf dem Papier sieht, den Inhalt der Zeichen aber nicht

41 Hutton: Damaris Cudworth (Anm. 40), S. 38.

42 Anonymous: The Secrecy Imposed on the Mysteries of Freemasonry. In: The Freemasons' Magazine. June 1, 1796, S. 24.

43 Cudworth: True Intellectual System of the Universe (Anm. 11), S. 137.

44 Carter: Ralph Cudworth (Anm. 29), S. 30. 
erfasst. Als weitere Beispiele fungieren die Musik, die nur dem versierten Hörer mehr als eine Serie aufeinanderfolgender Geräusche ist und seine Harmonie aus der besonderen Gestaltung von Tonabfolgen gewinnt, und - nicht zuletzt - die Baumetapher. ${ }^{45}$ Wie die Welt das Produkt eines schöpferischen Geistes sei, so trage auch ein Gebäude die Signatur eines kunstfertigen Architekten. Aber nur Betrachtern mit einem besonders wachen Geist gelänge es, die Schönheit eines Baus zu erkennen, die in seiner konkreten Form, seinen Maßen und der strukturellen Ausgewogenheit gründet. Nur ein versierter Betrachter besitze die Fähigkeit, diese Prinzipien zu durchdringen, als essentielle göttliche Prinzipien zu antizipieren und $\mathrm{zu}$ verinnerlichen.

Wahrnehmung sei, so Cudworth, niemals als passiver Akt zu verstehen, denn der Geist sei stets an der Aufnahme und Verarbeitung der Eindrücke beteiligt. ${ }^{46}$ Aus seiner Annahme, dass diese Lese- und Dechiffrierkompetenz jedoch nicht bei allen Menschen gleichermaßen ausgebildet und daher nicht jeder gleichermaßen in der Lage sei, in den Signaturen des Schöpfers zu lesen, leite sich auch der exklusive Zugang zur , arcane theology‘ als eine Geheimtheologie für eine gesellschaftliche Elite ab.

Dass Cudworth die Architektur als Beispiel wählt, ist für unseren Kontext besonders aufschlussreich, denn die Geometrie ist ja die vorherrschende Wissenschaft unter den liberalen Künsten, die dem Freimaurer tiefere Einsichten in die göttliche Schöpfung vermittelt, mit dem Ziel, aus den Funktionsweisen Prinzipien und Praktiken für die Formung der eigenen Person und die Gestaltung einer funktionierenden Gesellschaft abzuleiten. Für die Aufnahme in die Bruderschaft der Freimaurer wird nach Vorbild der operativen Bauzunft genau diese persönliche Anlage und Kompetenz in einer rituellen Wechselrede, dem sogenannten Catechism geprüft und es werden gleichsam erste esoterische Deutungsangebote für den heterotopischen Innenraum und die Arbeitsmittel, die dieser für die Ergründung freimaurerischer Mysterien bereithält, unterbreitet.

Davon ausgehend, dass es zwei Ebenen des Zeichenprozesses gibt, ist der ,Profane' lediglich in der Lage, die Oberfläche zu sehen und dem Göttlichen nur mittelbar, über diese ihm angebotenen einfachen Bilder und Allegorien zu begegnen. Der Wissende hingegen vermag mittels seiner Kompetenz, die Zeichen zu durchdringen, unmittelbaren Zugang zu göttlicher Weisheit zu erlangen. Das Ritual und die verschiedenen Formen der Unterweisung innerhalb der Bruderschaft der Free and Accepted Masons liefern die Anleitung, um zu dieser tieferen Bedeutung der Zeichen und Symbole vorzudringen. Die Bruderschaft versieht die Werkzeuge der Maurerzunft darüber hinaus zunehmend mit gleichnishaften Bedeutungen,

45 Cudworth: True Intellectual System of the Universe (Anm. 11), S. 92.

46 ,Knowledge is acquired deductively not inductively: the mind, to use Cudworth's expression, descends towards particulars: and, in comprehending the external world, the mind perceives not the external appeareance of things but the relational constants which reveal their immutable essence." Sarah Hutton in ihrer Einleitung zu Cudworths Treatise Concerning Eternal and Immutable Morality (Anm. 28), S. xxii-xxiii. 
um mit ihnen die Gestaltung eines, guten Lebens' zu visualisieren und anzuleiten. Initiations- und Beförderungsrituale werden schrittweise und im Zugriff auf die Zunftlegende ausgestaltet, um die Suche nach einem besonderen Wissen zu strukturieren und durch immer komplexer werdende Initiations- und Beförderungsrituale langfristig interessant zu halten.

Ist im Hinblick auf die Freimauerei von Rätseln (riddles) die Rede, so meist unter Verweis auf die altägyptische Sphinx als Hüterin eines Eintrittstores, das Würdige und Unwürdige scheidet.

If we turn our eyes to antiquity, we shall find the ancient Egyptians had so great regard for silence and secrecy in the mysteries of their religion, that they set up the god Harpocrates, to whom they paid peculiar honor and veneration, who was represented with his right hand placed near the heart, and the left down by his side, covered with a skin before, full of eyes and ears, to signify, that, of many things to be seen and heard, few are to be published.

And among the same people, their great Isis, the Minerva of the Greeks, had always an image of a Sphinx* placed at the entrance of her temples, to denote that secrets were there preserved under sacred coverings, that they might be kept from the knowledge of the vulgar, as much as the riddles of that creature. ${ }^{47}$

Hier wird ein innerer Bereich, der ein Geheimnis hütet, von einer äußeren Barriere umgeben und abgeschirmt, für deren Überschreitung ein Eingangsrätsel zu lösen ist. Das Rätsel hält den Unwürdigen fern, während der Würdige die Prüfung meistert und sich für das Geheimnis qualifiziert. An Rätsel und Geheimnis scheiden sich Außen- und Binnenperspektive. Das Undurchschaubare bleibt in der Außenperspektive stets rätselhaft, während die Beschäftigung mit dem Geheimnis und der gemeinsame Schutz dieses Geheimnisses in der Binnenperspektive ,wahre' Erkenntnis und Vervollkommnung verheißt. Das geheime Aufnahmeritual der Freimaurer trennt den Bruder in dieser Weise vom ,Profanen' und setzt, mit Bourdieu gesprochen, eine „dauerhafte Unterscheidung zwischen denen, die von diesem Ritus betroffen, und denen, die nicht von ihm betroffen sind“. ${ }^{48}$ Es etabliert zwei voneinander getrennte Ordnungen. Während der ,Profane' nur der einen angehört, bewegt sich der Freimaurer fortan in zwei verschiedenen, wenn auch aufeinander bezogenen Sphären. Er ist ein den Gesetzen und der Religion des Staates, in dem er lebt, verpflichteter Bürger, zugleich nimmt er sich selbst als Freimaurer als Teil von etwas Größerem wahr. Seine Stellung innerhalb der Bruderschaft leitet sich aus dem Grad der Durchdringung und seiner besonderen Einsicht in die Mysterien ab und kann von der sozialen Hierarchie des Alltags durchaus abweichen. Dieser Doppelstatus lässt sich mit der aus der hermetischen Tradition abgeleiteten Konzeption des homo duplex beschreiben. ${ }^{49}$

47 Anonymous: The Secrecy (Anm. 42), S. 23ff.

48 Pierre Bourdieu: Was heißt Sprechen? Die Ökonomie des sprachlichen Tausches. Wien 1990, S. 84.

49 Diesen Gedanken entfalte ich erstmals in meiner 2005 eingereichten Dissertationsschrift. Er 
Im Kontext der Vermittlung, Initiierung und Vertiefung eines esoterischen Erkenntnis-, Wandlungs- und Vervollkommnungsprozesses stehen Geheimnis und Darstellung in einem komplexen Wechselverhältnis. Die Gemeinschaft, in die der Bruder aufgenommen wird, ist selbst kein ruhender Bestand, sondern etabliert sich in einem permanenten Prozess der performativen Gemeinschaftsbildung im Ritual und der Verpflichtung zum Schutz eines gemeinsamen Geheimnisses. Das Spiel des Ver- und Enthüllens sowohl im Umgang mit der freimaurerischen Symbolik im Arkanum, als auch im Zusammenhang seines Schutzes gegenüber einem ,profanen' Außen resultiert aus dieser Konzeption als religio duplex, die dem Freimaurer ein paralleles Agieren in zwei Körperordnungen abfordert und sein Handeln zwischen performativer Vergegenwärtigung und ostentativer Verschleierung oszillieren lässt. Sichtbares Ergebnis der Arbeit an sich selbst mittels geheimer Rituale und Symbole in einem geheimnisgeschützten Raum ist die habituell verfestigte ,Schönheit des Lebensstils', ein freimaurerischer Habitus, ${ }^{50}$ der sich in einer besonderen Fairness, Gradlinig- und Verlässlichkeit sowie einer dem Gemeinwohl zugeneigten Verhaltensweise äußert. Dieses feste Verhaltensdispositiv ist Garant eben jener Spontaneität, Freiheit und Freiwilligkeit, die den Menschen aus sklavischer Gefolgschaft befreit und ihn zu einem eigenständigen moralischen Akteur qualifiziert. Das Geheimnis umsäumt den Schutzraum zur Einübung und Erprobung dieses Habitus in einem geschlossenen Kreis von Zuschauern, mit denen der Bruder in ein axiologisches Verhältnis tritt, sein Handeln an der Erfahrung von Anerkennung und Missbilligung ausrichtet. ${ }^{51}$ Die Veredelung des Einzelnen wird im Kontext einer Wertegemeinschaft erprobt und habituell verankert.

Der freimaurerische Habitus, den er auf diese Weise ausbildet, ist konsistent und doch ausreichend flexibel, um die Doppelrolle, die ihm sein Status als homo duplex aufbürdet, auszufüllen und sich wechselnden gesellschaftlichen Anforderungen anzupassen..$^{22}$ Die Ausübung einer solchen Doppelrolle bzw. die doppelte Perspektivierung des eigenen Handelns verläuft aufgrund der Geheimhaltungspflicht dennoch nicht immer widerspruchsfrei. Das Resultat ist ein Statusdilem-

erhält jedoch erst durch das von Jan Assmann ausführlich beleuchtete Konzept einer religio duplex (Anm. 10) sowie der elaborierten Darstellung seiner historischen Genese und Wirkmacht für die Geheimbünde der europäischen Aufklärung das notwendige Fundament. Kristiane Hasselmann: Die Rituale der Freimaurer. Zur Konstitution eines bürgerlichen Habitus im England des 18. Jahrhunderts. Bielefeld 2009 (zugl. Univ.-Diss., Freie Universität Berlin 2005).

50 Kristiane Hasselmann: Das freimaurerische Ritual als performative Selbstverpflichtung. Historische Linien einer praktischen Ethik. In: Quatuor Coronati Jahrbuch für Freimaurerforschung 51 (2014), S.37-56 und dies.: Freimaurerische Selbstbildung als moderne Habitusethik. Performative Aspekte der Freimaurerei. In: Jahrbuch der Forschungsloge Quatuor Coronati 46 (2009), S. 71-89.

51 Siehe hierzu den Abschnitt „Axiologische Aspekte der Verhaltensregulation in der Freimaurerei“ in meiner Dissertationsschrift, welcher den Spuren der praktischen Ethik John Lockes in der Freimaurerei nachgeht. Hasselmann: Rituale der Freimaurer (Anm. 49), S. 56-73.

52 Kristiane Hasselmann: [Art.] Freemasonry and Performance. In: Handbook on Freemasonry. Hg. von Henrik Bogdan und Jan A. M. Snoek. Leiden u. a. 2014, S. 330-356. 
ma, welches die Brüder durch Signale einer besonderen Verbundenheit untereinander abzufedern versuchen. Das konnte zuweilen durchaus amüsante Züge annehmen..$^{53}$

\section{Ritual und Habitus: Die Freimaurerbruderschaft als handlungswirksame symbol-sharing group}

Die Freimaurerbruderschaft ist eine symbol-sharing group, wie Lloyd W. Warner es nennt, die ihre Mitglieder mit symbolischen Mitteln und aus der operativen Zunft abgeleiteten Erkennungszeichen - wie Klopf- oder Handzeichen und einem geheimen Händedruck - ausstattet, um eine besondere Sphäre der Intimität und Solidarität zu etablieren und aufrecht zu erhalten. ${ }^{54}$ Eine schriftliche Einladung Friedrichs des Großen an Voltaire soll einmal wie folgt gelautet haben:

$$
\frac{P}{\text { venez }} \quad \text { à } \quad \frac{6}{100}
$$

Die Formel liest sich: Venez sous „P $\mathrm{P}^{\prime \prime}$ à cent sous six, also: Venez souper à Sanssouci. Wenn auch ohne direkten freimaurerischen Bezug, ist offensichtlich, dass hier zwei Personen kommunizieren, die einen gemeinsamen Code beherrschen. Voltaire soll wie folgt auf die Einladung geantwortet haben: "G a“ (zu lesen als: „G" grand - „a" petit, also: J'ai grand appétit). Diese Form der Verschlüsselung beinhaltet und schützt kein wirkliches Geheimnis, zeigt aber die Vertrautheit zweier Personen an, die ein besonderes Maß an Verbundenheit teilen und diese in einem intellektuellen Spiel auszudrücken wissen. Sie schüren damit zugleich die Neugier unbefugter Leser, die sie gleichsam kunstvoll auf Distanz halten. Intelligente Verschlüsselungen und spielerische Erkennungszeichen untereinander und in Gesellschaft ,Profaner' sind ein wichtiger Teil des „eleganten Spiels, das die Freimaurerei ist" ${ }^{\prime 5}$ Vor der Anwesenheit ,Profaner' warnt man sich unter Brüdern beispielsweise verklausuliert mit dem Hinweis „es regnet“ (in Anlehnung an den Eavesdropper, der an der Dachrinne lauscht).

Ein Nachteil der konspirativen Statuserhebung im Bund der Freimaurer beruht darauf, ${ }^{56}$ dass diese nicht offen ausgeplaudert werden, sondern nur im Stillen genossen werden darf, was dem Maurer eine schwere Prüfung seiner Verschwiegen-

53 Im folgenden Abschnitt wurden zentrale Passagen des Kapitels „Leben in zwei symbolischen Körperordnungen" meiner Dissertationsschrift Hasselmann: Die Rituale der Freimaurer (Anm. 49) übernommen (ebd., S. 231-235).

54 Lloyd W. Warner: The Living and the Dead. A Study of the Symbolic Life of Americans. New Haven 1959, S. 232.

55 Jan A. M. Snoek: Printing Masonic Secrets. Oral and Written Transmission of the Masonic Tradition. In: Alströmersymposiet 2003. Föredragsdokumentation. Hg. von Henrik Bogdan. Göteborg 2003, S. 39-56, hier S. 40.

56 Konspirativ ist die Statuserhebung nicht im Sinne geheimen Sektierertums oder einer gesetzwidrigen Verschwörung gegen andere gesellschaftliche Institutionen. Hervorgehoben werden soll, dass die Statuserhebung im Rahmen einer esoterischen Gemeinschaft vollzogen wird und von außen nicht einsichtig ist. 
heit auferlegt. Für einen Menschen, dem Status und Anerkennung wichtig sind, wird der Verkehr in zwei symbolischen Körperordnungen rasch zur Bürde. So bleibt nicht aus, dass der im Arkanum erfahrene Aufstieg bei Uneingeweihten, den sogenannten ,Profanen', im Alltag auf Unverständnis und mangelnde Anerkennung stößt:

Nach geschlossener Tafel, gieng ein Jeder seinen Weg. So bist du's denn nun! Wiederholt ich mir, als ich in mein Zimmer trat. Ich unterließ nun nicht, einigen meiner Bekannten wissen zu lassen, welch eine wichtige Person ich nun geworden sei, wollte eine Art Würde über sie behaupten und - wurde ausgelacht. Das ärgerte mich; denn ich bildete mir ein, man würde sich um mich drängen, meine Freunde würden sagen: ach, was sind Sie glücklich, in die Zahl so würdiger Männer aufgenommen zu seyn! Aber damit war es nichts! - Meine Eitelkeit war beleidigt, denn ich fühlte nur zu gut, dass Eitelkeit der Grund war, warum ich Maurer wurde; [...]..$^{57}$

Der Freimaurer ist zugleich Held eines poetischen Dramas und ,normaler' Bürger, wie Linda Simonis folgert, ${ }^{58}$ dessen besondere Qualifikationen vom ,profanen' Umfeld weder als solche zur Kenntnis genommen noch honoriert werden. Der Freimaurer ist auf die unkommentierte Lesbarkeit seines freimaurerischen Habitus angewiesen. Gelingt dies nicht, eröffnen die geheimen Zeichen der Bruderschaft ein unerschöpfliches und vor allem ständig ausbaubares Reservoir konspirativer Erkennungsweisen, die sich aus den Eiden der verschiedenen freimaurerischen Grade, ihren Symbolen und festgeschriebenen Handbewegungen über Hals, Brust oder Bauch, die die Zugehörigkeit zum Lehrlings-, Gesellen-, oder Meistergrad ausweisen, speisen. ${ }^{59}$ Bereits im Sloane MS 3329, einem frühen Katechismus um 1700, werden unter dem Titel A Narrative of the Freemasons Word and Signes Zeichen aufgeführt, mit denen sich Freimaurer in Anwesenheit ,Profaner' zu erkennen geben. ${ }^{60}$ Es werden Fragen und Antworten gelistet, die nur ein Bruder kennt, und neben den rituellen Erkennungszeichen, die aus der Logenarbeit bereits bekannt sind, werden eine ganze Reihe von Zeichen beschrieben, anhand derer sich Freimaurer auf mehr - oder weniger - subtile Weise in fremder Gesellschaft zu erkennen geben.

Es heißt dort, der Freimaurer mache sich in Gesellschaft kenntlich durch ein Ziehen des Hutes mit der rechten Hand, deren Zeige- und Mittelfinger über, deren Daumen und alle anderen Finger unterhalb der Krempe verborgen sind. Er

57 Anonymus: Unparteiische Ansichten eines tiefeingeweihten Freimaurers, enthaltend: was derselbe früher von der Freimaurerei dachte, was er während seiner Aufnahme empfand was er gefunden als er Maurer geworden - was er jetzt darüber denkt und wie sie der Laie zu betrachten hat. Bamberg 5817 (d. i. 1817), S. 33.

58 Linda Simonis: Handlung und Gespräch im freimaurerischen Ritual. Erziehung und Selbstreflexion als Drama. In: Jahrbuch der Forschungsloge Quatuor Coronati 40 (2003), S. 71.

59 Siehe beispielsweise Three Distinct Knocks (1769). In: English Masonic Exposures of 19601769. Hg. von A. C. F. Jackson. London 1986, S. 94.

60 Sloane MS 3329. In: The Early Masonic Catechisms (Anm. 3), S. 45-47. 
wedele seinen Hut von links nach rechts, bevor er ihn wieder auf den Kopf setze. Der Freimaurer wisse außerdem zwei Zeichen mit seinem Taschentuch auszuführen: Einmal greife er es mit der rechten Hand an einer Ecke, um es über die linke Schulter zu werfen und den Rücken herunter hängen zu lassen und so einige Schritte umher zu gehen. Ein anwesender Freimaurer würde - so verspricht die Anleitung - dieses Zeichen erkennen, ihm folgen und seine Hand greifen, um die entsprechenden Griffe auszutauschen. Er könne das Taschentuch auch in die rechte Hand nehmen, um sich die Nase zu schnauben. Anschließend sei es mit gestrecktem Arm vor sich zu halten und - in Anlehnung an das rituelle Klopfzeichen - zweimal ein wenig und einmal kräftig zu schütteln. Der Vollzug einiger Schritte vor und zurück, bei denen die Füße jeweils einen rechten Winkel bilden und im jeweils dritten Schritt kurz verharren, gälten genauso als sicheres Erkennungszeichen wie ein gleichzeitiges Verdrehen der Augen gen Osten und des Mundes gen Westen. Im Dunkeln hüstele der Freimaurer zweimal, als müsse er „einen Knochen oder Klumpen aus dem Halse treiben“ und ein anwesender Freimaurer würde antworten „am Tage soll man sehen, des nachts hören“.

Brüder sendeten sich schriftliche Nachrichten auf Papier, von welchem eine Ecke in rechtem Winkel eingeknickt ist, und legten ihre Handschuhe bei einem Besuch derart ab, dass dieser einen Geheimgriff andeute, bzw. ein Finger im rechten Winkel abgeknickt wird. Der Freimaurer treibe sein Pferd durch einen Klaps auf die linke Schulter an, und das von ihm abgestellte Pferd lasse sich von anderen dadurch sicher unterscheiden, dass der linke Steigbügel auf dem Sattel ruht. Um im Ausland Gleichgesinnte zu finden, wird der Vorschlag gemacht, auf das linke Knie zu sinken und die rechte Hand gegen die Sonne zu erheben, um vom fremden Bruder wieder aufgerichtet zu werden. Sollte dieser ebenfalls auf die Knie fallen - so der trockene Ratschlag -, ist er des Zeichens unkundig. Man könne ihn getrost an Ort und Stelle hocken lassen und sich selbst entfernen, denn mit einem Freimaurer habe man es in diesem Fall nicht zu tun.

Geheimzeichen bieten die Möglichkeit, ein aus operativen Zeiten überliefertes soziales Rückversicherungsnetz zu flechten, in welchem sich die Brüder untereinander ihrer Solidarität und gegenseitigen Hilfeleistung gewiss sein können. Das Spiel von Ver- und Enthüllung bietet jedoch auch ein Ventil, das Bedürfnis nach sozialer Distinktion auszuleben, ohne gegen die Tugend der Verschwiegenheit zu verstoßen. Die hier beschriebenen Zeichen zeugen von diesem frühen, ausgesprochen spielerischen Umgang mit konspirativen Erkennungszeichen, die dem Nichteingeweihten rätselhaft bleiben, aber sein Interesse schüren und so das soziale Prestige des Freimaurers erhöhen.

\section{Fazit: Lesarten des Freimaurerischen Geheimnisses}

Wechselnde historische und gesellschaftspolitische Konstellationen, die von der Freimaurerforschung bereits konkret beforscht werden, erfordern seitens der Bruderschaft eine stete Anpassung ihrer strategischen Maßnahmen des Publizierens und des Verbergens, zumal die Geheimhaltung nicht ausschließlich eine besonde- 
re Achtung gegenüber dem Bund generiert, sondern die Bruderschaft im Kontext einer diffusen Suche nach Ursachen gesellschaftlicher Übel auch leicht zur negativen Projektionsfläche werden lässt. Was das freimaurerische Geheimnis konkret beinhaltet, wird einerseits von diesen wechselnden historischen Konstellationen mitbestimmt, ist aber andererseits auch unterschiedlichen disziplinären Zugriffen seitens der Freimaurerforschung geschuldet und bestätigt die besondere Notwendigkeit einer Disziplinen übergreifenden Zusammenarbeit. ${ }^{61}$ Inhalt und Funktion des freimaurerischen Geheimnisses werden in ihr sehr unterschiedlich gedeutet: in soziologischer Hinsicht gilt das Geheimnis als Maßstab zur Bestimmung des Verhältnisses zwischen Menschen und/oder von Gruppen untereinander (Simmel), ${ }^{62}$ politisch wurde das Geheimnis primär als Demarkationslinie zwischen Politik und Moral und als Motor einer neuen Zivilgesellschaft untersucht (Koselleck) ${ }^{63}$. Dem gegenüber beschreibt die Esoterikforschung den individuellen Erkenntnisprozess als dialektisches Spiel zwischen Ent- und Verhüllung, das den Erhalt und die Weitergabe eines ,alten Wissens' in einer ungebrochenen Kette sichert (Faivre). ${ }^{64}$ Aus kulturhistorischer Sicht wurde das Geheimnis zuletzt als „Figur des lockenden Entzugs" interpretiert, in der es in permanenter Selbststeigerung letztendlich zum Selbstzweck einer eigenen „Geheimnisökonomie“ wird (Gregory). ${ }^{65}$

Worin das freimaurerische Geheimnis tatsächlich besteht, scheint auf den ersten Blick - und sofern man dessen Ergründung als eine individuelle innere Schau des Göttlichen und personengebundenen Erkenntnisprozess denken möchte nicht verallgemeinerbar. Ob es überhaupt ein Geheimnis gibt, ist abhängig von der Bereitschaft der Geschichtsschreibung, die Inhalte und symbolische Funktion von Glaubensanschauungen zu berücksichtigen. ${ }^{66}$

In der hermetischen Konzeption einer religio duplex und der Ableitung der Freimaurerei als solch einer Arkantheologie besteht das Geheimnis ideengeschichtlich in der Erkenntnis eines verborgenen Göttlichen und zieht spezifische performa-

61 Monika Neugebauer-Wölk: ,„... you shall not reveal any pairt of what you shall hear or see ....". Geheimnis und Öffentlichkeit in masonischen Systemen des 18. Jahrhunderts". In: Esoterik und Christentum. Religionsgeschichtliche und theologische Perspektiven. Hg. von Michael Bergunder und Daniel Cyranka. Leipzig 2005, S. 11-29.

62 Georg Simmel: Das Geheimnis und die geheime Gesellschaft. In: Ders.: Soziologie. Untersuchungen über die Formen der Vergesellschaftung (1908). 7. Aufl. Berlin 2013, S. $267-289$.

63 Reinhart Koselleck: Kritik und Krise. Eine Studie zur Pathogenese der bürgerlichen Welt (1959). 8. Aufl. Frankfurt a. M 1997.

64 Antoine Faivre: „The Notions of Concealment and Secrecy in Modern Esoteric Currents since the Renaissance". In: Rending the Veil. Conceilment and Secrecy in the History of Religion. Hg. von Elliot R. Wolfson. New York, London 1999, S. 155-176.

65 Stephan Gregory: Mysterienfieber. Das Geheimnis im Zeitalter der Freimaurerei. Wien u. a 2012.

66 Stephan Gregory unter Verweis auf Carlo Ginzburg in: Ders.: Mysterienfieber (Anm. 65), S. 13. Siehe hierzu auch Monika Neugebauer-Wölks Plädoyer für die Berücksichtigung esoterischer Grundlagen der Freimaurerei in der historischen Forschung. Dies.: „,Die Geheimnisse der Maurer. Plädoyer für die Akzeptanz des Esoterischen in der historischen Aufklärungsforschung“. In: Das achtzehnte Jahrhundert. Mitteilungen der Deutschen Gesellschaft für die Erforschung des 18. Jahrhunderts 21 (1997), S. 15-32. 
tive Praktiken nach sich. Da die Erkenntnis des All-Einen bereits einer gewissen Kenntnis des Selbst und der eigenen Position in der göttlichen Schöpfung bedarf, verschränken sich Darstellung, Geheimnis und Wissen auf intrikate Weise. Das Geheimnis kann im Hinblick auf die Freimaurerei als ein Akt des Erkennens und Begreifens beschrieben werden, in dem das Geheimnis selbst gewahrt und anerkannt wird. Das Geheimnis, so Hartmut Böhme in einem Beitrag für die Neue Züricher Zeitung aus dem Jahre 1997, ist eben kein Effekt des Nicht-Wissens, sondern bilde sich „immer erst auf der Höhe des Wissens und trotz seiner. Zu wenig wissen, heißt immer auch, nichts um das Geheimnis zu wissen“. Nicht-Wissen sei somit „ein Rätsel ohne Auflösung, aber kein Geheimnis“" ${ }^{67}$ Seine Verborgenheit ist eines der zentralen Merkmale des Göttlichen, welches sich in der Theologie des ,to hen kai to pan' jedoch in der Schöpfung zeige. Diese Erscheinungsform des Göttlichen als „,anwesend Abwesendes“ ist eine paradoxe Konstellation und lasse sich deshalb nur in sehr spezifischer Weise explorieren:

[...] Geheimnis ist nichts, was man sagen kann, sondern was sich einem auratischen Spüren kundtut. Das aussprechbare Geheimnis ist nur das Geheimgehaltene. Das Unaussprechliche, das dennoch anwesend ist, bedarf der Darstellung, und zwar einer solchen, die sich den ,magischen Kanälen' unserer Sinne öffnet. Die Sprache kann nur dann zum Träger des Geheimnisses werden, wenn sie zur magischen Vergegenwärtigung, also: zur Kunst wird, zum Bestandteil einer rituellen Szene. ${ }^{68}$

Darin liege, so Böhme, die „wesenhaftige Theatralität des Geheimnisses“ und sein verführerischer Reiz. ${ }^{69}$

Tatsächlich geht von der Suche nach immer tieferen Bedeutungsschichten und dem Bedürfnis, den eigenen Fortschritt in zusätzlichen Graden abzubilden in der Freimaurerei im 18. Jahrhundert ein gewisser Sog aus. Die stete Intensivierung der theatralen Ausgestaltung der Suche nach einem verlorenen Wissen führt zur Entwicklung relativ komplexer ritueller Mysterienspiele, in denen es auch um ein nekromantisches Nacherleben des Verlustes adamitischen Urwissens und seiner Restitution in der mystischen Gestalt Hirams, des Baumeisters des Salomischen Tempels im Meistergrad geht. Das in dieser Weise performativ ausgeschmückte rituelle Erlebnis, welches engrammatisch und transformierend auf den Initianden wirken soll, wird zum eigentlichen - und nicht anders als im persönlichen rituellen Erlebnis vermittelbaren - Geheimnis der Freimaurerei erhoben. Hochgradsysteme sollen vor allem einer Enttäuschung und Langeweile vorbeugen angesichts von Geheimnissen, die sich entweder einer ,herkömmlichen' Auflösung entziehen oder sich nicht in erwarteter Form einlösen. Diese Intensivierungsversuche speisen sich aus der Faszination eines altägyptischen Geheimwissens, biblischen

67 Hartmut Böhme: Das Geheimnis. In: Neue Züricher Zeitung, 20./21.12.1997, S. 65f., URL: https:/ www.hartmutboehme.de/static/archiv/volltexte/texte/geheimnis.html (18.01.2021)

68 Hartmut Böhme: Das Geheimnis (Anm. 67), S. 66.

69 Ebd. 
Erzählungen, aber auch der Macht mittelalterlicher Ritterorden. Eine Fülle künstlicher Mysterien und Legenden stellt im Verlauf des 18. Jahrhunderts immer neue Geheimnisschichten in Aussicht, ermöglicht den fortgesetzten Aufstieg innerhalb der in Graden organisierten Binnenhierarchie der Bruderschaft und entwickelt ein gewisses Eigenleben, das die Geheimnisökonomie der Freimauer immer weiter befeuert. Stephan Gregory interpretiert die Freimaurerei für das 18. Jahrhundert deshalb nicht ganz zu Unrecht als eine "Geheimnisveredelungsmaschine ${ }^{\text {“70 }}$ Dieses Verhältnis von Geheimnis und Darstellung gilt es, das vermitteln Gespräche mit Mitgliedern des Bundes sehr deutlich, bis in die heutige Zeit stets von Neuem auszutarieren.

70 Gregory: Mysterienfieber (Anm. 65), S.30f. 



\section{Autor*innenverzeichnis}

Maximilian Benz, Professor für Deutsche Literatur des Mittelalters und der Frühen Neuzeit an der Universität Bielefeld, Förderung durch das Heisenberg-Programm der Deutschen Forschungsgemeinschaft. Monographien: Gesicht und Schrift. Die Erzählung von Jenseitsreisen in Antike und Mittelalter. Berlin, Boston 2013; Arbeit an der Tradition. Studien zur literarhistorischen Stellung und zur poetischen Struktur der Werke Rudolfs von Ems. Zürich 2018; Fragmente einer Sprache der Liebe um 1200. 2. Aufl. Zürich 2019.

Simon Brandl, wissenschaftlicher Mitarbeiter im Teilprojekt "Alchemia poetica“ am Sonderforschungsbereich 980 Episteme in Bewegung an der Freien Universität Berlin. 2020 promoviert über das Thema „Mystik und Magie im Frühparacelsismus. Erkundungen um Alexander von Suchtens Traktat De tribus facultatibus". Forschungsschwerpunkte in der Literatur-, Wissenschafts- und Philosophiegeschichte der Frühen Neuzeit. Publikationen: „Alchemia rhodo-staurotica“? Paracelsistische Theoalchemie in Daniel Möglings Speculum sophicum rhodo-stauroticum. In: Tagungsband zur Veranstaltung "Johann Valentin Andreae und die Rosenkreuzer". Hg. von Wilhelm Schmidt-Biggemann und Volkhard Wels. StuttgartBad Cannstatt 2021 (im Erscheinen). Mitherausgeber von Heinrich Nolle: Spiegel des chymischen Parergon. Hg., übers. und komm. von Simon Brandl, Jost Eickmeyer und Volkhard Wels. Stuttgart-Bad Cannstatt 2021 (im Erscheinen).

Glenn Ehrstine, Associate Professor für deutsche Literatur des Mittelalters und der Frühen Neuzeit an der University of Iowa. Forschungsschwerpunkte: Katholisches und protestantisches Theater vor 1600; Konfessionspolemik; Fastnacht. Publikationen: Theater, Culture, and Community in Reformation Bern, 1523-1555. Leiden 2002; Crux interpretationis. Die Heiltumsweisung im Künzelsauer Fronleichnamsspiel. In: Das Theater des Spätmittelalters und der Frühen Neuzeit. Kulturelle Verhandlungen in einer Zeit des Wandels. Hg. von Elke Huwiler. Heidelberg 2015, S. 215-228; Raymond Peraudi in Zerbst. Corpus Christi Theater, Material Devotion, and the Indulgence Microeconomy on the Eve of the Reformation. In: Speculum 93 (2018), S. 319-356; Das Geistliche Spiel als Ablassmedium. Überlegungen am Beispiel des Alsfelder Passionsspiels. In: Religiöses Wissen im mittelalterlichen und frühneuzeitlichen Schauspiel. Hg. von Klaus Ridder, Beatrice von Lüpke und Michael Neumaier. Tübingen 2021, S. 259-297. 
Jutta Eming, Professorin für Ältere deutsche Literatur an der Freien Universität Berlin, Leiterin des Teilprojekts „Das Wunderbare als Konfiguration des Wissens in der Literatur des Mittelalters" am Sonderforschungsbereich 980 Episteme in Bewegung. Arbeitsschwerpunkte: Emotionalität, Wunderbares und Wissen, Zeitlichkeit in der Literatur von 1200-1600. Publikationen: Funktionswandel des Wunderbaren. Studien zum Bel Inconnu, zum Wigalois und zum Wigoleis vom Rade. Trier 1999; Emotion und Expression. Untersuchungen zu deutschen und französischen Liebes- und Abenteuerromanen des 12.-16. Jahrhunderts. Berlin, New York 2006; Magie und Wunderbares. Aspekte ihrer ästhetischen und epistemischen Konvergenz. In: Der Begriff der Magie in Mittelalter und Früher Neuzeit. Hg. von Jutta Eming und Volkhard Wels. Wiesbaden 2020, S. 81-111; Melancholie im Minnesang. Zu Morungens ,Narzisslied'. In: Gegen / Gewalt / Schreiben. De-Konstruktionen von Geschlechts- und Rollenbildern in der Ovid-Rezeption. Hg. von Melanie Möller. Berlin, Boston 2021, S. 27-52.

Ute Frietsch, Privatdozentin an der Humboldt-Universität zu Berlin im Fach Kulturwissenschaft. Forschungsschwerpunkte in der Kultur- und Wissenschaftsgeschichte der Frühen Neuzeit. Publikationen: Häresie und Wissenschaft. Eine Genealogie der paracelsischen Alchemie. München 2013; Magie im 16. Jahrhundert. Die Astronomia Magna oder Die gantze Philosophia sagax der grossen und kleinen Welt. In: Astronomie und Astrologie im Kontext von Religionen. Hg. von Gudrun Wolfschmidt. Hamburg 2018, S. 190-217; Der Alchemiker im Bild. Zum Verhältnis von Alchemie und Kunst. In: Alchemie - Genealogie und Terminologie, Bilder, Techniken und Artefakte. Forschungen aus der Herzog August Bibliothek. Hg. von Petra Feuerstein-Herz und Ute Frietsch. Wiesbaden 2021 (im Erscheinen).

Kristiane Hasselmann, Dr. phil., Wiss. Geschäftsführerin des Sonderforschungsbereichs 980 Episteme in Bewegung. Promotion im Fach Theaterwissenschaft mit einer historiographischen Arbeit, die den freimaurerischen Selbstformungsanspruch als Modellfall einer in aristotelischer Tradition verankerten, im 18. Jahrhundert erneuerten Habitusethik analysiert (Die Rituale der Freimaurer. Zur Konstitution eines bürgerlichen Habitus im England des 18. Jahrhunderts. Bielefeld 2009). Publikationen: [Art.] Freemasonry and Performance. In: Handbook on Freemasonry. Hg. von Henrik Bogdan und Jan A. M. Snoek. Leiden, Boston 2014, S. 328-356; Das freimaurerische Ritual als performative Selbstverpflichtung. Historische Linien einer praktischen Ethik. In: Quatuor Coronati Jahrbuch für Freimaurerforschung 51 (2014), S. 37-56; Entfesselung des Imaginären und Suche nach der perfekten Form. Zur Bedeutung freimaurerischer Referenzen in Matthew Barneys Cremaster 3 (2002). In: Spuren der Avantgarde: Theatrum alchemicum. Frühe Neuzeit und Moderne im Kulturvergleich. Hg. von Helmar Schramm, Ludger Schwarte und Jan Lazardzig. Berlin, Boston 2017, S. 518-541. 
Beate Kellner, Professorin für Germanistische Mediävistik an der Ludwig-Maximilians-Universität München, gemeinsam mit Susanne Reichlin Leiterin des Teilprojekts „Wachsamkeit und Achtsamkeit. Literarische Dynamiken von Selbstbeobachtung und Fremdbeobachtung in mittelalterlicher deutschsprachiger Lyrik" am Sonderforschungsbereich 1369 Vigilanzkulturen; Sprecherin des Internationalen Graduiertenkollegs „Philologie: Vormoderne Praktiken, globale Perspektiven und Zukunftskonzepte". Arbeitsschwerpunkte: Literaturtheorie; Wissensgeschichte; Beziehungen zwischen lateinischer und volkssprachlicher Literatur; mittelalterliche Lyrik, höfische Epik und geistliche Literatur; mittelalterliche Naturphilosophie und literarische Naturdarstellungen. Publikationen: Ursprung und Kontinuität. Studien zum genealogischen Wissen im Mittelalter. München 2004; Spiel der Liebe im Minnesang. Paderborn 2018; Naturphilosophie als Vision und integumentale Erzählung. Die Dame Natur in Alanus' ab Insulis De planctu naturae. In: Frühmittelalterliche Studien 54 (2020), S. 257-281.

Yoshiki Koda, Professor am Germanistischen Seminar der Keio-Universität, Tokyo/Japan. Vorstandsmitglied der Japanischen Gesellschaft für Germanistik sowie der Alexander-von-Humboldt-Gesellschaft Japan. Forschungsschwerpunkt in der Literatur- und Religionsgeschichte des Mittelalters, besonders in der christlichen Mystik des 13. und 14. Jahrhunderts. Publikationen: Mystische Lebenslehre zwischen Kloster und Stadt. Meister Eckharts Reden der Unterweisung und die spätmittelalterliche Lebenswirklichkeit. In: Mittelalterliche Literatur im Lebenszusammenhang. Ergebnisse der Troisième Cycle Romand 1994. Hg. von Eckart Conrad Lutz. Freiburg/Schweiz 1997, S. 225-264; Köln - Toulouse - Avignon. Die Verurteilung Meister Eckharts im Kontext der thomistischen Tradition in Südfrankreich. In: Mystik, Recht und Freiheit. Religiöse Erfahrung und kirchliche Institutionen im Spätmittelalter. Hg. von Dietmar Mieth und Britta Müller-Schauenburg. Stuttgart 2012, S. 96-122; Synderesis und Scham. Zur Genese des kognitiven und affektiven Gewissens im abendländischen Mittelalter. In: Neue Beiträge zur Germanistik 14 (2015), H. 1, S. 54-74; „Homo sacer“ im östlichen und westlichen religiösen Kontext. „Hiob“, „Oguri Hangan“ und „Kugai Jōdo“. In: Religiöse Erfahrung - Literarischer Habitus. Hg. von der Japanischen Gesellschaft für Germanistik. München 2020, S. 56-73.

Stephan Müller, Professor für Ältere deutsche Sprache und Literatur an der Universität Wien. Forschungsschwerpunkte in den Bereichen Althochdeutsche Sprache und Literatur, Theorie und Geschichte der Überlieferung und der Schrift. DFG-Projekt „Handbuch der deutschen Glossen und Texte des Mittelalters in Geheimschrift". Publikationen: Warum mittelalterliche Geheimschriften keine Geheimschriften sind. Am Beispiel des ,Trierer Teufelsspruches' (Trier Stadtbibliothek Hs. 564/806 8º. In: Schriftträger - Textträger. Zur materialen Präsenz des Geschriebenen in frühen Gesellschaften. Hg. von Annette Kehnel und Diamantis Panagiotopoulos. Berlin, München, Boston 2015, S. 169-178; gemeinsam mit Katha- 
rina Büsel und Lena Zudrell: Hic fuit Wog Hab aus Pas anno MDXX - Wolf Huber war hier. Über Altar-Graffiti des 16. Jahrhunderts und eine Geheimschrift im Werk Wolf Hubers. In: Graffiti. Deutschsprachige Auf- und Inschriften in sprachund literaturwissenschaftlicher Perspektive. Hg. von Ludger Lieb, Stephan Müller und Doris Tophinke. Wien 2017, S. 59-76; gemeinsam mit Wolfgang Haubrichs: Der Admonter Abrogans. Edition und Untersuchungen des Glossarfragments der Stiftsbibliothek Admont (Fragm. D1). Berlin, Boston 2021.

Falk Quenstedt, wissenschaftlicher Mitarbeiter am Sonderforschungsbereich 980 Episteme in Bewegung an der Freien Universität Berlin im Forschungsprojekt „Das Wunderbaren als Konfiguration des Wissens in der Literatur des Mittelalters" unter der Leitung von Jutta Eming. Forschungsschwerpunkte: Wissen und Literatur, Transkulturalität, Orientalismus, Literatur und materielle Kultur, Akteur-Netzwerk-Theorie. Publikationen: Mirabiles Wissen. Deutschsprachige Reiseerzählungen um 1200 im transkulturellen Kontext arabischer Literatur. Straßburger Alexander - Herzog Ernst - Brandan-Reise. Wiesbaden 2021 (im Erscheinen); The things narrative is made of. A Latourian reading of the description of Enite's horse in Hartmann of Aue's Erec. In: Things and Thingness. Perspectives on Material and Immaterial Objects (ca. 700-1600). Hg. von Jutta Eming und Kathryn Starkey. Berlin, Boston 2021 (im Erscheinen); Mediation neuen Wissens. Anekdoten in Marco Polos Divisament dou monde und dessen deutschsprachigen Fassungen. In: Wissen en miniature. Theorie und Epistemologie der Anekdote. Hg. von Melanie Möller und Matthias Grandl. Wiesbaden 2021, S. 85-106.

Susanne Reichlin, Professorin für Deutsche Literatur des Spätmittelalters und der Frühen Neuzeit bis 1700 mit einem Schwerpunkt auf der Texttheorie an der Ludwig-Maximilians-Universität München, gemeinsam mit Beate Kellner Leiterin des Teilprojektes „Wachsamkeit und Achtsamkeit. Literarische Dynamiken von Selbstbeobachtung und Fremdbeobachtung in mittelalterlicher deutschsprachiger Lyrik" am Sonderforschungsbereich 1369 Vigilanzkulturen. Arbeits- und Forschungsschwerpunkte: Literatur des Mittelalters und der Frühen Neuzeit mit besonderem Schwerpunkt auf Literarischen Ökonomien, Lyrik, Zeit und Erzählen. Rezente Publikationen: Stimmenarrangement. Figurierte Rede in Frauenlobs Marienleich. In: Poetica 52 (2021) [im Druck]; The Ambiguity of the Unambiguos. Figures of Death in Late Medieval Literature. In: Strategies of Ambiguity in Ancient Literature. Hg. von Martin Vöhler, Therese Fuhrer und Stavros Frangoulidis. Berlin 2021, S. 43-59; [Art.] Die pragmatische und mediale Dimension des Minnesangs. In: Handbuch Minnesang. Hg. von Beate Kellner, Susanne Reichlin und Alexander Rudolph. Berlin, Boston 2021, S. 233-256; [Art.] Thematisiertes Singen. In: Handbuch Minnesang. Hg. von Beate Kellner, Susanne Reichlin und Alexander Rudolph. Berlin, Boston 2021, S. 257-276; Kredit- und Vertrauenspraktiken im Fortunatus. In: Kredit und Bankrott in der deutschsprachigen Literatur. Hg. von Maximilian Bergengruen, Jill Bühler und Antonia Eder. Berlin 2020, S. 45-68. 
Johannes Traulsen, wissenschaftlicher Mitarbeiter im Arbeitsbereich Ältere deutsche Literatur und Sprache der Freien Universität Berlin. Forschungsschwerpunkte liegen in der religiösen Literatur des Mittelalters, der deutschsprachigen Karlsepik sowie der Mittelalterrezeption. Publikationen: Heiligkeit und Gemeinschaft. Studien zur Rezeption spätantiker Asketenlegenden im Väterbuch. Berlin, Boston 2017; Legendarisches Erzählen. Optionen und Modelle in Spätantike und Mittelalter (gemeinsam mit Julia Weitbrecht, Maximilian Benz, Andreas Hammer, Elke Koch, Nina Nowakowski und Stephanie Seidl). Berlin 2019; The Desert Fathers' Beasts. Crocodiles in Medieval German Monastic Literature. In: Interfaces 5 (2018), S. 78-89; Verteufelung des Mythos. Der Teufel als poetologische Figur in der Erzählung Das Meerwunder des Dresdner Heldenbuchs. In: Der Teufel und seine poietische Macht in literarischen Texten vom Mittelalter zur Moderne. Hg. von Jutta Eming und Daniela Fuhrmann. Berlin, Boston 2021, S. 87-102.

Beatrice Trînca, Gastprofessorin am Institut für Religionswissenschaft der Freien Universität Berlin und Privatdozentin für Ältere deutsche Sprache und Literatur an der Universität Hamburg. Forschungsschwerpunkte: Ästhetik, Plant Studies, mittelalterliche Mystik und Hagiographie, höfischer Roman, Mittelalterrezeption. Publikationen: Verrätselung und Sinnzeugung in Spätmittelalter und Früher Neuzeit. Hg. von Beatrice Trînca. Würzburg 2016; Amor conspirator. Zur Ästhetik des Verborgenen in der höfischen Literatur. Göttingen 2019; Ekel und Heil. Mystische Exzesse. In: Heil und Heilung. Die Kultur der Selbstsorge in der Kunst und Literatur des Mittelalters und der frühen Neuzeit. Hg. von Tobias Bulang und Regina Toepfer. Heidelberg 2020, S. 105-127.

Volkhard Wels, Professor für Wissensgeschichte der Frühen Neuzeit an der Freien Universität Berlin, Leiter des Teilprojekts "Alchemia poetica“ am Sonderforschungsbereich 980 Episteme in Bewegung. Forschungsschwerpunkte in der Literatur-, Wissenschafts- und Religionsgeschichte der Frühen Neuzeit. Publikationen: Manifestationen des Geistes. Frömmigkeit, Spiritualismus und Dichtung in der Frühen Neuzeit. Göttingen 2014; Die Alchemie der Frühen Neuzeit als Gegenstand der Wissensgeschichte. In: Magia daemoniaca, magia naturalis, zouber. Schreibweisen von Magie und Alchemie in Mittelalter und Früher Neuzeit. Hg. von Peter-André Alt, Jutta Eming, Tilo Renz und Volkhard Wels. Wiesbaden 2015, S. 233-265; Magie und (Al)Chemie im 16. Jahrhundert. Thesen zu ihrer Begründung im Neuplatonismus, bei Paracelsus und im Paracelsismus. In: Der Begriff der Magie in Mittelalter und Früher Neuzeit. Hg. von Jutta Eming und Volkhard Wels. Wiesbaden 2020, S. 157-201.

Friedrich Wolfzettel, Professur für Romanische Philologie an der Universität Gießen 1972 bis 1988, an der Goethe Universität Frankfurt am Main 1088 bis 2007. Gastdozenturen in Bielefeld, Siegen, Konstanz und Mendoza (Argentinien). Präsident der Deutschen Sektion der Internationalen Artusgesellschaft 1982 bis 2007, 
Präsident der Internationalen Artusgesellschaft 1990 bis 1993 und Ehrenpräsident. Mitherausgeber der Reihe „mimesis“ (Tübingen) 1985 bis 2007 und Mitherausgeber der Enzyklopädie „,̈̈sthetische Grundbegriffe“ (7 Bde., Stuttgart 2000 bis 2010), Mitherausgeber der Reihe "Schriften der Internationalen Artusgesellschaft" seit 1984. Spezialgebiete: Mittelalterliche Epik (insbes. Artusliteratur) und Lyrik, Geschichte des franz. ital. und span. Romans bis in die Moderne, Märchen und Mythos in Mittelalter und Neuzeit, Französische Literaturgeschichtsschreibung, Geschichte des Reiseberichts in der Romania vom Mittelalter bis ins 20. Jahrhundert. 